Universidad de Salamanca

Facultad de Educación

Dpto. Teoría e Historia de la Educación

\author{
TESIS DOCTORAL
}

\title{
Comunidad de Práctica para la promoción sociocultural de mujeres gitanas en entornos virtuales de aprendizaje
}

\author{
Mª Rosa Fernández Sánchez
}

\author{
Directores
}

Dr. Joaquín García Carrasco y Dr. Jesús Valverde Berrocoso 



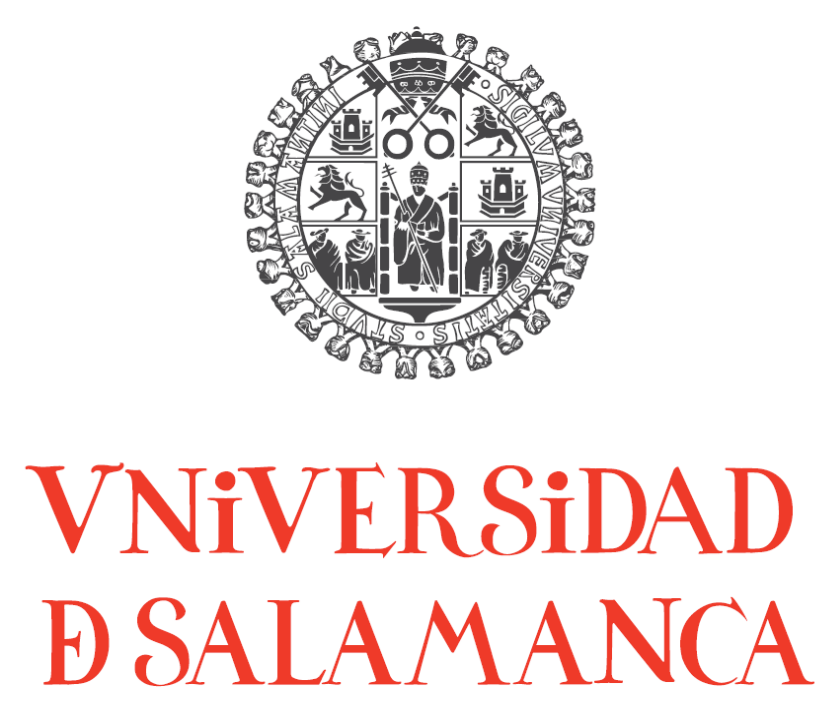

\section{Comunidad de Práctica para la promoción sociocultural de mujeres gitanas en entornos virtuales de aprendizaje}

Departamento de Teoría e Historia de la Educación

Universidad de Salamanca

Directores

Vo Bo Dr. D. Joaquín García Carrasco

V0 Bo Dr. D Jesús Valverde Berrocoso

Tutor

Dr. D. Antonio Víctor Martín García 

A mi padre y mi madre, Ángel y Rosa 



\section{Agradecimientos}

En esta primera página quiero dejar constancia de mi reconocimiento y gratitud para con todas aquellas personas que, de mil maneras, han hecho posible la realización de este trabajo.

La relación de personas es extensa, pero sin duda los primeros lugares están ocupados por el Dr. Joaquín García Carrasco y el Dr. Jesús Valverde Berrocoso, directores y guías de este trabajo de investigación. Al Dr. Joaquín García Carrasco le agradezco toda su atención, recomendaciones, aportaciones a todo mi trabajo y el que, desde el principio de mis estudios universitarios, haya estado presente. Gracias a todo ello y su confianza constante en mi persona, estoy presentando hoy esta Tesis Doctoral. Su práctica profesional y su larga trayectoria docente y científica, acompañada por la preocupación por los y las estudiantes, es todo un ejemplo que ha marcado mi vida profesional. Al Dr. Jesús Valverde Berrocoso, le agradezco sinceramente su completa disponibilidad, implicación, espíritu crítico y sabias decisiones que han sido fundamentales para desarrollar este trabajo; pero aún más, si cabe, lo han sido la confianza que siempre ha mostrado en mí y su constante aliento para no dejarme flaquear a lo largo del proceso. Todo ello con una paciencia de la que sólo un buen amigo es capaz. Con ambos, el espacio conjunto creado en torno a la tesis ha sido un lugar privilegiado para mí y espero que podamos seguir llenándolo de proyectos compartidos.

Estoy también en deuda con los compañeros y compañeras del Grupo de Investigación «Nodo Educativo» de la Universidad de Extremadura por su confianza, por su constante apoyo, por hacerme partícipe de tantos proyectos, por su espíritu de equipo y colaboración, de compartir interrogantes y de aprender juntos. He sido afortunada de poder encontrar apoyos, ayudas y afectos cuando las he necesitado por el simple procedimiento de recorrer unos metros hasta la puerta de sus despachos. Gracias por todo lo aprendido y por lo que espero seguir aprendiendo junto a vosotras y vosotros.

Así mismo quiero mostrar mi agradecimiento al profesor Marcelo Sánchez-Oro Sánchez $y$, por extensión, a los compañeros y compañeras de ACISE por las aportaciones, sabios consejos y por contar conmigo para sus interesantes proyectos.

Gracias especialmente a todos los profesores y profesoras que han marcado y seguido mi trayectoria. Debo mencionar a un profesor muy importante durante mis años de estudio, al Dr. Nicolás Martín Sosa, especialmente por aquella breve conversación, meses antes de marcharse para siempre,en el cruce de esa escalera de la Facultad de Educación de la Universidad de Salamanca, por animarme a realizar los cursos de Doctorado y a iniciar un camino, en el que la culminación de este trabajo marca un hito importante. 
He de dar las gracias a profesores y profesoras compañeras de la Facultad de Formación de Profesorado y al Departamento de Ciencias de la Educación de la Universidad de Extremadura por sus expresiones de ánimo y apoyo.

Muchas gracias a la Fundación Secretariado Gitano por darme la oportunidad de trabajar, desarrollarme y aprender tantas cosas sobre el pueblo gitano. Especialmente me gustaría mencionar a mis compañeros y compañeras de Extremadura, y de mi centro de trabajo, Cáceres, por su apoyo incondicional y por ayudarme en ese acceso directo al objeto de estudio. Quiero destacar al tío Valentín Suárez Saavedra, por su amistad, su confianza, su ejemplo de lucha, de gitaneidad. Mi eterno agradecimiento, a ti, a Mayte y a tu familia por vuestro apoyo.

Gracias a mis mujeres, a las mujeres gitanas que han participado en este trabajo, por su esfuerzo, su empeño, su ilusión y su participación, me siento muy orgullosa de todas vosotras. Vuestro afán de aprender ha superado todas mis expectativas, me habéis enseñado mucho. Sois grandes personas, grandes mujeres y grandes gitanas. Gracias de corazón.

Mi gratitud a mis amigos y amigas, y muy especialmente a mi familia por compartir esta tesis conmigo, por escucharme, por perdonarme las ausencias y por animarme a continuar.

Gracias a Rober, porque me ha acompañado en las inquietudes y ansiedades que han formado parte de este trabajo. Siempre has estado ahí con un gesto de cariño, pese al exilio forzado.

Gracias a mi madre, Rosa, y a mi padre, Ángel, por dedicarme su vida, su tiempo y por acompañarme y apoyarme hasta poner el punto final a este trabajo. 


\section{Índice}

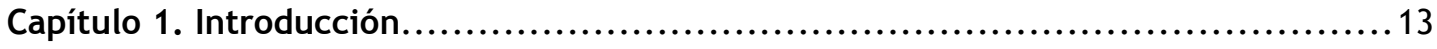

1.1. Abriendo puertas....................................................... 17

1.2. Antecedentes y contextualización............................................22

1.3. Objetivos de la investigación............................................. 34

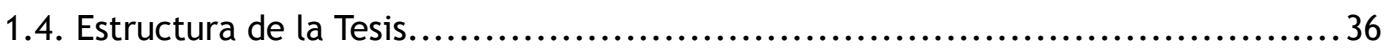

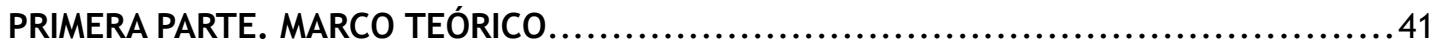

Capítulo 2. E-learning social: conceptualización y fundamentos.....................43

2.1. Contextualización. E-learning social: la formación apoyada en TIC desde una perspectiva/óptica social. .......................................... 47

2.1.1. Exclusión social, e-learning e inclusión digital. .........................47

2.1.2. La formación apoyada en TIC desde una perspectiva social: el e-learning social......................................................... 53

2.2. Fundamentos internacionales, nacionales y regionales y bases científicas del e-learning social............................................... 59

2.2.1. Estudios científicos sobre e-learning para la inclusión social.................59

2.2.2. Políticas, programas e iniciativas europeas, nacionales y

extremeñas sobre e-learning para la inclusión social. ............................64

2.3. Factores socioculturales del e-learning..................................... 110

2.4. El e-learning para la inclusión y el cambio social.............................118

Capítulo 3. E-learning social y Comunidades de Práctica..............................127

3.1. Las Comunidades de Práctica: modelos y desarrollo en entornos virtuales de aprendizaje.

3.1.1. Contexto: La perspectiva sociocultural. Aprendizaje colaborativo, procesos comunicativos y Tecnologías de la Información y Comunicación............131

3.1.2. Comunidades de Aprendizaje y Comunidades de Práctica en entornos virtuales................................................................. 143

3.2. El modelo de «Comunidad de Indagación» para el estudio y la construcción (cultivo) de Comunidades de Práctica en entornos virtuales de aprendizaje.

3.2.1. La construcción de Comunidades de Práctica en entornos virtuales de aprendizaje desde el modelo «Comunidad de Indagación».

3.2.2. El estudio de Comunidades de Práctica en entornos virtuales de aprendizaje desde los indicadores del modelo Comunidad de Indagación..........173

Capítulo 4. Políticas de inclusión digital y Comunidad Gitana..........................183

4.1. Políticas de inclusión social de la población gitana de ámbito europeo, nacional y regional: aspectos relacionados con las TIC.

4.1.1. Marco europeo: principales instrumentos de la Unión Europea con impacto sobre la inclusión social y digital de la población gitana.

4.1.2. Marco español: planes y programas para la inclusión social y digital de la población gitana. 
4.1.3. Marco regional: la inclusión social y digital de la población gitana en

Extremadura. ..............................................................2210

4.2. Tecnologías de la Información y Comunicación y pueblo gitano..................218

4.2.1. Las TIC y gitanos y gitanas............................................ 218

4.2.2. Experiencias previas de proyectos e-learning destinados a

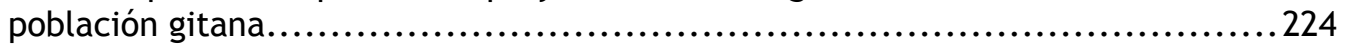

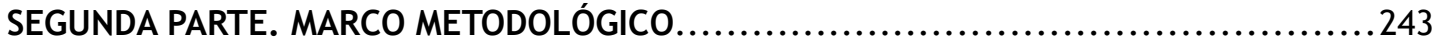

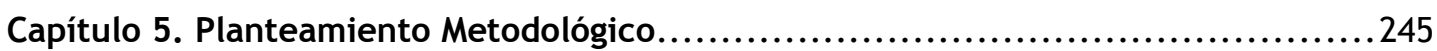

5.1. Fundamentación del enfoque metodológico de la investigación. ................249

5.1.1. Selección y fundamentación del enfoque metodológico..................249

5.1.2. Rigor científico en la metodología de investigación........................262

5.1.3. Cuestión ética en la metodología de investigación........................267

5.2. Problemática de partida y objetivos de la investigación........................269

5.3. Informantes y sujetos del estudio..........................................282

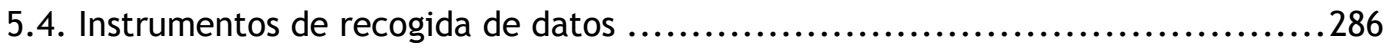

5.4.1. Análisis documental y Plantilla de Evaluación del Diseño...................287

5.4.2. Recogida datos en el Entorno Virtual de Aprendizaje......................288

5.4.3. Entrevistas en profundidad............................................ 288

5.4.4. Grupo de Discusión Comunicativo.......................................... 290

5.4.5. Cuestionario de evaluación de la acción formativa........................292

5.4.6. Cuestionario A.D.E.C.U.R...........................................293

5.5. Procedimiento para el análisis y tratamiento de datos..........................299

5.5.1. Estudio 1: revisión literaria para diseño. Evaluación de

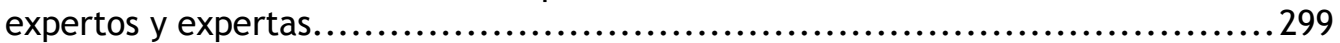

5.5.2. Estudio 2: Análisis de contenido cualitativo. ................................302

5.5.3. Estudio 3: datos descriptivos y triangulación de datos.....................306

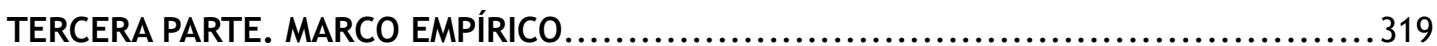

Capítulo 6. Diseño de la acción formativa virtual (Estudio 1)..............................321

6.1. Fase de Concepción...................................................... 325

6.1.1. Antecedentes del proyecto:La entidad promotora de la experiencia y el proyecto e-Kalex...................................................... 325

6.1.2. Motivaciones, reflexiones y finalidad de la acción formativa virtual. ........333

6.1.3. Selección de la Plataforma tecnológica de desarrollo de la acción formativa virtual. .............................................................. 340

6.1.4. Selección de expertos y expertas para la acción tutorial....................344

6.1.5. Modelo de planificación del diseño de la acción formativa. .................346

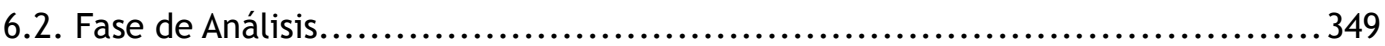

6.2.1. Análisis del público objetivo: destinatarias de la experiencia

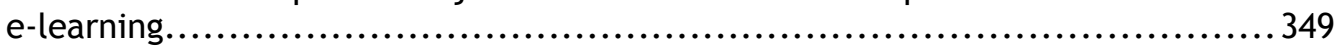

6.2.2. Resultados esperados en relación con los aprendizajes: método DAFO......363

6.2.3. Finalidad de esta experiencia formativa virtual con mujeres gitanas: cultivo de Comunidad de Práctica a través de entornos virtuales. 


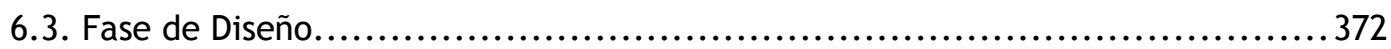

6.3.1. Diseño del Modelo Didáctico: Modelo de aprendizaje en el Espacio Virtual: estrategias didácticas y metodológicas..........................372

6.3.2. Diseño General de la acción formativa virtual. .......................... 385

6.3.3. Diseño de unidades de aprendizaje. ..................................... 393

6.3.4. Diseño de la estrategia de motivación. ................................400

6.3.5. Diseño de la interacción. .............................................408

6.3.6. Diseño del Sistema de evaluación.........................................448

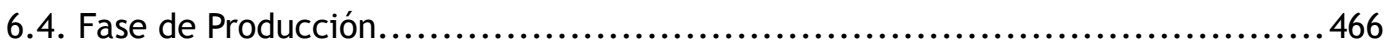

6.5. Fase de Evaluación..................................................... 478

Capítulo 7. La construcción de la Comunidad de Práctica a través de

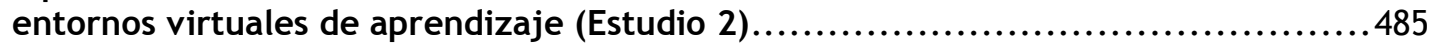

7.1. Contexto del estudio...................................................... 489

7.2. Análisis de foros........................................................... 491

7.2.1. Análisis de Foro «Entre Callis» .....................................494

7.2.2. Análisis de los Foro Sociales de Trabajo....................................528

7.2.3. Análisis del Foro de Tutorías.............................................577

7.3. Resultados......................................................... 580

7.3.1. Presencia Social...................................................... 580

7.3.2. Presencia Cognitiva................................................ 588

7.3.3. Presencia Docente............................................... 592

7.3.4. A modo de resumen.......................................................596

Capítulo 8. Evaluación de la aplicación de la acción formativa virtual (Estudio 3)....601

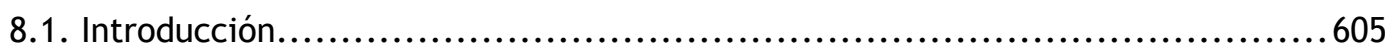

8.2. Datos relativos al Cuestionario de Evaluación del Curso: participantes...........606

8.3. Datos relativos a la Evaluación del Modelo de estrategias didácticas desarrolladas en el Curso: Expertos externos.........................................6622

8.3.1. Explicación del instrumento de evaluación y expertos seleccionados.

8.3.2. Resultados de la evaluación de expertos en referencia al modelo y estrategias didácticas utilizada en el curso virtual «/gualdad de Oportunidades y Liderazgo Social»

8.4. Análisis e interpretación de los datos obtenidos en la evaluación del desarrollo de la acción formativa virtual: participantes y profesorado-tutor..........630

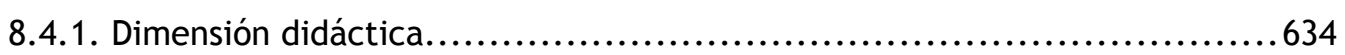

8.4.2. Dimensión sociocultural............................................6 672

8.4.3. Dimensión tecnológica.............................................693

8.4.4. Resumen de resultados por dimensiones. ..................................695

Capítulo 9. Conclusiones y Prospectiva.......................................... 703

9.1. Introducción: Cerrando Perspectivas........................................ 707

9.2. Conclusiones........................................................... 708

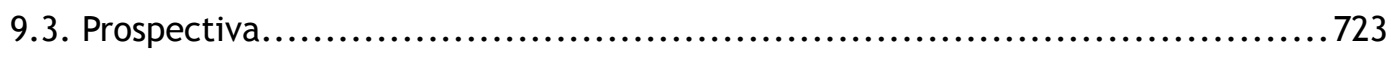


Apéndices................................................................... 731

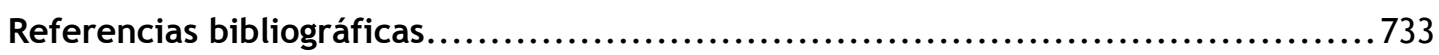

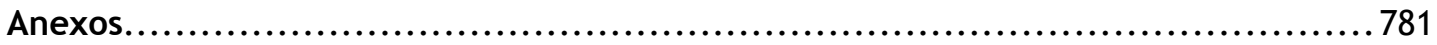

Índices de figuras, tablas y gráficos........................................ 783 


\section{Capítulo 1. Introducción}

«Pienso que la tecnología es como el caballo de Troya, porque en la historia real del Caballo de Troya, no fue el caballo el que fue efectivo, sino los soldados que contenía. Y la tecnología sólo será efectiva a la hora de transformar la educación si se introduce un ejército que esté decidido a llevar a cabo dicho cambio una vez superados los obstáculos» .

(Seymour Pappert, 1999)

\footnotetext{
$1 \quad$ Nota original: «I think the technology serves as a Trojan horse all right, but in the real story of the Trojan horse, it wasn't the horse that was effective, it was the soldiers inside the horse. And the technology is only going to be effective in changing education if you put an army inside it which is determined to make that change once it gets through the barrier». Disponible http://www.papert.org/articles/GhostInTheMachine.html.
} 

Figura 1. Estructura básica de la Tesis Doctoral

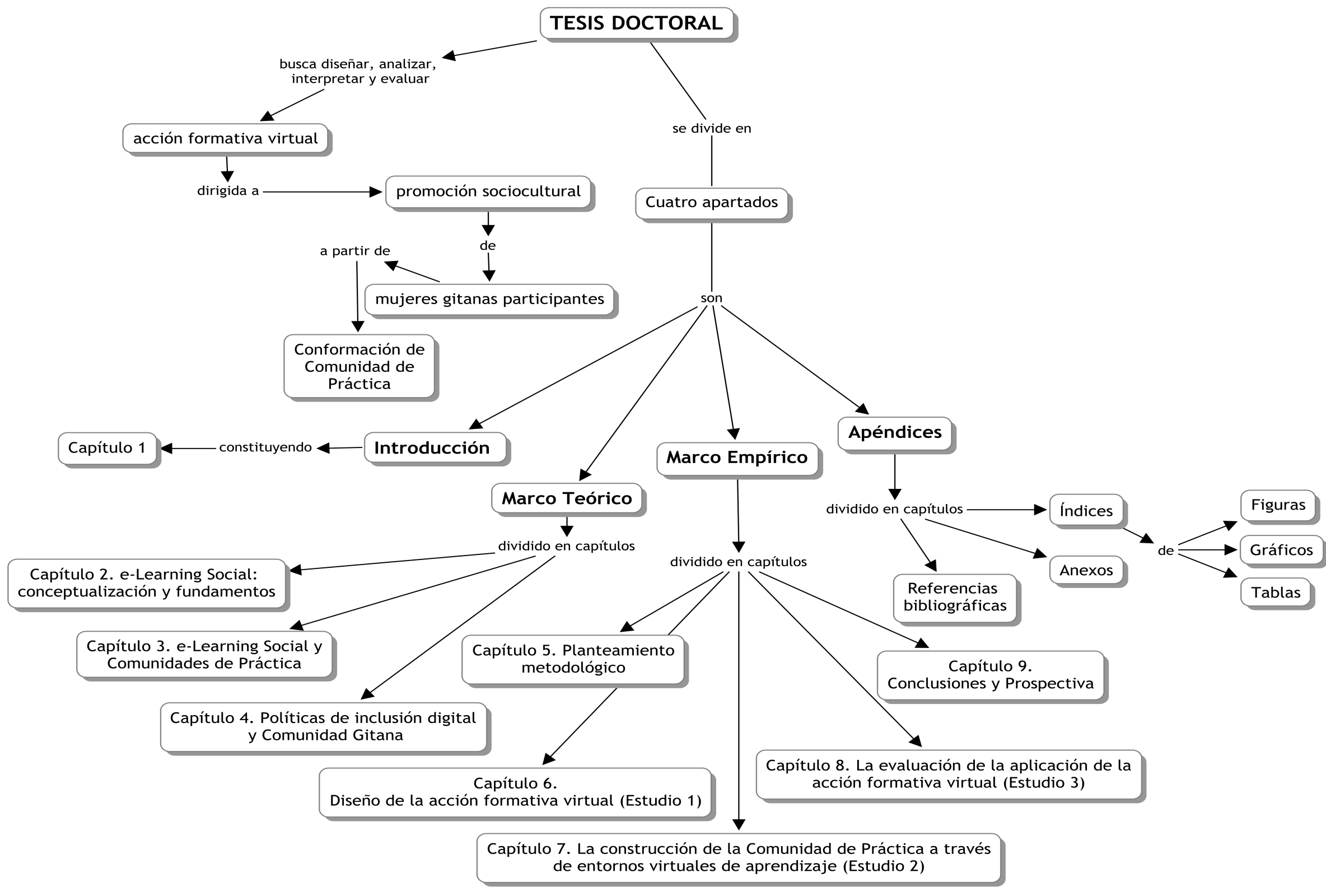





\subsection{Abriendo puertas...}

Observamos que, desde hace varios años, hay un continuo debate académico y variadas investigaciones sobre el uso de recursos tecnológicosdidácticos en la formación en los denominados entornos virtuales de aprendizaje (EVA). Cambios metodológicos, nuevos modelos de aprendizaje, nuevas estrategias didácticas, redefinición del rol del docente y del estudiante, entre otros, son los aspectos más debatidos en la actualidad entre los profesionales de la Tecnología Educativa. Cada vez encontramos más estudios y experiencias de calidad en e-learning desde un corte pedagógico, estudiando la combinación óptima entre los elementos tecnológicos, pedagógicos y organizativos de los entornos virtuales de aprendizaje en el ámbito de la educación formal. Sin embargo, en el ámbito no formal, aún se detecta una escasez de investigaciones empíricas o experimentales que comprueben la adaptación real de los espacios virtuales y su aplicabilidad eficiente a los procesos educativos, así como el diseño y aplicación de herramientas de evaluación rigurosas para garantizar qué estrategias han de prevalecer en qué circunstancias y contextos. Dicho de otra manera, podría decirse que aún no existe cultura disponible suficiente, aunque no sea más que por lo reciente de esta tecnología, para toda la variedad de contextos en los que tienen lugar los procesos de formación, en los que las tecnologías digitales podrían ser aplicables.

En este sentido, esta Tesis pretende aportar estrategias que puedan guiar procesos de e-learning en un ámbito no formal dirigidas a colectivos específicos, que se orienten a la creación de Comunidades de Práctica (Wenger, 2001) en entornos virtuales de formación. Estas estrategias, definidas a partir del constructivismo social (Vygotsky, 1979; Vygotsky, 1985) concretamente desde la perspectiva del aprendizaje colaborativo, 
(Koschmann, 1996; Crook, 1998; Lethinen et al., 1999; Rodríguez et al., 2000; Gros, 2002, 2008) van a guiar el diseño del proceso formativo para un grupo previamente constituido de mujeres gitanas, estableciendo como unidad de análisis una comunidad de aprendizaje virtual concreta, creada para el desarrollo de una acción formativa, orientada a impulsar la promoción social y cultural del grupo étnicamente diferenciado y dirigida a crear una Comunidad de Práctica (Kimble, Hildreth y Wright, 2001; Wenger, 2001; Kimble y Hildreth, 2008).

Tratamos de investigar, por una parte, la aplicación de estrategias didácticas para conformar un diseño pedagógico de una acción formativa en modalidad virtual, analizando, desde este punto de vista el proceso de diseño, elaboración, desarrollo y evaluación del mismo. Y por otra, investigamos el contexto, a través de las dimensiones de la práctica que dan coherencia a la comunidad en un espacio virtual de formación y la identidad de participación de las mujeres destinatarias en sus interacciones para la negociación de significados: la finalidad es poder llegar a interpretar, desde el modelo de presencia social, cognitiva y docente de Garrison y Anderson (2005) cómo el diseño propuesto, en el marco de una comunidad virtual, sirven de contexto para el aprendizaje (historias compartidas de aprendizaje) (Scardamalia y Bereiter, 1994, 2006; Garrido, 2003) y para la generación o construcción social de conocimiento en la comunidad étnica indicada. Esto es, pretendemos mostrar las posibilidades de empleo de las Tecnologías de la Información y Comunicación, en adelante TIC, para promover la construcción social de conocimiento, la motivación, la creatividad e incluso la promoción social y cultural. Todo ello desde una mirada pedagógica a lo que ocurre en una experiencia no formal, no escolarizada, autoiniciada y de interacción a través de las TIC, con mujeres que pertenecen a un grupo étnico definido, mujeres gitanas, y a un contexto sociocultural, económico, cultural, político y geográfico concreto: la Comunidad Autónoma de Extremadura. 
Creemos que la actual Sociedad de la Información y del Conocimiento nos sitúa en un escenario adecuado para intensificar la lucha por sociedades más igualitarias y más justas. Valverde (2011:9) afirma que, desde el marco de la Tecnología Educativa, los investigadores e investigadoras queremos contribuir a la mejora de la educación porque «entendemos que una ciudadanía bien formada conduce a una sociedad más justa y desarrollada». Este trabajo de investigación, y en concreto la acción formativa online que se ha diseñado e implementado, apostaba por la generación de sinergias que transformaran a las mujeres destinatarias en agentes multiplicadores dentro de su propia comunidad. Aunque actualmente Internet está muy presente en todos los ámbitos de la vida y se trabaja desde las instituciones públicas para que llegue a todas las personas, falta mucho para lograr que sea accesible para todos y todas. La inclusión digital no sólo fomenta el acceso a la información, sino que lo promueve como un derecho fundamental siendo un factor clave para el desarrollo democrático y la ciudadanía plena. En este sentido, los sectores más vulnerables se ven afectados por la existencia de la llamada brecha digital, que según Norris (2001) tiene su origen en múltiples factores interrelacionados tales como la pobreza, la falta de políticas adecuadas, el analfabetismo y los bajos niveles educativos. A su vez, la brecha digital impacta al interior de las sociedades por causas de género, edad, etnia y clase social. Una de estas desigualdades, especialmente la marcada por las relaciones de género, afecta especialmente a las mujeres en el uso y apropiación de las TIC, dando lugar a una infrautilización de las tecnologías como herramientas de participación civil y política, incidiendo en el pleno ejercicio de su ciudadanía. El espacio virtual va reproduciendo, entonces, las desigualdades existentes en el mundo real, aunque simultáneamente,. tiene el potencial de favorecer procesos de desarrollo y aumentar las opciones de acción en la toma de decisiones. Mediante la adquisición de los conocimientos básicos y necesarios, las mujeres pueden hacer un uso creativo 
y productivo de las TIC y de ese modo potenciar sus capacidades, amplificar sus voces y salir del espacio localizado territorialmente al espacio virtual.

Desde esta visión, las TIC pueden colaborar al empoderamiento de grupos, especialmente de mujeres, porque sirve como medio para aumentar las capacidades de organización y actuación, de defensa de los intereses a través de los recursos virtuales y, por otro lado, permiten acceder a información y conocimientos y compartirlos. También son medios que pueden ayudar a favorecer el aspecto individual porque brindan oportunidades de estudio y desarrollo personal debido al carácter flexible en el manejo del tiempo que permite combinar las aspiraciones de crecimiento laboral y profesional con las aspiraciones personales.

Bajo esta perspectiva, la propuesta que se presenta, apunta más allá de la inclusión digital de las mujeres gitanas, aportando una nueva formación que genere, a su vez, un modelo de intervención: queremos que la adquisición y apropiación de estas herramientas influya en sus radios de acción y en otras mujeres gitanas de su entorno. Y, además, provoquen algún proceso de transformación personal y social a través de la comunicación de experiencias, informaciones y conocimientos entre ellas que generen redes de colaboración e intercambio. La comunidad gitana, de manera tradicional, se ha organizado horizontalmente en el contexto de su grupo social, cuestión que facilitado la adquisición de competencias relacionadas con el trabajo en equipo y con las competencias comunicativas, también propias de la dedicación a actividades comerciales (Vargas, 2004). La forma de vida de las mujeres gitanas, dentro de este entorno, está vinculada al contexto social y familiar, tejiendo una red de relaciones con la que comparten sus actividades sociales, laborales y familiares. Pretendemos que esta red se amplíe en el espacio virtual, conformando, a través de esta acción, una Comunidad Virtual de Aprendizaje de Mujeres Gitanas que pueda desembocar en una Comunidad de Práctica. 
Creemos que las experiencias desarrolladas en el espacio virtual por estas mujeres van a servirnos de referente para demostrar cómo desde la participación activa y las redes de intercambio de experiencias, información y conocimiento, se puede generar conocimiento colectivo, clave para ir provocando pequeñas transformaciones en su ámbitos sociales cercanos.

Por otro lado, creemos que se logrará una mayor calidad en los procesos de aprendizaje movilizando aquellas estrategias didácticas que mejor respondan a las características de las estudiantes, a la materia que estamos trabajando, a la organización y al contexto. Por tanto, planteamos el diseño pedagógico de una acción formativa virtual, que puede considerarse como un proceso de experimentación de un modelo de enseñanza-aprendizaje innovador y que presenta una fórmula integrada y combinada de estrategias didácticas y metodologías mediadas por las TIC.

Así, desde este planteamiento y con el interés de verificar si este proceso formativo consigue estas finalidades, presentamos este trabajo de investigación en la presente Tesis Doctoral.

Desde este punto de vista, y antes de plantear brevemente los antecedentes, nuestro estudio se enmarca dentro de las investigaciones derivadas de varias disciplinas (Sociología, Psicología, pero especialmente, Pedagogía: Teoría de la Educación, Tecnología Educativa, Tecnologías de la Información y la Comunicación). En el seno de éstas, nos situamos en la intersección del paradigma del e-learning social (Casacuberta, 2004; Días, 2004; Luque, 2004; Planella y Rodríguez, 2004a, 2004b y 2004c; Ros, 2004; Varis, 2004 y Wahrhaftig, 2004) de las Comunidades de Práctica (Kimble, Hildreth y Wright, 2001 ; Wenger, 2001; Wenger, McDermott y Zinder, 2002) y de las políticas de promoción social y cultural de la población gitana, temas que ocupan el marco teórico de este trabajo. 


\subsection{Antecedentes y contextualización}

Antes de abordar con mayor profundidad el trabajo de investigación, se considera necesario situar a la investigadora en un espacio y tiempos determinados.

Partimos del Programa de Doctorado «Procesos de Formación en Espacios Virtuales», que dirigía el Prof. Dr. D. Joaquín García Carrasco, Catedrático de Teoría de la Educación de la Universidad de Salamanca. Este Programa, que comenzó en el año 2000 pretendía, según palabras del Dr. García Carrasco, formar especialistas en diseño y gestión de espacios de formación dentro de los contextos que se originan por la aplicación de las TIC, esto es, entornos virtuales de aprendizaje, que además promoviesen el diseño y producción en equipo de recursos TIC.

Según recoge en su trabajo de Tesis el Dr. Francisco I. Revuelta (2009), han sido varios trabajos de Tesis Doctoral presentados en varias parcelas de este campo, generando diferentes líneas de investigación, que clasifica de la siguiente manera:

a) Investigación básica en procesos de formación en espacios virtuales, profundizando en la estructura interna de las TIC y sus aplicaciones en cuanto a lenguaje para la construcción de modelos para la investigación sobre procesos psicológicos superiores.

b) Investigación aplicada en procesos de formación en entornos virtuales, ahondando sobre el diseño de simulaciones de objetos digitales para la construcción de recursos formativos para los procesos de enseñanzaaprendizaje.

c) Investigación de prácticas formativas mediadas por los recursos tecnológicos, profundizando en el conocimiento de la interacción cooperativa, 
los objetos de aprendizaje, los repositorios digitales, etc. destinados a experiencias prácticas mediadas por las TIC. Dentro de esta línea se podría situar este trabajo de Tesis Doctoral.

Añadimos a estas líneas, la abierta por Revuelta (2009):

d) Investigación sobre la socialización mediada por tecnología o socialización online, reflexionando, desde este campo, sobre la transmisión de normas y valores sociales a través del texto que se escribe a través de la red.

Pese a que el Programa de Doctorado finalizó con el bienio 2006-2008, todas las investigaciones derivadas de éste, van conformando un cuerpo de conocimiento científico que sigue avanzando con este trabajo de investigación.

En el periodo de docencia del programa de doctorado y con el Prof. Dr. Ángel García del Dujo, Catedrático de Teoría de la Educación en la Facultad de Educación de la Universidad de Salamanca, surgió la idea de la Tesina, dirigida a crear un diseño pedagógico de un espacio virtual de aprendizaje dirigido a la tutoría de trabajadores y trabajadoras de la Pequeña y Mediana Empresa. Nació así la que denominamos Tutoría Telemática de Análisis, Detección y Evaluación de Necesidades (A.D.E.N.) para la PYME.

En una mezcla de motivos personales y profesionales esta línea no continuó avanzando para la Tesis Doctoral, aunque unos años después, en una intersección entre casualidad y búsqueda, me incorporé a la labor investigadora con una nueva línea de trabajo que unía todo lo aprendido durante el periodo de docencia e investigación del Programa de Doctorado conjugado con el ámbito profesional en el que estaba desarrollando mi trabajo. En este sentido, las preguntas que sitúan el problema de estudio y los objetivos de este trabajo de investigación no responden a algo aislado, externo a la propia investigadora, sino que se integra en mi propia vida 
profesional marcada, desde el comienzo, por la mejora permanente en la intervención a favor de la promoción sociocultural de la población gitana, un valor que me infundieron los propios gitanos y gitanas, mis compañeros y compañeras de trabajo en una entidad cuyos principios marcaron mi vida profesional y personal: la Fundación Secretariado Gitano. En esta entidad trabajé durante siete años, del periodo 2002 al 2009, hasta que me incorporé como docente en la Facultad de Formación del Profesorado de la Universidad de Extremadura.

Esa reincorporación a la investigación es una oportunidad que me llegó de la mano del Dr. Joaquín García Carrasco que me puso en contacto con el Dr. Jesús Valverde Berrocoso, profesor Titular de la Universidad de Extremadura, dándome este profesor la posibilidad de integrarme en su Grupo de Investigación reconocido «Nodo Educativo» ${ }^{2}$ y participar en las investigaciones que giraban en torno a la incorporación de las TIC en diferentes ámbitos. Ambas cuestiones, trabajo con población gitana y grupo de investigación, junto con un viaje a Bolivia para conocer de cerca proyectos de liderazgo con población indígena desarrollados por la Universidad Nur, me marcaron personalmente y son fundamentales y el germen de este trabajo de Tesis.

Como es evidente la Tesis abarca varios aspectos dentro de un repertorio mucho más amplio de la investigación en el ámbito de la Tecnología Educativa, cuyas líneas actuales se presentan como las siguientes (Area, 2011):

1. Las TIC en la educación escolar, abarcando lo referente a la formación del profesorado en tecnología y cultura digital; las aplicaciones didácticas de las TIC en el aula, tanto el software como las distribuidas a través de la web; el análisis y evaluación de proyectos y experiencias para la integración e innovación pedagógica de las TIC en el sistema 
escolar; y las implicaciones organizativas de las tecnologías en los centros educativos.

2. Las TIC en la docencia universitaria, con líneas específicas sobre el diseño, desarrollo y mantenimiento de campus virtuales en instituciones universitarias; el diseño, desarrollo y evaluación de cursos y programas e-Learning; y la utilización de Internet como recurso de apoyo en la enseñanza presencial en las modalidades de blended-Learning (bLearning) o de móvil-Learning (mLearning), así como la creación y desarrollo de campus y aulas virtuales, el asesoramiento y formación del profesorado, la utilización de recursos informáticos en el aula, etc.

3. Las TIC en la educación no formal que se subdivide en líneas de trabajo relativas, a las aplicaciones de las tecnologías en la formación de trabajadores y en la formación continua, la educación de personas adultas, y en las aplicaciones de las TIC en espacios y escenarios formativos como las bibliotecas, asociaciones culturales y juvenil, museos, y aquellas otras actividades formativas extraescolares.

4. Diseño, desarrollo y evaluación de materiales didácticos y software educativo que implica la creación de material educativo en formato multimedia; el desarrollo de webs y cursos online; y la investigación sobre software con propósitos educativos apoyados en la Inteligencia Artificial, en el aprendizaje colaborativo, en los recursos de la Web 2.0 (blogs, wikis, redes sociales, repositorios de archivos, entre otros) y de tecnologías específicas para sujetos con necesidades educativas especiales.

5. Medios de comunicación social y enseñanza. Se vincula a los medios de comunicación de masas (televisión, prensa y radio), incluyendo entre las líneas específicas la televisión educativa, los programas y 
experiencias de prensa escolar, la educación o enseñanza audiovisual, y el estudio de los efectos de la televisión e Internet sobre la infancia y juventud en la formación de valores, ideas y actitudes. También destaca la línea específica, de actualidad, relacionada con los videojuegos y las redes sociales entre la juventud.

6. Educación, tecnologías y cultura. Esta última línea de trabajo se centra en el análisis sociocultural de las tecnologías en la sociedad contemporánea y de los retos educativos que implican. Así, se trabajan cuestiones relativas a la reflexión sobre las nuevas metas, formas y desafíos educativos de la sociedad informacional; los efectos de las tecnologías digitales en la cultura actual, los cambios que se están produciendo en la adquisición de la cultura en la infancia y juventud y como consecuencia del uso (y abuso) de las TIC; y la alfabetización digital de la ciudadanía.

Esta Tesis podría situarse en la confluencia de la línea de investigación referida a la educación no formal y a la que hace referencia a educación, las tecnologías y la cultura, bajo una perspectiva de innovación educativa. A esto último se refiere Valverde (2011:9) cuando afirma que «creemos que la innovación educativa ha de ser tecnológica, no por moda, simples intereses económicos o esnobismo, sino porque dadas las competencias que la sociedad actual exige de sus ciudadanos, no puede prescindir de las posibilidades que nos ofrecen las herramientas disponibles, ni de las capacidades humanas que potencian y desarrollan». 


\section{Investigación Grupo «Nodo Educativo»}

Procesos educativos, realidad e intervención social

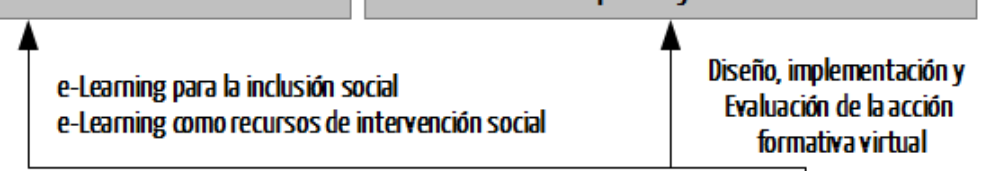

Investigación de prácticas formativas mediadas por los

융

recursos tecnológicos, profundizando en el conocimiento

de b interacción cooperativa, los objetos de aprendizaje.

los repositorios digitales, etc.

destinados a experiencias prácticas mediadas por bas MIC

\begin{tabular}{|l|c}
\hline $\begin{array}{l}\text { Acción formativa virtual } \\
\text { dirigida a mujeres gitanas }\end{array}$ & $\begin{array}{c}\text { Construcción de Comunidades de } \\
\text { Práctica desde el modelo } \\
\text { «Comunidad de Indagación» }\end{array}$
\end{tabular}

Análisis sociocultural de las tecnologís en la sociedad contemporánea y de los retos educativos que implican

\section{Investigación «Tecnología Educativa»}

Figura 2. Objeto de estudio de la tesis dentro del Grupo de Investigación Nodo Educativo, las investigaciones sobre Tecnología Educativa y las líneas del Doctorado.

Este trabajo se caracteriza por ser una conjunción especial entre teoría y experiencia, entre investigación y práctica, entre pedagogía y sociedad, fruto de unos años de trabajo constante para que la invisibilidad de las mujeres gitanas extremeñas deje paso a voces permanentes que serán escuchadas, de manera constante, con ayuda de los recursos tecnológicos de comunicación y difusión. He tenido la gran oportunidad de coordinar este proyecto de e- 
learning con mujeres gitanas. Con sinceridad, la cuestión tecnológica en referencia a las competencias básicas para el manejo del ordenador e internet en un curso online, no fue mi principal inquietud. El porqué está relacionado con el uso real de esta acción e-learning, es decir, mi preocupación principal se dirigía más a si funcionaría la estrategia de motivación, si participarían activamente, si abandonarían el proyecto, si entenderían esa metodología comunicativa y participativa que se alejaba de los modelos pedagógicos tradicionales que ellas habían vivido durante sus estudios primarios. Como indican Planella y Rodríguez (2004b:17):

\footnotetext{
«Lo más significativo no es tener las respuestas preparadas $-o$, si se quiere, conocer previamente la pregunta antes de que alguien la formule-; lo más significativo es estar abierto a la dimensión social del e-learning, ya que detrás de esta expresión que a veces puede sabernos a gustos «cool» aparecen los rostros de personas que con ilusión, esperanzas, utopías creen en la posibilidad de mejorar sus vidas, de mejorar sus relaciones y de transformar aquellos aspectos más problemáticos de su entorno».
}

Algunas lecturas relacionadas con estas temáticas, me ofrecieron la perspectiva de que es posible la mejora real de la práctica y la transformación social si incorporamos a nuestras prácticas, reflexiones, políticas e investigaciones lo que se ha denominado e-learning social (Casacuberta, 2004; Días, 2004; Luque, 2004; Planella y Rodríguez, 2004a, 2004b y 2004c; Ros, 2004; Varis, 200 y Wahrhaftig, 2004). Es, en el marco mencionado, donde se ubica el primer elemento de profundización de esta tesis, no solo conceptualizando la terminología, sino llevando a cabo una revisión de planes, programas y proyectos relacionados con el e-learning desde la perspectiva social. En esa línea también profundizamos sobre las políticas públicas de inclusión social de la población gitana, remarcando aquellas que se refieren a su inclusión digital. Las Comunidades de Práctica (Wenger, 2001), como nuestro punto de llegada, son abordadas desde la perspectiva de los modelos de «Comunidad de Indagación» de Garrison y 
Anderson (2005) y desde el estudio de las tres presencias, cognitiva, docente y social, para el cultivo, siguiendo a Wenger, de esa Comunidad de Práctica, que podríamos definir como social, por dirigirse, en última instancia, a la promoción sociocultural de las mujeres gitanas que la conformen.

Para todo ello, situándolo como segundo elemento clave, se realiza un primer estudio destinado a contextualizar y posteriormente diseñar, implementar y evaluar una práctica de e-learning dirigida a formar a mujeres gitanas en materia de Igualdad de Oportunidades y Liderazgo Social, fundamentada en competencias relacionadas con esa promoción sociocultural. Cabrera et. al (2005:82) en el estudio sobre «Nuevas Tecnologías y exclusión social» se centra en el análisis de el uso que se hace de las TIC en las entidades sociales que luchan contra la exclusión social, afirmando que «nunca o casi nunca se ha investigado en torno a las posibilidades que ofrecen las TIC para su incorporación social, como puede ser el caso de personas sin hogar, las minorías étnicas, los inmigrantes, los presos y ex presos, etc.».

Como tercer y cuarto elemento, situamos dos estudios derivados de esa implementación del diseño de la acción formativa virtual: un segundo estudio destinado a comprobar si se manifiestan las dimensiones del modelo «Comunidad de Indagación» (Garrison y Anderson, 2005) que derivan en la Comunidad de Práctica; y un tercer estudio que presenta los resultados de la evaluación de la acción formativa desde un análisis descriptivo-interpretativo de los resultados de las evaluaciones de las estudiantes, de expertas y expertos externos y del profesorado participante en el curso.

Los resultados de esta investigación aportarán estrategias concretas que pueden guiar la introducción de las TIC en la práctica educativa, en este caso desde un ámbito que vincula el formal y el no formal, reforzando esas nuevas formas de aprender en espacios virtuales colaborativos. Al caracterizar una comunidad virtual como herramienta de análisis y estudiarla desde una 
perspectiva educativa, en un entorno virtual de aprendizaje, vamos a aportar estrategias pedagógicas concretas que van a permitir aprovechar el potencial de la participación en estas comunidades para fines formativos. Debemos señalar que esta investigación tiene, además del valor científico que emerge de los resultados de la misma, uno social que aporta también originalidad al estudio desde el momento en que nuestro interés se dirige a estudiar cómo las TIC inciden en las dinámicas sociales y educativas y de qué manera, a través de ellas y en última instancia, se puede contribuir al bienestar y desarrollo general de un grupo de mujeres gitanas, que viven situaciones de hasta múltiple discriminación (Rey, 2008). Apuntamos que la contribución de las TIC al desarrollo sociocomunitario de esta comunidad puede constituir objetivo posible de investigación posterior derivada de esta tesis. Todo lo anterior implica un aporte al desarrollo de la denominada «perspectiva social del e-learning» (Planella y Rodríguez, 2004a, 2004b, 2004c). Por ello, planteamos un escenario en el que las TIC sean utilizadas desde una perspectiva social con el objetivo de contribuir a potenciar el empoderamiento de mujeres gitanas a través del aprendizaje a través de las TIC y, así, fomentar su liderazgo social dentro del grupo étnico al que pertenecen. Ante lo que puede ser un nuevo entorno de aprendizaje para estas estudiantes, se considera importante proporcionarles un ambiente que las anime a la construcción conjunta de conocimiento apoyándose en la reflexión crítica y la interacción social con otras en una comunidad que, al tener como objetivo común los aprendizajes, se puede identificar como una comunidad de aprendizaje (Palloff y Pratt, 1999; McConnell, 2000) facilitado por las TIC.

Por último, mediante este estudio detallado se extraen unas conclusiones, basadas en el análisis de los datos recogidos, que puedan servir como recomendaciones de mejora para diseñar, implementar y evaluar este tipo de acciones, destinadas a conformar Comunidades de Práctica. Las características de la investigación y la especificidad de la realidad estudiada, 
así como el periodo de estudio que se ha invertido en ella, hacen que se deba considerar como un estudio en profundidad, que abre nuevas líneas de trabajo y perspectivas de investigación.

La aproximación metodológica comprende la utilización conjunta de diversas metodologías, que se aplicarán a lo largo de las diferentes fases de la investigación, optando por una investigación multimétodo (Ruiz, 2008). Este enfoque puede ser entendido como una estrategia de investigación en la que se utiliza mas de un procedimiento para la indagación sobre un fenómeno u objeto de estudio a través de diferentes momentos del proceso de investigación. Dentro del enfoque multimétodo optamos por la tipología de métodos mixtos (Tashakkori y Teddlie, 2003) donde, en nuestro caso, teniendo una orientación epistemológica cualitativa, integramos algunas estrategias del enfoque cuantitativo para estudiar cuestiones referidas al mismo objeto de estudio. Categorizando los datos recogidos, con el posterior análisis e interpretación, cumpliremos con el objetivo general de la Tesis. Debemos aclarar que el desarrollo actual de investigaciones cualitativas en relación con las TIC y los espacios virtuales como lugares de interacción y de comunicación, nos permite determinar diferentes enfoques de la metodología cualitativa en estudios concretos, sus límites y sus posibilidades. En nuestro caso, situándonos en la fase central de la investigación, en la perspectiva de la investigación-acción, utilizando el método del estudio de caso trasladado a la virtualidad, tomando el ciberespacio como campo de estudio (Hine, 2000; Olsson, 2000; Domínguez, 2007). En este sentido tendremos que reformular y adaptar algunas técnicas en re-elaboración (Hine, 2000) por las características propias del campo de estudio. La muestra para la investigación está compuesta por un grupo de 20 mujeres gitanas.

La primera parte de nuestra investigación se encuadra dentro del área diseño pedagógico de un curso e-learning basado en teorías constructivistas del aprendizaje. A un nivel metodológico, para el desarrollo de este diseño, centramos nuestro trabajo en dos ejes principales: 
1. A través del análisis exhaustivo de la bibliografía más destacada y actualizada, del estudio de investigaciones existentes relacionadas con la temática y de un proceso de debate con expertos de las áreas relevantes, se elabora el primer borrador del diseño pedagógico proponiendo las estrategias más adecuadas al marco teórico que asumimos. La primera validación del diseño se lleva a cabo por especialistas en la materia que dan su visión de la misma. Con ello, se trató de generar un proceso interactivo de revisión y mejora que desemboque en una especificación final y detallada del diseño pedagógico definitivo, cuyas estrategias se derivarán a la herramienta que se va a utilizar para la aplicación del mismo: la plataforma Moodle. Hemos elegido Moodle por considerar que asume los principios y perspectiva teórica de nuestro estudio (constructivismo social).

2. Paralelamente, en esta fase se determinará el proyecto docente del curso que se va a desarrollar en el campus virtual de la Universidad de Extremadura, soportado con la plataforma indicada, tramitando todas la gestiones académicas y externas necesarias para la puesta en marcha del curso en 2009, así como el establecimiento de las personas expertas que tutorizaron en cada temática y la búsqueda de presupuesto para llevarlo a cabo.

En la segunda parte de la investigación, la metodología llevada a cabo desde la perspectiva cualitativa proviene del paradigma epistemológico interpretativo: la metodología del estudio de caso, adaptando algunas de las técnicas que se derivan del mismo a la virtualidad -etnografía virtualizada o en línea (Ardèvol et al., 2003)-. Dentro de esta parte, se procede a la aplicación del diseño propuesto a la comunidad de aprendizaje virtual formada por 20 mujeres gitanas con iniciativas en la temática de la igualdad de género, la dinamización y el liderazgo social. Durante el proceso de aplicación se va validando el diseño pedagógico en coherencia con la 
perspectiva teórica propuesta, a la vez que estudiamos el contexto donde lo aplicamos, es decir, esa Comunidad de Práctica. Como hemos indicado con anterioridad, con la finalidad de lograr este propósito, se realiza un estudio de caso virtual de corte etnográfico desde la aproximación cualitativa del trabajo de campo, por un lado desde análisis de contenido y, por otro, desde la triangulación de datos. En este marco se añade el uso de dos instrumentos de carácter cuantitativo para completar este estudio.

Para esta metodología de estudio ha sido necesario reformular y adaptar las técnicas al ámbito de la virtualidad, y desarrollar instrumentos de recogida de datos, así como de codificación e interpretación de los mismos, utilizando como técnica la categorización (comparación en base a la categorización).

Desde esta aproximación multimetodológica, aunque destacando como nuestro referente principal el derivado del campo de la investigación-acción, aplicamos algunas de las técnicas asociadas a esta metodología adaptadas, como hemos indicado, al espacio virtual:

- Observación Participante: periférica (Lave y Wenger, 1991), periféricaplena y participación plena, a través de la grabación automática de datos. Al desarrollar el estudio de manera virtual, las interacciones y comunicaciones entre las mujeres participantes en la formación quedan recogidas automáticamente a través del espacio virtual de formación.

- Entrevistas, semiestructurada y en profundidad en modalidad presencial (Taylor y Bodgan, 1987) y online (Ardèvol et al., 2003) al profesorado-tutor.

- Cuestionario de evaluación de la acción formativa aplicado a las estudiantes. 
- Grupo de discusión comunicativo con participantes posterior a la realización del curso (Flecha, Vargas y Dávila, 2004).

Con la información obtenida, se realiza un análisis cualitativo de los datos e información recogida, utilizando la técnica de la categorización con la posterior interpretación de los resultados de la investigación.

A lo largo de este proceso se ha contado, en todo momento, con la ayuda de las mujeres a quienes se dedica nuestro esfuerzo investigador y creativo. $\mathrm{Al}$ mismo mismo tiempo que nos han revelado datos e informaciones que nos han permitido comprender nuestro objeto de estudio, han participado en el hecho de su creación.

\subsection{Objetivos de la investigación}

El título de esta Tesis engloba la finalidad fundamental de la misma, cultivar una comunidad de práctica a través de una acción formativa virtual dirigida a la promoción social y cultural de un grupo de mujeres gitanas. Para analizar si la finalidad se ha logrado, establecemos como unidad de análisis una comunidad virtual de aprendizaje formada por un grupo de 20 mujeres gitanas de la Comunidad Autónoma de Extremadura. De ahí, fijamos el objetivo principal de la Tesis:

1. Estudiar la conformación de una Comunidad de Práctica de Mujeres Gitanas a través del diseño, desarrollo, implementación y evaluación de una práctica de e-learning enfocada desde una perspectiva social.

Del anterior se derivan los tres primeros objetivos específicos del trabajo de investigación que se corresponde con el marco teórico y el primer estudio:

1.1. Describir un marco teórico que sustente la investigación desde la perspectiva del e-learning social derivado de los planes, programas y 
estudios científicos actuales de índole europea, nacional y autónomica, además de las políticas sociales dirigidas a la población gitana.

1.2. Establecer el enfoque de «Comunidades de Práctica» (Wenger, 2001) como punto de llegada y medio de promoción social y cultural de las mujeres gitanas en entornos virtuales de aprendizaje.

1.3. Elaborar un diseño pedagógico para un curso e-learning basado en los principios del constructivismo social, buscando dotar a las personas participantes en este curso de herramientas de capacitación necesarias para el diseño, desarrollo y evaluación de distintas dinámicas en torno al género, a la igualdad entre mujeres y hombres y a ejercer, de manera activa, el liderazgo social, estableciendo estrategias pedagógicas para su consecución basadas en la perspectiva mencionada.

Sobre la unidad de análisis mencionada, se aplican dos estudios más que, unido al anterior, constituyen los objetivos específicos de la Tesis:

1.4. Desarrollar y evaluar este diseño en aplicación experimental en un grupo concreto de mujeres gitanas establecido con enfoque de «Comunidad de Práctica» situada en entornos virtuales de aprendizaje desde el modelo «Comunidad de Indagación» y el estudio de la presencial social, docente y cognitiva.

1.5. Valorar, en referencia a ese modelo, si el cultivo de la Comunidad de Práctica se ha producido.

1.6. Validar el diseño pedagógico constructivista en el contexto de aplicación del mismo (Comunidad de Práctica) en un espacio formativo virtual, como es el campus virtual de la Universidad de Extremadura (UEx), a través de la evaluación de expertos externos y de los agentes participantes en la experiencia. 


\subsection{Estructura de la Tesis}

Esta Tesis se estructura en nueve capítulos. El capítulo primero, en el que se sitúa actualmente el lector o lectora, es el referente introductorio donde se explica brevemente el trabajo realizado, los objetivos de investigación y la estructura planteada. Los capítulos dos, tres y cuatro centran su atención al marco referencial o teórico de la misma. Los cuatro siguientes comprenden la parte dedicada a los estudios empíricos. El último capítulo recoge las conclusiones más destacadas de este trabajo y la prospectiva que deriva del mismo.

Con el capítulo segundo, e-Learning Social: Conceptualización y fundamentos, se pretende presentar, a partir de la revisión de textos y contextos, una mirada al e-learning desde una perspectiva social. Son múltiples las miradas que se pueden realizar al e-learning y muchas las perspectivas y los enfoques que de ellas se desprenden (Planella y Rodríguez, 2004b). Como indican los autores: «la mirada social al e-learning forma parte de lo que podríamos denominar el compromiso de la universidad en la transformación de la sociedad, aunque más allá de los aspectos ligados a la investigación, entendemos que la universidad debe implicarse en la sociedad, y una forma clara de hacerlo es a través del e-learning»(p. 7). Este capítulo contextualiza la perspectiva social del e-learning como base teórica para nuestra investigación, presentando los factores socioculturales que se deben tener en cuenta para asumir la visión de éste como motor de cambio y transformación social. Por otro lado se analizan sus fundamentos políticos y sociales internacionales, nacionales y regionales y se muestran estudios científicos y experiencias prácticas con la finalidad de vislumbrar los retos y repercusiones que supone como estrategia para intervención social ante determinados problemas específicos de este ámbito. 
En el capítulo tercero, e-Learning Social y Comunidades de Práctica, se sitúa el marco de referencia de los modelos y desarrollos de las Comunidades de Práctica en entornos virtuales de aprendizaje. Para ello se realiza una aproximación a éstas desde la perspectiva sociocultural, estableciendo un discurso sobre los procesos comunicativos y el aprendizaje en colaboración mediados por las TIC para facilitar la creación de Comunidades de Práctica en entornos virtuales de formación. Esta aproximación es necesaria para conocer y justificar dónde situamos nuestro campo de investigación. Para el estudio y la conformación de la misma se propone el modelo de «Comunidad de Indagación» de Garrison y Anderson (2005), a través de sus dimensiones cognitiva, social y docente.

Posteriormente, y para finalizar el marco referencial de la Tesis, en el capítulo cuarto: Políticas de inclusión digital y Comunidad Gitana, revisamos el marco europeo, nacional y regional a favor de la inclusión social de la población gitana, destacando aquellos aspectos que tengan relación con las TIC, el contexto de las investigaciones y prácticas reales relacionadas con el e-learning social. Por un lado, recopilamos los instrumentos relacionados con la inclusión social de la población gitana en el marco europeo, nacional y regional, y revisamos los aspectos relacionados con las TIC y la población gitana. Por otro lado, presentamos investigaciones e iniciativas y experiencias prácticas relacionadas con el e-learning para la inclusión social de este grupo social.

En una segunda parte, presentamos el Marco Empírico de este trabajo, comenzando por el capítulo quinto, que lleva por título Planteamiento Metodológico. Se ofrece, en este capítulo, el marco metodológico de este trabajo, estableciendo las preguntas y los objetivos específicos de los estudios que planteamos y recogidos en los capítulos sexto, séptimo y octavo. También se recoge el diseño general de la investigación, presentando y justificando los instrumentos utilizados y creados para los estudios. 
El proceso de investigación se comienza con el capítulo sexto, Diseño de la acción formativa virtual (Estudio 1), a través de un diseño completo de la propia acción formativa virtual desde las fases de concepción, análisis, diseño, producción y evaluación, siguiendo en modelo de diseño genérico ADDIE. En la fase de concepción se realiza un recorrido por los antecedentes del proyecto, las motivaciones y las primeras reflexiones sobre los fines del mismo. También se establece la selección de la plataforma de formación y los expertos y expertas que se van a encargar de la labor tutorial, así como la planificación estratégica y los modelos pedagógicos que la justifican. La fase de análisis realiza un estudio previo sobre las destinatarias de la acción formativa, los resultados esperados y las metas de la propia acción formativa. En la fase de diseño se presenta y justifica el modelo pedagógico, así como el diseño de las unidades de aprendizaje, la estrategia de motivación, la planificación de las interacciones y el sistema de evaluación. La siguiente fase, denominada de producción, plantea la arquitectura pedagógica de la acción formativa, conformando el diseño pedagógico en la propia plataforma virtual. Y por último, la fase de evaluación, establece la definición del objetivo de la misma y la identificación de aspectos, momentos, selección de responsables de los mismos y elección de las técnicas más adecuadas para realizar esas evaluaciones.

El capítulo séptimo, La construcción de la Comunidad de Práctica a través de entornos virtuales (Estudio 2), se realiza el estudio sobre la conformación de la Comunidad de Práctica a través del análisis de contenido cualitativo realizado a los foros de discusión de la acción formativa en las dimensiones social, cognitiva y docente propuestas desde el modelo «Comunidad de Indagación» de Garrison y Anderson (2005). Al final del capítulo se establecen los resultados por dimensiones y un mapa completo del estudio que refleja esos resultados.

El capítulo octavo, Evaluación de la acción formativa virtual, se aborda la evaluación de la experiencia desarrollada procediendo a la organización, 
análisis e interpretación de los datos relativos a la pertinencia de la aplicación del diseño, metodología, planteado a través de espacio virtual de aprendizaje, desde el punto de vista de las estudiantes, de expertas y expertos externos y del profesorado-tutor participante. Para un análisis más minucioso se divide el capítulo en tres partes, correspondientes a los datos relativos al cuestionario de evaluación de las participantes, a los datos de expertos y expertas sobre la evaluación del modelo de estrategias didácticas desarrolladas en la acción formativa virtual y, por último, los datos resultantes de la triangulación de datos en la evaluación del desarrollo de la acción formativa virtual por parte de los datos obtenidos a través del Foro de Evaluación y Autoevaluación, del grupo de discusión comunicativo con las mujeres participantes y de las entrevistas al profesorado-tutor, en la dimensiones didáctica, sociocultural y tecnológica.

Finalizamos el trabajo con las reflexiones y conclusiones finales que conforman el capítulo noveno, Conclusiones y Prospectiva, en el cual se presentan las conclusiones derivadas de los objetivos de investigación que se han tenido presentes durante todo el proceso. Desde la prospectiva, se reflexiona sobre propuestas y nuevas líneas de investigación que derivan de este trabajo de investigación.

En último lugar situamos un apartado de Apéndices que incluyen las referencias bibliográficas del trabajo, los anexos y los índices de las tablas, gráficos y figuras que recogemos en esta Tesis. 



\section{PRIMERA PARTE. MARCO TEÓRICO}





\section{Capítulo 2. E-learning social: conceptualización y fundamentos}





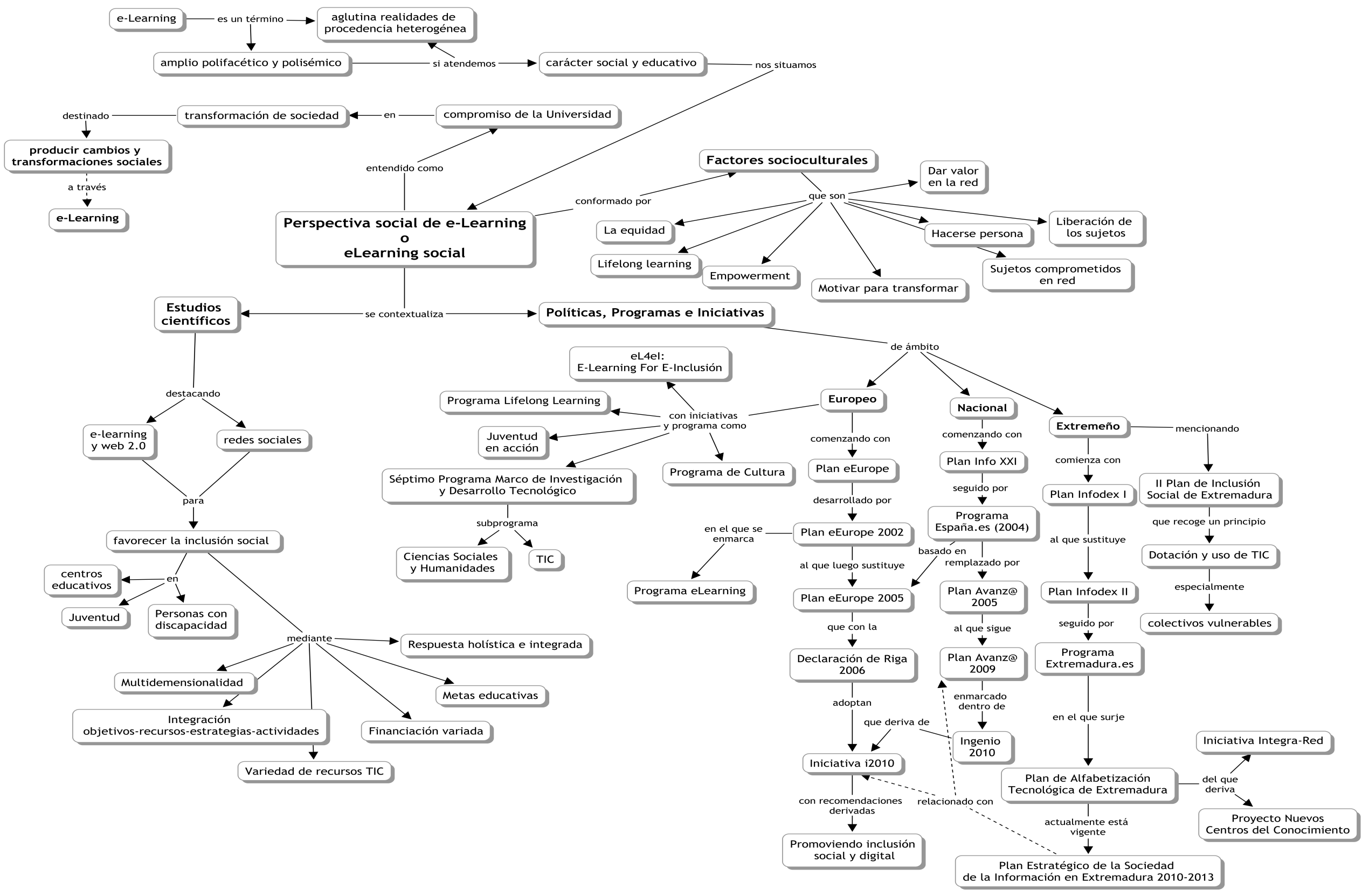





\subsection{Contextualización. E-learning social: la formación apoyada en TIC desde una perspectiva/óptica social.}

\subsubsection{Exclusión social, e-learning e inclusión digital.}

La sustitución del término «exclusión» por el de «pobreza» se produjo a partir de los años 80 por la Comisión Europea, debido a la extensión de un cierto consenso por superar la concepción economicista del concepto de pobreza, considerado como un problema de bajos ingresos (Laparra et al., 2007). El concepto de exclusión ofrece, en cambio, una perspectiva más amplia y compleja, además de dinámica, frente a la concepción estática anterior. La exclusión social incluye tres aspectos claves de las situaciones de dificultad: el carácter estructural, la idea multidimensional y la naturaleza procesual. Pese a las dificultades de plantear una definición, hay varios aspectos comunes en la mayoría de aproximaciones (Subirats y Gomà, 2004):

- La «exclusión social» se vincula a la idea de ruptura o déficits de los mecanismos de inclusión que existían en la sociedad industrial. El mercado laboral fordista y el Estado de Bienestar keynesiano no forzosamente generaban «igualdad», pero sí «inclusión».

- Se relaciona con los conceptos de «dinamismo» $\mathrm{y}$ «riesgo».

- La exclusión es un fenómeno dinámico: exclusión como trayectoria, itinerario, proceso y recorrido.

- Da una idea de democratización de los riesgos de exclusión (sociedad del riesgo). Ahora ya no podemos hablar de grupos vulnerables por definición y otros de no vulnerables; la exclusión es un fenómeno de geometría variable. 
- Se vincula con los conceptos de «diversidad», «pluralismo» y «complejidad». Ha tenido lugar una diversificación de los ejes de desigualdad. La exclusión no sólo se centra en el eje económicolaboral; nos encontramos en una sociedad más compleja y la exclusión tiene un carácter multidimensional.

Por otro lado, hace casi dos décadas que se viene debatiendo, sobre todo en el ámbito académico, el concepto «brecha digital» para referirse a la problemática generada por el impacto de la revolución tecnológica en las desigualdades que se acentuaban o generaban, debido a un acceso no equitativo a las Tecnologías de la Información y Comunicación, en primera instancia, en cuanto a infraestructura. Sumado al déficit de acceso a la infraestructura, se unían los debates sobre las desigualdades de uso, referido a la falta de equidad en la apropiación social de las mismas, es decir, en el valor que éstas tienen para procesar, seleccionar información, gestionar y producir conocimiento (Carracedo, 2006).

En la Carta Europea «e-Learning e Inclusión social» ${ }^{3}$ se sostiene que la brecha digital es multidimensional al igual que cualquier situación de exclusión social (Burchardt, Le Grand y Piachaud, 2002). Así se recoge:

«La brecha digital es un fenómeno multidimensional que incluye barreras de muy diverso tipo. Algunas de ellas -que resultan muy preocupantes- son de naturaleza mental, referida al lado del usuario de manera que la educación es la mejor estrategia para enfrentarse con estos problemas. Algunos de ellos, como la falta de confianza o de motivación están en el lado del usuario, pero también hay barreras en la producción de los sistemas e-learning, como el desarrollo de sistemas excesivamente formales, tecnologías no adaptadas, ausencia de contextos significativos y metodologías generalistas que no prestan la atención necesaria a los contextos culturales y sociales. (Carta Europea «e-Learning e Inclusión social», 2004:2).

Documento disponible en: learning_hacia_inclusion_social.pdf

http://tecnologiaedu.us.es/cuestionario/bibliovir/charter_E- 
Intentando equilibrar estas desigualdades y luchar contra la brecha digital, surgen acciones promovidas desde administraciones públicas y entidades sociales e incluso de empresa privada que promueven la inclusión digital de aquellos grupos sociales que, por diferentes factores -geográficos, étnicos, económicos, sociales y culturales-, se encuentran en situación de exclusión digital . Incluso, desde la sociedad y desde el ámbito educativo se comienza a mirar más allá de lo tecnológico, incorporando en proyectos y programas conceptos como «e-inclusión» o «e-exclusión» (Casacuberta, 2004).

La inclusión digital incide, como punto clave, en la necesidad de alfabetizar digitalmente (Area, Gros y Marzal, 2008), pero también sobre la relevancia de los contextos sociales y culturales de los grupos y/o personas con las que se interviene. Así, se entiende este concepto como un proceso que permite que todas las personas se aprovechen de todos los derechos y oportunidades que se derivan del acceso y uso de las TIC y además accedan a la información como un elemento esencial para la creación de igualdades sociales (Ortoll, 2007). La inclusión digital procura, de esta manera, dar a las personas herramientas y tecnologías que les permitan participar de manera democrática en la sociedad, cambiarla y mejorarla. En ese sentido Warschauer (2004) habla de una alternativa, basada en una reconceptualización de la brecha digital, del uso de la tecnología para la inclusión social.

En la literatura académica referida a esta temática, hasta hace relativamente poco tiempo, encontrábamos posicionamientos diferenciados sobre el papel de las TIC en cuanto a la dinámica inclusión-exclusión, en principio marcados por una cierta determinación tecnologista, con argumentos basados en el acceso y uso de las TIC en cuanto a infraestructuras o como herramientas -medios- y recursos (Carracedo, 2006).

En primer lugar, la argumentación más economicista giraba en torno a las TIC como nuevo factor de exclusión social, unida al concepto de «brecha 
digital». Desde este punto de vista las TIC provocan el progreso tecnológico, siendo parte ineludible del sistema económico de nuestra sociedad. En los grupos que, por determinadas circunstancias y de diversa naturaleza, no pueden acceder a estos medios, se aumenta la problemática existente, agravando, por consiguiente, su situación de exclusión social. Se puede decir, así, que la imposibilidad de acceso a las TIC se convierte en un nuevo factor de exclusión social. Siguiendo este argumento una persona estaría excluida digitalmente cuando «se ve privada de acceder a las oportunidades y a los derechos derivados del uso de las TIC o cuando no tiene capacitación para disfrutarlas» (Ortoll, 2007:4). Norris (2001) destaca que la brecha digital incluye tres fenómenos: una brecha global, la que se presenta entre los distintos países; la brecha social, que ocurre en el interior de una nación entre los diferentes grupos y la brecha democrática, que se refiere a la que existe entre quienes participan y quienes no participan online de los asuntos públicos.

Por otro lado, nos encontrábamos con el discurso de las oportunidades que ofrecen las TIC como complementarias a la inclusión social de estos grupos en situación de desfavorecimiento, es decir una argumentación con perspectiva más social. Así, los razonamientos se dirigen a las TIC como favorecedoras de nuevas formas de aprender, de acceder al conocimiento, de comunicarse, beneficiando considerablemente a estos grupos sociales. En este caso las TIC se analizan desde el punto de vista del e-learning, de la capacitación y formación y la validez de la información para las personas que pueden acceder a éstas.

Hallamos un tercer debate que se deriva del segundo, el más crítico, sobre la perspectiva de estar depositando una confianza excesiva en las TIC como procedimiento para remediar situaciones de exclusión social. Este discurso, resalta las posibilidades que las TIC ofrecen para los grupos a que nos referimos, pero insisten en la necesidad de incluir acciones políticas de tipo 
educativo, económico y social, que contribuyan a promover esta igualdad de oportunidades.

Estos debates se corresponden con el planteamiento de Martínez y Serrano (2003) sobre las diferentes etapas en las que se intenta aminorar la brecha digital, desde el comienzo con la dotación ordenadores y acceso a Internet pensando que sería suficiente para lograr un impacto en el crecimiento y desarrollo económico de las comunidades, a poner el énfasis en el aprendizaje y adquisición de competencias tecnológicas básicas. Definen así tres etapas u olas:

1. Una primera ola, que coincide con la burbuja de Internet, que calculó mal el grado de penetración de Internet en la población, y se basó en impulsar la dotación de equipos y accesos de Internet pero sin tener en cuenta, por ejemplo, la calidad del servicio (se implantaron muchas conexiones pero de baja calidad que restaban acceso a los mejores servicios). Esta etapa está caracterizada por la proliferación de telecentros, cibercafés, aulas de informática, etc.

2. La segunda ola avanzó más allá de la conectividad y se potenciaron aspectos de capacitación y formación, desarrollo de contenidos locales en base a las necesidades comunitarias. Es el período de la transición de telecentros a infocentros o centros comunitarios digitales. Estos centros incluyen servicios tecnológicos avanzados y favorecen la diseminación de la cultura digital en la población y su mejor aprovechamiento.

3. La tercera ola, en la que según los autores estamos en la actualidad, ya se cuentan con buenas prácticas y experiencias de desarrollo tecnológico comunitario y se puede valorar el impacto de las TIC en este ámbito. Los aspectos más importantes de esta tercera ola están siendo: favorecer el grado de participación comunitaria, innovación continúa en servicios y aplicaciones de los centros de desarrollo comunitario. En esta tercera etapa se ha logrado una relación importante con la economía y se está trabajando con las 
empresas de manera prioritaria logrando que el tejido productivo adquiera recursos tecnológicos y genere innovación.

Podemos entrever que la dinámica inclusión-exclusión digital es también un fenómeno multidimensional y complejo no sólo basado en el acceso o no a las tecnologías, sino además en cuestiones referentes a factores digitales, como la disponibilidad de contenidos, a competencias básicas en el uso de las TIC y a recursos sociales y comunitarios (Ortoll, 2007). Maya (2008) va más allá y afirma que la brecha digital se está transformando en una «brecha de innovación", donde el conocimiento, el trabajo en red, la educación y formación, además de la participación comunitaria conviertan los beneficios que nos aporta la tecnología en un bien social universal y que todo ello revierta al conjunto de la ciudadanía, entreviendo en esta idea que se considera a las TIC como motor de desarrollo sostenible. Por tanto, es necesario que esa tendencia mercantilista y tecnofílica se sitúe en posiciones que tengan en cuenta y acentúen la dimensión educativa, social y cultural de las TIC, y en concreto del e-learning, como motor para la construcción de engranajes sociales y para hacer frente a los retos y las desigualdades que inundan nuestra sociedad actual. En ese sentido ya hay algunas iniciativas comunitarias que sugieren que las TIC, en el desarrollo de grupos de mujeres en situación de vulnerabilidad social, suponen un elemento importante en la redefinición de las relaciones de género y de clase social (Lalueza, Crespo y Camps, 2008).

Cuestiones a tener en cuenta, como antes se indicaba en referencia a la Carta Europea EL4EI, es que la brecha digital no afecta de la misma manera a todos los grupos y sectores sociales, por tanto las soluciones que se aporten no podrán ser estandarizadas. Para promover la introducción de las TIC en un grupo determinado, es necesario hacerlo teniendo en cuenta la necesidad concreta del mismo, ya que la sola introducción de las TIC no garantiza el proceso de inclusión. En este sentido Londinsky (2011: para. 2) realiza esta reflexión: 
«Si bien generalmente se tiende a marcar los aspectos positivos y las posibilidades que se abren con las TIC, se corre el riesgo que parte de la sociedad quede rezagada en la sociedad del conocimiento y la información y que las TIC sean un factor mas de inclusión/exclusión en nuestras sociedades, es por esto que se hace cada vez mas relevante un análisis social a la hora de implementar programas y proyectos que abarquen estas tecnologías y en el e-learning en particular».

Con este marco, no es nuestra intención detenernos más en la brecha digital como modo de exclusión social, sino en profundizar en esos aspectos sociales del e-learning una vez superada la primera dificultad derivada de la brecha social que constituye, en primera instancia, el acceso a la información a través de las TIC.

\subsubsection{La formación apoyada en TIC desde una perspectiva social: el e-learning social.}

El hecho indiscutible de que las Tecnologías de la Información y Comunicación estén plenamente instaladas en el seno de nuestras relaciones, formas de comunicación, de formarnos y aprender, sigue superando nuestros límites geográficos, temporales e incluso, intelectuales. Constantemente, desde el mundo educativo, nos encontramos inmersos en debates, discusiones sobre soluciones creativas para hacer frente a los retos actuales que están provocando la incorporación de las TIC en nuestras vidas, y más concretamente, en el ámbito educativo. Como fenómeno social y cultural, se reflexiona e investiga sobre las transformaciones sociales, las nuevas formas de interacción, los nuevos cambios que tendremos que asumir en el futuro de la educación.

Cuando hablamos de e-learning y hacemos una revisión de literatura actual, observamos el amplio campo de significados que desde este concepto se abordan. Como indica Planella y Rodríguez (2004a) es un término amplio, polifacético y polisémico, que conlleva multitud de formas de definirlo, 
orientarlo, darle sentido desde el punto de vista de las diferentes implicaciones que refleja y da forma a una determinada visión del mismo. $\mathrm{O}$ como indica Barberà (2008), el concepto aglutina realidades de procedencia heterogénea. Este hecho se reafirma si observamos el siguiente cuadro propuesto por la autora sobre las fuentes principales de las que se nutre el concepto de «e-learning».

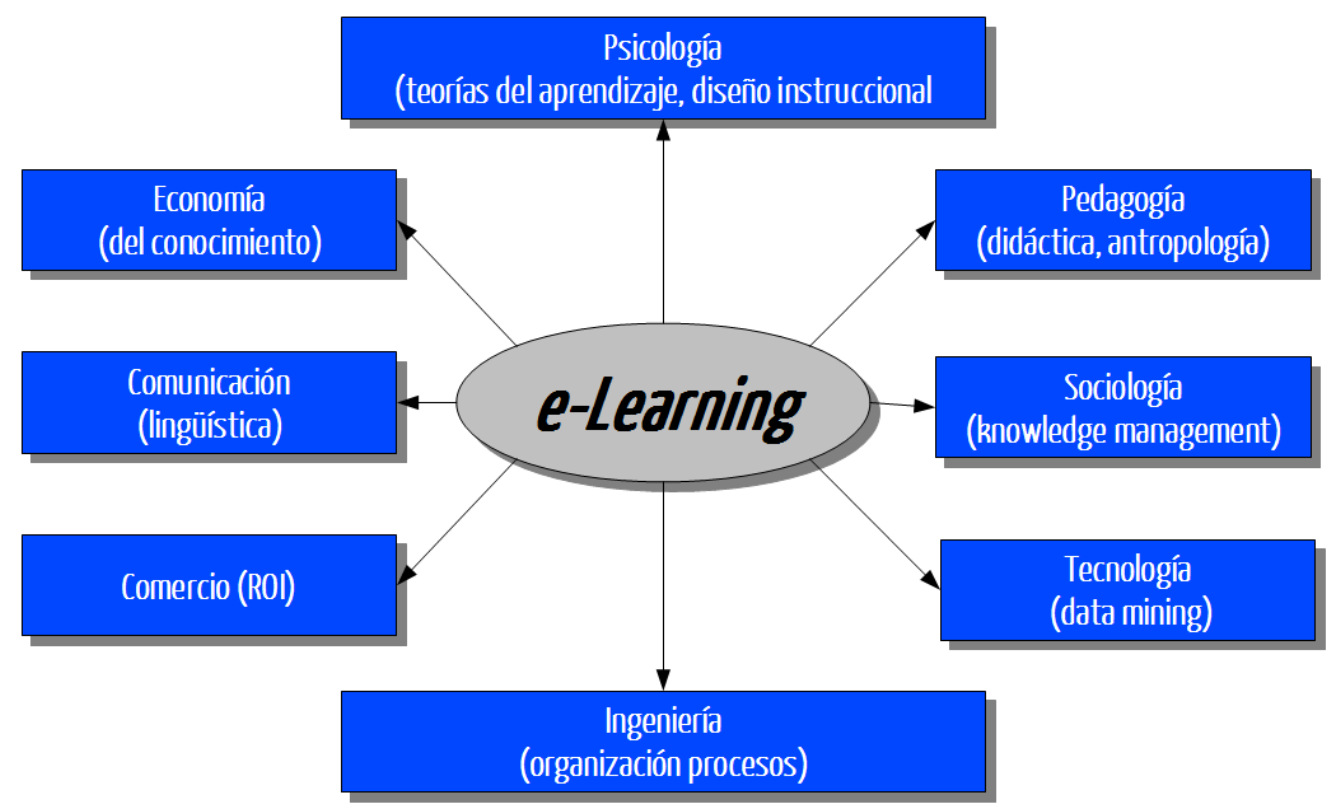

Figura 4. Fuentes principales de las que nutre el concepto de e-Learning (Barberà, 2008:24)

Es decir, dependiendo del reto, obstáculos, definiciones, usos $\mathrm{y}$ aplicaciones que se hagan en un determinado contexto social, educativo, económico e incluso geográfico, tendremos una visión diferente de un mismo concepto. Como ejemplo, Peña (2003) hace referencia a lo que llama «elearning solidario» como aquel que se utiliza para la sensibilización de la sociedad sobre temáticas o disciplinas del ámbito de la solidaridad, la cooperación al desarrollo, la cultura de paz, la sostenibilidad, etc.; la formación y capacitación de personal propio, cooperantes y voluntarios de 
entidades sin ánimo de lucro y vinculadas a los ámbitos enumerados anteriormente; la capacitación para el desarrollo, dirigida a dotar de habilidades a grupos en riesgo de exclusión o sociedades subdesarrolladas o en vías de desarrollo. Desde este punto de vista encontramos autores que manifiestan su carácter «jánico» (Planella y Rodríguez, 2004c), afirmando que puede ser representado como una práctica educativa con más de una cara.

De este modo, reconocemos el carácter polivalente, y sobre todo social y educativo, del e-learning, y es desde esta visión desde la que, atendiendo al carácter contextual de aplicación de un proceso de formación virtual (González y Hernández, 2008), nos situamos en la perspectiva social del elearning o, como lo denominan varios autores del e-learning social (Peña, 2003; Luque, 2004; Planella y Rodríguez, 2004a; Wahrhaftig, 2004; entre otros).

En 2004 el primer número de la Revista de Universidad y Sociedad del Conocimiento (RUSC), dedicó el monográfico al e-learning social. Los autores y autoras participantes en este número (Planella y Rodríguez, 2004a, 2004b y 2004c; Ros, 2004; Luque, 2004; Casacuberta, 2004; Días, 2004; Varis, 200 y Wahrhaftig, 2004) presentan su visión sobre la perspectiva social de e-learning, como un nuevo paradigma. Cuando hablamos de elearning social o la perspectiva social del e-learning nos estamos refiriendo, siguiendo a Planella y Rodríguez (2004b), al «compromiso de la universidad en la transformación de la sociedad». En este sentido la Universidad se implica en el proceso de transformación social, con desarrollo de modelos formativos que acojan la dimensión social, esto es, la responsabilidad y el compromiso social de disminuir determinadas desigualdades.

Ros (2004) destaca los motivos por los que es importante considerar el elearning desde esta perspectiva social: 
- Primero, porque el e-learning es una realidad basada en formas de interacción social.

- Segundo, porque plantea nuevos retos para la inclusión social de diferentes grupos sociales.

- Tercero, porque el e-learning plantea nuevas formas educativas que superan las fronteras territoriales y culturales.

- Cuarto, porque supone una transformación del entorno educativo que conlleva una redefinición de los roles de los diferentes agentes y del proceso de aprendizaje.

Hace ya unos años, desde la declaración de la conferencia «E-learning hacia la inclusión social», realizada en 2004, se hacían eco de la necesidad de investigaciones sobre la perspectiva social del e-learning:

«La investigación es clave. No disponemos de análisis precisos de los enlaces entre factores de exclusión y de cómo están relacionados con las TIC. Hay una necesidad muy clara de financiar programas de investigación que nos ayuden a comprender los diferentes grupos de exclusión en línea y en que difieren en función de edad, origen étnico o género» (Declaración eL4eI, punto 2)4.

Pese a que las investigaciones han aumentado sutilmente en los últimos años, siguen sin dedicarse los suficientes espacios, tiempos y recursos en los programas y publicaciones científicas. Planella y Rodríguez (2004b) dividen las investigaciones sobre e-learning desde una perspectiva social en dos niveles, el primero más desarrollado desde el punto de vista científico que el segundo.

- Uno referido a las investigaciones de aspectos más tecnológicos, es decir, estudios sobre plataformas digitales, costes, diseño instruccional, programación, etc.

\footnotetext{
4 Disponible en:

http://tecnologiaedu.us.es/cuestionario/bibliovir/charter_E-learning_hacia_inclusion_social.pdf
} 
- El otro sería el referido a los aspectos sociales, menos investigado, que presenta estudios sobre la interacciones social, la inclusión/exclusión social, las transformaciones sociales, etc.

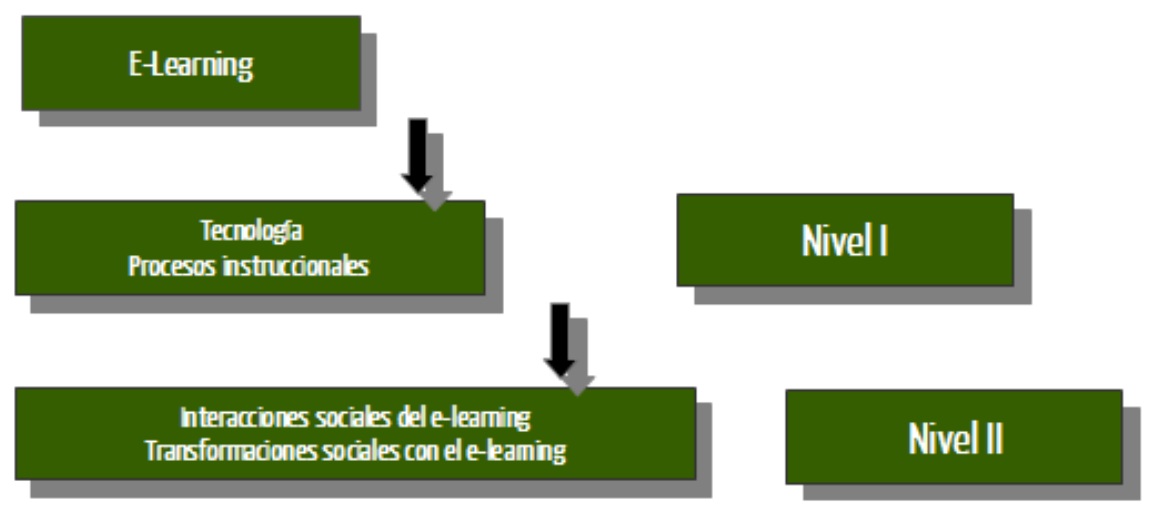

Figura 5. Niveles de investigaciones sobre e-learning social (Planella y Rodríguez, 2004b:12)

Hasta hace relativamente poco tiempo, las investigaciones primaban el primer nivel. Actualmente, y como veremos a continuación, se ha producido, sobre todo en los últimos años, un aumento de investigaciones referidas a este último nivel, sobre todo desde el ámbito europeo. Desde estas investigaciones se entiende que el e-learning es un agente social de cambio, destacando el aspecto transformador de realidades sociales, actuando como elemento preventivo, catalizador o favorecedor de la inclusión social, y digital por consiguiente, de las personas. Desde este punto de vista las investigaciones de procesos e-learning desde una mirada social, incorporan a los sujetos como actores de los estudios científicos, desarrollando procesos de Investigación-Acción Participativa, en los que las personas destinatarias de las acciones e-learning, se convierten en constructoras y productoras de conocimientos, investigando sus propios procesos.

Desde las teorías del aprendizaje, la mayoría de los proyectos que incluyen experiencias de e-learning social, están dominadas por el constructivismo y 
enfoques de aprendizaje colaborativo que fomentan la participación de las personas destinatarias como coproductores del conocimiento (Cullen et al., 2010).

Si se revisa la literatura sobre el e-learning y su vínculo con la exclusión social se muestran dos posiciones polarizadas: la perspectiva más positiva, cuyo argumento se centra en que la integración de las TIC en los ámbitos educativos, sociales, económicos y culturales están impulsando la e-inclusión (Selwyn y Facer, 2007; Redecker et al., 2009). Y la argumentación más pesimista cuyo razonamiento se sitúa más en que el acceso a las TIC, el uso y la calidad de uso está altamente relacionado con la exclusión social, y que ésta lo que provoca es un aumento de las diferencias sociales en lugar de disminuirlas (Helsper, 2008). Por ello, algunos autores (Larrañeta, 2004; Planella y Rodríguez, 2004b) nos sugieren que cuando queramos poner en marcha proyectos e-learning desde el punto de vista de la inclusión digital, desde el ámbito educativo, debemos cuestionarnos si realmente estos proyectos van a ser inclusivos y democráticos o si van a generar una brecha social aún más profunda. Londinsky (2011) nos indica a este respecto que son numerosos los proyectos que han fracasado por priorizar un enfoque tecnológico sin acompañarlo de una perspectiva pedagógica (García del Dujo y Martín, 2002), es decir, se limitan a facilitar el acceso a la tecnología pero sin incluir programas de acompañamiento, dinamización y capacitación para saber usar los recursos. 


\subsection{Fundamentos internacionales, nacionales $y$ regionales y bases científicas del e-learning social.}

\subsubsection{Estudios científicos sobre e-learning para la inclusión social.}

Los estudios científicos referidos a la inclusión social y las TIC son escasos en la actualidad, aunque en los realizados muestran su potencial para la inclusión social y la promoción de la participación de grupos en situaciones o riesgo de exclusión (Redeker et al., 2009; Cullen et al., 2010). Estos estudios se puede clasificar según cuatro finalidades:

- Reducir el aislamiento social.

- Promocionar la reinserción en el mundo educativo.

- Mejorar la salud y el bienestar de las personas con discapacidad.

- Mejorar la igualdad de oportunidades de determinados grupo, sobre todo en referencia al empleo.

Entre estos estudios, destacamos, en primer lugar, el trabajo de Joe Cullen, Clare Cullen, Damian Hayward y Veronique Maes (2009), con el título «Good Practices for Learning 2.o: Promoting Inclusion». Este estudio investiga en profundidad ocho iniciativas de e-learning con web 2.0 dirigidas a alumnado en riesgo de exclusión, poniendo de relieve el potencial del elearning para la apertura de oportunidades de aprendizaje a personas en riesgo de exclusión. Destacan varias problemáticas encontradas como las referidas a cuestiones técnicas, motivación y compromiso de los alumnos y alumnas, competencias digitales, acreditaciones finales y financiación de los proyectos. Sin embargo, también se identificaron varias tendencias favorables en referencia al e-learning: el enfoque constructivista basado en la 
participación del alumnado, la utilización del blended e-learning, el equilibrio entre las necesidades de los estudiantes y las opciones tecnológicas y pedagógicas seleccionadas, el aprendizaje colaborativo, todas consideradas estrategias clave del éxito de las prácticas estudiadas.

Otro estudio es el realizado por Christine Redecker, Kirsti Ala-Mutka, Margherita Bacigalupo, Anusca Ferrari e Yves Punie (2009), con el título «Learning 2.o: The Impact of Web 2.0 Innovations on Education and Training in Europe». Este constituye un informe de los resultados de un estudio exploratorio de 16 estudios de caso, destinado a investigar cómo las aplicaciones de la web 2.0 se pueden utilizar en entornos de aprendizaje organizados para mejorar y promover la inclusión en el mundo educativo. Entre las dificultades encontradas, muestra la resistencia del profesorado a las TIC, ya que las nuevas metodologías exigen nuevos roles docentes, que a su vez requieren formación didáctica para poder asumir ese nuevo papel. Por otro lado, se destacan como límites, la fiabilidad de los contenidos que generan los y las estudiantes, la evaluación adecuada de las estrategias utilizadas, de los aprendizajes y de las metodologías. En cuanto a los resultados de los estudios de caso, destacan que estas metodología basadas en e-learning pueden utilizarse para aumentar la motivación individual, mejorar la participación del alumnado y fomentar dinámicas sociales y colaborativas; además de para el aprendizaje de habilidades cognitivas superiores, como la reflexión y la metacognición, y para mejorar el aprendizaje autónomo, desarrollando el potencial personal de cada estudiante.

El estudio realizado por Jean Johnson, Jonny Dyer, Carole Chapman, Richard Hebenton, Ben Lockyer y Kate Luck (2009) titulado «Online Mobile Communities to Facilitate the Social Inclusion of Marginalised Young People (Come In): Literature Review on Online Communities». En este estudio se realiza una revisión de la literatura actual sobre el uso de redes sociales en los móviles para integrar a jóvenes en situaciones de exclusión. El 
informe muestra que los usos educativos se basan en un enfoque constructivista y en la utilización del modelo de los cinco pasos de Salmon (2004) para la creación de comunidades virtuales. Se añade que para crear esas comunidades online, las personas interesadas deben participar en su diseño, ya que el éxito de la creación de las mismas se sustenta en la participación personal. Entre otros factores de éxito incluyen: el propósito de la participación, las normas de conducta, un diseño adaptado y de fácil uso, la tecnología que se utilice, la definición de los roles de los agentes que participan y la creación de grupos pequeños.

Otra investigación destacable es el estudio realizado por Phil Euesden (2009) denominado «Widening elearning through participation: WIPEL Final Report, The Sheffield College (TSC)». Este informe examina el proyecto e-learning llevado a cabo en el Colegio de Sheffield con el objetivo de desarrollar la infraestructura técnica para el desarrollo de una Fundación basada en la comunicación virtual que apoye la flexibilidad, la diversidad, el empleo, la igualdad de oportunidades y la orientación profesional. La tecnología será un medio para ofrecer un curso online para cualquier persona adulta que se pueden beneficiar de él en cualquier momento de su vida en la forma y el tiempo que sea apropiado para su situación. El proyecto tiene que ver con la exploración y la aplicación de las tecnologías para enriquecer y personalizar la experiencia de aprendizaje y también mejorar el trabajo basado en la experiencia de aprendizaje para estudiantes. A través de este curso de formación online se han formado en recursos tecnológicos para el asesoramiento y la orientación profesional con la finalidad de permitir buscar empleo a través de las habilidades y conocimientos que han desarrollado. Utilizan blogs, como medio de reflexión individual, wikis para el trabajo colaborativo, un foro como espacio de comunicación online, y la creación y desarrollo de e-Portafolio, como medio para la orientación profesional. Destacan algunas dificultades técnicas como las referidas a la creación de la wiki, el mantenimiento del blog y las limitaciones del tiempo de los tutores 
para realizar seguimientos individualizados. En cuanto los resultados más significativos se destacan la motivación de los alumnos y alumnas participantes y la mejora de sus capacidades para usar la tecnología en la búsqueda de recursos y de empleo, lo que ha conllevado, a su vez, un aumento de su confianza personal.

En las últimas investigaciones encontradas sobre la temática base, situamos un estudio de ámbito europeo, realizado en 2009 y publicado en 2010: «Link-up: Learning 2.o for an Inclusive Knowledge Society (Link Up: Learning 2.o para una sociedad del conocimiento inclusiva)» realizado por Joe Cullen, Clare Cullen, Thomas Fischer, Simon Heid, y Véronique Maes, que presenta estudios de caso de 24 ejemplos de uso del e-learning y web 2.0 para la inclusión social, analizados desde una «teoría del cambio», refiriéndose a la evidencia del impacto que estos proyectos proporcionan. $\mathrm{Su}$ finalidad es presentar el potencial del e-learning para dar soporte a la integración social de grupos en riesgo de exclusión social, planteando lo que denominan el «panorama del e-learning 2.0 para la inclusión». Para ello profundizan en la comprensión de los recursos web 2.0 y cómo se están utilizando para apoyar las nuevas formas de aprendizaje y nuevas formas de apoyo a la inclusión social. El proyecto reúne un mapa del «paisaje del Learning 2.0 para la inclusión» mediante la revisión de experiencias prácticas en el ámbito académico y de investigaciones, analizando esas prácticas desarrolladas por profesionales del ámbito social que han usado recursos Web 2.0 para trabajar con grupos en situaciones desfavorecidas. Han utilizado una metodología de investigación-acción, recopilando y analizando datos obtenidos de evaluar el alcance de los cambios producidos por intervenciones innovadoras utilizando e-learning y recursos web 2.o. Este estudio se ha llevado a cabo en tres fases:

- Primera Fase: han realizado, en primer lugar, una revisión de la literatura académica y de investigación, para la creación de un mapa 
de los programas y proyectos que se relacionen con lo que denominan: «Learning 2.0 para la Inclusión».

- Segunda Fase: en la que han llevado a cabo 20 estudios de casos de experiencias significativas, destacando los factores de éxito y las principales dificultades encontradas. En este sentido realizaron una especie de «laboratorio de innovación» que recoge un documento con las prácticas investigadas.

- Tercera Fase: una última fase en la que han desarrollado un sitio web para compartir experiencias propias, con la posibilidad de unirse y compartirlas a través de una Comunidad Virtual de Práctica, para continuar con la investigación, que se mantiene en la actualidad.

De los resultados obtenidos en los estudios de caso se destaca cómo a través de estos proyectos y de la utilización de la web 2.o bajo las estrategias didácticas adecuadas, se adquiere capital individual, referido a la adquisición de habilidades digitales y de trabajo en equipo; capital social, reforzando la capacidad de crecimiento de las comunidades a través de la formación; y capital tecnológico, mejorando el acceso y uso de las tecnologías.

En general, puede decirse que de esos estudios en referencia al e-learning y la inclusión social se extraen varias ideas comunes:

Multidimensionalidad

Variedad de Fuentes de Financiación

Variedad de Recursos TIC

Integración objetivos-recursos-estrategias-

actividades

Respuesta holistica e integrada

Figura 6. Ideas comunes de estudios sobre e-learning e inclusión social 
- Las iniciativas adoptan una idea multidimensional de la aproximación al uso del e-learning para hacer frente a la exclusión social. Es decir, debe capacitarse a los grupos desde las diferentes dimensiones que el e-learning puede ofrecer, que en estos casos se determinan por una dimensión individual, una social y una tecnológica.

- Son financiados por una variedad de fuentes: administración pública, entidades privadas con y sin ánimo de lucro.

- Incorporan una amplia gama de plataformas y recursos TIC, todos derivados de la web 2.0: blogs, wikis, redes sociales, e-portafolio, etc.

- Se basan en la integración de objetivos, recursos, estrategias, actividades para conseguir unas metas educativas.

- Reflejan la idea de que la exclusión social es de naturaleza multidimensional y que, las necesidades de las personas en riesgo y situaciones de exclusión tienen también esa característica, lo que requiere que se utilice el e-learning como una respuesta holística e integrada.

\subsubsection{Políticas, programas e iniciativas europeas, nacionales y extremeñas sobre e-learning para la inclusión social.}

\section{a. Ámbito Europeo.}

Los programas de la Unión Europea, y por ende los nacionales y regionales, referidos al e-learning para la inclusión social son un hecho relativamente reciente, de aproximadamente una década. Pese a ello ya desde el 1994, la Unión Europea elaboró el Plan «Europa en marcha hacia la Sociedad de la Información», siendo el primer marco de actuación política que disponía de un conjunto de medidas con acciones para el proceso de 
liberalización de las telecomunicaciones, el marco regulador, las redes y servicios, los aspectos sociales y culturales y las actividades de promoción y sensibilización.

Todas las medidas de esta índole y de los estados miembros para facilitar la inclusión social a través de estrategias políticas que hagan referencia al elearning, estaban incluidas en políticas y modelos relacionados con la inclusión social en general. Esta visión puede basarse en la consideración anterior que se mencionó de la brecha digital como brecha social (Casado y Díez, 2006), y por tanto como una dimensión de la inclusión social, sin establecerlo como un aspecto separado de esta realidad. Algunos autores (Brants y Firssen, 2003; Area, Gros y Marzal, 2008) han descrito ésta como una nueva forma de exclusión social, como un nuevo factor que agrava las otras dimensiones de la exclusión social.

\begin{abstract}
"[...] aquellos ciudadanos que no estén cualificados para el uso de las tic tendrán mayores probabilidades de ser marginados culturales en la sociedad del siglo XXI. Este analfabetismo digital provocará, seguramente, mayores dificultades en el acceso y la promoción en el mercado laboral, indefensión y vulnerabilidad ante la manipulación informativa, incapacidad para la utilización de los recursos de comunicación digitales» (Area, Gros y Marzal, 2008: 39).
\end{abstract}

Este hecho se demuestra porque en los Planes Nacionales de Inclusión Social, cuyas directrices se elaboraron como una parte del método abierto de coordinación en materia de inclusión social acordado en el Consejo de Niza del año $\mathbf{2 0 0 0}^{5}$, contienen una sección sobre inclusión digital, que establece cuatro objetivos comunes en esta materia:

- Acceso al empleo y los recursos, derechos, bienes y servicios.

- Prevención de los riesgos de la exclusión social.

5 Conclusiones del Consejo de Niza: http://www.europarl.europa.eu/summits/nice1_es.htm 
- Ayuda para los grupos sociales más vulnerables.

- La movilización de todos los actores relevantes en la inclusión social.

El objetivo general de estas políticas era erradicar la pobreza y la exclusión social en el año $2010^{6}$ y para ello se aborda el principio de solidaridad en los Estados miembros de empleo, educación y formación, sanidad y vivienda y la definición de acciones prioritarias para determinados grupos ${ }^{7}$.

Desde entonces, las iniciativas de inclusión social, y específicamente digital, han sido vista con matices económicos, sobre todo las relacionadas con la estrategia de Lisboa, haciendo extensivo el uso de las TIC para promover una economía del conocimiento, que produzca, a su vez, crecimiento económico. Esta idea nos hace entender, que las políticas derivan del entendimiento de que la inclusión digital entonces, ayuda a un mayor crecimiento económico, y que a su vez, ésta impactará positivamente en las ciudadanas y ciudadanos europeos, que podrán participar en la vida económica y social.

Esta visión economicista de la inclusión social se destaca en los planes de acción eEuropa, que tiene como estrategia facilitar el acceso a las TIC por parte de la ciudadanía, sobre todo en lo referente a infraestructura. Esta iniciativa se lanza en diciembre de 1999 por la Comisión Europea, en la Cumbre de Helsinki, a través de una comunicación: «eEuropa - Una Sociedad de la Información para todos ${ }^{8}$, que se aprueba, posteriormente, en la Cumbre de Lisboa del año 2000.

6 Council Declaration on The European Year for Combating Poverty and Social Exclusion: Working together to fight poverty in 2010 and beyond. Disponible en:

http://www.consilium.europa.eu/uedocs/cms_data/docs/pressdata/en/lsa/118250.pdf

7 Estos grupos eran: familias monoparentales, los refugiados, sin hogar, niños en situación de riesgo, ancianos y personas con discapacidad.

8 Síntesis de la iniciativa en:

http://europa.eu/legislation_summaries/information_society/strategies/l24221_es.htm 


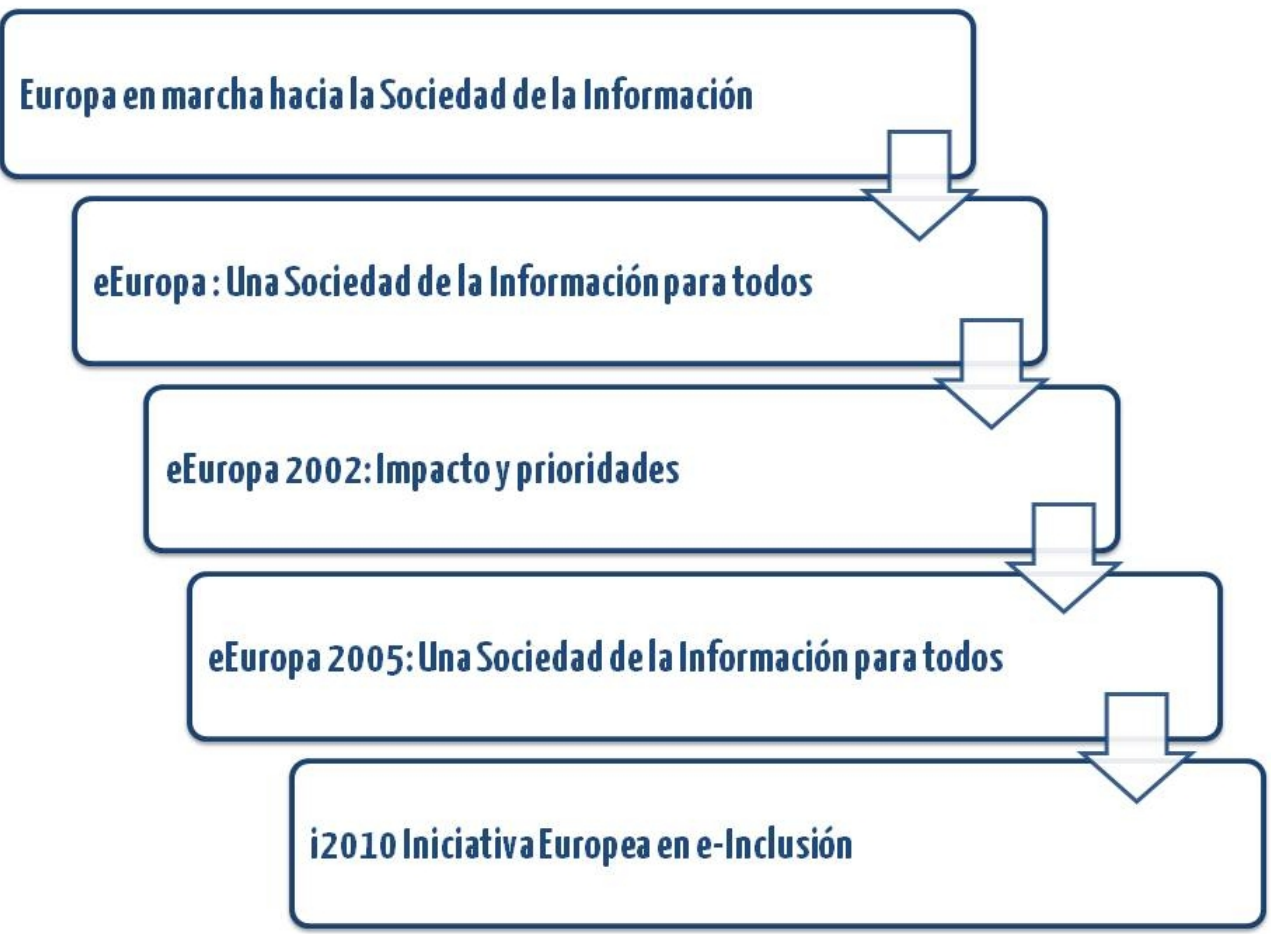

Figura 7. Iniciativas Europeas relaciondas con las TIC para la inclusión social

El 25 de septiembre del 2001 la Comisión aprobó la comunicación «eEuropa 2002: Impacto y prioridades» con la que se pretende superar los obstáculos para facilitar una mayor integración y un uso generalizado de las TIC. eEuropa 2002 viene acompañada de varias iniciativas que constituyen un refuerzo en otros campos, entre las que están: e-Learning, en el campo de la formación continua; e-Content, en el campo del desarrollo y comercialización de contenidos digitales europeos; y e-Twining ${ }^{9}$, en el campo de la promoción del intercambio de conocimientos y experiencias prácticas de centros escolares a través de Internet. La iniciativa e-Learning abarcó el periodo 2001-2004 y tenía como marco el Plan eEurope 2002 mencionado y el informe ${ }^{10}$ sobre los objetivos futuros de los sistemas educativos. Entre las lineas estratégicas se situaba a las Tecnologías de la Información y de la Comunicación para contribuir a promover los objetivos relacionados con la

Sitio web eTwinning: http://www.etwinning.net/

10 Informe disponible en:

http://europa.eu/legislation_summaries/education_training_youth/general_framework/c11049_es.htm 
capacitación para el empleo y la adaptabilidad de la estrategia europea también en el mismo ámbito. Se dirigía a cuatro bloques de objetivos:

- En cuanto a infraestructura, pretendían acelerar el despliegue en la Unión Europea de una infraestructura de calidad a costes accesibles, es decir una mejora de acceso a las redes digitales.

- En cuanto a la mejora del nivel de conocimientos de la población pretendía intensificar la formación, no sólo tecnológica, sino sobre el uso pedagógico de las TIC, para lo que profundiza en la necesidad de adaptación de las metodologías y la introducción de modelos educativos innovadores para lograr esa mejora.

- Relacionada con la anterior marcaba crear condiciones adecuadas para el desarrollo de contenidos, servicios y entornos de aprendizaje avanzados y pertinentes en el plano pedagógico. Por un lado, trataba de fomentar el desarrollo de servicios y de contenidos multimedia pertinentes y de calidad, y por otro transformar los centros de enseñanza y de formación en centros polivalentes adaptados a las necesidades de la sociedad.

- En cuanto a refuerzo de las relaciones entre los diferentes agentes, el objetivo era reforzar la cooperación y el diálogo estableciendo asociaciones entre los sectores público y privado para mejorar la articulación de acciones e iniciativas a todos los niveles y entre todos los agentes educativos.

Para la aplicación de este proyecto se han destinado los principales instrumentos comunitarios, como son:

- Los programas para la Educación y la Juventud Sócrates, Leonardo da Vinci y Juventud. 
- El Programa Marco para Investigación y Desarrollo (1998-2002): al Programa Tecnologías de la Sociedad de la Información (TSI) y la investigación socioeconómica, que abordaba el Programa eLearning, hay que añadir otros programas para el desarrollo tecnológico y la competitividad: Ten-Telecom, eContent y Go Digital.

- Los Fondos Estructurales: el FEDER han contribuido a la creación de infraestructuras y a los desarrollos sectoriales, mientras que el FSE dispuso de medios importantes para la adaptación de los sistemas educativos y de formación y para la generalización de los mejores modelos desarrollados a escala nacional o a escala europea.

- Las directrices para el empleo, que reforzaban el papel de la educación y de la formación permanente en una economía basada en el conocimiento e invitaban a los interlocutores sociales a celebrar acuerdos que permitan la adquisición de una cultura digital y formas de trabajo que facilitasen la participación de los trabajadores en el aprendizaje.

- El Banco Europeo de Inversiones (BEI), para la financiación de infraestructuras y equipamientos para la utilización de las TIC y, que, en el marco de su iniciativa Innovación 2000, podía financiar también proyectos en el ámbito de la innovación.

De esta manera, la iniciativa e-Learning, dispuso de cuatro líneas de acción principales destinadas a la dotación de infraestructura y equipamientos: relativa a la formación, la definición de buenas prácticas y la mejora de los sistemas de formación; acciones destinadas a favorecer los servicios, desde el punto de vista de la protección intelectual y desde ejes temáticos para la innovación y el desarrollo; y por último, acciones para reforzar la cooperación y el diálogo, a través del sitio web «eLearning 
Europa ${ }^{11}$, a lo que se añade el refuerzo de redes europeas para la educación y la formación mediante el intercambio de experiencias y la organización de eventos.

Posteriormente, en junio de 2002, el Consejo Europeo de Sevilla lanzó el plan de acción eEurope 2005 cuyo principal objetivo es ofrecer a todos la posibilidad de participar en la sociedad de la información mundial.

En ese sentido, la visión de la inclusión digital se implementa con acciones de un enfoque más preventivo que participativo, que, desde el punto de vista de la participación total de la ciudadanía se modifica con estrategias posteriores, como en la Declaración Ministerial de Riga de $2006^{12}$, cuyos principios rectores parten de la idea de que la Sociedad de la Información es para todos y todas, no pudiendo existir brechas digitales que afecten a la cohesión y a la prosperidad en Europa, para lo que establecieron: incrementar el uso de Internet entre la población, aumentar la cobertura de banda ancha, impulsar la alfabetización digital y garantizar las directrices de accesibilidad a contenidos web son los principios rectores de esta política.

En un seguimiento de esa declaración, los ministros de la Unión Europea (UE), cuya presidencia recaía en ese momento en Portugal, se reunieron en Lisboa en diciembre de 2007 con la finalidad de establecer un debate sobre la inclusión digital. En este sentido la presidencia llama a integrar la inclusión digital como una nueva dimensión de las políticas sociales y como una importante oportunidad para promover la inclusión social y para orientar las políticas nacionales y la UE instrumentos dirigidos a la integración social y el desarrollo socio-económico ${ }^{13}$.

${ }_{11}$ Sitio web: http://www.elearningeuropa.info/

12 Declaración Ministerial de Riga , disponible en: http://ec.europa.eu/information_society/events/ict_riga_2006/doc/declaration_riga.pdf

13 Tratado de Lisboa por el que se modifican el Tratado de la Unión Europea y el Tratado constitutivo de la Comunidad Europea, firmado en Lisboa el 13 de diciembre de 2007. Disponible en: http://eurlex.europa.eu/JOHtml.do?uri=OJ:C:2007:306:SOM:ES:HTML 
En ese mismo año se adopta la propuesta de «i2010 Iniciativa Europea en e-Inclusión. Formar parte de la Sociedad de la Información», cuyos elementos principales son, por un lado, un marco estratégico para aplicar la Declaración Ministerial de Riga y, por otro, una campaña de e-inclusión.

El marco estratégico derivado de la Declaración de Riga fija objetivos sobre amplias aspiraciones estructurales, como la mejora de la infraestructura y la promoción de la alfabetización digital:

\begin{abstract}
«Los países pondrán en marcha, en 2008, acciones de alfabetización en competencias digitales, a través de los sistemas de educación formal o informal, aprovechando las iniciativas existentes. Estas acciones se adaptarán a las necesidades de los colectivos en riesgo de exclusión social, a sus circunstancias, capacidades y necesidades especiales e irán dirigidas, de forma particular, a los desempleados, los inmigrantes, las personas con bajos niveles de alfabetización, personas con discapacidad y mayores, así como a los jóvenes en situación de exclusión, lo que contribuirá a su empleabilidad y a la mejora de sus condiciones de trabajo. La brecha digital en estos grupos y en la media de la población debe ser reducida a la mitad para el año 2010. Los avances en este objetivo se deben medir sobre la base de los indicadores disponibles y del trabajo futuro en el contexto de la iniciativa i2010» (art. 20 de la Declaración de Riga).
\end{abstract}

Para ello, la Comisión instó a los países europeos a explorar el potencial de nuevas tecnologías para generar servicios innovadores y capacitar a la ciudadanía con especial atención a los jóvenes en riesgo de exclusión, inmigrantes y minorías culturales, sobre todo teniendo en cuenta los idiomas y la adaptación de contenido. En segundo lugar, la Comisión reiteró el compromiso de apoyar las nuevas áreas de e-inclusión en relación con las personas jóvenes en riesgo de exclusión, a través del intercambio de prácticas 
y proyectos dirigidos a la investigación de la UE y los programas de despliegue (7PM ${ }^{14}$ e ICT-PSP $\left.{ }^{15}\right)$.

En el seno de la iniciativa i2010, además, aparecen algunas recomendaciones y comunicaciones interesantes ${ }^{16}$, entre las que destacamos (a) la Recomendación 2009/625/CE sobre alfabetización mediática; (b) la Comunicación de la Comisión al Consejo y al Parlamento Europeo «Mejorar el acceso de las zonas rurales a las modernas tecnologías de la información y la comunicación (TIC); (c) la campaña de sensibilización pública «eInclusion, ser parte de ella»; (d) la Comunicación de la Comisión, de 25 de abril de 2006, «Plan de acción sobre administración electrónica i201O: acelerar la administración electrónica en Europa en beneficio de todos»; y (e) la Comunicación de la Comisión al Parlamento Europeo, al Consejo, al Comité Económico y Social Europeo y al Comité de las Regiones, de 14 de junio de 2007, «Envejecer mejor en la sociedad de la información - Una iniciativa i2O1o - Plan de acción sobre Tecnologías de la Información y la Comunicación y envejecimiento».

La Recomendación 2009/625/CE de la Comisión (a), de 20 de agosto de 2009, sobre la alfabetización mediática en el entorno digital para una industria audiovisual y de contenidos más competitiva y una sociedad del conocimiento incluyente. La Comisión Europea considera la alfabetización mediática un reto importante, ya que proporciona a los ciudadanos europeos herramientas que les ayudan a familiarizarse con el entorno digital, cada vez

14 El Séptimo Programa Marco (7PM) agrupa todas las iniciativas comunitarias relativas a la investigación bajo un mismo techo y desempeña un papel crucial en el logro de los objetivos de crecimiento, competitividad y empleo, complementado por el nuevo Programa Marco para la Competividad y la Innovación (CIP), programas de educación y formación y Fondos Estructurales y de Cohesión en apoyo de la convergencia y la competitividad de las regiones. Constituye también un pilar fundamental del espacio europeo de investigación (EEI). Más información: http://cordis.europa.eu/fp7/home_es.html

15 ICT Policy Support Programme (ICT PSP) tiene como objetivo estimular el crecimiento inteligente y sostenible acelerando la incorporación y la optimización del uso de tecnologías y contenidos digitales por parte de ciudadanos, gobiernos y empresas. Se enmarca en el enmarcada en el llamado Programa CIP (Programa Marco para la Competitividad y la Innovación -Competitiveness and Innovation Framework Programme) que tiene como objetivo fomentar la competitividad de las empresas europeas que tiene como como objetivo estimular el crecimiento inteligente y sostenible acelerando la incorporación y la optimización del uso de tecnologías y contenidos digitales por parte de ciudadanos, gobiernos y empresas.

16 Para más información sobre estas comunicaciones e iniciativas, se puede consultar la página de la Unión Europea http://europa.eu/documentation/legislation/index_es.htm 
más presente en la sociedad europea. Para ello se recomienda a los Estados miembros promover y financiar investigaciones, estudios y proyectos que cubran los distintos aspectos y dimensiones de la alfabetización mediática en el entorno digital, que abran un debate en conferencias y otras actividades públicas sobre la inclusión de la alfabetización mediática en los planes de estudios, y como parte de la oferta de competencias clave para el aprendizaje permanente. Se insta a poner en marcha campañas nacionales de sensibilización sobre el patrimonio cultural destinadas a los ciudadanos y ciudadanas, y acciones de concienciación acerca de los riesgos asociados al tratamiento de datos personales a través de redes de información y comunicación. Y, por último se recomienda a la industria de los medios de comunicación que proporcione las herramientas necesarias para mejorar el nivel de alfabetización mediática, como por ejemplo:

- campañas informativas sobre el contenido digital y los motores de búsqueda;

- campañas de concienciación acerca de las técnicas empleadas para fines de comunicación comercial (colocación de productos $\mathrm{y}$ publicidad online);

- paquetes informativos destinados a los jóvenes sobre el tratamiento que reciben sus datos personales;

- jornadas informativas de economía creativa y derechos de autor.

La Comunicación de la Comisión al Consejo y al Parlamento Europeo (b) «Mejorar el acceso de las zonas rurales a las modernas tecnologías de la información y la comunicación (TIC)» [COM(2009) 103 final - no publicada en el Diario Oficial]. En las zonas rurales todavía existe una falta de acceso a las tecnologías de la información y la comunicación (TIC). Para reducir la brecha territorial en este sector, se alienta a los Estados miembros, a las regiones y a las autoridades locales a equipar mejor estas regiones. Los 
proyectos destinados a mejorar el acceso de las zonas rurales a las TIC se articulan en torno a tres ejes:

- el desarrollo del equipo de acceso a Internet;

- la creación de contenidos;

- el desarrollo de nuevas competencias para acceder a Internet.

En 2008, la Comisión puso en marcha una campaña de sensibilización pública (c). «e-Inclusion, ser parte de ella». La campaña establece un marco estratégico de acción en materia de inclusión digital, que tiene por finalidad mejorar el impacto de la inclusión digital a través de un conjunto coherente de acciones en tres áreas:

- Activar las condiciones para que la ciudadanía tome parte en la Sociedad de la Información. Este aspecto se dirige principalmente a hacer frente a tres cuestiones relacionadas con la reducción de la brecha digital: acceso a banda ancha, accesibilidad y formación en competencias digitales.

- Impulsar y apoyar la participación efectiva de los grupos y personas en riesgo de exclusión y mejorar la calidad de la vida. Este aspecto fue abordado a través de: la orientación social a grupos desfavorecidos; generar y desarrollar servicios públicos electrónicos; accesibilidad en la Sociedad de la Información para personas con discapacidad; la exploración de las TIC como promotoras de igualdad de oportunidades de jóvenes e inmigrantes en riesgo de exclusión.

- Integrar estas acciones en todas las políticas y garantizar la coordinación de actividades empresariales, organizaciones de usuarios y usuarias y las autoridades nacionales para maximizar el impacto a largo plazo. Este aspecto se abordó a través de dos objetivos: en primer 
lugar, mejorar y mantener el impacto a través de la coordinación y, en segundo lugar, mejorar la comprensión y la comparación de los avances de la inclusión digital a través del desarrollo de un conjunto de indicadores relevantes: el denominado «Riga Dashboard» (los indicadores de Riga).

Esta campaña y la Conferencia Ministerial celebrada a finales de 2008 constituyó una iniciativa para facilitar las acciones destinadas a aumentar la conciencia de la e-inclusión dentro de los Estados miembros y entre los principales grupos interesados, con el fin de apoyar la aplicación de las disposiciones de la Declaración de Riga. La iniciativa incorpora una serie de actividades que incluye folletos, eventos y actividades de apoyo a los estados, tanto a nivel estatal como regional. Dos elementos importantes fueron: los premios «e-inclusión», consistente en un concurso anual de las mejores prácticas de experiencias de e-inclusión, y una Comunidad Virtual de Práctica, dedicada a la recolección de estudios de caso sobre inclusión digital, apoyada por una serie de seminarios, talleres y otras actividades.

La Comunicación de la Comisión, de 25 de abril de 2006 (d): «Plan de acción sobre administración electrónica i2010: acelerar la administración electrónica en Europa en beneficio de todos» [COM (2006) 173 final - no publicada en el Diario Oficial]. A través de este plan de acción, la Comisión proponía:

- permitir a los particulares y las empresas obtener con mayor rapidez ventajas concretas en el terreno de la administración electrónica;

- asegurarse de que la administración electrónica a nivel nacional no crea nuevas trabas dentro del mercado interior debido, concretamente, a la falta de interoperabilidad;

- hacer extensivas las ventajas de la administración electrónica a toda la Unión Europea (UE) permitiendo que se realicen economías de escala. 
Para ello se dispusieron cinco ejes prioritarios:

1. Acceso para todos y todas, procurando el acceso de toda la ciudadanía a la administración electrónica.

2. Mayor eficiencia, instando a los Estados a comprometerse para conseguir una mayor eficiencia, mediante un uso innovador de las Tecnologías de la Información y la Comunicación, y a reducir sustancialmente la carga administrativa hasta 2010. Para ello establece la incorporación de un sistema para evaluar comparativamente el impacto y los beneficios de la administración electrónica y adoptar disposiciones para fomentar un mayor intercambio de experiencias.

3. Servicios de administración electrónica de gran impacto. La prestación transfronteriza de determinados servicios constituye un avance significativo para los particulares, las empresas y las administraciones y puede, de hecho, servir de exponente de la administración electrónica europea.

4. Establecimiento de las herramientas clave para que la instauración de la administración electrónica sea óptima, es indispensable disponer de determinadas herramientas clave, tales como: sistemas de gestión de la identificación electrónica (eIDM) para el acceso a los servicios públicos, autenticación de documentos electrónicos y archivado electrónico.

5. Mayor participación en el proceso democrático de decisión, abriendo las TIC como medio para implicar a la ciudadanía en el debate público y la toma de decisiones. Es decir, fomentar el uso de las TIC para incrementar la participación de la ciudadanía en la vida democrática. 
La Comunicación de la Comisión al Parlamento Europeo, al Consejo, al Comité Económico y Social Europeo y al Comité de las Regiones, de 14 de junio de 2007 (e): «Envejecer mejor en la sociedad de la información - Una iniciativa i2O1o - Plan de acción sobre Tecnologías de la Información y la Comunicación y envejecimiento» [COM (2007) 332 final - no publicada en el Diario Oficial]. Los objetivos del plan de acción de la Comisión se dirigen: a la ciudadanía para mejorar su calidad de vida y su salud; a las empresas, para ampliar el tamaño del mercado, las oportunidades comerciales, aumentar la cualificación y la productividad de la mano de obra y consolidar su posición en los mercados mundiales en expansión; y a las autoridades, para reducir costes, aumentando al mismo tiempo la eficacia y calidad global de la asistencia social y sanitaria. El plan de acción, que se deriva de esta Comunicación, está estructurado en torno a cuatro áreas:

1. Evaluar las posibilidades tecnológicas para superar los obstáculos jurídicos y técnicos para la adopción de las TIC que favorecen la autonomía

2. Sensibilizar en torno a las TIC para envejecer mejor.

3. Fomentar la adopción de estas tecnologías mediante, por ejemplo, un conjunto de proyectos piloto y de un sistema de premios europeos a hogares inteligentes y a aplicaciones que favorezcan una vida independiente.

4. Impulsar la investigación y la innovación, apoyando un programa conjunto de investigación público-privado relativo a la «vida cotidiana asistida por el entorno». Su objetivo es estimular la aparición de productos, servicios y sistemas innovadores, basados en las TIC, destinados a los mayores europeos, cada vez más numerosos.

Dentro de esta iniciativa los estados nacionales, España entre ellos, está realizando una serie de planes, programas e iniciativas con el fin de adaptarse 
a las recomendaciones de Europa y a los acuerdos suscritos para integrar e impulsar las TIC en los diferentes ámbitos de la sociedad española, mediante la llamada estrategia «Ingenio 2010», que trataremos en el siguiente apartado.

En referencia a políticas de e-inclusión, Cullen et al. (2010) muestran que existe un retraso en estas políticas de igualdad de oportunidades para la einclusión. Sus supuestos se basan en que las políticas europeas se han visto dominadas por el modelo de Molnar (2003). Este modelo sugiere una progresión lineal de la difusión de las TIC por fases, a los que corresponden determinadas acciones para la e-inclusión, centrándose en el acceso, la accesibilidad y la calidad de uso. El enfoque de «brecha de acceso» (o «brecha digital temprana» como primera fase) se centra en facilitar el acceso a aquellas personas y grupos que no lo tienen, para igualar los problemas de acceso a las TIC. El enfoque de dividir el uso («brecha digital primaria») establece activar la participación de aquellas personas que tienen acceso, pero no son usuarios. Por último, como tercera fase, la calidad de enfoque de uso («brecha digital secundaria»), incide en las diferencias en los niveles de participación de aquellas personas que tienen acceso y los usuarios reales. El modelo de Molnar sugiere que se alcanzará la e-inclusión si las políticas que se ponen en marcha en referencia a este aspecto, incluyen acciones para hacer frente a las tres fases de la brecha digital: acceso, uso y calidad de uso.

En este contexto, y como programas complementarios, debemos destacar la iniciativa antes mencionada: «EL4EI: E-Learning For E-Inclusión», que recordamos, es un proyecto financiado por la Unión Europea, bajo el marco del programa E-Learning, desarrollado desde noviembre de 2002 a abril de 2004 durante 18 meses. Su finalidad principal era la recopilación, evaluación y difusión de experiencias de e-learning para la inclusión digital de grupos en situación de exclusión. Sus destinatarios principales eran profesionales y expertos que participan en procesos de formación digital para personas en situaciones desfavorecidas. 
Los objetivos perseguidos se agrupaban en tres: proporcionar herramientas para evitar la brecha digital entre los ciudadanos de la Unión Europea; dinamizar la comunicación, el diálogo y la transferencia entre los profesionales, organizaciones y colectivos interesados y contribuir al desarrollo del aprendizaje digital en todos los grupos sociales. Para ello, se reunieron y catalogaron casos significativos de buenas prácticas de e-learning social y elaboraron una carta europea para servir de herramienta de referencia a los profesionales que trabajen en inclusión social.

Uno de los logros fundamentales del proyecto ha sido generar la necesidad de un nuevo paradigma que se base en entornos educativos más informales, en que la comunicación entre iguales sea fundamental y en que se eviten los estereotipos negativos de las nuevas tecnologías, comentando como futuro paradigma el e-learning social. Además, el proyecto muestra que, además de facilitar la infraestructura mínima para poder desarrollar prácticas de este tipo, es necesario incidir, no sólo en las competencias básicas en acceso y uso del ordenador e internet, sino en estrategias de motivación y contextualización de los programas.

De los diversos resultados del proyecto se destacan tres:

- Realización del «I Congreso Internacional, e-Learning e Inclusión Social » 15 y 16 de abril de 2004 en Barcelona, donde se analizaron y debatieron las posibilidades del aprendizaje a distancia para luchar contra la exclusión.

- Carta Europea para la Inclusión Digital y Social a través del e-learning, un manifiesto que muestra la potencialidad de los proyectos e-learning para la inclusión social.

- Creación de un observatorio digital europeo centrado en la recopilación, evaluación y difusión de experiencias de e-learning para grupos desfavorecidos. 
En la Carta Europea para la Inclusión Digital y Social a través del elearning, se establece como paradigma futuro el e-learning social y propone varias áreas claves como punto de partida para investigaciones:

a. Soluciones sociales a problemas sociales, que destaca la necesidad de tratar los problemas sociales de las personas y no tanto la ausencia de infraestructura. En este sentido manifiesta que debe tenerse en cuenta las diferencias entre las personas que necesitan entender y usar las TIC y quiénes sólo necesitan un conocimiento «formal» para conseguir ambas cosas.

b. Dimensión social, cultural y política de las comunidades: insiste, desde estas dimensiones en el papel de las TIC para expandir los horizontes culturales, sociales y políticos de las comunidades, y además del potencial de internet como medio de comunicación para describir y luchar contra la exclusión social. Incide en la posibilidad de trabajar con grupos de inmigrantes que trabajan lejos de sus lugares de origen y como medida a favor de la igualdad de oportunidades entre mujeres y hombres, para ayudar a éstas a trabajar con las TIC y transformarlas.

c. Hacia el PC transparente: con la consideración de estrategias y tecnologías que permitan que los programas sean fácil e intuitivos para el uso de todas las personas.

d. Metodología basada en la resolución de problemas para el e-learning: incide en evitar visiones academicista y construir materiales e-learning que sean útiles, prácticos y motivadores, teniendo en cuenta los contextos sociales y culturales específicos, que insiste el manifiesto «se olvidan cuando se piensan en estrategias e-learning». Recomienda el uso de una metodología basada en la resolución de problemas, por resultar más útil, práctica y motivadora.

e. Internet para todos: donde remarca la plasticidad del software para adaptarse a las necesidades específicas de los colectivos y grupos concretos. 
Requiere a las empresas y administraciones mejorar el aspecto de accesibilidad mediante las TIC.

Se recoge, a continuación, la manifestación completa de esta declaración Europea. 


\section{Declaración eL4eI}

1. A la hora de analizar la e-inclusión, vencer las barreras mentales es tan importante como solucionar el problema de acceso a redes y equipo asociado. La división digital no es sólo tecnológica: también es mental.

2. La investigación es clave. No disponemos de análisis precisos de los enlaces entre factores de exclusión y de cómo están relacionados con las TIC. Hay una necesidad muy clara de financiar programas de investigación que nos ayuden a comprender los diferentes grupos de exclusión en línea y en que difieren en función de edad, origen étnico o género.

3. A pesar de la existencia de resultados prometedores, cuando tenemos en cuenta a las personas con discapacidades, todavía necesitamos más investigación. Por ejemplo, es necesario individuar cuáles son las áreas más problemáticas, evitar un acercamiento generalista, y buscar soluciones que apunten a discapacidades específicas.

4. Un acercamiento meramente formal que insista en la importancia de las TIC en el lugar de trabajo no es suficiente. Hay que presentar las tecnologías digitales a los excluidos como algo atractivo. La diversión en el uso es también clave para evitar la falta de motivación.

5. Enlazar las TIC con la cultura y el estatus social es también una buena herramienta motivadora. Sin embargo, hay que procurar no abusar de ella. Los grupos objetivo nunca deberían llevarse la impresión de que no hay vida más allá de Internet.

6. Hay una imagen simbólica positiva asociada al uso y conocimiento de las TIC. Tener acceso (sic) y saberlas usar (incluso en un nivel modesto) es un sinónimo de integración. Es interesante utilizar este conjunto de valores en procesos de aprendizaje tanto en estudiantes como en profesores. Defendemos un modelo de e-learning que es participativo, construido «inter pares» $\mathrm{y}$ «mezclado».

7. Participativo: No definamos las interfaces a priori, basándonos en modelos previos. Permitamos que el usuario se implique en el proceso de creación del sistema desde el principio, de manera que podamos ver qué funciona y lo que no.

8. Aprendizaje «inter pares» (peer to peer): Ascender a los más jóvenes y a los estudiantes a profesores se ha probado varias veces y parece tener unos efectos motivadores muy importantes. Al ver como sus colegas han podido ser capaces de aprender los conocimientos básicos de las TIC y que además los pueden enseñar da a los estudiantes más confianza y motivación.

9. «Mezclado» (Blended): Cuando analizamos la inclusión social, vemos que un acercamiento blended (que combina el uso de los ordenadores con interacción en directo con el profesor) es mucho más exitoso que los acercamientos e-learning «puros». El contacto personal con el educador es clave cuando trabajar con el ordenador resulta más complejo y poco motivador. 
10. Es necesario no olvidar que, por mucho que nos esforcemos, no todo el mundo podrá entrar en la sociedad de la información. Las políticas y estrategias de inclusión deberían permitirnos también a ayudar al desarrollo completo de las personas que, debido a su situación económica, discapacidad física o cognitiva, aislamiento, etc. no son ni serán capaces de utilizar las TIC.

Por tanto, concluimos que las TIC son instrumentos sociales, con valores incluidos en ellas. Es nuestra tarea principal asegurar que estos valores nos lleven a una sociedad más inclusiva e igualitaria, donde puedan utilizarse para mejorar la participación democrática y dar poder a los socialmente excluidos.

En los últimos años, se recogen también una serie de programas europeos que tienen relación con la inclusión digital y las TIC (Cullen et al., 2010). Esta relación puede estar establecida en la finalidad del programa o en alguna de sus líneas de acción, como vemos a continuación.

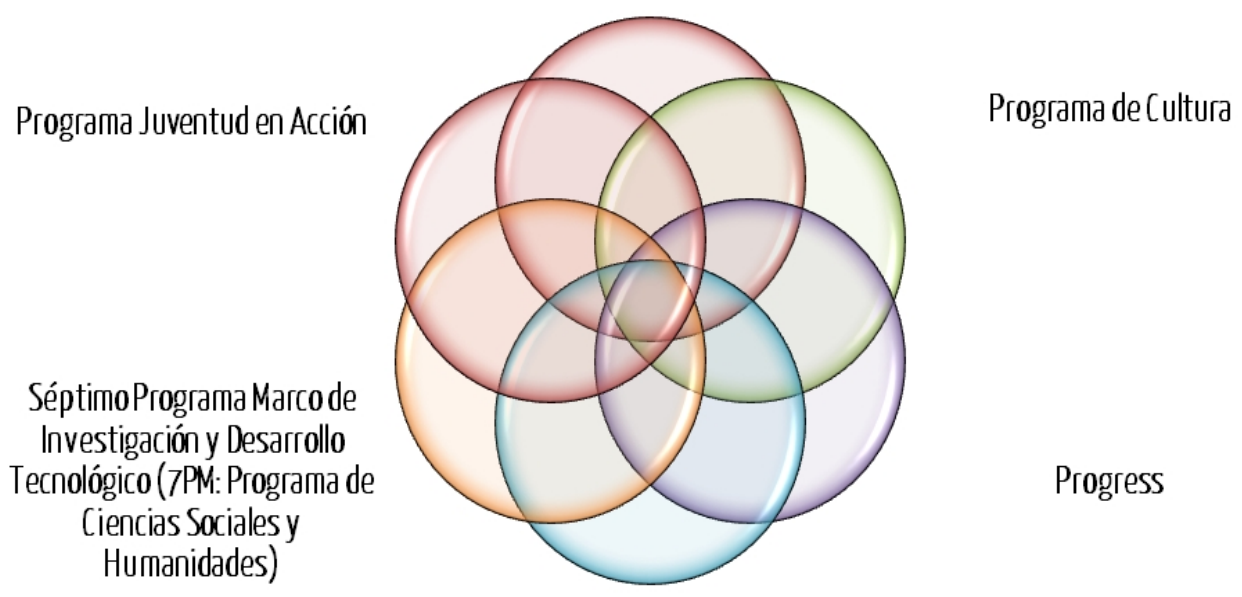
SéptimoPrograma Marcode Investigación y Desarrollo Tecnológico(7PM): TIC

Figura 8. Programas Europeos relacionados con la inclusión digital. 
a. Programa Lifelong Learning (Aprendizaje a lo largo de la vida) ${ }^{17}$.

Este programa permite a las personas de todas las edades adquirir experiencia a través de estudios, formación o aprendizaje en el extranjero, y apoya la cooperación entre escuelas, universidades y empresas de diferentes países europeos. Se financian cinco tipologías de estrategias para:

- Desarrollar estrategias de aprendizaje permanente y de movilidad.

- Fomentar la cooperación entre los ámbitos de la educación, formación y trabajo.

- Apoyar a la formación inicial y continua de profesores, formadores y gestores de la educación y de las instituciones de formación.

- Promover la adquisición de competencias clave en todo el sistema educativo.

- Promover la inclusión social y la igualdad de género en educación y formación, incluyendo la integración de las personas inmigrantes y gitanas.

Estas prioridades globales reflejan las principales cuestiones en la agenda política de educación y formación en la Unión Europea.

Los subprogramas sectoriales, dentro de este programa, se centran en diferentes etapas de la educación y la formación continua:

- Comenius, para los centros educativos.

- Erasmus, para las universidades.

- Leonardo da Vinci, para la formación profesional.

${ }_{17}$ El programa está disponible en: http://ec.europa.eu/education/llp/doc848_en.htm y todas las acciones y los subprogramas en http://eacea.ec.europa.eu/llp/index_en.php 
- Grundtvig. para la educación de adultos.

Estos programas se complementan con los denominados «programas transversales» que tienen por objeto apoyar los subprogramas sectoriales para garantizar que logren los mejores resultados posibles. Su objetivo es promover la cooperación europea en ámbitos que cubran dos o más de los subprogramas, además de tratar de incentivar la calidad y transparencia de la educación de los Estados miembros y los sistemas de formación. Estos programas transversales constan de cuatro actividades principales que se centran en: la política de cooperación y la innovación, los idiomas, las TIC, y la difusión y explotación de resultados. En referencia a las TIC, promueve la búsqueda de nuevas y más efectivas fórmulas de apoyo a la innovación pedagógica y organizativa en los sistemas de educación y formación. Las acciones se basan en uso de herramientas TIC para mejorar los ambientes de aprendizaje y experiencias. Esto incluye aspectos tales como el uso de simulaciones, aprendizaje por descubrimiento, intentando captar a los y las estudiantes que abandonan el sistema educativo, permitiendo un aprendizaje fuera del entorno escolar y también reduciendo la brecha digital entre quienes tienen acceso a tecnologías y conocimientos relevantes, y los que no. Las prioridades de las actividades en este programa transversal se fijan anualmente y las iniciativas están abiertas a cualquier organización o institución que trabaja directa o indirectamente en esos campos. El enfoque actual está en:

1. Los proyectos multilaterales para fomentar la innovación y la creatividad en la enseñanza y el aprendizaje y aumentar el uso de nuevas herramientas TIC, especialmente para los grupos en riesgo de exclusión como estudiantes con abandono prematuro del sistema educativo, las minorías étnicas y personas de edad avanzada. 
2. Redes multilaterales para promover una mayor vinculación entre las comunidades y la conectividad entre el aprendizaje y fomentar la creatividad y la innovación mediante el uso de las TIC.

\section{b. Programa de Cultura.}

El programa de la UE Cultura (2007-2013) cuenta con un presupuesto de 400 millones de euros dirigidos a proyectos e iniciativas que desarrollen la cooperación cultural transnacional entre operadores culturales procedentes de los países de la Unión Europea (UE) o no europeos que participen en el programa. El programa Cultura pretende dar apoyo a acciones de cooperación cultural y a organismos europeos activos en el ámbito cultural, así como recabar y difundir información del mismo área.

Aunque no hay medidas específicas en materia de inclusión y TIC, dos proyectos en la convocatoria 2009 están relacionados: uno sobre «remodelación de la vida urbana» a través de la creación de espacios comunes para la cultura y la creatividad dirigido a jóvenes que viven en ambientes de diversidad cultural, social y étnica; otro llamado «el arte de la inclusión» cuya finalidad es evitar la exclusión social a través de la cultura, fomentando la inspiración, el entretenimiento y la motivación por experimentar el arte a través de las TIC

\section{c. Progress.}

Este programa está relacionado con el empleo y el programa de solidaridad social, y se desarrolla de 2007 a 2013 con un presupuesto de 743,25 millones de euros. Tiene como fin apoyar la ejecución de los objetivos de la Unión Europea en materia de empleo, asuntos sociales e igualdad de oportunidades, tal como se establece en la Comunicación de la Comisión sobre la Agenda Social. Los proyectos deben fomentar cambios y modernización en cinco áreas: 
- Empleo.

- Protección e inclusión social.

- Condiciones de Trabajo.

- No discriminación y diversidad.

- Igualdad de género.

Algunas de las acciones financiadas desde este proyecto son las relacionadas con:

- Aprendizaje mutuo, sensibilización y difusión.

- Estudios y análisis de alcance europeo.

- Observatorios europeos.

- Formación de profesionales de los ámbitos jurídico y político.

- Redes de expertos para intercambiar y debatir asuntos derivados de la legislación de la UE y su aplicación.

- Redes de ONG de la UE que luchen contra la exclusión social y la discriminación por motivos de origen racial, orientación sexual, edad o discapacidad o que fomenten la igualdad de género.

- Campañas de sensibilización pública sobre las políticas y la legislación social y de empleo de la UE, incluidas las Conferencias de la Presidencia de la UE o el Foro de la Agenda Social.

En la convocatoria de 2009, sólo tres proyectos que incluyen las TIC para la inclusión social han sido financiados desde este programa. 
d. Séptimo Programa Marco de Investigación y Desarrollo Tecnológico (7PM): $T C^{18}$

Desde este programa, las Tecnologías de la Información y la Comunicación (TIC) son fundamentales para mejorar la competitividad de la industria europea y para satisfacer las demandas de su sociedad y economía. Consideran que las TIC tienen un efecto catalizador en tres áreas clave:

- productividad y la innovación, facilitando la creatividad y la gestión;

- modernización de los servicios públicos como salud, educación y transporte;

- avances de la ciencia y la tecnología mediante el apoyo a la cooperación y el acceso a la información.

De la financiación de 9,1 millones de euros asignados al programa en la programación de 2009, sólo cinco proyectos están dirigidos específicamente a los grupos en situación o riesgo de exclusión. Todos ellos están dirigidos a la juventud ${ }^{19} \mathrm{y}$ a la promoción de su inclusión social mediante el fomento de su acceso a las TIC, las competencias digitales, la educación y la formación, integración social y las oportunidades de empleo:

- COMEIN: para facilitar la inclusión social de jóvenes en situación o riesgo de exclusión a través de las redes sociales y los móviles.

- HANDS: destinado a ayudar a la juventud diagnosticada de autismo a navegar por internet y a promocionar su desarrollo social

- INCLUSO: promoción del software social para la inclusión de juventud en situaciones o riesgo de exclusión.

18 Toda la información sobre el programa en: http://cordis.europa.eu/fp7/ict/

19 Más información sobre estos proyectos en: http://www.incluso.org/; http://www.comein-project.eu/; http://www.replayproject.eu/; $\quad$ http://www.hands-project.eu/; http://is.jrc.ec.europa.eu/pages/EAP/eInclusion.html\#Youth 
- PUPPYIR: un entorno de código abierto para la construcción de servicios de información para niños y niñas.

- REPLAY: una plataforma de juegos para la reinserción social de jóvenes en situación o riesgo de exclusión social.

e Séptimo Programa Marco de Investigación y Desarrollo Tecnológico (7PM: Programa de Ciencias Sociales y Humanidades).

Las ciencias socioeconómicas y humanidades del programa es, en principio, una de las áreas clave en las que la investigación sobre las TIC pueden ser financiados. En la convocatoria del sexto y el séptimo programa marco, se incluyen algunos proyectos sobre TIC para la inclusión social, entre los que se encuentran ${ }^{20}$ :

- CIVICWEB, destinado a los jóvenes, Internet y la participación ciudadana.

- YOUNEX, que tiene como ejes la juventud, el desempleo y la exclusión en Europa desde un enfoque multidimensional a la comprensión de las condiciones y perspectivas de la integración social y política de la juventud desempleada.

- CSEYHP, dirigido a la lucha contra la exclusión social en la juventud y en las personas sin hogar.

- YIPPEE, para la creación de un fondo público de atención a la juventud como vía para acceder a la educación en Europa.

\footnotetext{
${ }_{20}$ Más información sobre estos programas en lo sitios webs: http://www.civicweb.eu/; http://www.younex.unige.ch/index.html;http://ec.europa.eu/research/social-sciences/projects/364_en.html; http://tcru.ioe.ac.uk/yippee/;
http://www.sv.uio.no/iss/english/research/projects/eumargins/ http://www.edumigrom.eu/;
} 
- EDUMIGROM, sobre el alumnado de diferentes culturas en el ámbito educativo y las perspectivas divergentes de la «juventud urbana» en una Europa ampliada.

- EUMARGINS, un proyecto sobre la juventud inmigrante adulta en siete países europeos.

\section{f. Programa Juventud en Acción.}

Este es el principal vehículo de financiación actual de apoyo a la política de la UE en materia de juventud, con 885 millones de euros asignados en los siete años del ciclo de programación 2007-2013.

Dentro de las cinco grandes acciones que promueven, nos situamos en la «acción 4.4.», donde se enmarca un proyecto financiado en 2007, «Speak out - Reach out» ${ }^{21}$ que tenía la finalidad de proporcionar conocimientos sobre TIC para promover la inclusión de la juventud en situación desfavorecida en cuatro ciudades: Stuttgart (Alemania), Palermo (Italia), Toledo (España) y Bucarest (Rumanía). El proyecto impulsó la formación de jóvenes en diseño de páginas web y audio-podcasting, para dar un impulso a su desarrollo personal a través de la adquisición de competencias TIC que además les servían para su incorporación al mundo laboral.

\section{b. Programas nacionales}

Las iniciativas en España relacionadas con el e-learning y la inclusión social nacen con en el Plan Info XXI: «La Sociedad de la Información para todos», derivado de los objetivos planteados en el Plan de Acción eEurope y desarrollado durante el periodo 2001-2003. Este plan está formado por un

${ }^{21}$ Recogido en la memoria de proyectos de Buenas Prácticas del Programa Juventud en Acción de 2009. Disponible en:

http://ec.europa.eu/youth/sharing-experience/doc/thematic_compendia/good_practices_creativity.pdf 
conjunto de iniciativas que pretender hacer posible el uso y la explotación de las herramientas que ofrece la nueva sociedad, sobre todo internet, para contribuir al crecimiento económico, a la competitividad y al desarrollo socio-cultural. Incluyó la implementación de más de 300 acciones, promovidas por la Comisión Interministerial de la Sociedad de la Información y de las Nuevas Tecnologías (creada por el Real Decreto 1289/1999 de 23 de julio), dirigidas a promover las Tecnologías de la Información y Comunicación a toda la ciudadanía, especialmente en materia de salud, educación y administración. El Plan contiene una serie de objetivos estratégicos que se centran en alcanzar una sociedad de la información para todos y vinculada a la creación de empleo, educación, cultura, desarrollo de la economía digital, calidad de vida, nuevos negocios e industrias y promotora de una administración transparente dirigida a la ciudadanía, y un tejido empresarial potente (Plan Info XXI ${ }^{22}$ ).

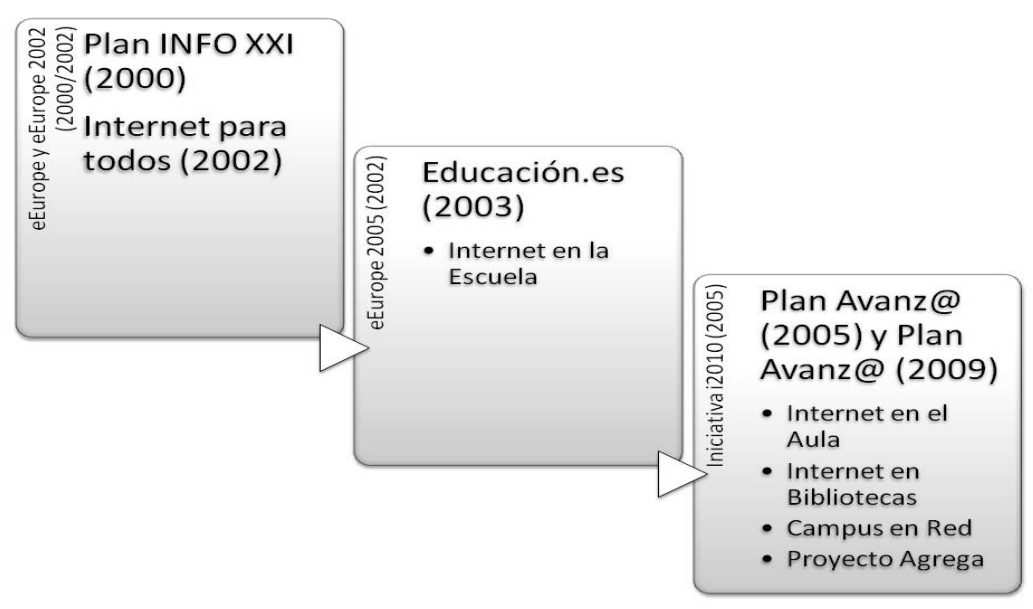

Figura 9. Relación políticas y planes Europeos y Nacionales.

Se apoya en siete líneas maestras acompañadas cada una de ellas de los respectivos programas y de sus objetivos y acciones prioritarias. En referencia a materia TIC e inclusión social, nos interesa mencionar las líneas referidas a:

${ }^{22}$ Este documento, elaborado por la Comisión Interministerial de la Sociedad de la Información y de las Nuevas Tecnologías, está disponible en: http://www.internautas.org/documentos/infoxxi.pdf 


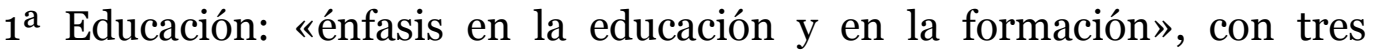
programas:

- Las autopistas de la educación.

- El conocimiento en el siglo XXI.

- Los modernos ciudadanos.

$2^{\mathrm{a}}$ Creación de empleo, entre las que se encuentra un programa de «Lucha contra la marginación laboral y prevención del desempleo»

$3^{\text {a }}$ Cohesión social, con un programa de «Atención a colectivos especiales»

- P.3: Desarrollo tecnológico del Sistema Nacional de Salud.

$4^{\mathrm{a}}$ Mejora de la calidad de vida de los ciudadanos, con programas como «Accesibilidad de los ciudadanos a las TIC», «Confort en el entorno doméstico y en espacios de uso colectivo», «Igualdad de oportunidades a través de las TIC».

En general, las acciones que contemplaba Info XXI estaban destinadas al acceso a las TIC y a la formación de la ciudadanía en competencias digitales, a servicios y comercio electrónico y a seguridad en las empresas. Además contaba con acciones dirigidas a la sociedad internacional mediante el programa «España en la Red», a través de los contenidos relacionados con las lenguas españolas, el patrimonio histórico, el turismo y la creación cultural. Entre las actuaciones incluidas dentro del Plan Info XXI destacaban un conjunto de 21 proyectos que abarcaban, entre otros, el Documento Nacional de Identidad electrónico, el portal único de la Administración, el desarrollo de Internet en la enseñanza y la puesta en marcha de la RedIRIS ${ }^{23}$, para la investigación y la difusión de contenidos digitales.

${ }^{23}$ Red para la investigación y la difusión de contenidos digitales. Sitio web: http://www.rediris.es/ 
En el año 2002, tras un análisis de la situación, se concluye que no se ha alcanzado el desarrollo esperado del plan, sobre todo, en referencia a la estrategia de «alfabetización digital» de la ciudadanía, la poca inversión para poner en marcha las acciones en las escuelas, el acceso en los hogares no llegaba a la mínima europea, entre otras. Para relanzar el Plan Info XXI surge el Programa «Internet para todos», en mayo de 2002, con acciones para asegurar el acceso de todos los ciudadanos y empresas a la Sociedad de la Información, potenciando las redes de banda ancha y propiciando una formación básica en nuevas tecnologías. Surgen críticas de la Asociación de internautas debido sobre todo a dos cuestiones: la poca accesibilidad de la web del programa para personas con discapacidad y el imposible acceso para personas que no eran usuarias de Microsoft. Así, este programa derivó en inversiones en banda ancha y administración electrónica, disminuyendo las acciones en materia de acceso a internet para todos, formación de trabajadores y trabajadoras e inversión en I+D.

En base a las recomendaciones de la Comisión Especial de Estudio para el Desarrollo de la Sociedad de la Información, el Ministerio de Ciencia y Tecnología presentó en julio de 2003 el programa «España.es» cuya finalidad es desarrollar un conjunto de acciones y proyectos concretos que impulsen el desarrollo de la Sociedad de la Información en España, con una duración de dos años (hasta 2005) y un coste aproximado de 1.029 millones de euros, de los que la Administración General del Estado aportará el 63\%, las Comunidades Autónomas el 26\% y el sector privado el 11\%.

El programa consta de 6 líneas maestras, tres verticales (Administración electrónica, educación y PYME) y tres horizontales (accesibilidad y formación, contenidos digitales y comunicación) que se dividen en diez medidas.

Dentro de las líneas de actuación se encuentra «Educación.es», que pretende mejorar el sistema educativo integrando las Tecnologías de la 
Información y Comunicación como herramienta habitual en el proceso de enseñanza-aprendizaje, sustituyendo las pizarras por proyectores digitales. Tuvo una vigencia de tres años (2004-2007) y desarrolló tres líneas principales:

- dotación de infraestructuras básicas en los centros,

- formación y dotación de medios informáticos para los docentes,

- desarrollo del portal educación.es con contenidos para profesores, alumnos y padres a través del Ministerio de Educación y Ciencia en colaboración con el sector privado y las comunidades.

En definitiva, se pretendía mejorar el sistema educativo integrando las TIC como instrumento habitual dentro de los procesos de enseñanza y aprendizaje, en consonancia con el objetivo prioritario de lograr que las nuevas generaciones, que se van formando, dispongan de las cualificaciones técnicas que demanda la Sociedad de la Información cuando finalicen el sistema educativo.

Otra línea interesante desde el punto de la inclusión social es el programa «Navega.es», que perseguía la incorporación a la Sociedad de la Información, de los ciudadanos no conectados, en dos líneas de actuación: creación de 2.000 nuevos centros de acceso público a Internet con conexiones de banda ancha para los municipios de entre 5.000 y 10.000 habitantes, y acciones de formación canalizadas a través entidades sin ánimo de lucro.

En marzo de 2003 el Ministerio de Agricultura, la Federación Española de Municipios y Provincias y Red.es ${ }^{24}$ suscribieron un Acuerdo de Colaboración

${ }^{24}$ Red.es es la Entidad Pública Empresarial adscrita al Ministerio de Industria, Turismo y Comercio (MITyC) encargada de impulsar el desarrollo de la Sociedad de la Información en España y ejecutar proyectos en el marco del Plan Avanza de acuerdo a las prioridades estratégicas de la Secretaría de Estado de Telecomunicaciones y para la Sociedad de la Información (SETSI), trabajando con Comunidades Autónomas, Diputaciones, Entidades Locales y el sector privado en materia de tecnologías de la información y comunicaciones. 
para la puesta en marcha del programa «Internet Rural». Este programa surge con el objetivo principal de acercar las TIC a la ciudadanía que reside en el medio rural. Para ello, se procedió a la instalación de centros de acceso a internet de carácter público y gratuito en los entes locales rurales, y se comienzan a desarrollar herramientas informáticas y software de interés para el sector primario. En esta iniciativa se involucran las Diputaciones Provinciales y Comunidades Autónomas Uniprovinciales, que cofinancian las acciones derivadas del programa, a la vez que enriquecen el mismo, con actividades de dinamización y formación para procurar alfabetización digital con el fin, por un lado, de acercar los beneficios de la Sociedad de la Información a las poblaciones rurales y por otro, contribuir a fomentar el desarrollo territorial de estas zonas. Con la buena marcha del programa se firma un nuevo acuerdo entre la Federación Española de Municipios y Provincias (FEMP) y Red.es para ampliar y reforzar las acciones ya desarrolladas., surgiendo el conocido programa Telecentros -dentro del conocido como Plan Avanza, que comentaremos a continuación-, cuyas actuaciones principales se desarrollaron a lo largo del periodo 2005-2007.

El Plan Avanza, aprobado por el Consejo de Ministros del 4 de noviembre de 2005, se enmarca en los ejes estratégicos del programa nacional de reformas diseñado por el Gobierno para cumplir con la Estrategia de Lisboa del año 2000: un plan de desarrollo de la Unión Europea, que tiene como objetivo convertir el mercado común en la economía más competitiva y dinámica del mundo. En concreto, el Plan Avanza se integra en el eje estratégico de impulso al I+D+i (Investigación+Desarrollo+innovación) que pone en marcha el Gobierno de España a través del Programa Ingenio 2010. 


\section{Plan Nacional de Reformas}

- Refuerzo de Estabilidad

Macroeconómica

- Plan Estratégico de

Infraestructura y Transporte

- Aumento y Mejora del Capital

Humano

- Estrategia I+D+i (Ingenio 2010)

- Competencia y Competitividad

- Mercado de trabajo y diálogo

social

- Plan de fomento empresarial

\section{Ingenio 2010}

- Avanz@: Potenciar la Sociedad de la Información

- CENIT: Aumentar la colaboración público-privada en $\mathrm{I}+\mathrm{D}+\mathrm{i}$

- CONSOLIDER: conseguir la excelencia investigadora

Figura 10. Relación entre iniciativas Ingenio 2010 y Avanz@

El Plan Avanza se desarrolla sobre la base de las siguientes premisas:

- Las TIC constituyen la clave del crecimiento económico y de la mejora de la productividad y la competitividad.

- Se debe hacer una política inclusiva, para mejorar la calidad de vida y aumentar la cohesión social.

- La elaboración y el desarrollo de un plan con estas características es una tarea común que requiere de la participación y el esfuerzo de toda la sociedad española. 
- El Plan se fundamenta en la iniciativa europea «i2010: Una Sociedad de Información Europea para el crecimiento y el empleo», presentada por la Comisión Europea el 31 de mayo de 2005.

Este plan se desarrolla de 2006-2010 y se orienta a conseguir la adecuada utilización de las TIC para contribuir al éxito de un modelo de crecimiento económico basado en el incremento de la competitividad y la productividad, la promoción de la igualdad social y regional y la mejora del bienestar y la calidad de vida de la ciudadanía. Plan Avanza contemplaba cuatro grandes áreas de actuación, entre las que nos interesa destacar tres de ellas por su relación con el e-learning y la inclusión social:

1. Ciudadanía Digital, cuyos objetivos iban dirigidos aumentar los hogares equipados con TIC e incrementar el conocimiento sobre el beneficio de la Sociedad de la información entre la ciudadanía para aumentar el uso diario. Las acciones base de este programa giran en torno a los objetivos y se refieren a la incorporación de equipamiento TIC en los hogares; el fomento del uso de las TIC en personas con discapacidad, especialmente con movilidad reducida, problemas visuales, auditivos y de comunicación y trastornos del espectro autista; el fomento de la igualdad de género en el uso de las TIC, con especial atención a mujeres del mundo rural, inmigrantes, amas de casa y mujeres emprendedoras; y en cuanto a infancia y mayores promover la alfabetización digital general. Estas actuaciones las desarrollan vía convenios, a través del Instituto de Crédito Oficial (ICO) (prestamos al o\% de interés), con las Comunidades Autónomas y con ayudas públicas para las entidades sociales sin ánimo de lucro.

2. Contenidos y Servicios Públicos Digitales, que tenía como metas conseguir una Administración Electrónica completamente desarrollada, garantizar el derecho de ciudadanos y empresas a relacionarse mediante internet con las Administraciones Públicas y 
transformar una educación basada en modelos tradicionales en una cimentada en la Sociedad de la Información. Dentro de éstos se sitúan los programas educativos:

- Internet en el Aula (equipamiento informático en centros no universitarios): Este programa se propuso como objetivo dotar a los 17.500 centros educativos de enseñanza obligatoria, bachillerato y formación profesional con 150.00o equipos para conectarse a Internet; dotar a las escuelas de conexiones a Internet de banda ancha; desarrollar software educativo multimedia, elaborar contenidos para la enseñanza obligatoria; formación del profesorado en TIC y adaptar los currículos para potenciar la utilización de las TIC.

- Internet en Bibliotecas (equipamiento informático y acceso público vía Web). Ya el Plan de Acción eEurope, adoptado en junio de 2000, proponía que se desarrollase una red de puntos de acceso público a Internet ubicados en espacios públicos, utilizando para ello los fondos estructurales. El Plan de Acción eEurope 2005, aprobado por el Consejo Europeo de Sevilla en junio de 2002, siguiendo las pautas del plan anterior, establece como actuación prioritaria el desarrollo de un programa de puntos de acceso público a Internet, usando preferentemente conexión de banda ancha. Este objetivo que señala el Plan de Acción eEurope 2005 es el que recoge y persigue el programa «Internet en las Bibliotecas». La amplia cobertura de la red de bibliotecas municipales permitiría alcanzar una gran extensión geográfica en la distribución de los puntos de acceso. La finalidad de este programa era introducir plenamente la Sociedad de la Información en el ámbito de las bibliotecas públicas. Las actuaciones comprendidas en este programa han 
sido: acceso público a internet en todas las bibliotecas públicas, desarrollo de aplicaciones informáticas y herramientas de gestión, mejora de la coordinación bibliotecaria de ámbito nacional y potenciación de nuevos servicios, a través del Portal de las Biblioteca Públicas Españolas y mediante la formación del personal de las bibliotecas y actividades de motivación para fomentar el uso de éstas por la ciudadanía.

- Campus en Red (acceso wifi a centros universitarios)

- Proyecto «Agrega»: contenidos para la enseñanza reglada no universitaria.

3. Contexto Digital, que pretende extender las infraestructuras de telecomunicaciones en áreas con demanda desatendida, extender la Banda Ancha y la movilidad y aumentar el grado de concienciación, formación y sensibilización de los ciudadanos, empresas y Administraciones Públicas, en materia de seguridad de las TIC. En este sentido se encuentran el Programa Extensión Banda Ancha, para extender cobertura a zonas rurales y el programa Telecentros.

En definitiva, las principales actuaciones del Plan Avanza 1, fueron desarrolladas por Red.es y se destinaron a:

- Modernizar la justicia, mediante el programa «e-Justicia», que promovía la digitalización de los registros civiles y los juzgados de paz.

- Modernizar la sanidad, a través de dotación de equipamiento informático, nueva tarjeta sanitaria, gestionar citas por internet, historia clínica y electrónica y receta electrónica.

- Modernizar la educación, con los programas ya señalados. 
El Plan Avanza 2 (periodo 2010-2015), vigente actualmente, va destinado a:

- Mejorar la calidad de los servicios prestados hasta el momento con el Plan Avanza 1.

- Hacer especial énfasis en las políticas locales por ser las más cercanas al ciudadano.

En ese sentido se pretende, en materia de Educación, aumentar el porcentaje de personas que utilizan Internet para buscar información sobre este ámbito y para realizar cursos online, desarrollar e implementar el proyecto Agrega, dotar de equipamiento a las escuelas, crear una plataforma de las mejores prácticas y capacitar a maestros y maestras.

\section{c. Programas en Extremadura}

En España, las Comunidades Autónomas, de acuerdo con el modelo nacional, han implantado en su medidas, programas y acciones dedicadas a regular y promover las exigencias derivadas de las directrices europeas y nacionales relacionadas con la Sociedad de la Información. Infodex nació en 1997 con el objetivo de analizar las posibilidades de la región para aprovechar las aplicaciones de las tecnologías de la información en la modernización de las actividades productivas. Al Plan Infodex I le sustituye el Plan Infodex II en 1999, que marca un plan estratégico para difundir y desarrollar la Sociedad de la información y de las telecomunicaciones en la comunidad extremeña. Para alcanzar esta meta, se marcaron objetivos:

- Conseguir que todos los niños y niñas y la juventud extremeña tengan acceso a las tecnologías de la información a través de los centros educativos. 
- Disponer en todos los órganos de gobierno y administración de la Junta de Extremadura de un conjunto de servicios corporativos de telecomunicaciones equivalentes a los disponibles en las regiones más avanzadas de Europa.

- Lograr que los habitats rurales dispongan, vía las TIC, de unas facilidades de consulta médica especializada equivalentes a las existentes en las ciudades de la región.

- Disponer en todos los centros médicos de Extremadura de acceso a las tecnologías de la información (voz, datos e imagen).

- Conseguir que las pequeñas y medianas empresas extremeñas conozcan las posibilidades existentes en la región para acceder al comercio electrónico y lograr un crecimiento significativo del número de empresas que lo aplican.

Para obtener los mencionados objetivos, se incluye un plan de acción compuesto de cinco programas con sus correspondientes líneas de acción.

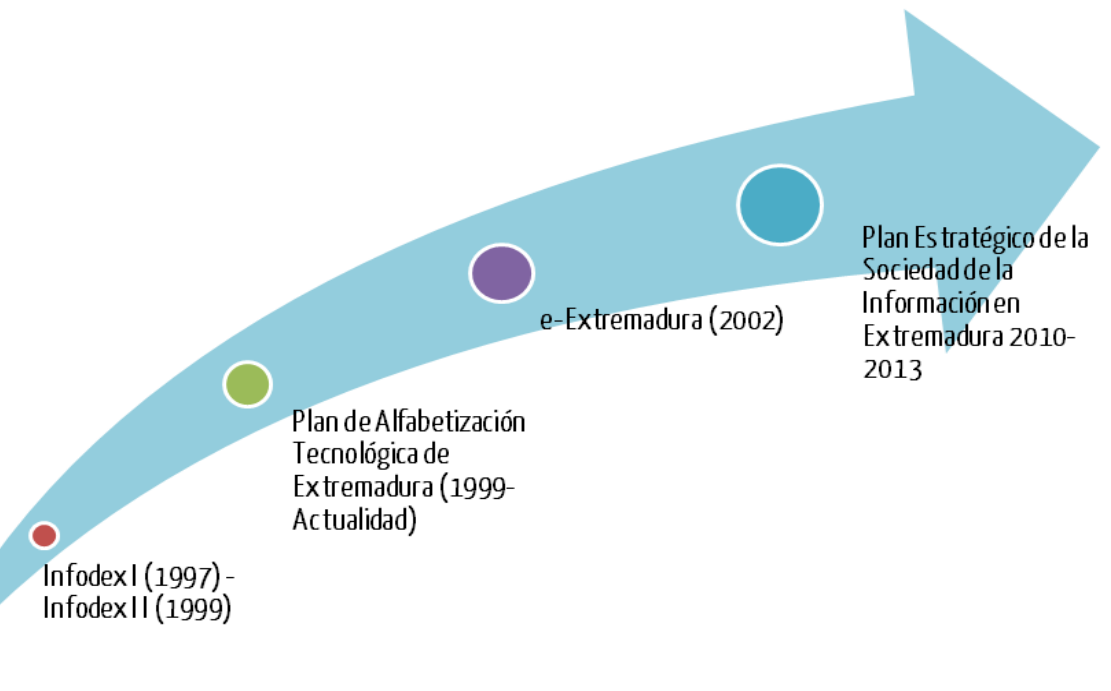


El Plan de Alfabetización Tecnológica y Software Libre de Extremadura surge en 1999 y parte de una acción estratégica diseñada para facilitar el acercamiento y la capacitación en el uso de las TIC a la ciudadanía extremeña mayor de 16 años, previniendo esas diferencias, brechas, distancias, desigualdades y desequilibrios que pueden llegar a producirse por cuestiones económicas, sociales, formativas, profesionales o geográficas.

Con el objetivo de desarrollar el Plan de Alfabetización Tecnológica de Extremadura, se crean los llamamos Nuevos Centros del Conocimiento (NCC) con la idea de diseñar un modelo propio, adaptado a las necesidades estratégicas de acceso generalizado de los ciudadanos y las ciudadanas a las TIC, en todos los pueblos, barrios y zonas de Extremadura y para dinamizar la participación de las organizaciones extremeñas. Este tipo de centros se ubican en entidades culturales o sociales, y ofrece servicios, a través de sus instalaciones y equipos informáticos conectados a Red, a todos los sectores de la población adulta. Los objetivos iniciales del proyecto se definían como (Junta de Extremadura, 2001):

- Promover el acceso democrático de los ciudadanos a las TIC.

- Difundir la cultura local y regional desde la participación y el compromiso colectivo de la ciudadanía extremeña.

- Desarrollar las habilidades y capacidades emprendedoras necesarias para afrontar los retos que Extremadura tiene planteados para el siglo XXI.

- Generar un espacio de encuentro social y virtual capaz de convocar a la diversidad de organizaciones sociales extremeñas.

- Crear redes de colaboración entre instituciones, empresas, asociaciones y personas con afinidad de intereses. 
- Generar manuales de buenas prácticas de Alfabetización Tecnológica y provocar un efecto multiplicador de iniciativas y proyectos emprendedores en todos los puntos de la geografía extremeña.

Los NCC son espacios públicos que cuentan con un equipamiento tecnológico completo y con un grupo de expertos y expertas responsable de todo el proceso de alfabetización tecnológica (cada centro tiene dos dinamizadores, uno sociocultural y otro informático con las funciones de socializar con las TIC, transferir conocimiento, sensibilizar y concienciar). Este programa que surgió en el año 2000 en el seno del Plan de Alfabetización Tecnológica de Extremadura, está gestionado por la Asociación de Universidades Populares de Extremadura (AUPEX) y cofinanciado por el Fondo Social Europeo y el Servicio Público de Empleo de la Junta de Extremadura; teniendo como eje claves la alfabetización tecnológica, la orientación laboral, los procesos de búsqueda activa de empleo, el emprendimiento y la formación para el empleo, conformando acciones en los siguientes bloques:

- Alfabetización en TIC para la ciudadanía, como una prioridad con el fin de continuar incorporando las TIC a la vida diaria de todos aquellos colectivos y grupos susceptibles de quedar al margen de las mismas: mujeres, personas jubiladas y desempleadas, jóvenes, personas con discapacidad, trabajadores/as, emprendedores/as, entre otros y otras.

- Orientación hacia el empleo a través de la TIC.

- Formación online, con acciones formativas a través de Moodle en materias que garanticen una alfabetización tecnológica básica dirigidas a personas, tanto empleadas como desempleadas, que no pueden acceder a la formación presencial tradicional por diferentes motivos: falta de tiempo, recursos económicos, desplazamientos, formación previa, etc. 
En el segundo semestre del 2000, surge una nueva iniciativa denominada «Integra-Red», como resultado de la experiencia llevada a cabo en el Centro Sociocultural de la Asociación de Vecinos de El Gurugú (Badajoz). El objetivo de Integra-Red también es la puesta en marcha del Plan estratégico de Alfabetización Tecnológica de Extremadura, haciendo llegar éste a barrios desfavorecidos de la región, a través de sedes de asociaciones de vecinos y casas de la mujer. El funcionamiento es similar al de los NCC, con la peculiaridad de que se concentran en barrios socialmente desfavorecidos con poblaciones superiores a los 20.000 habitantes. Tecnológicamente, todos los centros presentan características idénticas: siete ordenadores con conexión a Internet, impresora, así como un equipo multimedia compuesto por minidisc, cámara de foto digital, Webcam, etc.

El modelo actual de NCC/Integra-Red, además de formar para el uso de las TIC incorpora, como innovación en el proceso, la dinamización sociocultural e informática, implicando a todos los sectores sociales, culturales y económicos de la región. Es un modelo metodológico que supuso una innovación en este campo referida a la inclusión social y el e-learning.

A partir de enero de 2002, con la creación del Centro de Fomento de Nuevas Tecnologías y la creación del programa «e-Extremadura» se inicia una nueva etapa en la que el objetivo es contribuir a potenciar el uso de las nuevas tecnologías para impulsar el desarrollo económico de la región. El programa «e-Extremadura», que engloba el conjunto de las acciones innovadoras cofinanciadas por la Comisión Europea y la Junta de Extremadura para el desarrollo de Sociedad de la Información. Los objetivos del programa, que se desarrollaron en dos años, hasta fin de 2003, se basaron en optimizar el uso de las nuevas infraestructuras, materializadas en la Intranet regional. 
Actualmente vigente en Extremadura, se encuentra el Plan Estratégico de la Sociedad de la Información en Extremadura 201O-2013 (PESIEX 2013) ${ }^{25}$ El PESIEX 2013 nace con la intención de dar un impulso fundamental al desarrollo de la Sociedad de la Información en Extremadura. No sólo pretende definir las prioridades de la política regional en esta materia, con la correspondiente adscripción de recursos, sino que deberá ser un instrumento articulador de la acción regional en el ámbito de la Sociedad de la Información, catalizador de iniciativas innovadoras y eficaces $\mathrm{y}$, finalmente, impulsor de la integración tecnológica en la sociedad y la economía extremeñas. En el marco estratégico en el que se impulsa el PESIEX 2013 se identifican dos referencias con las que este plan deberá establecer una adecuada convergencia: La iniciativa i2010 -Una Sociedad de la Información europea para el crecimiento y el empleo- (a nivel europeo), con el Plan Avanza (a nivel nacional) y el Marco Estratégico de Convergencia de Extremadura (MECEX 2007-2013). Para ello, se inspira en la participación social, como eje vertebrador de una estrategia política abierta y flexible. La integración y la corresponsabilidad de agentes y colectivos afectados directa o indirectamente en la estrategia extremeña de Sociedad de la Información, inspiran y forman parte de la definición del propio plan.

El PESIEX 2013, además de ser la apuesta de la Junta de Extremadura para el desarrollo de la SI en los próximos tres años, lo plantean como una invitación a la participación de toda la ciudadanía en el progreso de la región.

Bajo un planteamiento estratégico, se marcan los siguientes ejes de actuación:

- $\quad$ Eje 1: ciudadanía digital.

- Eje 2: Empresas en red.

- Eje 3: Administración Pública.

25 El Plan está disponible en: http://eci.juntaextremadura.net/publicaciones/PlanSoc.pdf 
- Eje transversal: Observatorio Extremeño de la Sociedad de la Información.

- Eje transversal: $\mathrm{I}+\mathrm{D}+\mathrm{I}$.

Dentro de estos ejes, nos interesa el eje 1, destinado a la ciudadanía digital. Este eje tiene la finalidad de poner a disposición de la ciudadanía las herramientas necesarias para alcanzar o mejorar la existencia de equipamientos y la capacidad de su uso hasta donde cada ciudadano quiera integrarse en la SI. La normalización tecnológica es un proceso genérico que afecta a cada persona de forma singular, con desarrollos diversos. Por ello, la formación especializada, la capacitación en la adquisición de las habilidades necesarias para un uso efectivo de los equipamientos tecnológicos y la red, el fomento de la participación ciudadana en las cuestiones de interés público y la investigación dirigida a encontrar nuevas formas de facilitar el acercamiento a las TIC de las personas con dificultad, son los objetivos estratégicos en los que se apoya este primer eje de actuación.

Los objetivos operativos que se proponen son los siguientes:

a. Crear espacios de formación y capacitación especializados.

b. Reforzar y asegurar las políticas de e-Inclusión y e-Accesibilidad a través de la $\mathrm{I}+\mathrm{D}+\mathrm{i}$.

c. Promover actitudes de comunicación y participación en red.

d. Fomentar la creación de contenidos digitales de calidad en la red.

Dentro de esos objetivos, en referencia a la inclusión digital y el elearning, están las acciones derivadas de los objetivos a, b y c. En cuanto al «objetivo a»: 
- Capacitación: referida al fomento de los planes de capacitación TIC homologados existentes a través de centros acreditados. Estos planes se van a ejecutar en colaboración con la red de Telecentros.

- Formación: establecimiento de planes de formación por sectores para la búsqueda y mejora de empleo, formación en «e-portfolio», formación+experiencia+habilidades+evolución+comunidades de interés, etc. Estas acciones formativas se van a realizar en colaboración con el Servicio Extremeño Publico de Empleo y el Plan de Alfabetización Tecnológica. Además se pretende impulsar una plataforma regional de teleformación como repositorio de contenidos formativos en TIC.

- Internet Sensato: se refiere a acciones de promoción de la «econfianza» y las buenas conductas en la red dirigida a adultos y jóvenes. Constituye el objetivo de esta línea de actuación aumentar la confianza en las TIC de los ciudadanos, mediante la puesta en marcha de acciones que consigan elevar su grado de concienciación, formación y sensibilización en materia de seguridad.

En referencia al «objetivo $\mathrm{b} »$ :

- e-Inclusión: con medidas enfocadas a la investigación y desarrollo en la generación de nuevas interfaces de uso que permitan un acercamiento efectivo de los mayores a las nuevas tecnologías. Para ello se plantea el desarrollo de proyectos en colaboración con la Universidad de Extremadura.

- E-Accesibilidad: basado en la creación de herramientas de Software Libre para mejorar el acercamiento de las personas discapacitadas a la nueva Sociedad de la Información.

Por último en cuanto al «objetivo c»: 
- e-Participación: medidas para favorecer la participación de la ciudadanía en temas de interés para el desarrollo de su entorno a través del uso de las redes sociales, herramienta 2.0 o de plataformas de participación ciudadana tales como Extremadura Habla (Programa de la Consejería de Agricultura y Desarrollo Rural).

Existen, además, un número importante de convenios derivados del Plan Avanza que se recogen en su página web ${ }^{26}$.

Debemos destacar, también, los Planes de Inclusión Social en Extremadura, por considerar el acceso y uso de las TIC como una de las medidas principales, sobre todo en referencia al plan vigente actualmente. El I Plan de Inclusión Social (2005-2007), supuso un primer avance en materia de inclusión social. Esta evolución conllevó un mayor impulso de las políticas de intervención social contra la exclusión a nivel regional, dirigiendo las acciones a desarrollar políticas sociales comunitarias que comprometiesen, además de a la Administración regional, a todas las corporaciones locales, agentes sociales y entidades de iniciativa social que trabajan en Extremadura. El II Plan de Inclusión Social de Extremadura (2008-2011) ${ }^{27}$, entiende que el concepto de exclusión social no sólo abarca los niveles de renta como indicador de pobreza, sino también otros elementos o factores determinantes como: el acceso a determinados servicios, factores sociodemográficos, de situación sociocultural y de nivel de calidad de vida. A pesar de la complejidad y del carácter dinámico de este fenómeno, existe cierto consenso en que incluye dificultades o barreras en tres grandes dimensiones como son (Laparra et al., 2007): la dimensión económica, en referencia a la exclusión de la relación salarial normalizada y la pobreza económica; la política, relacionada con el acceso limitado a los derechos políticos y a los sistemas de

Disponible en:

http://www.planavanza.es/ActuacionesCCAA/BuscadorCCAA/Paginas/buscadorCCAA.aspx

27 El II Plan está disponible en:

http://ie.juntaex.es/proyectos/planinclusionsocial/PLAN_INCLUSION_SOCIAL.pdf 
protección social; y la dimensión social, referida la falta de apoyos y lazos sociales y las relaciones sociales conflictivas.

Concretamente en Extremadura, el II Plan de Inclusión Social, propone que el fin de cada medida y actuación dirigida a la lucha contra la exclusión social sea, a su vez, a favor de la Inclusión Social de las personas. Este planteamiento aporta una visión más positivista y motivadora del proceso social que trata de asegurar que aquellas personas y/o grupos poblacionales en situación o riesgo de pobreza y de exclusión social aumenten las oportunidades y los recursos necesarios para participar completamente en la vida económica, social y cultural; así como disponer de unas condiciones de vida y de bienestar que se consideran normales en la sociedad en la que viven y tengan una mayor participación en la toma de decisiones que afectan a sus vidas.

Este Plan se apoya en varios principios rectores, entre los que destaca el principio relacionado con las TIC:

«seguir dotando de las herramientas tecnológicas suficientes y facilitando su uso a toda la sociedad extremeña, y de esta manera conseguir que todas las acciones y medidas lleguen a los colectivos más vulnerables y que éstos puedan acceder a mayor número de recursos» (Pág. 22 del II Plan de Inclusión Social en Extremadura). 


\subsection{Factores socioculturales del e-learning.}

Planella y Rodríguez (2004b), reflexionan sobre lo que consideran los factores socioculturales del e-learning, con el fin de definir su perspectiva social y cultural. Sus análisis giran en torno a ocho variables:

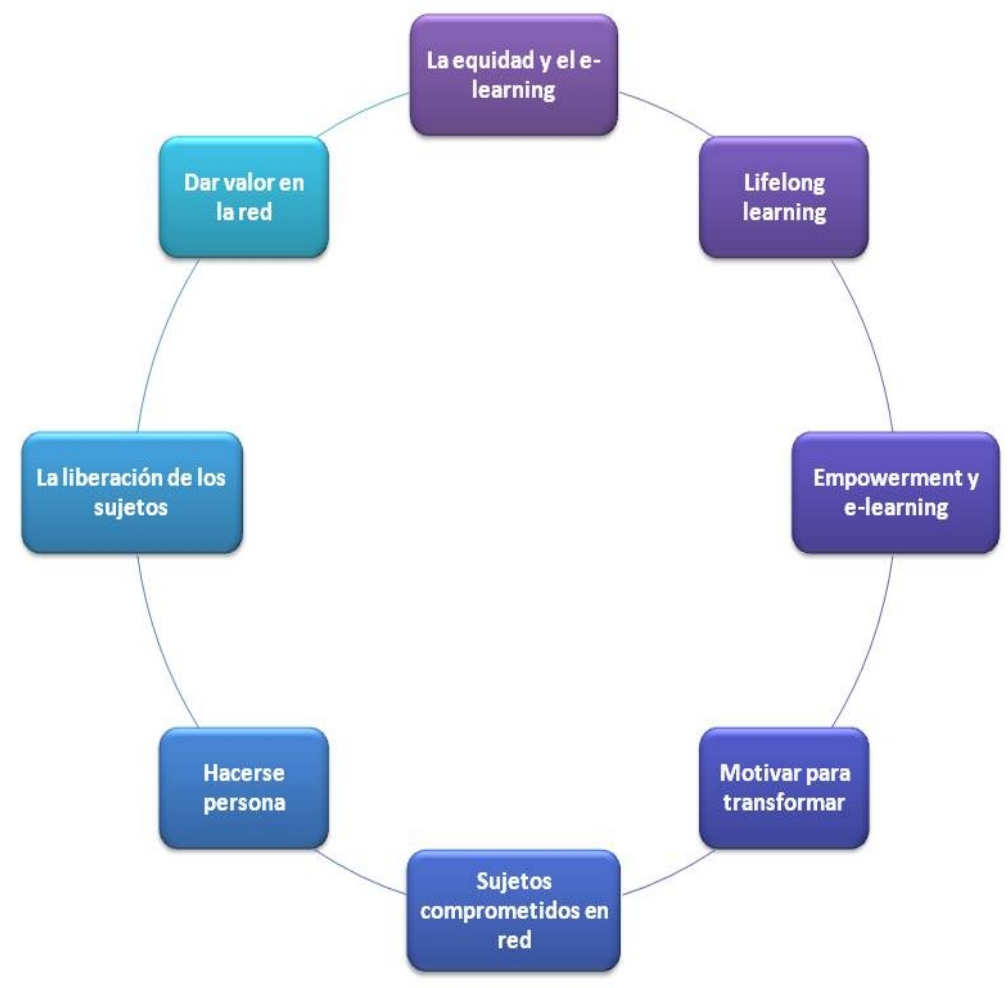

Figura 12. Factores socioculturales del e-learning

\section{a. La equidad y el e-learning.}

Se basa en la apertura de oportunidades para las personas desde el elearning, puesto que, a través de éste, se potencian otros puntos de vista y otras perspectivas de trabajo. De igual manera, debido a sus características propias, pueden reducirse o eliminarse diferencias estructurales de índole geográfica, económica, social, entre otras. Es decir, que, desde el e-learning 
se puede trabajar para reducir la doble brecha (social y digital), entendiendo que, a la vez que se reduce la brecha digital se reduce la brecha social derivada de esas diferencias estructurales, a las que se añaden aspectos como el género, la edad, las individualidades, etc.

«La alfabetización digital es importante porque es la clave de la inclusión. La brecha digital también es brecha social. Ambas se alimentan mutuamente. Por eso, la alfabetización digital es también la clave del desarrollo de la sociedad de la información» (Area, Gros y Marzal, 2008: 42).

Este factor tiene relación también con la reinvidicación actual del uso del diálogo para contribuir a democratización de la sociedad a través de las TIC. Sobre todo a través de la formación con el principio del diálogo entre iguales (Aubert et. al, 2008). Los procesos comunicativos que se deriven de acciones e-learning deben implicar y permitir el intercambio entre iguales, ya sean entre las mismas personas participantes como entre las personas participantes y los facilitadores. El trabajo de campo ha mostrado cómo es importante que las personas participantes puedan opinar en lo que quieren aprender y cómo lo quieren aprender, porque de esta forma se incrementa la calidad en la comunicación y el entorno de confianza, creando el sentido de comunidad. Grace (1998) centra su atención en la importancia de hacer partícipes a las personas implicadas de un proyecto porque esto añade calidad a la comunicación, creando un sentido de comunidad y estableciendo un ambiente de confianza, lo que deriva a su vez, en una mayor equidad de los sujetos. Este hecho puede transferirse a los proyectos de e-learning social.

También se encuentra una relación con el principio de igualdad de las diferencias (Flecha, 1999), es decir al derecho de toda persona de vivir de manera diferente. Desde este punto de vista la creación de espacios de diálogo que potencien el conocimiento entre las participantes, que las haga visibles, que mejoren su aprendizaje, fomentará procesos de comprensión del derecho a ser diferente (Aubert et al., 2008). Desde esta perspectiva, se 
resalta la visión de un modelo de formación con carácter participativo en la que el grupo de personas destinatarias sean las productoras ideológicas, teóricas y experimentales de sus acuerdos y propuestas. El proceso de aprendizaje se realiza a partir de la construcción intelectual y experiencial de cada una de los sujetos que integran el grupo de aprendizaje (Vygostky, 1979; Coll, 1990; Aubert et al., 2008).

\section{b. Lifelong learning.}

Este factor se refiere al paradigma de la «educación a lo largo de la vida» (García Carrasco, 1997, 2006), es decir, a que toda la sociedad está sujeta a un proceso permanente de aprendizaje y, por ende, a la necesidad continua de formarse en esta nueva sociedad, y a la potencialidad e implicaciones del e-learning en ello. Esta nueva dimensión pone en juego nuevas formas, nuevas implicaciones y nuevas relaciones sociales, como lo refleja el siguiente fragmento:

«La educación está en plena mutación; en todos los ámbitos se observa una multiplicación de las posibilidades de aprendizaje que ofrece la sociedad fuera del ámbito escolar, y la noción de especialización en el sentido tradicional está siendo reemplazada en muchos sectores modernos de actividad por las de competencia evolutiva y adaptabilidad. [...] En lo sucesivo, el período de aprendizaje cubre toda la vida y cada tipo de conocimiento invade el ámbito de los demás y los enriquece. [...] [La educación a lo largo de la vida] es un requisito fundamental para un dominio cada vez mayor de los ritmos y tiempos del ser humano, que supera con mucho la necesidad de adaptarse a los imperativos del mundo del trabajo. [...] La educación a lo largo de la vida representa para el ser humano una construcción continua de sus conocimientos y aptitudes y de su facultad de juicio y acción. Debe permitirle tomar conciencia de sí mismo y de su entorno y desempeñar su función social en el mundo del trabajo y en la vida pública. [...] La educación, sin límites temporales ni espaciales, se convierte en una dimensión de la vida misma. (UNESCO, 1996:111 y ss.). 


\section{c.Empowerment y e-learning.}

Este factor se refiere al cambio en las estructuras del proceso de enseñanza-aprendizaje y de los roles que los agentes educativos adquieren en ese proceso. Para ello se recurre a la idea de empowerment que se entiende como la delegación de diferentes cuotas de poder en una organización, es decir, de motivar, impulsar, proporcionar facilidades y desarrollar y explotar todas las capacidades de personas, grupos o instituciones para conseguir unos determinados objetivos. Se relaciona con la acción de participación social y las posibilidades que el e-learning ofrece para ejercer esa participación. Por tanto podemos indicar que los ejes de este factor serían la participación social igualitaria, el fomento de la participación en igualdad de condiciones y favorecer el empoderamiento.

En el contexto de las acciones e-learning concretas desde la perspectiva social, este factor se refiere a delegar poder en las personas que participan en esas acciones para tomar decisiones. Este hecho se relaciona con la psicología comunitaria, que postula que se debe posibilitar el aumento de poder de los actores sociales con los que se interviene, como estrategia para que las personas puedan actuar por sí mismas (Freire, 2003). Para ello toda intervención debe cumplir tres condiciones básicas: (a) respeto de la diversidad de las personas y las comunidades y el valor en la promoción de la autogestión; (b) la ubicación del locus de control y del poder en la comunidad; y (c) la unión inseparable de la teoría y la práctica.

\section{d. Motivar para transformar.}

Desde este punto de vista, se nos sugiere que, antes de comenzar proyectos relacionados con el e-learning social, debemos plantearnos varias cuestiones relacionadas con el aspecto sociopersonal (Planella y Rodríguez y, 2004b): ¿Qué puede interesar a los sujetos de Internet?, ¿qué ventajas tendrá para ellos dicho aprendizaje?, ¿en qué mejorará su vida el uso de la 
tecnología? Inciden sobre todo, en el tema de la motivación, ya que uno de los problemas que se indican es que en algunos colectivos las acciones e-learning no preven estrategias de motivación que vayan más allá del aspecto pragmático.

Desde el punto de vista de acciones de e-learning este factor sería aplicable desde los siguientes ejes:

- Usar elementos motivadores para las participantes. Planella y Rodríguez (2004b), insisten en que la motivación del alumno para participar activamente en el proceso de formación online es clave para un aprendizaje efectivo y significativo. Todas las demás variables críticas pueden estar bien gestionadas, pero si falta la motivación del alumno, el aprendizaje no se producirá. Por lo cual, recomiendan conocer cuáles son los intereses del participante y realizar todo el diseño e implementación del e-learning en función de sus intereses y motivaciones. Además, añaden unas pautas sobre aquellos aspectos que los usuarios del e-learning valoran especialmente:

- disponer de asistencia a través de tutorías virtuales vía e-mail y chat;

- lograr un aprendizaje colaborativo a través de foros de discusión;

- contar con retroalimentación en sus procesos de autoaprendizaje;

- conocer cuáles fueron sus errores en las evaluaciones; identificar sus avances y evolución aprendizaje.

- Hacer que los participantes vean útil la acción formativa, teniendo en cuenta ese aspecto contextual y pragmático. 
- Entender internet y sus recursos como herramienta para la acción colectiva (más allá del aspecto pragmático).

- Tener en cuenta la inteligencia cultural (Aubert et al.2008). Este principio parte de la idea de que todas las personas tenemos una inteligencia cultural adquirida a lo largo de nuestra experiencia de vida y que expresamos a través de las interacciones. La concepción de inteligencia cultural reconoce como tal a la inteligencia académica, práctica y comunicativa, contemplando la pluralidad de dimensiones de la interacción humana y las habilidades comunicativas como componentes de la inteligencia cultural. Desde esta concepción aplicada al punto de vista educativo, se parte del reconocimiento en los estudiantes de sus capacidades, no sólo de las habilidades académicas, sino también de las prácticas comunicativas, potenciando todas ellas. De este modo, los objetivos y los conocimientos se crean a través de las distintas experiencias, formas de conocimiento y puntos de vista. Así se facilita una interpretación de la realidad desde una perspectiva transformadora. Teniendo en cuenta este eje, debemos reconocer y valorar las habilidades y competencias que pueden aportar las personas que participan en la acciones de e-learning.

Por otro lado, además de motivar, se debe buscar, como indica este factor del e-learning social, una transformación explícita (Dutton, 2004). Es decir debemos plantearnos que los sujetos que participan en esas acciones, deben ser protagonistas de sus propios cambios, generados desde sus propias propuestas, llegando a acuerdos y contrastando sus diferencias, en la que una comunicación intersubjetiva (Aubert et al., 2008) llegue a orientar esas transformaciones sociales y personales.

Planella y Rodríguez (2004b) destacan varias investigaciones que muestran cómo el acceso a las TIC y su empoderamiento genera un desarrollo comunitario potencial mientras que, al mismo tiempo, implica cambios en las 
propias personas que forman la comunidad como, por ejemplo, descenso del sentimiento de soledad, un aumento de la auto-confianza, realza el acceso a amplios recursos de información $\mathrm{y}$ promueve mejores trabajos $\mathrm{y}$ oportunidades laborales.

\section{e. Sujetos comprometidos en red.}

Este factor se refiere al compromiso de los sujetos a través de las prácticas de e-learning. Es decir, es la necesidad de un compromiso de implicación por parte de las personas, profesionales, colectivos, voluntarios, agentes sociales, etc. involucrados, directa o indirectamente en esas experiencias, si de verdad se quiere producir un cambio.

Los ejes a tener en cuenta, por tanto, serían el compromiso de los agentes que participan en el proyecto de e-learning, y especialmente, el compromiso de las personas destinatarias del mismo.

\section{d. Hacerse persona.}

Se destaca el potencial socializador de las prácticas e-learning y se propone debatir y estudiar los efectos de la sociedad red y las prácticas de elearning y en las formas de subjetividad que éstas promueven, reproducen, fomentan o discuten. En esa línea, Revuelta (2009) estudia los mecanismos de socialización en una comunidad virtual de práctica y propone pautas de actuación en el diseño de programas educativos que incidan en la potencialización de estos mecanismos en entornos virtuales de aprendizaje. Detecta cinco mecanismos de socialización: identificación, internalización, asimilación, adaptación y aprendizaje social. En cada uno de ellos sugiere algunas pautas que pueden incorporarse a las prácticas formativas online. En el caso del mecanismo de identificación, se sugiere buscar estrategias de motivación desde el comienzo para que todas las personas participantes se auto-identifiquen con el grupo. En la internalización, las pautas se dirigen a hacer explícitas las normas de la comunidad también desde el principio, con 
la finalidad de que sean conocidas por todos y todas antes de que se produzca algún conflicto. En tercer lugar, la asimilación la basa en tres formas diferentes: (a) estrategia de explicitación de las creencias, es decir, plantear cuestiones sobre los conceptos abstractos y complejos en unión con todas las creencias de los distintos participantes de un grupo virtual lo que facilita la comprensión de los mismos, (b) superación de nuevas situaciones sociales que permite activar los mecanismos de asimilación, al igual que (c) los procesos de cambio. El siguiente mecanismo es el de adaptación, planteando por un lado, estrategias de adaptación al uso y manejo de los recursos tecnológicos de comunicación que facilitan las interacciones en la primera semana del curso y, por otro, a los contenidos, adaptándose a los conocimientos previos de los y las estudiantes. Por último destaca el mecanismo de aprendizaje social, con pautas dirigidas a mostrar los resultados de las soluciones a las actividades, para activar los conocimientos y comprobar la valoración de la auto-eficacia percibida por los estudiantes.

\section{f. La liberación de los sujetos.}

Este factor parte de que la alfabetización digital puede tener niveles, como el aprendizaje práctico de las TIC, haciendo referencia a manejo de sotfware, recursos, espacios, etc.) y el aprendizaje simbólico-social de las TIC (actividades y acciones que pueden llevarse a cabo con otras personas, colaborativo, etc.). Desde este punto de vista, se nos insta a mirar el elearning desde una perspectiva política, hablando de sujetos e-learning como sujetos de conocimiento con los que se cuenta para el diseño de acciones de esta tipología y no sólo como objetos de la misma (Flecha, 2004).

\section{g. Dar valor en la red.}

Este factor se refiere a los valores, sobre todos los ligados a la sociedad actual, y formas de relacionarnos, es decir, el tener en cuenta las prácticas elearning, como acciones ligadas a las transmisión y adquisición de valores. 
Para ello se mencionan unas palabras de Duart (citado en Planella y Rodríguez, 2004b): «El factor relevante [...] es el de la existencia de un espacio de relación, de una comunidad virtual de aprendizaje, que actúa como plataforma desde la cual es posible experimentar, vivir y explicitar los valores educativos».

Como ejes de este factor, se relacionan los valores de respeto $\mathrm{y}$ solidaridad, derivados de la interculturalidad y sociedad plural identificados por Planella y Rodríguez. En este sentido no sólo debemos tener en cuenta el fomentar valores de respeto ante opiniones y experiencias de las personas que participan en la acción de e-learning, sino el principio de solidaridad (Aubert et al., 2008). El principio de solidaridad es el factor clave en las prácticas educativas desde esta perspectiva que supone buscar el éxito de todos y todas. Este principio, debe guiar la acción de formación, situándola en la perspectiva dialógica, entendiendo que todas las personas aprenden de todas, y que todas se empoderan al dotarse de herramientas que les permita dotarse, a la vez, de autoridad para la participación. Esto conlleva la creación de redes solidarias entre los participantes del proyecto de e-learning para posibilitar transformaciones en las percepciones y cambios en cuanto a las desigualdades.

\subsection{El e-learning para la inclusión y el cambio social.}

Desde los años 70, diferentes investigadores han analizado los cambios sociales derivados de una profunda transformación tecnológica y que han desembocado en la Sociedad de la Información: la denominada industria del conocimiento (Machlup, 1962), la sociedad post-capitalista (Drucker, 1969), sociedad tecnotrónica (Brzezinski, 1970), la aldea gobal y galaxia Gutenberg (Toffler, 1981; McLuhan, 1985), sociedad postindustrial o de la tercera ola 
(Tourain, 1973; Bell, 1976), la sociedad global (Torres, 1994), la sociedad de la información (Masuda, 1984), la sociedad red (Castells, 1997), la sociedad del conocimiento (Stehr, 2002; UNESCO, 2005).

Castells (1997) ya advertía que la transformación tecnológica iba a incidir en transformaciones sociales y que esos cambios se iban a reflejar en todos los ámbitos, incluido en ámbito educativo, vinculando, dentro de este ámbito, la formación online (e-learning), que se ampliaría a todas las actividades educativas, de capacitación y formación. Posteriormente Stehr (2002) o la UNESCO (2005) añaden que la utilización de las TIC en procesos de enseñanza-aprendizaje en la educación superior ha potenciado la difusión del conocimiento a través de comunidades virtuales educativas, que se organizan a través de nuevos modelos pedagógicos con énfasis en la discusión a través de la red. Todo ello ha contribuido, según éstos autores, a propiciar otra transformación tecnológico-social hacia lo que llaman Sociedad del Conocimiento. Desde estos puntos de vista la asimilación y el uso de las TIC en las sociedades se ha relacionado con los procesos de transformación y cambio social. En ese sentido Cabrera et. al (2005:53) afirma que «un adecuado uso de las TIC puede generar capital social y, en consecuencia, un adecuado crecimiento económico que evite situaciones de inclusión ${ }^{28}$. Continúan explicando que, al estar extendidas, las TIC tienen un valor de uso porque «sirven para», y un valor de cambio, porque «aportan algo positivo» a quiénes las usan y manejan. Devuelven a las personas en situaciones de exclusión social un cierto reconocimiento social a un doble nivel, lo que supone que las TIC se convierten en un factor de «mediación para la inserción social»:

- Individual, ya que al adquirir cierto grado de competencias digitales se refuerza la autoestima y supone una autoafirmación personal.

${ }_{28}$ Estos autores entienden que el capital social es «el conjunto de redes sociales y las normas de reciprocidad asociadas a ellas». 
- Colectivo, en el sentido de que las TIC permiten desplegar un mundo de relaciones sociales, sacando del aislamiento en que algunas personas y grupos se pueden encontrar.

De esta forma se está empoderando a las personas, porque fomenta capacidades individuales que permiten a acceder a la información, al conocimiento y a compartirlo, aspecto que permite un desarrollo personal; y potencia formas de organización y de trabajos colectivos y en red, por ejemplo en la defensa de derechos e intereses y abre las puertas para actuar en cualquier ámbito. Como indican Planella y Rodríguez (2004b), mediante internet y los recursos que las TIC nos ofrecen «se erigen formas de sociabilidad y convivencia que son radicalmente distintas de formas sociales anteriores, sobre todo, por la posibilidades para la información y comunicación que ofrecen, que facilitan nuevas formas de expresión».

El estudio desarrollado por Cabrera et al. (2005), recoge los ámbitos de intervención y las principales estrategias de uso de las TIC para la inclusión y el cambio social:

1. Ámbito Personal. Desde este ámbito se trabaja formando en competencias básicas para el uso de las TIC como modo de rehabilitar las capacidades mentales y cognitivas de personas con estas capacidades deterioradas. Así, se ofrece un refuerzo pedagógico desde la formación y el acceso a la información y un refuerzo y motivación personales, ya que los nuevos aprendizajes contribuyen a alcanzar un «sentimiento constructivo y positivo» (p. 148), pasando del no saber al manejo básico, cuestión que da confianza en las posibilidades de uno mismo y abren la propia perspectiva del mundo, lo que consecuentemente mejora la autoestima.

2. Ámbito relacional. Desde este ámbito se utilizan estrategias para reducir esa fractura relacional-comunicativa que se producen en 
situaciones de exclusión social, mediante la comunicación con otras personas a través de chat, foros, y otros recursos TIC de comunicación. Por otro lado, manejan la estrategia de grupos de autoayuda, utilizando los recursos TIC de comunicación de forma anónima para salir de la incomunicación y ocultamiento de algunas personas con algún tipo de problema. En último lugar, desde el punto de vista de la cohesión grupal, utilizando los recursos TIC comunicativos, se fomenta la identidad colectiva y la cohesión de grupos reforzando los vínculos de pertenencia.

3. Ámbito laboral. Desde el ámbito laboral las TIC se están utilizando como fuente de búsqueda de empleo y como formación para el empleo, no sólo con cursos de alfabetización básica, sino mediante cursos profesionales.

4. Ámbito del ocio. Diversión, relación y primer acercamiento TIC. En este ámbito, además de los aspectos comunicativos y de relación a través de chats, navegar por páginas de interés -musicales, de películas, etc.- los juegos en internet se usan como estrategia para un primer acercamiento a las TIC.

Como hemos visto en proyectos mencionados anteriormente, se sostiene que el e-learning puede ser una herramienta para la inclusión social, que puede contribuir a reducir e incluso atajar, situaciones de desigualdad y exclusión social relacionadas con las posibilidades que ofrece para la enseñanza-aprendizaje. El e-learning, desde esta perspectiva, puede considerase, también, un instrumento para la transformación social. Para que se constituya como tal, se debe repensar como recurso destinado a la intervención social y educativa, de la misma manera que se entrevee en los proyectos que se han revisado con anterioridad. Además de facilitar el acceso a la tecnología, Basela (2003) propone varias medidas a tener en cuenta en estas intervenciones tales como realizar intervenciones centradas en el 
territorio (bajo la máxima de actuar localmente y pensar y decidir globalmente); la creación de redes que posibiliten el debate, transferencia de experiencias, de soporte, de comunicación de conocimientos adquiridos, poniendo en contacto a unos grupos y otros e intervenir desde acciones integradas que potencien la participación de las personas destinatarias.

Tanto, como hemos reseñado, desde el ámbito de planes y programas nacionales promovidos por administraciones públicas, como algunos programas de entidades privadas sin ánimo de lucro ${ }^{29}$, se están desarrollando iniciativas destinadas a reducir algunas situaciones de exclusión social mediante el uso de programas e-learning. Sin embargo, Cabrera et al. (2005) concluyen que las oportunidades ofrecidas por las TIC, desde el punto de vista educativo, no se están aprovechando lo suficiente, pese a que hay programas con bastante antigüedad en la ejecución. En consecuencia, este autor establece que es necesario determinar cuáles son los motivos por lo que las TIC no están siendo utilizadas de forma amplia para eliminar algunos de los problemas que afectan a los grupos destinatarios de esos programas. Aunque por otro lado, afirma que independientemente de los perfiles de población con los que se trabaje y los diferentes usos que se haga, los recursos TIC siempre pueden aportar aspectos positivos a los procesos de inserción social de los diferentes grupos. Planella y Rodríguez (2004b:7), reiteran que esto es lo que debe tenerse en cuenta desde la perspectiva del e-learning para el cambio social:

«[...] lo más significativo es estar abierto a la dimensión social del elearning, porque detrás aparecen los rostros de personas que con ilusión, esperanzas y utopías, creen en la posibilidad de mejorar sus vidas y sus relaciones $y$ de transformar aquellos aspectos más problemáticos de su entorno. $Y$ toda esta mejora que tiene la posibilidad real de transformar a la sociedad puede ser posible a

29 Cabrera et al. (2005) recoge programas desarrollados por algunas entidades destinados a mejorar la interrelación de las instituciones que realizan acciones de inclusión social y acercar las TIC a los grupos para utilizarlas en acciones que permitan su inclusión social. 
partir de incorporar en las prácticas, reflexiones, políticas $e$ investigaciones lo que hemos denominado social e-learning».

Desde este punto de vista, Luque (2004) plantea varias cuestiones a tener en cuenta para implementar procesos e-learning desde una perspectiva de cambio social:

- Reflexionar acerca de los grupos humanos en los que el e-learning pretende introducirse, porque afirma que el encuentro con el conocimiento representa una «movilización subjetiva».

- Considerar qué distancia es la que se debe salvar (espacial, temporal, tecnológica, cultural) al utilizar el e-learning para procesos de formación para resolverla.

- Establecer en las modalidades de e-learning las estrategias que hagan posible realizar una vigilancia crítica de contenidos y actividades, desde el punto de vista de la calidad.

- Pensar cuál es la naturaleza de los problemas que se requieren resolver desde una perspectiva social del e-learning ya que éste puede colaborar aportando soluciones, para lo que se propone esclarecer su misión y función desde la universidad.

Pero la estrategia no sólo es diseñar e implementar programas e-learning desde la perspectiva social, sino producir un avance que pueda provocar un cambio social. Desde esta perspectiva Casacuberta (2007) nos insta a desarrollar enfoques alternativos basados en dos imperativos que considera fundamentales. Por un lado superar las barreras mentales, es decir, ir más allá de la superación de las barreras de acceso teniendo en cuenta el factor de desconfianza que puedan tener los grupos hacia las TIC y, además, buscar contenidos atractivos y útiles para esas personas. Por otro lado, centrarse en la capacitación, y no en el uso inmediato, es decir, fomentar el aprendizaje 
por competencias para, por ejemplo, acceder al mundo laboral. También en aspectos cognitivos como generar pensamiento crítico, por un lado fomentando la creación de opiniones y, por otro, desde una perspectiva más social y cultural, para organizarse socialmente.

También se deriva de la revisión realizada de la literatura y de los estudios y programas presentados, que se necesita una evaluación del contexto, contando con la participación de las personas destinatarias, para poder adaptar los proyectos a las condiciones que exijan las necesidades y potencialidades de los lugares, comunidades, grupos, personas a los que vaya dirigida las acciones de e-learning. Además de lo anterior Cullen et al. (2010) destacan que si se quiere conseguir un impacto social que produzca una transformación, es necesario la participación de todos los agentes. Y Planella y Rodríguez (2004c:72) insisten en que, además de contar con todos los agentes, hay que tener muy en cuenta el contexto de aplicación y a las personas destinatarias:

\begin{abstract}
«acercar el e-learning, convertirlo en un motor de transformación social y cultural, implica contar con un acerbo de actores, instituciones y recursos importante, además de conseguir que éstos trabajen en la misma dirección [...] No hay inclusión posible sin una buena detección de necesidades, sin una evaluación contextual, sin una participación de las comunidades y actores a los que se dirige, y sin una apropiación significativa por parte del contexto que condiciona las necesidades y potencialidades de estas plataformas».
\end{abstract}

Para finalizar, recogemos las cinco estrategias clave para establecer buenas prácticas en el uso del e-learning para la inclusión social y digital, según las últimas investigaciones (Casacuberta, 2007):

- Combinar la enseñanza de las TIC con otros conocimientos no digitales pero igualmente importantes para la inclusión social. En este sentido se recomienda asociar para motivar y combinar objetivos de aprendizaje para una mejor eficiencia en el proceso. Es decir, 
asociar el aprendizaje con algo que realmente interese a las personas destinatarias, así de esta manera, a la vez que se aprenden competencias TIC, aprenden otro tipo de cuestiones que pueden servirles en la promoción laboral o en su vida diaria.

- Comunicar con los grupos diana. Se debe tener en cuenta la negociación y participación con el grupo destinatario, pues, aunque esté muy bien diseñada la acción e-learning, puede no interesar o no ser conocida por el grupo destinatario. Así, se debe establecer una comunicación con los grupos diana por medios no digitales en un primer momento. Establecemos una relación entre esto y las críticas fundamentadas de Flecha (2004) que destacan las investigaciones, en este caso, sobre el pueblo gitano sin contar con los propios afectados. Este autor muestra que haciendo esto, tomamos a los sujetos protagonistas como una parte de la realidad analizada, convirtiéndose en objetos de investigación, privándoles del carácter de sujeto, lo que no contribuye a la superación de desigualdades, de situaciones de discriminación ni fomenta una convivencia intercultural. Esta es una muestra de la importancia de la comunicación y negociación con los grupos diana desde el comienzo de cualquier investigación, conjunto de acciones o actividades concretas que se quieran realizar.

- Establecer sistemas de enseñanza entre iguales. Se recomienda desde esta estrategia fomentar el que algunos y algunas estudiantes aprendan entre ellos y ellas mismas, para reforzar de forma significativa la relevancia cognitiva del aprendizaje y aumente la motivación de estas personas.

- Crear entornos informales; desde esta estrategia se insta a crear entornos menos formales de aprendizaje, para que las personas que participan se sientan cómodas y encuentren el espacio como propio. 
- Recurrir a profesorado que muestre afinidad con los estudiantes, especialmente en casos de e-learning destinado a mujeres, es decir establece una enseñanza basada en la empatía cultural o de género. Ya que se ha documentado, según Casacuberta, que esto produce una motivación más alta en las personas que participan.

En resumen, en este capítulo hemos contextualizado la visión social del elearning, por una parte, desde el panorama de las políticas internacionales, nacionales y regionales $\mathrm{y}$, por otra, desde estudios científicos y programas relacionados con experiencias de e-learning para la inclusión social. Con este análisis, hemos estudiado las repercusiones y retos que el e-learning implica como estrategia de intervención social. Por último, se han definido siete factores socioculturales del e-learning que se deben tener en cuenta para asumir la visión de éste como motor de cambio y transformación social: la equidad, lifelong learning, empowerment, motivar para transformar, sujetos comprometidos en red, hacerse persona, la liberación de los sujetos y dar valor en la red. 


\section{Capítulo 3. E-learning social y Comunidades de Práctica}





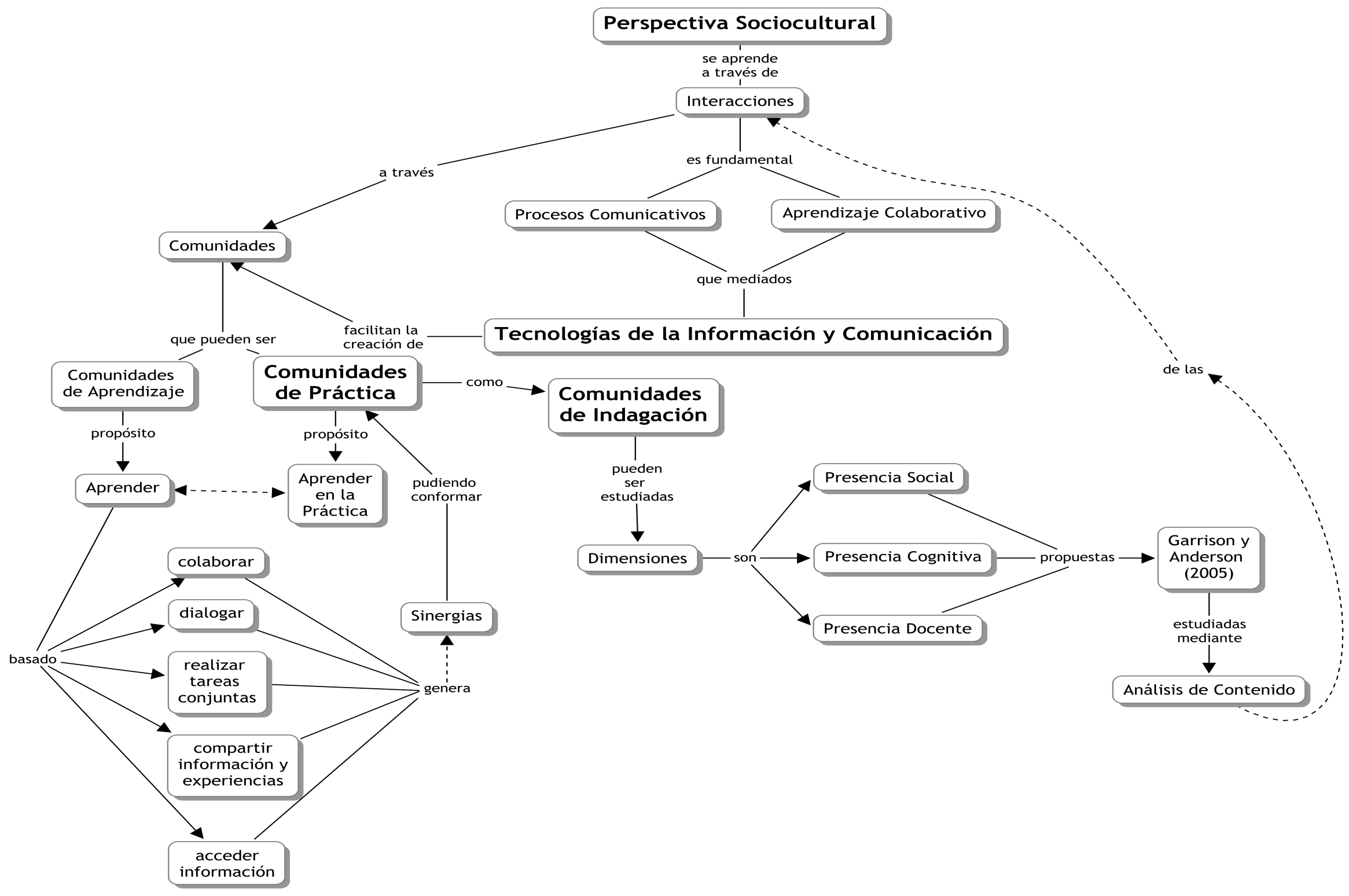





\subsection{Las Comunidades de Práctica: modelos y desarrollo en entornos virtuales de aprendizaje.}

\subsubsection{Contexto: La perspectiva sociocultural. Aprendizaje colaborativo, procesos comunicativos y Tecnologías de la Información y Comunicación.}

En la década de los 90, la teoría constructivista era considerada el «paradigma del cambio», teniendo una influencia considerable en la educación científica (Matthews, 1998; 2002). Esta consideración ha dado lugar a múltiples enfoques de esta perspectiva desde las vertientes filosóficas, psicológicas y educativas, que han derivado en diferentes «concepciones constructivistas» (Luque, Ortega y Cubero, 1997). Dentro de esas diferentes concepciones del constructivismo, vamos a centrarnos en la «perspectiva sociocultural».

Desde esta perspectiva, el aprendizaje es entendido como una actividad vinculada necesariamente a un contexto (Vygotsky 1979; Leontiev, 1978 y Luria, 1987; Rogoff, 1993; Lave, 1997; Bereiter, 1997; Engeström y Cole, 1997; y Wenger, 2001). Los aprendizajes, así, no pueden darse al margen de las interacciones sociales, siendo el contexto social y los instrumentos mediacionales los que, a través de los procesos de interiorización, forman los procesos psicológicos superiores (Vygotsky, 1979). El proceso de aprendizaje, desde este postulado, es un proceso fundamentalmente social, siendo en la cultura donde se encuentran los organizadores de la experiencia, y es esa práctica social la que permite su interiorización, esto es, el aprendizaje y el conocimiento. Así, por lo tanto, enfatiza la importancia de la cultura y el contexto para el entendimiento de lo que está sucediendo en la sociedad y para construir conocimiento basado en esa comprensión. 
Desde este punto de vista, el ambiente de aprendizaje más óptimo es aquel donde existe una interacción dinámica entre docentes, estudiantes y actividades. Estos ambientes dotan de oportunidades a los alumnos y alumnas para crear su propio conocimiento en base a la interacción. Coll y Solé (1990, citado en Díaz y Hernández, 2002:103), refiriéndose al concepto de interacción señalan que, desde el ámbito educativo, la interacción evoca situaciones en las que los protagonistas actúan simultánea y recíprocamente en un contexto determinado, en torno a una tarea o contenido de aprendizaje con el fin de lograr unos objetivos más menos definidos.

En este contexto, Vygotsky plantea el concepto de «zona de desarrollo próximo» definida como «la distancia entre el nivel de desarrollo, determinado por la capacidad de resolver independientemente un problema y el nivel de desarrollo potencial, determinado a través de la resolución de un problema bajo la guía de un adulto o en colaboración con otro compañero más capaz» (Vygotsky, 1979:133). El concepto de «zona» según García Carrasco $^{30}$ (2001) hace referencia a un sistema interactivo, a una situación de interacción, a historia evolutiva y experiencial individual y a una estructura de apoyo que aporta la asimetría de competencia, en la actividad entre actores participantes en la situación. De igual manera la «zona» se instituye en toda situación de cooperación en una tarea con actores de experiencia desigual, independiente del carácter formal o informal del plan. De ahí que el ámbito de actividad de la zona haga referencia al contenido de la acción, a lo que se hace y al cómo lo hacen, al diseño y artificio del proceso. Lo anterior presupone que las operaciones psicológicas superiores tienen origen sociocultural, y se encuentran mediadas socialmente.

Siguiendo a Rodríguez Mena (2007), con este postulado ocurre una variación importante en la comprensión del conocimiento como categoría: primero, porque los conocimientos están asociados a determinados valores

3о Tomado de «La zona de construcción del sujeto» documento interno elaborado por el Dr. D. Joaquín García Carrasco, procedente del Doctorado Procesos de Formación en Espacios Virtuales. Universidad de Salamanca. Año 2001. 
que las personas les atribuyen en su aplicación a partir del contexto sociocultural al que pertenecen; y en segundo lugar, porque la separación entre el conocimiento teórico y práctico se relativiza a situaciones específicas. De este modo, el conocimiento es una práctica social de la realidad. Desde esta óptica el proceso de aprendizaje está íntimamente ligado a la experiencia de formar parte de una comunidad, y por tanto los estudiantes son sujetos en interacción dentro de esa comunidad. En esa experiencia son fundamentales los procesos comunicativos y el aprendizaje en colaboración que se produce en el contexto de esa comunidad. La perspectiva del aprendizaje colaborativo se centra en el proceso de construcción del conocimiento a través del aprendizaje que resulta de la interacción con un grupo y mediante tareas realizadas en cooperación con otros y otras. En este sentido Crook (1998:168) señala que «los estudios sobre el aprendizaje colaborativo se centran en las ventajas cognitivas derivadas de los intercambios más íntimos que tienen lugar al trabajar juntos». Así el aprendizaje colaborativo está centrado elementalmente en el diálogo y la negociación, aprendiendo de manera conjunta. Aprender es un proceso dialéctico y dialógico, en el que los estudiantes comparten la interacción, el intercambio de ideas y conocimientos entre todos los miembros, esperando que éstos participen activamente, y se responsabilicen y apropien del proceso.

El concepto de aprendizaje colaborativo se desarrolla a través de distintas líneas que buscan una aproximación a su significado. Así, Gros (2000) señala que en un proceso de aprendizaje colaborativo, las partes se comprometen a aprender algo juntos, cuestión que sólo se consigue con el trabajo del grupo desarrollado en colaboración. El grupo debe decidir cómo realiza la tarea, qué procedimientos sigue, cómo divide el trabajo, etc. La comunicación y la negociación, según esta autora, son claves en este proceso. Salinas (2000:200) aporta que el aprendizaje colaborativo es «la adquisición de destrezas y actitudes que ocurren como resultado de la interacción en grupo». Según Díaz Barriga (1999), el aprendizaje colaborativo se caracteriza 
por la igualdad que debe tener cada individuo en el proceso de aprendizaje y la mutualidad, entendida como la conexión, profundidad y bidireccionalidad que alcance la experiencia, siendo ésta una variable en función del nivel de competitividad existente, la distribución de responsabilidades, la planificación conjunta y el intercambio de roles.

Dillenbourg (1999), sin embargo, no intenta definir este término por la existencia de una multitud de variedades de uso del concepto, planteando que la que más se acerca a su comprensión, aunque es «insuficiente» es que el aprendizaje colaborativo se trata de «una situación en la que dos o más personas aprenden o intentan aprender algo juntos». Añade que esta definición puede interpretarse de varias maneras, entendiendo por ejemplo que: «dos o más» puede interpretarse como un par, un pequeño grupo (3-5 sujetos), una clase (20-30 alumnos), una comunidad (unos pocos cientos o miles de personas), una sociedad (varios miles o millones de personas) y todos los términos intermedios; "Aprender algo» puede ser interpretado como «un curso», «el material del curso de estudio», «realizar actividades de aprendizaje tales como la resolución de problemas», «aprender de la práctica del trabajo de toda la vida», etc.; y que «juntos» se puede interpretar como las diferentes formas de interacción: cara a cara o a través del ordenador, sincrónico o no, frecuentes en el tiempo o no, si es verdaderamente un esfuerzo conjunto o si el trabajo se divide en una forma sistemática.

Driscoll y Vergara (1997), exponen que para que exista un verdadero aprendizaje colaborativo no sólo se requiere trabajar juntos sino que hay que cooperar para alcanzar una determinada meta que no podría lograrse de forma individual. Y señalan para comprender el término, cinco elementos que lo caracterizan:

1. Responsabilidad individual: todos los miembros son responsables de su desempeño individual dentro del grupo. 
2. Interdependencia positiva: los miembros del grupo deben depender los unos de los otros para lograr la meta común.

3. Habilidades de colaboración: las habilidades necesarias para que el grupo funcione en forma efectiva, como el trabajo en equipo, liderazgo y solución de conflictos.

4. Interacción promotora: los miembros del grupo interactúan para desarrollar relaciones interpersonales y establecer estrategias efectivas de aprendizaje.

5. Proceso de grupo: el grupo reflexiona en forma periódica y evalúa su funcionamiento, efectuando los cambios necesarios para incrementar su efectividad.

Calzadilla (2002), a su vez, indica algunos pasos destinados a producir aprendizaje colaborativo:

1. Estudio pormenorizado de capacidades, deficiencias y posibilidades de los miembros del equipo

2. Establecimiento de metas conjuntas, que incorporen las metas individuales

3. Elaboración de un plan de acción, con responsabilidades específicas y encuentros para la evaluación del proceso

4. Chequeo permanente del progreso del equipo, a nivel individual y grupal

5. Cuidado de las relaciones socioafectivas, a partir del sentido de pertenencia, respeto mutuo y la solidaridad.

6. Discusiones progresivas en torno al producto final. 
Como ideas añadidas a todo lo mencionado, tenemos en cuenta las cuatro dimensiones señaladas por Der-Thanq y Hung (2002) para el diseño instruccional en referencia a conseguir entornos de aprendizaje colaborativo:

- Aprendizaje situado: Debemos tener en cuenta el fomento de actividades contextualizadas, tareas y proyectos auténticos, basados en necesidades y demandas reales, tomando en cuenta el conocimiento explícito e implícito sobre el asunto en cuestión (creencias, normas del grupo).

- Comunalidad: Debemos fomentar la comunalidad, en la medida en que hay intereses y problemas compartidos entre los integrantes de la comunidad, lo que permite el establecimiento de metas compartidas.

- Interdependencia: La interdependencia sucede en la medida en que los participantes varíen en el nivel de competencia, es decir, si hay diferencias en conocimiento, habilidades, perspectivas, opiniones y necesidades, y siempre y cuando se logren entablar relaciones de beneficio mutuo (como ejemplo se establece que los novatos obtienen apoyo y respuestas de los expertos, partiendo de la idea de que completar una tarea no será posible si se maneja de manera individual).

- Infraestructura: Implica la existencia de reglas o sistemas que promueven la motivación y participación, una serie de mecanismos de rendición de cuentas de los participantes y la disposición de estructuras de facilitación de la información y la interdependencia.

Siguiendo la perspectiva sociocultural de Vygostky, el ordenador se convierte en una herramienta útil para la interacción con la información, el conocimiento y las personas, y la dinámica de trabajo en grupo, en la cual los participantes pueden llegar a formar un espacio común de aprendizaje donde compartir conocimientos y recursos (Crook, 1998). En sentido Gros (2002) 
nos sitúa el aprendizaje colaborativo mediado por ordenador como una de las formas ideales para trabajar en la «Zona de Desarrollo Próximo». De esta manera, la autora expresa dos ideas importantes en torno al aprendizaje colaborativo mediado por ordenador:

- La idea de aprender de forma colaborativa, en la que el aprendiz se contempla en interacción con los demás. La importancia por compartir objetivos y distribuir responsabilidades son formas deseables de aprendizaje.

- Se enfatiza el papel del ordenador como «elemento mediador» que apoya ese proceso. Se trata pues de aprender a colaborar y colaborar para aprender.

Aprender en colaboración supone que, a través de una serie de interacciones, se promueve un cambio en la actividad cognitiva del estudiante, permitiendo confrontar sus ideas con las ideas de otros, ya sea por la generación de un conflicto o por la simple descripción de las mismas (Crook, 1998). Así, los entornos virtuales de aprendizaje, desde el punto de vista pedagógico, ofrecen una serie de posibilidades para procesos de colaboración, donde el alumnado produce conocimiento de forma activa, formulando ideas por escrito que son compartidas y construidas a partir de las reacciones y respuestas de los demás (Resnick, 2002). Surge un nuevo centro de interés en las ciencias de la educación en torno al denominado «Aprendizaje colaborativo Mediado por Ordenador» (Computer Supported Collaborative Learning-CSCL-). Este concepto, surgido del ámbito empresarial desde el «Trabajo Colaborativo Mediado por Ordenador» (Computer Supported Collaborative Work -CSCW) se convierte en un paradigma emergente de la investigación educativa en los años 90 a partir del cual se desarrollan una variedad de trabajos relacionados con el CSCL desde diferentes marcos teóricos, metodologías instruccionales y de investigación, debido a su carácter multidisciplinar (Barberà et al, 2008). En 
cualquier caso, estos estudios comparten el interés por entender cómo las TIC pueden facilitar procesos de desarrollo colaborativos en situaciones de enseñanza-aprendizaje, y sobre cómo los entornos de aprendizaje colaborativo pueden mejorar y potenciar la interacción, el trabajo en grupo, y por consiguiente, el resultado del proceso de aprendizaje de los participantes (Jorrín et. al, 2007; Rubia, Jorrín y Anguita, 2009).

Entre las ventajas que los entornos virtuales de aprendizaje representan para el proceso de aprendizaje colaborativo se encuentran las siguientes (Calzadilla, 2002):

1. Estimulan la comunicación interpersonal, posibilitando el intercambio de información y el diálogo entra las personas que forman parte del proceso. Desde el punto de vista del diseño, existen herramientas que facilitan estos procesos comunicativos, como los foros, correo electrónico, Chat, etc.

2. Facilitan el trabajo colaborativo, al permitir que los aprendices compartan información, trabajen con documentos conjuntos $\mathrm{y}$ faciliten la solución de problemas y toma de decisiones. Existen utilidades específicas como las WIkis, foros, calendario, glosario, para trabajar estos aspectos.

3. Seguimiento del progreso del grupo, a nivel individual y colectivo, mediante los test evaluativos, el seguimiento de la participación en los foros, posibilidades de obtener estadísticas de los itinerarios del alumnado, las herramienta de comunicación antes mencionadas, etc.

4. Acceso a información y contenidos de aprendizaje: mediante buscadores, páginas webs, bases de datos, etc., que permiten al alumnado intercambiar direcciones, recursos e integrar perspectivas múltiples. 
5. Gestión y administración de los alumnos: permiten tener acceso a toda aquella información vinculada con el estudiante, su expediente e información adicional, que le pueda ser útil al docente.

6. Creación de ejercicios de evaluación y autoevaluación, con los que se puede conocer el progreso de alumnado en cuanto a los objetivos de aprendizaje y da feedback a los mismos, así como la posibilidad de introducir cambios, rediseñando la experiencia de aprendizaje.

Por tanto, las TIC favorecen el aprendizaje colaborativo en cuanto que proporcionan herramientas y recursos para la comunicación, organización, exposición de ideas, elaboración colaborativa de documentos, entre otros. Desde la perspectiva del diseño de entornos colaborativos, deberemos tener en cuenta la interactividad (Revuelta y Pérez, 2009) porque para que se produzca aprendizaje colaborativo, tiene que producirse interacción entre los estudiantes, y negociación como parte de esa interacción, ayudándonos de las herramientas comunicativas que nos ofrecen las TIC para fomentar este tipo de aprendizaje. En este sentido, Sigalés (2001: para. 33) destaca que las perspectivas constructivistas de los procesos de enseñanza aplicados a la educación a distancia pueden ayudar a entender y analizar el potencial interactivo de los entornos virtuales. Sigalés afirma que «los procesos de enseñanza y aprendizaje confluirían en los procesos de interacción, en los que se produciría la construcción de significados compartidos entre profesor y estudiante y entre estudiantes». Así, menciona el autor, que la construcción del conocimiento se desarrollaría en fases como las descritas por Gunawardena et al. (1997), compartiendo y comparando información, descubriendo el desacuerdo entre ideas y conceptos, negociando el significado, revisando la síntesis efectuada y aplicando el nuevo conocimiento. De este modo, todo ese conjunto de acciones mentales y sociales y la actividad general que despliegan los participantes para realizar las tareas de enseñanza y aprendizaje, constituye lo que se denomina interacción en contextos educativos virtuales (Barberà, 2008). 
Situando esta perspectiva en entornos virtuales de aprendizaje, Onrubia (2005) expone que caracterizar el aprendizaje en entornos virtuales como un proceso de construcción supone, esencialmente, afirmar que lo que el alumno o alumna aprende en un entorno virtual no es simplemente una copia o una reproducción de lo que en ese entorno se le presenta como contenido a aprender, sino una reelaboración de ese contenido mediada por la estructura cognitiva del aprendiz. En la perspectiva sociocultural del aprendizaje, la interacción social y el discurso son elementos básicos para el desarrollo de los procesos cognitivos superiores (Vygotsky 1979). Las interacciones con los demás participantes y con el docente, pasan a ser elementos esenciales para la construcción social del conocimiento. El aprendizaje es el resultado, no del trabajo individual, sino del trabajo colaborativo y el rol del alumno pasivo y el profesor transmisor de conocimiento se modifican sustancialmente. Ambos actores del proceso educativo son, bajo este marco teórico, activos en la construcción de conocimientos, el primero como eje central y el segundo como facilitador. En resumen, pasa a ser una enseñanza centrada en el alumno: de un proceso centrado en la enseñanza a un proceso centrado en el aprendizaje.

Estos aspectos son resaltados por el uso de las TIC (Adell, 1997; Hernández y González, 2002; Salinas, 2003; Cabero, 2004) porque ofrecen características de la multidireccionalidad, pues permite la comunicación de tú a tú, además de entre un usuario y un grupo, entre grupos usuario o entre diferentes grupos en diferentes lugares; la interactividad, ya que puede sostener interacciones complejas, tiene múltiples formas de codificación de la información; y la flexibilidad, porque puede establecerse comunicación tanto síncrona como asíncrona (Bates, 1995; Harasim et al., 2000; Ryan et al., 2000; Salmon, 2000), reconociéndose que esta última permite más tiempo para considerar las aportaciones, opinar de forma más reflexiva y es más efectiva para discutir ideas complejas (Hathorn y Ingram, 2002). Con relación a los procesos comunicativos mediados por recursos TIC para 
potenciar la construcción de conocimiento, Jonassen (1994) afirma que en el aprendizaje online el estudiante se muestra más comprometido con las discusiones y las interacciones con pares, cuestión que hace que se promueva la exploración, reflexión, discusión y la negociación social de los significados.

En cuanto al aprendizaje colaborativo Harasim (1989:51) indica que para los procesos comunicativos las TIC «ofrecen oportunidades al aprendizaje colaborativo que hasta ahora han sido imposibles». Entre ellas señala que facilita compartir conocimientos, trabajar juntos en espacios y tiempos iguales o distintos y la interacción reflexiva. Bates (1995) menciona las potencialidades pedagógicas de estos procesos comunicativos mediados por TIC, entre los que destaca:

- Desarrollo del discurso académico de los participantes, capacitando en el análisis, construcción y defensa de un argumento.

- Permite la construcción de conocimiento.

- Facilita el aprendizaje colaborativo.

- Maximiza el conocimiento y experiencia de todos los participantes.

- Incremento equitativo de la participación, porque todos tienen la oportunidad de intervenir con la sola valoración de su aportación.

- Desarrollo de habilidades de escritura reflexiva.

- Feedback y contacto directo con el equipo académico central, recibiendo retroalimentación por parte de tutores.

- Cruce cultural, si participan personas de diferentes culturas y/o procedencias. 
Estas posibilidades comunicativas permiten introducir metodologías de trabajo virtual, donde la interacción con los pares, la reflexión y la construcción del conocimiento en forma colaborativa, son aspectos centrales. Desde este punto de vista, se ofrecen enormes posibilidades para crear entornos de aprendizaje basados en modelos constructivistas de carácter sociocultural, posibilitando el trabajo colaborativo y potenciando la construcción de conocimiento en una comunidad virtual de aprendizaje.

Se insiste en la multidireccionalidad, interactividad y flexibilidad ya mencionadas, como características principales, que hacen que el proceso de aprendizaje sea dinámico y promueva, asimismo, un aprendizaje dialógico y colaborativo. En este sentido, es necesario tener en cuenta estos elementos a la hora de incorporar esta herramienta en el diseño instructivo de un entorno virtual, la sola incorporación de recursos comunicativos en entornos virtuales, como chats, foros, etc. no garantiza la interacción, el desarrollo del discurso, la colaboración ni la construcción de conocimiento, entre las señaladas anteriormente. Swan et al. (2000) indica que existen tres factores de éxito que contribuyen a que los ambientes de aprendizaje virtual tengan éxito: una interfaz transparente, un docente que interactúe frecuentemente y constructivamente con los estudiantes y una discusión valorada y dinámica. En este sentido, como afirman autores como Adell y Sales (1999), Cabero (2001), Salmon (2000), Salinas (2003), Garrison y Anderson (2005), entre otros, el rol del tutor/a es fundamental en el éxito de la experiencia formativa virtual, sobre todo, en el desarrollo de la discusión destinada a promover el aprendizaje colaborativo.

Para los aspectos mencionados con anterioridad, la plataforma debe disponer de espacios para la interacción, que sean accesibles en todo momento, y también contar con espacios para acciones distintas de carácter técnico y administrativos (Barberà y Badia, 2004; Pérez, 2004). Aunque debemos matizar que las experiencias negativas observadas en el aprendizaje 
colaborativo se debían mucho más a problemas de comunicación que a los aspectos técnicos o plataformas usadas (Gunawardena, 1995).

Herramientas comunicativas como el chat, los foros, los blogs, etc. permiten facilitar la puesta en común de ideas, el compartir, reflexionar, desarrollar trabajos de carácter colaborativo, recibir retroalimentación y orientaciones por parte del tutor o tutora (Anderson y Kanuka, 1997; Crook 1998; Cabero 2001; Gros, 2000).

\subsubsection{Comunidades de Aprendizaje y Comunidades de Práctica en entornos virtuales.}

De la comprensión y el estudio de la naturaleza social del conocimiento, surge el concepto sociocultural de comunidad de práctica ${ }^{31}$ acuñado por los autores Lave y Wenger (1991), como modelo que permite comprender, explicar e investigar la forma real en que las personas aprenden. Una Comunidad de Práctica es «un grupo de personas que comparten una preocupación, un conjunto de problemas o un interés común acerca de un tema, y que profundizan su conocimiento y pericia en esta área a través de una interacción continuada» (Wenger, McDermott y Zinder, 2002). Según este concepto podemos hablar de grupo sociales constituidos con la finalidad de desarrollar un conocimiento especializado, compartiendo aprendizajes basados en la reflexión conjunta sobre experiencias prácticas. Este concepto se describe, siguiendo a Rodríguez Mena (2007) en términos de «participación en la práctica» lo que produce «cambios en los participantes»:

${ }^{31} \quad$ Este concepto es acuñado por Wenger, aunque también se le atribuye John Seely Brown y Paul Duguid por un artículo sobre los reparadores de fotocopiadoras Xerox que publicaron en el año 1991. Los antecedentes del término se pueden establecer en los siguientes documentos:

- 1991: Jean Lave y Etienne Wenger: Situated Learning: Legitimate peripheral participation. New York: Cambridge University Press

- 1991: John Seely Brown yPaul Duguid: Organizational learning and communities of practice. Toward a unified view of working, learning and innovation. Organization Science, 2, 40-57.

- 2001: Etienne Wenger: Comunidades de práctica: Aprendizaje, significado e identidad. Barcelona: Paidos. 
- Participación: pertenencia legítima a una comunidad, la aceptación por los demás participantes, la implicación personal y el compromiso, la identidad durante el movimiento de participación.

- En la práctica: que se identifica con las actividades características de una comunidad, sea simbólica o material, y que incluye los procesos, artefactos, instrumentos, significados y discursos implicados para realizarla.

- Y que produce cambios en los participantes: el aprendizaje es la condición obligatoria de las Comunidades de Práctica, tengan o no el propósito explícito o consciente de producirlo y en base al desarrollo de sus participantes.

Una comunidad de práctica, según Wenger (2001), tiene tres dimensiones fundamentales:

- Un interés común (lo que denomina como empresa conjunta cuando se refiere al ámbito profesional), que es la dimensión clave para que surja la Comunidad de Práctica.

- Un compromiso mutuo, por trabajar de manera conjunta y por la responsabilidad en el funcionamiento de la Comunidad de Práctica.

- Un repertorio conjunto, el desarrollo de un repertorio compartido que incluye recursos, palabras, instrumentos o maneras de hacer y que han pasado a formar parte de la práctica. Esto es, la base de recursos que los miembros no sólo comparten sino que también contribuyen a crear y renovar.

Las Comunidades de Práctica se caracterizan, según Lave y Wenger (1991), por los siguientes aspectos: existe un objetivo común entre los participantes, mantiene una memoria colectiva en forma de conocimiento explícito, existe una fuerte relación de confianza y respeto entre quiénes 
forman la comunidad, están orientadas a compartir el conocimiento y a colaborar para generar nuevo conocimiento.

El cambio de unidad de análisis que implican las Comunidades de Práctica desde el contexto de los individuos al contexto de la comunidad, conlleva que el aprendizaje se entienda como el desarrollo de una identidad como miembro de una comunidad y la adquisición de conocimientos y habilidades como parte de ese proceso (Lave y Wenger, 1991). El aprendizaje, desde este sentido, supone la participación en una comunidad, con lo que se entiende como un proceso de participación social que estos autores llaman «participación periférica legítima». Con este concepto se refieren a la participación del nuevo miembro, que se va moviendo desde la periferia de la comunidad hasta el centro de la misma. En este momento pasa a ser un miembro activo, comprometido con la cultura de la comunidad y asume una nueva identidad en la construcción de las interacciones con los demás miembros, influenciada también, por el contexto donde se inscribe la comunidad. Dentro de las Comunidades de Práctica no existe una separación entre el desarrollo de la identidad y el del conocimiento, sino que ambos interactúan de manera recíproca, mediante el proceso de participación periférica legítima en el contexto de la comunidad. Wenger (2001) establece que en una comunidad de práctica la transferencia informal de conocimiento se vuelve explícita, ofreciendo una estructura formal que permite la adquisición de más conocimiento a través de las experiencias que se comparten en el seno de los grupos, lo que a su vez refuerza la propia identidad del grupo cuyo aprendizaje es un proceso de participación y liderazgo compartido.

Teniendo en cuenta que todas las personas participamos en diferentes Comunidades de Práctica en nuestra vida diaria, que nos vinculan a diferentes redes de interacción en base a la ideología, los significados culturales, el ocio, etc., Rodríguez Mena (2007) expone que, en cada 
comunidad, somos los mismos porque reconocemos nuestra identidad a lo largo de nuestras trayectorias de participación, pero también diferentes, en tanto que esas participaciones requieren la adopción de nuevos roles, identidades, expectativas, etc. contextualizada para esa práctica concreta. Con esto este autor afirma que «toda comunidad de práctica es al mismo tiempo una comunidad de aprendizaje porque exige una continua modificación de nuestras acciones a tono con la comunidad en la que participamos en un momento dado»(p. 19)

Una comunidad de aprendizaje, según la definición de Fulton y Riel (2005: para. 3), es «un grupo de personas que comparten un interés común sobre una temática o área específica, que adoptan una forma particular de discurso sobre los fenómenos de ese tópico, que usan herramientas y enfoques teóricos para construir un conocimiento colaborativo así como una serie de valores comunes».

La definición de Rodríguez Mena establece una relación estrecha con las Comunidades de Práctica, entendiendo que las comunidades de aprendizaje son un «modo de funcionamiento sistémico de una comunidad de práctica cuyos miembros son genuinos y mantienen interacciones constantes $y$ múltiples dirigidas por el propósito de aprender en, desde, y para mejorar, tal práctica, lo que se convierte en su meta de desarrollo permanente» (Rodríguez Mena et al., 2004:107). En este sentido una Comunidad de Práctica debe realizar acciones conscientes para potenciar el aprendizaje grupal e individual de los miembros que forman parte de la misma.

Siguiendo este punto de vista, cultivando una Comunidad de Práctica sobre el propósito de aprender estaremos trabajando sobre una Comunidad de Aprendizaje (Lai et al., 2006). La vía fundamental para que todo esto pueda construirse es el diálogo (discusión y argumentación), puesto que a través de él se genera la reflexión (Vygotsky 1985), es decir, a través de la discusión dialogada y argumentada se agudizan las habilidades para razonar, 
investigar y crear. Además, como indica Lipman (1991), cuando las personas dialogan están obligadas a reflexionar, a concentrarse a tener en cuenta alternativas, a cuidar la precisión de los significados, realizando un amplio número de actos mentales, que de otra manera no habrían surgido. Por su parte, Lozano (2004: para. 4) señala que:

«las Comunidades de Aprendizaje parten de un principio regulador, el aprendizaje dialógico. Esta concepción comunicativa defiende que el aprendizaje depende principalmente de las interacciones entre personas, de la construcción conjunta de significados. Un modo de desarrollar el diálogo reflexivo es a través de grupos interactivos. En estos grupos se estimula el cambio de roles, unas veces se enseña y otras se aprende del otro, la cooperación y la colaboración. Esta consideración del papel del alumno se aleja de los enfoques constructivistas de corte más cognitivo, básicamente centrados en los procesos del alumno, y se centra en otros de índole más social. La atención se centra ahora en la dinámica interactiva de coconstrucción del conocimiento entre profesor y alumno».

Es un hecho que las Tecnologías de la Información y Comunicación han mejorado enormemente el desarrollo de comunidades virtuales (Yus, 2007; Rodríguez, 2008). Actualmente, participar en una comunidad virtual para compartir conocimientos, experiencias, ideas, es relativamente sencillo. Algunas de estas comunidades virtuales en las que participamos pueden ser considerados como Comunidades de Práctica online (Wenger et al., 2005), que se facilitan para crear, mejorar, compartir y utilizar conocimientos de manera efectiva (McDermott, 2007).

El término Comunidades Virtuales surgió ligado a las propiedades comunicativas de Internet, como modo de comunicación de personas distanciadas geográficamente y que usaban las TIC para mantener el contacto e intercambiar información (Cabero, 2006). En primera instancia surgieron en el ámbito profesional, pero con el desarrollo de las características de esta red Internet, estas comunidades se ha sido ampliando a otros ámbitos como 
el educativo. En este contexto, García Aretio (2003:180) las define como "grupos humanos, comunidades de personas que se basan en los intereses, afinidades y valores personales, que discuten, contrastan pareceres $y$ puntos de vistas o intercambian información, a través de Internet, en forma relativamente continuada o lo largo del tiempo y atendiéndose a unas determinadas reglas».

Por otra parte, Salinas (2003) considera que en una Comunidad Virtual:

- Se reúnen personas para intercomunicar mediante ordenadores y redes, interactuando de una forma continuada y siguiendo unas reglas preestablecidas.

- El intercambio de información (formal e informal) y el flujo de información dentro de una comunidad virtual constituyen elementos fundamentales.

- La existencia de comunidades virtuales entre profesionales para el intercambio de ideas o experiencias y el desarrollo profesional y personal de sus miembros, tiene su origen en las grandes posibilidades de socialización y de intercambio personal que proporcionan las redes y constituyen un entorno privilegiado de aprendizaje sobre relaciones profesionales.

Rheingold (2002) sitúa las comunidades virtuales como entornos sociales organizados alrededor de intereses comunes y que se comunican a través de los medios que la web pone a su disposición. Seufert et al. (2002), como conjuntos de agentes, que comparten un lenguaje común, un espacio y unos valores en términos de enfoque pedagógico, conocimientos a adquirir y a perseguir una meta común mediante la comunicación y la cooperación a través de los medios electrónicos durante el proceso de aprendizaje. Mason (2005), por último, las define como un grupo de personas que se comunican entre sí a través de Internet para compartir información, aprender más sobre 
un tema y trabajar en un proyecto de interés común. Como vemos en todas las definiciones, la interacción constituye un aspecto clave, al igual que el matiz de delimitación en el espacio en el que se desarrolla y organiza, incluso como indica Ridings et al. (2002:273) de tiempo: «las comunidades virtuales pueden definirse como grupos de personas con intereses $y$ prácticas comunes que se comunican con regularidad y con cierta duración y de forma organizada en Internet mediante una localización o mecanismo común». También, debemos destacar que en la revisión realizada, observamos que la mayoría de las definiciones de comunidades virtuales mencionan el vínculo de unión que la sostiene, es decir, la finalidad de compartir un determinado tipo de información, experiencia o interés común.

Una excepción es Hunter (2002:96), que enfatiza más las características de la comunidad que el carácter virtual de la misma:

\begin{abstract}
«un grupo de personas que interactúan entre sí, aprendiendo del trabajo de otras y proporcionando recursos de conocimiento $e$ información al grupo en relación a temas sobre los que hay un acuerdo de interés mutuo. Una característica definitoria de una comunidad virtual en este sentido es que una persona o institución debe de ser un contribuyente a la base de conocimiento en evolución del grupo y no solamente un receptor y consumidor de los servicios o base de conocimientos del grupo».
\end{abstract}

En cuanto a organización, estructura y gestión de las comunidades virtuales, Shumar y Renninger (2002) proponen características que remarcan la virtualidad como el eje principal:

- Están deslocalizadas en el tiempo y espacio, y en ese sentido, son más intencionales y simbólicas que las comunidades físicas.

- Se definen por intereses compartidos y/o por proximidad. 
- El tiempo de interacción puede expandirse o comprimirse si se compara con otros tipos de interacción (por ejemplo el correo electrónico frente al correo postal, o el correo electrónico ante una conversación cara a cara).

- Permiten que se amplíe el tipo, forma y volumen de recursos para la interacción.

- Abren nuevas posibilidades para la interacción (formas de organización de los recursos, relaciones con otros, etc.)

- Permite que se almacenen las ideas aportadas y compartidas, lo que facilita un nivel de reciprocidad en relación a otros tipos de relación.

Aunque este término está ampliamente extendido por diferentes estudios relacionados con los agrupamientos virtuales, existen distintas taxonomías propuestas por diversos autores. La división más común es la que realiza Cicognani (1998) que divide las comunidades virtuales en sincrónicas, si las personas se conectan y comunican al mismo tiempo, y asincrónicas, si se produce en un espacio temporal distinto.

Hamman (2001), por otro lado, distingue tres tipologías de comunidad virtual: las que resultan de personas que no se conocen cara a cara, las que son consecuencia de un conocimiento previo físico fuera de la red, y las que combinan personas que mantienen ambos tipos de relación. La primera división se centra más en las relaciones establecidas en el espacio físico real por las personas, mientras que la segunda se basa en el tipo de comunicación que se establece.

Barnes (2003) propone una clasificación de comunidades virtuales basándose en diferentes finalidades: 1. Redes de acceso libre: cuyos propósitos suelen estar relacionados con salud, ocio, educación, eventos, etc. al que todas las personas pueden acceder; 2. Redes comunitarias, son 
comunidades que, compartiendo un espacio físico como un barrio, una escuela, un pueblo, etc. establecen una misma red en la virtualidad; 3 . Comunidades de interés, que reúnen a personas que comparten una orientación, opinión, interés, etc.; 4. Comunidades multi-usuario, que son de índole lúdica y van destinadas a establecer relación con otras personas en determinados ambientes virtuales predefinidos o incluso creados por los propios usuarios; 5. Comunidades de apoyo, como un servicio para contar experiencias, compartirlas, ayudarse, etc.; 6. Comunidades de público, que se constituyen por seguidores y seguidoras de una determinada persona famosa, programa, serie, película, etc.; 7. Comunidades mediáticas, generadas por los propios medios de comunicación de masas para difundir sus contenidos y programaciones; y, por último, 8. Comunidades de páginas web, que permiten unir intereses ubicados en diferentes páginas web de la red, facilitando la búsqueda de información, compartir recursos, etc.

Desde el ámbito educativo, Coll et al. (2008:306-309) agrupan las comunidades virtuales desde el punto de vista de los beneficios asociados a los objetivos y desde las expectativas de sus miembros, matizando que, en ocasiones, es difícil delimitar las fronteras entre ambas. Distinguen entre «comunidades virtuales de interés», que son aquellas que permiten a las personas participantes obtener información actualizada sobre ese objeto de interés en cualquier momento y se basan en el interés por acceder a otras personas para buscar información, relacionarse, solicitar ayuda, etc. Por otro lado, sitúan las «comunidades virtuales de participación», cuyos miembros quieren participar e involucrarse, situándose en un nivel más de implicación que va un poco más allá de buscar información, apoyo, etc. y conlleva un sentido de responsabilidad colectiva que lleva a los miembros a implicarse para mejorar las prácticas, encontrar las mejores soluciones, etc. En último lugar, aparecen las «comunidades virtuales de aprendizaje», que son las que tienen como objetivo explícito el aprendizaje y cuyos miembros desarrollan estrategias, planes, actividades y roles específicos para alcanzar los objetivos. 


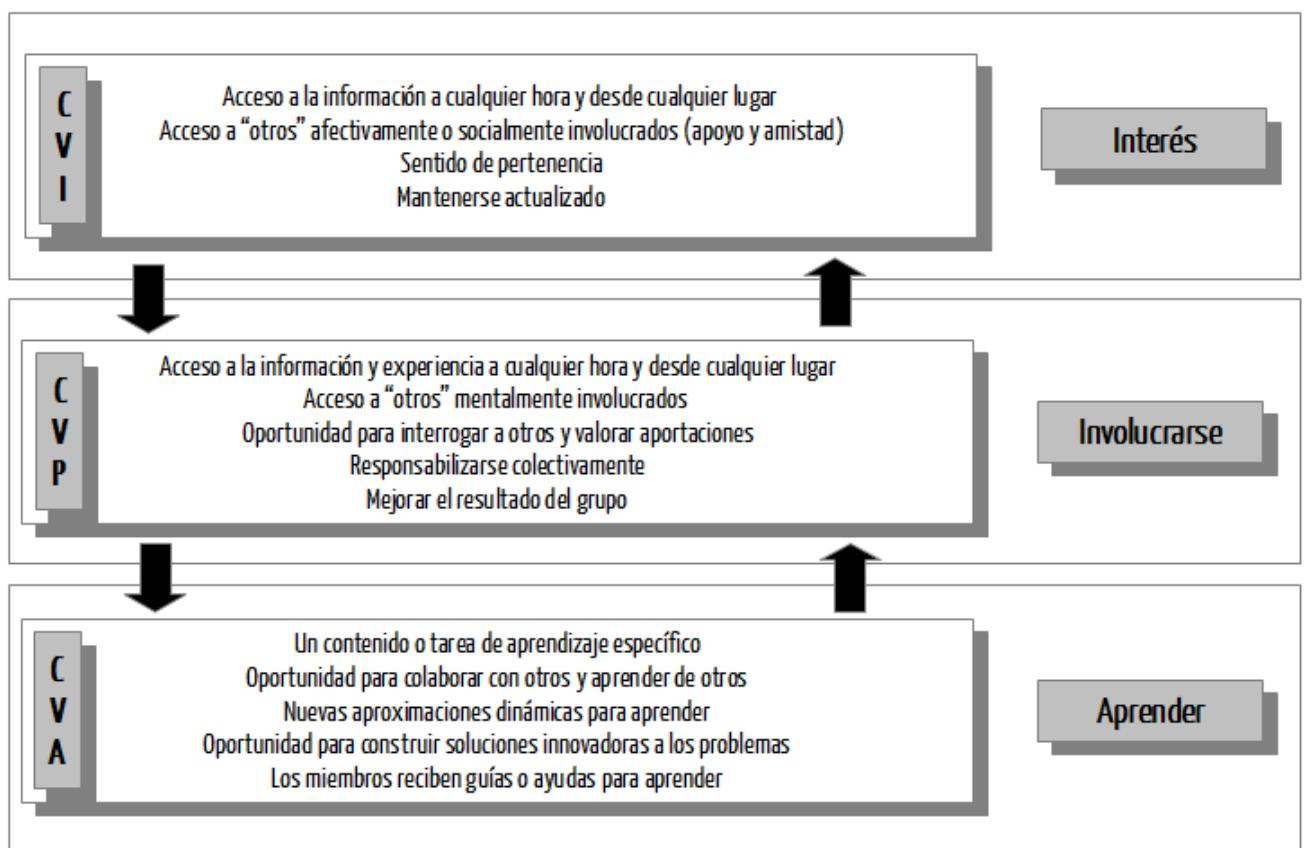

Figura 14. Dinámicas de los tipos de comunidades virtuales en función de los objetivos de sus miembros (Coll et al., 2008:309)

Estos autores plantean la heterogeneidad y variedad de planteamientos que giran en torno a la comunidades virtuales de aprendizaje, difiriendo en función de sus miembros, contextos, alcance institucional, naturaleza del contenido, de la actividad, de su temporalidad, etc.

Lai et al. (2006:13), afirman que todas las Comunidades de Práctica son Comunidades de Aprendizaje: «Las Comunidades de Práctica son comunidades de aprendizaje, mientras que algunos grupos en línea, por ejemplo, los grupos de interés, no lo son». En este sentido Riel y Polin (2004) ya sugerían tres tipos de Comunidades de Aprendizaje, que están diseñadas intencionalmente para apoyar éste. Los tres tipos de comunidades pueden coexistir en una organización de aprendizaje (por ejemplo, una escuela, universidad) y puede estar apoyadas por las tecnologías: 
- Orientadas a las tareas. Basadas en el trabajo de Comunidades de Aprendizaje son similares a los equipos o grupos de proyecto, donde la gente está organizado en torno a una tarea y que «trabajan intensamente en conjunto por un período determinado de tiempo para producir un producto» (p. 20).

- Orientadas a la práctica. En una práctica basada en la Comunidad de Aprendizaje «se hace hincapié en la mejora continua de una de las prácticas con el fin de apoyar el funcionamiento eficaz del sistema de actividad» (p. 28).

- Orientadas a la construcción de conocimiento. Basadas en el conocimiento, las comunidades se centran en la producción «deliberada y formal de conocimiento externo sobre la práctica» (p. 21). Son parecidas a las anteriores, pero con el matiz de producir algún tipo de conocimiento como resultado de la discusión sobre la práctica.

Según el enfoque de Scardamaglia y Bereiter (1999) sobre la construcción del conocimiento, Hakkarainen et al. (2004) distinguen entre las comunidades que buscan la adquisición de conocimientos, las que participan activamente en la comunidad y las que crean el conocimiento nuevo conjuntamente entre los participantes.

En este contexto, Wenger et al. (2005) reflexionan sobre el cambio significativo desde la introducción de recursos de la Web 2.0 en cuanto a la Comunidades de Práctica, confirmando que ya no se limitan por la ubicación porque siempre y cuando haya tecnología apropiada para sus necesidades, se pueden comunicar a través de la red. En la actualidad hay herramientas que pueden ayudar a gestionar las relaciones emergentes y configurar una forma única en la que interactúan como son las redes sociales. Lesser y Storck 
(2001) apuntan estas cuestiones como ventajas que las TIC aportan a la práctica de estas Comunidades de Práctica:

1. Visibilidad del experto o experta de cara a la comunidad. Probablemente por las veces que interviene (números de mensajes) o por los comentarios que hacen el resto de los miembro sobre esa persona, es mucho más fácil, en un tipo de Comunidad de Práctica que utiliza como canal de comunicación las TIC, identificar quién es el experto o experta.

2. Mantener la memoria, por ejemplo, en temas de movilidad. El espacio de trabajo virtual común permite almacenar, organizar y descargar presentaciones, herramientas y otros materiales. Además, el sistema de repositorio y los metadatos permiten y facilitan la identificación del autor o autora del documento, el contexto en que se desarrolló, reforzando la credibilidad y el valor del contenido.

3. Visibilidad de la Comunidad de Práctica. Permite entender el contexto a las personas que se incorporen. Con un simple vistazo, revisando los mensajes, alguien recién llegado puede captar y entender en qué consiste la actividad de la comunidad.

4. Relatos estructurados para preservar la memoria de la Comunidad de Práctica. Son relatos orales y entrevistas recogidas a través de tecnologías multimedia como audio o vídeo. En este apartado, los miembros tienen en cuenta la posibilidad de dejar registros de conversaciones donde conservar el vocabulario (palabras, conceptos o símbolos) de cara a nuevos miembros (repertorio compartido de Wenger).

Además, Sanz (2005) sugiere que, en las Comunidades de Práctica en entornos virtuales, es necesaria la figura de un moderador-animador, o emoderador como indica Salmon (2000) que pertenezca a la propia Comunidad de Práctica, cuyas funciones principales serían animar y dinamizar el enriquecimiento mutuo y el intercambio de experiencias. A esta 
figura se refiere Wenger (2001) cuando habla del coordinador, enumerando siete funciones concretas:

- Identificar temas importantes que deben tratarse en el ámbito de la Comunidad de Práctica.

- Planificar y facilitar las actividades.

- Conectar informalmente a los miembros superando los límites entre las unidades organizacionales, y gestionar los activos del conocimiento.

- Potenciar el desarrollo de los miembros.

- Gestionar la frontera entre la Comunidad de Práctica y la organización formal.

- Ayudar a construir la práctica, incluyendo el conocimiento base, la experiencia adquirida, las mejores prácticas, las herramientas y los métodos, y las actividades de aprendizaje.

- Valorar la salud de la Comunidad de Práctica y evaluar las contribuciones de los miembros a la organización.

Sanz (2005) destaca, además, que un buen moderador de una Comunidad de Práctica tiene conocimiento y pasión por el tema que se debate y que debe ser un miembro respetado por el resto de los integrantes del grupo pero, generalmente, no debe ser el líder, ya que esto puede provocar limitaciones en el número de intervenciones de los miembros del grupo. Además indica que debe aprovechar las ventajas que los recursos TIC proporcionan para las Comunidades de Práctica. En este sentido, Johnson (2001) realiza una revisión de la literatura sobre éstas, diferenciando el concepto de comunidades virtuales (definidas como comunidades diseñadas soportadas mediante las TIC) de las Comunidades de Práctica, que emergen dentro de la 
comunidad virtual diseñada por las formas en que sus participantes usan esa comunidad. Las ventajas principales que establece en las Comunidades de Práctica en la virtualidad es que la colaboración está basada en información textual, las normas son más reducidas y que facilita que las personas compartan sus ideas en igualdad de condiciones, superando la timidez que puede surgir en comunidades físicas. Como desventajas detecta el problema de desgaste que lleva a poner fin a este tipo de Comunidades, un problema que el autor dice que puede ser menor si se utilizan metodologías adecuadas. Si tenemos en cuenta las ventajas, las TIC pueden contribuir en la creación de Comunidades de Práctica y consolidarlas (Coll et al., 2008).

Lai et al. (2006) diferencian entre las Comunidades de Práctica virtuales y las que denomina locales o localizadas, en varios aspectos:

1. Diseño: las Comunidades de Práctica se diseñan generalmente de arriba hacia abajo, mientras que las virtuales, en general, surgen de los grupos existentes y se diseñan de abajo a arriba.

2. Miembros/Participantes. Las comunidades de la práctica online suelen ser abiertas, mientras que las localizadas generalmente son cerradas.

3. Liderazgo. Los líderes de las Comunidades de Práctica online son captados, mientras que los líderes en las Comunidades de Práctica pueden surgir de la comunidad.

4. Forma de comunicación. En las Comunidades de Práctica online la comunicación es, sobre todo, mediada por ordenador, mientras que en las otras es, generalmente, cara a cara.

5. Tiempo para desarrollar la comunidad. Se necesita más tiempo para desarrollar una comunidad de práctica online que una comunidad de práctica localizada. 
6. Apoyo tecnológico. Es esencial para la comunidad de la práctica online, pero no para las otras.

7. Existen comunidades virtuales además de las Comunidades de Práctica online; son las comunidades basadas en el comercio, como sitios webs de subastas (comunidades de e-comercio); las comunidades basadas en intereses comunes, tales como sitios online de asociaciones de alumnos y alumnas (comunidades de interés); y las comunidades basadas en el aprendizaje, tales como cursos online (comunidades e-learning). Estas pueden ser o no comunidad de la práctica, diferenciándose de otras comunidades online en términos del nivel de colaboración y compromiso.

Aunque se muestra la dificultad del concepto y su variedad en cuanto a la cantidad de matices, taxonomías y caracterizaciones de las que pueden ser objeto, entendemos que una Comunidad de Aprendizaje en entornos virtuales es un espacio interactivo donde docentes y participantes acceden a la información, la comparten y desarrollan actividades basadas en el diálogo, la participación y la colaboración. En el seno de la Comunidad Virtual de Aprendizaje se aprovechan las sinergias que se dan entre los agentes que participan, para conseguir el logro de los objetivos comunes y adquirir las competencias y habilidades necesarias para la resolución de las tareas y/o actividades propuestas, lo que puede desembocar, en las últimas fases en una Comunidad de Práctica (Lai et al., 2006; Rodriguez Mena, 2007; Coll et al., 2008).

Las Comunidades de Práctica en entornos virtuales deben ser sostenibles y tener un impacto en la práctica, y para ello deben ser diseñadas teniendo en cuenta todos los aspectos técnicos, pedagógicos y de organización que van a permitir que sean exitosas. Wenger, McDermott y Snyder (2002) se refieren al diseño de Comunidades de Práctica desde siete principios a tener en cuenta para «cultivarlas»: 
1. Diseñar para crecer, para evolucionar. La naturaleza dinámica de las comunidades es clave para su evolución y desarrollo dado que se construyen a través las redes existentes y evolucionan más allá de cualquier diseño. Desde este principio se remarca la necesidad de ayudar a la comunidad en ese desarrollo siendo la clave que los elementos de diseño deben ser los catalizadores de la evolución natural de una comunidad.

2. Abrir un diálogo entre las perspectivas internas y externas. El diseño de la comunidad requiere una buena comprensión de la misma, de su potencial para desarrollar y administrar el conocimiento, pero los autores afirman que es interesante también adoptar una perspectiva externa para ayudar a los miembros a ver las posibilidades $\mathrm{y}$ potencialidades de la comunidad.

3. Invitar a los diferentes niveles de participación. Las personas participan en las comunidades por diferentes razones (por interés, por oportunidad, etc.) y en diferentes niveles (algunos participan mucho constituyendo el núcleo de la comunidad y otros sólo observan). En este sentido se da valor a los participantes «periféricos» (o «lurker») que intervienen en alguna ocasión y observan la participación de los miembros más activos de la comunidad. Así, los autores recomiendan diseñar oportunidades para que estos miembros intervengan, respetando los diferentes niveles de interés y participación en la comunidad de práctica.

4. Desarrollar espacios comunitarios tanto públicos como privados. Desde este principio se incide en el impulso de comunicaciones y relaciones, tanto a través de eventos públicos y privados, dado que, a partir de esas relaciones, las personas pueden afianzar el sentimiento de miembro de la comunidad. En este sentido, los autores afirman que la relación uno a uno genera confianza y crea una vía para el 
intercambio de información con un número más limitado de personas. Cuando las relaciones individuales entre los miembros de la comunidad son fuertes, se fortalecen, a su vez, las relaciones dentro de ella.

5. Centrarse en el valor. Desde este principio se considera como clave para la comunidad el valor que de ella se genera. En el diseño se debe tener en cuenta lo que para los miembros es el resultado que consiguen de la misma, intentando que hagan explícito ese valor, no sólo al principio de la creación de la comunidad, sino durante todo su crecimiento. Así se consiguen datos para su continuidad y para ir evaluando su desarrollo.

6. Combinar la familiaridad y el entusiasmo. Una comunidad de práctica exitosa sería aquella que logre proporcionar un ambiente de familiaridad que permita a los miembros aprender y momentos de emoción, que se producen al encontrar situaciones para debatir de manera agradable y productiva. De este modo se incentiva la participación de todos los miembros en la comunidad, creando un nivel de estabilidad y confort que invita a debates sinceros y profundos.

7. Crear un ritmo para la comunidad. Desde este último principio, el ritmo es el principal indicador de vitalidad de una comunidad. Una comunidad exitosa sería aquella que logre combinar y encontrar el equilibrio entre momentos de mayor y menor actividad, encontrando la dinámica adecuada en cada etapa. De ese modo, se evita el abandono propio de comunidades de ritmos muy acelerados o muy lentos.

Por otro lado, Lai et al. (2006) realizan una revisión de la literatura en torno a las Comunidades de Práctica online y establece, basándose en una 
síntesis de los estudios recogidos, los 6 principios fundamentales del diseño de Comunidades de Práctica eficaces en entornos virtuales:

- Principio 1: Las Comunidades de Práctica online deben ser cultivadas para crecer de forma natural. En este sentido, los autores se refieren a que no se deben crear sino facilitar, mediante una combinación de diseño y desarrollo natural, es decir, el diseño debe permitir que el desarrollo de la Comunidad de Práctica online se produzca. Este diseño debe asegurar, como eje clave, una invitación a la interacción y debe producirse de abajo hacia arriba para fomentar un sentido de pertenencia a los miembros que les lleve al compromiso para mantenerla. Este principio conlleva varias estrategias: llevar a cabo una evaluación de necesidades para formar un propósito claro; fomentar un sentido de pertenencia; tomarse el tiempo suficiente para que la comunidad de práctica crezca $\mathrm{y}$, por último, fomentar la diversidad.

- Principio 2: Las Comunidades de Práctica deben ser diseñadas para apoyar la socialización y la participación. La sociabilidad y la facilidad de uso son factores clave para el diseño de Comunidades de Práctica online. La primera, se refiere a cómo los miembros de una Comunidad de Práctica interactúan entre sí. La usabilidad se refiere principalmente a cómo los miembros interaccionan con los recursos tecnológicos. En este principio se identifican una serie de estrategias para apoyar la socialización y la participación de los miembros: dar tiempo a los miembros, agregar valor a la Comunidad de Práctica, crear un sentido de comunidad, permitir diferentes niveles de participación, desarrollar las relaciones sociales y la confianza, realizar políticas claras de funcionamiento y asegurar la facilidad de uso de los recursos tecnológicos utilizados. 
- Principio 3: Las Comunidades de Práctica deben atraer a diversidad de miembros. Es importante asegurarse que una masa crítica de personas pertenezcan a la Comunidad de Práctica online. En este sentido, son tres las estrategias que se marcan. Se indica que las comunidades necesitan límites bien definidos y coherentes, a la vez que precisan líderes para promover activamente la transparencia y el cambio, reclutando nuevos miembros y teniéndolos en cuenta. Otro aspecto es permitir que haya participantes periféricos (Bowes, 2002), también conocidos como «lurker o mirones», que leen los mensajes pero no participan en un principio, ya que estos son potenciales miembros de la Comunidad de Práctica online. Por último, se sugiere que debe utilizar la estructuración en subcomunidades para permitir que más personas interactúen, teniendo en cuenta la diversidad geográfica y de contextos que existe.

- Principio 4: Las Comunidades de Práctica deben ser gestionadas mediante el desempeño de diferentes roles: líderes, miembros del núcleo central de la comunidad, personas de apoyo y miembros. Esta característica es beneficiosa para su desarrollo porque ofrece seguridad, seriedad, continuidad de roles que van determinando la historia de la comunidad, conectándola con su pasado y estructura, cuestión que ayuda a los miembros para compartir conocimientos y experiencias.

- Principio 5: Las Comunidades de Práctica deben utilizar la tecnología para apoyar la socialización y el intercambio de conocimientos. Para este principio se deben considerar las necesidades de la comunidad, el nivel de acceso a la tecnología y nivel de financiación disponible. Mencionan a Wenger et al. (2005) y su debate sobre la contribución que las TIC pueden hacer a las Comunidades de Práctica. Desde su argumentación, las TIC pueden ayudar al cultivo de la comunidad, 
proporcionar recursos necesarios para fomentar el sentido de unión de los miembros y hacerles sentir parte de la comunidad. También afirman que para participar con éxito en múltiples comunidades, es necesario preservar un sentido de identidad, y que las TIC pueden apoyar la participación individual, fomentando la propia identidad. Se señalan las TIC como impulsoras y mediadoras del desarrollo de la Comunidad de Práctica en entornos virtuales, porque facilitan la conexión de los miembros, el trabajo en equipo, aumentan la creación de repositorios de conocimiento, la construcción del sentido de comunidad, la participación, la identidad y presencia, la tutoría y el elearning.

- Principio 6: Las Comunidades de Práctica requieren un enfoque mixto para el desarrollo en actividades virtuales con el apoyo de las actividades offline. Las razones que establecen para justificarlo son que generan mayores niveles de satisfacción, ayudan en la construcción de relaciones de confianza y proporcionan un sentido de comunidad.

Entre las fases de construcción de comunidades de aprendizaje en entornos virtuales para el cultivo de Comunidades de Práctica destacadas por varios autores (Palloff y Pratt, 1999; Haythornthwaite et al., 2000; Seufer et al., 2002; entre otros), seleccionamos, en primer lugar, la propuesta de Lewis y Allan (2005, 2006):

- Fase1: Fundación. La fundación tiene relación con las decisiones relativas al diseño, tales como: la estructura, la forma de trabajo y aprendizaje, la infraestructura tecnológica y las características y el tipo de diseño del entorno virtual de aprendizaje.

- Fase 2: Inducción. La fase de inducción hace referencia a los primeros pasos para la puesta en marcha: las reglas de confidencialidad de la 
comunidad, frecuencia, forma y extensión de la participación esperada, valores como el respeto y la identificación de las expectativas de las personas participantes.

- Fase 3: Incubación. En esta fase es necesaria la creación de una zona de confianza para que favorezca la voz propia de los y las participantes. La identifican con la presencia social (Garrison y Anderson, 2005), para crear una zona de afectividad, corresponsabilidad, codependencia y colaboración.

- Fase 4: Mejora del desempeño o de la ejecución. Una vez definida esa presencia social, esta fase nos lleva al comienzo del trabajo efectivo en cuanto al compromiso de los miembros para avanzar en el logro de los objetivos.

- Fase 5: Implementación. Se refiere a la puesta en marcha de la comunidad virtual de aprendizaje

Durante las fases anteriores se destacan tres aspectos importantes para el mantenimiento y la gestión de la comunidad: primero, la creación de una zona de interacción social para la libre expresión, para dar importancia a la participación de los miembros e ir modelando las características del tipo de aportaciones que se esperan; segundo, el diseño de actividades de aprendizaje exprese, claramente, la meta, la definición de los objetivos, la estructura de la tarea y de la interacción; y tercero, el seguimiento del proceso de participación mediante el registro de las intervenciones.

- Fase 6: Cierre o cambios. Esta última fase se refiere a la evaluación y valoración de resultados. Es una reflexión sobre el desarrollo de la comunidad, el grado de éxito alcanzado en el trabajo colaborativo y el nivel de consecución de los objetivos de aprendizaje, posibilitando que 
la comunidad derive en otra con nuevos objetivos, una comunidad de práctica, de participación o de interés.

Lai et al. (2006) definen tres fases en el ciclo de vida de una Comunidad de Práctica en entornos virtuales y las tareas principales correspondientes a cada fase:

- Fase 1: Formación. Se destacan una variedad de actividades que tienen lugar en la fase de formación de una comunidad de práctica online: (a) identificar el potencial de la comunidad; (b) determinar el propósito y el alcance de la comunidad; (c) construcción de la Comunidad; (d) crear un diseño preliminar para la comunidad; (e) incubar y ofrecer valor inmediato; y (f) lanzamiento de la comunidad.

- Fase 2: Mantenimiento / maduración. En la segunda fase, la atención se centra en el mantenimiento y la maduración de la comunidad de práctica a través del liderazgo; tutorizar nuevos miembros; buscar relaciones y puntos de referencia fuera de la organización; establecer la comunidad y un repositorio de conocimientos compartidos; y evaluar el propósito y dirección.

- Fase 3: Transformación. La tercera fase es de transformación o desconexión. En este sentido las Comunidades de Práctica pueden experimentar una expansión o una desactivación y, por tanto, conducir a su finalización.

Johnson (2001) sostiene que las TIC, especialmente Internet, permiten a estas comunidades virtuales existir. Esta autor entiende que las comunidades virtuales son grupos que utilizan las TIC para comunicarse y colaborar y las Comunidades de Práctica surgen del diseño de una organización de aprendizaje. Esto no quiere decir que del diseño de una comunidad virtual, surja una Comunidad de Práctica; para ello, debe existir una necesidad de aprendizaje subyacente basada en la práctica. Así, Johnson señala que se 
necesita unas bases metodológicas adecuadas fundamentadas en los procesos comunicativos y en la colaboración para la conformación de esta tipología de comunidades.

Coll et al. (2008) consideran tres aspectos fundamentales para el diseño y puesta en marcha de Comunidades Virtuales de Aprendizaje con la finalidad de la creación de Comunidades de Práctica:

1. Necesidad de un marco teórico que guíe el proceso de enseñanzaaprendizaje en la virtualidad.

2. Conocer la variedad de herramientas disponibles, así como sus características y potencialidades pedagógicas para realizar una elección adecuada a la comunidad y sus miembros.

3. Definir los roles de los miembros de la comunidad, especialmente el de administrador y coordinador.

Ninguno de los estudios revisados por Johnson (2001), sin embargo, constituyó una comunidad virtual con el fin deliberado de orientarla hacia una comunidad de práctica. En este contexto indica la posibilidad de diseñar y crear Comunidades de Práctica desde comunidades virtuales. Potenciar el desarrollo de una comunidad de práctica sería el último objetivo, incidiendo en el diseño y creación de una comunidad virtual, la observación de los comportamientos de la comunidad emergente, y apoyar, como último paso la implementación y desarrollo de ésta mediante metodologías que faciliten la colaboración, participación, comunicación, proporcionando la orientación adecuada. Este autor propone la realización de un estudio de caso en cinco fases: (1). diseño de una comunidad virtual; (2.) herramientas de apoyo; (3.) predecir y anteponerse a cómo se van a utilizar los elementos diseñados; (4). analizar cómo la comunidad se desarrolla a partir del diseño previsto; y (5). aplicar las revisiones necesarias y establecer las claves que pueden hacer que el aprendizaje sea más eficiente. 
Para finalizar, nos gustaría resaltar la afirmación de Downes (2008) quien sostiene que, lo más cercano a una red social en el mundo del e-learning, son las Comunidades de Práctica facilitadas desde entornos virtuales de aprendizaje.

\subsection{El modelo de «Comunidad de Indagación» para el estudio y la construcción (cultivo) de Comunidades de Práctica en entornos virtuales de aprendizaje.}

\subsubsection{La construcción de Comunidades de Práctica en entornos virtuales de aprendizaje desde el modelo «Comunidad de Indagación».}

Situando la perspectiva constructivista en los modelos de aprendizaje online, podemos hablar de que los entornos de aprendizaje constructivistas son «un lugar donde los alumnos deben trabajar juntos, ayudándose unos a otros, usando una variedad de instrumentos y recursos informativos que permitan la búsqueda de los objetivos de aprendizaje y actividades para la solución de problemas» (Wilson, 1996:27). Garrison y Anderson (2005), hablan de la educación online como el proceso de enseñanza mediante el uso de tecnologías en red, aprovechando la velocidad y el poder de las comunicaciones para enviar, recibir y usar información, en el que desaparecen los obstáculos espacio-temporales. Los principales rasgos de la educación online, siguiendo a Anderson y Elloumi (2004), son:

- Se produce la experiencia educativa independientemente del tiempo de interacción y del lugar geográfico donde se encuentren los participantes en el proceso de enseñanza-aprendizaje. 
- Se pueden utilizar diversos formatos que permitan presentar y gestionar información, con lo que se logra acceder, a través de Internet, a un enorme repositorio de contenidos que ayudan y apoyan al proceso cognitivo.

- Soporta la interacción entre los individuos y el ordenador, de modo sincrónico y asincrónico. Esta cuestión se logra con el uso de herramientas de interacción, entre las que se pueden mencionar los foros de discusión, el correo electrónico y los chats.

Garrison, Anderson y Archer (2000) proponen un modelo conceptual de aprendizaje online desde el cual se fomente la interacción entre docentes y estudiantes, con el fin de construir, facilitar, validar la comprensión y desarrollar capacidades que se dirijan a una continuidad de la formación, fomentando, simultáneamente, la independencia cognitiva y la interdependencia social. La característica primordial de este modelo reside en su potencial comunicativo e interactivo. Lo denominaron modelo «Comunidad de Indagación». Este modelo distingue tres elementos fundamentales: «presencia social», «presencia cognitiva» y «presencia docente» y establece que los aprendizajes serán más profundos y significativos cuando converjan los tres componentes mencionados. Estas dimensiones tienen la característica de poder ser aportadas a la comunidad por los distintos participantes, incluso más allá de sus roles específicos de estudiantes o docentes, con lo que supone un modelo flexible que permite captar la dinámica horizontal de una comunidad. Las tres presencias son indispensables y se retroalimentan mutuamente en una experiencia de aprendizaje colaborativa de calidad. 


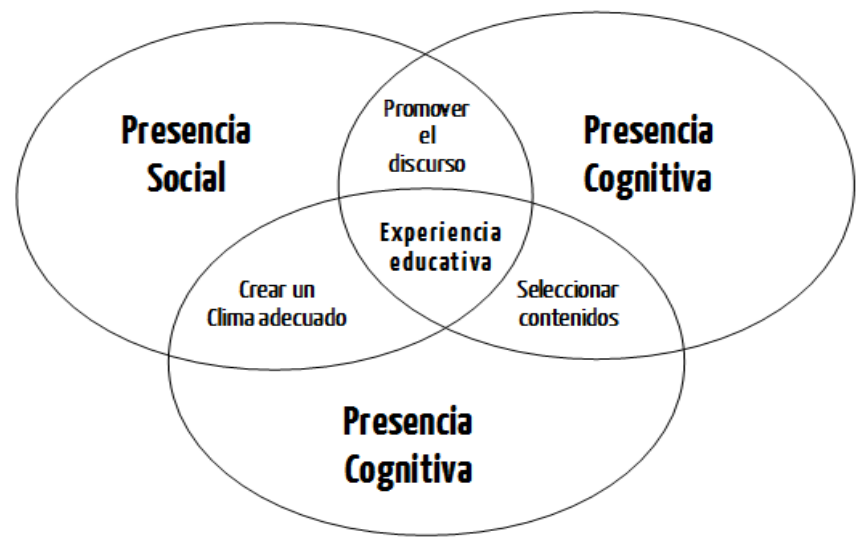

Figura 15. Modelo «Comunidad de Indagación» (Garrison y Anderson, 2005: 49)

La presencia cognitiva, es «el punto hasta el cual los estudiantes son capaces de construir significados mediante la reflexión continua en una comunidad de investigación» (Garrison y Anderson, 2005:50). El docente en este componente es el diseñador de la experiencia educativa, desarrollando un plan de estudios, determinando los objetivos, los métodos de trabajo, seleccionando los contenidos, la temporalización, estableciendo los mecanismos de interacción entre alumnos y alumnas. En este sentido, la presencia cognitiva tiene que ver con la adquisición y aplicación del conocimiento a través de la reflexión, construcción y confirmación de significados. Se basa en el modelo de pensamiento crítico, por el cual los integrantes de la comunidad avanzan en un proceso de indagación que pasa por distintos momentos que definen, a su vez, las categorías de este elemento: un evento desencadenante, exploración en busca de información, integración en una idea coherente y resolución mediante la aplicación de la idea o hipótesis generada. En este sentido, esta presencia se hace evidente a través de cuatro fases que se corresponden con el proceso de investigación práctica (Garrison y Anderson, 2005): (a) una fase de iniciación, que se 
considera un hecho desencadenante, (b) una fase de exploración, que se caracteriza por cuestionamiento de ideas y el intercambio de información, (c) una fase de integración, que se caracteriza por la construcción de significado y (d) una fase de resolución, que se caracteriza por la resolución del problema creado por el evento desencadenante.

La presencia social se relaciona con el establecimiento de un ambiente de apoyo en el que los alumnos y alumnas sientan comodidad y seguridad para expresar sus ideas, sus puntos de vista, sus reflexiones, en un contexto de colaboración en la que alumnos y alumnas y profesorado se apoyan y ayudan. El docente, desde este componente, es quien debe crear y favorecer un clima adecuado para que se produzca un aprendizaje exitoso. Según Garrison, Anderson y Archer, 2000) la presencia cognitiva se manifiesta y sostiene más cuando el grado de presencia social se ha establecido y es significativo. Por tanto el profesorado debe idear y poner en práctica actividades para fomentar la discusión entre estudiantes y entre estudiantes y docente. Tiene un trabajo fundamental para mantener el interés, la motivación y el compromiso de los y las estudiantes en la búsqueda de lograr los objetivos establecidos en la acción de formación. Esta presencia es la que construye el clima de grupo, aquella que brinda las bases sociales de confianza, calidez, bienestar, empatía, compromiso, necesarias para abrirse a un dialogo comprometido, crítico y sustentable. Aunque esta presencia por sí sola no es suficiente para sostener una Comunidad de Indagación «altos niveles de presencia social acompañados de altos grados de compromiso y participación son necesarios para el desarrollo de habilidades de pensamiento de alto orden y trabajo colaborativo» (Garrison et al., 2000:94). En definitiva, esta dimensión es la que establece el eje fundamental de la construcción de una Comunidad de Práctica real, en conjunción con las otras dos dimensiones.

La presencia docente, incluye los roles que debe asumir el profesorado en la acción formativa para crear un aprendizaje eficaz. La presencia docente, 
según Garrison y Anderson (2005:51), es la «acción de diseñar, facilitar y orientar los procesos cognitivo y social con el objetivo de obtener resultados educativos personalmente significativos y de valor docente». Implica que el docente es una persona experta en la materia, sabe diseñar programas docentes y adopta el rol de un animador/dinamizador social. De esta manera sus funciones (Anderson et al., 2001) se corresponderían, en primer lugar, como especialista en el diseño de la experiencia, incluyendo aspectos de planificación, gestión y evaluación y certificación. En segundo lugar, como facilitador y co-creador de un entorno social, de un ambiente propicio para el aprendizaje activo y exitoso y, por último, como un experto o experta en la materia creando condiciones para experiencias de construcción de conocimientos.

Las interacciones en este modelo son el componente básico del proceso de aprendizaje, considerando que mediante éstas los estudiantes ponen a disposición del grupo sus conocimientos, experiencias, habilidades e información, y permiten llegar a conocimientos enriquecidos. Por ello, son parte esencial del aprendizaje colaborativo y de la construcción social del conocimiento. Garrison y Anderson (2005), determinan que la interacción mediada por las tecnologías permite mantener el ritmo de aprendizaje, configurar y reforzar la adquisición de nuevas capacidades, desarrollar relaciones entre los nuevos contenidos y los esquemas mentales existentes, facilitar al docente la labor de orientar el modo en que los estudiantes interactúan, potenciar la consecución de sus propios intereses y situar la vía o el camino hacia la investigación.

Para estudiar las tres presencias, desarrollan una serie de categorías e indicadores, como se muestran en la tabla, que permiten determinar, a través de un análisis de contenido, si se han producido en la comunidad virtual que se analice. 
PRESENCIA SOCIAL

\begin{tabular}{|c|c|c|}
\hline \multirow{3}{*}{ Afecto } & Expresión de emociones & $\begin{array}{l}\text { Expresiones convencionales o no convencionales de emoción (puntuación repetitiva, proliferación de } \\
\text { mayúsculas, emoticones, etc.) }\end{array}$ \\
\hline & Recurrir al humor & Bromas, ironías, medias palabras, sarcasmo \\
\hline & Expresarse abiertamente & Presenta detalles de la vida fuera de la clase, o expresa vulnerabilidad \\
\hline \multirow{6}{*}{$\begin{array}{l}\text { Comunicación } \\
\text { abierta }\end{array}$} & Seguir el hilo & Emplear el signo de respuesta del software, en vez de iniciar un nuevo hilo de comunicación \\
\hline & Citar los mensajes de otros & $\begin{array}{l}\text { Emplear los recursos del software para citar los mensajes completos de otros o cortar y pegar fragmentos } \\
\text { de otros mensajes }\end{array}$ \\
\hline & Referirse explícitamente a los mensajes de otros & Hacer referencia a los contenidos de otros mensajes \\
\hline & Hacer preguntas & Las estudiantes hacen preguntas de otros estudiantes o del moderador. \\
\hline & Expresar aprecio & Felicitar a las demás (hacer cumplidos) por el contenido de sus mensajes \\
\hline & Expresar acuerdo & Expresar acuerdo con otros o con el contenido de sus mensajes \\
\hline \multirow{3}{*}{ Cohesión } & Vocativos & Dirigirse o referirse a los participantes por sus nombres \\
\hline & Dirigirse o referirse al grupo usando pronombres inclusivos & Dirigirse al grupo como «nosotras», «nuestro grupo» \\
\hline & Elementos fáticos, saludos & Comunicación que desempeña meramente una función social; saludos, despedidas \\
\hline \multicolumn{3}{|c|}{ PRESENCIA COGNITIVA } \\
\hline Hecho desencadenante & Evocativo (inductivo) & Reconocer el problema, Confusión \\
\hline Exploración & Inquisitivo (divergente) & Divergencia, Intercambio de información, Sugerencias, Lluvia de ideas, Saltos intuitivos \\
\hline Integración & Tentativo (convergente) & Convergencia, Síntesis, Soluciones \\
\hline Resolución & Comprometido (deductivo) & Aplicar, Comprobar, Defender \\
\hline \multicolumn{3}{|c|}{ PRESENCIA DOCENTE } \\
\hline \multirow{3}{*}{$\begin{array}{l}\text { Diseño Educativo e } \\
\text { organización }\end{array}$} & Fijar el programa de estudios & «Esta semana hablaremos de...» \\
\hline & Diseñar métodos & «Voy a repartiros en diferentes grupos y comentaréis...» \\
\hline & Establecer un calendario & «Envía un mensaje antes del viernes por favor» \\
\hline
\end{tabular}




\begin{tabular}{|c|c|c|}
\hline & Emplear el medio de forma efectiva & «Cuando contestes (por e-mail), intenta referirte a temas que otros hayan planteado» \\
\hline & $\begin{array}{l}\text { Establecer pautas de conducta y cortesía en la } \\
\text { comunicación electrónica (netiquette) }\end{array}$ & «Intenta escribir mensajes breves» \\
\hline & $\begin{array}{l}\text { Plantear observaciones en el nivel macro del contenido de } \\
\text { los cursos }\end{array}$ & $\begin{array}{l}\text { «Esta presentación pretende ofreceros una gama amplia de herramientas y competencias que podréis } \\
\text { utilizar para decidir cuándo y cómo emplear las diferentes técnicas de investigación» }\end{array}$ \\
\hline \multirow{6}{*}{ Facilitar el discurso } & Identificar áreas de acuerdo/desacuerdo & «Juan, María ha aportado un contraejemplo fuerte a tu hipótesis, ¿qué le contestarías?» \\
\hline & Intentar alcanzar un consenso & «Creo que, de hecho, Juan y María están diciendo lo mismo» \\
\hline & $\begin{array}{l}\text { Animar, reconocer o reforzar las contribuciones de los } \\
\text { estudiantes }\end{array}$ & «Gracias por tus observaciones, son muy acertadas» \\
\hline & Establecer un clima de estudio & $\begin{array}{l}\text { «No te preocupes demasiado por evitar pensar en voz alta en el forum. Después de todo, este es un lugar } \\
\text { para ensayar ideas» }\end{array}$ \\
\hline & Extraer opiniones de los participantes, promover el debate & «¿Algún comentario más sobre este asunto? ¿̇alguien quiere decir algo más sobre esto?» \\
\hline & Evaluar la eficacia del proceso & «Creo que aquí nos estamos derivando un poco» \\
\hline \multirow{7}{*}{ Enseñanza directa } & Presentar contenidos/cuestiones & ¿Qué pensáis? \\
\hline & Centrar el debate en temas específicos & «Creo que esto es un callejón sin salida» «Te pediría que consideraras...» \\
\hline & Resumir el debate & $\begin{array}{l}\text { «a cuestión original era... J. dijo... M. dijo...hemos llegado a la conclusión de que... Aún no hemos tocado } \\
\text { el tema relativo a...» }\end{array}$ \\
\hline & $\begin{array}{l}\text { Confirmar lo que se ha entendido mediante la evaluación y } \\
\text { el feedback explicativo }\end{array}$ & Estás cerca, pero no has dado cuenta de...y eso es importante porque...» \\
\hline & Diagnosticar los errores de concepto & «Recuerda que habla desde una perspectiva administrativa, por tanto, ten cuidado cuando dices...» \\
\hline & $\begin{array}{l}\text { Inyectar conocimiento desde diferentes fuentes, por } \\
\text { ejemplo libros de texto, artículos, Internet, experiencias } \\
\text { personales }\end{array}$ & «Estuve en una lectura con B. una vez, y dijo...Puedes encontrar las actas en http://www...» \\
\hline & Responder a las preocupaciones técnicast & «Si quieres incluir un hyperlink en tu mensaje, tienes que...» \\
\hline
\end{tabular}

Tabla 1. Dimensiones, categorías e indicadores de análisis del modelo «Comunidad de Indagación» de Garrison y Anderson (2005) 
En las últimas investigaciones realizadas en el marco del modelo de «Comunidad de Indagación» (Rourke y Kanuka, 2009) ${ }^{32}$ se demuestra que el fuerte sentido de comunidad aumenta, no sólo la persistencia de los estudiantes en programas e-learning, también enfatiza la necesidad de generar el sentido de «presencia social» en las comunidades virtuales. Desde este punto de vista se realza la importancia de la interacción que posibilita el trabajo colaborativo porque incrementa el sentimiento de cohesión social. Este es un elemento que puede ayudar a desarrollar los aprendizajes en las propuestas e-learning (Dede, 1996; Wellman, 1999).

«Sin una sensación de comunidad en las personas que participan, es probable que los participantes ante los retos de un proceso de formación se muestren ansiosos, defensivos y poco dispuestos a tomar los riesgos implicados en la tarea de aprender» (Wegerif, 1998:48).

\subsubsection{El estudio de Comunidades de Práctica en entornos virtuales de aprendizaje desde los indicadores del modelo Comunidad de Indagación.}

Analizar la interacción es un aspecto clave en los procesos educativos que se sustentan en la construcción social del conocimiento ya que permiten realizar aproximaciones al conocimiento y la comprensión de esos procesos. Estos análisis se han establecido como un área de conocimiento que está aglutinando a investigadores e investigadoras de ámbitos muy diversos ${ }^{33}$.

Por destacar algunos, tomamos en primer lugar, el modelo de Henri (1992) que ha sido uno de los primeros investigadores que se centró en

${ }^{32}$ El propósito de este estudio fue investigar el aprendizaje en las comunidades de investigación que los términos están definidos en modelo de Garrison, Anderson y Archer (2000). Se identificaron 252 informes de 2000 hasta 2008 que hacen referencia este marco.

33 Algunos de los estudios citados quedan recogidos en Marcelo y Perera (2007). 
analizar la calidad de la interacción en los foros online. Propone un sistema de categorización para analizar las transcripciones de las discusiones basado en un enfoque cognitivo del aprendizaje a través de dos dimensiones: participativa, refiriéndose al número de unidades de significado en un mensaje en un foro concreto, e interactiva. Esta última se divide en tres subdimensiones: interacción explícita, que se refiere a cualquier declaración en la que, con claridad, se haga referencia a otro mensaje, persona o grupo; interacción implícita, que es cualquier declaración que se refiera, sin nombrarlo, claramente a otro mensaje, persona o grupo; y la interacción independiente, que es cualquier declaración que se refiera al tema que se está discutiendo, pero en el que no hay ningún comentario ni respuesta a otro comentario. Su modelo se ha aplicado en numerosas investigaciones especialmente en trabajos publicados en la década de los noventa.

Otros estudios se han centrado en el análisis de las formas de interacción online: discusión, intercambio de información, reflexión y formulación de preguntas de alto y bajo nivel, figura del profesor e interacción desde la intervención de éste. De este modo, las aportaciones de Henri son útiles para analizar las interacciones pero no dan demasiada información sobre cómo evaluar si realmente ha habido un proceso de construcción colaborativa del conocimiento.

Gunawardena et al. (1997) utilizaron un enfoque de teoría fundamentada (Glaser y Strauss, 1967) para desarrollar un modelo de análisis de transcripciones de foros de debate online. La idea general con este modelo es buscar que sus aportaciones en la discusión vayan sustentadas, desde la emisión de una opinión hasta acuerdos y aplicación de los mismos. Esto es, una vez que emitan una opinión podrán discernir puntos de vista con base en ella, negociándola, probándola o modificándola hasta aplicarla. A través de un análisis de contenido, desarrollaron un sistema para estudiar la construcción de conocimiento en interacción social, identificando cinco fases en el proceso de evolución de un debate online: 
1. Compartir/Comparar información, se refiere a expresar una observación u opinión, estar de acuerdo con uno o más participantes, corroborar ejemplos propuestos por participantes, preguntas y respuestas para clarificar detalles, definición, descripción o identificación de un problema.

2. El descubrimiento y exploración de disonancia o inconsistencia entre las ideas, conceptos o declaraciones, se refiere a identificación de desacuerdos, preguntas y respuestas para clarificar el origen del desacuerdo, utilizando citas bibliográficas, experiencias y propuestas para apoyar argumentos.

3. Negociación de significados y co-construcción del conocimiento. Se identifican como la negociación o clarificación de significados, negociación de la importancia de los argumentos, identificación de áreas de acuerdos contra desacuerdos, propuesta y negociaciones (nuevas) de declaraciones que encierran compromisos y coconstrucción del conocimiento y/o propuesta de integración de metáforas y analogías.

4. Ensayar y modificar la síntesis co-construida, es la comprobación de la síntesis propuesta, comprobación para un esquema cognitivo existente, comprobación contra experiencias personales, comprobación contra datos formales y comprobación de la síntesis propuesta contra testimonios contradictorios dentro de la literatura.

5. Declaración de acuerdos y aplicaciones que sumaricen los acuerdos, que apliquen nuevos conocimientos y que se hagan reflexiones metacognitivas que ilustren el entendimiento y el cambio de las formas de pensamiento como resultado de la interacción.

Van Dijk (2000) realiza una recopilación de estudios en las que se plantea la idea de que el discurso lo utilizan las personas para comunicar ideas o 
creencias, y lo hacen como parte de sucesos sociales más complejos. El análisis del discurso debe incorporar, así y necesariamente, un estudio del lenguaje utilizado, de las creencias que se comunican y de la interacción en situaciones de índole social. Blanton, Moorman y Trathen (1998) hicieron una propuesta para organizar las formas de comunicación en ambientes virtuales, diferenciando entre situaciones convergentes y divergentes, dependiendo de las interpretaciones de los usuarios. A partir de este trabajo, Shotsberger (1999) aplicó diferentes categorías para el análisis de diálogos asincrónicos a través de chats. Las consideradas eran: afirmación, creencias, preocupaciones, práctica, deseo, intención, pregunta y resultado. Mercer (2001) señala que uno de los problemas que se plantea en la investigación es la dificultad de establecer sistemas de categorización que puedan llegar a hacer justicia a la variedad natural de la comunicación. Es útil para comprender la relación existente entre las maneras en que usamos el lenguaje para resolver problemas y crear conocimiento y los tipos de orientación cognitiva adoptada hacia los demás al hacerlo. Este autor establece una categorización a partir de la utilización de tres tipos diferentes de conversaciones:

1. Conversación exploratoria. Es aquella en la que los interlocutores abordan de una manera crítica pero constructiva las ideas de los demás. Se ofrece información pertinente para su consideración conjunta. Se pueden debatir y apoyar propuestas, pero dándose razones y ofreciéndose alternativas. Se busca el acuerdo como una base para el progreso conjunto. «El conocimiento es explicable públicamente y el razonamiento es visible en la conversación» (Mercer 2001: 131).

2. Conversación disputativa. Los participantes inician un proceso de discusión utilizando argumentos para dar razón o rebatir los argumentos de los demás. 
3. Conversación acumulativa. Cada interlocutor va complementando las aportaciones del otro añadiendo información propia $\mathrm{y}$, mediante su mutuo apoyo y aceptación, los dos construyen una comprensión y un conocimiento compartido.

Schrire (2006), por otro lado, analiza el nivel de aprendizaje de los participantes en foros asincrónicos usando, entre otros instrumentos, los niveles identificados por Blomm: conocimiento, comprensión, aplicación, análisis, síntesis y evaluación.

Estos estudios se basan sobre todo en acercamientos cuantitativos relativos a número de intervenciones, distribución de las intervenciones, etc., que son útiles para tener una primera aproximación a las interacciones producidas en el espacio virtual pero resultan insuficientes para la investigación de los procesos de aprendizaje generados. Por ello, es preciso utilizar metodologías de análisis cualitativo que permitan dar cuenta del proceso generado a partir de las intervenciones de los distintos participantes. El modelo de categorización propuesto por Garrison y Anderson (2005) resulta interesante y factible para este tipo de análisis. Centrándonos en este marco, Rourke y Kanuka (2009) realizan una revisión de estudios basados en este modelo, resaltando que la mayoría de éstos se enmarcan dentro de estudios empíricos, siendo una minoría los que realizan revisiones e investigaciones teóricas sobre el mismo.

En el marco de los estudios empíricos, este modelo ha sido utilizado para varias finalidades entre las que se encuentran: estudiar la dinámicas de las interacciones en los foros virtuales (destacamos el estudio de Marcelo y Perera, 2007); estudiar la calidad de esas interacciones, como referente para estudios construcción de comunidades de aprendizaje colaborativo en blended-learning (como por ejemplo los estudios de Ripa, 2007, Bussone, 2010); o el contenido de esas interacciones (García et al., 2008). También se encuentran los que estudian y analizan una determinada dimensión: 
cognitiva (Vaughan y Garrison, 2005; Kanuka et al., 2007), social (Tu y McIsaac, 2002; Swan y Shih, 2005; Arbaugh y Benbunan-Fich, 2006) o la docente (Meyer, 2003; Shea, Li y Pickett, 2006; Arbaugh y Hwang, 2006; Shea, Vickers y Hayes, 2010; Coll, Bustos y Engel, 2011).

Con relación al estudio de las dinámicas y el contenido de la interacción para la creación de comunidades o redes de aprendizaje, destacamos varias investigaciones.

Perera y Torres (2005), realizan un estudio en el que, basándose en el modelo de «Comunidad de Indagación», identificaron nuevas categorías dentro de las dimensiones propuestas por el modelo, buscando obtener información acerca de la enseñanza y el aprendizaje con relación a la naturaleza de los procesos cognitivos, sociales y didácticos reflejados en el foro de discusión online. Como conclusiones significativas de su estudio, destacan que el aspecto social, sobre todo en referencia a la comunicación, de los grupos en el foro, es un factor que contribuye a enriquecer los procesos interactivos de enseñanza y aprendizaje. Por otro lado, inciden en que los estudiantes comparten ideas pero no acaban de profundizar en el conocimiento a a través del debate en los foros y que profesorado y alumnado adquieren diferente roles y tareas en comparación con la enseñanza tradicional. Así el profesorado adquiere roles diversos (facilitador, moderador, asesor, gestor, etc.) y el alumnado asumen un rol más activo en cuanto a participación.

Marcelo y Perera (2007) presentan los resultados de una investigación en la que se analizan los procesos de comunicación asincrónica en foros de elearning. En esta investigación desarrollan un sistema de categorías, basados en el modelo «Comunidad de Indagación», que permite el análisis de la interacción didáctica. Muestran, con este estudio, la importancia de atender a los elementos de comunicación social, cognitiva y didáctica para que el aprendizaje en contextos virtuales se desarrolle de manera más eficaz. 
Ripa (2007) estudia las interacciones virtuales colaborativas de una comunidad de aprendizaje blended-learning, aplicando el modelo de comunidad de indagación con la metodología del análisis de contenido cuantitativo. Desde este estudio se muestra la utilidad del modelo para el análisis y caracterización de las interacciones colaborativas virtuales, fundamentalmente la flexibilidad de los constructos presencia social y presencia docente para adaptarse a diversas configuraciones didácticas. Propone, además, una nueva categoría (presencia vicaria) para aplicar el modelo a la modalidad blended learning y se señala la falta de indicadores para la actividad de auto-organización grupal que generalmente implican las tareas colaborativas. El trabajo aporta la utilización del modelo para analizar cómo se construyen las distintas presencias en el grupo, lo cual permite caracterizar el estilo participativo y horizontal de la comunidad de aprendizaje. El modelo resultó útil para la comprensión de las particularidades del diseño didáctico que se propuso y lo realizado en la práctica, concluyendo que la modalidad blended-learning condiciona la naturaleza misma de la interacción virtual que se quiere analizar: por un lado la limita como material de estudio (ya que lo que se observa allí no se explica por si mismo ni constituye toda la interacción que sucede en el grupo), por otro lado incorpora elementos nuevos (aparece la que llama «interacción vicaria», reflejo de la interacción presencial).

García et al. (2008) proponen un modelo de análisis de la interacción y la construcción del conocimiento en entornos educativos apoyados en la comunicación mediada por el ordenador. Dentro de este modelo, utilizan la propuesta de «Comunidad de Indagación» para estudiar los procesos de interacción en cuanto a contenido de las mismas. Los datos que obtienen indican que el alumnado utiliza formas de interacción social en las que prevalece hacer preguntas o referencia a mensajes de otros, sin incluir aspectos relacionados con la «cohesión» (Presencia Social) como los que utiliza el docente. 
Bussone (2010) utiliza el modelo «Comunidad de Indagación» como referente para la construcción de comunidades de aprendizaje colaborativo en la modalidad blended-learning; y el posterior análisis del discurso electrónico en un enfoque de comunicación, cualitativo, para entender cómo se realizan la presencia social, la presencia didáctica y la presencia cognitiva soportadas por el discurso electrónico en una comunidad de aprendizaje o de indagación desarrollada. Analiza para ello algunas de las interacciones realizadas en un ambiente de aprendizaje virtual creado para la formación de docentes de Italiano (Lengua Italiana como Lengua Extranjera) en el cual la autora de este trabajo participó de manera directa como cotutora de formación online.

Desde nuestra propuesta, utilizaremos este modelo para observar las interacciones en la construcción de una Comunidad de Práctica a través de entornos virtuales de aprendizaje, transitando desde la construcción de una Comunidad Virtual de Aprendizaje e indagando, desde el análisis del discurso a través de los indicadores propuestos desde el modelo «Comunidad de Indagación», sobre la conformación de esa comunidad.

En conclusión, en este capítulo se aborda el enfoque sociocultural donde el aprendizaje se produce a través de interacciones en un contexto determinado. Los procesos comunicativos y el aprendizaje en colaboración son fundamentales para fomentar ambientes interactivos en los que se produzca construcción del conocimiento. Actualmente las Tecnologías de la Información y Comunicación facilitan ambos procesos, promoviendo, a su vez, la creación de comunidades en entornos virtuales de aprendizaje que pueden llegar a convertirse en Comunidades de Práctica. Las tecnologías son medios que ayudan en la conformación y consolidación de estas comunidades. Enfocadas según el modelo «Comunidad de Indagación», 
pueden ser cultivadas, estudiadas y analizadas desde las tres dimensiones social, cognitiva y docente propuestas por Garrison y Anderson (2005). 

Capítulo 4. Políticas de inclusión digital y Comunidad Gitana 



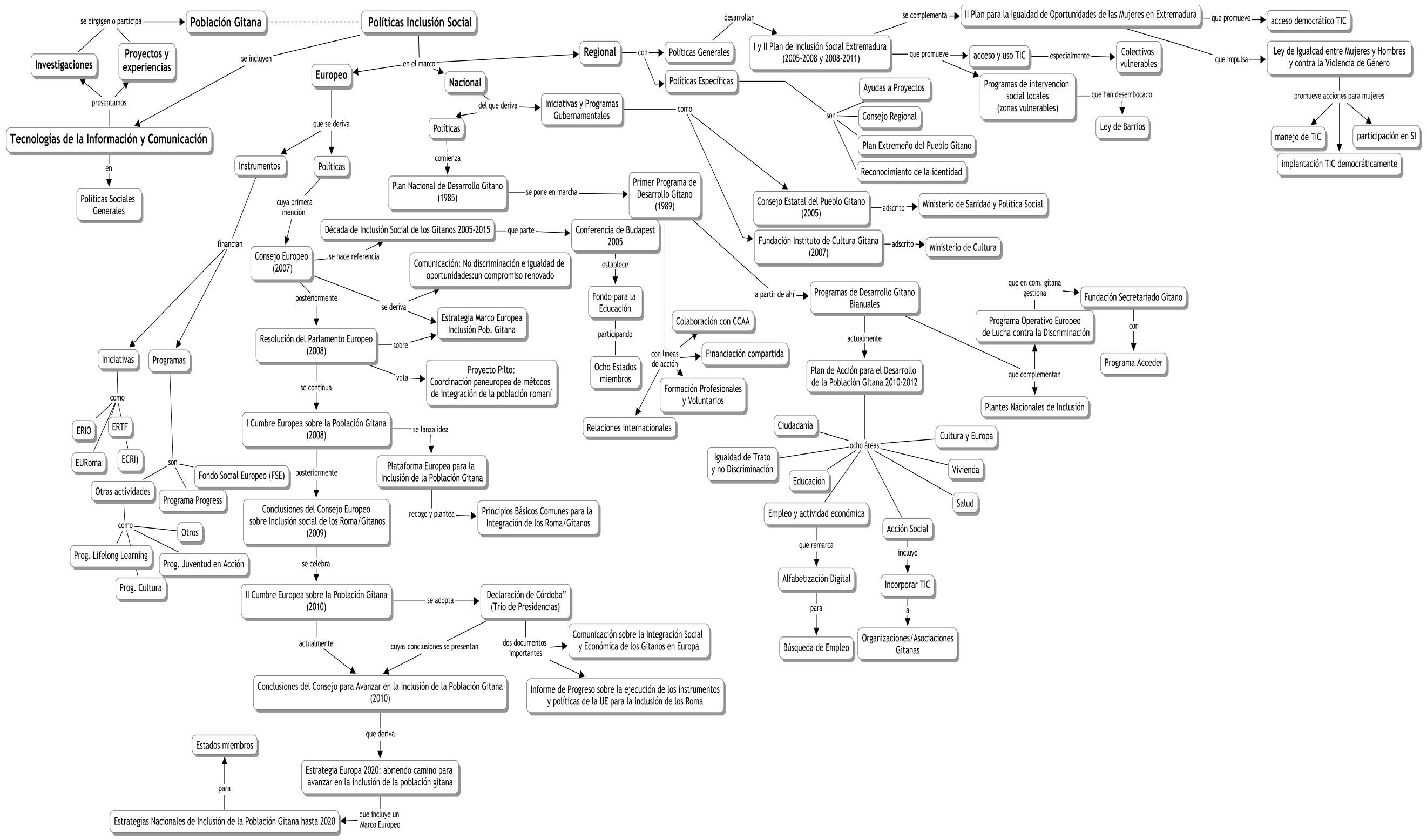





\title{
4.1. Políticas de inclusión social de la población gitana de ámbito europeo, nacional y regional: aspectos relacionados con las TIC.
}

La inclusión social de la población gitana está siendo uno de los objetivos prioritarios de la estrategia de inclusión social de la Unión Europea, en adelante UE, al igual que lo es la integración de la ciudadanías en la Sociedad de la Información. Esta prioridad viene de la propuesta establecida en el plan de acción eEurope, en el que se recoge que:

\begin{abstract}
«la integración en la sociedad de la información es uno de los primeros objetivos de la nueva estrategia para la inclusión social, que pivota sobre las dos dimensiones. Se trata de explotar plenamente el potencial de la sociedad de la información y de las nuevas tecnologías de la formación y de la comunicación procurando que nadie quede al margen» (recogido en Planella y Rodríguez, 2004a: $\left.6^{34}\right)$.
\end{abstract}

Aunque la realidad es que la alfabetización digital y el acceso a las TIC aparecen como aspectos recogidos dentro de las declaraciones institucionales que contemplan la atención al pueblo gitano, dichas iniciativas se enmarcan dentro de las problemáticas generales y eso conlleva que encontremos pocas menciones a este aspecto, o que los que encontramos, se incluyen dentro del ámbito de intervención más general.

Pese a ello nos interesa remarcar el marco europeo que promueve la inclusión social del pueblo gitano, pues es la base de las políticas públicas e instrumentos desarrollados tanto en España como en Extremadura, a favor de la inclusión social, en el sentido amplio, de la población gitana y de los programas de e-learning para su inclusión social, de forma concreta. Posteriormente se establece el marco español y regional destacando aquellos

34 Recogido en Planella y Rodríguez (2004a) haciendo referencia a: CCE (2001) e-Inclusion. Le potentiel de la société de l'information au service de l'insertion sociale en Europe. Bruselas. 
aspectos de las políticas e instrumentos que tienen relación con las Tecnologías de la Información y Comunicación para la inclusión social.

\subsubsection{Marco europeo: principales instrumentos de la Unión Europea con impacto sobre la inclusión social y digital de la población gitana.}

En los últimos años, la inclusión social del pueblo gitano ha ido adquiriendo una gran relevancia política en la agenda Europea y en la de todos los Estados miembros. La Unión Europea, en este sentido, está desempeñando un importante papel para la mejora de las condiciones de vida de los gitanos y gitanas en dos niveles: en primer lugar, en asegurar el respeto al principio de no-discriminación; en segundo lugar, en coordinar, estimular, promover y liderar la acción coordinada de los Estados de acuerdo a unas bases comunes. Para lo primero, la UE dispone de capacidad legislativa. Para lo segundo, cuenta con algunos instrumentos y programas con potencial para ser utilizados por los Estados y otros actores a favor de las comunidades roma/gitanas.

Después de la incorporación de nuevos países, en 2004 y 2007, en la Unión Europea, la población gitana se ha convertido en la principal minoría étnica europea (Vargas, 2004; Macias, 2005). Esta expansión ha conllevado nuevos retos y oportunidades, generando un creciente interés por parte de las instituciones europeas y de los Estados miembros en contrarrestar la creciente desigualdad entre las ciudadanas y ciudadanos gitanos y el resto de la ciudadanía en la UE, en acelerar su inclusión social y en facilitar su empoderamiento político, con lo que se ha constituido un marco sólido para avanzar en la inclusión social de esta comunidad.

Actualmente, el discurso más extendido es que la inclusión social de la población gitana europea es una responsabilidad compartida entre los Estados miembros y las instituciones de la UE, aunque los estados tienen 
competencias y responsabilidad directa en este hecho. La población gitana como principal minoría europea en situación de desventaja se sitúa en las agendas de todos los Estados miembros y de la propia Comisión, que va adaptando todos sus instrumentos para poder favorecer la inclusión social de esta minoría. Además, ésta juega un importante papel en coordinación, liderazgo e impulso político, avances legislativos, promoción de la cooperación entre Estados y provisión de recursos en este ámbito. Estos recientes avances institucionales a nivel europeo con relación a la población gitana en Europa, suponen un claro progreso en términos de compromiso político para avanzar en su inclusión social, ya que son objetivos y enfoques comunes. Vamos a realizar un recorrido en el tiempo por esos instrumentos que la Unión Europea ha puesto en funcionamiento en los últimos años y que han sido los promotores, junto con el marco legislativo, de este avance por la inclusión social de la población gitana, cuestión que justifica todo lo comentando anteriormente.

La primera mención a la situación de la población gitana en el Consejo Europeo fue en $2007^{35}$, en el que se hace referencia a la situación en que se encuentran los gitanos y gitanas de los países de la Unión Europea y se insta a todos los Estados miembros y a la propia Unión a utilizar todos los medios a su alcance para mejorar la inclusión social.

Un año después el Parlamento Europeo aprueba la «Resolución del Parlamento Europeo, de 31 de enero de 20o8», sobre una estrategia europea relativa a esta población gitana una resolución en que solicita que se desarrolle una Estrategia Marco en Europa, buscando coherencia política, en lo que se refiere a mejorar la inclusión social de este grupo social. Unos meses después, el 2 de Julio de 2008, la Comisión hace pública la Comunicación «No discriminación e igualdad de oportunidades: un compromiso renovado» ${ }^{36}$, que pone de manifiesto el interés de la Comisión en dar

35 Se puede revisar en: .http://www.consilium.europa.eu/ueDocs/cms_Data/docs/pressData/en/ec/97669.pdf

${ }^{36}$ Disponible en: http://eur-lex.europa.eu/LexUriServ/LexUriServ.do?uri=COM:2008:0420:FIN:es:PDF 
cumplimiento al mandato del Consejo Europeo de diciembre 2007, haciéndose eco de la Resolución del Parlamento Europeo de 31 de enero de 2008 y de las demandas de la sociedad civil, examinando las políticas e instrumentos comunitarios existentes para mejorar las condiciones de vida y la inclusión social de la población gitana europea.

En septiembre de ese mismo año se celebra en Bruselas la «I Cumbre Europea sobre la Población Gitana» que reunió a los representantes de los Estados miembros, así como a los Estados participantes en la Década para la Inclusión de los Roma/Gitanos, al Parlamento Europeo, a la Comisión Europea, a la presidencia francesa, a la representación de las organizaciones gitanas y de la sociedad civil, contando, asimismo, con representantes del Banco Mundial. En esta Cumbre se afianzan los esfuerzos comunes en lucha contra la situación de discriminación y exclusión social en que se encuentra este pueblo en Europa, y se lanza, por primera vez la idea de una «Plataforma Europea para la Inclusión de la Población Gitana».

El Parlamento Europeo vota en diciembre de 2008 la incorporación en el presupuesto de la Comisión de un Proyecto Piloto para la inclusión de los romaníes llamado «Coordinación paneuropea de métodos de integración de la población romaní» con una dotación económica de cinco millones de euros. El proyecto piloto tenía cuatro ámbitos de intervención y su intención era contribuir a identificar y difundir políticas y buenas prácticas eficaces que pretendan mejorar el acceso de niños y niñas gitanas a una educación de calidad, facilitar el autoempleo, luchar contra la discriminación de la comunidad gitana a través de campañas de información y sensibilización y mejorar los métodos de evaluación y recogida de datos de proyectos dirigidos a la inclusión de este grupo social. El proyecto piloto apoyaba los enfoques innovadores e integrados para tratar los problemas multidimensionales sobre la comunidad gitana y potenciaba formas de mejorar la integración de la población gitana mediante actividades educativas, sociales y económicas, 
cooperación transfronteriza e intercambio de buenas prácticas basadas en experiencias pasadas.

La Dirección General de Política Regional de la Comisión Europea publicó en julio de 2009, en el Diario Oficial de la Unión Europea ${ }^{37}$, una convocatoria de subvenciones, dirigidas a organizaciones sin ánimo de lucro para la presentación de propuestas con la finalidad de mejorar el proyecto piloto, en los siguientes campos de intervención:

1. Atención y Educación de la Primera Infancia.

2. Autoempleo y microcréditos.

3. Información y sensibilización.

La presidencia checa del Consejo de la Unión Europea junto con la Comisión Europea organizaron en Praga los días 26 y 27 de febrero de 2009 una reunión preparatoria de expertos para avanzar el contenido y la estructura de la «Plataforma Europea para la Inclusión de los Gitanos ${ }^{38}$ », siguiendo las conclusiones de la Primera Cumbre Europea sobre los Gitanos que tuvo lugar en septiembre 2008 en Bruselas, así como de la Decisión del Consejo de Ministros de la UE de diciembre 2008. En la conferencia organizada conjuntamente por Vladimír Špidla, Comisario europeo de Empleo, Asuntos Sociales e Igualdad de Oportunidades y Michael Kocáb, Ministro checo de Derechos Humanos y Minorías Nacionales se presentó oficialmente la Plataforma Europea para la Inclusión de los Gitanos el 24 de abril de 2009 en Praga. Esta iniciativa tiene por objetivo principal la coordinación de las acciones que se desarrollan en los países europeos para erradicar la exclusión que sufre la mayor minoría étnica en los Estados miembros de la Unión y estimular la cooperación y los intercambios de

DOUE C 171/o8 , 23/07/2009. Convocatoria de propuestas -Comisión Europea- DG REGIO. Proyecto piloto: Coordinación paneuropea de métodos de integración de la población romaní: http://programasue.info/documentos/2009-C171-08.pdf

${ }_{38}$ Página web de la Plataforma: http://romaplatform.net/index.jsp 
experiencias sobre prácticas y políticas exitosas de integración de la población gitana. El último encuentro de la Plataforma ha tenido lugar los días 7 y 8 de abril de 2011 en el marco de la Presidencia húngara de la UE. En estos encuentros se reúnen representantes de los gobiernos de los Estados miembros, de la UE, de organizaciones internacionales y de la sociedad civil gitana.

Los «Principios Básicos Comunes para la Integración de los Roma/Gitanos ${ }^{39}$ » se presentaron por primera vez en la reunión de la Plataforma Europea para la inclusión de los gitanos en Praga el 24 de abril de 2009. El 8 de junio de 2009, el Consejo de Ministros responsable de Asuntos Sociales anexó los Principios a sus conclusiones e invitó a los Estados miembros y a la Comisión a tenerlos en cuenta. Estos 10 principios básicos se constituyen como una herramienta de trabajo para diseñar y aplicar acciones dirigidas a la inclusión de la comunidad gitana. Esta herramienta, a la que denominan el «vademécum» de la inclusión de la población gitana, proporciona una lista de 10 principios y su aplicación: $1^{\mathrm{o}}$ Políticas constructivas, pragmáticas y no discriminatorias; $2^{\circ}$ Centrarse explícita pero no exclusivamente en los gitanos; $3^{\circ}$ Planteamiento intercultural; $4^{\circ}$ Apuntar a la incorporación total de gitanos y gitanas en la sociedad; $5^{\circ}$ Conciencia de la dimensión de género; $6^{\circ}$ Transmisión de políticas basadas en pruebas; $7^{0}$ Uso de instrumentos comunitarios; $8^{\circ}$ Participación de las administraciones regionales y locales; $9^{\circ}$ Participación de la sociedad civil; y $10^{\circ}$ Participación activa de los gitanos

1. Políticas constructivas, pragmáticas y no discriminatorias. Este primer principio busca basar las políticas a favor de la inclusión social de la población gitana en situaciones reales y no en ideas preconcebidas, prestando atención a estudios, realizando visitas sobre el terreno e implicando a gitanos y gitanas en el diseño de las políticas y los proyectos de intervención. Se sustenta sobre la promoción del

39 Obtenidos de: http://ec.europa.eu/social/BlobServlet?docId=5689\&langId=es 
desarrollo económico y social de los gitanos como base para lograr la igualdad de oportunidades para el pueblo gitano.

2. Centrarse explícita pero no exclusivamente en los gitanos y gitanas. Este principio se basa en el enfoque normalizador que implica centrarse en esta comunidad como grupo objetivo sin excluir a otras personas que viven en condiciones socioeconómicas similares. De esta forma, todas las intervenciones con población gitana no se desvinculan de iniciativas más amplias, teniendo en cuenta, a su vez, el posible impacto que políticas y decisiones más amplias tengan sobre ésta.

3. Planteamiento intercultural. Este principio sugiere que, en lugar de hacer referencia a identidades culturales, las políticas y los proyectos se centren en la promoción del aprendizaje y de habilidades interculturales para comprender las diferentes culturas.

4. Apuntar a la integración total de gitanos y gitanas en la sociedad. Desde este principio se incide en la promoción de la inclusión de los gitanos en la sociedad mayoritaria como objetivo principal de todas las políticas, evitando la segregación.

5. Conciencia de la dimensión de género. Este principio presta atención a la circunstancias especiales y necesidades de las mujeres gitanas, abordando cuestiones como las discriminaciones múltiples, los problemas de acceso a la atención sanitaria y al cuidado de hijos e hijas, a la violencia doméstica y a la explotación.

6. Transmisión de políticas basadas en pruebas. El sexto principio establece la necesidad de aprender de la experiencia propia, así como de intercambiar y compartir experiencias con otros interlocutores o profesionales con el propósito de extraer conclusiones para el trabajo de inclusión de la población gitana. 
7. Uso de instrumentos comunitarios. Este principio presta su atención en la necesidad de utilizar los instrumentos legales (Directiva de igualdad de trato independientemente del origen racial, Decisión marco sobre el racismo y la xenofobia), financieros (Fondo Social Europeo, Fondo Europeo de Desarrollo Regional, Fondo Europeo Agrícola de Desarrollo Rural, Instrumento de Preadhesión) y de coordinación (método abierto de coordinación) que la UE pone al servicio de los Estados miembros para desarrollar políticas y proyectos de apoyo a la inclusión de la población gitana.

8. Participación de las administraciones regionales y locales. El principio octavo se refiere a los gobiernos regionales y locales, en cuanto a que los Estados miembros, tienen que concebir, desarrollar, aplicar y evaluar las iniciativas políticas de inclusión de la comunidad gitana en estrecha colaboración con las administraciones regionales y locales, ya que desempeñan una función esencial en su aplicación práctica.

9. Participación de la sociedad civil. Se refiere a la cooperación con organizaciones no gubernamentales (ONG), agentes sociales, académicos e investigadores, para que participen activamente en el diseño, aplicación, supervisión y evaluación de las políticas y los proyectos.

10. Participación activa de los gitanos. Como último principio, establecen la implicación y participación de gitanos y gitanas en todas la fases de desarrollo de las políticas y proyectos de inclusión para aumentar la eficacia de las intervenciones. Para ello se convierte en esencial respaldar la participación integral del pueblo gitano en la vida pública, estimular su ciudadanía activa y desarrollar sus recursos humanos. 
En las Conclusiones del Consejo Europeo sobre Inclusión social de los Roma/Gitanos del 8 de junio de $2009^{40}$, el Consejo invita a la Comisión y a los Estados miembros de conformidad con sus respectivas competencias a:

- Tener en cuenta los principios básicos comunes para el diseño e implementación de políticas que promuevan la plena inclusión de la población gitana y para las políticas de protección de los derechos fundamentales, de defensa de la igualdad de género, de lucha contra la discriminación, la pobreza y la exclusión social, y las que garantizan el acceso a la educación, la vivienda, la salud, el empleo, los servicios sociales, la justicia, el deporte y la cultura, y las relaciones de la Unión Europea con otros países.

- Hacer uso de la Plataforma Europea para la Inclusión de la Población Gitana para el intercambio de buenas prácticas y experiencias entre los Estados miembros y con los países con una perspectiva de la adhesión a la UE en materia de inclusión social de la comunidad gitana.

- Continuar con el trabajo de la Plataforma Europea para la Inclusión de los Roma/Gitanos, incluida la consideración de la posibilidad de desarrollar aún más su estructura.

Previo a la realización de la «II Cumbre Europea sobre la Población Gitana», el 25 de marzo de 2010 el Parlamento Europeo aprobó una Resolución ${ }^{41}$ sobre esa II Cumbre, en la que se insta nuevamente a que la Comisión desarrolle una Estrategia Europea para la Inclusión de la Población Gitana como instrumento necesario para combatir la discriminación y exclusión social de la población gitana en Europa, y exige a los Comisarios que prioricen el tema gitano en sus agendas.

40 Documento disponible en:

http://www.consilium.europa.eu/uedocs/cms_data/docs/pressdata/en/lsa/108377.pdf

${ }^{41}$ Resolución del Parlamento Europeo, de 25 de marzo de 2010, sobre la II Cumbre Europea sobre la Población Gitana. Disponible en: http://www.europarl.europa.eu/sides/getDoc.do?pubRef=-//EP//TEXT+TA+P7-TA2010-0085+O+DOC+XML+Vo//ES 
La «II Cumbre Europea sobre Acciones y Políticas a favor de la Población Gitana» se celebró los días 8 y 9 de abril de 2010 en Córdoba organizada por la Comisión Europea y el Ministerio de Sanidad y Política Social de España en el marco de las actividades de la presidencia española de la UE. El lema de esta Cumbre es, como indica su nombre, «Políticas en favor de la población gitana».

Los ponentes destacaron que estos retos y oportunidades están relacionados con dimensiones demográficas - con una estimación de entre 10-12 millones de gitanos y gitanas en la UE-, espaciales/geográficas -la segregación en Europa del Este de la población gitana-, económicas -referido al coste económico de la exclusión de este grupo- y de derechos fundamentales ${ }^{42}$. En este sentido aparecen en la Cumbre tres mensajes clave: 1) La Unión Europea no puede quedarse indiferente ante los problemas de la población gitana; 2) Es necesario un liderazgo político en esta materia por parte de la Unión y responsabilidad compartida con los Estados miembros; 3) Son necesarias soluciones a largo plazo que se desarrollen de modo integrado y desde una perspectiva transversal.

Esta Cumbre muestra el compromiso de la UE y los Estados miembros por avanzar en la inclusión social de la población gitana, y, en este sentido se adopta, por el denominado Trío de las Presidencias (española, belga y húngara) una declaración final de la Cumbre, llamada la «Declaración de Córdoba», que establecía el compromiso común para la incorporación del tema gitano en todas las políticas relevantes de la UE, un avance para el trabajo de la Plataforma, el uso efectivo de los Fondos Estructurales, y la adopción de Conclusiones que la presidencia española presentó al Consejo Europeo en junio de 2010.

Presenta dos documentos en este contexto: la Comunicación de la Comisión al Consejo, al Parlamento Europeo, al Comité Económico y Social

42 Información tomada del Dossier de la Fundación Secretariado Gitano relacionado con esta II Cumbre. Disponible en: http://www.gitanos.org/servicios/prensa/dossieres/49295.html 
y al Comité de las Regiones sobre la Integración Social y Económica de los Gitanos en Europa ${ }^{43}$ y un Informe de Progreso sobre la ejecución de los instrumentos y políticas de la UE para la inclusión de los Roma (2008$2010)^{44}$.

El Consejo de la UE en su reunión de 7 de junio de 2010 adoptó las Conclusiones del Consejo para Avanzar en la Inclusión de la Población Gitana $^{45}$. Este Consejo, celebrado en Luxemburgo bajo la presidencia española de turno de la UE, difunde las Conclusiones para la inclusión social de la comunidad gitana europea que se desprenden de la Declaración del trío de presidencias así como de la Comunicación de la Comisión sobre la integración económica y social de la población gitana adoptadas en la II Cumbre Europea, con la implementación de la «Estrategia Europa 202O: abriendo camino para avanzar en la inclusión de la población gitana». Entre estas conclusiones se establecen que ha supuesto un paso adelante el mejor uso de los instrumentos financieros y políticas así como de la cooperación entre la UE y los gobiernos nacionales, se invita a avanzar en la integración socioeconómica de la población gitana desde la transversalidad y desde los 10 principios básicos que a continuación se comentan. Por último se insiste en el desarrollo de un marco de acción en el contexto de la «Plataforma para la Inclusión de la Población Gitana».

La «Estrategia Europa 2020: abriendo camino para avanzar en la inclusión de la población gitana» establece tres prioridades y cinco indicadores comunes que deben alcanzarse combinando medidas nacionales y europeas. Las tres prioridades son crecimiento inteligente, sostenible e integrador capaz de conseguir niveles altos de empleo, productividad y

43 Comunicación disponible en: http://www.gitanos.org/upload/65/94/roma_communication_en.pdf

44 Roma in Europe: The Implementation of European Union Instruments and Policies for Roma Inclusion (Progress Report 2008-2010). Disponible en: http://www.gitanos.org/upload/30/95/roma_report_en.pdf

45 Disponible en: http://www.euromanet.eu/upload/74/16/council_conclusions_2010.pdf 
cohesión social. En cuanto a los indicadores comunes, tres tienen una relevancia importante para el progreso de la población gitana ${ }^{46}$ :

- el 75\% de la población de 20 a 64 años de edad deberá tener empleo.

- la tasa de abandono escolar deberá ser inferior al 10\% y por lo menos el 40\% de los jóvenes deberá completar estudios de nivel terciario.

- la reducción, al menos en 20 millones, del número de personas en situación o riesgo de pobreza y exclusión social.

Cada Estado miembro debe traducir estos objetivos en metas nacionales que reflejen las diferentes realidades y circunstancias nacionales y que ayuden a alcanzar los objetivos europeos.

La Comisión Europea da un paso fundamental en pro de la inclusión de la población gitana en Europa al presentar el 5 de abril de 2011 sus propuestas sobre la creación de un Marco Europeo que exige a los veintisiete Estados miembros desarrollar Estrategias Nacionales de Inclusión de la Población Gitana hasta 2020 mediante una Comunicación ${ }^{47}$ al Parlamento, el Consejo, el Comité Económico y Social Europeo y el Comité de las Regiones En esta comunicación se establece un marco común para el desarrollo de medidas y políticas en el ámbito nacional a partir de enfoques, objetivos y ámbitos de trabajo compartidos por todos los Estados miembros de la UE. La Comunicación recibió el respaldo del Consejo de Ministros de la UE del 19 de mayo y del Consejo Europeo del 24 de junio, el máximo órgano de gobierno de la UE, con lo que la inclusión de este grupo social llega a lo más alto de la agenda política europea. Este nuevo Marco Europeo obliga a todos los Estados miembros, en proporción a su número de población gitana, a

46 Tomado de:

http://www.euromanet.eu/newsroom/archive/estrategia_europa_2020_abriendo_camino_para_avanzar_en _la_inclusion_de_la_poblacion_gitana.html

47 Comunicación sobre el Marco de la Unión Europea (UE) para las Estrategias Nacionales de Inclusión de la Población Gitana hasta 2020. Disponible en: http://eur-lex.europa.eu/LexUriServ/LexUriServ.do? uri=COM:2011:0173:FIN:ES:PDF 
presentar sus propias Estrategias Nacionales antes de finales de año, que deben cumplir con objetivos comunes, basados en indicadores comunes, comparables y fiables, en los cuatro ámbitos prioritarios establecidos: la educación, el empleo, la salud y la vivienda. Se destaca la importancia de mejorar el acceso de gitanos y gitanas a los derechos fundamentales, la implementación de medidas explícitas para evitar o subsanar las desventajas de las personas gitanas, la lucha contra la discriminación y propone soluciones para abordar las barreras que existen a la hora de utilizar de forma eficaz los fondos de la UE, sentando las bases para el establecimiento de un mecanismo de seguimiento que garantice resultados concretos para esta población gitana.

Por otro lado, además de estos instrumentos políticos que marcan las estrategias a seguir a favor de la inclusión de la población gitana en Europa, la propia Unión Europea dispone de diferentes fuentes de apoyo destinadas a favorecer la inclusión social de gitanos y gitanas y entre las que se encuentran acciones relacionadas con la inclusión digital:

A) El Fondo Social Europeo (FSE), desde el marco de los Fondos Estructurales, que presta apoyo a la mejora de las condiciones de vida y de trabajo de los gitanos en particular, invirtiendo en educación y desarrollo de habilidades. Y desde el Fondo Europeo de Desarrollo Regional (FEDER), que presta apoyo al desarrollo regional, al cambio económico, a la mejora de la competitividad y a la cooperación territorial en toda la UE.

B) El Programa PROGRESS (que incluye la campaña informativa «Por la diversidad. Contra la discriminación»), que financia actividades para intensificar la concienciación al respecto con el objetivo de combatir la discriminación contra los gitanos y presta apoyo a las conexiones entre las ONG que representan a los gitanos y defienden sus derechos. 
C) Otras actividades de la Comisión Europea y mecanismos de financiación relacionados.

A) El marco del Fondo Social Europeo para la inclusión social de la población gitana: Fondos Estructurales y FEDER.

La Comisión Europea, en los últimos tiempos, está fomentando el uso de los Fondos Estructurales de la UE por parte de los Estados miembros para apoyar la integración de la población gitana. Este proceso está respaldado por la Red EURoma, que posteriormente mencionamos, compuesta actualmente por representantes de 12 Estados miembros y que tiene como objetivo fomentar el uso de los Fondos Estructurales para mejorar la efectividad de las políticas dirigidas a los gitanos y aumentar así su integración social.

Cabe destacar también la mención específica de la intervención del Fondo Social Europeo (FSE) a través de los Fondos Estructurales que son el marco para las personas y a las regiones que precisan de apoyo para desarrollarse. La financiación de estos fondos se canaliza a través de los Estados miembros y las regiones, a través de colaboraciones entre éstos y la Comisión, que se materializan en Programas Operativos, que implementan las estrategias de acción concretando la manera en que los estados miembros y las regiones van a utilizar los fondos en actuaciones concretas. Estos programas pueden ejecutarlos tanto entidades públicas como privadas y en referencia a población gitana las áreas de intervención se sitúan en problemas de pobreza y exclusión social.

Estos fondos pueden combinarse con el Fondo Europeo de Desarrollo Regional (FEDER) ${ }^{48}$ para la construcción de infraestructuras.

${ }_{48}$ Información disponible en: http://ec.europa.eu/regional_policy/funds/feder/index_es.htm 
Los Fondos Estructurales han financiado también actividades de cooperación e intercambio de conocimientos y experiencias entre Estados. Un ejemplo relevante para la cuestión roma es la «Red Europea sobre la Inclusión social y la Población Gitana en el Marco de los Fondos Estructurales-EURoma ${ }^{49}$ ». La Red está formada por representantes de doce Estados miembros decididos a fomentar el uso de los Fondos Estructurales para mejorar la eficacia de las políticas destinadas a la comunidad gitana y promover su inclusión social.

B) El Programa PROGRESS (2007-2013) $)^{50}$

Como se ha indicado en el Capítulo 2, Progress es el programa comunitario para el fomento del empleo y la solidaridad social (asuntos sociales e igualdad de oportunidades), cuya actividad se desarrolla en paralelo a la de los Fondos Estructurales, desde 2007 hasta el 2013. Trabaja, recordemos, sobre cinco ámbitos: empleo, inclusión y protección social, condiciones de trabajo, no discriminación e igualdad de género, con un presupuesto de 743,25 millones de euros en el periodo marcado (2007-2013). En cuanto a actividades relacionadas con la comunidad gitana, Progress ha financiado algunas actuaciones, ninguna de ellas hace referencia a las TIC:

- Apoyo financiero a la Oficina Europea de Información sobre Gitanos/as (European Roma Information Office), que coordina una de red de apoyo a las organizaciones gitanas para la mejora de sus actividades de promoción pública y en la formulación de sus necesidades ante las autoridades.

- Apoyo financiero a iniciativas emprendidas por los Estados miembros, con un enfoque específico para la comunidad gitana.

49 Sitio web de EURoma. Red Europea para la Inclusión Social de la Población Gitana en el Marco de los Fondos Estructurales: http://www.euromanet.eu/

50 Más información disponible en: http://ec.europa.eu/employment_social/progress/index_en.html 
- Financiación de la primera Cumbre Europea sobre los Gitanos/as de septiembre de 2008 en Bruselas.

- Estudio para mejorar el impacto de las políticas, programas y proyectos dirigidos a la inclusión social y la no discriminación de la comunidad gitana en la UE con el objeto de identificar modelos de éxito de las políticas de inclusión y formular recomendaciones dirigidas a los diferentes niveles de actores (locales, de regionales, nacionales, comunitarias e internacionales).

C) Otras actividades de la Comisión Europea y mecanismos de financiación relacionados.

Destacamos, dentro de estas actividades, varios programas promovidos por la Comisión Europea dirigidos a la participación de la sociedad civil y a iniciativas de desarrollo internacional.

Entre estos programas se encuentran algunos ya mencionados en el Capítulo 2, relacionados con las TIC para la Inclusión Social, entre los que se encuentran: El Programa de Formación Permanente (Lifelong learning), Programa «Juventud en acción», el Programa Cultural (2007-2013), entre otros. En todos los programas se menciona la necesidad de prestar atención específica a la comunidad gitana.

La Comisión Europea fomenta la implicación activa de la sociedad civil gitana en la toma de decisiones a nivel europeo, a través de varios instrumentos: la Plataforma Europea para la integración de la población gitana, las Cumbres Europeas sobre los Gitanos y mediante un programa de formación que facilita a jóvenes gitanos licenciados trabajar durante cinco meses en la Comisión Europea. También, dentro de esta participación, se encuentra la Oficina Europea de Información sobre los Gitanos (ERIO) ${ }^{51}$, con la que la Comisión Europea ha firmado un acuerdo de colaboración.

${ }^{51}$ Sitio web de la Oficina: http://erionet.org/site/ 
La Comisión Europea participa en iniciativas que apoyan la inclusión social de la población gitana con un alcance internacional más amplio y colabora con las distintas organizaciones internacionales que operan en este ámbito. El trabajo de la Comisión Europea se basa en los conocimientos prácticos y las experiencias de la «Década de Inclusión Social de los Gitanos 2005-2015 $5^{5^{2}}$ » e iniciativas como el Fondo Educativo para la Población Gitana, el Plan de Acción de la OSCE (Organización para la Seguridad y la Cooperación en Europa) y las recomendaciones del Consejo de Europa y Naciones Unidas. También participa en el Grupo de Contacto Informal sobre los Gitanos de organizaciones internacionales.

En la Conferencia «Los Gitanos en una Europa ampliada: Desafios para el Futuro» celebrada en Budapest en julio de 2003 por iniciativa del Banco Mundial y el Open Society Institute, se acordó el inicio de este programa por los Primeros Ministros de los primeros ocho gobiernos participantes firmaron la «Declaración de la Década de la Inclusión de los Roma» en Sofía el 2 de febrero de 2005. Esta iniciativa de cooperación entre Estados (doce países entre los que se encuentra España), organismos internacionales y sociedad civil es un compromiso para mejorar la situación socio-económica y la inclusión social de la población gitana. Incide en cuatro áreas prioritarias educación, empleo, salud y vivienda, además del desarrollo de Planes de Acción nacionales que planteen metas e indicadores de progreso en esas áreas, incorporando además como ejes transversales la perspectiva de género, la pobreza y la lucha contra la discriminación.

El Fondo para la Educación es el instrumento más importante de la Década. Este fondo lo crea el Banco Mundial en 2005 con el objetivo de disminuir el fracaso escolar y mejorar el rendimiento académico de gitanos y gitanas. Los recursos financieros los disponen gobiernos, organizaciones y fuentes privadas, y financian proyectos dirigidos a:

${ }^{2}$ Sitio Web de esta iniciativa: http://www.romadecade.org/ 
- Asistencia técnica a la reforma de políticas de educación.

- Experimentación de intervenciones piloto con potencial para influir en las políticas.

- Refuerzo de la capacidad institucional de entidades gubernamentales y de asociaciones gitanas.

- Investigaciones y análisis sobre temas relativos a la educación de gitanos y gitanas.

- Acciones de sensibilización.

- Programa de Becas para financiar estudios universitarios a gitanos y gitanas.

Para finalizar esta revisión de la política e instrumentos europeos, mencionar que España participa activamente en varias iniciativas de las mencionadas y en otras promovidas por el Consejo Europeo.

El Gobierno español ratificó en 1998 el Convenio Marco para la Protección de las Minorías Nacionales, del cual se debe elaborar un informe periódico sobre el cumplimiento de este convenio por el Estado, emitiendo posteriormente el Comité de Ministros del Consejo de Europa la correspondiente Resolución al respecto.

Como se ha indicado, España está representada en la Década para la inclusión social de la población gitana (2005-2015), a través del Ministerio de Sanidad y Política Social. En el ámbito del Consejo de Europa, el Gobierno español, a través del Ministerio de Sanidad y Política Social, participa en las reuniones periódicas y actividades del Grupo de Expertos sobre los Roma/Gitanos. Hay que mencionar también que tres representantes de las organizaciones del movimiento asociativo de la población gitana participan en el Forum Europeo de Roma e Itinerantes (ERTF), constituido en el seno 
del Consejo de Europa el pasado noviembre de 2005, así como también en el Foro Europeo de Jóvenes Roma.

Otro órgano del Consejo de Europa, en el que se participa activamente, es la Comisión Europea contra el Racismo y la Intolerancia (ECRI), elaborando las observaciones oportunas a los informes que otros países hacen sobre España en relación con la población gitana y participando en los órganos directivos de la Comisión. También se colabora con la Organización para la Seguridad y Cooperación en Europa (OSCE) ${ }^{53}$, que lleva a cabo un Plan de Acción para los «roma-sinti-gitanos» en cuyo diseño participó el país.

También se participa como socio en la Red europea sobre la inclusión social de la población gitana (EURoma), siendo uno de los promotores la Unidad Administradora del Fondo Social Europeo del Ministerio de Trabajo e Inmigración.

La relación de los programas e instrumentos presentados indican que existe un marco de políticas de la UE que puede ser utilizado para promover la inclusión social de la población gitana complementando la acción de los Estados miembros.

\subsubsection{Marco español: planes y programas para la inclusión social y digital de la población gitana.}

En España la comunidad gitana ${ }^{54}$ han alcanzado unas condiciones de vida y cotas de integración social altas si las comparamos con Europa (Rodríguez, 2011), pero pese a estos avances, la pertenencia a la comunidad gitana sigue siendo un factor de desigualdad. Desde hace unas tres décadas la población gitana española vive en un fuerte proceso de transformación que les ha permitido avances significativos en materia de promoción social, cuestión a la

53 Sitio web: http://www.osce.org/odihr/18148.html

54 Se estima que la población gitana española se encuentra entre las 750.000 (Fundación Secretariado Gitano, 2007) y las 900.000 personas (FOESSA, 2008). 
que ha contribuido el enfoque del modelo español de inclusión de la población gitana. Según Fresno (mencionado en Rodríguez, 2011), el pilar fundamental ha sido que el sistema de bienestar y de protección social ha mantenido un carácter universal, para toda la ciudadanía en sus prestaciones $\mathrm{y}$ ha sido claramente inclusivo con las personas gitanas. Hay otro pilar que ha impulsado este avance además de las medidas universales, según Rodríguez, y es la puesta en marcha de políticas con medidas de acción específicas para la comunidad gitana en ámbitos como la educación, empleo, vivienda y salud, que, a pesar de ir dirigidas de manera concreta a la población gitana, se establecían mediante el objetivo de la normalización y no de la segregación.

Vamos a hacer un recorrido por esos programas, destacando aquellos aspectos en referencias a las TIC que se incluyan en esas medidas.

El Parlamento español aprueba el 3 de octubre de 1985, la Proposición no de Ley de creación de un Plan Nacional de Desarrollo Gitano, en cumplimiento del mandato constitucional de "promover las condiciones para que la libertad y la igualdad del individuo y de los grupos en que se integra sean reales y efectivos». Así, en el año 1989 se puso en marcha el primer Programa de Desarrollo Gitano, que significó un paso importante para la mejora de las condiciones de vida de la población gitana, con la asignación constante y continuada de recursos y la colaboración y participación de todas las administraciones públicas, así como con un apoyo económico al fortalecimiento del movimiento asociativo de la población gitana. Actualmente esta adscrito al Ministerio de Sanidad y Política Social y tiene como objetivos la mejora de la calidad de vida de la población gitana, favoreciendo su participación en la vida pública social, favorecer el movimiento asociativo y combatir la discriminación y el racismo. Las líneas de actuación del programa son las siguientes:

- Colaboración con las comunidades autónomas, que se instrumenta mediante acuerdos de cooperación técnica y financiera, ya que son las 
propias comunidades, sus corporaciones locales y entes públicos de carácter local las que promueven y gestionan este programa.

- Financiación del Programa: depende del Ministerio de Sanidad, Política Social e Igualdad y las comunidades autónomas que asumen la corresponsabilidad en la financiación, con, al menos, dos tercios de la cantidad financiada por el Ministerio. Estas convocatorias se hacen públicas y se seleccionan los proyectos, atendiendo a criterios de integralidad, continuidad, coordinación con instituciones, participación efectiva de gitanos y gitanas., la inclusión de los proyectos en programas de bienestar más amplios y la demanda de las administraciones en cuanto a necesidad de los proyectos.

- Formación de profesionales y voluntarios que trabajan con población gitana.

- Relaciones Internacionales, a través de la Colaboración con la Unión Europea, las Naciones Unidas, el Consejo de Europa, la Organización para la Seguridad y Cooperación en Europa (OSCE) y con otros Organismos Internacionales

En las dos últimas memorias disponibles de este Programa (2008, 2009) no se han encontrando menciones a la alfabetización digital o las TIC para favorecer la inclusión social en las diferentes áreas. Este hecho puede ser debido a que cada Comunidad Autónoma gestiona este programa y se desarrolla en cada Ayuntamiento.

En los últimos años, se ha progresado en otro ámbito fundamental como es el de la participación de las asociaciones gitanas en la esfera pública, con la creación en el año 2005 del Consejo Estatal del Pueblo Gitano ${ }^{55}$, como un órgano colegiado interministerial, consultivo y asesor, adscrito al Ministerio

55 Real Decreto 891/2005, de 22 de julio. Disponible en:

http://www.boe.es/aeboe/consultas/bases_datos/doc.php?id=BOE-A-2005-14549 
de Sanidad y Política Social, para el desarrollo de políticas de bienestar social que posibiliten la promoción integral de la población gitana. También en el reconocimiento de su cultura y la puesta en valor de su contribución a la cultura española en general, a través de la puesta en marcha de la Fundación Instituto de Cultura Gitana ${ }^{56}$ en el año 2007, promovida por el Ministerio de Cultura cuyos objetivos son el desarrollo y la promoción de la historia, la cultura y la lengua gitanas, y la difusión de su conocimiento y reconocimiento a través de estudios, investigaciones y publicaciones.

Más recientemente se ha puesto en marcha el Consejo para la Promoción de la Igualdad de Trato y No Discriminación de las Personas por el Origen Racial o Étnico, regulado por Real Decreto ${ }^{57}$, en cuyo seno se encuentran representadas dos asociaciones de defensa de los intereses de la comunidad gitana.

Todos estos avances están contribuyendo a una mejora de la situación social de los gitanos y gitanas y de sus condiciones de vida, pero sigue siendo necesario impulsar nuevas acciones que continúen trabajando sobre los desequilibrios existentes y favorecer nuevas formas de participación $y$ desarrollo social, por lo que se está implementando, actualmente, el Plan de Acción para el Desarrollo de la Población Gitana 2010-2012, aprobado por Acuerdo del Consejo de Ministros de 9 de abril de $2010^{58}$. Bajo los principios rectores de igualdad, ciudadanía y participación, inclusión social y cooperación institucional, se plantea el objetivo fundamental de «impulsar nuevas acciones que corrijan los desequilibrios existentes entre la población gitana y el conjunto de la población residente en España y promover diversas formas de participación y desarrollo social para favorecer el pleno ejercicio de derechos y el acceso a los bienes y servicios de la población

${ }^{6}$ Sitio web: http://www.institutoculturagitana.es

57 Real Decreto 1262/2007, de 21 de septiembre. Disponible en: http://www.boe.es/aeboe/consultas/bases_datos/doc.php?id=BOE-A-2007-17281

${ }_{58}$ Plan de Acción para el Desarrollo de la Población Gitana 2010-2012. Disponible en: http://www.msc.es/politicaSocial/inclusionSocial/docs/planDefinitivoAccion.pdf 
gitana»(p. 10). El Plan ha contado con la participación de las organizaciones gitanas en su diseño y destaca entre sus principales objetivos promover acciones para facilitar el acceso al empleo de la población gitana, teniendo en cuenta que los jóvenes, las mujeres y las personas con menor cualificación son quienes tienen más dificultades para acceder al empleo. Las áreas de actuación se centran en ocho: Ciudadanía, Igualdad de Trato y No Discriminación, Educación, Empleo y Actividad Económica, Acción Social, Salud, Vivienda, Cultura y Europa (la población gitana en la agenda europea). En referencia a las TIC encontramos en primer lugar el área de Empleo y Actividad Económica, el objetivo 1, destinado a impulsar la formación para asegurar el acceso permanente a las tecnologías y la promoción en el área del empleo. Dentro de este objetivo se encuentra «Impulsar la formación en nuevas tecnologías (TIC) de la población gitana, para abordar la alfabetización digital como un elemento transversal que facilite la mejora de la empleabilidad y el acceso al mercado de trabajo».(p. 25). También se hace referencia a la necesidad de alfabetización digital de las entidades que trabajan con este grupo social. Así, en el Área de Acción Social, dentro del objetivo 2 , que pretende fomentar la participación de la población gitana en la vida pública y en la resolución de las cuestiones que les afectan, se encuentra «financiar programas gestionados por organizaciones del movimiento asociativo de la población gitana e incorporar las nuevas tecnologías a estas organizaciones» (p. 31).

Por otro lado, Rodríguez (2011) destaca las subvenciones a las ONG gitanas, que mediante convocatorias anuales pueden optar a ayudas derivadas del $0,7 \%$ de la contribución fiscal de la población española. Estas subvenciones cuentan con un apartado destinado a la comunidad gitana.

En el mismo contexto, las políticas europeas han impactado en las políticas españolas en cuanto a inclusión de la población gitana. En primer lugar mediante los Plantes Nacionales de Inclusión, cuyas directrices se establecieron en la Estrategia de Lisboa y que, a través del denominado 
Método Abierto de Coordinación, exigía la elaboración de estos Planes Nacionales de Acción para la Inclusión Social que comenzaron en 2001 y que incorporan un capítulo específico para la comunidad gitana.

A los Planes Nacionales de Inclusión se une el Programa Operativo Europeo de Lucha contra la Discriminación, financiado mediante los Fondos Estructurales, constituyendo un instrumento de mucha trascendencia para las políticas e intervenciones con población gitana en España. El Programa Operativo Plurirregional de lucha contra la Discriminación 2000-2006 y ahora en el periodo 2007-2013, ha contribuido de una manera decisiva a implementar una actuación específica dirigida a los grupos en situaciones graves de exclusión social. El papel de algunas grandes $\mathrm{ONG}^{59}$ en la gestión e implementación de estas actuaciones, hecho novedoso en Europa, ha permitido diseñar proyectos flexibles y adaptados a cada uno de los grupos sociales. En el caso de la comunidad gitana, ha sido la Fundación Secretariado Gitano la entidad responsable de desarrollar el Programa Acceder, un programa de acceso al empleo cuyos resultados han sido la consecución de 40.000 contratos de trabajo, con 58.000 personas atendidas $^{60}$ en 50 ciudades de implantación. Las medidas relacionadas con las TIC se han establecido de manera diferente por cada entidad local o regional, siempre de manera transversal a la áreas principales de intervención, por lo que es complejo situar, de manera específica, estos aspectos.

59 Cruz Roja Española, Cáritas Española, Fundación ONCE, Fundación Luis Vives y Fundación Secretariado Gitano participan en el Programa Operativo como operadores privados.

60 Datos tomados de la página web del programa Acceder de la Fundación Secretariado Gitano: http://www.gitanos.org/acceder/ 


\subsubsection{Marco regional: la inclusión social y digital de la población gitana en Extremadura.}

En la Comunidad Autónoma de Extremadura residen en la actualidad unos 15.000 gitanos y gitanas ${ }^{61}$, que pese al importante proceso de transformación y mejora de su situación social y condiciones de vida, sigue siendo uno de los grupos con más vulnerabilidad y con mayor riesgo de vivir situaciones de exclusión social.

En Extremadura, al igual que en el ámbito europeo y nacional, no se desarrollan políticas en exclusividad para la temática de inclusión digital dirigidas a la población gitana, que se integra en las políticas generales relacionadas con la Sociedad de la Información. Pese a ello, vamos a plantear, brevemente, el mapa de las iniciativas en Extremadura dirigidas a esta comunidad.

Recordemos que, en el capítulo 2, hemos indicado que en el II Plan de Inclusión Social Extremadura (2008-2011), uno de los principios se refiere a las TIC, incidiendo en la dotación continuada de tecnologías para facilitar su utilidad a toda la sociedad extremeña, especialmente, para que, a través del acceso y uso de las mismas, la información, acciones y medidas lleguen a los grupos sociales más vulnerables, dentro de los cuales se encuentra la población gitana. El carácter multidimensional del II Plan de Inclusión Social de Extremadura 2008-2011 y la transversalidad del propio objeto del plan, «la inclusión social de personas y grupos poblacionales en situación o riesgo de exclusión social», le vinculan con otros planes autonómicos, con los que se correlaciona y coordina (Figura 17) entre los que se encuentra el Plan de Alfabetización Tecnológica de Extremadura, del que hablamos en el capítulo primero de este trabajo, y el III Plan para la Igualdad de Oportunidades de las Mujeres en Extremadura62. En este último Plan

61 Dato tomado de la Memoria de Actividades FSG-Extremadura de 2008.

62 Disponible en: http://imex.juntaex.es/index.php?option=com_content\&task=view\&id=91\&Itemid=89 
también se contemplan las TIC en el «Área 1: la transversalidad como principio», formulando el siguiente objetivo: «impulsar el acceso democrático de las mujeres a las nuevas tecnologías». Para conseguir esta meta, sitúan seis medidas, que desarrollan habilidades para fomentar las capacidades emprendedoras de las mujeres a través de las TIC, entre las que se encuentran: utilizar internet y el software libre como un instrumento para generar valor cultural y social en igualdad de género; elaborar manuales de alfabetización tecnológica para promocionar los espacios de encuentro entre mujeres; utilizar las TIC para retransmitir eventos en relación con la igualdad de oportunidades; aplicar las TIC a la prevención de la violencia de género y establecer, utilizando las TIC como medio, redes en todos los niveles para fomentar la colaboración en igualdad de oportunidades entre instituciones, empresas y asociaciones de mujeres.

Una mención merece la Ley de Igualdad entre Mujeres y Hombres y contra la Violencia de Género ${ }^{63}$, publicada en el Diario Oficial de Extremadura del 25 de marzo de 2001. En el capítulo V, dedicado a otras políticas sectoriales, en el artículo 70 se denomina Sociedad de la Información y se recoge que se deben activar acciones que impulsen y favorezcan la implantación de las TIC, en base a criterios de igualdad y se promoverá la participación de las mujeres en la Sociedad de la Información y conocimiento. Además debe facilitarse el acceso de las mujeres al manejo de las TIC, mediante medidas y programas de formación que rompan con las barreras que dificultan esa igualdad de condiciones en el acceso y uso de los recursos tecnológicos, como ocurre en las mujeres gitanas.

Pese a todo ello, como veremos a continuación, en ninguna de las iniciativas destinadas exclusivamente a la población gitana en la región se

63 Ley 8/2011, de 23 de marzo, de Igualdad entre Mujeres y Hombres y contra la Violencia de Género en Extremadura. DOE de 25 de marzo de 2011. Disponible en: http://doe.juntaex.es/pdfs/doe/2011/590O/11010008.pdf 
recoge ninguna mención a las TIC o a la inclusión digital en relación a gitanos y gitanas.

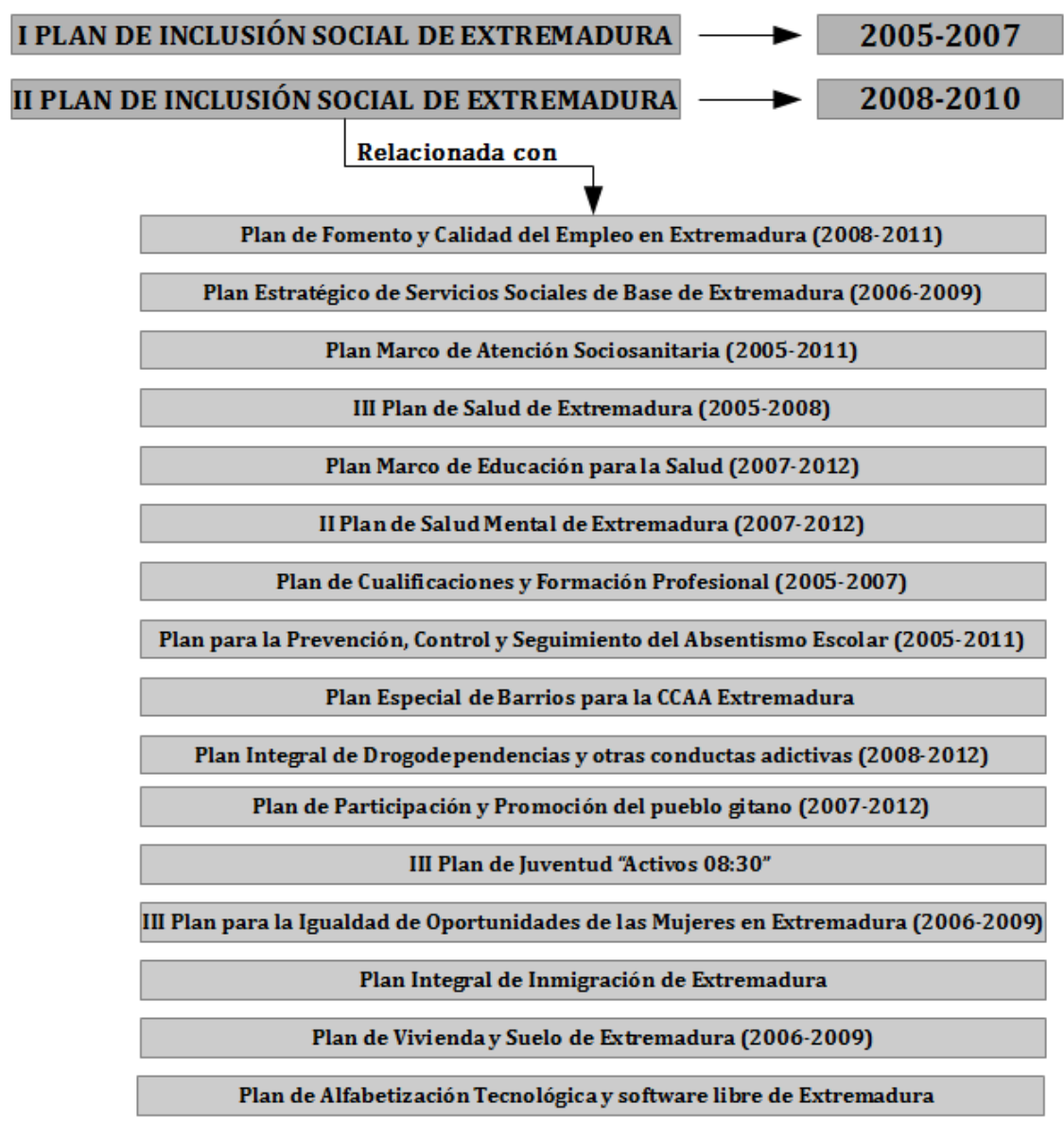

Figura 17. Planes de Inclusión Social de Extremadura y relaciones con otros planes regionales.

En el marco de este II Plan de Inclusión Social 2008-2011, la Consejería de Igualdad y Empleo establece convenios de colaboración con los Ayuntamientos de Badajoz, Cáceres, Mérida y Plasencia, en el ámbito de sus competencias en servicios sociales, para desarrollar Programas de Intervención Social en zonas especialmente vulnerables. El objetivo de estos programas es la inclusión social a través de la puesta en marcha de medidas que favorezcan la integración, eliminando el riesgo de exclusión y 
favoreciendo la igualdad de oportunidades. En 2008, se ponen en marcha en las barriadas de Los Colorines y Suerte de Saavedra en Badajoz; Aldea Moret en Cáceres; San Lázaro en Mérida; y La Data y Polígono de La Data en Plasencia. Estas actuaciones se ampliaron, en 2009, a las barriadas del Noke en Don Benito, Plaza de Salamanca en Villanueva de la Serena y otras zonas de especial vulnerabilidad en Almendralejo. Los programas se centran, especialmente, en tres áreas de trabajo: servicios sociales, formación y empleo y coordinación. Las actuaciones desarrolladas, hasta el momento, se han dirigido al análisis de la realidad social de estas áreas urbanas, acompañamiento para facilitar el acceso a los recursos y reforzar el papel de los servicios sociales de base, orientación, formación y empleo, mujer y tareas de coordinación.

La Ley 16/2010 de la Comunidad Autónoma de Extremadura sobre actuación integral en zonas de atención especial, conocida con el nombre corto de «Ley de Barrios», fue aprobada el jueves 21 de Diciembre de 2010 en el Parlamento Autonómico. El objetivo de esta normativa es crear un marco legal para, por un lado, coordinar las políticas de la Administración regional, local y entidades de iniciativa social que ya trabajan en estas áreas urbanas, con el objetivo de favorecer la inserción social y laboral de las personas en situación o riesgo de exclusión social que residen en ellas; y por otro, propiciar una actuación integral y más efectiva, que englobe todo el conjunto de acciones de carácter urbanístico, de vivienda, económico y social que mejore la atención a esta ciudadanía. Para ello, establece mecanismos para la coordinación entre las administraciones y entidades de iniciativa social, y determina la elaboración de un Plan de Actuación Integral en Zonas de Atención Especial en la Comunidad Autónoma, que recogerá la planificación general que se desarrollará en el conjunto de las zonas consideradas de atención especial, teniendo en cuenta los programas de cada ayuntamiento. 
La Junta de Extremadura ${ }^{64}$, actualmente, está desarrollando iniciativas específicas para conseguir la plena y efectiva integración, propiciando el acceso a los sistemas de protección social, a la vivienda pública, a los sistemas de salud y educación:

1. Ayudas a Proyectos para la Intervención Social dirigidos a Minorías Étnicas.

2. Consejo Regional para la Comunidad Gitana.

3. Plan Extremeño para la Promoción y Participación Social del Pueblo Gitano.

4. Proposición no de ley de la Asamblea de Extremadura de 9 de noviembre de 2006, por la que se reconoce la identidad del pueblo gitano y el valor de su cultura.

Vamos a comentar estos programas, en los que no se hace ninguna referencias a las TIC ni al marco de la inclusión digital en relación con la población gitana, siguiendo la línea de Europa y España, en cuanto a la transversalidad de este tema.

1. Ayudas a Proyectos para la Intervención Social dirigidos a Minorías Étnicas.

Las ayudas para los proyectos de intervención social dirigido a minorías étnicas se hacen públicas en el Diario Oficial de Extremadura, cada año, mediante una Orden en la que se convocan subvenciones a entidades públicas de la Comunidad Autónoma de Extremadura para la realización de proyectos de intervención social dirigidos a minorías étnicas, para el ejercicio 2011. La finalidad de estas acciones debe ser: «atender las necesidades de la población gitana más desfavorecida y promover el desarrollo del pueblo gitano, en el marco de los derechos y deberes constitucionales y del respeto 
a su cultura». Van destinadas a Entidades Públicas de la Comunidad Autónoma de Extremadura que desarrollen Proyectos de Intervención Social dirigidos a Minorías Étnicas y deben llevar la aprobación del proyecto y compromiso de colaboración por la o las asociaciones de ámbito local, comarcal o en su defecto regional, afectadas por la ejecución del mismo.

Estos programas suelen presentarlo los Ayuntamientos y Mancomunidades, no encontrando ningún programa que recoja referencia a la inclusión digital o a las TIC en relación a la población gitana.

\section{Consejo Regional para la Comunidad Gitana ${ }^{65}$.}

El Consejo Regional para la Comunidad Gitana se crea en 2001 para reforzar la integración plena del pueblo gitano en Extremadura. Es un órgano con carácter colegiado, consultivo y de participación en materia de identificación de necesidades y promoción de igualdad real de gitanos y gitanas en los diversos ámbitos de la vida económica, política, cultural y social. Lo integran representantes de todas las Consejerías, dos representantes de la Administración Local y uno de la Diputación, más 10 representantes de asociaciones gitanas. Elabora programas, informes, canaliza información, entre otras funciones.

\section{Plan Extremeño para la Promoción y Participación Social del Pueblo} Gitano.

El Consejo Regional para la Comunidad Gitana, órgano colegiado y de participación en materia de igualdad real de gitanos y gitanas, aprobó por unanimidad, fruto del consenso entre las organizaciones gitanas y la administración, en su sesión del 1 de marzo de 2007, el Plan Extremeño para la promoción y participación social del Pueblo Gitano.

65 Decreto 179/2001, de 20 de noviembre, por el que se crea el Consejo Regional para la Comunidad Gitana. Disponible en:_http://ie.juntaex.es/pdfs/Inmigracion_gitanos_consejo.pdf 
Con la puesta en marcha del citado Plan se van a adoptar una serie de actuaciones de carácter integral, desarrollando medidas en áreas que se consideran claves como son la educación, la salud, la vivienda, la cultura, el empleo, la mujer o la juventud, que acaben con la situación de exclusión social que viven muchos gitanos y sitúe a todos los ciudadanos y ciudadanas en un mismo nivel de oportunidades independientemente de su origen étnico.

En ninguno de los objetivos de intervención propuestos para cada área se hace ninguna referencia a las TIC.

4. Proposición no de ley de la Asamblea de Extremadura de 9 de noviembre de 2006, por la que se reconoce la identidad del pueblo gitano y el valor de su cultura ${ }^{66}$.

La identidad y cultura compartida por el pueblo gitano, a pesar de su heterogeneidad, fue reconocida por el Congreso de los Diputados en una Proposición no de Ley el 27 de septiembre de 2005. Este hecho genera que en 2006, mediante la aprobación por unanimidad el 9 de noviembre de una Proposición no de Ley en la Asamblea de Extremadura, se inste a la Administración Regional a difundir el reconocimiento de la cultura gitana, así como a prevenir e identificar actuaciones discriminatorias por origen racial o étnico. El reconocimiento en la región pretende contribuir a mejorar la relación y el respeto a la población gitana extremeña.

66 Resolución 105/VI, subsiguiente a la Proposición no de Ley 255/VI (PNL-280), por la que se insta a la Junta de Extremadura a difundir el reconocimiento de la cultura gitana y su valor para la sociedad extremeña, y a prevenir e identificar prácticas discriminatorias por origen racial o étnico. Boletín Oficial $\mathrm{n}^{0} 448$ de 14 de noviembre de 2006. Disponible en: http://ie.juntaex.es/pdfs/Inmigracion_gitanos_proposicion.pdf 


\subsection{Tecnologías de la Información y Comunicación y pueblo gitano.}

\subsubsection{Las TIC y gitanos y gitanas}

Desde la concepción de Granados (2008) sobre la tecnología en sentido amplio $^{67}$, en referencia no sólo a las herramientas y a los artefactos, sino también aquellas formas de proceder que responden a una lógica de ejecución de toda actividad humana de carácter racional, éste afirma que el pueblo gitano ha desarrollado una tecnología propia centrada en la práctica de determinadas artes o destrezas para el desempeño de actividades sujetas a un conjunto de reglas y procedimientos que han tenido, generalmente, una proyección económica de sustento básico. Estas formas de proceder se han venido transmitiendo de padres a hijos en el seno de las familias extensivas, constituyendo la base de lo que conocemos como oficios gitanos tradicionales. Este autor realiza un recorrido desde el inicio de esta concepción en la historia del pueblo gitano hasta su estabilización geográfica, incluyendo ahí, las relaciones de éstos con las TIC, tal y como las entendemos en este trabajo, a través de uso y consumo de determinados artefactos refiriéndose, en ese momento, a los primeros electrodomésticos. En este sentido, el autor reflexiona sobre el componente simbólico que para las familias gitanas representan el consumo de unos determinados productos relacionados con la tecnología, concluyendo que este grupo social «ha quedado relegado del uso dominante de la tecnología» (p. 433). Este autor indica además que las familias gitanas no han percibido aún, de forma mayoritaria, las ventajas que los recursos informáticos ofrecen como herramientas para el conocimiento comparándola con la poca confianza que estas familias muestran en la escuela como vehículo de promoción laboral y

67 Entendida como el «conjunto de formas de acción y de pensamiento de median la relación del ser humano con su entorno» (Granados, 2008:430). 
social, y que los que aparecen son vinculados a entretenimiento y ocio a excepción de la minoría gitana alfabetizada:

\begin{abstract}
«los recursos informáticos se encuentran hoy, pues, muy lejos de las expectativas y pretensiones de la mayoría de las familias gitanas porque además de constituir una importante inversión para sus precarias economías, también hay que saber qué hacer con los ordenadores; obtener rendimiento de su utilización requiere un cierto nivel de alfabetización y de comprensión del entorno en el que nos vemos inmersos cuando los utilizamos» (Granados, 2008:438)
\end{abstract}

Desde nuestro punto de vista, y como se ha comentado en el primer capítulo, impera la necesidad de acceder y usar las TIC como un requisito indispensable de inclusión. En este sentido la incorporación masiva de ordenadores a las aulas en las escuelas, con el actual proyecto Escuela 2.0, con el que se persigue implantar en las aulas, de manera generalizada y progresiva, la utilización de las tecnologías de la información y la comunicación como herramientas habituales de trabajo en todas las áreas de conocimiento. Todos los cursos y, por ende, todos los niños y niñas gitanos escolarizados tienen acceso al ordenador y están trabajando para aumentar su competencia digital y de tratamiento de la información desde la perspectiva de multialfabetización o alfabetizaciones múltiples (Area, 2009; García Carrasco, 2009). En este sentido, ya mencionaba García Andújar (2001:27) que el acceso y uso de las TIC por parte de las minorías es una de las claves de inclusión: «el pueblo gitano, sumido en una última trinchera de resistencia cultural, ha de participar en esta nueva utopía de libertad y acceso global al conocimiento, de lo contrario, nos perpetuaremos en una dinámica espiral viciosa de marginación, racismo y aislacionismo».

En último Informe Anual de la Fundación Secretariado Gitano (2011:58), se hacen varias referencias a este hecho, incluyendo la idea de que la inclusión social de la comunidad gitana requiere un abordaje integral: 
«Un aspecto también relevante ha sido fomentar la creación y organización de servicios que rompan la brecha digital que la comunidad gitana está en riesgo de padecer, y favorezcan el acceso y uso de las nuevas tecnologías de la información y la comunicación, garantizando con ello su incorporación a la sociedad de la información».

Es oportuno mencionar algunas investigaciones que contemplan el uso de las TIC como parte del proceso de inclusión que se pretende llevar a cabo con población gitana desde diferentes ámbitos.

En este sentido destaca la investigación coordinada y realizada por el Centro Especial de Investigación en Teorías y Prácticas Superadoras de Desigualdades de la Universidad de Barcelona (CREA) que señala el potencial social y relacional de las personas gitanas adultas en relación con experiencias de acercamiento a las TIC (Flecha, Vargas y Dávila, 2004; Serradell, Larena y Fisas, 2004; Serradell, Sordé y Vargas, 2006). El proyecto de investigación Workalo ${ }^{68}$ : The creation of new occupational patterns for cultural minorities: the Gypsy Case, financiado por el $5^{\circ}$ Programa Marco de Investigación de la Comisión Europea dentro del Programa Improving the Socioeconomic Knowledge Base (2001-2004) la investigación se ha llevado a cabo en los siguientes países europeos: España, Francia, Portugal, Reino Unido y Rumanía. CREA-UB fue la entidad coordinadora del proyecto, gestionando las tareas que llevaba a cabo cada uno de los equipos de los diferentes países participantes. Este proyecto iba destinado a definir estrategias innovadoras de desarrollo social y económico orientado a la cohesión social, teniendo en cuenta que las minorías étnicas, en general, y la comunidad gitana en particular, tienen mucho que aportar a la cohesión social de Europa (Serradell, Sordé y Vargas, 2006). En esta investigación se remarca que la población gitana tiene desarrolladas competencias equivalentes a las necesarias requeridas en el ámbito laboral de la Sociedad del Conocimiento, como son el trabajo en equipo, la organización

68 Para más información consultar la página web del proyecto Workaló: http://www.neskes.net/workalo/ 
cooperativa, la flexibilidad y capacidad de adaptarse a los cambios, las competencias interculturales y los trabajos y actividades dinámicos y de autoaprendizaje. Pese a ello, se destaca que existen barreras institucionales y legales, y de actitudes y comportamientos que se sitúan como las principales razones de la exclusión del pueblo gitano en el mercado laboral. Entre las propuestas para la inclusión laboral de la comunidad gitana, fruto del trabajo realizado en ese proyecto se deriva la «inclusión de las personas gitanas en el sector de las TIC», para las cuales hacen falta directrices políticas que promuevan la inclusión de personas gitanas y otras minorías culturales en este sector. Desde este proyecto se deriva el Informe «Competencias y necesidades de la comunidad gitana en la sociedad del conocimiento ${ }^{69}$ que insiste en esta propuesta, desde la creación de una oferta formativa que facilite las herramientas necesarias para el acceso de las personas gitanas a los perfiles profesionales emergentes, donde estarían presentes las TIC, basando esta formación en potenciar esas competencias presentes en la población gitana:

«La comunidad gitana puede aportar muchos beneficios a la sociedad del conocimiento ya que, como hemos observado, no tan sólo posee las habilidades para buscar y gestionar la información sino también de otras, como por ejemplo aquellas relacionadas con la organización y cooperación, que pueden influir positivamente en la sociedad actual. El reconocimiento de estas habilidades es un factor importante de inclusión para las personas gitanas» (p. 35).

En este sentido, la alfabetización y formación en TIC, como se indica, es crucial para el acceso al empleo. Algunas directrices a este respecto, se encuentran en las Conclusiones y Recomendaciones del Informe sobre Población Gitana y Empleo (Fundación Secretariado Gitano, 2005a:20) donde se constataba que el desempleo se seguía concentrando especialmente en «aquellas personas con mayores dificultades en el acceso al mercado de trabajo, como es el caso de la población gitana». Una de las barreras

69 Informe disponible en: http://www.neskes.net/workalo/Habilidadesynecesidades.pdf 
fundamentales que se destacaban era el nivel de acceso a las TIC, lo que refrendaba una necesidad «urgente» de alfabetización digital. Afirman que este hecho, está suponiendo no sólo una barrera para la consecución de empleos, sino que puede suponer un nuevo riesgo de exclusión social, por lo que sugiere que se lleven a cabo actuaciones, no sólo con jóvenes, sino también con personas adultas.

Lalueza y Crespo (2003), indican, además, que proporcionar herramientas como las TIC deviene un elemento fundamental para superar una situación de exclusión, ya que infunden oportunidades para el desarrollo de sus miembros y de la comunidad como un todo (Lalueza, Crespo, Pallí y Luque, 1999; Crespo, Lalueza y Pallí, 2002; Lalueza y Crespo, 2003; Lalueza, Crespo y Bria, 2008; Lalueza, Crespo y Camps, 2008). Este hecho lo demuestran con una investigación de índole más comunitaria que la anterior denominada «La Casa de Shere Rom ${ }^{70}$. «La Casa de Shere Rom» fue un proyecto de investigación-acción local que se puso en marcha en 1998 por el Grupo de Investigación DEHISI@, de la Universidad Autónoma de Barcelona, en colaboración con la Asociación Gitana del barrio de San Roc en Badalona. Tras un proceso de negociación, buscando la implicación de la población gitana de la barriada en el proyecto, ambas entidades ponen en marcha una Comunidad de Aprendizaje -gestionada por la Asociación y diseñada y asistida por el grupo de investigación-, cuyo objetivo compartido era proporcionar a los niños y niñas de la comunidad herramientas que les ayuden a superar la situación de fracaso general que sucedía en la escuela, garantizando el acceso a las tecnologías de la información y comunicación. Con la puesta en marcha de un plan de dinamización en la barriada, el Ayuntamiento financia tres proyectos conjuntos de la Asociación y la Universidad: dos destinados a formación de adultos, llevados a cabo por la Asociación, y «La Casa de Shere Rom». Este proyecto comunitario se perfila

${ }_{70}$ En este apartado vamos a comentar los resultados como proyecto de investigación. Se recoge también, como experiencia de proyectos de intervención social con población gitana y TIC en el apartado siguiente. 
como una adaptación de la experiencia « 5 th Dimension $»^{71}$ diseñada y puesta en marcha por el Laboratory of Compared Human Cognition, dirigido por Michael Cole en 1996. Se situaba en un local con disposición de ordenadores y consistía en un software lúdico, en el que una persona llamada Shere Rom guiaba y orientaba a los niños y niñas participantes a través de juegos y actividades. Los resultados del proyecto de investigación, además de la alfabetización digital de la comunidad, muestran la potencialidad del modelo 5D para proporcionar una nueva microcultura generadora de nuevas formas de motivar y aprender, postulando una serie de premisas (Crespo et al. 2004 y 2005) basadas en los principios del aprendizaje colaborativo y en el modelo $5 \mathrm{D}$, entre las que están: partir de los intereses de los diferentes actores a través de un proceso de negociación, basar la actividad en la participación de todos los agentes, organizar el aprendizaje como colaboración en la obtención de metas, flexibilizar el desarrollo de la actividad y desarrollar una microcultura a partir de las culturas existentes en el contexto, adaptándose al entorno.

Por último se destaca una investigación lleva a cabo por la antropóloga Mayte Heredia (2004, 2005, 2008), que estudia los usos sociales de Internet por parte de jóvenes gitanos y gitanas y cómo se construye la identidad gitana en entornos virtuales. Para ello lleva a cabo una investigación basada en la etnografía virtual, indagando en chats donde interactúan personas gitanas. Entre sus resultados, afirma que la juventud gitana va ampliando sus posibilidades de comunicación gracias a internet, creando nuevas formas de sociabilidad, y además que lo utilizan como herramienta de liberación de la carga cultural, puesto que en internet utilizan un lenguaje diferente y hablan de temas que cara a cara no podrían. Pero, por otro lado, la usan como herramienta de «mantenimiento étnico» a través de la selección de los miembros que forman la comunidad virtual. Para la investigadora, internet es el nuevo medio que está ofreciendo, como ningún otro, las posibilidades de

${ }^{71}$ Puede encontrarse información detallada sobre la experiencia en el sitio web: http://www.5d.org 
acceder y materializar los cambios que se están produciendo en la población gitana, especialmente en la juventud. En ese sentido, indica que estamos en un momento clave para que cultura gitana tenga su presencia en la red (Heredia, 2008), no sólo en las páginas webs institucionales, sino también para la creación de redes sociales de gitanos y gitanas que conformen un «Planeta Gitano en la red», con los objetivos de visibilizar la presencia gitana en internet, constituir un espacio de reflexión, intercambio y debate y desarrollar actividades divulgadoras y de interés común.

En este sentido, como indicaba García Andújar (2001), internet es una herramienta que puede adaptarse para el desarrollo de proyectos muy concretos entre la comunidad gitana. Así, afirma Heredia (2008:67):

«Los gitanos y gitanas del siglo XXI tenemos que ser conscientes del
poder de presión que tienen las Nuevas Tecnologías y de que
nuestras identidades colectivas se pueden y deben convertir en
fuentes de credibilidad y participación. Esto sin duda nos hará ser
más fuertes, y podremos convertirnos en un grupo de presión
influyente en ámbitos culturales, sociales, políticos y mediáticos para
participar en igualdad de condiciones en las diferentes esferas de
poder y decisión».

\subsubsection{Experiencias previas de proyectos e-learning destinados a población gitana.}

La recogida de experiencias previas significativas de proyectos de formación e-learning/blended-learning se ha realizado atendiendo a diferentes fuentes:

- VI Congreso de Telecentros y Redes de Telecentros, celebrado en Mérida, los días 15 y 16 de Marzo de 2007. 
- El V Encuentro de e-inclusión (Telecentro 2.0) que tuvo lugar durante los días 5, 6 y 7 de Noviembre de 2008 en Centre Esplai, El Prat de Llobregat (Barcelona), en el marco del programa Red Conecta.

- Dispositivos FSG de toda España: se remitió un e-mail (enero 2009) a todos los dispositivos de la Fundación Secretariado Gitano en España, preguntando acerca de proyectos que reuniesen los requisitos establecidos y que se exponen a continuación.

- Búsquedas en la Red (en 2009) con palabras clave como: «elearning», «tic», «gitanos», «gitanas», «virtual», «formación virtual», entre otras.

Los requisitos establecidos en la búsqueda del proyecto se dividen en tres:

- Proyectos de e-learning, esto es, proyecto que conlleven formación en la red, bien como parte de una acción formativa virtual o blendedlearning.

- Destinados a población gitana o que la población gitana participe en la iniciativa.

- Las posibles entidades implicadas en estas iniciativas se dividen en: entidades sociales, administraciones o entidades públicas $\mathrm{y}$, por último, universidades.

Atendiendo a las fuentes mencionadas y en base a los requisitos mencionados, se detectan varias experiencias que corresponden a proyectos e-learning dirigidos a población gitana o en la que participan algunas personas gitanas por ser programas o proyectos implementados en barrios o zonas donde conviven grupos culturales diferentes.

En la siguiente tabla se muestra la clasificación de los proyectos encontrados: 


\begin{tabular}{|c|c|c|}
\hline INICIATIVA & PARTIPACIÓN & EXCLUSIVIDAD \\
\hline \multirow{4}{*}{$\begin{array}{l}\text { Entidades sociales en } \\
\text { convenio con } \\
\text { Administraciones } \\
\text { Públicas }\end{array}$} & a1. Proyecto Xarxa-OMNIA & b1. El Ratón Verde \\
\hline & a2. Proyecto Red Conecta & b2. Romi.net \\
\hline & \multirow{2}{*}{$\begin{array}{l}\text { a3. Proyecto Nuevos Centros del } \\
\text { Conocimiento (Plan de Alfabetización } \\
\text { Tecnológica y Software Libre de } \\
\text { Extremadura -España) }\end{array}$} & $\begin{array}{l}\text { b.3. Proyecto de formación básica, } \\
\text { trabajo familiar y desarrollo } \\
\text { personal y comunitario a través de } \\
\text { las TIC. }\end{array}$ \\
\hline & & b.4. Otros proyectos. \\
\hline $\begin{array}{l}\text { Universidades en } \\
\text { convenio con } \\
\text { entidades sociales }\end{array}$ & --- & c1.La Casa de Shere Rom \\
\hline
\end{tabular}

Tabla 2. Clasificación de proyectos e-learning dirigidos, o en los que participa, población gitana.

\section{a. Proyectos en los que participa población gitana. Iniciativa: entidades sociales en convenio con administraciones públicas.}

\section{a.1. Proyecto Xarxa-ÒMNIA (Generalitat de Catalunya-España).}

$\mathrm{El}$ proyecto Òmnia (palabra latina que significa «todos») ${ }^{72}$ nace a finales de 1998 por una iniciativa conjunta con el entonces Departament de Benestar Social y el Comissionat per a la Societat de la Informació del Gobierno de la Generalitat de Catalunya, para dar respuesta a una demanda social basada en la necesidad de acceder a las tecnologías de la información y la comunicación, como medida para prevenir y combatir la exclusión social y con la voluntad de impulsar este acceso a toda la población.

El proyecto se define, por un lado como «innovador» -por ser proyecto socioeducativo y participativo que busca favorecer la autonomía de las personas y la dinamización de la comunidad- y por otro como «preventivo» -porque favorece el acceso de la población a la Sociedad de la Información, especialmente a los grupos en situaciones o riesgo de exclusión, evitando una brecha social social más acentuada con la brecha digital- consiste en la creación de espacios dotados con infraestructura necesaria y disposición de

${ }^{72}$ Sitio Web: http://www.xarxa-omnia.org/ 
educadores y educadoras para garantizar el acceso a las TIC en poblaciones y zonas que se ven afectadas por situaciones de exclusión social (Basela, 2003). Se fundamenta en tres líneas de actuación: la formación, la inserción social y laboral y el uso comunitario. La última línea de acción se establece como clave en este proyecto, contextualizándola en el trabajo compartido y la interculturalidad. Igualmente, como eje del proyecto también se resalta la figura del profesional que da soporte en los centros como dinamizador y dinamizadora. El papel de estos profesionales en los centros se considera fundamental y se basa en una metodología que potencia la iniciativa, la espontaneidad, la creatividad, basada en la concepción constructivista de los aprendizajes, en la transversalidad, en la creación de ambientes ricos y motivadores a nivel de expresión y comunicación, además de adaptado al usuario, a sus problemáticas y motivaciones (Basela, 2003).

Si centramos la atención en los usuarios y usuarias que acceden a estos puntos se muestra mucha diversidad:

- Personas que por problemas socieconómicos no pueden disponer de un ordenador en casa.

- Infancia y Juventud, como una oportunidad para divertirse formándose y relacionándose, y que a partir de las diferentes actividades van adquiriendo un mayor conocimiento de la tecnologías de la información.

- Mujeres amas de casa que no tienen ningún conocimiento de informática y para las que estos centros constituyen espacios de relación y de aprendizaje de las nuevas tecnologías.

- Mujeres en edad laboral como oportunidad para formarse y reciclarse profesionalmente, así como nuevas posibilidades de encontrar trabajo. 
- Personas inmigradas que acceden al proyecto para formarse y para buscar trabajo.

- Gente mayor interesada en aprender informática.

- Grupos y personas con especiales dificultades derivados por los profesionales que trabajan en los diferentes servicios del territorio.

- Entidades del territorio que, mediante el centro, acceden a herramientas y recursos que les permiten desarrollar mejor su tarea de gestión, de planificación y la ejecución de actividades así como un espacio donde poder buscar información, elaborar material de difusión, herramientas que les faciliten la tarea de gestión de la propia entidad.

Caracterizan esta heterogeneidad como favorecedora de las relaciones y de las situaciones personales ya que en el centro se producen acercamientos a las diferencias de unas y otras personas. Además, las personas participantes conforman una red virtual mediante la cual se comunican, difunden, etc., actividades realizadas en cada punto Òmnia haciendo extensible a la totalidad de centros, no sólo lo desarrollado en cada uno de ellos sino también fomentando un espacio dónde las personas compartan intereses, información, servicios y necesidades.

Dentro de los grupos mencionados, y formando parte de esa diversidad, se encuentran algunas personas gitanas que participan en las actividades que se desarrollan en estos centros.

\section{a.2. Proyecto Red Conecta (Ámbito nacional- España).}

Red Conecta ${ }^{73}$ se define como «un proyecto social compartido» por una red de Organización No Gubernamental (ONG), que pretende fomentar la inclusión social de todas las personas utilizando las nuevas tecnologías como

73 Sitio Web del Proyecto: http://www.redconecta.net/ 
herramienta. Es un proyecto estatal cuya entidad coordinadora central es la Fundación Esplai y que está subvencionados por el Ministerio de Trabajo e Inmigración, Ministerio de Igualdad (INJUVE), Ministerio de Educación, y por las empresas privadas Microsoft Ibérica y Wrigley.

Red Conecta se dirige a la población en general, pero en especial a jóvenes de 13 a 30 años, mujeres con dificultades de acceso al mundo laboral, desempleados de larga duración y personas con dificultades de inserción social.

Las características principales que describen este proyecto son:

Una base asociativa, ya que se trabaja desde la idea de proximidad local, es decir, intentando conformar redes con entidades y asociaciones que trabajan en un mismo ámbito social, facilitando así atención a personas en riesgo de exclusión en barrios y municipios.

- Un enfoque comunitario, puesto que todos los centros forman parte de un proyecto comunitario, en el todas las personas implicadas participan de manera activa y comparten lo que van aprendiendo con otras.

- Trabajo en red, con asociaciones y entidades de su ámbito de acción, con otros centros Red Conecta, y con otras redes de alfabetización digital para favorecer la e-inclusión de las personas.

- Alianza entre sectores, con relaciones de implicación por parte del sector privado, administraciones, ONGs.

- Metodología de trabajo basada en un conjunto de recursos de aprendizaje diseñados, específicamente, para los diferentes grupos que participan en los cursos, a través de: 
- Un aula con un equipamiento informático de, aproximadamente, nueve ordenadores con acceso a Internet aportados por Fundación Esplai o la entidad promotora, dos impresoras, escáner, webcam y software actualizado.

- Personas dinamizadoras, que son el factor clave para conducir el proceso, tanto desde el punto de vista técnico, como especialmente de acompañamiento de los/as participantes. Prestan una atención personalizada, cuentan con un buen conocimiento del entorno, con especialización en aspectos de inclusión social. Se encargan de planificar las actividades, organizar los grupos, contactar con las asociaciones próximas y mantener el equipamiento. Reciben formación especializada por la entidad coordinadora responsable. En los centros, además, cuentan con personal voluntario colaborando con la labor de la persona dinamizadora.

- Coordinación territorial, como modo de organización para facilitar la adecuada implantación y la apropiación del proyecto en cada una de las entidades locales, así como el seguimiento del trabajo en los centros.

Entre las principales actividades que se realizan en un centro, se encuentran:

- Cursos de formación.

- Cursos de alfabetización digital e iniciación básica a la informática, con el apoyo directo de las personas dinamizadoras.

- Actividades de autoformación. 
- Ejercicios y programas de autoaprendizaje, mediante el programa «Ordenador Práctico», desarrollado exclusivamente para el programa, apoyados por la dinamización.

- Acompañamiento en la búsqueda de empleo.

- Atención personalizada en el uso de los recursos para buscar empleo.

- Acceso libre para el uso personal de los equipos en horarios abiertos disponibles.

- Uso de los equipos y recursos por parte de otras ONGs de la zona, bien para gestión propia, bien para la gestión o dinamización de proyectos comunitarios y para la realización de proyectos para el barrio.

Las personas gitanas que viven en esas barriadas participan en las actividades que organizan o en el tiempo de acceso libre. Tienen, además, varios centros Red Conecta en colaboración con asociaciones y fundaciones que trabajan en la promoción del pueblo gitano.

En Extremadura, el programa Red Conecta (mediante Fundación Esplai) tiene tres telecentros:

- Dos en colaboración con el Ayuntamiento de Cáceres y Don Benito y la Fundación Secretariado Gitano.

- Uno en colaboración con la Asociación ACUDEX ${ }^{74}$ de Zafra.

\section{a.3. Proyecto Nuevos Centros del Conocimiento.}

Como hemos indicado en el capítulo 1, los Nuevos Centros del Conocimiento (NCC), son espacios públicos que cuentan un equipamiento tecnológico completo y una grupo de dinamizadores y dinamizadoras que se encargan de acercar y formar en competencias digitales a la ciudadanía.

74 Más información en su web: http://acudex.org/ 
Las personas gitanas participan en las actividades y cursos de formación que organizan ya que viven en las barriadas donde están ubicados estos centros. En algunos se han desarrollado, conjuntamente con otras entidades, alguna actividad muy concreta, dirigida a población gitana. En Cáceres, por ejemplo, se han organizado actividades conjuntas concretas relacionadas con el Empleo a través del Programa Acceder de la Fundación Secretariado Gitano ${ }^{75}$.

\section{b. Proyectos destinados en exclusiva a población gitana. Iniciativa entidades sociales en convenio con administraciones públicas.}

b.1. La Souris Verte (El ratón verde): el «vehículo multimedia» ${ }^{76}$ (Francia).

«La Souris Verte», traducido como el «ratón verde», es una de las acciones que el Centre Ressources Illettrisme (Centro de Recursos para el Analfabetismo) lleva a cabo desde el año 2005 en el marco del Acuerdo Consejo General de Inclusión Social. Circula por la provincia francesa de Puyde Dôme (Auvergne), acercando a las comunidades gitanas al descubrimiento y uso de las nuevas tecnologías, así como el acercamiento a conocimientos básicos como la lectura y escritura. Consiste en un camión de $9 \mathrm{~m}^{2}$, que denominan el «vehículo multimedia itinerante», equipado con ordenadores y otros materiales como periódicos, información de ciudades, libros sobre cultura gitana, pretendiendo suscitar una orientación positiva hacia la lectura y fomentar el uso de las TIC en la población gitana itinerante en riesgo de exclusión:

- Dentro del camión, como espacio de aprendizaje.

\footnotetext{
75 Puede consultarse en la Memoria de Actividades 2008 de la Fundación Secretariado Gitano en Cáceres. Disponible bajo solicitud: fsg.caceres@gitanos.org

${ }^{76}$ Información sobre el proyecto: http://www.tucamon.es/contenido/ciudadania-poblacion-gitana-tic
} 
- Fuera del camión, como espacio para el café, la lectura, etc.

Su lema es: «Las TIC son una pasarela para la integración de las comunidades gitanas». Con esta idea, se trasladan a pueblos donde están caravanas de personas gitanas. La finalidad es acabar con el analfabetismo tanto digital como de los conocimientos básicos con la ayuda de las nuevas tecnologías, que aportan el incentivo de un idioma común, para «construir una pasarela que acabe con la brecha entre las personas gitanas y no gitanas». Así, fijan tres grandes objetivos con este proyecto:

- Restaurar, promover y favorecer el gusto por la lectura y la escritura, respetando las particularidades culturales.

- Favorecer el descubrimiento y la utilización de las TIC promoviendo una variedad de enfoques basados en la curiosidad, el gusto y los intercambios culturales.

- Asegurar que las situaciones de la vida cotidiana se transformen en una oportunidad y por tanto en procesos de aprendizaje.

Su pretensión con el uso de las TIC es:

- Combatir la brecha digital, y el analfabetismo tanto el digital como el de los conocimientos básicos.

- Permitir a personas cuya cultura es oral, suscitar ganas de trabajar los textos escritos de modo lúcido para garantizar el gusto y el descubrimiento de lo leído.

- Tienen que usar las TIC para procurarse el acceso a la cultura escrita.

- Intercambios interculturales y enriquecimiento mutuo, favorecedores de comunicación intercultural. 
Partiendo de la invitación a un café -lo llaman café pedagógico porque abre la puerta a la actividades educativas que se promueven desde este vehículo- destacan varios bloques de actividades:

1. Introducción e inicio al uso de ordenadores: se proponen una serie de talleres para conocer el uso de herramientas, procesamiento de textos, de imágenes, iniciación al uso de internet y programas de software educativo (no diseñado por ellos sino ya establecidos) para fomentar la lectura la escritura, el cálculo, la lógica, etc.

2. Actividades relacionadas con la lectura: libros, periódicos, juegos de cartas, juegos de lógica, manuales de circulación.

3. Actividades relacionadas con la escritura: cartas de motivación, métodos de lectura, talleres de escritura, juegos autodefinidos, sudokus, crucigramas, juegos de lógica y trabajo en los ordenadores para ejercitar la escritura.

Las personas que participan en esta experiencia, acuden al vehículo a trabajar en grupos de lectura y escritura para mejorar la comprensión, así como realizar talleres de iniciación en procesadores de texto, imágenes o Internet.

En 2008 contaban con 3.537 visitas de personas tanto gitanas como no gitanas, lo que permitido que interactúen y se conozca más a fondo su cultura en las regiones de esta provincia.

«Está claro que internet imposibilita el hecho de conocer de antemano la etnia de la persona que, por ejemplo, escribe un post, cuelga una foto o aporta un comentario en internet. Eso es bueno; nos ahorramos el filtro de los estereotipos». Entrevista a Stéphane Gardé, responsable del Proyecto ${ }^{77}$.

77 Entrevista disponible en formato audiovisual: http://www.masticable.org/tag/etnia-gitana/ 


\section{b.2. Proyecto Romi.net (Ámbito nacional, España)}

En el marco del Plan Avanza ${ }^{78}$ 2006/2007, con el apoyo del Ministerio de Industria y en colaboración con la Fundación Esplai, la Fundación Secretariado Gitano, puso en marcha el proyecto Romi.net. El fin último de este proyecto es garantizar la igualdad de oportunidades y de género en la sociedad de la información para sectores de población en situación de exclusión por razón social y por género, como son las mujeres gitanas, facilitando su acercamiento a las Tecnologías de la Información y Comunicación.

La estrategia fundamental de este proyecto ha partido de la formación de un grupo de 20 dinamizadoras, en su mayor parte gitanas, que se han formado específicamente en la sensibilización, la dinamización y la formación a diferentes niveles sobre el acceso y uso de las TIC. Éstas serán las responsables de compartir los conocimientos adquiridos con otras mujeres de su entorno y de gestionar cada una de las 15 aulas informáticas que se pusieron en marcha en diferentes localidades.

El contenido principal de este proyecto se basa en el desarrollo de actuaciones, específicas y adaptadas, de acercamiento y formación para mujeres gitanas en el uso de las nuevas tecnologías de la comunicación y la información. Estas actuaciones se desarrollarán a través de servicios de acceso a TIC mediante aulas informáticas preparadas específicamente para ello.

Las cinco acciones concretas que se llevaron a cabo fueron:

- Organización de un grupo de dinamizadoras de los servicios de acceso a TIC (aulas de informática): estará formado por 20 mujeres (mayormente gitanas) procedentes de 8 comunidades autónomas (Extremadura, Madrid, Andalucía, Aragón, Castilla y León, Castilla La

${ }_{78}$ Sitio Web: http://www.planavanza.es/Paginas/Inicio.aspx 
Mancha, Comunidad Valenciana y Murcia), y que serán en parte personal de la FSG y en parte personal de otras organizaciones colaboradoras que desarrollan programas de apoyo para mujeres gitanas.

- Puesta en marcha de 15 servicios de acceso a nuevas tecnologías repartidas por las 8 comunidades autónomas: León, Alicante, Elche, Mérida, Ciudad Real, Sabadell, Tarrasa, Valladolid, Valencia, Murcia, Zaragoza, Albacete, Badajoz, Madrid y Sevilla.

- Formación específica al grupo de dinamizadoras sobre nuevas tecnologías de la comunicación y la información y su uso por parte de mujeres gitanas.

- Desarrollo de materiales de alfabetización digital básica e igualdad de oportunidades para mujeres gitanas.

- Divulgación del proyecto y difusión de sus productos y resultados.

b.3. Proyecto de formación básica, trabajo familiar y desarrollo personal y comunitario a través de las TIC.

La Asociación Proyecto San Fermín ${ }^{79}$ en Madrid cuenta, además de con un Centro Red Conecta y Conecta Joven, con un proyecto de formación básica, instrumental y desarrollo personal utilizando las TIC como herramienta prioritaria dentro del Proyecto Innova-Integra (Acercamiento de las Nuevas Tecnologías para la Integración), financiado por la Consejería de Servicios Sociales de la Comunidad de Madrid (Proyecto RMI - Renta Mínima de Inserción). La finalidad fundamental es la de mejorar la calidad de vida de las personas participantes a un nivel integral, enfocando la práctica desde un

79 Sitio web: http://www.san-fermin.org/ 
punto de vista comunicativo, intentando desarrollar un metodología próxima a las Comunidades de Aprendizaje.

En este proyecto, se trabaja con hombres y mujeres mayoritariamente de etnia gitana y con sus hijos e hijas, a través de "grupos interactivos» con el objetivo de realizar un aprendizaje mutuo, una implicación educativa y una mayor participación comunitaria, planteándose un modelo de intervención donde, todos los miembros de la unidad de convivencia o de toda una comunidad, co-participen en el aprendizaje de todos. Toman estos procesos, como un medio para la integración de las personas en su entorno de referencia, favoreciendo además la convivencia.

Dividen las acciones en cuatro bloques:

- Abecé experimental, donde se realizan actividades de refuerzo en la alfabetización y lectura comprensiva, utilizando para ello software educativo y recursos de internet.

- Escuela práctica, donde se trabajan habilidades básicas e instrumentales, economía doméstica y alimentación, transporte, gestiones administrativas e igualdad de oportunidades. En este bloque, se trabaja con las TIC como herramienta cultural, de información y de participación

- Introducción a la informática básica, con acciones formativas de alfabetización digital.

- Trabajo familiar (Comunidad de Aprendizaje), con acciones dirigidas a las familias e hijas/os, actividades de refuerzo escolar y de aprendizaje de personas adultas, grupos interactivos y tertulias literarias, voluntariado y participación en otras actividades comunitarias. 


\section{b.4. Otros proyectos.}

Se han identificado otros proyectos, desarrollados por entidades sociales, de manera puntual y temporalmente limitados, debido a la resolución de subvenciones específicas.

En este sentido, se encuentra la Asociación Jovesólides de Valencia que puso en marcha un proyecto de «Ludoteca TIC», desarrollada en Valencia durante los años 2005/2006, destinados a niños/as durante el horario del «culto evangelista» durante 6 meses. En ella se desarrollaban juegos entre los que se incluían «juegos a través del ordenador».

Otra entidad, la Asociación de Payas y Gitanas Romí de Palencia, que además de contar con un centro Red Conecta, cuenta con un Programa que favorece itinerarios de inserción social en los sectores de exclusión social. En el marco de este programa se desarrollan acciones con TIC dirigidas al ámbito del empleo, especialmente a mujeres gitanas, a través de dos objetivos fundamentales:

- Acercar las TIC a población en riesgo de exclusión.

- Mejorar las capacidades para la inserción laboral a través de las TIC.

Para conseguirlos, pusieron en marcha varios cursos de formación, a través del centro Red Conecta, y acciones específicas de orientación laboral con mujeres gitanas. 
c. Proyectos destinados en exclusiva a población gitana. Iniciativa universitaria en convenio con entidades sociales.

\section{c.1. La Casa de Shere Rom (Lalueza et al., 1999).}

La Casa de Shere Rom se perfila como un adaptación de la experiencia " $5^{\text {th }}$ Dimension» ${ }^{80}$ diseñada y puesta en marcha por el Laboratory of Compared Human Cognition, dirigido por Michael Cole en 1996.

La primera iniciativa de este proyecto surge en 1998 por un grupo de investigadores/as (Grupo DEHISI@ ${ }^{81}$ ) del Departamento de Psicología Social de la Universidad Autónoma de Barcelona. La finalidad de la intervención está orientada a disminuir el fracaso escolar mediante un proyecto con nuevas tecnologías digitales dirigido, en concreto, a la comunidad gitana de la ciudad de Badalona (España) que vive en el barrio de Sant Roc, especialmente a niños y niñas. Para ello los investigadores toman contacto con la Asociación Gitana de Badalona y en el proceso de negociación conjunta surge la Casa de Shere Rom (cuyo nombre se refiere a un personaje histórico de la comunidad gitana europea) una actividad dirigida a niños/as y sus familias, fuera del horario y del espacio escolar, de acceso voluntario, con un sistema explícito de reglas de participación, en la que se utilizan herramientas informáticas y una estructura de funcionamiento que provee una relación individualizada entre el «aprendiz» y un educador que media en la actividad. Se desarrolla en un local de la Asociación Gitana y se abre a todo el barrio. En este espacio se puede encontrar:

- Varios ordenadores con conexión a internet y disponibilidad de impresora.

8o Sitio Web: http://www.5d.org

81 Para indagar más sobre este proyecto, puede visitarse el sitio web del grupo DEHISI@ de la Universidad Autónoma de Barcelona: http://psicologiasocial.uab.es/dehisi/ca/casa-de-shere-rom 
- Un fichero donde localizar software de juegos educativos, cada uno con una ficha en la que se detalla el contenido y los diversos niveles que se pueden alcanzar en su uso.

- Un conjunto de juegos no informáticos

- La maqueta de un laberinto, con habitaciones numeradas y puertas que comunican unas con otras.

- Un fichero con fichas de los participantes, en las que se señalan sus progresos.

- Un reglamento o «Ley de la Casa», expuesto de forma visible, que detalla el funcionamiento de la actividad, las reglas de uso del material y las atribuciones de cada uno de los roles correspondientes a los usuarios.

Los principales objetivos del proyecto se enumeran en cinco:

a) Facilitar acceso al tipo de conocimiento que proporciona la escuela evitando el rechazo que ésta genera al ser una institución percibida como ajena.

b) Favorecer el desarrollo de las capacidades cognitivas y comunicativas necesarias para la participación en la escuela.

c) Colaborar para que el acceso a la escuela y la adquisición de los correspondientes conocimientos y conductas se efectúe evitando la deculturación y la pérdida de los vínculos de la comunidad gitana.

d) Estimular la participación de las personas adultas gitanas en un proyecto educativo que sea percibido como propio de la comunidad.

e) Garantizar el acceso a las TIC. 
Conseguir estos objetivos genera un proceso de intervención que, por un lado, pretende:

1. Organizar actividades que favorezcan el desarrollo cognitivo y social en un entorno que niños y niñas gitanos puedan considerar un espacio propio.

2. Crear un contexto de actividad que, por su voluntariedad y contenido lúdico, favorezca la implicación de niños y niñas.

3. Desarrollar prácticas no escolares en las que se utilicen los códigos de lenguaje propios de la actividad escolar.

4. Hacer del uso de ordenadores una práctica cotidiana.

5. Organizar la actividad de acuerdo a unas reglas que no se perciban como una imposición «paya», sino como fruto del consenso en el contexto de una institución propia de la comunidad.

6. Coordinar con las escuelas del entorno el contenido de las actividades, atendiendo a las implicaciones en la dinámica de la comunidad.

7. Implicar a las familias en el proceso educativo de sus hijos e hijas.

Por otro lado, da una visión investigadora a esta acción, que ha permitido obtener resultados desde tres líneas:

1. Estudiar el desarrollo humano desde una perspectiva cultural, aportando nuevos datos para el desarrollo teórico de la psicología evolutiva

2. Estudiar los procesos en la zona de desarrollo próximo a través de la colaboración entre sujetos con diferente nivel de experiencia 
3. Facilitar un contexto controlado de prácticas para estudiantes de Psicología, Psicopedagogía y Educación Social de la Universidad Autónoma de Barcelona.

En este capítulo se ha revisado y hemos proporcionado una perspectiva global del marco europeo, nacional y regional de las políticas sociales e instrumentos públicos a favor de la inclusión social de la población gitana, destacando aquellos aspectos que tienen relación con las Tecnologías de la Información y Comunicación. Del análisis de las políticas sociales dirigidas a la población gitana, tanto a nivel europeo, nacional y autonómico, se hace evidente que existe un gran avance y se siguen realizando esfuerzos para que la estrategia de inclusión social de la población gitana tenga influencia en los diversos planes, proyectos e iniciativas en el ámbito de la política social de la Comunidad Autónoma de Extremadura. Aunque la realidad es que la alfabetización digital y el acceso a las TIC aparecen como aspectos recogidos dentro de las declaraciones institucionales que contemplan la atención al pueblo gitano, dichas iniciativas se enmarcan dentro de las problemáticas generales y eso conlleva que se encuentren pocas menciones a este aspecto o, los que encontramos, se incluyan dentro del ámbito de intervención más general. Por otro lado, y para finalizar, se ha situado el contexto de investigaciones y experiencias relacionadas con el e-learning social y la población gitana. Se destacan cuatro investigaciones relacionadas con este ámbito (Lalueza y Crespo, 2003; Heredia, 2004; Fundación Secretariado Gitano 2005a; Serradell, Sordé y Vargas, 2006) y alrededor de siete proyectos e iniciativas en las que la población gitana participa. 


\section{SEGUNDA PARTE. MARCO METODOLÓGICO}



Capítulo 5. Planteamiento Metodológico 



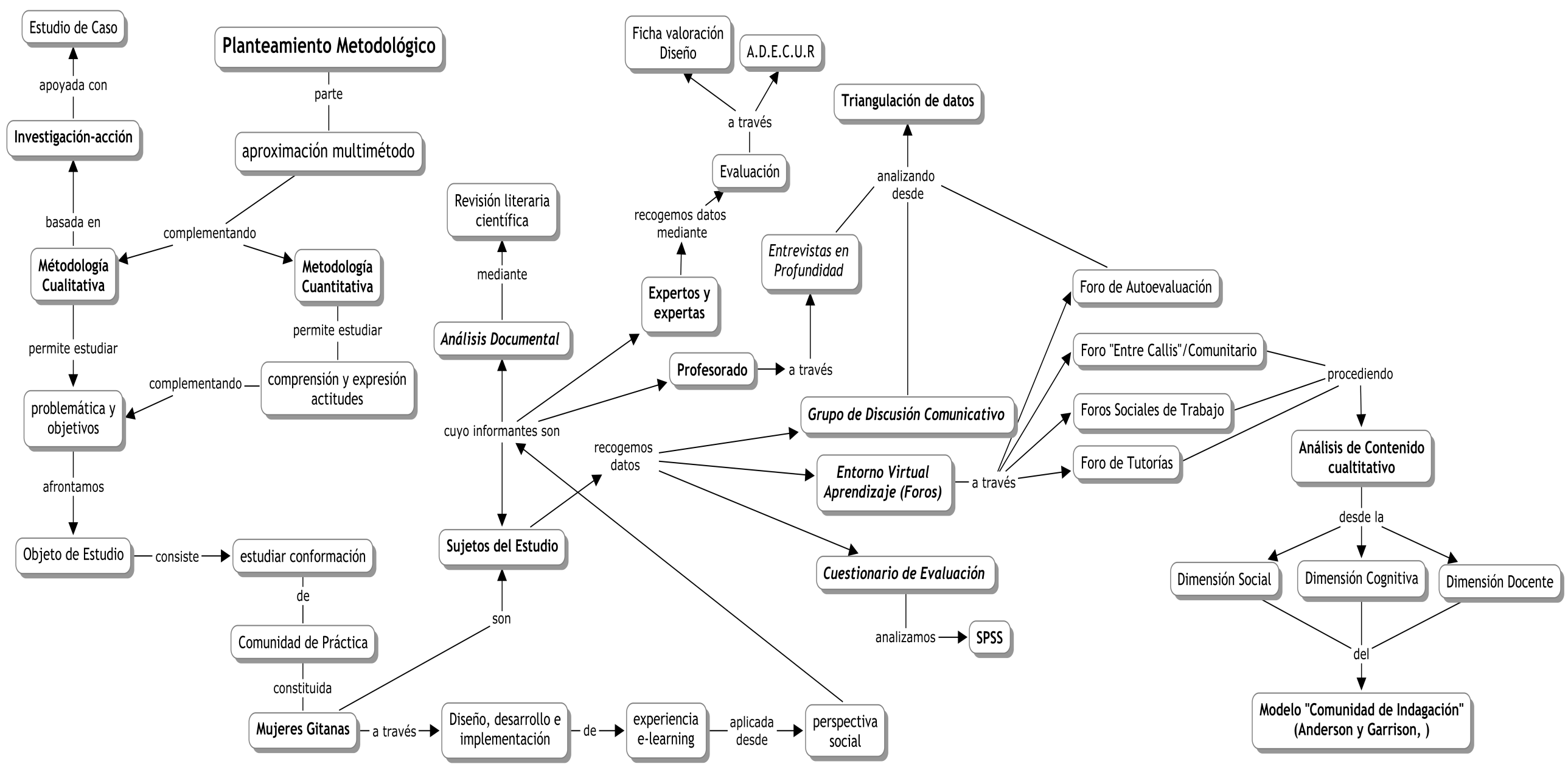





\subsection{Fundamentación del enfoque metodológico de la investigación.}

\subsubsection{Selección $y$ fundamentación del enfoque metodológico.}

La metodología que se selecciona en cada investigación, es la que determina el camino a seguir y la configuración de todo el proceso. En este sentido, adoptamos un marco metodológico adecuado a los planteamientos epistemológicos y contextuales de la misma, seleccionando las herramientas más adecuadas para la obtención de datos útiles para la investigación. Como indica Ander-Egg (1995), el método es el camino y posee el carácter global y de coordinación de las operaciones a realizar y las técnicas el modo de recorrerlo y de operar en la práctica. De este modo, las técnicas se engloban dentro de un método y, a su vez, un método emplea el uso de diferentes técnicas.

Desde este punto de vista, optamos por una aproximación multimétodo, incorporando dos vías de análisis complementarias, aunque debemos destacar que una prevalece sobre la otra por las características del fenómeno investigado, como veremos a continuación. Este enfoque puede ser entendido como una estrategia de investigación en la que se utilizan más de un procedimiento para la indagación sobre un fenómeno u objeto de estudio a través de diferentes momentos del proceso de investigación (Ruiz, 2008). Dentro del enfoque multimétodo optamos por la tipología de métodos mixtos (Tashakkori y Teddlie, 2003) en el que, en nuestro caso teniendo una orientación epistemológica cualitativa, integramos algunas estrategias del enfoque cuantitativo para estudiar cuestiones referidas al mismo objeto de estudio. 
Nuestra primera vía de análisis utiliza una metodología cualitativa, puesto que nos permite abordar de manera satisfactoria la problemática y objetivos a los que nos enfrentamos. Además, utilizamos una metodología cuantitativa, ya que nos ayuda a acceder a la comprensión y expresión de actitudes, complementarias al análisis cualitativo En este sentido, la técnica del cuestionario nos resultaba mucho más plausible para orientar, posteriormente, el análisis de contenido de las contribuciones de los agentes participantes y como técnica para la triangulación con otras dos técnicas cualitativas. Nos situamos así en la concepción de Waterman et al. (2001), que afirma que el conocimiento puede avanzar a través de la reflexión y la investigación, utilizando métodos tanto cualitativos como cuantitativos para la recogida de datos. Seguimos a Strauss (1987) cuando establece la diferencia fundamental entre ambos tipos de enfoque: la investigación cuantitativa se centra en el estudio de las relaciones entre variables cuantificadas, mientras que la investigación cualitativa lo hace en contextos estructurales y situacionales. Así en esta investigación las técnicas cuantitativas utilizadas pretenden obtener un resultado que luego nos sirva para orientar la evaluación del proceso en el que usamos las técnicas cualitativas. Morales y Moreno (1993) admiten que durante el proceso de investigación puede haber momentos en los que se puede utilizar métodos cuantitativos y en otros cualitativos, considerándose como compatibles (Cook y Reichardt, 1986).

Si durante una etapa los métodos cuantitativos predominaban como herramienta fundamental en la investigación educativa y social, es cierto que la metodología cualitativa gana terreno en el campo de la Pedagogía y las Ciencias Sociales como un modelo flexible y fiable, que permite observar, analizar e interpretar mejor el estudio de los contextos educativos y de las interacciones sociales (Sandín, 2003). Es decir, desde la metodología cualitativa se propone estudiar en profundidad un determinado fenómeno social, partiendo de la realidad de lo investigado. 
La decisión de optar por estos enfoques obedece a la flexibilidad que ésta permite para describir y comprender un fenómeno social en su propio contexto, en este caso en una acción formativa virtual, la interactividad generada a través de las herramientas de comunicación del mismo, pues por ser holística permite reconstruir las formas de intercambio simbólico de la praxis social real, percibe e interpreta al objeto de estudio a partir de su contexto y permite reconstruir esa realidad desde las propias participaciones de sus protagonistas, en este caso, mujeres gitanas. Nuestra decisión también se justifica desde la propia concepción de los métodos cualitativos como inductivos, permitiendo la observación y análisis de eventos particulares (acción formativa virtual), sin buscar la generalización de resultados ni el establecimiento de leyes universales. Además esta metodología da cabida a lo inesperado, tema fundamental en nuestro planteamiento, ya que en este caso estamos hablando de procesos y actividades planeadas desde el diseño del curso y la interacción comunicativa, y cuyo devenir no es posible prever. Los planteamientos metodológicos cualitativos asumen que la realidad se construye a partir de los significados sociales que las personas asignan al mundo que las rodea.
«[...] en el paradigma cualitativo el investigador se aproxima al problema para comprenderlo; este enfoque se interesa por estudiar a los sujetos en su ambiente natural, utilizando técnicas que le permitan acercarse a la realidad. Este enfoque no pretende trabajar con muchos individuos sino más bien con algunos, pero considerándolos en toda su complejidad» (Mena y Méndez, 20o9:1).

Dado que el objetivo principal de esta investigación es diseñar una acción formativa virtual, dirigida a 20 mujeres gitanas para la conformación de una Comunidad de Práctica y conocer lo que sucede en el microcontexto de ese aula virtual, la metodología cualitativa nos permite adentrarnos en ese contexto desde una visión antropológica, intentando comprender qué es y cómo funciona; y desde una visión interpretativa y constructivista, en la que 
la comprensión del fenómeno implica la consideración de una amplia variedad de contextos temporales y espaciales, históricos, políticos, económicos, culturales, sociales y personales.

Esta investigación pretende mostrar las posibilidades de empleo de las TIC para promover la construcción social de conocimiento, la motivación, la creatividad, e incluso la promoción social y cultural, para conocer y comprender lo que ocurre en una experiencia no formal, no escolarizada, autoiniciada y de interacción a través de las TIC, con mujeres que pertenecen a un grupo étnico definido y a un contexto geográfico concreto Para ello se aborda el intercambio y reconstrucción de significados entre las participantes a partir del intercambio y decodificación de mensajes; por ello se rescatan los propios textos de los participantes, entre otras técnicas de recogida de datos, para entender y reconstruir esa realidad. Previamente, se justifica y plantea el diseño y las estrategias didácticas propuestas, desarrollándolo, posteriormente, en la comunidad de aprendizaje virtual conformada por las mujeres gitanas participantes en una acción formativa online sobre la temática de la igualdad de género, la dinamización y el liderazgo social. Durante el proceso de aplicación se va validando el diseño pedagógico según la perspectiva teórica propuesta, a la vez que estudiamos el contexto mismo de aplicación. Con la finalidad de lograr este propósito, se realiza un estudio de caso virtual de corte etnográfico, desde la aproximación cualitativa del trabajo de campo, por un lado desde análisis de contenido y por otro desde la triangulación de datos.

En este estudio, la investigadora puede definirse como una observadora permanente y participativa cuyo interés en el tema de investigación surgió como resultado de un proceso de reflexión derivado de su práctica profesional, en el trabajo con mujeres gitanas, de los cuestionamientos surgidos durante el proceso de aprendizaje en los cursos de doctorado «Procesos de Formación en Espacios Virtuales» y de los comienzos, como 
miembro del Grupo de Investigación «Nodo Educativo». La investigadora, en este sentido, forma parte del contexto y del escenario en el cual se desarrolla la investigación, participando con las funciones de dinamizadora en la acción formativa y en algunos de los foros estudiados realizando funciones de profesora-tutora del grupo de participantes, lo que, de acuerdo con Schön (1998), sirve como instrumento de reflexión sobre la práctica misma y aporta la experiencia de conocer el mundo que se estudia, lo cual abre la opción de considerar este trabajo cómo un proceso de investigación-acción. Debido a que he formado parte del proyecto como dinamizadora y profesora-tutora, mi presencia no ha sido intrusiva, sino que las participantes tomaron como algo cotidiano mi labor en el desarrollo de la experiencia. En este caso se cumple un elemento indispensable para asegurar la validez de los estudios cualitativos: la observación persistente, que se refiere más que al concepto de tiempo, al de profundidad, a fin de distinguir las características relevantes de las que no lo son.

El desarrollo actual de investigaciones cualitativas en relación con las TIC y los espacios virtuales como lugares de interacción y de comunicación, nos permite determinar diferentes enfoques de la metodología cualitativa en estudios concretos, sus límites y sus posibilidades. En nuestro caso, situándonos en el eje central que ocupa la investigación, esta tesis está ligada concretamente al paradigma de la Investigación-Acción (IA), utilizando como apoyo el método del estudio de caso trasladado a la virtualidad, tomando el ciberespacio como campo de estudio (Hine, 2000; Olsson, 2000; Domínguez, 2007). En este sentido tendremos que reformular y adaptar algunas técnicas (Hine, 2000) por las características propias del campo de estudio -etnografía virtualizada o en línea (Ardèvol et al., 2003)-.

Para esta metodología, además de reformular y adaptar las técnicas al ámbito de la virtualidad, y plantear instrumentos de recogida de datos para cada objetivo, se ha procedido a la codificación e interpretación de los mismos, utilizando como técnica la categorización (comparación en base a la 
categorización). Desde esta aproximación metodológica, como nuestro referente conceptual, en el campo de la investigación-acción, aplicamos algunas de las técnicas asociadas a esta metodología, adaptadas, como hemos indicado, al espacio virtual:

- Observación Participante: periférica (Lave y Wenger, 1991), periféricaplena y participación plena, a través de la grabación automática de datos en el entorno virtual (Campus Virtual de la Universidad de Extremadura). Al desarrollar uno de los estudios de manera virtual, las interacciones y comunicaciones entre las mujeres participantes en la formación quedan recogidas automáticamente a través del espacio virtual de formación.

- Entrevistas, semiestructuradas y en profundidad, en modalidad presencial (Taylor y Bodgan, 1987) y online (Ardèvol et al., 2003) al profesorado-tutor.

- Cuestionario de evaluación de las estudiantes.

- Grupo de discusión comunicativo (Flecha, Vargas y Dávila, 2004) con participantes posterior a la realización del curso.

La literatura sobre el paradigma de investigación-acción es bastante amplia y en crecimiento, sobre todo desde el punto de vista educativo, entre autores más destacados aparecen los trabajos de Carr y Kemmis (1988), Kemmis y McTaggart (1988); Elliott (1990), McKernan (2001); Latorre (2003); y actualmente, Kemmis (2009). Kember y Gow (1992) realizan en los años noventa una revisión histórica, hasta el momento, de la investigaciónacción, comenzando por Lewin (1946) que la conceptualiza como un proceso de investigación orientado al cambio social, caracterizado por una participación activa y democrática en la toma de decisiones. Estos autores resaltan que los trabajos de Lewin fueron los que condujeron a la adopción de este paradigma en el campo educativo, siendo posteriormente Stenhouse 
(1985) el que favorece la adopción de la misma en la educación con el avance de la idea de docentes como investigadores. Carr y Kemmis (1988) son los que aportan la base teórica a la investigación-acción, apoyados en el concepto de ciencia crítica desarrollado por Habermas (2001a, 2001b). Estos autores continúan los trabajos aplicando la investigación-acción al campo del desarrollo curricular, de los profesionales y de la mejora de los programas y las políticas educativas. Posteriormente, se destacan trabajos específicos dirigidos a mejorar las prácticas y programas educativos (Wals y Alblas, 1997; Robottom y Colquhoun, 1992), a la formación del profesorado (Hunsaker y Johnston, 1992), a la IA como instrumento de cambio educativo (Dana, 1995), sobre problemas implicados en la colaboración (Miller y Martens, 1990; Miller, 1992), o la influencia del proceso de colaboración en el trabajo del grupo (Smulyan, 1988; Suárez, 1998). Waterman et al. (2001) define la investigación-acción como una metodología que describe, interpreta y explica las situaciones sociales, interviniendo en ella para dar un cambio destinado a la mejora y la participación. En este sentido, la investigación se convierte en una actividad fundada en la colaboración entre investigadores, las personas participantes y la acción, todos ellos están involucrados en el proceso de cambio. De este modo, hemos incorporado a nuestra investigación el diálogo igualitario (Aubert et al., 2008), basado en pretensiones de validez de todas las argumentaciones, independientemente del rol que se desempeñe. De esta forma, se puede detectar y describir con más matices los elementos de análisis del contexto social y contribuir a su transformación. Todas las argumentaciones son útiles para la investigación, reconociendo la subjetividad de los actores sociales que forman parte de los procesos de interpretación (Habermas, 2001a).

La investigación acción, de este modo, es una tipología de investigación que muestra una creciente consolidación entre los y las profesionales del campo educativo y social en la actualidad, incorporándose, además a una progresiva reflexión académica, no sólo en prácticas docentes, sino en 
publicaciones científicas. Como recoge Martí (2008) se percibe el creciente aumento del número de artículos registrados en el «Social Science Citation Index» bajo el tópico «action research»: 100 artículos anuales en 1999 que se incrementaron a 167 anuales en 2007. En el año 2010 fueron 493 artículos y en $2011^{82}$ ya van 307 documentos que recogen estos términos. En la base de datos ERIC (Education Resources Information Center), actualmente aparecen 23.190 registros con este tópico ${ }^{83}$.

Según Ander-Egg (1995) existen muchas maneras de hacer investigaciónacción. Se trata de un paradigma de investigación que abarca una variedad de enfoques y en el cual hay varias metodologías establecidas. Algunos ejemplos son los planteamientos epistemológicos de Patton (1990) desde un enfoque evaluativo; Checkland (1981) desde el análisis de sistemas blandos; Argyris, Putnam y Smith (1985), con los cuestionamientos sobre la ciencia de la acción; y Carr y Kemmis (1988) con la denominada investigación-acción crítica. Cada una de estas metodologías se basa en una serie de métodos para la recolección de información e interpretación, entre los que se encuentran las entrevistas y análisis de contenido. En base a estas tres líneas, paradigmametodología-métodos, en el seno de la investigación-acción, se opta por la investigación-acción participativa (Carr y Kemmis, 1988; Kemmis y McTaggart, 1988), desde la concepción de la transformación y el cambio (Cox, Erlich, Rothman y Tropman, 1987) apoyada con el método del Estudio de Caso (Martínez y Musitu, 1995; Stake, 1998; Vázquez y Angulo, 2003). El estudio de casos se utiliza para obtener una comprensión en profundidad de una situación y de su significado para todos los agentes implicados en ella. El interés se pone en el desarrollo del proceso, en el contexto, más que en una variable específica, es decir, la estrategia de indagación se caracteriza por tratar de interpretar el fenómeno en el contexto en el que tiene lugar (Cronbach, 1975), enfocándose en descripciones y explicaciones holísticas. Los estudios de casos se basan en descripciones y análisis en profundidad de

82 Búsqueda actualizada a Octubre de 2011.

$8_{3} \quad$ Búsqueda actualizada a Octubre de 2011. 
unidades simples o de sistemas delimitados (Smith, 1978) tales como un individuo, un programa, un acontecimiento, un grupo, una intervención, o una comunidad.

Merrian (1988) caracteriza el estudio de caso como particularista, puesto que se enfoca a una situación, acontecimiento o fenómeno concreto; descriptivo, pues pretende una descripción rica y densa del objeto de estudio; heurística, porque muestra al investigador una comprensión global del fenómeno estudiado, dando lugar al descubrimiento de nuevos significados, a ampliar la experiencia o a confirmar algo que sabe (Latorre, 2003); e inductivo, porque llega a generalizaciones, conceptos o hipótesis a través de procedimientos de carácter inductivo, caracterizándose más por el descubrimiento de nuevas relaciones y conceptos que por verificación de hipótesis predeterminadas.

Teniendo en cuenta lo anterior, el diseño que delimita la estructura de esta Tesis parte de esa metodología siguiendo las bases de la InvestigaciónAcción (IA). La IA se concibe como una forma de estudiar, de explorar una situación social y educativa con la finalidad de mejorarla en la que participan las personas implicadas en la realidad investigada: «unifica la investigación, la mejora, la actuación y el desarrollo de las personas en su papel profesional» (Elliot, 1990:53). Así, la hipótesis o hipótesis de acción, en caso de recogerlas dentro de esta metodología de investigación, deben plantearse mediante un enunciado que relaciona el planteamiento del problema con una posible respuesta o acción pertinente para la resolución del mismo.

Carr y Kemmis (1988), argumentan que, para que una investigación pueda considerarse como IA se deben dar tres condiciones: que el proyecto sea planteado como una práctica social susceptible de mejora, que ese proyecto avance según los ciclos de planeamiento, acción, observación y reflexión y que se implique a todas la personas que participan en esa práctica, manteniendo un control colaborativo de todo el proceso de investigación. 
Además de todo lo expuesto anteriormente, unimos otras razones de la elección de esta tipología de investigación. Desde nuestro punto de vista, consideramos que es un tipo de investigación que se integra fácilmente en la práctica, se presta al uso en situaciones de trabajo y comunidad, ya que los profesionales y las personas implicadas trabajan como sus propios agentes de cambio en actividades normalizadas diariamente. Por otro lado, el ciclo de investigación-acción puede ser considerado como un ciclo de aprendizaje (Kolb, 1984). Schön $(1983,1987)$ argumenta que la reflexión sistemática es una manera eficaz de aprendizaje para los profesionales. Como perspectiva de conjunto, la IA

\begin{abstract}
«nos permite dar una justificación razonada de nuestra labor educativa ante otras personas porque podemos mostrar de qué modo las pruebas que hemos obtenido y la reflexión crítica que hemos llevado a cabo nos han ayudado a crear una argumentación desarrollada, comprobada y examinada críticamente a favor de lo que hacemos» (Kemmis y McTaggart, 1988: 34).
\end{abstract}

Con el paso del tiempo, el tratamiento que se ha hecho de los planteamientos de la investigación-acción participativa ha ido reconstruyéndose según las transformaciones contextuales en que se insertan los investigadores e investigadoras que la utilizan. No obstante, se han mantenido tres elementos centrales o claves: a) ser una metodología para el cambio; b) fomentar la participación y autodeterminación da las personas que la utilizan, y c) ser la expresión de la relación dialéctica entre conocimiento y acción.

El trabajo que presentamos bajo el marco de la investigación-acción participativa pretende generar un conocimiento (acción) que sea compartido por los miembros de la comunidad estudiada y que sirva a las participantes para actuar en sus propios entornos. Es decir, pretende mostrar unos resultados que son, en sí mismos, el cambio y el aprendizaje de las personas que participan y además, busca ser transferible, proponiendo unas 
conclusiones y una prospectiva, en base al análisis de los datos, que puedan servir como recomendaciones de mejora para diseñar, implementar y evaluar acciones formativas virtuales con la finalidad de conformar Comunidades de Práctica. En este sentido partimos de una doble concepción, la primera de entender el trabajo de investigación como una intervención en un marco local de investigación, y la segunda, tratar de generar un conocimiento científico y profesional.

Así, planteamos la investigación como un proyecto propio derivado de la práctica profesional de la propia investigadora para introducir el método y la reflexión, intentando promover un cambio en el entorno, es decir, la investigadora se sitúa en el posicionamiento en el cual se investiga su propia práctica para mejorarla. Pero también se pretende introducir, más globalmente, una reflexión externa y teórica desde el proceso de investigación acción participativa en su conjunto. De este modo, a la vez que establecemos un nuevo conocimiento científico, devolvemos a la comunidad los aprendizajes que se derivan de la propia investigación.

Blández (2000) define las características generales que tiene un proceso metodológico de investigación-acción en el ámbito educativo. En primer lugar debe ser colectiva, es decir, que requiere de un grupo de trabajo que se implique y comparta las inquietudes y quiera mejorar la práctica profesional. Una segunda característica es la de provocar el encuentro entre la teoría (lo que se piensa) y la práctica (lo que se hace). La tercera característica la define como ecológica, porque se desarrolla en escenarios naturales, reflexionando sobre esa realidad, haciendo a las personas implicadas en el objeto de investigación partícipes del mismo. Como cuarta, se establece la flexibilidad en el desarrollo de la investigación. Una característica más es la creatividad pues siempre se parte de la capacidad de imaginación del grupo. El dinamismo es la siguiente característica, ya que es un proceso inmerso en una dinámica ligada a la práctica que nos compromete con el tiempo y no nos permite pausar el proceso. También es formativa, ya que es, 
simultáneamente, proceso de investigación y proceso de aprendizaje, transformación y concienciación sobre la propia práctica, cuestión que incide en el propio desarrollo profesional. Y por último, es crítica, pues fomenta la actitud crítica ante un proceso, analizándolo, profundizando en la forma de proceder, emitiendo juicios, entre otros.

La IA se estructura en varios ciclos o etapas de investigación, que quedan representadas como se observa en la figura.

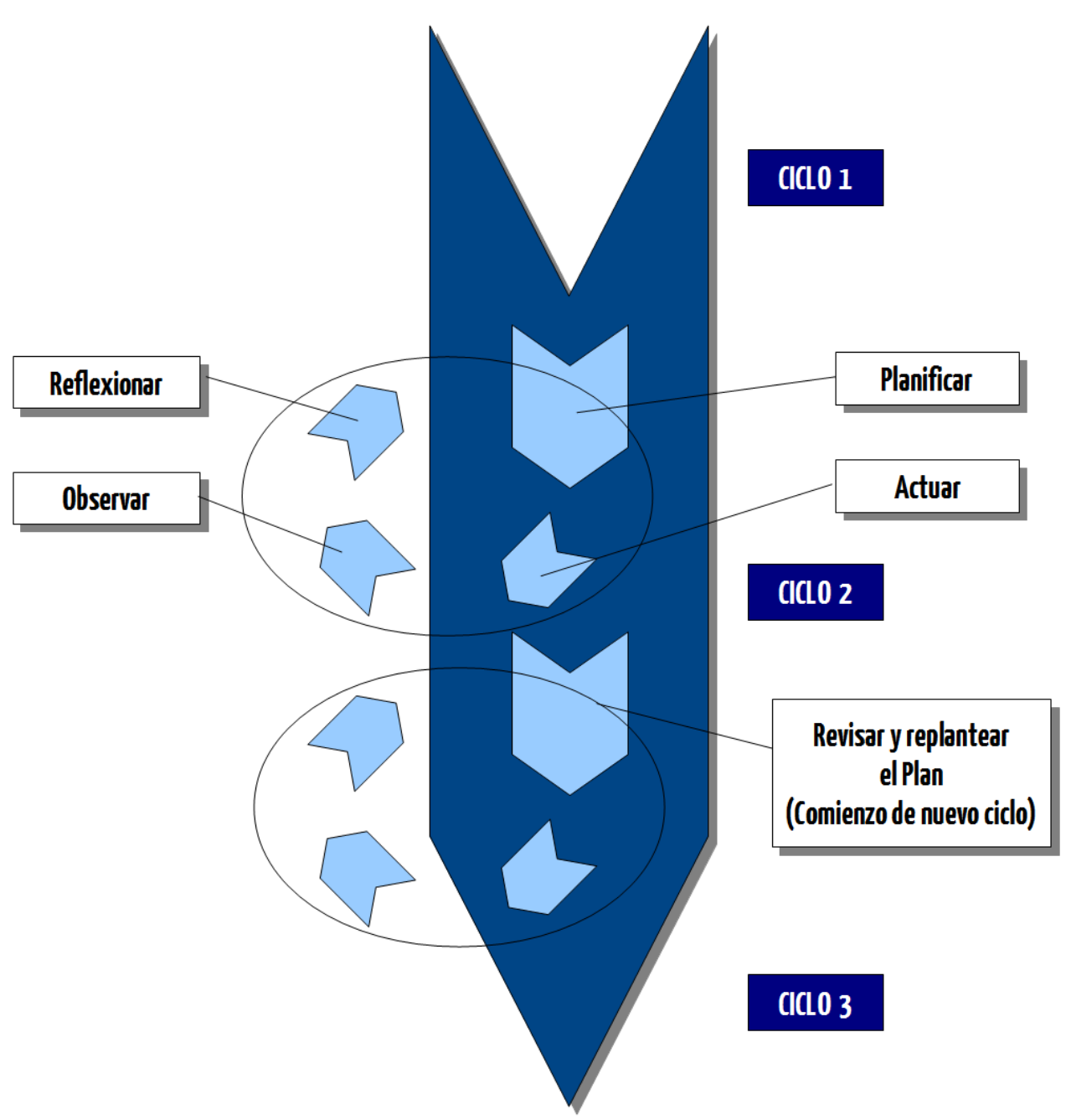

Figura 19. Proceso Cíclico de la investigación-acción (basado en Carr y Kemmis, 1988) 
Según este modelo se cuenta con cuatros momentos clave en el proceso, estrechamente interrelacionados: fase de planificación, fase de acción, fase de observación y fase de reflexión (planificar, actuar, observar y reflexionar), generando esta última un nuevo ciclo de investigación. En un primer lugar, se determina la preocupación temática sobre la que se va a investigar, identificando problemas de la propia práctica que pueden ser resueltos a través de soluciones también prácticas. Ahí comienza una primera reflexión con preguntas acerca del origen y evolución de la situación, intentando comprender lo que estamos haciendo y cuáles podrían ser los obstáculos de nuestra propuesta de cambio. La planificación es la especificación de un plan general que debe contar con flexibilidad para poder incorporar aspectos no previstos en el transcurso de la investigación, y donde debe describirse la situación, el funcionamiento del grupo, delimitar los objetivos, el plan de acción, cómo se va a relacionar el grupo de investigación con otras personas implicadas o interesadas en los cambios esperados y determinar cómo se van a controlar las mejoras generadas por la investigación. La observación y la acción es la puesta en práctica de ese plan, la acción observada sobre el desarrollo del mismo y, por tanto, constituye la etapa de recogida de datos. Por último, la fase reflexiva se caracteriza por el análisis, interpretación de la información recogida y el establecimiento de resultados y conclusiones.

Los resultados de nuestro trabajo deben presentarse a modo de preguntas de acción futura, en el sentido que Elliott (1990) le confiere a ese término, entendido como una invitación a explorar los límites dentro de los cuales el significado atribuido a un hecho o proceso determinado podría generalizarse a situaciones propias. En este sentido son de máxima importancia la calidad de los procesos que se hayan generado. 


\subsubsection{Rigor científico en la metodología de investigación}

En el campo de la investigación-acción no existe ningún paradigma totalmente estructurado. Existen sólo algunos principios generales de todo el proceso: éste es visto como una acción social (una intervención) y como un proceso de aprendizaje. Al no existir un núcleo propio de principios metodológicos y una epistemología clara que guíen las diversificadas acciones y prácticas investigativas, es muy cuestionado el tema del rigor científico.

Debido al carácter divergente y heurístico de esta metodología de investigación, debemos avalar el procedimiento con unos parámetros que garanticen su rigor científico. Reason y Bradbury (2006) debaten la necesidad de contar con criterios de validez ya que parece existir una incompatibilidad entre su comprensión y esta metodología de investigación. Así, autores y autoras que trabajan en la línea de la investigación-acción defienden la posibilidad de garantizar el rigor científico en los procesos de investigación. Para ello se sugieren la aplicación de procesos holísticos, tendiendo en cuenta la profundidad y la complejidad de la información, usando diversas fuentes, y sobre todo, mostrando las transformaciones reales producidas, tanto en ideas, como en la práctica o en el contexto (Elliott, 1990).

El que la muestra seleccionada para la investigación, como explicaremos a continuación, no se haya sometido a un procedimiento de muestreo estadístico, ya que se toma el escenario natural de práctica que se va a llevar a cabo, hace que la misma sea una muestra incidental o causal, es decir, elegida por el fácil acceso de la investigadora, formando parte del grupo con el que se trabaja habitualmente. Esto hace que ésta no sea estadísticamente representativa, con vistas a obtener resultados generalizables a otras muestras (otros contextos formativos) de la misma población (es este caso, mujeres gitanas). En consecuencia, los resultados obtenidos del proceso de IA carecerían de validez externa, es decir, sus resultados sólo son aplicables a 
una determinada situación educativa, ya que se desarrolla en un contexto social y espacio-temporal muy específico y sus características pueden no ser válidas para otras situaciones. Sin embargo, desde los resultados, observaremos que podemos realizar una determinada transferencia de conocimientos que pueden adaptarse a otros contextos. Autores como Wals y Alblas (1997) establecen una concepción denominada «generalización naturalista», mediante la cual un lector o lectora puede generalizar o no generalizar los resultados de la investigación a su propia situación o contexto específico, y, en todo caso, puede ampliar su comprensión sobre el objeto de estudio. Teniendo en cuenta todo ello, se describen minuciosamente las posibles peculiaridades del escenario en el que se ha desarrollado la experiencia, de las personas implicadas, de sus rasgos distintivos y características socioculturales y del proceso que hemos llevado a cabo. En referencia a la validez interna, se determina por los instrumentos de recogida de datos y por las herramientas utilizadas en el contraste de la hipótesis. Para mostrarla, se exponen y estudian los acontecimientos producidos en el proceso, recogemos los cambios que se van efectuando en las personas implicadas y usamos la triangulación, ofreciendo diferentes perspectivas de los hechos. También justificamos los instrumentos utilizados, haciendo referencia a las investigaciones previas y las fuentes de referencia. La validez, en este sentido, avala la calidad de la investigación, dándola consistencia y firmeza.

Pérez (1990), en referencia a la fiabilidad, afirma que no puede existir una fiabilidad perfecta por la propia complejidad del fenómeno investigado y por la idiosincrasia del mismo. La fiabilidad interna se presenta cuando las participantes coinciden en la descripción de los hechos. Para asegurarnos esa fiabilidad contrastamos los datos entre agentes participantes a través de diferentes instrumentos y grabamos y transcribimos los datos que se recogen. La fiabilidad externa, sin embargo, se produce cuando en una investigación no puede ser replicado su desarrollo. Para asegurar hemos elegido y 
justificado los métodos de recogida y análisis de datos, utilizando diversos instrumentos que nos ofrecen la mayor cantidad de datos posibles con respecto a la propia investigación teniendo en cuenta el contexto especificado. Por otro lado, hemos establecido el rol de investigador y explicitamos, más adelante, el código ético de esta tipología de investigación.

Nos interesa remarcar, así mismo, los criterios que dan rigor al proceso de investigación y que también apoyan la fiabilidad y la validez de la misma. Tal y como resume Guba (1983), las preocupaciones principales son el valor de la verdad o veracidad, la aplicabilidad, la consistencia y la neutralidad.

\begin{tabular}{ccc}
\hline Aspecto & Término científico & Término naturalístico \\
\hline Valor de verdad & Validez interna & Credibilidad \\
\hline Aplicabilidad & $\begin{array}{c}\text { Validez externa } \\
\text { Generalizabilidad }\end{array}$ & Transferibilidad \\
\hline Consistencia & Fiabilidad & Dependencia \\
\hline Neutralidad & Objetividad & Confirmabilidad \\
\hline
\end{tabular}

Tabla 3. Términos Racionalistas y Naturalistas apropiados para los cuatro aspectos de credibilidad (Guba, 1983:153)

Tanto en la investigación cualitativa como en la cuantitativa, podemos decir que existen mecanismos de autorregulación que permiten la evaluación de la calidad del proceso de investigación. En el caso de la cualitativa, y de la IA de forma concreta, los criterios generales de validez y fiabilidad son difícilmente aplicables a una IA. En este sentido, varios autores (Denzin y Lincoln, 1994; Guba y Lincoln, 1994) establecen el valor de verdad a través de la credibilidad, la aplicabilidad a través de la transferibilidad, la consistencia a través de la dependencia y la neutralidad a través de la confirmabilidad, cuya relación se refleja en la tabla anterior.

Comenzando por la credibilidad, pretende mostrar que la investigación se ha realizado de forma pertinente, garantizando que el tema se ha identificado y descrito con exactitud. Según Guba (1983) hay varios procedimientos que 
permiten asegurarla: a) el trabajo persistente, que permite al observador comprobar los prejuicios propios y de los estudiantes a fin de concretar la investigación y aportarle mayor verosimilitud; b) la triangulación, que permite comparar y someter a contraste la información sobre una situación educativa observada desde distintas perspectivas; c) el intercambio de opiniones con otros investigadores expertos; d) la recogida de material referencial como pueden ser vídeos, documentos o grabaciones, con el propósito de hacer una comparación con el desarrollo de nuestra investigación; y, por último, e) las comprobaciones con los participantes que tienen por objeto evitar errores y conseguir más información sobre los puntos oscuros de la investigación, llevando a cabo revisiones y comprobaciones con los estudiantes observados. Para garantizarla en nuestro estudio se ha utilizado:

- La recogida de datos a través del entorno virtual de trabajo durante todo el proceso (desde el comienzo hasta la finalización de la acción formativa).

- Se ha contado con expertos que han verificado y avalado la pertinencia del diseño pedagógico y posterior evaluación de la aplicación del mismo.

- Se ha utilizado la triangulación de datos aplicando diferentes técnicas y en diferentes contextos y tiempos a los agentes implicados en la acción formativa.

- Juicio crítico de expertos, que consistió en someter a valoración de otras y otros investigadores el desarrollo de la acción, así como la pertinencia en la aplicación del modelo de estrategias didácticas, afrontando cualquier cuestión que pudiera plantearse.

La transferibilidad es la medida en la que los resultados y conclusiones de un estudio pueden aplicarse a otros estudios, a la posibilidad de aplicar los 
descubrimientos a otros contextos (Guba y Lincoln, 1994). En la IA, Elliott (1990) establece que los resultados obtenidos en un estudio de caso, en lugar de intentar aplicarlos literalmente a otras situaciones educativas, deben ser considerados como fuente de reflexión y orientación para que otros y otras profesionales planteen sus propias investigaciones prácticas con sus estudiantes. En el caso de nuestro estudio, no podemos realizar una generalización, como en el caso de estudios positivistas, sino que las ideas que se van a obtener de nuestros resultados, van dirigidas a mejorar la calidad de acción (Pérez, 1994). Como estrategias para asegurar, al menos, la transferibilidad de esos conocimientos obtenidos de los resultados, se utilizó la recogida de abundante información, a través del espacio virtual, contando con todos y todas las agentes participantes en la acción formativa, utilizando grabaciones en audio y video en toda la recogida de datos. Además, se llevaron a cabo grabaciones en video durante las sesiones presenciales. Por otra parte, la presencia de la investigadora como parte activa del proceso le permitió recabar aún más información.

La dependencia de la investigación se refiere al grado en que se repetirían los resultados en caso de volver a replicarse la investigación y es una limitación en cualquier estudio cualitativo, dado que es imposible replicar las personas, los lugares y los acontecimientos de un estudio cualitativo. Guba (1983) determina como criterios para asegurarla el establecimiento de medios para revisar los procedimientos seguidos, revisar el proceso de investigación por investigadores/as externos y la aplicación de métodos solapados, donde se emplean varios métodos y procedimientos en la recogida de información a fin de tener diferentes perspectivas en el análisis de los datos. Para garantizar la dependencia en nuestra investigación, hemos establecido todo el proceso llevado a cabo remarcando el rol de la investigadora y el código deontológico, además de explicitar las limitaciones de la investigación. De esta forma, describimos minuciosamente los procesos, identificación y descripción de las técnicas de análisis y obtención de la 
información y hemos delimitado el contexto físico, social e interpersonal de la investigación.

La confirmabilidad consiste en confirmar la información, la interpretación de los significados y la generación de conclusiones. Este criterio se refiere a la comprobación del posible sesgo de los resultados de la investigación por motivaciones, intereses o perspectivas del investigador/a (Guba, 1983). Esto se valida a través de registros concretos de datos, transcripciones textuales, citas directas de fuentes documentales; revisión de los hallazgos con otros investigadores; y recogida mecánica de datos mediante grabaciones en video y audio. Para garantizarla, en nuestro estudio utilizamos el ejercicio de reflexión, dando a conocer explícitamente los supuestos epistemológicos subyacentes que llevaron a la investigadora a plantear y orientar la investigación, cuyas fases metodológicas se han descrito en detalle. Hemos utilizado, como indicamos anteriormente, la triangulación de datos, además de las transcripciones y citas textuales proporcionadas por los y las informantes y la recogida mecánica de datos mediante grabaciones de audio y video, y mediante el entorno virtual de trabajo dependiendo de la técnica aplicada.

\subsubsection{Cuestión ética en la metodología de investigación}

La cuestión ética en la investigación-acción han sido abordados por diversos autores entre los que destacan Morton (1999), Walker y Haslett (2002), Coghlan y Shani (2005), Buendía y Berrocal (2001), entre otros.

En el estudio de Buendía y Berrocal (2001) se afirma que en la mayoría de la bibliografía consultada aparecen cuatro problemas éticos fundamentales: ocultar a los participantes la naturaleza de la investigación o hacerles participar sin que lo sepan, exponerlos a actos que podrían perjudicarles o disminuir su propia estimación, invadir su intimidad y privar a los participantes de los beneficios que se obtengan de la misma. 
Para ayudar a establecer los principios éticos McKernan (2001: 262) establece una serie de cuestionamientos, referidos a la investigación-acción educativa que integran los establecidos por Kemmis y McTaggart (1988) y que la investigadora ha tenido en cuenta:

1. Todos las personas afectadas por una investigación-acción tienen derecho a ser informadas, consultadas y aconsejadas acerca del objeto de la investigación. El «equipo asesor», especialmente la investigadora, ha explicado el objeto de la investigación, las finalidades y las cuestiones éticas de la misma y ha respondido a todas las cuestiones de las personas implicadas en la investigación.

2. La investigación-acción no debe seguir adelante a menos que se haya obtenido un permiso de las personas implicadas. Se ha obtenido permiso por escrito de todas las mujeres participantes, del uso de los datos y material fotográfico y audiovisual recogido para las finalidades propias del estudio y su difusión.

3. Ningún participante individual tiene derecho unilateral a vetar el contenido del informe de un proyecto.

4. La pruebas documentales, como los archivos, la correspondencia y objetos semejantes, no se deben examinar sin permiso oficial.

5. Se debe observar siempre estrictamente la ley de la propiedad intelectual.

6. La investigadora es responsable de la confidencialidad de los datos.

7. La investigadora está obligada a llevar registros eficientes del proyecto y a ponerlos a disposición de las personas implicadas y autoridades cuando así lo soliciten. 
8. La investigadora es responsable ante la comunidad y los agentes que toman parte del proyecto.

9. La investigadora es responsable de comunicar el progreso del proyecto a intervalos periódicos. Este criterio ayudará también a satisfacer la necesidad de evaluación continua para determinar nuevas líneas de interés y la redefinición del problema.

10. No se debe emprender una investigación que pueda causar daño físico o mental a cualquiera de los sujetos implicados.

11. La investigadora tiene derecho a comunicar el proyecto completo.

12. La investigadora debe dar a conocer los criterios éticos contractuales a todas las personas implicadas.

13. Los investigadores e investigadora tienen derecho a que su nombre figure en cualquier publicación que resulte del proyecto.

Estos principios han sido dados a conocer a todas las personas participantes en la investigación, que mostraron su acuerdo con los mismos antes de comenzar el trabajo.

\subsection{Problemática de partida y objetivos de la investigación}

El problema central de esta investigación viene determinado por la práctica profesional. Nos situamos en el contexto del trabajo de la investigadora en el seno de una entidad social, Fundación Secretariado Gitano, en un región concreta, Extremadura. 
Dentro de esta entidad, que tiene como finalidad la promoción social del pueblo gitano, se trabaja en varias áreas entre las que destaca el área de Igualdad de Género. Aunque los objetivos estratégicos se establecen desde el área en su unidad central, ubicada en Madrid, estos objetivos se adaptan al contexto específico donde se planifican y desarrollan las intervenciones. En la unidad central se cuenta con la participación del denominado GMG -Grupo de Mujeres Gitanas- que consensúan y deciden sobre el camino de la entidad en las cuestiones por las que se ven afectadas las mujeres gitanas. Desde este marco el objetivo principal, desde la unidad central, era conformar un grupo de mujeres gitanas en cada Comunidad Autónoma para que participaran activamente en los movimientos relacionados con la igualdad de oportunidades y las mujeres en cada región. Ese objetivo podría considerarse la misión de cada territorio. La visión general, que va más allá, era hacer visible el movimiento gitano femenino desde su promoción sociocultural.

En la entidad en Extremadura, ya se nos había demandado por parte de mujeres gitanas usuarias, la realización de acciones de formación dirigidas a ellas mismas, encuentros formativos y de convivencia, entre otras actividades. Así se crea el proyecto e-Kalex en 2009 como una iniciativa innovadora de respuesta a las demandas y necesidades de las mujeres gitanas extremeñas, con un misión específica: conformar un grupo de mujeres gitanas que visibilicen y puedan ser representación del colectivo en la región. Si nos remontamos a los inicios del proyecto, de dónde surge esa idea, no sólo parte de lecturas científicas de la investigadora, sino también del trabajo conjunto con otras personas de la entidad mencionada. De este modo, para desarrollar el proyecto e.-Kalex, se establecieron espacios de diálogo con un equipo de trabajo conformado por personal de la entidad Fundación Secretariado Gitano (miembros del Grupo de Mujeres Gitanas de la FSG, dirección territorial de Extremadura y la investigadora) y una profesora del «Grupo Nodo Educativo» de la Universidad de Extremadura. Las funciones de este equipo son aportar conocimientos y reflexiones, revisar 
documentación, orientar sobre el desarrollo del proyecto, controlar que éste se desarrolle teniendo en cuenta todas las voces y valorar todo el proceso de investigación y las conclusiones, para que los resultados contribuyan a transformar la realidad de las mujeres gitanas participantes. De este modo, el proyecto surge desde las propias mujeres gitanas, que son quiénes reflexionan junto con la investigadora en todo el proceso.

Se consensuaron los primeros planteamientos del proyecto, entre los que se encontraba la contextualización de la acción. Para desarrollar la misión necesitábamos analizar el contexto de aplicación, no sólo desde un punto de vista profesional, sino también científico con el fin de que la práctica revirtiese en la investigación que se presenta. Así surge el marco teórico de la investigación y el primer objetivo:

Describir un marco teórico que sustente la investigación desde la perspectiva del e-learning social derivado de los planes, programas y estudios científicos actuales de índole europea, nacional y autonómica, además de las políticas sociales dirigidas a la población gitana.

Una vez analizado, descubrimos un paradigma sobre el que enmarcar el estudio y la misión, la teoría y la práctica: el e-learning social; y un contexto sobre el que desarrollar la misión: las políticas sociales dirigidas a la población gitana.

Una vez justificado el marco de sustento, nos pusimos en marcha, intentando conjugar las necesidades y demandas de las mujeres gitanas extremeñas con la misión encomendada por el área central. Ese, específicamente, fue nuestro primer problema, que aunque demandas y misión parecían conjugar adecuadamente, el contexto que nos encontramos no era tal. 
La principal problemática era la diversidad de perfiles de mujeres gitanas usuarias de la entidad: edades diversas, algunas con hijos e hijas y familiares a su cargo, trabajadoras, estudiantes, en situación de desempleo, además de la distancia geográfica, ya que sus domicilios están en diferentes puntos de la geografía extremeña.

¿Cómo adecuamos esos perfiles para cumplir nuestra misión?

Otra pregunta era la forma y enfoque que íbamos a asumir para lograr la misión.

¿Qué planteamiento o fórmula adoptamos para conformar ese grupo?

Tras un análisis de la situación en que nos encontrábamos, llegamos a varios acuerdos sobre la problemática:

- Las mujeres muestran una alta motivación, expectativas e interés en conformar el grupo, aprender cosas nuevas y conocer a otras mujeres gitanas.

- Estas mujeres tienen problemáticas concretas derivadas de la conciliación familiar y situaciones laborales diferentes, lo que hace que la disponibilidad de tiempo sea limitada.

Cuando conjugamos estas dos cuestiones vimos que una acción de formación a través de entornos virtuales sería una posible solución a todo lo anterior, pero a su vez, nos deparaba nuevos retos. Según los datos de los perfiles de las mujeres gitanas usuarias de la entidad, existe una escasa alfabetización digital, limitándose algunas al uso del ordenador a nivel básico. La posesión de equipación informática en el hogar es baja, al igual que el acceso a internet. Y además, ninguna de las mujeres gitanas usuarias ha realizado una acción formativa a distancia ni formación online. 
En una entrevista con un profesor de la Universidad de Extremadura para otras cuestiones, surge una conversación en referencia a la problemática de nuestra misión, proponiéndonos que la acción se desarrolle a través del Campus Virtual de una Universidad, por tanto, acceden a un lugar donde se cursan estudios superiores. Al llevar la propuesta al equipo, se valoraron ciertas oportunidades: novedad de la propuesta, virtualidad y flexibilidad horaria para el desarrollo de la acción formativa, posibilidad de contar con profesorado especialista con conocimiento del grupo al que se dirige y con experiencia en tutoría virtual. Además podríamos optar a una certificación oficial, emitida por la Universidad de Extremadura, del aprovechamiento de la acción de formación.

Consensuamos que, teniendo en cuenta las oportunidades, las dificultades podrían solventarse tomando la decisión de potenciar las fortalezas y oportunidades que teníamos e intentar paliar las amenazas y dificultades que podría suponernos el reto de desarrollar una acción formativa virtual con mujeres gitanas. Para potenciar las fortalezas y oportunidades, además de preparar un diseño pedagógico justificado bajo un marco científico por parte de la investigadora, íbamos a contar con profesorado preparado para el desarrollo de la acción formativa virtual. Decidimos, además, crear la figura de una persona dinamizadora que fomente y potencie todos los aspectos positivos que llevarían al éxito la acción formativa. Se establece que la investigadora debe ser la persona dinamizadora de la acción. Para paliar las debilidades y amenazas, además de contar con esa figura de dinamización que intentará disminuir estos factores a través de diferentes estrategias fundamentadas didácticamente, se tendrán en cuenta tres aspectos: adaptación del diseño pedagógico completo a las destinatarias de la acción, siendo éstas el punto central del mismo; flexibilidad de tiempos en el desarrollo, para que cada estudiante se pueda organizar los tiempos de estudio; y disponibilidad de ordenadores en préstamo con posibilidad de acceso guiado, de forma presencial, al espacio virtual de formación, a través 
de los centros de la entidad Fundación Secretariado Gitano en Extremadura y de personal de cada centro seleccionado para esta labor.

Nos quedaba por definir el enfoque a adoptar para la consecución de la misión. Tras una revisión profunda de la literatura por parte de la investigadora, propone al equipo el enfoque «Comunidad de Práctica».

De ahí surge el siguiente objetivo de la investigación:

Establecer el enfoque de «Comunidades de Práctica» (Wenger, 2oo1) como punto de llegada y medio de promoción social y cultural de las mujeres gitanas en entornos virtuales de aprendizaje.

A toda la problemática que nos encontramos con anterioridad se une la búsqueda de fondos para poder realizar el proyecto a través de los recursos y la certificación de la Universidad de Extremadura. Tras meses de negociación por diferentes entidades y administraciones, el Instituto de la Mujer de Extremadura financia el mismo.

Partiendo de la negociación y reflexión conjunta sobre el proceso a poner en marcha en la planificación de la acción formativa virtual, se identifica, por el equipo de trabajo un objetivo:

Diseñar, a través del trabajo en equipo multidisciplinar conformado por la investigadora y personas gitanas de la Fundación Secretariado Gitano, responsables de los programas de Mujer, Nuevas Tecnologías, Dirección Autonómica y Mujeres de la Región, una acción formativa virtual dirigida a capacitar en temáticas de igualdad de oportunidades y liderazgo social.

Para este objetivo se debe dar la condición fundamental de que tanto el proceso de diseño, como el desarrollo, se realice en interacción permanente 
con aquellas personas a quiénes se dirige o involucra en este proceso. Por eso, la concreción de esta acción no sólo debe ajustarse a las necesidades y demandas de las protagonistas, sino que es necesario dar sentido de «apropiación de la acción», como un elemento fundamental para aumentar las probabilidades de éxito en la propuesta. De ahí que, uno de los puntos clave del proceso sea la participación. Promover la apropiación del proceso es una tarea compleja y constante, no exenta de obstáculos. Por ello, determinamos mecanismos de seguimiento y respuesta ante los posibles inconvenientes que puedan surgir: la figura de la persona que dinamiza el proceso. Por otro lado se ve la necesidad de que la acción formativa sea de calidad mediante una fundamentación pedagógica del diseño, identificando aquellas metodologías y recursos didácticos que hayan ayudado a desarrollar prácticas de éxito e innovadoras con TIC.

Situamos como otro de los puntos clave la flexibilidad del proceso. Es necesario desarrollar un proceso suficientemente abierto para tener en cuenta futuros aspectos imprevistos vinculados, fundamentalmente, al contexto donde se va a desarrollar la acción. Esta característica debe estar presente a lo largo de todo el proceso, tanto de planificación como de desarrollo y evaluación de la acción.

Por último, necesitamos una sustentabilidad para la implementación de la acción. El proyecto se desarrolla en un contexto institucional que requiere satisfacer compromisos con diferentes organizaciones de carácter financieroeconómico, de gestión y de participación.

La opción por esta modalidad viene determinada, principalmente, por las destinatarias de la acción formativa, en referencia a varios aspectos:

- Localización geográfica de las participantes: esta formación se oferta para mujeres gitanas residentes en Extremadura. En este sentido, debemos optar por una modalidad no presencial en su mayor parte, 
pues si el proyecto completo se desarrollara de forma presencial no sería posible si tenemos en cuenta la perspectiva de género ${ }^{84}$.

- Oportunidad de la presencialidad. Se considera la necesidad de realizar tres talleres presenciales con el fin de facilitar a las participantes el conocimiento directo y el establecimiento de relaciones personales complementarios a los encuentros virtuales previos y/o posteriores. Si nuestra finalidad es conformar una Comunidad de Práctica, debemos potenciar, desde el primer momento, la «presencia social» (Garrison y Anderson, 2005). En este sentido, además, consideramos dos cuestiones (Barberà, 2008): desde los cursos presenciales incrementamos el tiempo de contacto, aumentando las posibilidades de interacción entre las estudiantes (virtual y presencial). Por otro lado, si la mirada se realiza desde un curso totalmente virtual, intentamos agilizar e incrementar la calidad de la interacción virtual, añadiendo espacios de relación cara a cara con las estudiantes.

La opción final, se establece como una modalidad semipresencial en la acción formativa, con un porcentaje de virtualidad bastante mayor que de presencialidad (6\% frente al 94\%). Atendiendo a este porcentaje de presencia de las TIC como vehículo educativo-comunicativo, se corresponde a un curso «con ascendente online» (Barberà, 2008), es decir, con alta presencia de las TIC (por encima del 50\%), de ahí la consideración de acción formativa virtual.

La población diana de la acción formativa virtual van a ser 20 mujeres gitanas extremeñas, vinculadas o no al mercado de trabajo, que realizan diversas actividades en pro del desarrollo de su comunidad, bien como parte de su trabajo remunerado o bien de modo voluntario. Su base se sustenta en una acción formativa virtual consensuada entre un equipo de trabajo

${ }^{84}$ Como veremos más adelante, en los datos recogidos en las entrevistas a docentes-tutores/as y a participantes, esta afirmación queda completamente demostrada. 
conformado por personal de la entidad Fundación Secretariado Gitano (miembros del Grupo de Mujeres Gitanas de la FSG, dirección territorial de Extremadura e investigadora), profesorado de la Universidad de Extremadura, y personal del Instituto de la Mujer de Extremadura. Esta acción se sitúa en el marco de la Universidad de Extremadura y en temáticas relacionadas con la igualdad de oportunidades entre hombres y mujeres y el empoderamiento y liderazgo social. La pretensión última de este proyecto es fortalecer el trabajo que ya realizan estas mujeres a nivel local, empoderarlas a nivel personal y abrirles nuevas puertas a su propia promoción. Todo ello, desde una perspectiva comunicativa del aprendizaje a través del espacios virtuales.

Se establece como unidad de análisis una Comunidad Virtual de Aprendizaje formada por un grupo de 20 mujeres gitanas de la Comunidad Autónoma de Extremadura

En este contexto encontramos el objetivo principal de la Tesis:

Estudiar la conformación de una Comunidad de Práctica de Mujeres Gitanas a través del diseño, desarrollo, implementación y evaluación de una práctica de e-learning enfocada desde una perspectiva social.

Para su logro, la primera labor es el desarrollo del diseño, que se concreta en el siguiente objetivo:

- Elaborar un diseño pedagógico para un curso elearning basado en los principios del constructivismo social, buscando dotar a las personas participantes en este curso de herramientas de capacitación necesarias para el diseño, desarrollo y evaluación de distintas dinámicas en torno al género, a la igualdad entre 
mujeres y hombres y a ejercer, de manera activa, el liderazgo social, estableciendo estrategias pedagógicas para su consecución basadas en la perspectiva mencionada.

Los siguientes objetivos se establecen en referencia a la evaluación de la acción en la consecución o no de la misión y responde a la pregunta: ¿hemos conformado la Comunidad de Práctica de Mujeres Gitanas? Para dar respuesta a la misma, se fijan los siguientes objetivos específicos que van a corresponderse con los tres estudios que se desarrollan a continuación en el trabajo de investigación:

- Desarrollar y evaluar este diseño en aplicación experimental en un grupo concreto de mujeres gitanas establecido con enfoque de «Comunidad de Práctica» situada en entornos virtuales de aprendizaje desde el modelo Comunidad de Indagación y el estudio de la presencial social, docente y cognitiva.

Ante el nuevo entorno de aprendizaje para las mujeres destinatarias y, teniendo en cuenta nuestra misión, se considera que debemos facilitar un ambiente de aprendizaje que las anime a la construcción conjunta de conocimiento apoyándose en la reflexión crítica y la interacción social. Si tomamos como referencia común los aprendizajes de las participantes, podemos considerar el espacio como una comunidad de aprendizaje facilitada a través de la virtualidad (Palloff y Pratt, 1999; McConnell, 2000). La investigación realizada en comunidades demuestra que el sentido de comunidad aumenta, no solamente la persistencia de los y las estudiantes en programas de formación virtuales, también enfatiza la necesidad de generar el sentido de «presencia social» en las comunidades virtuales, es decir, realza la importancia de la interacción a partir del flujo de información que va 
posibilitando el trabajo colaborativo, incrementando el sentimiento de cohesión social, lo cual es un elemento que puede ser clave para nuestra misión. Autores como Dede (1996), Wegerif (1998) y Wellman (1999) afirman que la sensación de comunidad entre las personas que aprenden disponen, implican y animan a asumir los riesgos que conlleva la tarea de aprender, y es por ello que el sentido de presencia social es clave en la comunidad y en la formación de la misma (Rovai, 2002; Garrison y Anderson, 2005). Por tanto, la formación de la Comunidad de Práctica va a requerir un sentido de «presencia social» entre las participantes. Así, el siguiente objetivo es:

- Valorar, en referencia a ese modelo, si el cultivo de la Comunidad de Práctica se ha producido.

Y por último:

- Validar el diseño pedagógico constructivista en el contexto de aplicación del mismo (Comunidad de Práctica) en un espacio formativo virtual, como es el campus virtual de la Universidad de Extremadura (UEx), a través de la evaluación de expertos externos y de los agentes participantes en la experiencia.

Podemos entender que el propio diseño de las estrategias pedagógicas es, en sí mismo, una hipótesis de investigación que reflejará y compilará en cada momento todas nuestras asunciones e hipótesis operativas sobre cómo debería ser el aprendizaje desde la perspectiva propuesta. En la medida en que este diseño se valide por expertos, se aplique, evalúe y estudie dentro del contexto de una Comunidad de Práctica establecida en entornos virtuales de formación, estaremos ante la validación más fiable de la componente estratégica de la investigación. 
Por otro lado, se considera fundamental para el logro de los objetivos trabajar en un plano de igualdad con las mujeres gitanas destinatarias, es decir, valoramos las aportaciones sobre la base de los argumentos y no por la posición ocupada por el hablante, propio del denominado «diálogo igualitario» (Aubert et al., 2008). 
Misión: Cultivar una Comunidad de Práctica a través de una acción formativa virtual dirigida a la promoción social y cultural de un grupo de mujeres gitanas.

Unidad de análisis una comunidad virtual de aprendizaje formada por un grupo de 20 mujeres gitanas de la Comunidad Autónoma de Extremadura.

Objetivo principal: Estudiar la conformación de una una Comunidad de Práctica de Mujeres Gitanas a través del diseño, desarrollo, implementación y evaluación de una práctica de e-learning enfocada desde una perspectiva social.

\section{Objetivos específicos:}

- Describir un marco teórico que sustente la investigación desde la perspectiva del e-learning social derivado de los planes, programas y estudios científicos actuales de índole europea, nacional y autonómica, además de las políticas sociales dirigidas a la población gitana.

- Establecer el enfoque de «Comunidades de Práctica» (Wenger, 2001) como punto de llegada y medio de promoción social y cultural de las mujeres gitanas en entornos virtuales de aprendizaje.

- Elaborar un diseño pedagógico para un curso e-learning basado en los principios del constructivismo social, buscando dotar a las personas participantes en este curso, de herramientas de capacitación necesarias para el diseño, desarrollo y evaluación de distintas dinámicas en torno al género, a la igualdad entre mujeres y hombres y a ejercer, de manera activa, el liderazgo social, estableciendo estrategias pedagógicas para su consecución basadas en la perspectiva mencionada.

- Desarrollar y evaluar este diseño en aplicación experimental en un grupo concreto de mujeres gitanas establecido con enfoque de «Comunidad de Práctica», situada en entornos virtuales de aprendizaje, desde el modelo Comunidad de Indagación y el estudio de la presencial social, docente y cognitiva.

- Valorar, en referencia a ese modelo, si el cultivo de la Comunidad de Práctica se ha producido.

- Validar el diseño pedagógico constructivista en el contexto de aplicación del mismo (Comunidad de Práctica) en un espacio formativo virtual, como es el campus virtual de la Universidad de Extremadura (UEx), a través de la evaluación de expertos externos y de los agentes participantes en la experiencia. 


\subsection{Informantes y sujetos del estudio.}

Mediante el marco teórico y la formulación de preguntas y objetivos ha quedado claro que estamos ante un problema de investigación. Es ahora el momento de obtener evidencia empírica para poder contrastar la hipótesis inicial y conseguir esos objetivos anteriormente mencionadas. Debemos explicar quienes serán los sujetos que participarán en este estudio con la intención de recoger datos útiles.

Como ya se ha indicado, la muestra del estudio no ha sido sometida a ningún muestreo estadístico y es una muestra incidental o causal (Buendía, Colás y Hernández, 2001). Ha sido elegida por la cercanía a la investigadora y porque es con quien desarrolla las intervenciones socioeducativas en la práctica profesional. Eso es un elemento clave, pues la investigadora posee una base sólida de conocimiento sobre la intervención con población gitana, que se ha ido adquiriendo mediante la experiencia profesional. Pese a ello, seguimos a León y Montero (2002) cuando indica que al menos debemos procurar tres características: representatividad, es decir que los sujetos participantes en esta investigación tienen que ser representativos para la finalidad de la misma; la idoneidad, en cuanto a que los y las participantes tienen que estar relacionados con los fenómenos que se intentan investigar; y la accesibilidad, en cuanto a que se deben tener en cuenta las limitaciones espacio temporales de la investigación. A pesar de que la muestra es causal, se cumplen los tres requisitos que estos autores recomiendan.

La unidad de análisis de esta investigación la constituye una comunidad virtual de aprendizaje formada por un grupo de 20 mujeres gitanas de la Comunidad Autónoma de Extremadura. Dicho esto, hay que tener en cuenta dos limitaciones fundamentales que ya se han comentado en cuanto a fiabilidad y validez: que la elección de la muestra se realizó por el fácil acceso de la investigadora, ya que son las mujeres interesadas en la acción 
formativa, y que la muestra no es representativa de toda la población gitana y de todas las mujeres gitanas, por lo tanto la generalización es más restrictiva. Pese a esto, como se ha indicado, se han ido buscando mecanismos de autorregulación metodológica y de evaluación de la calidad del proceso de investigación-acción participativa.

Los informantes clave son todos los agentes que participan en la acción formativa: el equipo asesor, el profesorado de las sesiones presenciales, el profesorado-tutor de las sesiones virtuales, las destinatarias de la acción y la propia investigadora como docente y dinamizadora. Además se ha contado con expertos externos a la propia investigación para validar la pertinencia del diseño pedagógico, antes y después de su desarrollo, y de los instrumentos creados. Todo lo que ocurre en el entorno virtual queda recogido a través del mismo, con lo que se tiene acceso durante todo el proceso a lo que ocurre dentro del mismo entorno de formación virtual. Es muy importante en la tipología de investigación que desarrollamos la participación de las personas destinatarias en la propia investigación y el haber obtenido su consentimiento, intentando además, que la participación de la investigadora se produzca en un plano de igualdad con el grupo que se establece.

Teniendo en cuenta lo anterior, tras el análisis de documentos realizado sobre las políticas y proyectos referidos al e-learning social y a la promoción social de la población gitana, así como la indagación sobre el enfoque de Comunidades de Práctica que se ha llevado a cabo y todas las propuestas pedagógicas que tienen relación con estas perspectivas, se ha desarrollado:

a) Un diseño completo, utilizando el modelo genérico ADDIE, referido a la acción formativa virtual. Este diseño, antes de redefinirse y aplicarse ha sido revisado por cuatro expertos y expertas, mediante una plantilla creada para el análisis (Anexo I). Estos y estas especialistas fueron: 
- Dr. Joaquín Paredes Labra. Profesor Titular de Universidad del Departamento de Didáctica y Teoría de la Educación de la Universidad Autónoma de Madrid.

- Dr. Antonio Víctor Martín García. Profesor Titular de Universidad del Departamento de Teoría e Historia de la Educación de la Universidad de Salamanca.

- Dra. Rocío Anguita Martínez. Profesora Titular de Escuela Universitaria del Departamento de Pedagogía de la Facultad de Educación de la Universidad de Valladolid .

- Dra. Prudencia Gutiérrez Esteban. Profesora Ayudante Doctora del Departamento de Ciencias de la Educación de la Universidad de Extremadura.

b) Se ha realizado un análisis interpretativo de lo sucedido en el entorno virtual de trabajo, a través de un análisis de contenido cualitativo partiendo de las dimensiones cognitiva, social y docente propuesta por el modelo «Comunidad de indagación» de Garrison y Anderson (2005). Este estudio ha permitido conocer si la Comunidad de Práctica se ha creado a través de la acción formativa. Las informantes en este caso, han sido tanto las estudiantes como el profesorado participante en los foros analizados.

c) Se ha evaluado, por parte de personas expertas externas, la pertinencia en la aplicación del diseño en torno al modelo pedagógico utilizado. Para ello se ha utilizado la herramienta A.D.E.C.U.R. Estos profesionales han sido:

- Dra. Laura Alonso. Profesora del Área de Teoría e Historia de la Educación del Departamento de Ciencias de la Educación de la Universidad de Extremadura. 
- Dr. Francisco Revuelta Domínguez. Profesor del Área de Didáctica y Organización Escolar del Departamento de Ciencias de la Educación de la Universidad de Extremadura.

- Dr. Eloy López Meneses. Profesor del Departamento de Ciencias Sociales de la Universidad Pablo de Olavide de Sevilla. Creador de la herramienta A.D.E.C.U.R.

d) Se han llevado a cabo 7 entrevistas en profundidad, tres realizadas presencialmente y cuatro realizadas mediante recursos de comunicación virtual al profesorado-tutor de la acción formativa. Dos de ellos eran tutores sólo presenciales, uno era tutor de un taller presencial y virtual y cuatro profesoras-tutoras de la parte virtual. La finalidad era obtener datos para la evaluación de la acción formativa y comprobar si ha sido pertinente el desarrollo del diseño pedagógico en varias dimensiones especificadas, que se presentan en el procedimiento para el análisis y tratamiento de los datos.

e) Para la misma finalidad se ha realizado un Grupo de Discusión con siete de las estudiantes que han participado en la acción formativa.

f) Para completar esa evaluación se ha pasado un cuestionario a las mujeres participantes en la acción formativa, contestado por 16 de las 20 estudiantes. Este cuestionario ha sido validado por la técnica del pretest y utilizando la evaluación externa de expertos, contando con:

- Dr. Marcelo Sánchez-Oro Sánchez, profesor Contratado Doctor del Área de Sociología del Departamento de Dirección de empresas y Sociología de la Universidad de Extremadura.

- Dña. Yolanda García García, profesora de Escuela Universitaria del del Área de Economía Financiera y Contabilidad del 
Departamento de Economía Financiera y Contabilidad de la Universidad de Extremadura.

- Pretest: tres mujeres de similares características a las participantes en la acción formativa.

\subsection{Instrumentos de recogida de datos}

Como hemos indicado, nuestra finalidad última es mejorar la práctica al tiempo que se mejora la comprensión que de ella se tiene y los contextos en los que se realiza (Carr y Kemmis, 1988), es decir, pretendemos mejorar acciones, ideas y contextos, lo que constituye un marco idóneo como puente de unión entre la teoría y la práctica, la acción y la reflexión. Para ello debemos recoger esas prácticas e ideas que van a ser objeto de estudio y de ellas se deben extraer evidencias, de un modo flexible y abierto: registrar lo que sucede y analizarlo mediante juicios de valor, impresiones, sentimientos, para lo cual resulta de utilidad que el proceso que analizamos se realice a través de entornos virtuales, donde todo queda registrado automáticamente. Por otro lado, consideramos que la investigación es participativa y colaboradora, estimulando la creación de una Comunidad de Práctica que tienen como meta la promoción sociocultural de las mujeres gitanas participantes.

Para la obtención de la información, debemos tener en cuenta una serie de cuestiones:

- Diferentes informantes de un mismo escenario de investigación: espacio virtual, profesorado, mujeres participantes. 
- Varias técnicas de recogida de información: espacio virtual, entrevistas en profundidad, cuestionario de evaluación y grupo de discusión.

- En este sentido, se ha trabajado con todas las fuentes de información que el estudio nos permitía. Debemos aclarar, en este sentido, que del «equipo asesor», dos mujeres participaron en el curso y otras dos eran docentes, por lo que también se ha recogido información de estas agentes.

Se detallan a continuación las técnicas e instrumentos utilizados en el proceso.

\subsubsection{Análisis documental y Plantilla de Evaluación del Diseño}

En esta fase se ha estudiado la contextualización teórica para realizar el diseño pedagógico de la acción formativa. Se identificaron, caracterizaron y compararon las fuentes y enfoques teóricos que los sustentan, llevando a cabo un análisis de fuentes documentales, que ha permitido la obtención de ideas e información fiable y actual, que justifican las opciones por las estrategias de aprendizaje más adecuadas y que se reflejan en el diseño de la acción formativa virtual. Para valorar la pertinencia del diseño inicial, se expone a juicio de cuatro expertos y expertas en la materia mediante una «Plantilla de Evaluación del Diseño para Expertos/as», que recoge cinco apartados de valoración: enfoque pedagógico, marco contextual, selección de estrategias didácticas (metodológicas, de motivación y de aprendizaje), diseño de la acción formativa e interactividad, soporte y elementos de comunicación (Anexo I). 


\subsubsection{Recogida datos en el Entorno Virtual de Aprendizaje.}

El entorno virtual de aprendizaje, a través de la plataforma Moodle y sus recursos, nos permite la obtención de datos contextualizados que pueden ayudarnos a comprender e interpretar el objetivo de estudio. Los foros virtuales, en nuestro caso, han constituido una fuente principal de recogida de datos. Minguez y Fuentes (2004) hacen referencia a que los foros sirven para recoger el intercambio de ideas y opiniones en la red. Por analogía, este tipo de recogida de datos podría equipararse a la técnica de observación permanente, ya que, en el caso del entorno virtual, todo queda recogido sistemáticamente: cuándo acceden, qué revisan y qué aportan.

\subsubsection{Entrevistas en profundidad.}

Las entrevistas en profundidad se basan en preguntas con respuesta abierta con la intención de obtener datos sobre los significados del profesorado. Este tipo de entrevistas no están sujetas a ninguna estructura formalizada de antemano, pero aún así, las entrevistas en profundidad nos han permitido obtener información a partir del establecimiento de un listado de temas. En nuestro caso, los elementos sobre los que hemos focalizado las entrevistas a los diferentes sujetos han sido las siguientes:

- Desarrollo general de la acción formativa.

- Desarrollo del tópico o tema/desarrollo del taller presencial.

- Tareas didácticas como tutor o tutora.

- Aspectos socioculturales de la acción formativa.

- Aspectos tecnológicos de la acción formativa. 
Partiendo de los objetivos planteados, debíamos indagar y profundizar en la visión del profesorado-tutor en relación a la pertinencia del desarrollo de la acción formativa para conocer su valoración.

Estas entrevistas pretenden acercarse a la ideas y supuestos mantenidos por las personas informantes, siendo lo realmente importante sus explicaciones (Rodríguez, Gil y García, 1996). La entrevista, en este sentido, se desarrolla a partir de cuestiones que persiguen reconstruir qué significa el problema de estudio para la persona entrevistada. Se han realizado en modo presencial a tres docentes y, a través de correo electrónico a cuatro docentes (Anexo I y Anexo VI). En el caso de las entrevistas virtuales (e-mail), debían programarse algunas preguntas que provocasen una respuesta lo más amplia posible, así que se idearon una seria de cuestiones abiertas relacionadas con los temas mencionados.

En definitiva, las entrevistas en profundidad nos han permitido conocer cómo el profesorado-tutor implicado ha valorado la acción formativa al completo, cómo la interpretan y cómo abordan esa evaluación. Esto nos va a posibilitar la valoración de la congruencia de los logros con los objetivos planteados en el diseño. Ese proceso de evaluación se va a realizar mediante la triangulación de datos, tanto los recogidos en el entorno virtual, como los resultantes de los cuestionarios y del grupo de discusión con las participantes.

Cabe reseñar que no es suficiente con recoger la información. La investigadora debe realizar una revisión y un análisis e interpretación posterior, para lo que debían quedar registradas las entrevistas presenciales. En este caso se han recogido con una grabadora para luego realizar las transcripciones con la finalidad del posterior análisis. Las que han sido virtuales, han quedado recogidas automáticamente. 


\subsubsection{Grupo de Discusión Comunicativo.}

Planteamos esta técnica de investigación cualitativa con el fin de profundizar y comprender, a través del diálogo y del debate, cuestiones centrales de la investigación, combinado con las demás técnicas de recogida de datos, y situándola en las últimas fases de la investigación como ayuda a la interpretación (Folch-Lyon y Trost, 1981). Al utilizar el grupo de discusión como técnica y estrategia de investigación, hemos tenido en cuenta varios aspectos clave como la claridad en el establecimiento de los objetivos del grupo, la cuestión del espacio y tiempo, el contacto con las participantes y el planteamiento por el que nos decantamos en el desarrollo. Si la investigación quiere resaltar la importancia de estudiar los discursos de las participantes en un ambiente grupal, de tal manera que el discurso de una provoque la reacción y el discurso de otra, así como los propios discursos den pie a aclaraciones, modificación de puntos de vista, reconocimiento de ideas, etc., el grupo de discusión se convierte en una adecuada opción metodológica.

Ibañez (2000), indica que el moderador o moderadora del grupo de discusión podía ser la investigadora o una persona conocedora de lo que se busca en la investigación. Considera que, en cualquier caso, debe ser una persona desconocida para los participantes en el ejercicio. Desde nuestra perspectiva este criterio también puede variar dependiendo del problema y objetivos de la investigación, pues en relación con el aspecto anterior, una persona conocida puede generar mayor confianza en el grupo, y más tratándose de las características de las estudiantes del curso. Optamos, siguiendo esta idea, por la técnica del «grupo de discusión comunicativo» según Flecha, Vargas y Dávila (2004), que tiene como característica propia la interpretación y reflexión de forma colectiva y entre iguales, siendo la moderadora la propia investigadora. En esta variante de la técnica, las personas que forman parte del grupo se conocen y tienen relación como participantes en una actividad común, en nuestro caso, la acción formativa 
virtual. Dicha característica nos facilita un entorno de confianza y diálogo. Por otro lado la investigadora, como moderadora, se ha integrado en el grupo, procurando que las interpretaciones partiesen del conjunto.

En la presentación del tema se recordaron los objetivos de la investigación y la meta particular del grupo de discusión planteado, que ya conocían antes de comenzar la acción formativa. Se explicó la dinámica de la reunión y se presentaron los temas generales motivo del diálogo inicial.

El número de participantes en el grupo de discusión realizado asciende a siete estudiantes. Por otro lado, en lo referido al tiempo de desarrollo, se establece que la duración de la sesión debe ser de una hora y media de máximo (Mena y Méndez, 2009), debiéndose avisar al comienzo de la sesión, para que la duración total no dependa del preceptor, tema que indicaría que el consenso a que llegue el grupo depende de su acuerdo: «sólo un conocimiento anticipado del tiempo de concluir precipita el consenso» (Ibáñez, 2000: 274). En nuestro caso de estudio el tiempo del grupo de discusión se estableció en 45 minutos-1 hora. Se respetó este tiempo, siendo, finalmente de 53 minutos.

Para el contacto y reclutamiento de los participantes hemos seguido la estrategia de Mena y Méndez (2009:3) en que las autoras utilizan esta técnica con individuos que se conocen, lo cual no ha afectado el desarrollo del proceso, manifestando que la confianza provoca que se genere un ambiente de confianza que permite obtener más información:

«[...] los individuos expresan que se sienten en un ambiente de confianza en donde si no se les ocurre con anterioridad decir algo, al escuchar a otro se sienten con la confianza de manifestarlo, enriqueciendo el trabajo con coincidencias o puntos de vista encontrados, que al investigador le pueden ofrecer mayor información». 
En todo caso, afirman que esta decisión dependerá siempre del problema y de los objetivos que se deseen lograr en la investigación.

En cuanto al espacio más adecuado para realizar el grupo de discusión, debe ser un sitio agradable y sin ruidos y con una disposición de asientos que no determine ninguna preeminencia en las condiciones del diálogo (Ortí, 1994). También se debe tener en cuenta que el contexto debe estar separado de la vida real de los participantes y no ha de ofrecer una contradicción con los valores simbólicos del grupo (idem). Con estas indicaciones, el lugar seleccionada se determinó como un aula-seminario de la Facultad de Formación de Profesorado de la Universidad de Extremadura, cuya disposición se corresponden con la siguiente figura:

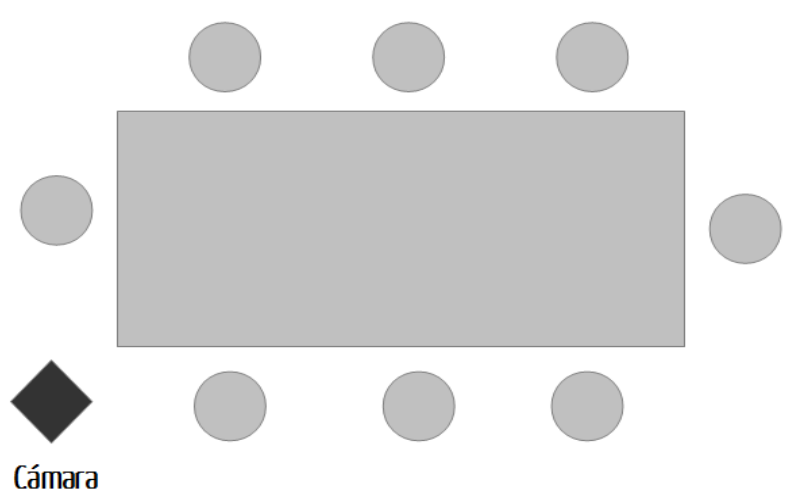

Figura 20. Disposición del espacio en el desarrollo del Grupo de Discusión Comunicativo.

\subsubsection{Cuestionario de evaluación de la acción formativa.}

Este cuestionario va a permitirnos obtener datos descriptivos de la evaluación de las participantes sobre la acción formativa virtual desarrollada. Según Fox (1981) se deben tener en cuenta varias cuestiones en su diseño: 
una limitación de la extensión para no dedicar un tiempo excesivo a la respuesta; una estructuración del modelo de repuesta para reducir al mínimo lo que escriban las personas sobre las que se va a aplicar; realizar una introducción para que los sujetos conozcan la finalidad del mismo y el uso de los datos posteriores; e intentar arbitrar un sistema para que estos sujetos conozcan los resultados obtenidos.

Las características básicas del cuestionario que se ha aplicado en este estudio se pueden resumir en el siguiente listado pudiéndose enmarcar en un enfoque de estadística descriptiva:

- Se ha utilizado un cuestionario que incorpora preguntas cerradas en dos escalas tipo Likert ( 1 a 5 ) sobre aspectos predeterminados sobre la valoración final de la acción formativa y sus dimensiones didácticas, sociocultural y tecnológica. Se han incluido cinco preguntas abiertas para obtener el sentimiento y/o la reflexión de las estudiantes.

- Con la información de los cuestionarios se han realizado análisis estadísticos (frecuencias, medias y desviaciones típicas) con el programa informático SPSS en la versión 15.O.

\subsubsection{Cuestionario A.D.E.C.U.R.}

El instrumento utilizado se denomina A.D.E.C.U.R., análisis didáctico de los modelos y estrategias de enseñanza de cursos universitarios en red, y está elaborado por el Dr. Eloy López Meneses, fruto de su Tesis Doctoral titulada «Análisis de los modelos didácticos y estrategias de enseñanza en Teleformación: diseño y experimentación de un instrumento de evaluación de las estrategias de enseñanza de cursos telemáticos de formación universitaria», dirigida por los catedráticos Julio Cabero Almenara y Pedro 
Cañal de León de la Facultad de Ciencias de la Educación de la Universidad de Sevilla.

Este instrumento didáctico evalúa dos grandes dimensiones en cursos universitarios online, con la finalidad de observar a qué modelo de enseñanza responden éstos: la dimensión psico-didáctica y la dimensión técnicaestética. Estas dimensiones recogen varios elementos que a su vez se derivan en componentes como se refleja en la tabla siguiente. Los componentes se dividen en ítems con sus correspondientes criterios de evaluación. Cada criterio debe responderse en dos únicas opciones: un «1» si se cumple el criterio enunciado, $\mathrm{y} « \mathrm{O} »$ en caso de no aparecer en el curso virtual evaluado. 


\begin{tabular}{|c|c|c|}
\hline Dimensión & Ejes de progresión didáctica & Componentes de los ejes \\
\hline \multirow{20}{*}{ Psico-didáctica } & a) Ambiente virtual & 1) Relaciones de poder y afectivas \\
\hline & \multirow{4}{*}{ b) Aprendizaje } & 2) Significatividad y comprensión \\
\hline & & 3) Interacción social \\
\hline & & 4) Integración \\
\hline & & 5) Funcionalidad \\
\hline & \multirow{2}{*}{ c) Objetivos } & 6) Función \\
\hline & & 7) Formulación \\
\hline & \multirow{3}{*}{ d) Contenidos } & 8) Función \\
\hline & & 9) Diversidad de contenidos y de fuentes \\
\hline & & $\begin{array}{l}\text { 10) Significatividad potencial y validez } \\
\text { didáctica }\end{array}$ \\
\hline & \multirow{6}{*}{ e) Actividades y secuenciación } & 11) Tipos de actividades \\
\hline & & 12) Colaboración \\
\hline & & 13) Autonomía \\
\hline & & 14) Secuenciación \\
\hline & & $\begin{array}{l}\text { 15) Coherencia entre objetivos, } \\
\text { contenidos y actividades }\end{array}$ \\
\hline & & 16) Contextualización \\
\hline & \multirow{4}{*}{ f) Evaluación y acción tutorial } & 17) Tipo de evaluación \\
\hline & & 18) Instrumentos de evaluación \\
\hline & & 19) Criterios de evaluación \\
\hline & & 20) Tipo de acción tutorial \\
\hline \multirow{3}{*}{ Técnica-estética } & \multirow{3}{*}{ g) Recursos y aspectos técnicos } & 21) Calidad del entorno hipermedia \\
\hline & & 22) Diseño y sistema de navegación \\
\hline & & 23) Facilidad de uso (Usabilidad) \\
\hline
\end{tabular}

Tabla 4. Dimensiones, ejes de progresión y componentes de los ejes de la herramienta A.D.E.C.U.R. (basado en López y Roso, 2009:29).

La dimensión psico-didáctica, recoge los principales elementos curriculares, entre los que se encuentran: las intenciones y finalidades 
educativas, la información que se muestra, las actividades que presenta el curso y su secuenciación, el ambiente de aprendizaje, la tipología evaluativa y el seguimiento tutorial que se realiza. Esta dimensión se compone de seis ejes de progresión, que según Cabero y López (2009) vienen a representar el conjunto de componentes referidos a las concepciones didácticas y al pensamiento y la práctica del docente, y son las siguientes.

- El «ambiente virtual», que los autores lo definen como «el espacio virtual de interacción y comunicación de los participantes, el lenguaje empático utilizado, el contexto motivador, cordial y democrático» que se pone de manifiesto en el curso virtual. En este eje de progresión se incluye un sólo componente denominado «Relaciones de poder y afectivas», que evalúa si el entorno virtual es motivador y democrático, recogiendo datos sobre las relaciones sociales entre los y las participantes del curso a través del diálogo, si existen normas de convivencia y el empleo de la personificación del entorno de trabajo para expresar estados de ánimo agradables, a través de animaciones o figuras animadas que acompañen al estudiante en su proceso formativo.

- El «tipo de aprendizaje que se promueve», se refiere a si responde a recursos didácticos para conseguir aprendizajes significativos, promoviendo la comprensión y la colaboración y éstos se pueden aplicar en el ejercicio profesional en el que se forma. Este eje lo completan cuatro componentes: «significatividad/comprensión», referidos a los procedimientos y recomendaciones didácticas orientadas hacia la comprensión y el aprendizaje significativo y los recursos que contribuyen a relacionar los nuevos contenidos y experiencias con ideas y experiencias personales; «interacción social», que se refiere a si existe negociación y puesta en común de experiencias personales y concepciones de los y las estudiantes; 
«integración», en el que se analizan la totalidad de recursos didácticos orientados a facilitar las relaciones entre ideas y conocimientos; y «funcionalidad», evaluando si las actividades favorecen la aplicación de los conocimientos adquiridos a contextos reales y cotidianos para las y los estudiantes.

- Los «objetivos», valorando la formulación y expresión clara y concisa de las principales competencias (conocimientos, habilidades y actitudes) a conseguir. Tiene dos componentes: «función», expresando que los y las estudiantes pueden conseguir resultados de aprendizaje diferentes siguiendo su propio ritmo formativo. Y «formulación», donde se tiene en cuenta su definición.

- Los «contenidos», que hacen referencia a cualquier tipo de fuente que se utilice en el curso virtual, y su relevancia, estructuración, lenguaje empleado, actualización y adaptación al nivel de los conocimientos del estudiante. Sus componentes son: «función», que recoge el uso de los diferentes contenidos como una fuente de información para la construcción de los aprendizajes formulados en los objetivos; «diversidad de contenidos y de fuentes», evaluando la variedad de materiales y recursos que se ofrecen en el curso virtual, la participación de agentes externos, si son válidos y están actualizados y si las ideas y conocimientos previos de los y las estudiantes como contenidos del curso; y, por último, «significatividad potencial $\mathrm{y}$ validez didáctica», analizando la relevancia e importancia de la información ofrecida y construida en el proceso de aprendizaje, el abordaje de los contenidos por nivel de complejidad adaptándose al nivel de los y las estudiantes y si se utilizan diversas fuentes de información, a la vez que el uso de lenguaje científico (directo, conciso y adaptado a estudiantes). 
- Las «actividades y su secuenciación», evaluando si las actividades están orientadas desde un enfoque constructivista e investigador, con seis componentes: «tipos de actividades», que analizan las diferentes tipologías de actividades que se suceden en el curso virtual evaluado; «colaboración», incluyendo las actividades que promueven el trabajo en grupo y que favorecen el intercambio de ideas y experiencias; «autonomía», que hace referencia a la progresiva toma de decisiones, responsabilidades, sugerencias, propuestas por parte del estudiante en cuanto a actividades; «secuenciación», analizando las secuencias de las actividades, como situaciones diseñadas para facilitar el enfoque integrador; "coherencia entre objetivos, contenidos y actividades», evaluando la congruencia de la totalidad de elementos didácticos del curso virtual (objetivos, contenidos, actividades, procesos de evaluación); y «contextualización», en cuanto a que las actividades plantean situaciones reales y familiares, funcionales y significativas para los y las estudiantes.

- La «evaluación y acción tutorial», que analiza si la evaluación se aborda desde múltiples perspectivas y la figura del tutor/a como dinamizador, orientador y facilitador de aprendizajes. Se recoge en cuatro componentes: «tipo de evaluación», analizando si la evaluación es continua y se basa en la reflexión y en la acción práctica educativa, incluyendo procesos de autoevaluación y heteroevaluación; «instrumentos de evaluación», valorando si se incluyen diferentes pruebas para evaluar los resultados de aprendizaje; los «criterios de evaluación», analizando la coherencia de los indicadores de evaluación con el enfoque integrador; y para finalizar, el «tipo de acción tutorial», aludiendo al rol del profesorado en aspectos relacionados con el seguimiento, supervisión, orientación, dinamización del proceso formativo online y la disposición de recursos para ejercer de manera adecuada sus funciones. 
La dimensión técnica-estética, por otro lado, valora todo lo referente al diseño del entorno, su sistema de navegación, usabilidad y elementos hipermedia. El eje de esta dimensión se denomina «recursos y aspectos técnicos» $\mathrm{y}$ se configura por tres componentes: «calidad del entorno hipermedia», en el que se valoran los elementos multimedia de ese entorno (texto, imágenes fijas y en movimientos, sonidos, iconos) y si éstos son significativos, intuitivos, didácticos y relevantes para la formación del estudiante; «diseño y sistema de navegación», es decir si éste es homogéneo, uniforme, consistente, transparente y tiene una navegación adecuada, además de incluir recursos de planificación temporal; en último lugar, se valora la «facilidad de uso (usabilidad)», esto es, si es fácil de usar, manejar, utilizar y si es atractivo e intuitivo para los y las estudiantes.

\subsection{Procedimiento para el análisis y tratamiento de datos}

En el diseño de investigación hemos manifestado que nuestra opción, a la hora de abordar tan compleja realidad educativa, ha sido la combinación de métodos cuantitativos y cualitativos en los tres estudios que se han realizado. A continuación presentamos el tratamiento de datos, para cada uno de los estudios.

\subsubsection{Estudio 1: revisión literaria para diseño. Evaluación de expertos y expertas.}

Realizamos una revisión literaria con la finalidad de analizar científicamente la documentación publicada en nuestro área del conocimiento y de estudio, para proporcionar un contexto y una justificación 
de los modelos y estrategias seleccionadas en el diseño de la acción formativa virtual.

Para esta revisión se han utilizado diversas búsquedas bibliográficas exhaustivas en bases de datos del área y fuentes documentales en internet, a la vez que bibliografía disponible en diferentes bibliotecas universitarias. Toda la información se ha ido registrando y organizando en un base de datos creada por la investigadora.

Una vez realizada la revisión se procede a documentar una primera versión del diseño pedagógico de la acción formativa virtual, en constante relación con el equipo coordinador de la experiencia. Para valorar la pertinencia del diseño inicial se expone a juicio de cuatro expertos en la materia; para ello se envía un e-mail previo donde se les solicita la participación en la valoración del mismo.

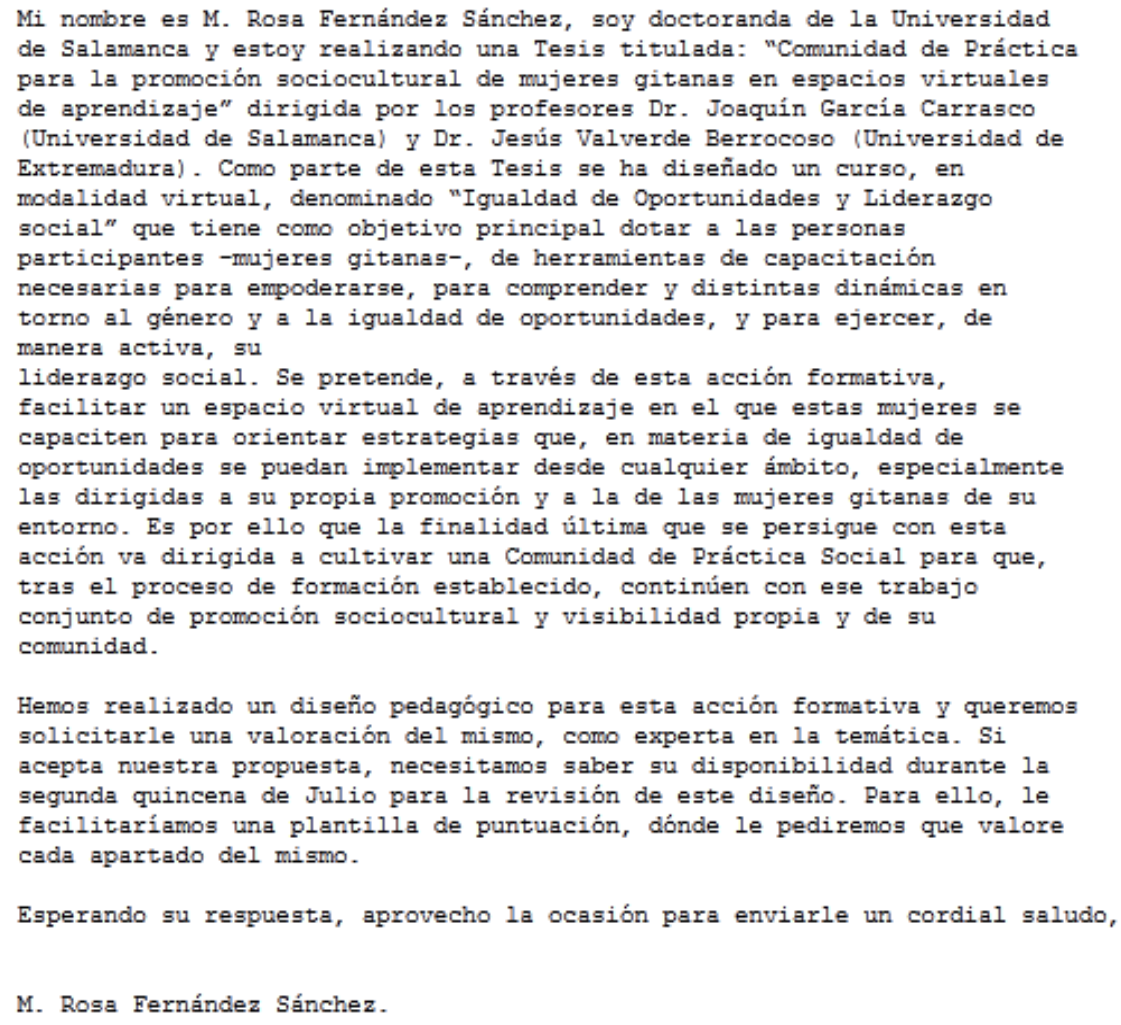


Una vez aceptada la participación, se les remitió un nuevo e-mail que incluye la «Plantilla de Evaluación del Diseño para Expertos/as» (Anexo I), que sitúa cinco grandes apartados de valoración con preguntas abiertas, y el diseño de la acción formativa.

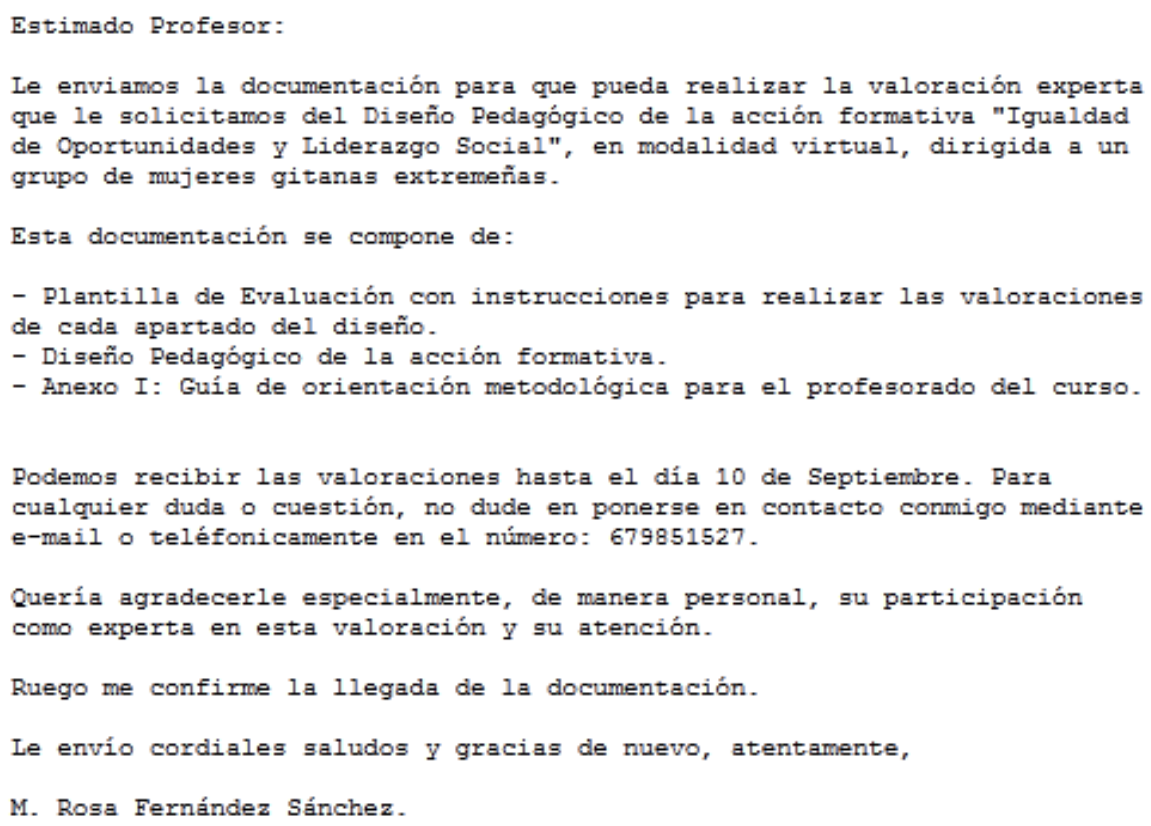

Las sugerencias clave de la revisión de expertos se sitúan, de forma genérica en las siguientes:

- Revisión de los principios pedagógicos del diseño inicial y su estructura.

- Reducir las competencias y agruparlas. Incluir una competencia relacionada con el empoderamiento y mejora del autoconcepto y sobre análisis crítico de información.

- La génesis de las innovaciones tiene detrás una historia: plantear el contexto de la acción en la propia entidad e indagar sobre otras 
acciones virtuales y experiencias previas similares, que pueden ayudar a fundamentar algunas decisiones.

- Establecer, de manera clara, la labor tutorial en un apartado diferente.

- Ampliar la temporalización inicial (dos meses).

- Situar estrategias que promuevan la interacción entre las estudiantes.

- Realizar un análisis de género de las mujeres participantes.

- Revisar el lenguaje utilizado (evitar las barras, utilizar genéricos relacionados con el lenguaje no sexista)

- Aclarar algunas expresiones y corregir algunas erratas.

Teniendo en cuenta estas sugerencias se reestructura el diseño completo, que se ofrece en el siguiente capítulo como Estudio 1.

\subsubsection{Estudio 2: Análisis de contenido cualitativo.}

El segundo estudio se centra en el análisis de contenido de la comunidad virtual de aprendizaje generada a través de la acción formativa virtual «Igualdad de Oportunidades y Liderazgo Social», dirigida a mujeres gitanas de diferentes puntos geográficos de Extremadura y desarrollado a través del Campus Virtual de la Universidad de Extremadura.

El análisis de contenido es una metodología de investigación que se basa en los procedimientos para hacer inferencias válidas a partir de texto (Anderson, et al., 2001). Aunque esta técnica de investigación es a menudo utilizada, las normas no están todavía establecidas. De hecho, algunos autores (Rourke et al., 2000; De Wever et al., 2006; Strijbos y Fisher, 2007), han destacado que pese a ser una de las metodologías más usadas, sus revisiones han detectado una falta de rigor metodológico con la que se aplica 
en ocasiones, subrayando como principal limitación, la ausencia de marcos teóricos que sustenten las categorías de análisis. Desde este punto de vista encontramos que los instrumentos aplicados reflejan una amplia variedad de enfoques y difieren en su nivel de detalle y el tipo de categorías de análisis utilizado, además de en la base teórica, la cantidad de información y la elección de la unidad de análisis. Gros y Silva (2006) realizan una excelente revisión de metodologías e instrumentos desarrollados para el análisis de contenido. En las dos últimas décadas se han desarrollado instrumentos para el análisis de la comunicación sincrónica y asincrónica en entornos virtuales de aprendizaje. Entre los estudios de mayor relevancia se encuentran los modelos de Henri (1992) y Gunawardena et. al (1997), ya destacados, los trabajos de Bullen (1997), Mercer (2001), Veerman et al. (2001), Jarvela y Hakkinen (2002), Bereiter y Scardamalia (Bereiter, 2002; Bereiter y Scardamalia, 2003; Scardamalia y Bereiter, 1994, 1999, 2006), Garrison y Anderson (2005) y Resta y Laferrière (2007). En todos estos estudios las alternativas son variadas, fundamentalmente en relación a las unidades de análisis aplicadas. En unos casos se han escogido unidades temáticas (Henri), en otros se analizan mensajes completos (Gunawardena; Veerman) y en el análisis de Javerla, toda la discusión es una unidad de análisis.

En referencia al análisis de contenido cualitativo, y concretamente de foros electrónicos de debate asíncronos, los modelos también son variados. De Wever et al. (2006), realizan una revisión de los principales modelos utilizados en investigaciones: Henri (1992), Newman et al. (1995), Gunawardena et al. (1997); así como los instrumentos de Zhu (1996); Bullen (1997); Garrison, Anderson y Archer (2000); Anderson et al., (2001); Rourke et al. (2001); Veerman y Veldhuis Diermanse (2001); Peña-Shaff y Nicholls (2004), entre otros.

Para el estudio de esta comunidad virtual de aprendizaje, hemos tomado como referencia varios temas de los foros que forman parte de la acción formativa virtual mencionada $y$ que han constituido el soporte 
comunicacional fundamental en el aprendizaje de las estudiantes y son específicos para cada una de las propuestas temáticas de la formación.

El tratamiento de los datos se ha realizado a través del análisis de contenidos, siendo la unidad de análisis y codificación el mensaje en el contexto del «tema» abierto, seleccionando las unidades sintácticas como la palabra, la proposición, la frase o el párrafo para el estudio de las diferentes «presencias o dimensiones» del modelo propuesto por Garrison, Anderson y Archer (2000), con las categorías e indicadores en referencia a cada dimensión. En la tabla siguiente se muestran las categorías de cada una de ellas:

\begin{tabular}{ll}
\hline \multirow{2}{*}{ Dimensión o Presencial Social } & Afecto \\
\cline { 2 - 2 } & Comunicación abierta \\
\cline { 2 - 2 } & Cohesión \\
\hline \multirow{2}{*}{ Dimensión o Presencia Cognitiva } & Hecho desencadenante \\
\cline { 2 - 2 } & Exploración \\
\cline { 2 - 2 } & Integración \\
\cline { 2 - 2 } & Resolución \\
\hline \multirow{2}{*}{ Dimensión o Presencia Docente } & Diseño educativo y organización \\
\cline { 2 - 2 } & Facilitar el discurso \\
\cline { 2 - 2 } & Enseñanza directa \\
\hline
\end{tabular}

Tabla 5. . Dimensiones y categorías del modelo «Comunidad de indagación»

Los criterios de clasificación son semánticos (categorías temáticas), de estructuración del lenguaje (delimitación del texto por mensajes) y de perfiles de los participantes (para identificar la figura de estudiantes y profesorado/tutor). El análisis de este sistema de categorías ha sido adaptado a partir del análisis cualitativo de los datos que hemos recopilado en esta investigación a través del entorno virtual en el que se ha desarrollado la acción formativa y, concretamente de los foros virtuales. Debemos añadir 
que, a pesar de que esa unidad de codificación ha sido el mensaje completo, un mensaje puede hacer referencia a las tres presencias (Garrison y Anderson, 2005), de ahí que que se tome la palabra, frase o párrafo/fragmento para el estudio de cada una de las categorías. Se procedió, por tanto, para una identificación más minuciosa, a segmentar las comunicaciones de las participantes en aquellas categorías que estos investigadores proponen, recurriendo al uso de puntos suspensivos y paréntesis en la indicación del segmento del discurso seleccionado a modo de «posting».

Podemos resumir básicamente en siete etapas todo el proceso de construcción del sistema de categorías empleado en nuestra investigación. Éstas son: $1^{\mathrm{a}}$ ) adopción de un modelo de referencia; $2^{\mathrm{a}}$ ) definición de la unidad de análisis e identificación de las categorías; $3^{\text {a) }}$ aplicación del sistema de referencia en la codificación de datos y comprobación de la estructura del sistema; $4^{\mathrm{a}}$ ) codificación inicial; $5^{\mathrm{a}}$ ) doble categorización; y $6^{\mathrm{o}}$ ) comprobación con expertos; $7^{\circ}$ ) codificación final. Cada una de estas fases constituyó, en su conjunto, un momento preliminar al tratamiento y a la sistematización de los datos.

Esta metodología de análisis de contenido mediante categorización de datos por indicadores ha implicado un doble análisis que asegure el rigor científico del estudio. Para ello se ha recurrido a la doble categorización, comprobando aquellos mensajes que pudiesen dar lugar a dudas con investigadoras e investigadores del Grupo de investigación «Nodo Educativo» de la Universidad de Extremadura conocedores del modelo aplicado. De este modo se valida el estudio con la doble categorización por parte de la investigadora y la discusión con otros expertos, lo que permite asegurar un consenso en la aplicación e interpretación de los datos posterior. 


\subsubsection{Estudio 3: datos descriptivos y triangulación de datos.}

Para realizar el Estudio 3 recogemos información desde diferentes perspectivas y en diferentes contextos con el fin de contrastar y comparar los hechos y observar las diferencias y semejanzas. Para ello se han utilizado instrumentos de corte cualitativo y cuantitativo, para lograr, además, una combinación de los resultados: un cuestionarios estandarizados, entrevistas en profundidad, grupo de discusión comunicativo y los datos obtenidos del foro dedicado a la evaluación continua, en el entorno virtual de desarrollo de la acción formativa. Mediante esta manera de investigar complementando métodos cuantitativos y cualitativos, Flick argumenta que se puede avanzar «hacia un enriquecimiento adicional y un perfeccionamiento del conocimiento y hacia una transgresión de los (siempre limitados) potenciales epistemológicos del método individual» (2004: 244).

\section{a) Construcción y tratamiento de datos del cuestionario.}

La construcción del cuestionario ha seguido una serie de fases:

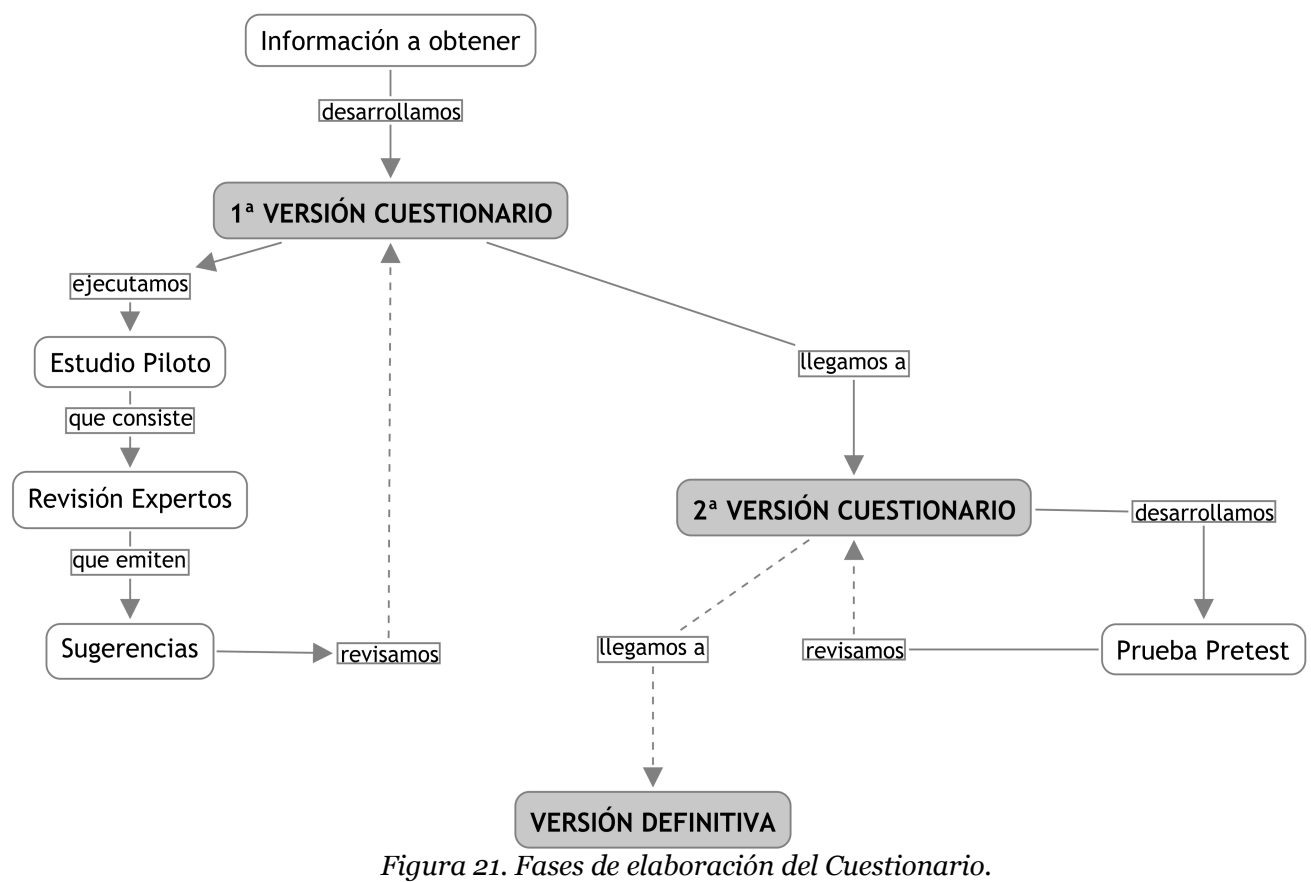


En primer lugar, se elaboró una primera versión del cuestionario a través de ejes generales de evaluación sobre la acción formativa virtual. Estos ejes no son independientes sino que están relacionadas entre sí.

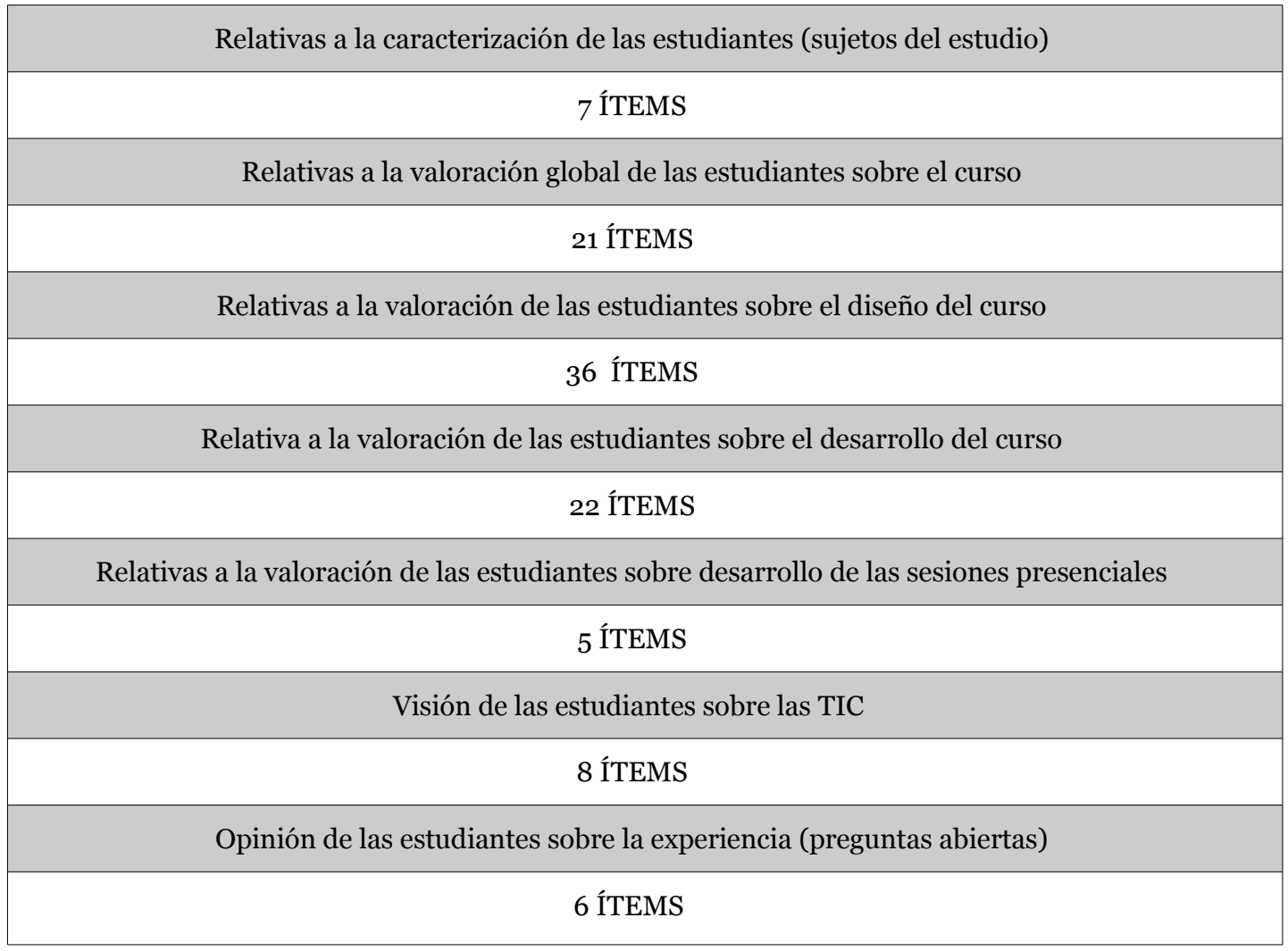

Tabla 6. Distribución de ítems por ejes de evaluación (Cuestionario de Evaluación)

Para las respuestas se han utilizado dos escalas tipo Likert en forma de confirmación ante el ítem requerido con cinco alternativas, cuyas claves han sido: (a) «totalmente en desacuerdo», «en desacuerdo», «indiferente», «de acuerdo», «totalmente de acuerdo»; (b) «nada», «poco», «regular», «bastante», «mucho». Se incluyen, además, cinco preguntas abiertas.

En la elaboración del cuestionario piloto, se tuvieron en cuenta las etapas destacadas por Selltiz et al. (1980): decisión sobre qué información buscamos, redacción del primer borrador, revisión de las preguntas, comprobación previa de cuestionarios y valoración y determinación de 
procedimientos para su utilización. El cuestionario definitivo quedó configurado una vez revisadas dichas etapas. Una vez distribuidos los cuestionarios y recogidas las respuestas se procede al análisis descriptivo y al estudio de sus elementos (análisis de ítems).

En primer lugar, y con el fin de determinar la adecuación del cuestionario construido al modelo de partida, se desarrolla un estudio piloto consistente en la revisión del cuestionario por expertos y el desarrollo de una prueba pretest.

El proceso de validación del cuestionario se realiza por parte de los dos expertos y se organizó a partir de una ficha registro, con el fin de valorar la pertinencia y ubicación de cada uno de los ítems, lo que permitió su revisión junto con las aportaciones realizadas en el pretest. Se planteó a los expertos la conveniencia de la ubicación de los ítems, alternativas a la misma, lenguaje y adecuación, estructura y otros aspectos en seis preguntas:

1. A su juicio, ¿̇qué otros aspectos debería incluir?

2. ¿Debería suprimirse alguno de los ítems?

3. Valore la estructura del cuestionario.

4. ¿Considera adecuado el formato del cuestionario, a la hora de cumplimentarlo? Justifíquelo.

5. ¿Considera adecuado el lenguaje utilizado?

6. ¿Qué otros aspectos considera que podrían incluirse?

Las sugerencias de los expertos sobre el cuestionario indican:

- La existencia de un lenguaje demasiado técnico para las personas a las que va dirigida, indicando algunos ítems como de «difícil comprensión». 
- Sugieren la introducción de alguna cuestión abierta que exprese alguna reflexión o sentimiento de las participantes.

- En el ítem (recursos) sugieren situar una puntuación para cada recurso, de cara a obtener un ranking en el uso de los recursos.

La valoración del contenido en general es positiva, consideran que es adecuada a la investigación y recoge los aspectos fundamentales para valorar el desarrollo de la acción formativa. A partir de estas sugerencias se revisa toda la estructura y formulación del cuestionario, en una segunda versión que se utiliza para realizar el pretest.

La prueba pre-test se aplica a tres personas de similares características que las estudiantes, permitiéndonos revisar si el cuestionario es adecuado a las destinatarias y si las preguntas pueden formularse sin explicaciones añadidas. La prueba pre-test la realiza la propia investigadora que aplica el cuestionario directamente e individualmente a cada persona. Estas tres informantes sugieren aclarar el lenguaje general de todo el cuestionario para las participantes entiendan las preguntas. Recomiendan:

- Utilizar palabras sencillas o aclaraciones a éstas entre paréntesis.

- Cambiar la palabra «competencias» por «objetivos» para facilitar la comprensión de la misma a las estudiantes.

Esta prueba nos ha permitido modificar aquellas preguntas que pueden no comprenderse por las destinatarias. Se llega, así, a la tercera y versión definitiva del cuestionario.

La administración del mismo, se realiza en la sesión de clausura de la acción formativa virtual. Se aplica a 16 de las 20 participantes, presentándoles la finalidad del mismo y el tratamiento de datos por parte de la investigadora. 
El tratamiento de los datos del cuestionario se efectúa a través de técnicas tanto cuantitativas como cualitativas, éstas últimas referidas al análisis de las preguntas abiertas del cuestionario, y las cuantitativas referidas a las exigencias del modelo estadístico y a los objetivos de la investigación. Estos datos han sido tratados a nivel descriptivo, que nos permite conocer las características del desarrollo de la acción formativa virtual. Para ello se llevaron a cabo diversos estadísticos descriptivos con el programa SPSS $^{85}$ (Anexo V).

En cuanto a los datos cualitativos, recogidos de las preguntas abiertas, se analizan tras la separación de la información de cada uno de los ítems en unidades con significado (Bardin, 1986), uniendo todas las que pertenecen a la misma unidad, conformándose las siguiente unidades:

\begin{tabular}{|c|c|}
\hline \multicolumn{2}{|c|}{$\begin{array}{c}\text { Opinión de las estudiantes sobre la experiencia } \\
\text { (Preguntas abiertas) }\end{array}$} \\
\hline Opinión general & Aplicación de lo aprendido \\
\hline Comunidad Virtual de Aprendizaje & Aspectos positivos y negativos \\
\hline Curso de formación online & Otra opinión no preguntada \\
\hline
\end{tabular}

Tabla 7. Unidades de las preguntas abiertas del cuestionario

\section{b) Evaluación de expertos de la pertinencia del modelo pedagógico desarrollado: A.D.E.C.U.R.}

La herramienta A.D.E.C.U.R. es un instrumento didáctico, presentado en formato .xls, configurado para puntuar entre o y 1 , dependiendo de si se cumple o no se cumple el criterio enunciado en el ítem. El propio instrumento muestra los resultados de la evaluación una vez finalizada, mostrando el porcentaje obtenido en la puntuación de las dimensiones y el modelo didáctico que se desarrolla en la acción formativa evaluada.

$8_{5}$ Para más información sobre el Statistical Package for the Social Sciences (SPSS) se puede visitar el portal de la empresa desarrolladora: http://www.spss.com 
El procedimiento seguido ha partido de la solicitud de evaluación de la acción formativa a dos expertos y una experta en la temática mediante contacto telefónico. Una vez aceptada la participación se ha enviado un email adjuntando el instrumento A.D.E.C.U.R. y facilitando el acceso al curso mediante la matriculación en el mismo.

\begin{abstract}
Estimada compañera, estimados compañeros:
Les solicito una evaluación experta de la acción formativa on line "Igualdad de Oportunidades y Liderazgo Social", en base al Modelo ADECUR, diseñado por el Dr. Eloy López Meneses, para la evaluación del modelo didáctico y de las estrategias de enseñanza utilizadas en cursos telemáticos de formación universitaria. Nuestro fin es conocer su opinión y valoración experta en torno a las estrategias utilizadas en esta acción, para comprobar si su desarrollo ha respondido a modelos integradores de enseñanzaaprendizaje, tal y como establecimos en el diseño pedagógico previo.

Para facilitarles el acceso a este curso, se les ha matriculado en el mismo a través del Campus Virtual de la Universidad de Extremadura (https://campusvirtual.unex.es/), por lo que deben introducir sus datos de acceso personales y aparecerá como uno de sus cursos.

En el modelo adjunto (ADECUR) se encontrará una serie de Items organizados en torno a los ejes que articulan las dimensiones de los modelos didácticos y estrategias didácticas que se ponen de manifiesto en cada uno de ellos. El grado de posesión de tal característica se estima en función de la presencia o no de un conjunto de indicadores potenciales positivos. Por tanto, en cada item debe puntuar 0 , en el caso de que esa característica no esté presente en la acción formativa que le proponemos evaluar y 1 , en el caso de estar presente en la misma. Una vez realizada la valoración debe guardar los cambios en el archivo y enviarlo por correo electrónico a la dirección: rofersan@unex.es
\end{abstract}

Como fecha máxima de la valoración, le rogamos nos la envíe lo antes posible, siendo la fecha límite el 30 de Septiembre de 2010.

Agradeciéndoles de antemano su ayuda y trabajo, les envía cordiales saludos,

Mª Rosa Fernández Sánchez

Una vez realizada la evaluación, nos la remiten vía e-mail para su posterior tratamiento de datos (Anexo VIII).

Como el propio instrumento nos facilita los gráficos obtenidos en la evaluación individual de cada experto/a, procedemos directamente a la interpretación de resultados a través de la confrontación de la evaluación de los tres expertos. 


\section{c) Triangulación de datos de entrevistas, grupo de discusión, resultados del estudio de la comunidad virtual}

Para evaluar la experiencia de e-learning social desarrollada, consideramos la triangulación de datos como la mejor manera de estudiar este caso y para ello, hemos seleccionado varios instrumentos para la recogida de los mismos, como ya se ha explicado con anterioridad.

Bericat (1998) identifica tres estrategias para la integración metodológica: la complementación, la combinación y la triangulación. La complementación, refiriéndose al uso de las metodologías cuantitativas y cualitativas para abordar una dimensión diferente del objeto de estudio, respondiendo, por tanto, a diferentes interrogantes. La combinación, indica el uso de uno de los métodos con respecto al otro, con la finalidad de aumentar la validez del resultado. Finalmente, la triangulación, o convergencia, supone el uso de las metodologías cualitativa y cuantitativa para abordar un mismo aspecto de la realidad. Por tanto la triangulación es un procedimiento para organizar los diferentes tipos de datos en un marco de referencia o relación coherente para compararlos y contrastarlos (Elliott, 1990). La clasificación clásica de la triangulación realizada por Denzin (1978), responde a cuatro tipologías: de datos, referida al contraste entre diferentes fuente de datos en un estudio, en concordancia o discrepancia entre esas fuentes, pudiendo triangular informantes, tiempos y espacios o contextos; teórica, contrastando diversas teorías en una misma investigación para abordar el mismo objeto de estudio; metodológica, aplicando diferentes métodos en la misma investigación; y de investigadores e investigadoras, contrastando las aproximaciones entre las disciplinas, perspectivas y experiencias de varios investigadores. Algunos autores añaden otras tipologías como la triangulación interdisciplinaria (Janesick, 1994), similar a la de investigadores e investigadoras, y la de tiempos y espacios (Cohen y Manion, 1994), o la de análisis (Arias, 2000), utilizando varias tipologías de las anteriores en el propio estudio, comparando los resultados de los diferentes análisis de datos. 
Recordemos que se han realizado:

a. Entrevistas en profundidad: 7 entrevistas en profundidad a profesorado-tutor participante en el curso con la intención de recabar información, opiniones y valoraciones sobre el proceso y resultados de la práctica e-learning desarrollada.

b. Grupo de discusión comunicativo: 1 grupo de discusión con algunas de las mujeres participantes en la práctica e-learning.

En este caso, además de una triangulación basada en la validación complementaria y cruzada de los enfoques cuantitativo y cualitativo, se utilizan varias fuentes de datos que permite dar una visión holística y una reconstrucción de la realidad más fidedigna.

En este estudio, al contrario que el anterior, el proceso de análisis no parte de un sistema de categorías predefinido. Como hemos comentado, se parte de grandes dimensiones que, tras el proceso de recogida de datos, se convertirán en las categorías e indicadores que configurarán el modelo de análisis e interpretación de los datos recogidos. La categorización hace posible clasificar conceptualmente las unidades que son cubiertas por un mismo tópico. Las categorías soportan un significado o tipo de significado y pueden referirse a situaciones, contextos, actividades, acontecimientos, relaciones entre personas, comportamientos, opiniones, sentimientos, perspectivas sobre un problema, métodos, estrategias, etc. La codificación, sin embargo, constituye la operación concreta por la que se asigna a cada unidad un indicativo propio de la categoría en la que se considera incluida. Los indicadores, que representan a las categorías, consisten, por tanto, en marcas que se añaden a las unidades de datos, para indicar la categoría a que pertenecen. Estas marcas en nuestro estudio son abreviaturas de palabras con las que se han etiquetado las categorías. Tras la recogida de datos, se constituyó el modelo de categorías e indicadores que, tras el proceso de 
codificación de los datos requirió de varios ajustes y modificaciones, hasta llegar al modelo final (Plantilla final disponible en Anexo VIII): 


\section{CATEGORÍAS}

\begin{tabular}{|c|c|c|c|}
\hline \multirow{18}{*}{ 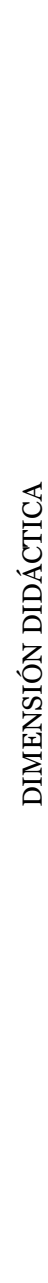 } & \multirow{5}{*}{ GENERAL } & Experiencia profesorado & DIEX \\
\hline & & Valoración global de la experiencia & DIVALEX \\
\hline & & Diferencias con otros cursos & DIDIF \\
\hline & & Debilidades de la experiencia & DESDEB \\
\hline & & Fortalezas de la experiencia & DESFOR \\
\hline & \multirow{5}{*}{ DISEÑO DIDÁCTICO-COMUNICATIVAO } & Motivación & DIMOV \\
\hline & & Actividades & DESACT \\
\hline & & Materiales & DESMAT \\
\hline & & Diseño & DIDISE \\
\hline & & Comunicación e Interacciones & DICOM \\
\hline & COGNITIVA & Presencia Cognitiva & DESCOG \\
\hline & \multirow{5}{*}{ ACCIÓN TUTORIAL } & Orientación & TUTOR \\
\hline & & Evaluación & TUEVA \\
\hline & & Coordinación & TUCORD \\
\hline & & Problemas & TUPRO \\
\hline & & Guía Tutores/as & DIGUIA \\
\hline & \multirow{2}{*}{ ASPECTOS ORGANIZATIVOS } & Flexibilidad & ORGFLEX \\
\hline & & Presencialidad vs Virtualidad & ORGVIRPRE \\
\hline \multirow{6}{*}{ 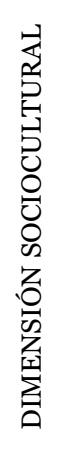 } & CONTEXTUALIZACIÓN & Contextualización & SOCON \\
\hline & PRESENCIA SOCIAL & Presencia social & SOSOL \\
\hline & \multirow{3}{*}{$\begin{array}{l}\text { EMPODERAMIENTO PARTICIPACIÓN } \\
\text { SOCIAL Y COMUNIDAD DE PRÁCTICA }\end{array}$} & Empoderamiento & SOEMP \\
\hline & & Participación Social & SOPAR \\
\hline & & $\begin{array}{l}\text { Comunidad Virtual de Aprendizaje/ } \\
\text { Comunidad de Práctica }\end{array}$ & SOCVA \\
\hline & TRANSFERIBILIDAD & Transferencia & SOTRANS \\
\hline \multirow{3}{*}{ 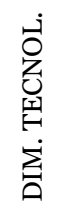 } & \multirow{3}{*}{ PLATAFORMA } & Valoración general & \multirow{3}{*}{ TECVIR } \\
\hline & & Facilidad de acceso y uso & \\
\hline & & Problemas técnicos & \\
\hline
\end{tabular}

Tabla 8. Dimensiones, categorías e indicadores del modelo de análisis de datos (Triangulación)

\section{INDICADORES/CÓDIGO}

DIEX 
Los principios que caracterizan a la categorización de datos en nuestro estudio fueron:

- Exhaustividad: que cubrió todas las unidades diferenciadas de los datos.

- Exclusión mutua: cada unidad se incluye en una sola categoría.

- Único principio clasificatorio: las categorías son el único criterio de ordenación y clasificación.

- Objetividad: las categorías fueron inteligibles para cada uno de los codificadores.

- Pertinencia: las categorías fueron relevantes respecto de los objetivos del estudio y se adecuaron al contenido analizado (Rodríguez, Gil y García, 1996).

El trabajo de categorización se inició partiendo de las siete entrevistas de profesorado, almacenadas como archivos de audio .mp3, transcritas posteriormente en formato de texto. Tras esta categorización se procedió a la misma tarea con el grupo de discusión almacenado como archivo de video: .avi, que posteriormente también fue transcrito en formato textual. Se relacionaron, posteriormente, los resultados obtenidos en el Estudio 2 a través de la recogida de datos de evaluación del curso mediante el cuestionario aplicado a las participantes.

Los primeros pasos del análisis cualitativo de los textos fueron los siguientes:

- Se separó el texto en unidades temáticas.

- Se señalaron con abreviaturas los indicativos de una unidad tema (conversaciones, sucesos, actividades, etc.) 
- Se encontraron segmentos referidos a un mismo tema.

- Se agruparon las unidades de datos para identificar en ellos componentes temáticos que permitieron construir las categorías de contenido.

- Se definieron estas categorías operacionalmente, lo que permitió distinguir subcategorías.

- A partir de una categoría de mayor o menor potencial conceptual se enfocó en las propiedades de la misma para sistematizar a través de la codificación. Se procedió a categorizar y codificar el texto seleccionado y al final se asignó un código a cada categoría inicial.

- Una vez que se obtuvieron estas categorías se volvió al texto para asegurarse que las frases estaban correctamente ubicadas en las categorías correctas. Dicho proceso permitió percibir la existencia de diferentes atributos dentro de las categorías, por lo cual se generaron subcategorías.

En este capítulo se ha determinado la opción metodológica que se sigue en este trabajo de investigación, que se acerca a la aproximación multimétodo, incorporando dos vía de análisis complementarias: la metodología cualitativa, puesto que nos permite abordar de manera satisfactoria la problemática y objetivos a los que nos enfrentamos; y la metodología cuantitativa, que nos ayuda a acceder a la comprensión y expresión de actitudes, complementarias al análisis cualitativo. Aunque, se debe destacar, que es el paradigma cualitativo y, especialmente, la investigación-acción, la que prevalece en este trabajo que utiliza como apoyo el método del estudio de caso trasladado a la virtualidad, tomando el ciberespacio como campo de estudio. La misión principal, definida como cultivar una Comunidad de 
Práctica a través de una acción formativa virtual dirigida a la promoción social y cultural de un grupo de mujeres gitanas, nos ha llevado a situar el problema inicial de la investigación y los objetivos de la misma, dirigidos a estudiar la conformación de una Comunidad de Práctica de Mujeres Gitanas a través del diseño, desarrollo, implementación y evaluación de una práctica de e-learning enfocada desde una perspectiva social. Los sujetos del estudios son las 20 mujeres gitanas participantes en esa experiencia e-learning y los informantes están constituidos por: las propias estudiantes, el profesorado participante y expertos y expertas externos que han valorado tanto el diseño como el modelo didáctico desarrollado. Para recoger los datos de este estudio hemos fijado varios instrumentos entre los que se encuentran el análisis documental, la herramienta A.D.E.C.U.R. aplicada por expertos y expertas, entrevistas en profundidad al profesorado, el entorno virtual de desarrollo del curso a través de los foros, un cuestionario de evaluación aplicado a las participantes y un grupo de discusión comunicativo con siete estudiantes. Todos los datos recogidos han sido tratados y analizados mediante varios procedimientos: revisiones literarias científicas, evaluaciones expertas del diseño didáctico de la acción formativa, análisis de contenido cualitativo, análisis de cuestionarios mediante el programa SPSS y triangulación de datos. 


\section{TERCERA PARTE. MARCO EMPÍRICO}





\section{Capítulo 6. Diseño de la acción formativa virtual (Estudio 1)}



Figura 22. Diseño de la acción formativa virtual

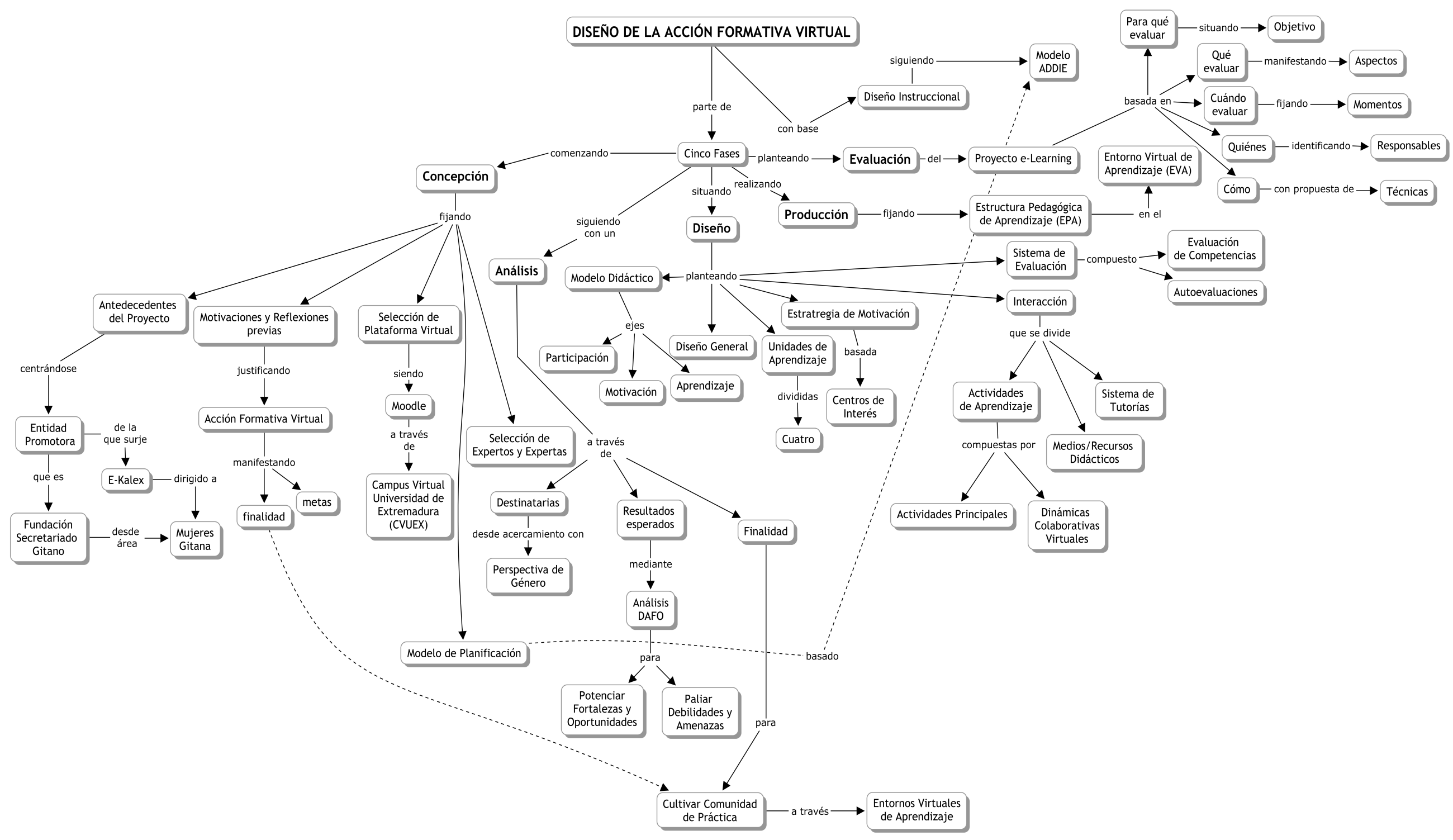





\subsection{Fase de Concepción}

\subsubsection{Antecedentes del proyecto:La entidad promotora de la experiencia y el proyecto e-Kalex.}

La Fundación Secretariado Gitano ${ }^{86}$ es una entidad social sin ánimo de lucro que presta servicios para el desarrollo de la comunidad gitana en los ámbitos español y europeo. Su actividad como asociación comenzó en los años 6o, y se constituyó como fundación en el año 2001. La misión de esta entidad es «la promoción integral de la comunidad gitana desde el respeto a su identidad cultural», mediante acciones que se dirigen a mejorar sus condiciones de vida, centrándose en compensar las desventajas existentes con relación a miembros de la comunidad, así como a potenciar el reconocimiento, el apoyo y el desarrollo de su identidad cultural. Desde este marco, la entidad aspira a contribuir a la construcción de una sociedad cohesionada e intercultural, donde las personas gitanas ejerzan libre y plenamente su ciudadanía. Para alcanzar estos objetivos se establecen dos líneas de actuación generales. Por un lado, servicios directos a la comunidad gitana para promocionar y mejorar sus condiciones de vida, y, por otro lado, actuaciones destinadas al fomento de políticas más activas dirigidas a la comunidad gitana. Ambas líneas de actuación se concretan a su vez en: trabajo por la promoción e incorporación plena de los gitanos y gitanas en la sociedad española; mejora de la imagen pública del pueblo gitano y difundir sus valores culturales en la sociedad; desarrollo de programas de promoción en los campos educativo, sanitario, juvenil, de empleo, mujer, así como aquellos ámbitos que contribuyan a mejorar las condiciones de vida de la comunidad gitana; oferta de servicios de información, formación, orientación $\mathrm{y}$ asesoramiento a las asociaciones, administraciones y todas aquellas

86 Sitio web de la entidad: http:www.gitanos.org 
entidades que estén interesadas en las cuestiones gitanas; desarrollo de medidas de sensibilización y campañas generalistas con el objetivo de incidir en las causas estructurales de la desigualdad; y defensa y apoyo de los intereses del pueblo gitano tanto a nivel nacional como internacional, intentando influir en la toma de decisiones de los niveles políticos que afecten a la comunidad gitana, especialmente, en la Europa ampliada incrementando la colaboración con los nuevos miembros y candidatos a la Unión Europea y tratando de influir en las políticas que puedan afectar a la comunidad gitana de estos países.

Si nos centramos en los ámbitos de trabajo de la Fundación Secretariado Gitano, se dividen en 13 áreas:

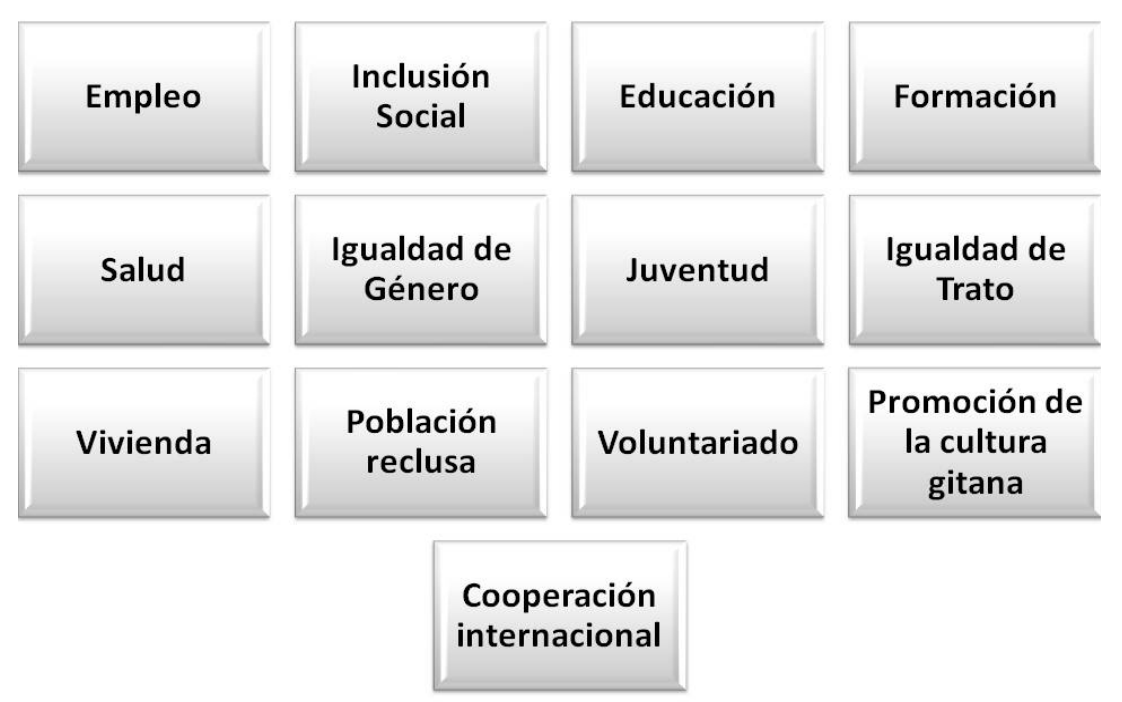

Figura 23. Áreas de trabajo de la Fundación Secretariado Gitano.

1. Empleo (Programa Acceder): la finalidad de este área se centra en mejorar la empleabilidad de la comunidad gitana, para facilitar la incorporación al mercado laboral y como medio para paliar la situación de exclusión social en que se encuentran. 
2. Inclusión social: en este área se desarrollan programas integrales denominados «Intervención Social de base Territorial», que intervienen, de manera global, en situaciones complejas relacionadas con la inserción social de la comunidad gitana.

3. Educación: es un área que aplica programas de intervención, sensibilización, o investigación con el objetivo de facilitar la promoción educativa en todos los niveles y edades.

4. Formación: el objetivo principal de este área es dar respuesta a las demandas de formación de las personas que trabajan o participan en acciones dirigidas a la promoción de la comunidad gitana. Con este fin desarrollan actividades formativas para la especialización de profesionales en el trabajo con gitanos, formación de mediadores, formación de formadores, seminarios, jornadas y encuentros específicos de los diferentes ámbitos de intervención y asistencias técnicas a otras entidades en temáticas relacionadas con la comunidad gitana.

5. Salud: a través de este área se desarrollan programas de mejora de las condiciones sociales, ambientales y económicas de la comunidad gitana mediante acciones de prevención, sensibilización, creación de materiales didácticos, o investigaciones, entre otras.

6. Igualdad de Género: desde este área se impulsan proyectos y acciones de formación adecuados a la realidad cultural de las mujeres gitanas, para dotarlas de habilidades individuales, sociales y pre-laborales con un fin de promoción personal.

7. Juventud: este área tiene como objetivo el fomento de la participación social de la juventud gitana, para facilitar su proceso 
de incorporación social, así como el acceso a los recursos y servicios normalizados destinados a la participación juvenil.

8. Igualdad de trato: La lucha contra la discriminación es un eje fundamental de esta entidad, incorporando esta idea a los métodos de trabajo, enfoques y principios de acción. En este sentido su trabajo va destinado a sensibilizar a todos los agentes sociales clave, fomentar la política social para la promoción de la igualdad de trato, desarrollar proyectos de cooperación transnacional y acompañar y asesorar a las víctimas de discriminación por motivos étnicos.

9. Vivienda: este área ofrece asistencia técnica a familias gitanas, como la intermediación en la compra de viviendas o el acompañamiento y mediación con familias gitanas realojadas o con problemática específica relativa a la vivienda.

10. Población reclusa: el objetivo de este área es apoyar la reinserción social de gitanos y gitanas que se encuentran recluidos en centros penitenciarios,

11. Voluntariado: con el fin de lograr un tejido social suficientemente articulado, este área desarrolla un Plan de Voluntariado, considerando que el voluntariado supone una manifestación de solidaridad entre el pueblo gitano y como una oportunidad para la normalización social de la participación de las personas gitanas, mediante un apoyo social a las personas más vulnerables dentro de dicha comunidad.

12. Promoción de la Cultura Gitana: su finalidad es eliminar estereotipos y fomentar la presencia positiva y la producción cultural en la comunidad gitana. 
13. Cooperación Internacional: desarrolla proyectos de cooperación con diversos países, especialmente de Europa del Este.

El trabajo que realiza esta entidad dirigido a mujeres gitanas, parte del siguiente principio: para que las mejoras en la calidad de vida y la igualdad de oportunidades sean reales, se precisa extender las transformaciones emprendidas por algunas mujeres al resto de la comunidad e ir superando las barreras que existen para su acceso a la formación, al mercado laboral, a la política y al ocio. Es por ello, que, además de articular mecanismos propios para la intervención y apoyo a la inclusión social adaptados a los intereses y peculiaridades de las mujeres gitanas, inciden sobre la puesta en marcha de políticas públicas para favorecer la igualdad de oportunidades entre mujeres y hombres, así como entre diferentes culturas.

Son necesarios mecanismos y recursos de apoyo que favorezcan los procesos de inclusión social de la comunidad gitana y en especial de las mujeres gitanas, poniendo en marcha servicios específicos y adaptados a sus peculiaridades e intereses. Con relación a los objetivos de la investigación de esta tesis doctoral, destacamos la siguiente afirmación de la Fundación Secretariado Gitano ${ }^{87}$ : «es muy importante conseguir impulsar proyectos que creen recursos de formación cercanos a la realidad cultural de las mujeres gitanas, donde se les dote de aquellas habilidades personales, sociales y prelaborales que vayan normalizando poco a poco su situación, y les facilite conseguir su promoción personal».

Los principios que orientan el trabajo con mujeres gitanas desde la Fundación Secretariado Gitano son seis:

1. Inclusión de la perspectiva de género en todas las actuaciones y programas que ponen en marcha.

87 Tomada de la página web de la Fundación Secretariado Gitano: http://www.gitanos.org/areas/igualdad_de_genero/fsgg.html 
2. Promoción integral de las mujeres gitanas a partir de la atención a sus necesidades más específicas.

3. Modelo intercultural que fomente las referencias a las mujeres gitanas en las actuaciones de igualdad de oportunidades entre hombres y mujeres no gitanos.

4. Acceso a los recursos normalizados de igualdad de oportunidades.

5. Sensibilización de los agentes sociales, administraciones públicas y sociedad mayoritaria para la eliminación de estereotipos.

6. Fomento de la participación de las mujeres gitanas en los distintos ámbitos de la vida pública como la educación, el empleo el asociacionismo, entre otros.

$\mathrm{Y}$, en coherencia con estos principios se establecen las siguientes áreas de trabajo:

- Educación formal y desarrollo personal, con talleres destinados a construir un espacio de encuentro y reflexión entre mujeres, de desarrollo de sus habilidades relacionales y autoestima, además de un desarrollo de la lectoescritura y las competencias instrumentales básicas.

- Conciliación de la vida laboral, familiar y personal, mediante acciones que promuevan el reparto igualitario del trabajo doméstico, así como la asunción de los roles de «cuidadoras» $\mathrm{y}$ «educadoras» que siguen manteniendo dentro de la familia de manera casi exclusiva, para que se facilite el acceso al empleo.

- Formación, orientación y acompañamiento al empleo desde el Programa de Empleo «Acceder». Fomento de la formación ocupacional y del conocimiento de los recursos del empleo 
normalizados, con el objetivo de ampliar las oportunidades de las mujeres gitanas en el mercado laboral.

- Promoción de la salud de la mujeres gitanas.

- Atención individualizada, tratando de prestar el apoyo adaptado a cada situación.

- Participación social, apostando por las redes de participación social. En este sentido se promueve la participación de las mujeres gitanas en jornadas y seminarios, tanto organizados por la propia Fundación Secretariado Gitano, como participando de los organizados por otras entidades, favoreciendo el encuentro, la creación de vínculos, el debate y la participación social, así como un mejor conocimiento de la situación actual que ellas mismas están viviendo y el esfuerzo que están desarrollando para mejorarla.

- Sensibilización, con campañas específicas que luchan contra los prejuicios y estereotipos y con la participación de personas de la entidad como ponentes, dando a conocer la realidad de la mujer gitana actual.

El Programa Acceder se pone en marcha, en Extremadura, en el marco del Fondo Social Europeo, y en colaboración con los Ayuntamientos de Badajoz y Mérida, en el año 2000; Ayuntamiento de Cáceres en el 2003 y Ayuntamiento de Don Benito en el 2007. Su objetivo ha sido impulsar, a través de acciones centradas en el acceso a la formación profesional y al empleo, la inclusión social de la población gitana y colaborar a que alcance las condiciones medias de vida de las que disfruta ya la mayoría de la ciudadanía extremeña. Esta iniciativa ha promovido acciones y programas que intentan dar respuesta a las necesidades de los gitanos y gitanas de la Comunidad Autónoma. En este marco se están realizando actividades de promoción educativa en etapas universitarias y también se han impulsado actividades 
relacionadas con su promoción a través de Instituto de la Mujer en Extremadura $^{88}$, así como acciones de dinamización y formación de la Juventud Gitana extremeña, a través del Gabinete de Iniciativa Joven ${ }^{89}$. También se realizan actividades de promoción y divulgación de la cultura gitana y de las mujeres, en concreto, mediante charlas en centros escolares, y en la participación en actividades culturales propias de la región.

El proyecto e-Kalex surge en 2009 como una iniciativa innovadora de respuesta a las demandas y necesidades de creación de un grupo de mujeres gitanas de referencia en la región, como se ha explicado en el capítulo anterior. Su base se sustenta en una acción formativa virtual dirigida a 20 mujeres extremeñas, consensuada entre un equipo de trabajo conformado por la investigadora y personas gitanas de la Fundación Secretariado Gitano responsables de los programas de Mujer, Nuevas Tecnologías, Dirección Autonómica y Mujeres de la Región, que hemos llamado «Equipo Asesor», al que se une, posteriormente, Dña. Ma del Carmen Garrido Arroyo, profesora de la Universidad de Extremadura, como directora del curso. Esta acción se sitúa, por tanto, en el marco universitario y en temáticas relacionadas con la igualdad de oportunidades entre hombres y mujeres, el empoderamiento y liderazgo social.

La pretensión última de este proyecto es fortalecer el trabajo que ya realizan estas mujeres a nivel local, empoderarlas a nivel personal y abrirles nuevas puertas a su propia promoción. Todo ello desde una perspectiva comunicativa del aprendizaje (Aubert et al., 2008) desarrollado a través de un entorno virtual.

En los siguientes apartados, se va ampliando el contexto y la información sobre este proyecto que engloba la acción formativa.

88 Dirección web del Instituto de la Mujer en Extremadura: http://imex.juntaex.es/

89 El Gabinete de Iniciativa Joven es un proyecto de la Junta de Extremadura para el fomento del empredimiento creativo y el apoyo a juventud emprendedora. Dirección web: http://www.iniciativajoven.org/ 


\subsubsection{Motivaciones, reflexiones y finalidad de la acción formativa virtual.}

Partiendo de la negociación y reflexión sobre el proceso de planificación educativa a poner en marcha se identifican, de manera conjunta por el equipo de trabajo, varias premisas que se enuncian a continuación.

Por un lado, realización de un diseño colaborativo en el que está implicadas todas las componentes del «Equipo Asesor». Se debe dar la condición fundamental de que tanto el proceso de diseño como el desarrollo, se realice en interacción permanente con aquellas personas a quiénes se dirige o involucra en este proceso. Por eso, la concreción de esta acción no sólo debe ajustarse a las necesidades y demandas de las protagonistas, sino que es necesario dar sentido de «apropiación de la acción», como un elemento fundamental para aumentar las probabilidades de éxito en la propuesta. De ahí que, uno de los puntos clave del proceso sea la participación. Promover la apropiación del proceso es una tarea compleja y constante, no exenta de obstáculos, por lo que deben articularse mecanismos de seguimiento y respuesta ante los posibles inconvenientes que puedan surgir. Para ello se establece la figura de una persona que dinamice el proceso desde esta primera fase de negociación.

Por otro lado, se destaca la necesidad de una acción formativa de calidad fundamentada pedagógicamente. Para ello es preciso que se fundamenten e identifiquen metodologías didácticas innovadoras con TIC. También, es necesario desarrollar un proceso suficientemente flexible para tener en cuenta aspectos imprevistos vinculados, fundamentalmente, al contexto donde se va a desarrollar la acción. Esta característica debe estar presente a lo largo de todo el proceso, tanto de planificación, como de desarrollo y evaluación. 
Se debe tener en cuenta, de igual manera, la sustentabilidad para la implementación de la acción. El proyecto se desarrolla en un contexto institucional que requiere satisfacer compromisos con diferentes organizaciones de carácter financiero-económico, de gestión y de participación.

Por último, existe la necesidad de optar por una modalidad semipresencial en la acción formativa con un porcentaje de virtualidad bastante mayor que de presencialidad (6\% frente al 94\%). Atendiendo a este porcentaje de presencia de las TIC como vehículo educativo-comunicativo, se corresponde a un curso «con ascendente online» (Barberà, 2008), es decir, con alta presencia de las TIC (por encima del 50\%), de ahí la consideración de acción formativa virtual. Este modelo, según la autora, tiene unas características propias:

- Aporta flexibilidad a los procesos de formación.

- Modifica el rol del estudiante, centrando el proceso en su actividad.

- Posibilita a los docentes una visión global y progresiva del aprendizaje, lo que permite valorar el avance de alumnos y alumnas y una mayor visualización de la planificación de los cursos.

- Permite la vinculación a comunidades virtuales a través de la comunicación (intercambio de ideas, dudas, preguntas, etc.)

- Ofrece la posibilidad de acceder a recursos y materiales de estudio compartidos.

- Amplía el ámbito geográfico de acción formativa, no sólo porque permite que alumnado de diferentes lugares acceda, sino porque se puede contar con personas expertas y profesionales de cualquier lugar. 
- Posibilita una comunicación multidireccional y una individualización de la oferta, adaptándose a demandas y necesidades de las personas destinatarias.

- Incluye canales multimediados que permiten mejorar el proceso de formación.

- Incorpora a las sesiones presenciales un conjunto importante de medios comunicativos virtuales y actividades diferentes en relación con los objetivos.

- Tiene una interactividad telemática entre los agentes educativos, profesorado y estudiantes.

- Tiene una elevada funcionalidad, con un diseño ágil de actividades y potencialmente cambiante.

- Tiene múltiples espacios comunicativos que se integran en los espacios virtuales.

- Tiene una ratio de estudiantes moderada si se enfoca, como es nuestro caso, a la creación de redes de aprendizaje.

- Está dirigido al desarrollo de habilidades generales como la indagación, la creación, la valoración y la predicción.

La opción por esta modalidad viene determinada, principalmente, por las destinatarias de la acción formativa, en referencia a varios aspectos:

- Localización geográfica de las participantes: esta formación se oferta para mujeres gitanas residentes en Extremadura. En este sentido, debemos optar por una modalidad no presencial en su mayor parte, 
pues si el proyecto completo se desarrollara de forma presencial no sería posible, si tenemos en cuenta la perspectiva de género ${ }^{90}$.

- Oportunidad de la presencialidad. Se considera la necesidad de realizar tres talleres presenciales, con el fin de facilitar a las participantes el conocimiento directo y el establecimiento de relaciones personales complementarios a los encuentros virtuales previos y/o posteriores. Si nuestra finalidad es conformar una Comunidad de Práctica debemos potenciar, desde el primer momento, la «presencia social» (Garrison y Anderson, 2005). En este sentido, además, consideramos dos cuestiones (Barberà, 2008); si miramos desde los cursos presenciales, aumentamos el tiempo de contacto, aumentando las posibilidades de interacción entre las estudiantes (virtual y presencial); por otro lado, si la mirada se realiza desde un curso totalmente virtual, intentamos agilizar e incrementar la calidad de la interacción virtual, añadiendo espacios de relación cara a cara con las estudiantes.

Observamos que, desde hace varios años, hay un intenso debate académico y numerosas investigaciones educativas en torno a la introducción y uso de las Tecnologías de la Información y Comunicación (TIC) en la formación en los denominados Espacios Virtuales de Aprendizaje (EVA). Cambios metodológicos, nuevos modelos de aprendizaje, nuevas estrategias didácticas, redefinición del rol tutorial en entornos virtuales son, entre otros, los aspectos más estudiados actualmente entre los profesionales de la Educación. Se van destacando, cada vez más, estudios y experiencias de calidad en e-learning desde un enfoque más pedagógico, estudiando la combinación óptima entre los elementos tecnológicos, pedagógicos y organizativos de los entornos virtuales de aprendizaje.

90 Como veremos más adelante, en los datos recogidos en las entrevistas a docentes-tutores/as y a participantes, esta afirmación queda demostrada. 
La acción formativa virtual «e-Kalex» tiene como meta mostrar las posibilidades de uso de las TIC en la promoción de la construcción social del conocimiento, la motivación, el desarrollo de la creatividad, así como la promoción social y cultural de las participantes, desde una investigación pedagógica que explore los fenómenos presentes en una experiencia educativa no formal, no escolarizada, auto-iniciada y de interacción a través de las TIC, con mujeres que pertenecen a un grupo étnico definido (comunidad gitana) y a un contexto geográfico concreto (Extremadura). Una de las preguntas de corte metodológico que recoge este trabajo, como se ha indicado con anterioridad, se relaciona estrechamente con este diseño que presentamos: creemos que se logrará una mayor calidad en los procesos de aprendizaje movilizando aquellas estrategias didácticas que mejor respondan a las características del alumnado, a la materia que estamos trabajando, a la organización y al contexto. Por tanto el diseño, puede considerarse un proceso de intervención siguiendo un modelo de enseñanza-aprendizaje innovador y dialógico que presenta una fórmula integrada y combinada de estrategias didácticas y metodologías mediadas por las TIC.

En las últimas décadas, según señala Díaz Barriga (2005:5) se han empleado muchos esfuerzos para el desarrollo o reconceptualización de «teorías y modelos educativos enfocados a la creación de entornos y comunidades de aprendizaje apoyados con las tecnologías de la información y la comunicación, que han incluido pautas para el diseño, implementación y evaluación de materiales educativos, unidades didácticas, actividades experienciales y objetos de aprendizaje».

Somos conscientes de que para crear un diseño no existe un modelo único, una secuencia única ni pasos fijos a seguir. Nuestra idea ha sido trabajar sobre un conjunto de principios teóricos, técnicas y procedimientos metodológicos, de entre los cuales hemos seleccionado los que mejor se adecuan a la situación que enfrentamos: una acción formativa a través de espacios virtuales dirigida a mujeres gitanas extremeñas. En la propuesta 
didáctica que presentamos, hemos comprobado la necesidad de una formación centrada en experiencias prácticas basada en la comunicación y en escenarios reales, la posibilidad de conseguir aprendizajes significativos, aplicar el conocimiento y solucionar problemas con relevancia disciplinar y social, y promover la adquisición de habilidades superiores complejas. El eje del sistema didáctico lo constituyen el contexto, la situación y el escenario de aprendizaje, y allí es donde se desarrollan metodologías de enseñanza y las relaciones de comunicación (Salinas, Pérez y de Benito, 2008). Cada situación didáctica, ofrece una combinación única e irrepetible de los elementos curriculares y cada situación requiere una estrategia también única que resultará del conjunto de decisiones que se tomen en las fases de planificación y aplicación de la metodología. Otra dimensión que ha de ser considerada en estas situaciones, está relacionada con el aspecto social del alumnado: desde estrategias configuradas para el alumno y alumna individual, hasta las que se sustentan en la actividad de la comunidad.

Mediante la planificación de la acción formativa virtual, concretamos el análisis, organización y presentación con el propósito de lograr las competencias requeridas, planteando el desarrollo de actividades, métodos, materiales, recursos e instrumentos de evaluación necesarios para conseguir una experiencia satisfactoria de aprendizaje. En este sentido, debemos considerar los escenarios más adecuados, para desarrollar un contexto óptimo, dónde las estudiantes construyan su conocimiento, desarrollen habilidades, e incrementen su comprensión, retención y logros de los aprendizajes, teniendo en cuenta las condiciones socioculturales, la heterogeneidad de los estilos de aprendizaje o las motivaciones,

Desde el punto de vista del diseño pedagógico debemos buscar la innovación educativa con una propuesta didáctica flexible, adaptada a las participantes de la acción formativa, con varios modelos metodológicos combinados que prevean estrategias de enseñanza-aprendizaje, seleccionen y faciliten recursos didácticos, diseñen tareas de aprendizaje, y establezcan 
modalidades de evaluación acorde a un modelo orientado a la participación activa, al diálogo igualitario y al trabajo en colaboración para la construcción conjunta de aprendizajes profundos.

Así, en este contexto que presentamos:

1. El modelo de enseñanza-aprendizaje propuesto atribuye un papel central a las alumnas como participantes de su propio proceso de aprendizaje. En este sentido nos referiremos a las alumnas como «las participantes o las estudiantes». Entendemos un espacio virtual de aprendizaje flexible, en el que tutores y tutoras asumen un rol complejo, ejerciendo un papel activo y participativo. En este modelo, el proceso didáctico es entendido como un proceso interactivo de toma de decisiones, tanto por las alumnas como por tutores y tutoras.

2. Nuestra concepción del aprendizaje se basa en que el conocimiento debe ser construido y aplicado por las alumnas, lo cual exige compromiso y participación activa. El método que vamos a presentar incluye un enfoque de aprendizaje cooperativo y dialógico, con la creación de situaciones de aprendizaje que permitan al alumnado la participación en la exploración activa y en la colaboración social.

3. Siguiendo este enfoque, $\mathrm{y}$ desde el punto de vista del diseño, se definen estrategias de aprendizaje centradas en las participantes que respondan a actividades colaborativas y basadas en la discusión y en la construcción del conocimiento. Para ello se disponen de espacios abiertos para el fomento de interacciones entre participantes en la formación y, en cada área temática, espacios de comunicación, discusión, para compartir recursos o realizar preguntas. También se incluyen lugares para la organización de aspectos administrativos, técnicos u otros en relación con el buen desarrollo y progreso del curso. 
A través de esta acción formativa, se pretende facilitar un espacio virtual de aprendizaje en el que las mujeres participantes se capaciten para orientar estrategias que, en materia de igualdad de oportunidades se puedan implementar desde cualquier ámbito, especialmente las dirigidas a su propia promoción y a la de las mujeres gitanas de su entorno.

La finalidad última se dirige a promover el inicio de una Comunidad de Práctica para que, tras el proceso de formación establecido, continúen con ese trabajo conjunto de promoción sociocultural y visibilidad propia y de su propia comunidad. Esta Comunidad de Práctica resultaría tras el proceso formativo, constituyendo un grupo de mujeres gitanas referentes para el desarrollo de acciones de promoción, en materia de igualdad de oportunidades, con población gitana extremeña. Dicho de otro modo, lo que se pretende impulsar es la promoción sociocultural de las mujeres gitanas, fomentando y estimulando la creación de una Comunidad de Práctica, para la generación de conocimiento e información sobre la situación de la mujeres gitanas extremeñas en varios ámbitos y para establecer nuevos lazos de comunicación entre las mismas. De manera transversal, la adquisición y apropiación de algunas herramientas tecnológicas por parte de mujeres gitanas puede influir en sus comunidades, ya que esos conocimientos impactarán principalmente en el desempeño de sus funciones, renovando el formato de sus prácticas de participación actuales.

\subsubsection{Selección de la Plataforma tecnológica de desarrollo de la acción formativa virtual.}

Al pensar en la plataforma tecnológica para llevar a cabo la acción formativa virtual se tienen en cuenta varias cuestiones fundamentales para un buen desarrollo: que funcione con una configuración de hardware básico, que sea compatible con especificaciones técnicas internacionales, que sea 
accesible a través de cualquier navegador de Internet y que resulte fácil de utilizar. Añadido a lo anterior, uno de los componentes más importantes para el éxito en la formación online es el mantenimiento de interacciones consistentes y de calidad ya que la eficacia del proceso de enseñanza y aprendizaje es proporcional a la riqueza de flujos que se establecen entre los participantes (Marcelo et al., 2002). Por tanto, hay que asegurarse de que el entorno virtual nos ofrezca herramientas para facilitar la comunicación e interacción entre todas y todos los agentes participantes en una acción formativa. Desde esta visión y teniendo en cuenta el valor añadido que se infunde al curso si se realiza en un ámbito universitario, se selecciona el Campus Virtual de la Universidad de Extremadura y por tanto, su plataforma de sustento. El Campus Virtual de la Universidad de Extremadura está soportado bajo la plataforma Moodle que tiene una arquitectura basada en el trabajo colaborativo para el desarrollo de curso en línea, constituyendo un soporte que permite a los y las estudiantes coordinar sus trabajos en grupo, compartir información y recursos y disponer de un espacio en la red accesible desde cualquier ordenador que disponga de conexión a Internet. Moodle es un sistema de gestión de cursos de distribución libre (mediante licencia Open Source) que ayuda a los educadores a crear comunidades de aprendizaje en línea, iniciado por Martin Dougiamas, como alternativa a las plataformas comerciales de difícil acceso desde las instancias educativas por el alto coste y además por la falta de herramientas tecnológicas en las que se tengan en cuenta aspectos pedagógicos (Dougiamas y Taylor, 2002, 2003). Es una plataforma especializada en contenidos de aprendizaje y ofrece funcionalidades didácticas muy interesantes y variadas, con un entorno basado en un diseño modular flexible, lo que ha provocado que, actualmente, sea la plataforma más utilizada en el mundo académico. La primera versión apareció en agosto de 2002 (Dougiamas y Taylor, 2003) y hasta julio de 2008 tiene más de 21 millones de usuarios distribuidos en 46.00o lugares en todo el mundo y está traducida a más de 75 idiomas ${ }^{91}$. Además, permite la

${ }_{91}$ Datos tomados de la enciclopedia libre Wikipedia: http://es.wikipedia.org 
importación y exportación de datos, acepta paquetes educativos (Learning Objects) en formato SCORM y está preparado para migrar desde y hacia cualquier plataforma educativa.

El interés clave, a nuestro punto de vista, para el uso de este Campus Virtual en Moodle es el carácter de software libre, el enfoque y la filosofía de corte constructivista sobre la que está diseñado y la gran interactividad que presenta, favoreciendo una intensa participación del alumnado en la labor del aprendizaje. Además, es accesible desde cualquier ordenador que posea un navegador (Internet Explorer, Mozilla Firefox, Chrome u otros navegadores).

La plataforma Moodle, que como decimos, sustenta el Campus Virtual de la Universidad de Extremadura, tiene un diseño basado en los principios del constructivismo social. El principio fundamental que guía este diseño, es que la construcción de conocimientos se realiza en el ámbito de un grupo social el aprendizaje es un fenómeno social-, creando colaborativamente -trabajo colaborativo- una pequeña cultura de artefactos compartidos con significados compartidos. En este espacio, la comunicación entre los participantes tiene un espacio relevante para la construcción de conocimientos y el docente debe convertirse en facilitador, animando a los estudiantes a generar conocimiento trabajando en la resolución de problemas reales en un proceso social colaborativo. Desde esta perspectiva, las actividades son la base fundamental de este sistema de gestión de cursos.

Así, Moodle nos permite la organización adecuada del curso, en base al diseño presentado, y su gestión. El formato de presentación nos permite adaptarnos a un tipo de navegación acorde al diseño pedagógico presentado. En este sentido, las maneras de organización del espacio que ofrece Moodle, son interesantes para agrupar las propuestas de contenido de manera significativa en torno a las perspectivas que se quieran desarrollar. 
De cara a los principios de participación y colaboración de nuestro diseño, nos da la posibilidad de crear espacios adecuados a los diferentes grupos de trabajo y de poder gestionar esos propios espacios, además de hacer posible el trabajo colaborativo mediante los módulos disponibles, el compartir materiales y definir actividades. Por otro lado, consideramos que la facilidad y sencillez de acceso al espacio compartido, por parte de las participantes, permite el seguimiento adecuado durante todo el curso. Además, es una plataforma actual, en constante proceso de mejora y posee una curva de aprendizaje de corto recorrido, lo que permite facilitar la interacción entre las personas usuarias del sistema.

El contexto de Moodle nos permite establecer metodologías de trabajo en torno a información compartida y nos posibilita el proceso de comunicación por el que se van a regular las actividades colaborativas e interacciones entre las participantes, fundamentales para el proyecto pedagógico que subyace en nuestra propuesta. Para todo ello, la plataforma Moodle ofrece una diversidad de módulos que constituyen un conjunto de servicios herramientas para el diseño del sistema de actividades y tareas de los cursos.

Otra característica de Moodle es la conexión, ya que permite una navegación sencilla a través de los enlaces, que siempre están visibles. El alta de una cuenta inicial puede hacerla el propio alumno y alumna o el administrador/a. Cada estudiante se puede conectar en cualquier momento, desde cualquier lugar para acceder al curso y pueden especificar la zona horaria y el idioma que desean utilizar. El profesorado pueden exigir una palabra clave para permitir la inscripción en un curso. Si los y las estudiantes se inscriben a los foros, los nuevos mensajes serán enviados vía correo electrónico.

El entorno virtual Moodle tiene una gran potencialidad como herramienta para la comunicación y el trabajo conjunto (Correa, 2005). De este modo esta plataforma nos facilita un soporte para gestión de información y 
documentación (funcionalidades relacionadas con la planificación y gestión), del alumnado (organización del trabajo, cronograma de actividades, tareas de evolución, etc.) y, lo más significativo, como espacio virtual para el desarrollo de actividades en el ámbito del aprendizaje colaborativo a través de las diferentes actividades didácticas que se ofrecen (funcionalidades vinculadas a la comunicación) como Tareas, Foros, Wikis, Glosarios, Chat y Cuestionarios.

\subsubsection{Selección de expertos y expertas para la acción tutorial.}

El equipo de docentes debe ser el adecuado a los requisitos del curso. Nuestro interés, en esta línea, es identificar a expertos y expertas en la materia. Para ello, el equipo de trabajo determina tres criterios fundamentales para su selección:

- La experiencia profesional o académico-científica en el campo propuesto (pueden ser del ámbito universitario o profesional).

- Experiencia en tutorización en cursos virtuales.

- Experiencia previa o sensibilización en temáticas relacionadas con población gitana.

Se proponen posibles candidatos y candidatas para cada temática, seleccionando, finalmente:

Ámbito universitario.

- Jesús Valverde Berrocoso. Profesor Titular de Universidad. Experto en Tecnología Educativa. Director del Campus Virtual de la Universidad y Director del Grupo de Investigación reconocido «Nodo Educativo». Universidad de Extremadura. 
- Joaquín García Carrasco. Catedrático de Pedagogía de la Universidad de Salamanca. Fue coordinador del Laboratorio de Diseños Educativos multimedia y teleeducación y dirigió el Programa de Doctorado «Procesos de Formación en Espacios Virtuales». Pertenece a un grupo de investigadores interdepartamental (Departamento de Teoría e Historia de la Educación, Departamento de Informática y Automática y CEDETEL-Centro para el Desarrollo de las Telecomunicaciones de Castilla y León).

- $\mathrm{M}^{\mathrm{a}}$ del Carmen Garrido Arroyo. Profesora Titular de Escuela Universitaria. Experta en Animación Sociocultural e Interculturalidad. Miembro del Grupo «Nodo Educativo». Universidad de Extremadura.

- Beatriz Muñoz González. Profesora de Sociología. Experta en políticas de igualdad. Experiencia relacionada con población gitana. Universidad de Extremadura.

- Fernando Rey Martínez. Catedrático de Derecho Constitucional de la Universidad de Valladolid. Experto en Igualdad de Oportunidades y de Trato. Patrono de la Fundación Secretariado Gitano.

- Joan Barstow Hernández. Experta en Liderazgo Social. Experiencia en formación en liderazgo de agentes sociocomunitarios en población indígena. Universidad Nur (Santa Cruz-Bolivia).

Ámbito Profesional:

- María García Sánchez. Licenciada en Derecho. Experta en Igualdad.

- Valentín Suárez Saavedra. Experto en Historia, Identidad y Cultura Gitana. Patrono de la Fundación Secretariado Gitano. 
- Tamara Carrasco Torres. Licenciada en Pedagogía. Experta en Igualdad y mujer gitana. Responsable Área de Igualdad de Género de la Fundación Secretariado Gitano (Estatal).

- Instituto de la Mujer de Extremadura -IMEX- (personal a cubrir). Experto/a en políticas de igualdad.

\subsubsection{Modelo de planificación del diseño de la acción formativa.}

Al planificar una acción formativa, es necesario desarrollar un marco que permita alcanzar los resultados deseados de modo eficaz y eficiente. Ese marco debe tener una naturaleza didáctica intentando desarrollar y generar, desde la base, las competencias a adquirir definidas previamente. Desde nuestro objetivo de desarrollar un entorno de aprendizaje virtual, el diseño didáctico es fundamental, concibiendo el diseño como «la selección, la estructuración y el diseño orientado a las competencias y a los objetivos de aprendizaje de posibles contenidos de aprendizaje para convertirlos en contenidos de aprendizaje reales» (Blumschein y Fischer, 2007:19). En todo este proceso, debemos tener en cuenta la calidad de la formación virtual por la que se apuesta, valorándose criterios que den un enfoque sistémico al contexto educativo en el que se desarrolla la acción formativa. Gustafson y Branch (2002) afirman que existe una gran variedad de modelos de diseño instruccional y que el propósito de los mismos es ofrecer pasos para el diseño, guía y opciones de colaboración entre los encargados y encargadas del diseño, de la implementación y de aquellos y aquellas estudiantes que van a recibirla. Según los autores, el modelo de diseño se puede definir como una forma de hacer algo, una representación explícita de la realidad. Nos sirve para conceptualizar el esquema o proceso complejo del diseño instruccional, en diferentes etapas que a su vez se relacionan entre sí. La aplicación y el valor 
de un modelo va a depender de la situación y contexto formativo en el que lo desarrollemos (Ryder, 2006).

Desde nuestra perspectiva nos centramos en el modelo de planificación educativa del diseño instruccional -DI- (Instructional Design) planteado por Blumschein y Fischer (2007) por medio del enfoque ADDIE (cfr. Strickland, 2006), basando cada fase en estrategias que se derivan del modelo «Comunidad de Indagación» de Garrison y Anderson (2005) para la conformación de Comunidades de Práctica, como se ha fundamentado en el marco teórico asumido en esta Tesis Doctoral. Desde el enfoque del diseño instruccional ADDIE se hace referencia a la sistematización interdisciplinaria de cinco elementos: análisis, diseño, desarrollo, implementación y evaluación (Leshin, Pollock y Reigeluth, 1992; Dick y Carey, 1996; Niegemann et al., 2002).

En cuanto a la primera fase, Análisis, se debe identificar el problema de aprendizaje, las metas y competencias a desarrollar, las necesidades de las personas destinatarias de la formación y sus conocimientos previos, además de cualquier otra características que se puede considerar relevante. El análisis también considera el ambiente de aprendizaje, las limitaciones de la acción formativa y la temporalidad propuesta.

El Diseño, se considera un proceso sistemático donde se especifican competencias, propuestas temáticas o unidades de aprendizaje, el diseño de las interacciones, actividades didácticas y tipologías de evaluación a desarrollar.

La fase de Desarrollo se basa en la producción de todo lo planteado en el diseño al entorno virtual de la acción formativa, es decir, cómo se organiza el diseño planteado dentro de la plataforma seleccionada, constituyendo la estructura pedagógica de la acción formativa, 
La Implementación, como cuarta fase, en la ejecución del plan de acción diseñado y producido.

La quinta fase, Evaluación, define la necesidad de estar presente en todas las fases del proceso basado en el diseño ADDIE, a modo de evaluación formativa, revisando aquellas cuestiones que se consideren necesarias. Debe establecerse una evaluación final o sumativa, en el que se asegure la oportunidad de retroalimentación por parte de las estudiantes.

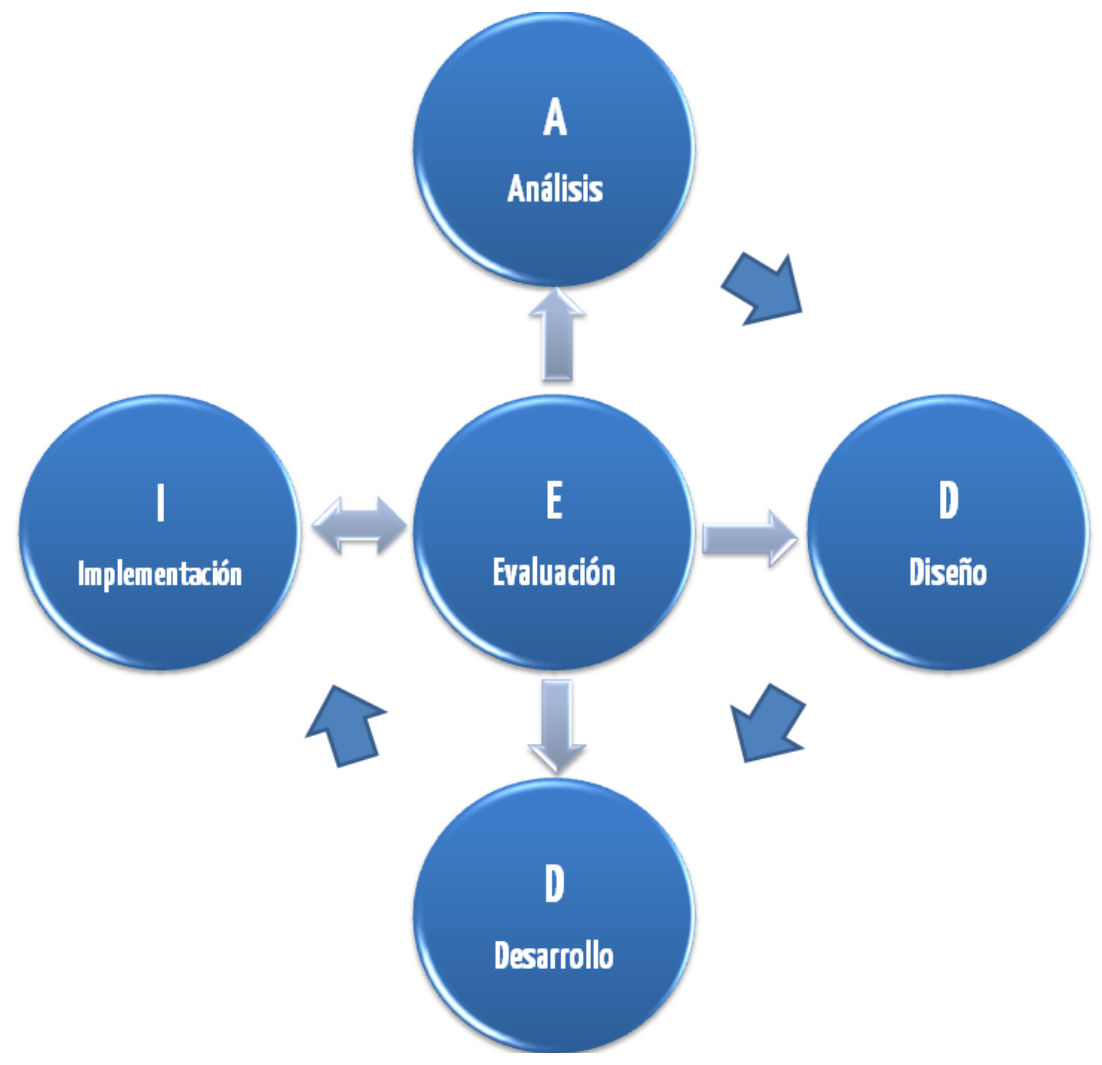

Figura 24. Proceso de diseño de la acción formativa virtual siguiendo el Modelo ADDIE.

Este modelo general incide en la retroalimentación continua, mientras el diseño está siendo creado, flexibilizando el proceso. En este marco, la planificación del diseño didáctico se centra en el proceso de planificación y realización de acciones formativas centradas en las propias estudiantes, como veremos en los apartados siguientes. 


\subsection{Fase de Análisis}

\subsubsection{Análisis del público objetivo: destinatarias de la experiencia e-learning.}

Desde una perspectiva didáctica, el análisis del grupo meta o análisis de las características del alumnado es el criterio decisivo en todo tipo de acción formativa, especialmente, si se trata de acciones de e-learning (Blumschein y Fischer, 2007). Es por ello que se presenta el análisis del grupo meta, desde la visión más amplia, las mujeres gitanas, para luego centrarnos en las mujeres gitanas de Extremadura, y más concretamente, en las mujeres gitanas solicitantes y, por tanto, destinatarias de la experiencia e-learning.

\subsubsection{Las mujeres gitanas: un acercamiento desde la perspectiva de género.}

La comunidad gitana española se caracteriza por ser muy heterogénea en su composición, situación social, comportamiento y modos de vida, si bien se reconocen a sí mismos como parte de una cultura e identidad étnica que comparte valores, creencias y costumbres (San Román, 1997).

En este contexto, la comunidad gitana se encuentra en un proceso de transformación importante en relación estrecha con los cambios que se están produciendo en el entorno social más amplio del que forma parte, esto es, la sociedad española actual. Sin embargo, aunque se encuentran opiniones similares sobre esta circunstancia (Clavería, 2004; Sánchez, 2004; González, 2005; Suárez, 2007; Moro, 2009) faltan estudios sociales específicos sobre la incidencia de los cambios actuales en el entorno de su cultura, sobre las

pautas de conducta que permanecen inalterables y cuáles están transformándose en este momento. Esta circunstancia se puede transferir si 
hablamos de las mujeres gitanas, aunque desde diferentes entidades y asociaciones que trabajan para la promoción de éstas, coinciden en que es el momento propicio para que las mujeres gitanas asuman un rol protagonista en ese cambio propio que, con esta sociedad y con su propia comunidad, están experimentando.

Moro (2009:10), sustenta esta opinión:

«Hay que aprovechar la situación de hoy en día para que cada mujer gitana pueda alcanzar sus logros, más allá de los roles de género asignados tradicionalmente, sin quedar atrapadas en los mandatos externos $y$, en lo posible, sin tener que pagar un precio demasiado alto por decidir y elegir por sí mismas. Coexisten realidades diversas entre las mujeres gitanas $y$ es difícil transmitirlas sin caer en simplificaciones estereotipadas».

Es un hecho que «[...] hoy en día, en la sociedad española, como grupo étnico-cultural, padecen una situación diferente con respecto a una mayoría, viéndose afectados doblemente: por ser mujeres en una sociedad patriarcal y por pertenecer a una minoría étnica» (Villalba et al., 2000:20). $\mathrm{Y}$ es que, las mujeres gitanas, pertenecen a una cultura cuyos valores de género están asociados «casi exclusivamente a la función de madre y esposa disminuyendo sus posibilidades de promoción», (Fundación Secretariado Gitano, 2009:4), con el hándicap de pertenecer a una minoría étnica que recibe la más baja valoración social, según los últimos barómetros del Centro de Investigaciones Sociológicas ${ }^{92}$. $\mathrm{Si}$, además, todo lo anterior se asocia a escasez de recursos económicos y a exclusión social, nos encontramos ante una situación de máxima desprotección social. En referencia a la salud, los datos muestran una menor esperanza de vida de mujeres gitanas frente a hombres gitanos y mujeres no gitanas, tasas de fecundidad más altas en comparación con las mujeres no gitanas, envejecimiento prematuro y

92 Disponibles en: http://www.cis.es/cis/opencm/ES/11_barometros/index.jsp 
enfermedades no comunes a su edad (Villalba et al., 2000; Fundación Secretariado Gitano, 2005b).

En el informe presentado por la Fundación Secretariado Gitano ante el Comité para la Eliminación de todas las formas de discriminación contra las mujeres en la sede del Alto Comisionado de Naciones Unidas, en Nueva York (Fundación Secretariado Gitano, 2009), se destaca que las mujeres gitanas, al igual que le ocurre al resto de la comunidad, se sienten víctimas de los estereotipos, llegando estos a dictaminar todos sus comportamientos. Profundizando en las visiones estereotipadas sobre las mujeres gitanas españolas, González (2005:1) diferencia entre:

- un estereotipo idealizado que se genera desde dentro de la comunidad en el que se les otorgan determinados atributos, como el de «ser puras, vírgenes, fieles (conyugal y comunitariamente), trabajadoras y con obediencia ciega a todo rasgo tradicional gitano».

- y uno desde fuera de la comunidad, el imaginario social que representa a una mujer gitana «como subyugada por la familia, sucia, perezosa, analfabeta, casada a los 14 años, madre de numerosísimos hijos/as y ubicadas siempre entre el hogar y los mercados». Además, existe una visión general de obediencia a los hombres de su familia, como recoge Mateo Maximoff (citado en Moro, 2009:10): «Cuando es pequeña obedece a su padre, de jovencita a su padre y a sus hermanos; de casada al marido y de vieja a los hijos».

Aunque se reconoce que las gitanas contribuyen notablemente a la producción y a la subsistencia familiar más allá del trabajo doméstico debiendo buscar recursos, sobre todo económicos, fuera del ámbito familiar; se niega la existencia de este perfil y características en algunas mujeres gitanas, reclaman el reconocimiento de la heterogeneidad del grupo como característica del mismo (Fundación Secretariado Gitano, 2009). 
Fundamentan esta idea en que las mujeres gitanas cumplen con un papel más activo que el que presentan los estereotipos mencionados y los prejuicios de los exogrupos con los que se convive en un mismo contexto social:

\begin{abstract}
«[...] Ninguna mujer vive en correspondencia con los estereotipos tradicionales. La modernidad ha significado cambios profundos en la feminidad y en la vida cotidiana tradicional de las mujeres (deculturación), independientemente de que eso las beneficie o las perjudique. Asimismo, la modernidad ha irrumpido en sus vidas, más allá de su voluntad y conciencia e, incluso, en contra de su voluntad» (Lagarde, 2000:45).
\end{abstract}

Según la última investigación publicada con relación a la situación del pueblo gitano en Extremadura, (Moreno y Sánchez-Oro, 2006), el rol de la mujer gitana en la región, sigue siendo en lo esencial «muy tradicional», esto es, volcada en el matrimonio, relegada a las tareas domésticas y de apoyo a la función económica del marido. En este estudio los datos reflejan que siguen dedicándole una exclusividad a las tareas del hogar, la atención y el cuidado a mayores y niños/as, siendo pocas las que trabajan fuera del hogar. Los hombres gitanos consideran que la situación de sus mujeres ha cambiado mucho en los últimos años y afirman que ellas muestran un mayor interés por formarse. No obstante, este estudio concluye que la autopercepción de las mujeres gitanas sobre su situación es de ligero cambio.

La realidad de la vida diaria de las mujeres gitanas es más variada y compleja de lo que cabría esperar de un análisis superficial y simplista y explica la doble moral a la que se tienen que enfrentar:

«En el intento de responder a los mandatos tradicionales y a las tendencias modernas, las mujeres gitanas contemporáneas viven una doble vida, de trabajo visible e invisible, de esfuerzos reconocidos y no reconocidos. En ocasiones, al intentar salvaguardar la identidad gitana, se producen radicalizaciones de los modelos femeninos tradicionales, las mujeres se apropian de 
rasgos culturales típicamente gitanos que permitan una diferenciación cultural con el exogrupo como estrategia de resistencia: para que el grupo de pertenencia vea que no dejan de ser gitanas aunque asuman algunos comportamientos «más modernos». Esto ocurre, sobre todo, en los casos en que aún se considera que la formación de las mujeres está reñida con el ser una «buena gitana». Impera una doble moral que, por un lado, alienta a seguir con los procesos individuales de superación, y por otro, cuestiona el que se abandonen rasgos tradicionales de la identidad cultural gitana» (Moro, 2009: 28).

Pese a todo ello, van superando obstáculos, compaginando las tendencias de la vida actual con sus tradiciones, lo que va provocando cambios en su entorno socio-cultural, en el que se va encontrando apertura a comportamientos «más flexibles y abiertos, a transformaciones y adaptaciones al entorno que parecen necesarias para la propia supervivencia» (Moro, 2009:31).

Esto se muestra en estudios y artículos relacionados con esta temática (Domínguez, Flecha y Fernández, 2004; Fundación Secretariado Gitano, 2005c; Valls et al. , 2005; Elboj y Vicen, 2007; Montañés, 2011), en los que se determina que la mujer gitana de hoy tiene ante sí nuevos retos relacionados con su situación en la sociedad y dentro de su propia cultura. Sobre todo en los últimos años, en los que las mujeres gitanas, especialmente las jóvenes, están perdiendo el miedo a la libertad. En este sentido, las mujeres gitanas equilibran en el desempeño de su rol los valores más tradicionales que le exigen el desarrollo de su función como hija, madre y esposa, con otros nuevos, consecuencia de la mayor participación en otros ámbitos de la sociedad. De hecho, el asociacionismo en la población gitana ha sido un movimiento social protagonizado eminentemente por mujeres y que ha favorecido su promoción (Sánchez, 2004). Pese a que el asociacionismo en la mujeres gitanas tiene una trayectoria de alrededor de 20 años, con el 
nacimiento de la primera asociación de mujeres gitanas en Granada en los años 90, no se han sentido identificadas con el movimiento feminista en España (de Botton, Elboj y Martín, 2001), aunque sí que se encuentra alguna reseña referida al «feminismo gitano» (Sánchez, 2004). De ahí que a principios del siglo XXI se comenzara a hablar de «feminismo dialógico» (Puigvert, 2001), fundamentado desde el diálogo igualitario entre todas las mujeres, independientemente de su cultura, edad y nivel educativo, cuyo principio marco parte del reconocimiento de todas las mujeres como seres de transformación y del concepto de igualdad de las diferencias, entendiendo que la verdadera igualdad incluye el mismo derecho de toda persona a vivir de forma diferente (Flecha, 1997).

Junto al asociacionismo, otros factores han propiciado el avance de la situación de las mujeres gitanas:

- El acceso a la Educación y a la formación, con la escolarización generalizada de niñas y niños gitanos (Moro, 2009). El estudio desarrollado por la Fundación Secretariado Gitano sobre la incorporación y trayectoria de las niñas gitanas en la Educación Secundaria Obligatoria (Fundación Secretariado Gitano, 2006) concluye que se ha conseguido normalizar la escolaridad en la etapa de educación obligatoria, pero continua el problema del absentismo en los cursos superiores de la enseñanza obligatoria. Aunque ese dato se refiere a ambos sexos, es interesante subrayar que las chicas muestran un mayor esfuerzo y motivación hacia los estudios y mejores resultados académicos que los chicos, pese a que los obstáculos de permanencia en las aulas son mayores para las gitanas que para los gitanos. Por otro lado se revela que en la escuela las niñas se adaptan mejor al planteamiento educativo, en la adquisición de patrones de conducta, incorporación a la rutina escolar, y también mejoran en la relación que mantienen con compañeros y compañeras. Además, se 
incide en el cambio significativo que están protagonizando, continuando sus estudios más allá de la Educación Primaria. En referencia a mujeres gitanas adultas, manifiestan más interés en formarse, aunque tienen menos oportunidades que los hombres por las responsabilidades que tienen a su cargo, que integra la ocupación del tiempo por parte de las mismas, debido a la imposición del rol tradicional de cuidadoras y educadoras. También se apunta a que, aunque la mujer fue la primera en acceder a niveles superiores de la enseñanza reglada, es decir, a Secundaria no obligatoria y a la Universidad, actualmente es poco significativa la diferencia numérica respecto al hombre.

- La inserción laboral está siendo un eje fundamental de las políticas de inclusión social europeas, sobre todo en referencia a mujer gitana y mercado laboral, que está contribuyendo a superar su triple exclusión (Serradell, Sordé y Vargas, 2006). Con las nuevas ocupaciones, a la necesidad de colaborar en el sustento familiar, se empieza a unir un deseo de promoción personal e independencia (Moro, 2009). Para ello, es necesario que vayan superando las inseguridades relacionadas con su percepción de capacidad para desarrollar el trabajo que deban ejercer y la habilidad para gestionar el tiempo. Todo ello va unido al valor del tiempo de las mujeres gitanas y la necesidad de traspasar las limitaciones temporales que impone su dedicación al hogar o al cuidado de hijos e hijas, personas enfermas o ancianas, para invertir en formación o tiempo de ocio.

- También cabe destacar el proteccionismo ejercido por la familia hacia las jóvenes, que puede influir en la continuación de su formación o la búsqueda de un empleo y su mantenimiento. Por eso para la mejora de la empleabilidad se han de tener en cuenta, su modo de vida y rol dentro de la familia, así como su promoción personal y laboral. 
- La participación social y la globalización de las relaciones entre mujeres (Sánchez, 2002). Las mujeres gitanas están asumiendo un papel más activo en el ámbito público, tomando posiciones en el mundo de la representación civil y en la organización social, sobre todo a través del asociacionismo. Pero no sólo, sino que cada vez más participan con mujeres de otras culturas en debates sobre la superación de las desigualdades sociales, encontrando nuevas formas de convivencia e intervención educativo-social. $\mathrm{Y}$ en proyectos de educación no formal, (como talleres, escuela de madres y padres) en los que su contenido sea cercano a su modo de vida, y satisfaga sus necesidades y objetivos.

Desde varios frentes (asociaciones, entidades del tercer sector social, poderes públicos, etc.) destacan que el momento actual es favorable para el empoderamiento de las mujeres gitanas. En este sentido, en el «Informe Sombra» ${ }^{93}$ (Fundación Secretariado Gitano, 2009), incide en los factores de cambio que están favoreciendo la mejora actual de su situación:

- En primer lugar, existe una actitud transformadora de un número importante de mujeres gitanas, especialmente jóvenes, que propulsan el cambio dentro de sus propias comunidades y de la sociedad en general. Esta actitud se muestra mediante una creciente motivación hacia el acceso al empleo, la formación y el ocio, un aumento significativo de las mujeres gitanas que estudian y trabajan, un mayor retraso en la edad del casamiento y una mayor capacidad para decidir entre matrimonio o soltería, una mayor convivencia en espacios abiertos como centros de formación, universidades, espacios de trabajo, entre otros. Este último aspecto, además, les proporciona un

93 El Comité para la Eliminación de todas las formas de Discriminación contra la Mujer, entre sus últimas recomendaciones al gobierno de España incluyó que sus informes aportaban escasos datos sobre niñas y mujeres gitanas, por lo que la Fundación Secretariado Gitano apostó por la elaboración de un «Informe Sombra» para la 44th Sesión (http://www2.ohchr.org/english/bodies/cedaw/cedaws44.htm) de la Convención sobre la eliminación de todas las formas de discriminación contra la mujer (CEDAW) en 2009 en la oficina del Alto Comisionado de la ONU en Nueva York. 
desarrollo de su autonomía personal, por la necesidad de aprender estrategias y recursos individuales para comunicarse, resolver problemas o buscar información.

- Un segundo factor tiene relación con las cualificaciones informales que aprenden en el seno familiar en torno a la experiencia que desde muy jóvenes desarrollan con relación a sus responsabilidades domésticas y el cuidado de personas mayores y menores.

- Un tercer factor, en relación con el anterior, es el sentimiento de responsabilidad, una actitud que practican desde muy pequeñas $y$, gracias al cual, responden positivamente a acciones formativas y de capacitación que se les ofrece desde diferentes entidades.

Aunque todo ello refleja una visión muy positiva en el desarrollo y promoción de las mujeres gitanas, aspecto que se va viendo reflejado en las políticas públicas, hay algunas cuestiones que aún deben mejorar, como las que se desprenden del «Informe Sombra» (Fundación Secretariado Gitano, 2009):

- Lentitud en la implantación de la directiva referida a la Igualdad de Trato y no discriminación (Directiva 2000/43/CE).

- La ausencia de datos desagregados por sexos y etnia dificulta que se conozcan el grado real de acceso de las mujeres gitanas a servicios tales como educación, empleo vivienda, salud y participación política, aún reconociendo en los Planes de Inclusión Social la importancia de estos datos.

- El desconocimiento de la cultura gitana de los recursos normalizados destinados a la atención a víctimas de violencia de género contra las mujeres y el escaso uso que se hace de ellos por parte de las mismas. 
- Los estereotipos y prejuicios, especialmente los referidos a las mujeres gitanas, que ofrecen los medios de comunicación.

- La escasa participación de mujeres gitanas en la vida política, concretamente en referencia a la participación de mujeres gitanas en candidaturas que se presentan a elecciones locales, autonómicas y generales.

- El insuficiente apoyo a las niñas y jóvenes gitanas para permanecer en el sistema educativo.

- La incapacidad de las políticas públicas de empleo para subsanar, en las mujeres gitanas, la menor tasa de actividad laboral, la mayor tasa de paro, una marcada temporalidad en el empleo, el desempeño de trabajos de jornada a tiempo parcial el gran peso en obligaciones familiares que resta posibilidades en el acceso al empleo remunerado.

- La mejora de la atención sanitaria de la mujer gitana (Fundación Secretariado Gitano, 2005b): establecimiento en los centros sanitarios de protocolos adaptados para mejorar el entendimiento entre profesionales de la sanidad y estas mujeres; potenciar la relación empática y los aspectos culturales en los curriculum universitarios de titulaciones del ámbito de ciencias de la salud; mejorar y aumentar los programas de intervención en temáticas de salud y mujeres gitanas, ampliando los existentes en algunas comunidades autónomas, contando con medios y respaldo político e institucional.

A pesar de los obstáculos, el informe sostiene que nos encontramos en el «tiempo de las mujeres» de la Comunidad Gitana y que, a través del diálogo, la reflexión, de su esfuerzo y de la participación creciente en diferentes ámbitos de la sociedad, están aportando nuevos significados a la identidad cultural del pueblo gitano. Estas mujeres que participan en dispares ámbitos 
sociales están convirtiéndose en referentes para otras personas gitanas, transmitiendo nuevos valores a las generaciones más jóvenes.

En el Manifiesto, elaborado el 8 de Marzo de 2010, día de la mujer trabajadora, del Grupo de Mujeres Gitanas de la Fundación Secretariado Gitano, se resume el estado actual y la principal reivindicación de las mujeres gitanas en la sociedad actual ${ }^{94}$ :

«[...] A pesar de estos obstáculos en el camino hay aspectos muy favorecedores para la mejora de la situación de las mujeres gitanas, como son una actitud transformadora de cada vez un número mayor de gitanas, una creciente motivación hacia la educación y la formación, y el comienzo de la inclusión de las mujeres gitanas en la universidad, donde podemos encontrar datos tan relevantes como que ellas representan el $80 \%$ de las personas gitanas que acceden a una carrera universitaria. Además se está produciendo un incremento de gitanas que se incorporan al mercado laboral, y una mayor convivencia en espacios abiertos e interculturales. Todo esto está dando lugar no solo a cambios dentro de la propia comunidad gitana, sino en toda la sociedad.

\section{$[\ldots]$}

La especificidad de género y cultura supone tener en cuenta aquellas características que provocan que las oportunidades de las gitanas se vean disminuidas en relación con los varones de su comunidad y con la sociedad en general. Y por eso estas son las garantías que una sociedad debe poner en marcha para atender a las problemáticas específicas, comprendiendo que el punto de partida no es el mismo para todas las mujeres $y$, por lo tanto, el camino a recorrer debe $y$ puede ser diferente.

Las mujeres gitanas somos mujeres, somos gitanas, somos diversas, mujeres entre muchas aguas... pero dueñas de nuestras vidas $y$ nuestros destinos»

94 Tomado de la Comunicación de Prensa de la Fundación Secretariado Gitano con motivo del Día Internacional de la Mujer Trabajadora en 2010 http://www.gitanos.org/servicios/prensa/comunicados/49408.html 


\subsubsection{Las mujeres gitanas extremeñas solicitantes de la acción formativa.}

Las mujeres gitanas destinatarias potenciales del proyecto e-learning tienen dos rasgos identitarios comunes: son extremeñas y gitanas. Aún así, van a responder a una heterogeneidad de circunstancias propias que hacen que no se puedan establecer más características similares: algunas serán estudiantes universitarias, algunas trabajarán dentro del hogar, otras estarán incorporadas al mundo laboral por cuenta ajena; unas tendrán hijos, otras no; unas estarán casadas, otras no; etc. Con esto queremos decir que no podemos establecer un perfil genérico de las potenciales participantes fuera de las dos características mencionadas, no por ello dejamos de tener en cuenta algunas cuestiones que se presentan, adaptando los puntos propuestos por Schüpbach, Guggenbühl y Krehl, (2003, mencionado en Blumschein y Fischer, 2007:24) y basándonos en el cuestionario de solicitud (Anexo II) de la acción formativa propuesta:

La solicitud de acceso a la acción formativa virtual la realizaron 32 mujeres gitanas de la región. El proceso de selección se realizó atendiendo al riguroso orden de inscripción.

- Características sociodemográficas:

Edades: Las edades de las solicitantes oscilaban entre los 18 y los 47 años.

Estado civil: Son casadas ${ }^{95}$ o solteras.

Lugar de procedencia: Extremadura, con una mayor demanda de mujeres residentes en la provincia de Badajoz.

95 Consideramos en casadas a las mujeres gitanas reconocidas como tales por la Comunidad Gitana aunque no estén legalmente en este estado. 
Nivel educativo: el nivel de estudios va desde el certificado de escolaridad hasta estudios universitarios, con predominio de la certificación escolar y graduado escolar o ESO.

Situación laboral: Entre las demandantes hay estudiantes a tiempo completo, desempleadas y trabajadoras. Entre las mujeres con trabajo remunerado, los empleos se ubican en empresas de servicios, en venta ambulante o en el tercer sector social.

- Conocimientos previos de las participantes:

En referencia a la temática del curso virtual, sólo dos de las solicitantes afirma conocer «algo» sobre igualdad de oportunidades. Las demás muestran la necesidad de saber y aprender sobre ello, pero destacan el desconocimiento sobre los contenidos de la acción formativa.

En cuanto a conocimientos de informática y telemática (competencia digital), varias de las solicitantes lo utilizan a diario para consultar su correo electrónico, buscar información con la finalidad de hacer trabajos o proyectos relacionados con los estudios o, en el caso de una de las solicitantes, relacionados con el partido político en el que comienza a militar. Algunas destacan, además, su uso como medio de trabajo.

Aunque algunas han realizado una capacitación digital básica a través de telecentros ${ }^{96}$ (en blended-learning), ninguna ha realizado ni participado en acciones formativas a través de espacios virtuales.

- Motivación (expectativas) e interés:

Uno de los aspectos más importantes que se ha tenido en cuenta en la Fase de concepción del proyecto e-Learning que presentamos, es la

96 La red Telecentros se constituyó por un programa dirigido a los municipios de zonas rurales y a núcleos urbanos desfavorecidos a través de administraciones públicas, cuyo objetivo era facilitar el acceso a las nuevas tecnologías tanto a las poblaciones rurales como a los colectivos menos integrados, a fin de lograr su participación efectiva en la Sociedad de la Información. Conforma una red de centros con acceso a internet donde se impartía formación para la alfabetización digital en esas zonas. 
concepción que las destinatarias tienen del aprendizaje y su punto de vista de qué quieren aprender y por qué. En este sentido, se han contemplado expectativas de las participantes sobre la formación, que se recogen a través del documento de solicitud y preinscripción (Anexo II). Las aportaciones realizadas se han dirigido a

- Adquirir conocimientos para mejorar la realidad de su comunidad, especialmente de las mujeres gitanas con el fin de poner en marcha iniciativas conjuntas.

- Mejorar su formación y sus competencias digitales.

- Mostrar a las familias que pueden formarse

Se muestra la aportación de una de las solicitantes, donde aparecen todos los aspectos que se han destacado:

\begin{abstract}
«Realmente estoy motivada en la realización de este curso, primeramente para que mi familia cercana comprenda que yo también puedo hacer cursos. En segundo lugar, me preocupa la realidad social de los gitanos y gitanas de este país y fuera de él, debido a la discriminación que sufrimos. De este modo, es necesario conocer de antemano la igualdad de oportunidades sobre todo, como dice mi hijo, en mi rol como mujer y como gitana. Espero sobre todo pasarlo bien y adquirir competencias para poder hablar en público en diferentes encuentros futuros».
\end{abstract}

- Valor del tiempo de las participantes: debemos tener en cuenta que algunas de las mujeres solicitantes indican que tienen responsabilidades familiares, tema de máxima importancia en referencia a la gestión del tiempo de dedicación que puedan invertir en la acción formativa virtual. 
- Recursos: Disposición de ordenador y lugar de acceso. Un número importante de mujeres solicitantes no disponen de ordenador. En ese caso tendremos en cuenta varios recursos:

- Posible acceso desde la oficina más cercana de la Fundación Secretariado Gitano.

- Posible acceso desde el telecentro más cercano.

- Préstamo de ordenador portátil (internet a cuenta de la participante).

Se observa que la situación de cualquiera de las mujeres solicitantes puede ser diferente aunque todas, como hemos indicado, tienen unas metas comunes: quieren una transformación social, están comprometidas, quieren mejorar las condiciones de su comunidad y quieren ser visibles para la sociedad. Estas mujeres, reúnen las características que se han definido en la visión de género. Además algunas son referentes en sus barrios y comunidad, bien por la formación (estudios universitarios), bien por su trabajo en el tercer sector social (con su propia comunidad), bien por la participación en partidos políticos. Algunas de ellas están experimentando un proceso de crisis interna y «redefinición identitaria» (Rea, 2006) debido al proceso de transformación que su propia comunidad está experimentando (González, 2005; Domínguez, Flecha y Fernández, 2004; Elboj y Vicen, 2007; Montañés, 2011).

\subsubsection{Resultados esperados en relación con los aprendizajes: método DAFO.}

En cuanto a los resultados esperados, se identifican aquellos factores que creemos que podrían ser decisivos del éxito o fracaso de la acción formativa. Esta matriz DAFO se realiza, de manera conjunta, entre miembros de la entidad organizadora de la acción y la investigadora. 


\begin{tabular}{|c|c|}
\hline Debilidades & Fortalezas \\
\hline $\begin{array}{l}\text { - } \begin{array}{l}\text { Escasa alfabetización digital: uso del } \\
\text { ordenador a nivel básico. }\end{array} \\
\text { - } \begin{array}{l}\text { Algunas no poseen ordenador ni } \\
\text { conexión a Internet. }\end{array} \\
\text { - } \begin{array}{l}\text { Ninguna ha realizado una acción } \\
\text { formativa a distancia ni formación } \\
\text { online. }\end{array} \\
\text { - } \begin{array}{l}\text { Disponibilidad de tiempo para el } \\
\text { desarrollo de la acción formativa } \\
\text { virtual. }\end{array}\end{array}$ & $\begin{array}{l}\text { - } \begin{array}{l}\text { Muestran un alta motivación y } \\
\text { expectativas. }\end{array} \\
\text { - } \quad \text { Muestran interés en la temática. } \\
\text { - } \quad \text { Muestran interés en aprender cosas } \\
\text { nuevas y conocer a otras mujeres gitanas. }\end{array}$ \\
\hline Amenazas & Oportunidades \\
\hline $\begin{array}{l}\text { - Posible abandono del proyecto por } \\
\text { alguna participante, debido a: } \\
\text { - } \quad \text { cuidado de la familia } \\
\text { - } \begin{array}{l}\text { posible incorporación al } \\
\text { mundo laboral }\end{array}\end{array}$ & $\begin{array}{l}\text { La acción se desarrolla en el Campus } \\
\text { Virtual de una Universidad, por tanto, } \\
\text { acceden a un lugar donde se cursan } \\
\text { estudios superiores. } \\
\text { - } \quad \text { Novedad de la propuesta. } \\
\text { - Virtualidad y flexibilidad horaria para el } \\
\text { desarrollo de la acción formativa. } \\
\text { - Profesorado especialista con dominio de la } \\
\text { temática, con conocimiento del grupo al } \\
\text { que se dirige y en tutoría virtual. } \\
\text { Certificación oficial del aprovechamiento } \\
\text { de la acción de formación. }\end{array}$ \\
\hline
\end{tabular}

Tabla.9. Matriz DAFO de factores claves del éxito de la acción formativa

Para potenciar las Fortalezas y Oportunidades, además de contar con profesorado preparado para el desarrollo de la acción formativa virtual, se contará con la figura de una persona dinamizadora que fomente y potencie todos los aspectos positivos que llevarían al éxito de la acción formativa.

Para paliar las debilidades y amenazas, además de contar con esa figura de dinamización, que intentará disminuir estos factores, se tendrá en cuenta:

- Adaptación del diseño pedagógico completo a las destinatarias de la acción: deben ser el punto central del mismo.

- Flexibilidad de tiempos en el desarrollo, para que cada estudiante se pueda organizar los tiempos de estudio. 
- Acceso a ordenadores en préstamo y posibilidad de acceso guiado al espacio virtual de formación, a través de los centros de la entidad Fundación Secretariado Gitano en Extremadura y de la persona de cada centro seleccionada para esta labor.

\subsubsection{Finalidad de esta experiencia formativa virtual con mujeres gitanas: cultivo de Comunidad de Práctica a través de entornos virtuales.}

La actual Sociedad de la Información nos sitúa en un escenario adecuado para intensificar la lucha por sociedades más igualitarias y más justas. Este trabajo de investigación, de manera general, y esta acción formativa como parte de ese trabajo, apuesta por la generación de sinergias que transformen a las mujeres en multiplicadoras dentro de su propia comunidad. Aunque actualmente Internet está muy presente en todos los ámbitos de la vida, falta mucho para lograr que sea accesible para todos y todas. La inclusión digital no sólo fomenta el acceso a la información, sino que lo promueve como un derecho fundamental. Este factor es clave para el desarrollo democrático y la ciudadanía plena.

Los sectores más vulnerables se ven afectados por la existencia de la llamada brecha digital, que tiene su origen en una serie de factores interrelacionados entre los que se encuentran la pobreza o la falta de políticas adecuadas, el analfabetismo y los bajos niveles educativos (Warschauer, 2004). A su vez, la brecha digital impacta al interior de las sociedades por causas de género, edad, etnia y clase social.

El conocimiento abierto, compartido y fluido empodera capacidades individuales y potencia formas de organización y de trabajos colectivos, fomentando el aprendizaje mutuo de grupos y actores sociales que actúan por alcanzar la equidad entre hombres y mujeres en las comunidades locales y 
globales (Anguita y Alario, 2004). Las desigualdades marcadas por las relaciones de género afectan especialmente a las mujeres en el uso y apropiación de las TIC, ya que muchas de ellas no las utilizan aún como herramientas de participación civil y política, afectando el pleno ejercicio de su ciudadanía. El espacio virtual reproduce entonces las desigualdades existentes en la sociedad, pero a la vez tiene el potencial de favorecer procesos de desarrollo y aumentar las opciones de acción en la toma de decisiones. Mediante la adquisición de los conocimientos básicos y necesarios, las mujeres pueden hacer un uso creativo y productivo de las TIC y de ese modo potenciar sus capacidades, amplificar sus voces y salir del espacio localizado territorialmente al espacio virtual. Puede entenderse, desde este punto de vista, que el uso adecuado de las TIC puede empoderar porque:

- Aumenta la capacidad de organización y actuación: organización, defensa de derechos e intereses y actuación en cualquier ámbito.

- Permite acceder y compartir información y conocimientos.

Además, las TIC pueden favorecer el desarrollo individual de las mujeres, ya que brindan importantes oportunidades de estudio y desarrollo personal, se caracterizan por dotar de mayor flexibilidad el manejo del tiempo y permiten combinar las aspiraciones de crecimiento laboral y profesional con las aspiraciones personales. En lo social las TIC son una herramienta para la difusión del conocimiento y la experiencia, favorecedora del trabajo en red (Anguita y Alario, 2004).

La propuesta planteada, apunta a ir más allá de la inclusión digital de las mujeres gitanas participantes aportando una nueva formación que genere, a su vez, un modelo de intervención. Queremos que la adquisición y apropiación de estas herramientas influya en sus contextos de acción y en otras mujeres gitanas de su entorno y que provoquen algún proceso de 
transformación personal y social mediante la comunicación de experiencias personales, la ampliación de la interrelación con otras mujeres gitanas o el establecimiento de redes de colaboración entre ellas.

La comunidad gitana se organiza en torno al colectivo, partiendo de la necesaria inclusión de todas las personas que se sientan identificadas con su cultura y forma de ser. La forma de vida está vinculada al entorno social y familiar, por lo que las mujeres gitanas van tejiendo una red de relaciones con la que comparten sus actividades sociales, laborales y familiares. Pretendemos que esta red se amplíe en el espacio virtual, conformando, ya que es una acción formativa una Comunidad Virtual de Aprendizaje de Mujeres Gitanas que desemboque en una Comunidad de Práctica.

Creemos que las experiencias desarrolladas en el espacio virtual por mujeres van a servirnos de referente para demostrar cómo desde la participación activa y las redes de intercambio de experiencias, información y conocimiento, se puede generar conocimiento colectivo, clave para ir provocando pequeñas transformaciones en su ámbitos sociales cercanos.

Es importante observar que en la comunidad gitana, con independencia de las TIC, de modo tradicional se establece culturalmente una organización en red que permite establecer vínculos de pertenencia, ayuda, solidaridad y comunicación (Sánchez, 2004). Afirma Sánchez que, cuando se organizan y asocian, las mujeres gitanas suelen adoptar esta forma de trabajo en redes, basándose en una comunicación fluida donde se puedan incluir proyectos y ayudarse unas a otras, aunando esfuerzos para sacar adelante ideas y actuaciones. La toma de decisiones dentro de la comunidad gitana, está siempre determinada por el diálogo, que se convierte en la base de la convivencia.

Creemos que la unión de práctica común, beneficio mutuo y sentido comunitario e identidad, es la mejor combinación para la creación e 
intercambio de conocimiento y aprendizaje colaborativo para el nacimiento de una Comunidad de Práctica.

Con este diseño, como hemos indicado, queremos cultivar el desarrollo de una Comunidad de Práctica, estableciendo relaciones entre las mujeres participantes en la formación, que permitan establecer cambios en su autopercepción y ampliando sus expectativas futuras Para esta transformación es necesario el aprendizaje, de ahí la propuesta de formación que presentamos. Wenger, McDermott y Snyder (2002), exponen que la clave es cultivar la comunidad, no crearla facilitando recursos, ideas o apoyando decisiones. Una Comunidad de Práctica debe surgir voluntariamente desde sus miembros, lo que no significa que no se pueda fomentar y motivar para la participación en las mismas.

Las Comunidades de Práctica constituyen una herramienta para el aprendizaje colaborativo basado en la práctica (Wenger, 2001), clave para la difusión y el intercambio de conocimientos; además de compartir el que se adquiere mediante la formación, se comparte el conocimiento adquirido a partir de propias experiencias vitales. Por tanto, la propuesta de formación en modalidad virtual es el marco adecuado donde las participantes, al interaccionar, tienen la posibilidad de dialogar e intercambiar sus experiencias, construyendo el conocimiento de manera compartida a través de las interacciones sociales que se produzcan entre ellas, facilitando el nacimiento de la Comunidad de Práctica.

Esta Comunidad de Práctica constituye una fuente de innovación en las prácticas sociales de intervención, ya que el intercambio de informaciones, reflexiones y opiniones, conlleva negociar y generar nuevas ideas $\mathrm{y}$ conocimientos que pueden transformar las prácticas actuales.

Añadimos las posibilidades de los entornos virtuales para facilitar la colaboración en Red, y por ende la construcción de comunidades de práctica, 
con la finalidad de avanzar hacia la construcción de comunidades de aprendizaje e incluso, como señalan Garrison y Anderson (2005) de «Comunidades de Investigación o Indagación».

El modelo pedagógico que proponemos, para el entorno de aprendizaje en el que las mujeres van a participar, parte de la generación paulatina de una Comunidad de Práctica orientada al fomento de proyectos comunes y de experiencias compartidas, de un aprendizaje que sea reflejo del entorno real y construido sobre la colaboración y el diálogo igualitario. Nuestro modelo de Comunidades de Práctica sitúa a las participantes de manera colectiva en situaciones auténticas, donde ocurren actos sociales de construcción de conocimientos que tienen sentido en contextos de aplicación y uso determinados (Díaz Barriga, 2003).

Desde esta perspectiva, consideramos desarrollar un modelo pedagógico que permita a «las aprendices» a confrontar teoría y práctica desde sus propias experiencias, logrando aprendizajes significativos. Partimos además, de la premisa de que esta acción formativa diseñada pedagógicamente para esta finalidad última va a reforzar la identidad de participación en las mismas, el sentimiento de cohesión y de grupo («Presencia Social», Garrison y Anderson, 2005), facilitando el trabajo colaborativo mediante las interacciones entre las personas pertenecientes a esa Comunidad de Práctica que se irá cultivando.

Otro elemento relevante es la selección de un entorno virtual que contribuya a posibilitar la generación de esa Comunidad de Práctica a través de una Comunidad Virtual de Aprendizaje, que pueda dotar a los participantes de las herramientas de comunicación y de trabajo colaborativo indispensables para el diálogo y la interacción mediante recursos digitales. Pretendemos que el entorno virtual que se presentará conforme a este diseño, se constituya como un sistema de prácticas socioculturales, que promuevan la promoción de las participantes. 
La acción formativa que presentamos surge con un matiz fundamentalmente social, facilitando la formación de un grupo social en situación de desigualdad en el seno una institución académica de estudios superiores, posibilitando la adquisición de conocimientos y la capacitación en estrategias y metodologías que les faciliten activar procesos para alcanzar el marco de igualdad de hecho, que les corresponde por derecho. Usando las TIC como medio y herramienta tecnológica para superar las distancias geográficas existentes entre las participantes. Con esta formación también pretendemos impulsar la participación ciudadana de las mujeres gitanas. Se trata de crear un espacio social regido por nuevas pautas nacidas de la negociación y creatividad colectiva.

Con esta actuación se espera contribuir a la dinamización y potenciación de las tareas que ya desempeñan, fortaleciendo capacidades y abriendo nuevos campos de actuación y liderazgo, impulsados por una utilización efectiva de herramientas que son hoy indispensables para el trabajo, tales como el manejo del e-mail, la búsqueda de información en Internet, la implementación de mecanismos de difusión propios (e-boletines, blogs, wikis) y la participación activa en la elaboración de contenidos para medios ya existentes.

La acción formativa tiene como finalidad dotar a las personas participantes de herramientas de capacitación necesarias para empoderarse, para comprender distintas dinámicas en torno al género y a la igualdad de oportunidades, y para ejercer, de manera activa, su liderazgo social, estableciendo estrategias pedagógicas para su consecución basadas en los principios mencionados. Todo ello en un espacio formativo universitario virtual, que aporte un valor añadido a su desarrollo personal y profesional. En definitiva, colaborar a la promoción sociocultural de estas mujeres a través del impulso de una Comunidad de Práctica, cultivada e impulsada mediante esta acción formativa y situada en entornos virtuales de aprendizaje. Para ello consideramos necesario: 
- Fomentar la creación de un ambiente de confianza para que las participantes se sientan seguras, cómodas y respetadas. Las participantes, como hemos indicado, tienen características heterogéneas y diversas, aunque comparten objetivos comunes en cuanto a la promoción del grupo cultural al que pertenecen y con el que se identifican. Cada una puede expresarse libremente y emitir juicios de valor que deben ser respetados, así como también sus características culturales.

- Respetar diversos ritmos de aprendizaje.

- Informar en todo momento sobre las características del proceso formativo: objetivos, temas que se van a trabajar y cuál es nuestra propuesta metodológica.

- Motivar a las participantes para que se expresen, que se animen entre ellas, para evitar el abandono prematuro.

- Visibilizar los logros alcanzados por las participantes, dando valor a sus conocimientos, experiencias y aportaciones, a nivel individual y, sobre todo, como colectivo.

En conclusión, se presenta la acción formativa virtual: «Igualdad de Oportunidades y Liderazgo social» que tiene como objetivo principal dotar a las personas participantes -mujeres gitanas- de herramientas necesarias para empoderarse, para comprender distintas dinámicas en torno al género y a la igualdad de oportunidades, y para ejercer, de manera activa, su liderazgo social. Se pretende, a través de esta acción formativa, facilitar un espacio virtual de aprendizaje en el que estas mujeres se capaciten para orientar estrategias que, en materia de igualdad de oportunidades, se puedan implementar desde cualquier ámbito, especialmente las dirigidas a su propia promoción y a la de las mujeres gitanas de su entorno. La finalidad última que se persigue con esta acción, es cultivar una Comunidad de Práctica para 
que, tras el proceso de formación establecido, continúen con ese trabajo conjunto de promoción sociocultural y visibilidad propia y de su comunidad.

\subsection{Fase de Diseño}

\subsubsection{Diseño del Modelo Didáctico: Modelo de aprendizaje en el Espacio Virtual: estrategias didácticas y metodológicas.}

La formación online, desde el diseño didáctico, requiere el establecimiento de modelos pedagógicos orientados a promover un proceso de aprendizaje que combine la flexibilidad con una programación y una planificación didáctica bien estructurada. Todo ello con el establecimiento de vías abiertas de comunicación e intercambio en el aula virtual, las cuales facilitarán la creación de entornos que promuevan la construcción del conocimiento adaptado a las necesidades particulares de cada participante. (Valverde y López, 2009). Desde este punto de vista el modelo didáctico de esta acción formativa virtual se constituye a partir de tres elementos: teorías del aprendizaje que sustentan el modelo pedagógico y que se han establecido en la parte inicial de este trabajo de investigación; las estrategias didácticas por las que se opta en relación a esas teorías, y el proceso de orientación en el aprendizaje guiado por los tutores y tutoras y la figura de la persona que ejerce el rol de dinamizadora.

En este modelo destaca, de manera significativa, la función de las estrategias didácticas las cuales relacionan todo el modelo, intentando establecer un conjunto de acciones y procedimientos para aplicarlos en las actividades didácticas y, al mismo tiempo, ser una guía para el docente en la conducción del programa. 
Para una mejor comprensión del modelo se definen, a continuación, los ejes de la estrategia didáctica, las etapas de la misma en relación con las teorías de aprendizaje, el modelo metodológico centrado en las estudiantes y el factor motivación que rodea a toda la estrategia didáctica.

\section{Ejes de la estrategia.}

Todas las etapas de la estrategia didáctica están situadas en tres ejes que conducirán el proceso. Estos son el de participación, motivación y el de aprendizaje/interacción. La participación involucra todas las acciones que se susciten en el ambiente de aprendizaje del entorno virtual. Se ve reflejado el grado de trabajo que se requiere en cada etapa de la estrategia, como veremos a continuación. La motivación es un paso previo al aprendizaje y motor del mismo. Este eje es clave en el diseño de un curso de estas características por la modalidad virtual y, sobre todo, por las personas destinatarias del mismo. Se debe definir claramente una estrategia de motivación que mantenga un buen nivel de participación durante todo el desarrollo de la acción formativa y evitar el abandono prematuro. Por último, el aprendizaje se desarrolla conforme se avanza de una etapa a otra, sin embargo el componente de interacción hace visible el grado de colaboración y la cooperación que se debe generar como parte del proceso comunicativo comunitario.

\section{Etapas de la estrategia.}

Constituyen las fases que se van desarrollando en torno a los ejes de participación y de aprendizaje/interacción. Como modelo adecuado a las etapas de la estrategia, se utilizó el modelo de cinco pasos propuesto por Gilly Salmon (2004) y para el proceso de dinamización general del curso se adoptó el esquema de cinco etapas para la construcción de diálogo que proponen Pérez, Salinas y de Benito (2008). 
2. a.- Modelo de los Cinco Pasos de Gilly Salmon (Five Step Model).

El modelo de cinco pasos fue diseñado por Gilly Salmon (2000) para mostrar cómo motivar a los participantes en una formación en línea, cómo construir el aprendizaje a través de las e-actividades apropiadas y cómo marcar la pauta de las «aprendices» mediante programas de formación y desarrollo. Este modelo se basa en cinco etapas en la que los participantes en la formación adquieren, progresivamente, confianza y habilidad en el trabajo en red y la formación en línea. En este caso vamos a adaptar este modelo a la acción formativa que vamos a desarrollar.

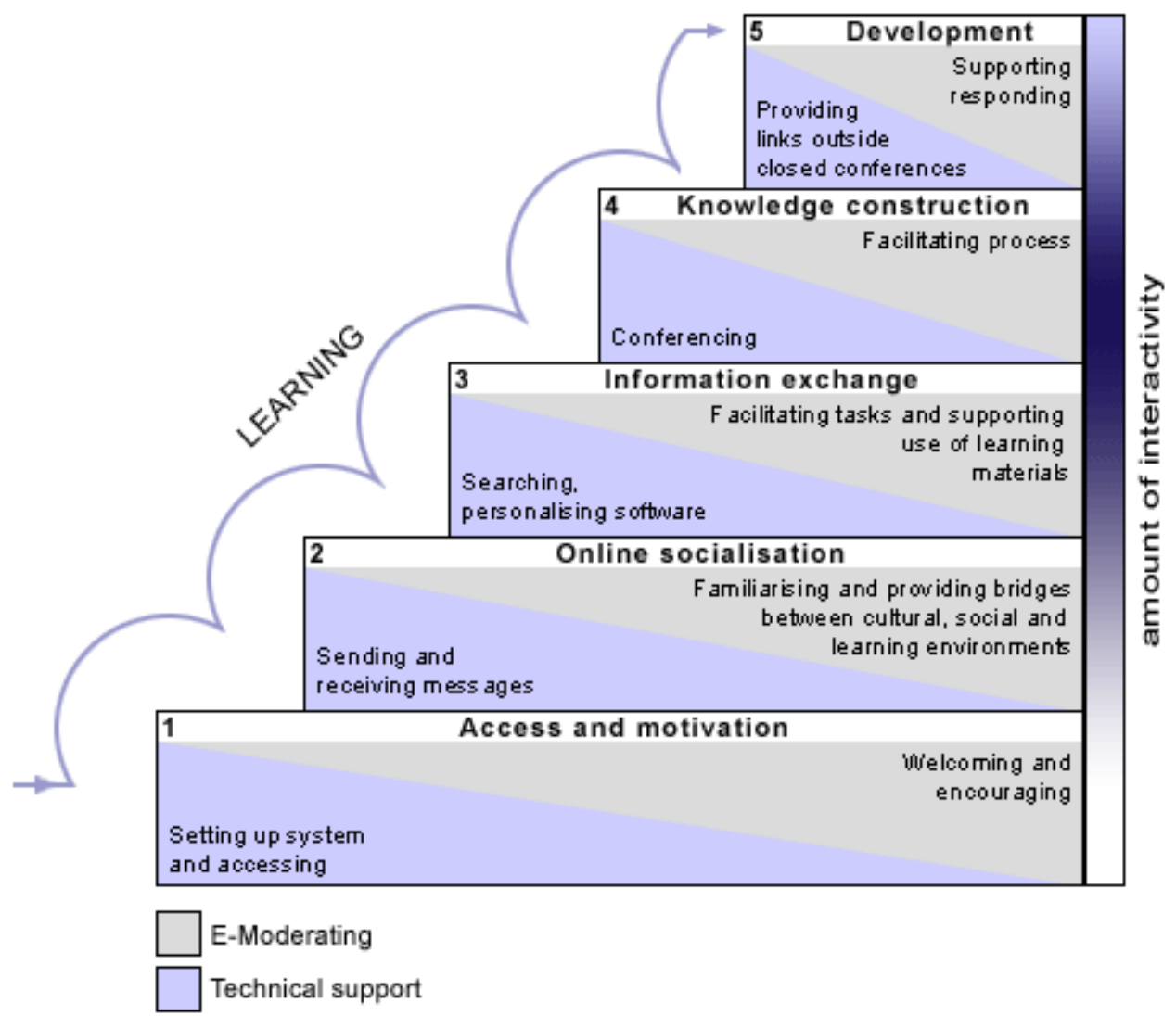

Figura 25. Modelo de Cinco Pasos de Gilly Salmon (Imagen tomada de: http://www.atimod.com/eactivities/5stage.shtml) 
$1^{\mathrm{o}}$ Acceso y motivación. En esta primera etapa será importante dar instrucciones sobre cómo acceder al Campus Virtual, cómo usar los recursos del campus y conseguir la confianza de las alumnas para que participen, persistan en la tarea, se comprometan y se sientan seguras y respetadas. Se corresponde con una presentación y orientación inicial sobre la acción formativa. El grado de participación y de aprendizaje/interacción en esta primera etapa puede ser bajo, según indica la autora. En esta primera fase, es muy relevante el trabajo de la dinamización y la tutoría, puesto que debe existir una ayuda pedagógica (basada en una orientación inicial). La colaboración de las estudiantes parte de un «compromiso de participación» que ellas previamente establecen.

$2^{\mathrm{O}}$ Socialización en línea. En esta segunda etapa, debe fomentarse la unión de las participantes, que se conozcan e identifiquen y comiencen a trabajar juntas. Facilitar la creación de una visión compartida. Para ello se van a crear mecanismos de comunicación entre ellas, a través de un foro creado exclusivamente para fomentar debates e interrelaciones.

$3^{\circ}$ Dando y recibiendo información. En la tercera etapa, se debe animar a las participantes a que contribuyan, reflexionen, opinen, tejiendo la información que van construyendo. El grado de participación y de aprendizaje/interacción debe ser alto. El paso que se da desde la colaboración a la cooperación toma impulso en los debates y proyectos en grupo, que hacen posible que el aprendizaje sea recíproco. Se hará énfasis en el contenido a través de situaciones problematizadas en contextos reales (aprendizaje a partir de las propias vivencias) y también desde múltiples perspectivas (para favorecer flexibilidad cognitiva).

$4^{\mathrm{o}}$ Construcción del conocimiento. En la etapa cuarta, es importante mantener los procesos de colaboración mediante feedback, estimulando la comunicación dialógica y el desarrollo de las competencias comunicativas. Así, se debe plantear tanto el trabajo individual necesario para reforzar el 
conocimiento, como el colaborativo a través de debates y actividades grupales. También se debe tener en cuenta la «Presencia Docente» (Garrison y Anderson, 2005) en esta etapa y la labor de dinamización para mantener la motivación de las estudiantes.

$5^{\mathrm{o}}$ Desarrollo. La última etapa debe ir dirigida a sentar las bases de la Comunidad de Práctica. Las participantes se identifican, comprometen y responsabilizan. El trabajo con el docente y con la dinamización se acentúa en la medida que se hacen evaluaciones continuas y se realiza una retroalimentación final.

2.b. Modelo para el Proceso de Construcción del Diálogo.

Basándose en las propuestas pedagógicas de Dempster (2004) y los estudios de interacción de Gunawardena et al. (1997), Pérez, Salinas y de Benito (2008) nos proponen un modelo de cinco etapas para la construcción del diálogo que, complementario al anterior, constituye las etapas clave para la construcción y negociación de conocimientos por parte de las personas participantes.

\begin{tabular}{|c|c|c|}
\hline \multicolumn{2}{|r|}{ Construir } & Construcción de significados. Negociación \\
\hline \multicolumn{2}{|c|}{ Compartir } & Intercambio información \\
\hline \multicolumn{2}{|c|}{ Comunicación Grupal } & Intercambio ideas iniciales \\
\hline \multicolumn{2}{|c|}{ Presentación Información } & Presentación material y trabajo individual \\
\hline \multicolumn{2}{|l|}{ Exploración } & Acomodación al Campus Virtual \\
\hline
\end{tabular}

Figura 26. Adaptación del modelo de construcción del diálogo de Pérez, Salinas y de Benito (2008).

- Exploración: acomodación del grupo a la tecnología. En nuestro caso, la adaptación de las participantes al entorno de e-learning, para que conozcan cómo participar y hagan uso de los recursos comunicativos. 
También forma parte de este proceso la presentación entre tutores/as y participantes al comienzo del curso.

- Presentación de la información: Esta etapa corresponde a la presentación, por parte del tutor/a responsable, del material de estudio que deben leer para participar en el foro y resolver la actividad correspondiente a ese material.

- Comunicación en un grupo grande: respuesta a preguntas. Tutores y tutoras responsables deben abrir diferentes líneas de debate en el Foro de trabajo (Foro Social). En base a la temática, se producirán los primeros intercambios de ideas, aportaciones, experiencias y opiniones y reflexiones iniciales por parte de las participantes.

- Compartir: intercambio de información y formulación de preguntas y respuestas. Comienzan los procesos complejos de reflexión conjunta, se comparten ideas y se responden entre sí. Se va determinando el grado de acuerdo o desacuerdo.

- Construir la interacción: negociación, colaboración. En esta etapa construyen acuerdos (co-construcción cooperativa de conocimiento), negocian significados, argumentos, y se producen las reflexiones metacognitivas que provocan la transformación como resultado de la interacción y el diálogo compartido. Este proceso concluye con los primeros indicios de manifestación de la Comunidad de Práctica Social.

A partir de la perspectiva pedagógica que seguimos, las estrategias metodológicas que proponemos siguen una adecuación al contexto y situación concreta de las participantes en la acción formativa. Es decir, partimos de los intereses y motivaciones de las participantes y de sus conocimientos previos, situando la actividad dialógica y constructiva como base fundamental de la organización metodológica propuesta. No creemos 
que exista una sola metodología en términos absolutos para nuestro diseño, sino que pensamos en la buena combinación de la parte que consideramos más adecuada y útil de cada una de ellas en la aplicación a la propuesta que estamos realizando. En este caso seguimos, como puede observarse, en las claves anteriores, una perspectiva globalizadora (Zabala, 1989) e integradora (Duart y Sangrà, 2000) que establece pautas para organizar el proceso de enseñanza-aprendizaje basados en los intereses de la alumnas y la organización de la actividad constructiva y comunicativa.

Existen diferentes puntos de vista a la hora de clasificar las estrategias metodológicas. Fandos y González (2006) recogen la clasificación de Jiménez González que considera que existen cuatro modalidades básicas:

- Tipos de procedimiento. Que se refiere a definir la línea general o filosofía que orientará el desarrollo temático de los procesos de aprendizaje. Indican que son «la guía interna de los métodos de enseñanza» y clasifican los tipos de procedimientos en inductivos, deductivos, analíticos, sintéticos, lógico-psicológicos, activos-pasivos, por globalización, por especialización, dogmáticos-heurísticos.

- Metodologías centradas en la transmisión de la información. Que hacen alusión a la trasmisión de conocimientos del docente al estudiante, predominando el primero sobre el segundo, el proceso de enseñanza sobre el de aprendizaje. Se clasifican en: expositiva, demostrativa, interrogativa o por descubrimiento.

- Metodologías centradas en los procesos de aplicación. Se clasifican en torno a las recomendaciones que debe tener en cuenta el profesorado alrededor de la planificación de las distintas fases del proceso de didáctico. Son: metodologías de presentación, ampliación y diferenciación y búsqueda de soluciones. 
- Metodologías centradas en la actividad del estudiante Son aquellas metodologías que incrementan el papel autónomo y activo de los alumnos y alumnas, y las analiza desde la perspectiva de la enseñanza grupal y de la enseñanza individualizada.

Dentro de esta clasificación fijamos nuestro interés en las metodologías centradas en la actividad del estudiante. Desde esta perspectiva pedagógica se sitúa una mayor incidencia en el aprendizaje que en la instrucción. Estas metodologías provienen del aprendizaje centrado en el estudiante, (Brown, Collins, Duguid, 1989; Jonassen, 1991, 1994; Jonassen, Pek y Wilson, 1999; Rodríguez, 2003). En éstas, el alumnado debe responsabilizarse de su aprendizaje y de cómo aprender. El diseño consiste en orientar con metodologías adecuadas esa forma particular de aprender, que combinen los materiales y actividades que guíen y ayuden al descubrir el aprendizaje. Supone un enfoque abierto de la experiencia de aprendizaje, considerando algunos determinantes educativos como son los objetivos de aprendizaje, las actividades principales, las orientaciones metodológicas del docentes y la evaluación durante todo el proceso.

Entre las metodologías centradas en el estudiante, optamos por una modalidad de enseñanza grupal, por la adaptación a nuestro modelo y las ventajas que ofrece (Rodríguez y Medrano, 1993):

- Facilitan la participación de los miembros del grupo.

- Fomentan la responsabilidad sobre el aprendizaje, el sentido crítico y la capacidad de análisis.

- Aseguran la motivación de los y las estudiantes.

- Favorecen la modificación de actitudes; sobre todo las técnicas grupales. 
- Posibilitan el desarrollo de habilidades complejas de toma de decisiones y el trabajo en grupo

Para todo ello se concretan, con posterioridad, las estrategias de aprendizaje y los recursos didácticos que utilizaremos para el desarrollo de esta modalidad. Nuestra opción es la combinación de metodologías que se centran en el aprendizaje del estudiante, buscando su participación, implicación, responsabilidad, interés y motivación.

En este sentido, las estrategias para el aprendizaje que seleccionamos con relación al marco pedagógico, se dirigen a generar habilidades de cuestionamiento y prueba sistemática de conjeturas por parte de las participantes en base al diálogo y la participación conjunta. Así seleccionamos, como grupo de estrategias fundamentales para el aprendizaje, las basadas en la investigación social y el trabajo colaborativo. Este tipo de estrategias combinan, como indica Salinas, Pérez y de Benito (2008), las estrategias de descubrimiento propias a toda investigación y la relación con los otros, puesto que llevan consigo intercambiar, recabar información, compartirla en un procedimiento de trabajo que planteamos colaborativamente. Un proceso de intercambio de información, búsqueda del consenso y propuesta común. Están basadas en la interacción en grupo y pretenden el logro común de un objetivo (en este caso un proyecto colaborativo) a través de la actividad individual, de la interacción, y de la participación activa de las alumnas. Estas estrategias tienden a favorecer una toma de decisiones consensuadas sobre las acciones colectivas que se requieren para alcanzar el resultado final de la investigación, reforzando aprendizajes profundos, estructuras de relación nuevas y reflexiones críticas aplicado sobre la práctica real.

Los fundamentos pedagógicos de este tipo de estrategias parten de la misma base teórica constructivista que las basadas en proyectos y en 
problemas. Salinas, Pérez y de Benito señalan varios aspectos pedagógicos de éstas:

- La investigación como base metodológica, fomenta el desarrollo de tareas de investigación lo que lleva a la construcción de conocimiento al favorecer el desarrollo de competencias de comprensión y aplicación, el descubrimiento de estructuras profundas y relaciones nuevas y la práctica de reflexión crítica.

- Comparte algunos de los principios del social-constructivismo desde el momento en que el aprendizaje colaborativo concibe el conocimiento como un constructo social que surge de la interacción socialmente activa con los pares.

- El aprendizaje situado concibe el conocimiento como algo inseparable de un contexto particular. Si el proceso de aprendizaje se aísla del contexto, el conocimiento logrado será incompleto y poco significativo. El aprendizaje se convierte así en un método participativo de adquisición de conocimiento al desarrollarlo y aplicarlo en actividades auténticas.

- El conocimiento de la identidad cultural, de la comunidad, de la diversidad, de nuevas formas de relación ha constituido, desde siempre, motivo de atención en la metodología didáctica, al relacionarse con la importancia que dicho conocimiento tiene por la contribución a las destrezas, actitudes y conocimientos relacionados con el crecimiento en la comunidad.

- Las comunidades virtuales de aprendizaje actúan como escenarios para la colaboración activa y la construcción e intercambio dinámico de conocimientos. Las comunidades de aprendizaje surgen cuando los estudiantes comparten intereses comunes. Las TIC pueden contribuir a conectar a estudiantes de la misma clase o de todo el mundo, con el 
objeto de lograr objetivos comunes. Para ello, los participantes pueden conducir investigaciones (lecturas, estudio, visionado, consulta a expertos) y compartir la información buscando significado o tareas consecuentes.

- Prepara a los y las estudiantes para la sociedad de la información desde la perspectiva del aprendizaje flexible. La finalidad del proceso educativo es proporcionar a las generaciones jóvenes los conocimientos requeridos para desenvolverse en la sociedad; ha de preparar para la vida y debe integrar la recreación del significado de las cosas, la cooperación, la discusión y la negociación y resolución de problemas. Para ello, se requieren metodologías activas que favorezcan la interacción entre el alumnado, la integración social, la capacidad de comunicarse, de colaborar, el cambio de actitudes, el desarrollo del pensamiento y el descubrimiento del placer de aprender, al tiempo que se fomenten actitudes de cooperación y solidaridad.

Así, a través de estas estrategias es posible llevar a cabo la construcción colectiva del conocimiento, motivando a las estudiantes para que desempeñen un rol más activo, dinámico y comprometido con su propio aprendizaje.

Por otro lado, este modelo de estrategia que conlleva estudiante-profesor implicados en el proceso de investigación activa, basan el aprendizaje en la comunicación como elemento central, acorde a las perspectivas pedagógicas que fundamentan este diseño.

Los proyectos colaborativos, como el que proponemos, promueven un modelo de aprendizaje basado en la realización de diferentes tareas, cuya ejecución requiera la participación y colaboración de todas las componentes del grupo destinatario de la acción formativa (Del Moral y Villalustre, 2008). 
El apoyo de herramientas tecnológicas para el desarrollo de estas estrategias proporcionan un marco adecuado para la construcción activa del conocimiento, así como la adquisición de nuevos aprendizajes por parte de los estudiantes a partir de la interacción mutua entre sí y con el propio contexto.

En nuestro caso, basándonos en estas líneas pedagógicas, se pretende la reflexión, el descubrimiento y las propuestas creativas para la solución de un problema social. Esto da sentido al aprendizaje como actividad social que se construye a través de la investigación colaborativa. En este caso proponemos una experiencia de indagación sencilla que combine el estudio de la realidad, en base a la problemática del grupo étnico al que pertenecen las participantes, y las propuestas de mejora, con una actuación colaborativa en todas las fases del proyecto de investigación. La estrategia clave que proponemos en este diseño es un proyecto colaborativo basado en la construcción conjunta de un documento sobre la realidad social de las mujeres gitanas extremeñas, recogiendo un manifiesto de peticiones y cuestiones a tener en cuenta para conseguir su promoción social en la comunidad autónoma de referencia. Se propone, en este sentido, una experiencia de aprendizaje a través de las TIC, que involucra a las participantes en un proyecto real, en el cual van aplicar conocimientos y habilidades. Las participantes van a determinar la búsqueda y selección de información, el desarrollo del documento, así como la presentación de los resultados utilizando la red. Esta estrategia estará ajustada al nivel de conocimientos de las participantes y se centrará en el intercambio de saberes y el trabajo colaborativo, como características fundamentales que identificarán el proceso de aprendizaje de las mujeres que participan en la acción formativa.

Este tipo de proyectos colaborativos de investigación se caracterizan por poner énfasis, como indican Salinas, Pérez y de Benito (2008), en el carácter cooperativo y en la autonomía del estudiante para conducir y guiar el propio 
proceso de investigación. Los expertos -tutores y tutoras, dinamizadorafacilitarán los recursos y la información base y las participantes serán las encargadas de buscar y transformar la información, participando de forma activa y colaborativa para conseguir el resultado del proceso de indagación que además, revierte en su realidad y en la de su propia comunidad.

Puesto que la formación es a través de las TIC, constituirán en sí mismas un instrumento de investigación ya que permiten el almacenamiento, organización y recuperación de la información; un medio para comunicarse, para construir colaborativamente documentos; y medio de visualización, para dar a conocer los resultados de la investigación desarrollada.

Este proyecto colaborativo busca promover un modelo de aprendizaje que requiera la realización de diversas tareas cuya resolución conlleva el trabajo, la participación, el diálogo y la colaboración de todas las destinatarias.

Se pretende que con ello se lleve a cabo una construcción colectiva del conocimiento motivando a las participantes a ejercer roles activos, dinámicos y, sobre todo, que estén comprometidas con su propio aprendizaje. Para ello, los tutores, tutoras y la dinamizadora, tienen un papel clave en el desarrollo del ambiente de aprendizaje interactivo y comunicativo, apoyándose en los recursos y herramientas propuestas para que se propicie esa construcción activa y conjunta de conocimientos y la adquisición de aprendizajes partiendo de la interacción mutua entre participantes, expertos (tutores, tutoras y dinamizadora) y contexto. Siguiendo este planteamiento, debemos seleccionar recursos didácticos que faciliten y amplíen las posibilidades de comunicación e interacción, de intercambio de información entre las participantes y que favorezcan el trabajo colaborativo que se genera dentro de este espacio virtual de aprendizaje. 
Continuemos, en primer lugar, con el diseño general de la acción formativa virtual, y posteriormente, se centrarán las unidades de aprendizaje, la interacción (actividades y recursos didácticos) y el sistema de evaluación.

\subsubsection{Diseño General de la acción formativa virtual.}

\section{a. Nombre de la acción formativa.}

Este proyecto se sitúa dentro del proyecto social denominado e-Kalex, contextualizado y presentado con anterioridad. El proyecto e-Kalex apuntaba, recordamos, a trabajar con aproximadamente 20 mujeres gitanas extremeñas, de cara a la creación un grupo de referencia para el desarrollo de acciones de promoción en materia de igualdad de oportunidades, con población gitana extremeña. Con este proyecto se pretende contribuir, dinamizar y potenciar las tareas que esas mujeres gitanas ya desempeñan como referentes sociales, fortaleciendo capacidades y abriendo nuevos campos de actuación y liderazgo impulsados por una utilización efectiva de herramientas que son hoy indispensables para el trabajo, tales como el manejo del e-mail, la búsqueda selección de información en Internet, la implementación de mecanismos de difusión propios (en nuestro caso a través de los Blogs y las redes sociales) y la participación activa en la elaboración de contenidos sobre igualdad de oportunidades y mujeres gitanas para medios ya existentes en la Comunidad Autónoma.

Dentro de este proyecto, se sitúa la acción formativa virtual «Igualdad de oportunidades y liderazgo social» en la que, desde un punto de vista social, las mujeres participantes se dotarán de herramientas de capacitación necesarias para empoderarse, para comprender distintas dinámicas en torno al género y a la igualdad de oportunidades, y para que puedan ejercer, de manera activa, su liderazgo social. Todo ello en un espacio formativo universitario virtual, que aporte un valor añadido a su desarrollo personal y profesional. 


\section{b. Palabras clave.}

Tecnologías de la Información y Comunicación, recursos didácticos digitales, actividades interactivas, participación, liderazgo social, perspectiva de género, aprendizaje permanente.

\section{c. Objetivos de aprendizaje.}

A través de esta acción formativa se facilita un espacio virtual de aprendizaje en el que las mujeres participantes se capaciten para orientar estrategias que, en materia de igualdad de oportunidades, se puedan implementar desde cualquier ámbito, especialmente las dirigidas a su propia promoción y a la de las mujeres gitanas de su entorno.

La finalidad última se dirige a cultivar una Comunidad de Práctica, para que, tras el proceso de formación establecido, continúen con ese trabajo conjunto de promoción sociocultural y visibilidad propia y de su propia comunidad. Esta Comunidad de Práctica resultaría tras el desarrollo del proceso formativo con la creación de un grupo de mujeres gitanas referentes en la región. En otras palabras, se pretende impulsar la promoción sociocultural de las mujeres gitanas, fomentando y estimulando la creación de una Comunidad de Práctica, para la generación de conocimiento e información sobre la situación de la mujeres gitana extremeñas en varios ámbitos y para establecer nuevos lazos de comunicación entre las mismas.

De manera transversal, la adquisición y apropiación de las herramientas TIC por parte de mujeres con influencia en sus comunidades, impactará principalmente en el desempeño de sus funciones como referentes locales, renovando el formato de sus prácticas para participar globalmente en los circuitos de información actuales.

Para esta acción formativa se establecen las siguientes competencias generales y subcompetencias 
- C.1.Capacidad para informarse y comprender conocimientos relacionados con la igualdad de oportunidades y el liderazgo social.

- C1/A. Poseer conocimientos de terminología básica relacionada con la igualdad de oportunidades entre hombres y mujeres y el liderazgo social femenino.

- C1/B. Incorporar y aplicar terminología básica relacionada con la temática a sus propias reflexiones y discursos.

- C.2. Ser capaces de utilizar las TIC

- C2/A. Saber comunicarse con otras a través de un espacio virtual de trabajo.

- C2/B. Ser capaz de buscar información y sintetizarla.

- C2/C. Saber participar en un proyecto grupal en red a través de la comunicación virtual.

- C2/D. Ser capaz de postear o poner textos en la red con un discurso coherente y claro.

- C.3. Mostrar actitudes positivas hacia la formación y el autoconocimiento personal.

- C3/A. Mostrar una actitud basada en el respeto, la tolerancia y la asertividad, expresar y comprender puntos de vista diferentes, negociar significados y manifestar empatía.

- $\quad$ C3/B. Ser capaz de auto-reflexionar sobre sus conocimientos y sentimientos.

- C2/C. Mostrar buena actitud ante el uso de las TIC para realizar futuras formaciones en modalidad virtual. 
- C.4. Capacidad para llevar a cabo trabajos colaborativos.

- C4/A. Trabajar en equipo en entornos virtuales, aportando, reflexionando sobre las ideas, experiencias, etc. que se compartan en el espacio virtual de trabajo.

- C4/B. Ser capaz de desarrollar estrategias colaborativas.

\section{d. Propuesta Temática.}

La propuesta temática se aborda desde 3 bloques de contenidos, mas un bloque dedicado a un Trabajo Práctico Colaborativo continuado.

\begin{tabular}{|c|c|}
\hline Ref. & Propuesta temática \\
\hline BLOQUE I & $\begin{array}{l}\text { Construyendo conceptos básicos: Conceptos básicos y nuevas perspectivas en } \\
\text { torno al género. Introducción a las TIC. }\end{array}$ \\
\hline Bl. I-A & $\begin{array}{l}\text { Conceptos básicos sobre Igualdad de Oportunidades y Marco Político de la } \\
\text { Igualdad. }\end{array}$ \\
\hline Bl. I-B & $\begin{array}{l}\text { Sociedad del conocimiento, tecnologías e igualdad de oportunidades desde una } \\
\text { perspectiva social. }\end{array}$ \\
\hline $\begin{array}{l}\text { Bl. I-B } \\
\text { (presencial) }\end{array}$ & Taller TIC \\
\hline BLOQUE II & $\begin{array}{l}\text { Construyendo nuestra base de conocimientos: Empoderamiento, dinamización } \\
\text { y liderazgo social. }\end{array}$ \\
\hline Bl. II-A & $\begin{array}{l}\text { Dinamización, cultura, participación social y ciudadana: Educación para la } \\
\text { participación igualitaria. }\end{array}$ \\
\hline $\begin{array}{l}\text { Bl. II-A (Taller } \\
\text { presencial) }\end{array}$ & Taller Igualdad de Oportunidades. \\
\hline Bl. II-B & Liderazgo social e identidad cultural. \\
\hline $\begin{array}{l}\text { Bl. II-B (Taller } \\
\text { presencial) }\end{array}$ & Taller Liderazgo. \\
\hline BLOQUE III & Construyendo habilidades. \\
\hline Bl. III-A & $\begin{array}{l}\text { Sociedad del conocimiento, tecnologías e igualdad de oportunidades desde una } \\
\text { perspectiva social II. }\end{array}$ \\
\hline TPC & TRABAJO PRÁCTICO CONTINUADO. \\
\hline
\end{tabular}

Tabla 10. Propuesta temática de la acción formativa. 


\section{e. Estrategia docente.}

Con la estrategia docente definimos de qué manera se abordan los contenidos del curso.

En este caso, esta acción formativa está planteada por competencias, trabajando las mismas a través de Unidades de Aprendizaje que engloban a uno o varios docentes. Aproximadamente el 80\% de la docencia se realizará a través del campus virtual en modalidad virtual, a excepción de tres sesiones presenciales.

El tutor o tutora, además del documento base y los contenidos complementarios cuya concepción y gestión se explican posteriormente, debe proponer una tarea de aprendizaje que requiera una revisión teórica, discusión o aplicación práctica en torno a los contenidos de uno o varios temas, siempre relacionado con los objetivos de aprendizaje y la finalidad última del proyecto de e-learning. Se deben seguir las siguientes directrices generales:

- Deberá ser una actividad que promueva el diálogo y la colaboración, debiendo desarrollarse y evaluarse a través de los recursos que ofrece la plataforma y basándose en las competencias de la Unidad de Aprendizaje.

- La actividad debe estar diseñada de modo que su realización pueda plasmarse en un documento digital y utilizando los recursos que se proponen (procesador de texto, el glosario colaborativo, en el foro, la wiki, el blog, una página web, etc.).

- Las actividades de aprendizaje deberán desarrollarse durante un período de tiempo que oscilará en referencia al tiempo establecido de dedicación a los bloques, teniendo en cuenta el trabajo de lecturas 
previo. Las participantes deben conocer los calendarios de entrega de las tareas propuestas en las actividades.

- Todo este proceso tendrá la ayuda y orientación de la dinamizadora del curso.

\section{f. Estructura General.}

El contenido de la acción formativa incluye 4 unidades de aprendizaje. El curso se realizará en el Campus Virtual de la UEx utilizando todos los recursos que ofrece la plataforma Moodle. Como añadido se impartirán tres talleres presenciales: uno inicial para el uso de la plataforma virtual y de las herramientas que vamos a utilizar, y otros dos talleres prácticos de apoyo a la parte virtual. Cada bloque se activará de manera progresiva para ofrecer una mayor flexibilidad de trabajo y adaptabilidad a los ritmos de aprendizaje y a la disponibilidad horaria de cada participante. En cada bloque se presentarán:

- Foro Social donde se realizan las aportaciones, debates, ideas, etc. a la temática que se está trabajando en ese momento.

- Material propuesto, proporcionado por la tutora o tutor responsable.

- Material de ampliación, proporcionado por tutores/as responsables y de apoyo.

- Actividad o tarea a realizar.

De manera general, en todos los bloques se trabajarán:

- WebQuest y Wiki colaborativa (tarea principal del curso).

- Glosario colaborativo. 
- Blog grupal.

- Diario virtual a través del blog.

- Foro de Evaluación.

- Foro de Tutorías.

- Otros foros opcionales.

La tarea principal del curso está definida a través de una WebQuest que debe superarse de manera progresiva. Además, los/as tutores/as responsables añadirán a esta tarea la actividad colaborativa complementaria, siguiendo las directrices marcadas con anterioridad.

De manera general, tendremos un Foro de Tutorías para aquellos aspectos que surjan en relación con la labor tutorial. Se podrán fijar tutorías online síncronas mediante del recurso Mensajes o mediante Skype o ooVoo. Se intentará desarrollar, al menos en alguna ocasión, video-chat con tutoras/es.

\section{g. Calendario General.}

La iniciativa de formación establece dos meses y medio para el desarrollo de la acción formativa, correspondientes entre Octubre-Diciembre 2009, con fecha de evaluación final y cierre del curso en enero de 2010. Debemos tener en cuenta la flexibilidad al afrontar esta propuesta de curso, pudiendo modificarse si es necesario, formando parte de la evaluación continua que se realizará durante el progreso del mismo.

\section{h. Requerimientos técnicos.}

A continuación se presentan los requerimientos tecnológicos necesarios que deben tener los equipos para participar en la acción formativa en modalidad virtual. Debemos aclarar que, aunque las destinatarias no tengan a su alcance un equipo informático, la entidad promotora (Fundación 
Secretariado Gitano) pone a su disposición ordenadores portátiles o aulas con equipos de las características que se indican, en las localidades en las que disponen de sedes como son Cáceres, Mérida, Badajoz y Don Benito.

Realizada esta aclaración, los requerimientos técnicos mínimos necesarios para poder realizar esta acción de formación virtual son:

\begin{tabular}{|c|c|}
\hline \multicolumn{2}{|c|}{ Plataforma y Hardware } \\
\hline \multicolumn{2}{|c|}{ Windows, Ubuntu, Linux } \\
\hline \multicolumn{2}{|c|}{ Mac Os } \\
\hline \multicolumn{2}{|c|}{ Capacidad de Audio y Sonido } \\
\hline \multicolumn{2}{|c|}{ WebCam } \\
\hline \multicolumn{2}{|c|}{ Resolución en pantalla } \\
\hline \multicolumn{2}{|c|}{$1024 \times 768$} \\
\hline \multicolumn{2}{|c|}{ Conexión al Internet } \\
\hline \multicolumn{2}{|c|}{ Recomendable ADSL } \\
\hline \multicolumn{2}{|c|}{ Internet Browser (Exploradores) } \\
\hline \multicolumn{2}{|c|}{ Mozilla Firefox, Internet Explorer, Safari u Opera, Chrome } \\
\hline \multicolumn{2}{|c|}{ Pop-up Blockers } \\
\hline \multicolumn{2}{|c|}{$\begin{array}{l}\text { Algunos de los contenidos o mensajes emitidos durante la actividad del curso requerirán la } \\
\text { apertura de Pop-up en pantalla. Se deberá deshabilitar el sistema de bloqueo de éstos en su } \\
\text { navegador de Internet. }\end{array}$} \\
\hline \multicolumn{2}{|c|}{ Programados (Applications Software) } \\
\hline \multicolumn{2}{|c|}{ Open Office: www.openoffice.org. } \\
\hline \multicolumn{2}{|c|}{ Microsoft Office } \\
\hline \multicolumn{2}{|c|}{ Multimedia Plugins } \\
\hline Windows Media Player & Flash player \\
\hline Real Player & ShockWave player \\
\hline Apple Quicktime & Java Applets \\
\hline Acrobat reader & Java Mac OSx \\
\hline $\begin{array}{l}\text { En casos particulares será nece } \\
\text { concretos. En esos casos, la dinam }\end{array}$ & $\begin{array}{l}\text { ama en específico o plug-ins } \\
\text { cciones necesarias para realizar }\end{array}$ \\
\hline
\end{tabular}

Tabla 11. Requerimientos técnicos mínimos para realizar acción formativa 


\subsubsection{Diseño de unidades de aprendizaje.}

Para conseguir que los contenidos de la formación online se adecuen a las características del medio, la opción más aconsejable consiste en elaborar unidades de aprendizaje breves, independientes entre sí, que sigan estrategias didácticas bien definidas y sean susceptibles de agregación (Moreno y Bailly-Baillière, 2002). Esta afirmación requiere, desde nuestro punto de vista, un matiz y es que el conocimiento del mundo real no es estrictamente independiente, por lo que el grado de independencia de las unidades de aprendizaje es también forzosamente limitado.

Las inconsistencias terminológicas de lo que se entiende por «unidad de aprendizaje» (lección, unidad mínima, unidad didáctica, etc.) también afecta a la definición de su extensión, tanto más cuando dicha extensión hace referencia a un tiempo de aprendizaje que, en la práctica, depende de cada estudiante y es, además, relativo (unos estudiantes aprenden en menos tiempo más que otros, o cosas distintas, o de distinto modo). La apreciación del tiempo que puede suponer para cada estudiante la asimilación de una unidad de aprendizaje tiene un carácter subjetivo, mientras unos autores consideran que esa extensión debe estar entre los 5 y los 20 minutos (Kottler et al., 2000) otros determinan que cualquier lectura facilitada por un sistema online sea breve y dividida en secciones muy reducidas, de entre uno y tres párrafos (Draves, 2000). Moreno y Bailly-Baillière (2002) sugieren que la extensión de las unidades se acomoden:

1. Al tipo de estudiantes al que originalmente está dirigido el aprendizaje.

2. A la materia de que se trate (densidad de información, nivel cognitivo al que se dirige, etc.). 
3. A los condicionantes de los redactores (hábitos de enseñanza, tiempo disponible para su formación, etc.).

4. Y, para la toma de decisión final -que tendrá en cuenta los elementos anteriores y otros de carácter económico o logístico-, el modelo de enseñanza-aprendizaje que cada institución debe definir para un contexto didáctico determinado.

Teniendo en cuenta todos estos aspectos, entendemos por unidad de aprendizaje en el marco de espacios virtuales de formación, pequeñas unidades instructivas compuestas por tres elementos básicos: propuestas temáticas, interactividad y evaluación. Las características que identifican a estas unidades son las siguientes:

- Tienen unos objetivos claros y evaluables.

- Presentan unas propuestas temáticas de extensión breve.

- Incorporan unas estrategias didácticas específicas que consideran diversas actividades de aprendizaje e incluyen un sistema de evaluación que permite determinar si las estudiantes han adquirido los conocimientos previstos.

- Se pueden personalizar, según necesidades específicas.

- Se pueden reutilizar, siempre contextualizándolas a las características de la nueva acción formativa.

- Son independientes, pero se pueden agrupar para formar estructuras didácticas modulares.

- En cuanto a la temporalización, se adecuará siguiendo las claves de Moreno y Bailly-Baillière (2002), y por tanto la duración en tiempo puede ser más o menos amplia dependiendo de los factores indicados. 
Para definir cada unidad de aprendizaje, debemos precisar:

- Nombre, que debe ser corto, conciso y estar relacionado con los objetivos y las propuestas temática.

- Objetivos, que debemos plantearlos considerando la competencia que debe tener adquirida cada estudiante cuando finalice esta unidad.

- Relación de contenidos correspondientes con la propuesta temática.

- Palabras clave, es decir, definir aquellas palabras que identifican las propuestas temáticas de la unidad.

- Estrategia didáctica: definiendo la metodología y actividades que se desarrollarán.

- Pre-requisitos: indicando, en caso necesario, los conocimientos básicos que la estudiante debe manejar para desarrollar con éxito esta unidad.

- Temporalización, determinando los tiempos de la unidad, en referencia al tiempo de trabajo de las estudiantes.

- Recursos para el aprendizaje, concretando los medios que vamos a utilizar para la adquisición de las competencias

- Roles: Se deben identificar los roles que desempeñarán los agentes, en referencia al personal experto y la dinamizadora, asignando tutorías virtuales y talleres presenciales.

- Bibliografía: se pueden añadir, de manera opcional, recursos bibliográficos en referencias a las temáticas tratadas. En este caso, no incluimos bibliografía en las Unidades de Aprendizaje puesto que cada 
tutor/a proporcionará la documentación precisa de cada propuesta temática.

Así, para la acción formativa virtual que se presenta, definimos 4 unidades de aprendizaje: 


\section{UNIDAD DE APRENDIZAJE 1}

Nombre Uso básico de las TIC: buscar información, comunicarse, expresarse, compartir información y publicar contenidos en la web.

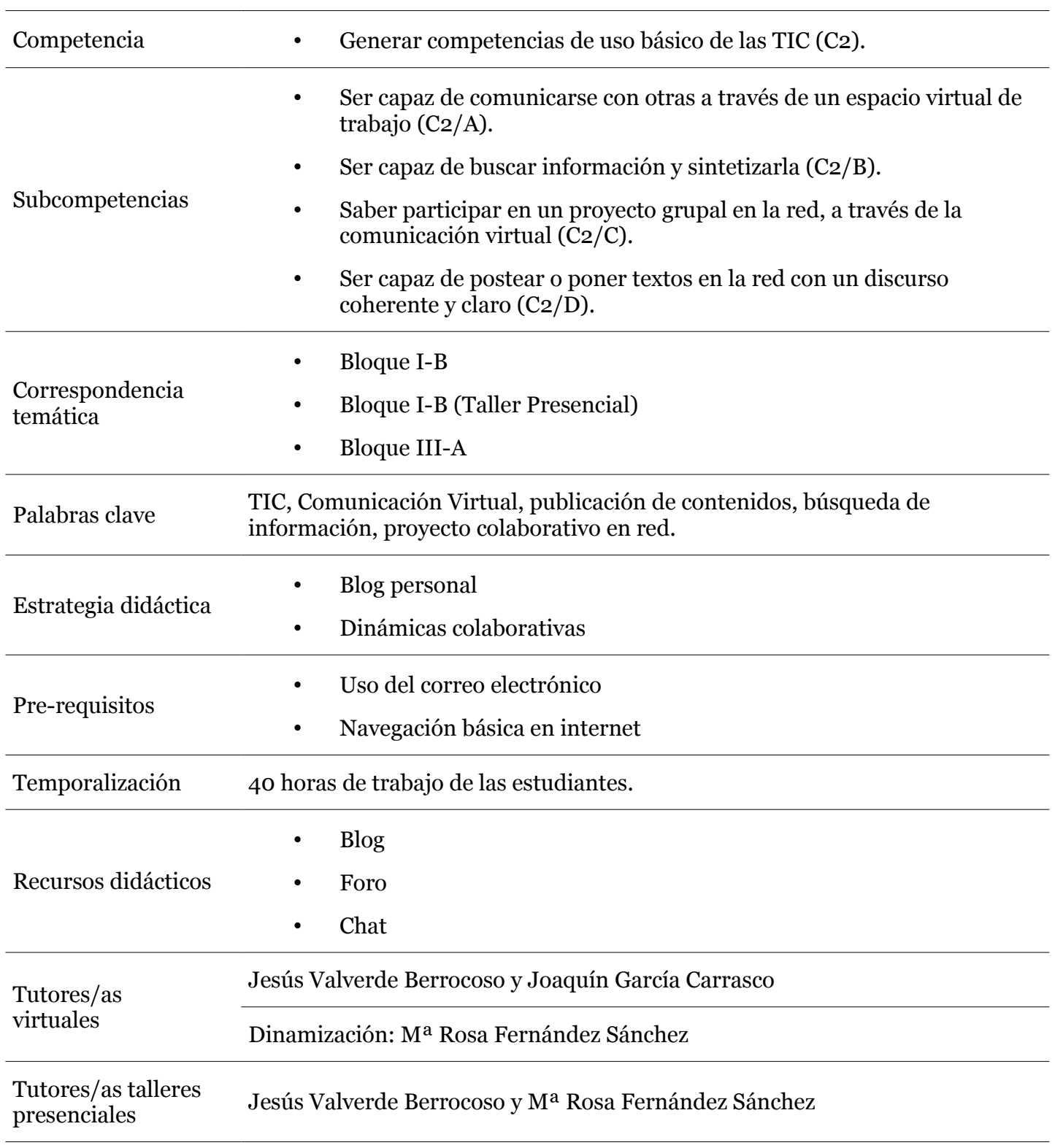

Tabla 12. Unidad de aprendizaje 1 


\section{UNIDAD DE APRENDIZAJE 2}

\begin{tabular}{lll}
\hline Nombre & Igualdad de oportunidades y el liderazgo social. \\
\hline Competencia & $\bullet$ & $\begin{array}{l}\text { Generar conocimientos básicos sobre la igualdad de oportunidades y } \\
\text { el liderazgo social (C1). }\end{array}$ \\
\hline Subcompetencias & $\begin{array}{l}\text { Poseer conocimientos de terminología básica relacionada con la } \\
\text { igualdad de oportunidades entre hombres y mujeres y el liderazgo } \\
\text { social femenino (C1/A). }\end{array}$ \\
& $\begin{array}{l}\text { Incorporar y aplicar terminología básica relacionada con la temática a } \\
\text { sus propias reflexiones y discursos (C1/B). }\end{array}$ \\
$\begin{array}{ll}\text { Correspondencia } \\
\text { temática }\end{array}$ & Bloque I-A \\
& Bloque II-A \\
\hline
\end{tabular}

Palabras clave Igualdad de Oportunidades, Igualdad de Género, Liderazgo social, Mujeres gitanas.

\section{Estrategia}

didáctica

Dinámicas colaborativas

\begin{tabular}{|c|c|}
\hline Pre-requisitos & Ninguno. \\
\hline Temporalización & 20 horas de trabajo de las estudiantes. \\
\hline $\begin{array}{l}\text { Recursos } \\
\text { didácticos }\end{array}$ & $\begin{array}{ll}\text { - } & \text { Foro } \\
\text { - } & \text { Glosario Virtual colaborativo }\end{array}$ \\
\hline
\end{tabular}

virtuales

Personas expertas: Beatriz Muñoz González, María García Sánchez, Ma del Carmen Garrido Arroyo, Joan Barstow Hernández

Dinamización: Ma Rosa Fernández Sánchez.

Tutores/as talleres presenciales
Tamara García Carrasco, Valentín Suárez Saavedra, Fernando Rey Martínez, Persona asignada del Instituto de la Mujer de Extremadura (IMEX).

Tabla 13. Unidad de aprendizaje 2 
UNIDAD DE APRENDIZAJE 3

\begin{tabular}{|c|c|}
\hline Nombre & Aprendizaje permanente y autoconocimiento personal. \\
\hline Competencia & $\begin{array}{l}\text { - Generar actitudes positivas hacia la formación y el autonocimiento } \\
\text { personal (C3). }\end{array}$ \\
\hline \multirow{3}{*}{ Subcompetencias } & $\begin{array}{l}\text { - Mostrar una actitud basada en el respeto, la tolerancia y la asertividad, } \\
\text { expresar y comprender puntos de vista diferentes, negociar } \\
\left.\text { significados y manifestar empatía ( } \mathrm{C}_{3} / \mathrm{A}\right) \text {. }\end{array}$ \\
\hline & $\begin{array}{l}\text { - Ser capaz de auto-reflexionar sobre sus conocimientos y sentimientos } \\
\text { (C3/B). }\end{array}$ \\
\hline & $\begin{array}{l}\text { - Mostrar una buena actitud ante el uso de las TIC para realizar futuras } \\
\text { formaciones en modalidad virtual }\left(\mathrm{C}_{3} / \mathrm{C}\right) \text {. }\end{array}$ \\
\hline \multirow{2}{*}{$\begin{array}{l}\text { Correspondencia } \\
\text { temática }\end{array}$} & - $\quad$ Bloque II-B \\
\hline & - $\quad$ Bloque II_B (Taller Presencial) \\
\hline Palabras clave & Aprendizaje permanente, comunicación y expresión social, autoformación. \\
\hline \multirow{2}{*}{$\begin{array}{l}\text { Estrategia } \\
\text { didáctica }\end{array}$} & - Dinámicas colaborativas \\
\hline & - $\quad$ Blog personal \\
\hline \multirow{2}{*}{ Pre-requisitos } & - Uso de correo electrónico \\
\hline & - $\quad$ Navegación básica en internet \\
\hline Temporalización & 20 horas de trabajo de las estudiantes \\
\hline \multirow{2}{*}{$\begin{array}{l}\text { Recursos } \\
\text { didácticos }\end{array}$} & - $\quad$ Blog \\
\hline & - $\quad$ Foros \\
\hline \multirow{2}{*}{$\begin{array}{l}\text { Tutores/as } \\
\text { virtuales }\end{array}$} & Experto: Jesús Valverde Berrocoso \\
\hline & Dinamizadora: Mª Rosa Fernández Sánchez \\
\hline $\begin{array}{l}\text { Tutores/as } \\
\text { talleres } \\
\text { presenciales }\end{array}$ & Jesús Valverde Berrocoso y Ma Rosa Fernández Sánchez \\
\hline
\end{tabular}

Tabla 14. Unidad de aprendizaje 3 


\section{UNIDAD DE APRENDIZAJE 4}

\begin{tabular}{|c|c|}
\hline Nombre & Trabajo Colaborativo \\
\hline Competencia & - $\quad$ Generar habilidades de trabajo colaborativo. \\
\hline \multirow[t]{2}{*}{ Subcompetencias } & $\begin{array}{l}\text { - Trabajar en equipo en entornos virtuales, aportando, reflexionando, } \\
\text { sobre las ideas, experiencias, etc. que se compartan en el espacio } \\
\text { virtual de trabajo (C4/A). }\end{array}$ \\
\hline & - $\quad$ Ser capaz de desarrollar estrategias de trabajo colaborativas. \\
\hline $\begin{array}{l}\text { Correspondencia } \\
\text { temática }\end{array}$ & - $\quad \mathrm{TPC}$ \\
\hline Palabras clave & Proyecto colaborativo virtual, trabajo colaborativo. \\
\hline $\begin{array}{l}\text { Estrategia } \\
\text { didáctica }\end{array}$ & Proyecto Colaborativo \\
\hline Pre-requisitos & Trabajo previo en Unidad de Aprendizaje 1. \\
\hline Temporalización & 25 horas de trabajo de las estudiantes \\
\hline \multirow{2}{*}{$\begin{array}{l}\text { Recursos } \\
\text { didácticos }\end{array}$} & WebQuest \\
\hline & Wiki \\
\hline \multirow{2}{*}{$\begin{array}{l}\text { Tutores/as } \\
\text { virtuales }\end{array}$} & $\begin{array}{l}\text { Personas expertas: Ma Rosa Fernández Sánchez, Ma del Carmen Garrido } \\
\text { Arroyo y María Sánchez García. }\end{array}$ \\
\hline & Dinamizadora: Ma Rosa Fernández Sánchez. \\
\hline
\end{tabular}

Tutores/as talleres presenciales

No se recoge taller presencial en esta unidad.

Tabla 15. Unidad de aprendizaje 4

\subsubsection{Diseño de la estrategia de motivación.}

Como recursos para motivar y animar a la participación en esta acción formativa, situamos algunos centros de interés de las participantes basándonos en principios colectivos comunes. Estos centros de interés están basados y adaptados de la Guía de motivación y recursos Mujeres Gitanas y nuevas tecnologías, editada por la Fundación Secretariado Gitano (2007).

La actual Sociedad de la Información y del Conocimiento nos sitúa en un escenario adecuado para intensificar la lucha por sociedades más igualitarias 
y más justas. Esta acción formativa, situada dentro de un proyecto amplio de promoción y visibilidad de las mujeres gitanas extremeñas, pretende fomentar la generación de sinergias que transformen a las mujeres en agentes multiplicadoras dentro de su propia comunidad.

Aunque actualmente Internet está presente en todos los ámbitos de la vida, aún no es accesible para todas las personas, existiendo, como hemos indicado anteriormente, la llamada «brecha digital», que afecta a los sectores más vulnerables, entre los que se encuentran las mujeres en general y las mujeres gitanas en particular, que sufren desigualdades en el uso y apropiación de la TIC. La inclusión digital incide en la necesidad de alfabetizar digitalmente, pero también teniendo en cuenta los contextos sociales y culturales de los colectivos y/o personas con las que se interviene. Así se entiende este concepto, siguiendo a Ortoll, como un proceso que permite que todas las personas se aprovechen de todos los derechos y oportunidades que se derivan del acceso y uso de las TIC y además accedan a la información como un elemento esencial para la creación de igualdades sociales (Ortoll, 2007). La inclusión digital procura, de esta manera, dar a las personas herramientas y tecnologías que les permitan participar de manera democrática en la sociedad, cambiarla y mejorarla. Por tanto, el acceso y uso de la información a través de medios digitales es un factor clave para la participación y la ciudadanía plena. En este sentido, se ha comentado antes, que el acceso al conocimiento empodera capacidades individuales y potencia formas de organización y de trabajo colectivo, en cuanto a que permiten aumentar la capacidad de organización y actuación, y acceder a información y conocimientos pudiendo compartirlos.

Desde este matiz, Plaza (2007: para. 39) argumenta:

«además las TIC favorecen el aspecto individual de las mujeres, brindan importantes oportunidades de estudio y desarrollo personal, por la flexibilidad en el manejo del tiempo permiten combinar las 
aspiraciones de crecimiento laboral y profesional con las aspiraciones personales. En lo social las TIC son una herramienta para la difusión del conocimiento y la experiencia. Las TIC favorecen el trabajo en red dado que a través de ellas se puede compartir mucha información, intercambiar conocimientos, demandas, participar en asuntos políticos, etc.»

Algunas posibilidades que facilitan las TIC a las mujeres gitanas son (Fundación Secretariado Gitano, 2007):

- Compartir informaciones, conocimientos y experiencias.

- Fortalecimiento de las redes de mujeres y la puesta en marcha de trabajos conjuntos a partir del intercambio de esas experiencias.

- Acceso a la formación y a las oportunidades educativas que se brindan a través de la red.

- Fomento de la comunicación y la expresión de necesidades e intereses.

- Movilización conjunta, apoyo mutuo y oportunidades para generar un movimiento activista para luchar contra las injusticias que padecen como colectivo

A continuación presentamos la propuesta de tres centros de interés que se trabajarán en función de cada uno de los tres bloques temáticos del curso. Para ello, vamos a plantear las ideas básicas sobre cada centro de interés, por qué debemos trabajarlo y para qué debemos trabajarlo. 


\begin{tabular}{ll}
\hline Bloque & Centro de interés \\
\hline BLOQUE I & Mujeres gitanas en la red. \\
\hline BLOQUE II & Participando. \\
\hline BLOQUE III & Enredadas y creando redes: abriendo caminos. \\
\hline
\end{tabular}

Tabla 16. Correspondencia de Centros de interés con bloques temáticos.

\section{a. Centro de Interés 1: Mujeres gitanas en la red.}

El auge de las TIC está generando nuevas formas de comunicación y relación social, paralela y complementaria, con las formas de relación social tradicionales. La red Internet permite mantener conversaciones y participar en grupo, con ahorro en costes y tiempo de desplazamientos, además de eliminar barreras físicas.

Las mujeres gitanas, como indica Méndez:

«han mantenido y mantienen una comunicación muy estrecha con su
círculo familiar cercano, pero les falta comunicación (salvo
excepciones cada vez más numerosas) con otras mujeres gitanas que
no sean sus hermanas, sus madres, tías, sobrinas, primas...necesitan
comunicarse con otras mujeres gitanas, de otras familias, de otros
lugares y con mujeres de otras culturas» (Fundación Secretariado
Gitano, 2007:49)

Las TIC están abriendo la participación a mujeres gitanas al ámbito público, estableciendo un círculo de relaciones más amplio y virtual. La red brinda la oportunidad de expresarse libremente, abrir el abanico de la comunicación y ayudar y apoyarse entre unas mujeres y otras, estableciendo lazos de complicidad y solidaridad, conociendo a mujeres de todo el mundo con intereses compartidos.

¿Por qué trabajar este centro de interés? 
Las mujeres gitanas durante muchos años han tenido que enfrentarse a la hora de la integración a unas dificultades dobles: las que encuentran en la sociedad mayoritaria y en su propia comunidad. Como señala Méndez (Fundación Secretariado Gitano, 2007:50):

«poco a poco, ellas han sido protagonistas de una especie de «revolución tranquila. Han sabido modernizarse, sin renegar de sus raíces, provocando cambios con prudencia y cautela dentro de su comunidad».

Las mujeres gitanas son consideradas el motor del cambio en su comunidad, por eso es importante que no se queden atrás y peleen; es fundamental incorporar las TIC a la forma habitual de organizarse y movilizarse, que siempre ha sido en base al trabajo en redes. Hoy día se puede hablar de que es el tiempo de las mujeres (González, 2005): a través del diálogo, de la reflexión, del esfuerzo y de su creciente participación en la sociedad, están aportando nuevos significados a la identidad gitana, se están convirtiendo en referentes para otras personas de su comunidad y están transmitiendo todo lo aprendido a las generaciones que las siguen.

Por tanto se debe tomar conciencia de que las mujeres gitanas también disponen de unas herramientas accesibles y fáciles de utilizar para comunicarse, formarse, compartir, en definitiva, para participar.

¿Para qué este centro de interés?

- Reflexionar sobre las oportunidades de las TIC, sobre todo Internet, como espacio de reflexión, expresión y comunicación.

- Tomar conciencia de las grandes posibilidades que ofrece Internet para establecer relaciones con otras mujeres.

- Conocer las herramientas básicas que se usan en Internet para participar. 
- Dar a conocer iniciativas y espacios de mujeres gitanas en la red con el objetivo de compartir información, experiencias, inquietudes, proyectos, etc., desde de su propia voz en primera persona.

- Sentir que una ilusión inicial de acercamiento entre las mujeres gitanas puede llegar a convertirse en un proyecto viable gracias a las herramientas que nos ofrece Internet.

\section{b. Centro de Interés 2: Participando.}

Las mujeres gitanas son víctimas de estereotipos muy extendidos, llegando éstos a condicionar en muchos casos sus comportamientos. Como ocurre con todos los estereotipos, una parte de la realidad se convierte en el todo configurando la representación social de la mayoría. En este sentido, es cierto que algunas mujeres se ajustan al perfil de estos estereotipos pero hay otras que tienen unas características diferentes, por tanto tenemos una realidad heterogénea y con perfiles muy distintos, como ocurre en todos los colectivos. Sin embargo, en la Red se continúan esos estereotipos y prejuicios sobre las mujeres gitanas, que reflejan una imagen simplista, sesgada y uniforme de este grupo de mujeres. Es importante, desde este punto de vista, que las mujeres gitanas estén presentes en la Red para mostrar otras realidades que hagan de referentes, especialmente para otras mujeres gitanas, venciendo esa idea estereotipada y generalizada sobre este grupo. Algunas mujeres gitanas son cada vez más protagonistas de los cambios que se están dando en su propia comunidad: participan en las asociaciones y toman la iniciativa en proyectos de investigación y de intervención sobre su comunidad. Estos grupos de mujeres representan una «punta de lanza» y son referentes para muchas mujeres (Fundación Secretariado Gitano, 2007). Las TIC, especialmente Internet, pueden ayudar a que las demás mujeres de su comunidad tomen conciencia de sus potencialidades para compartir, 
construir alternativas y conseguir logros. Las mujeres gitanas han luchado durante décadas por mantener su identidad en la sociedad en la que viven. Ahora también es posible que luchen por definir y hacer visible su identidad en sus propios términos en los espacios virtuales.

La sociedad actual, sometida continuamente a procesos de cambios sociales muy acelerados que influyen en la comunidad gitana, está provocando cuestionamientos y «crisis de identidades» en muchas mujeres gitanas (Fundación Secretariado Gitano, 2007). La creación de espacios de encuentro, mediados por las TIC, donde se traten esos conflictos, se compartan las experiencias, los sentimientos, etc., desde un enfoque participativo, hace que las mujeres que participan en ellos se sientan apoyadas y animadas a conseguir las metas propuestas.

¿Por qué trabajar este centro de interés?

Internet se está convirtiendo en un espacio en el que las mujeres gitanas expresan sus voces en primera persona y se dan a conocer, además de consultar la información que la Red ofrece, promoviendo su participación social y la expresión de su identidad cultural. Estas formas de expresión ayudan a poner en contacto a diferentes mujeres gitanas de distintos lugares que se unen para exponer sus reivindicaciones, contando con la Red para plasmarlas, discutirlas y buscar apoyos de otras mujeres.

¿Para qué este centro de interés?

- Tomar conciencia y conocer la función social de Internet y su utilización como nueva herramienta de reivindicación cultural gitana y de participación social. 


\section{c. Centro de Interés 3: Enredadas y creando redes: abriendo caminos.}

Como hemos indicado, Internet está permitiendo poner en contacto a mujeres procedentes de distintos lugares y hacer visible la lucha de muchas de ellas por sus derechos, tejiendo redes de solidaridad. Es una herramienta muy útil y eficaz para estimular y crear redes de apoyo, comunicación y solidaridad entre mujeres, para establecer contactos, intercambiar ideas y experiencias desde diferentes realidades económicas, culturales y sociales. A través de ello, mujeres de diferentes etnias, países y culturas se expresan, se dan conocer, se organizan y crean vínculos de apoyo entre ellas.

Las mujeres gitanas también cuentan con este espacio, donde poder relacionarse y establecer lazos con otras mujeres, conocer otros referentes femeninos que van a permitir reflexionar sobre las necesidades y problemas, proponer objetivos a corto y medio plazo y plantear estrategias y proyectos para conseguir las metas que se establezcan. En definitiva para crear redes y trabajar conjunta y colectivamente.

¿Por qué trabajar este centro de interés?

Muchas mujeres gitanas participan plenamente en Internet y se comunican y organizan en la Red. Es un reto conseguir que, cada vez más mujeres gitanas, aprovechen Internet para generar redes de mujeres conectadas, intercambiando información, comunicándose y compartiendo apoyos y solidaridad.

¿Para qué este centro de interés?

- Tomar conciencia de la necesidad de crear redes de mujeres gitanas a través de Internet. 
- Participar en algunas redes de mujeres y direcciones webs interesantes para las mujeres gitanas.

- Proponer una iniciativa entre las mujeres que realicen el curso.

\subsubsection{Diseño de la interacción.}

\section{A. Actividades de aprendizaje.}

Las actividades planteadas en esta acción formativa virtual, buscan construir una representación mental coherente y auténtica, a partir del material presentado y su posterior trabajo colaborativo sobre el mismo. Este material lo constituyen todos los documentos de apoyo, en cualquier formato, que los tutores/as presentan en cada bloque.

La resolución de las actividades propuestas requiere el uso de variadas herramientas de comunicación como foros, chats, correo electrónico, así como herramientas y utilidades de trabajo en grupo (glosario, wiki, blogs, todos ellos compartidos).

Se destaca que la selección y diseño de las actividades de esta acción formativa ha sido una tarea compleja, puesto que se necesitaba una variedad de recursos que potenciaran la interactividad y la posibilidad de colaboración entre las mujeres participantes para lograr los objetivos de aprendizaje propuestos. Implicó una reflexión alrededor de tres ejes ya justificados con anterioridad:

- La aplicación de estrategias didácticas desde una perspectiva constructivista en el campo conceptual de la educación de adultos/as y aportar estrategias activas centradas en el proceso de aprendizaje de las alumnas en el marco de entornos virtuales de aprendizaje. 
- Los objetivos de aprendizaje, la finalidad del proyecto e-learning y las destinatarias de la acción formativa con sus características personales y culturales.

- El establecimiento de actividades que potencien la motivación e implicación de las participantes en base a los centros de interés seleccionados.

A partir de estos requisitos, se diseñaron las actividades que se presentan a continuación.

\section{A.1. Actividades principales: Proyecto colaborativo, Glosario Colaborativo, Blog Personal.}

$\underline{\text { Proyecto colaborativo }}$

La actividad principal de esta acción formativa está basada en un proyecto colaborativo que consiste en la elaboración conjunta de un documento, que recoja algunas reflexiones de las participantes sobre cuáles son las necesidades y demandas de las mujeres gitanas extremeñas de cara a los próximos años y de qué manera ellas mismas quieren concretar esa transformación. Este documento conjunto serviría para presentarlo como manifiesto a diferentes entidades autonómicas con competencias en esas demandas que se consensúen. El documento, con un fin organizativo, se va a dividir en cuatro áreas principales: Educación, Salud, Mercado Laboral y Participación Social y Cultural. Para ayudar a la realización conjunta de esta actividad se trabajará a través de la resolución de una WebQuest, siguiendo un esquema de trabajo basado en la estructura de este recurso.

Los datos, textos y opiniones que vayan recopilando y generando las participantes serán compartidos en una Wiki que constituirá el trabajo conjunto del proyecto y dónde será presentado el resultado final del mismo. En la wiki se crearán varios apartados correspondientes a las áreas 
principales que van a trabajar las participantes, apoyadas por Foros específicos de cada área donde irán consensuando las ideas más significativas. La finalidad de la Wiki es facilitar la interacción entre las participantes y contribuir al desarrollo de forma conjunta de las tareas que constituyen la actividad propuesta. Como añadido a esta actividad, se utilizará el Blog individual como diario del trabajo propuesto en este proyecto colaborativo.

\section{Glosario Colaborativo}

Como punto de partida para la construcción de conocimientos en torno a los conceptos base de la acción formativa virtual, se establece la actividad de elaboración de un glosario de términos de forma colaborativa. La tutora propone algunos conceptos clave relacionados con las temáticas del curso, y todas las participantes deben asignar una definición, comentario, explicación a cada uno de ellos basándose en las anteriores aportaciones, si las hubiese.

\section{Blog Personal}

Cada participante debe realizar un blog personal donde recoja, además de temáticas relacionadas con la acción formativa, reflexiones y opiniones personales de temas de interés para cada una de ellas, intentando que cada una se identifique con su diario digital. Con el desarrollo del blog se fomentan competencias relacionadas con los objetivos de aprendizaje expuestos comprobando si se van poniendo en práctica y adquiriendo, pretendiendo que las participantes sean conscientes de su propio proceso de adquisición de destrezas y habilidades y de cómo éstas van desarrollándose, desde la repetición misma de esas capacidades, a su aplicación a contextos reales (Stones, 1989). En este contexto, el blog personal sirve para mostrar al resto de compañeras y visitantes las reflexiones sobre los temas de interés para las autoras, permitiendo una apertura de sus opiniones a toda la red. Esto permite que las participantes interactúen con otras personas que comentan 
sus publicaciones, intercambiando o matizando sus opiniones, lo que aporta diferentes puntos de vista.

\section{A.2. Actividades propuestas por tutores/as: dinámicas virtuales de trabajo colaborativo.}

Como su propio nombre indica, esta propuesta de actividades pretende dinamizar el trabajo de las participantes y contribuir a la generación de conocimiento compartido. En este sentido se presentan una serie de dinámicas virtuales de trabajo colaborativo, como ayuda al profesorado, para que pueda seleccionar aquella que más se ajuste a las tareas de su módulo.

En este sentido debemos señalar:

- Trabajamos para desarrollar capacidades complejas que implican actividades poco estructuradas. En el único caso en que se ha «semiestructurado» ha sido en el desarrollo de la primera sesión presencial, destinada a la exploración de los ambientes de la plataforma virtual, los espacios de comunicación, el uso de las herramientas básicas de trabajo, etc., con un conjunto de actividades destinadas a adquirir las competencias técnicas básicas en el uso de la plataforma, sus espacios de comunicación e interacción entre compañeras y tutores/as.

- Todas las participantes deben utilizar el mismo material para el tipo de estrategia de aprendizaje que se está estudiando y aplicando, no obstante se ponen a su disposición lecturas y materiales adicionales que pueden consultar voluntariamente.

- El tipo de tareas se coordina con los objetivos de aprendizaje para su logro, por lo que podrán sufrir modificaciones en función de las necesidades y/o dificultades que vayan surgiendo. 
En el siguiente cuadro se presentan un grupo de dinámicas didácticas colaborativas que se proponen al profesorado para seleccionar la correspondiente a su temática, siempre en coherencia con el desarrollo de la competencia a la que corresponde la unidad de aprendizaje de su tema.

\begin{tabular}{|c|c|c|c|c|}
\hline Actividad & Objetivo/s & Descripción & Desarrollo & Herramientas \\
\hline EL CONCEPTO & $\begin{array}{l}\text { Investigar, } \\
\text { explorar y } \\
\text { aplicar ideas y } \\
\text { teorías } \\
\text { conceptuales }\end{array}$ & $\begin{array}{l}\text { La persona } \\
\text { dinamizadora } \\
\text { selecciona un } \\
\text { concepto o } \\
\text { conceptos clave } \\
\text { del tema. Se pide } \\
\text { a las participantes } \\
\text { que encuentren y } \\
\text { apliquen } \\
\text { ejemplos. Se } \\
\text { comparan los } \\
\text { ejemplos } \\
\text { encontrados. }\end{array}$ & $\begin{array}{l}\text { 1. Presentación } \\
\text { de la actividad. } \\
\text { 2. Reflexión } \\
\text { individual de } \\
\text { cada } \\
\text { participante con } \\
\text { la lectura del } \\
\text { tema. } \\
\text { 3.Búsqueda y } \\
\text { propuesta de } \\
\text { ejemplos. } \\
\text { 4. Debate. } \\
\text { 5. Conclusiones. }\end{array}$ & $\begin{array}{l}\text { - Foro de } \\
\text { discusión. } \\
\text { - Blog. } \\
\text { - Chat. }\end{array}$ \\
\hline ARGUMENTOS & $\begin{array}{l}\text { - Estimular la } \\
\text { discusión, } \\
\text { haciendo } \\
\text { énfasis en la } \\
\text { identificación } \\
\text { de ideas } \\
\text { comunes y } \\
\text { diferentes, } \\
\text { argumentación, } \\
\text { negociación y } \\
\text { toma de } \\
\text { decisiones en } \\
\text { conjunto. } \\
\text { - Promover y } \\
\text { motivar para la } \\
\text { participación. }\end{array}$ & $\begin{array}{l}\text { La persona } \\
\text { dinamizadora } \\
\text { presenta el tema } \\
\text { acompañándose } \\
\text { del documento } \\
\text { que ha elaborado. } \\
\text { En base a éste } \\
\text { realiza una } \\
\text { pregunta } \\
\text { generadora, que } \\
\text { produzca un } \\
\text { debate entre las } \\
\text { participantes. }\end{array}$ & $\begin{array}{l}\text { 1. Presentación } \\
\text { de la actividad. } \\
\text { 2. Exposición } \\
\text { breve del tema. } \\
\text { 3. Generación } \\
\text { de la pregunta. } \\
\text { 4. Comienzo de } \\
\text { debate libre. } \\
\text { 5. Comparar } \\
\text { opiniones y } \\
\text { autoevaluación. }\end{array}$ & $\begin{array}{l}\text { - Foro de } \\
\text { discusión. }\end{array}$ \\
\hline $\begin{array}{l}\text { LLUVIA DE } \\
\text { IDEAS } \\
\text { INTERACTIVA }\end{array}$ & $\begin{array}{l}\text { - Liberar la } \\
\text { creatividad. } \\
\text { - Generar un } \\
\text { número extenso } \\
\text { de ideas. } \\
\text { - Involucrar a } \\
\text { todas las } \\
\text { participantes en } \\
\text { el proceso. } \\
\text { - Tomar un } \\
\text { primer contacto } \\
\text { con el tema en } \\
\text { el que } \\
\text { posteriormente }\end{array}$ & $\begin{array}{l}\text { La persona } \\
\text { dinamizadora } \\
\text { propone una } \\
\text { temática/problem } \\
\text { a/ etc., y las } \\
\text { participantes dan } \\
\text { ideas o soluciones } \\
\text { creativas a la } \\
\text { propuesta } \\
\text { realizada. } \\
\text { Con el listado de } \\
\text { ideas, las } \\
\text { participantes } \\
\text { deben ponerse de } \\
\text { acuerdo en la }\end{array}$ & $\begin{array}{l}\text { 1. El/la } \\
\text { dinamizadora } \\
\text { formula la } \\
\text { temática, } \\
\text { pregunta, } \\
\text { problema, etc. } \\
\text { 2. Las } \\
\text { participantes } \\
\text { responden } \\
\text { espontáneamen } \\
\text { te dando sus } \\
\text { ideas. } \\
\text { 3. Debate para } \\
\text { determinar las }\end{array}$ & $\begin{array}{l}\text { - Foro de } \\
\text { discusión. } \\
\text { - Blog grupal. } \\
\text { - Chat. } \\
\text { Nota: se pueden } \\
\text { combinar } \\
\text { ambas } \\
\text { herramientas. } \\
\text { Recogida de } \\
\text { ideas: Chat o } \\
\text { Blog. Y debate. } \\
\text { Blog o Foro. }\end{array}$ \\
\hline
\end{tabular}




\begin{tabular}{|c|c|c|c|c|}
\hline & $\begin{array}{l}\text { se va a } \\
\text { profundizar. } \\
\text { - Promover la } \\
\text { participación. } \\
\text { - Evaluar las } \\
\text { ideas de las } \\
\text { participantes } \\
\text { sobre un tema. }\end{array}$ & $\begin{array}{l}\text { selección de las } \\
\text { que consideran } \\
\text { más adecuadas o } \\
\text { mejores, y las } \\
\text { prioricen. } \\
\text { Es muy } \\
\text { importante tener } \\
\text { en cuenta que } \\
\text { todas las ideas } \\
\text { iniciales son } \\
\text { importantes y no } \\
\text { debemos } \\
\text { enjuiciarlas. }\end{array}$ & $\begin{array}{l}\text { más adecuadas } \\
\text { o importantes. } \\
\text { 4. Priorizan las } \\
\text { ideas } \\
\text { seleccionadas. } \\
\text { 5. Evaluación } \\
\text { de los diferentes } \\
\text { momentos } \\
\text { seguidos. }\end{array}$ & \\
\hline EL ESCENARIO & $\begin{array}{l}\text {-Proponer } \\
\text { escenarios para } \\
\text { motivar el } \\
\text { comienzo de la } \\
\text { discusión sobre } \\
\text { un tema y } \\
\text { fomentar la } \\
\text { creatividad. }\end{array}$ & $\begin{array}{l}\text { La persona } \\
\text { dinamizadora } \\
\text { propone un } \\
\text { escenario } \\
\text { concreto } \\
\text { animando a crear } \\
\text { la visión de lo que } \\
\text { ocurre. Deben } \\
\text { negociar y } \\
\text { acuerdan } \\
\text { conjuntamente la } \\
\text { solución. } \\
\text { Un ejemplo: } \\
\text { * Te encuentras } \\
\text { chateando en la } \\
\text { red con un apodo } \\
\text { (nick) y se te abre } \\
\text { una ventana de } \\
\text { alguien que no } \\
\text { conoces que te } \\
\text { llama por tu } \\
\text { nombre, ¿qué } \\
\text { haces? } \\
\text { * Estás en casa y } \\
\text { llaman a la } \\
\text { puerta. Al abrirla } \\
\text { te encuentras una } \\
\text { mujer que te pide } \\
\text { que la escondas, } \\
\text { ¿que ha pasado y } \\
\text { qué haces? } \\
\text { * Vuelves de } \\
\text { compras y te das } \\
\text { cuenta de que te } \\
\text { falta una bolsa, } \\
\text { ¿qué ha pasado } \\
\text { por el camino? }\end{array}$ & $\begin{array}{l}\text { 1. El tutor/a } \\
\text { presenta el } \\
\text { escenario. } \\
\text { 2. Se desarrolla } \\
\text { un intercambio } \\
\text { de ideas al } \\
\text { respecto, } \\
\text { analizando las } \\
\text { situaciones } \\
\text { posibles. } \\
\text { 3. Discusión. } \\
\text { 4. Evaluación } \\
\text { de la actividad. }\end{array}$ & $\begin{array}{l}\text { - Foro de } \\
\text { discusión. } \\
\text { - Blog grupal. }\end{array}$ \\
\hline $\begin{array}{l}\text { JUEGO DE } \\
\text { ROLES } \\
\text { (ROLE } \\
\text { PLAYING) }\end{array}$ & $\begin{array}{l}\text { - Imaginar la } \\
\text { forma de actuar } \\
\text { y las decisiones } \\
\text { que tomaría } \\
\text { cada una en }\end{array}$ & $\begin{array}{l}\text { La persona } \\
\text { dinamizadora } \\
\text { presenta una } \\
\text { situación } \\
\text { problemática, }\end{array}$ & $\begin{array}{l}\text { 1. Presentación } \\
\text { de la actividad. } \\
2 . \\
\text { Planteamiento }\end{array}$ & $\begin{array}{l}\text { - Foro de } \\
\text { discusión. } \\
\text { - Chat. }\end{array}$ \\
\hline
\end{tabular}




\begin{tabular}{|c|c|c|c|c|}
\hline & $\begin{array}{l}\text { base a los } \\
\text { personajes o } \\
\text { roles asignados, } \\
\text { en situaciones } \\
\text { diferentes. } \\
\text { - Fomentar la } \\
\text { creatividad y la } \\
\text { participación. }\end{array}$ & $\begin{array}{l}\text { como si de un } \\
\text { guión de cine se } \\
\text { tratara, y } \\
\text { distribuye los } \\
\text { roles entre las } \\
\text { participantes } \\
\text { buscando generar } \\
\text { diferentes puntos } \\
\text { de vista y } \\
\text { alternativas de } \\
\text { solución ante el } \\
\text { problema. Al final } \\
\text { podrán asumir } \\
\text { una posición real } \\
\text { frente al } \\
\text { problema (no } \\
\text { desde personaje) } \\
\text { y analizar las } \\
\text { argumentaciones } \\
\text { presentadas. }\end{array}$ & $\begin{array}{l}\text { del problema. } \\
\text { 3. Asignación y } \\
\text { distribución de } \\
\text { roles. } \\
\text { 4. Puesta en } \\
\text { marcha de los } \\
\text { roles. } \\
\text { Intercambio de } \\
\text { opiniones. } \\
\text { Debate. } \\
\text { 5. Conclusiones }\end{array}$ & \\
\hline $\begin{array}{l}\text { LAS POSTURAS } \\
\text { (Juego de Roles } \\
\text { en grupos) }\end{array}$ & $\begin{array}{l}\text { - Promover la } \\
\text { reflexión } \\
\text { proponer a las } \\
\text { participantes } \\
\text { que defiendan } \\
\text { una postura } \\
\text { contraria a la } \\
\text { que puedan } \\
\text { tener. }\end{array}$ & $\begin{array}{l}\text { La persona tutora } \\
\text { publica una lista } \\
\text { en el espacio } \\
\text { virtual en la que } \\
\text { aparecerá una } \\
\text { división en } \\
\text { grupos; cada } \\
\text { grupo adopta una } \\
\text { determinada } \\
\text { postura en torno a } \\
\text { un tema. } \\
\text { Se nombra una } \\
\text { portavoz en cada } \\
\text { grupo que será } \\
\text { quién enuncia las } \\
\text { ideas iniciales de } \\
\text { ese tema en torno } \\
\text { a la postura de su } \\
\text { grupo. } \\
\text { Todas las } \\
\text { portavoces } \\
\text { enuncian sus } \\
\text { ideas, y a partir de } \\
\text { ahí comienza la } \\
\text { discusión. } \\
\text { Cada participante } \\
\text { debe defender el } \\
\text { argumento inicial } \\
\text { de la portavoz de } \\
\text { su grupo. }\end{array}$ & $\begin{array}{l}\text { 1. Presentación } \\
\text { de la actividad y } \\
\text { división de } \\
\text { grupos. } \\
\text { 2. El tutor/a } \\
\text { propone el tema } \\
\text { y determina las } \\
\text { posturas que } \\
\text { cada grupo va a } \\
\text { asumir. } \\
\text { 3. Los grupos se } \\
\text { reúnen para } \\
\text { establecer los } \\
\text { argumentos } \\
\text { iniciales que } \\
\text { expone el } \\
\text { portavoz. } \\
\text { 4. Debate en } \\
\text { grupo grande. }\end{array}$ & $\begin{array}{l}\text { - Foro de } \\
\text { discusión. } \\
\text { - Chat. }\end{array}$ \\
\hline $\begin{array}{c}\text { LAS } \\
\text { PREGUNTAS }\end{array}$ & $\begin{array}{l}\text { - Ofrecer a las } \\
\text { participantes } \\
\text { preguntas } \\
\text { sencillas para } \\
\text { que se ejerciten } \\
\text { en los }\end{array}$ & $\begin{array}{l}\text { Se basa en un } \\
\text { ciclo de preguntas } \\
\text { que las } \\
\text { participantes } \\
\text { deben ir } \\
\text { contestando. }\end{array}$ & $\begin{array}{l}\text { 1. Presentación } \\
\text { de la actividad. } \\
\text { 2. El tutor/a } \\
\text { propone la } \\
\text { primera } \\
\text { pregunta. }\end{array}$ & $\begin{array}{l}\text { - Blog grupal. } \\
\text { - Foro de } \\
\text { discusión. } \\
\text { - Chat. }\end{array}$ \\
\hline
\end{tabular}




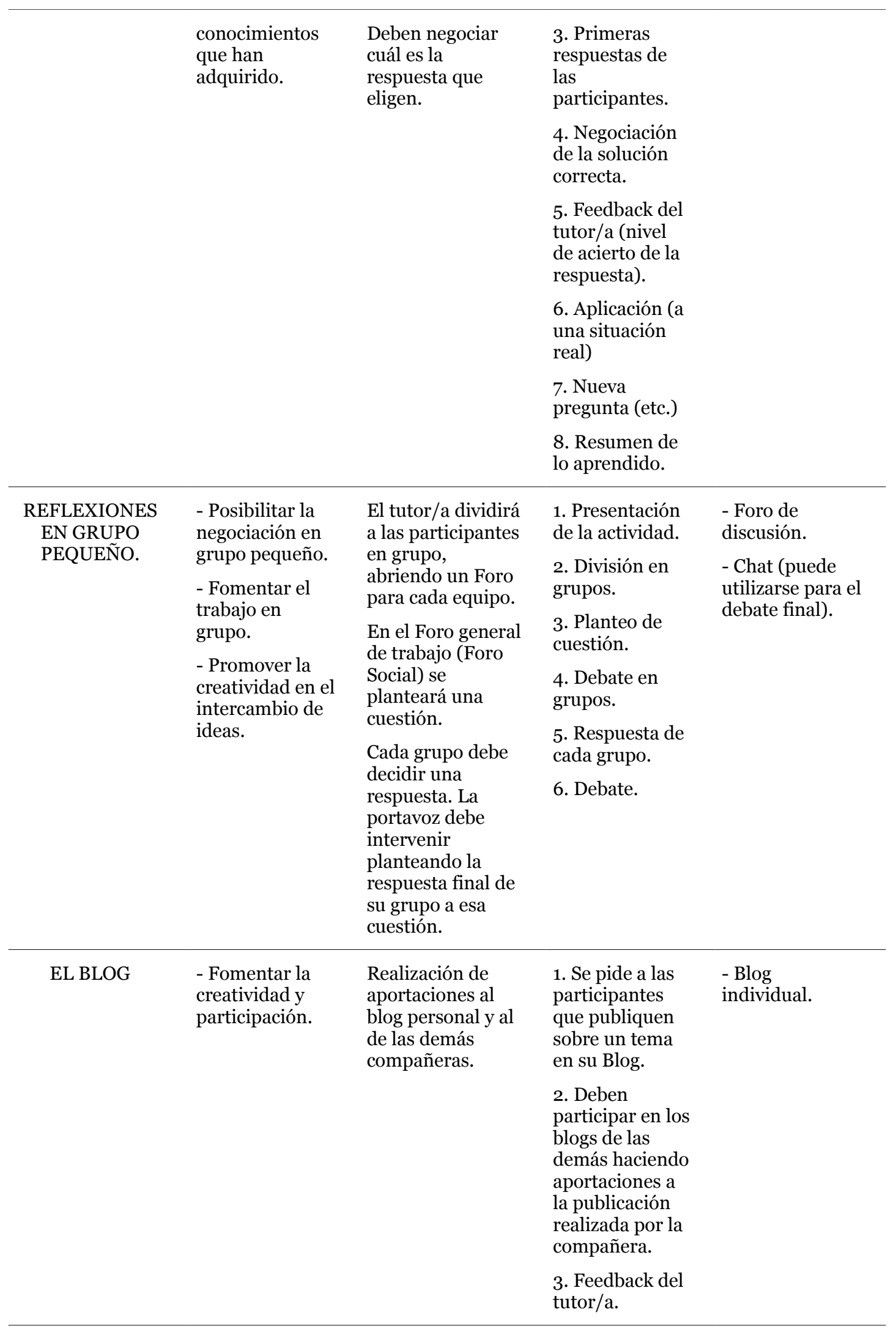


Comunidad de Práctica para la promoción sociocultural de mujeres gitanas en entornos virtuales de aprendizaje

\begin{tabular}{|c|c|c|c|c|}
\hline $\begin{array}{c}\text { GLOSARIO } \\
\text { COLABORATIVO }\end{array}$ & $\begin{array}{l}\text { - Promover la } \\
\text { colaboración de } \\
\text { las } \\
\text { participantes. } \\
\text { - Desarrollar } \\
\text { capacidades } \\
\text { cognitivas de } \\
\text { construcción de } \\
\text { conceptos. }\end{array}$ & $\begin{array}{l}\text { Las participantes } \\
\text { deben debatir las } \\
\text { definiciones } \\
\text { previamente } \\
\text { incorporadas. }\end{array}$ & $\begin{array}{l}\text { 1. Presentación } \\
\text { de la actividad. } \\
\text { 2. } \\
\text { Planteamiento y } \\
\text { aclaración de } \\
\text { las definiciones. } \\
\text { 3. Discusión } \\
\text { sobre algún } \\
\text { término. }\end{array}$ & $\begin{array}{l}\text { - Glosario } \\
\text { colaborativo. }\end{array}$ \\
\hline $\begin{array}{l}\text { ANÁLISIS } \\
\text { CRÍTICO }\end{array}$ & $\begin{array}{l}\text { - Fomentar y } \\
\text { practicar } \\
\text { destrezas } \\
\text { relacionadas } \\
\text { con el análisis } \\
\text { crítico de } \\
\text { lecturas } \\
\text { realizadas. }\end{array}$ & $\begin{array}{l}\text { Tras la lectura de } \\
\text { un tema, el } \\
\text { tutor/a propone } \\
\text { preguntas guía } \\
\text { que faciliten el } \\
\text { análisis crítico y } \\
\text { colaborativo de } \\
\text { lecturas. }\end{array}$ & $\begin{array}{l}\text { 1. Presentación } \\
\text { de la actividad. } \\
\text { 2. } \\
\text { Planteamiento } \\
\text { de preguntas } \\
\text { guía. } \\
\text { 3. Análisis } \\
\text { crítico, } \\
\text { respuestas y } \\
\text { reflexiones. } \\
\text { 4. Conclusiones. }\end{array}$ & $\begin{array}{l}\text { - Blog grupal. } \\
\text { - Foro de } \\
\text { discusión. }\end{array}$ \\
\hline EXPERIENCIAS & $\begin{array}{l}\text { - Intercambiar } \\
\text { experiencias } \\
\text { entre } \\
\text { participantes. }\end{array}$ & $\begin{array}{l}\text { Cada participante } \\
\text { hará preguntas a } \\
\text { otras tres } \\
\text { (personalizando } \\
\text { su mensaje) sobre } \\
\text { su experiencia. } \\
\text { Posteriormente se } \\
\text { reflexiona en base } \\
\text { a sus respuestas. }\end{array}$ & $\begin{array}{l}\text { 1. Presentación } \\
\text { de la actividad. } \\
\text { 2. Cada } \\
\text { participante } \\
\text { idea sus } \\
\text { preguntas y a } \\
\text { quién se las va a } \\
\text { realizar. } \\
\text { 3. Comienza el } \\
\text { turno de } \\
\text { preguntas y } \\
\text { respuestas. } \\
\text { 4. Reflexiones. }\end{array}$ & - Blog Grupal. \\
\hline
\end{tabular}




\begin{tabular}{|c|c|c|c|c|}
\hline $\begin{array}{l}\text { REFLEXIONES } \\
\text { (AUTOEVALUACIÓN) }\end{array}$ & $\begin{array}{l}\text { - Promover la } \\
\text { autoevaluación. } \\
\text { - Facilitar } \\
\text { reflexiones } \\
\text { sobre la } \\
\text { experiencia } \\
\text { global de } \\
\text { aprendizaje. }\end{array}$ & $\begin{array}{l}\text { Solicitar a las } \\
\text { participantes la } \\
\text { revisión de } \\
\text { algunos mensajes } \\
\text { y que rectifiquen } \\
\text { o aclaren cuál } \\
\text { refleja mejor la } \\
\text { situación actual. } \\
\text { Que las } \\
\text { participantes } \\
\text { comenten los } \\
\text { diversos roles que } \\
\text { adoptaron } \\
\text { durante el } \\
\text { desarrollo del } \\
\text { curso. } \\
\text { Animar a las } \\
\text { participantes a } \\
\text { exteriorizar las } \\
\text { emociones que } \\
\text { sintieron en } \\
\text { diversos } \\
\text { momentos y los } \\
\text { motivos. }\end{array}$ & $\begin{array}{l}\text { 1. Presentación } \\
\text { de la actividad. } \\
\text { 2. Reflexiones } \\
\text { de las } \\
\text { participantes. } \\
\text { 3. Debate y } \\
\text { opiniones. } \\
\text { 4. Conclusiones. }\end{array}$ & $\begin{array}{l}\text { - Blog grupal. } \\
\text { - Foro de } \\
\text { discusión. } \\
\text { - Chat. }\end{array}$ \\
\hline
\end{tabular}

La metodología que se sigue en la propuesta de las actividades colaborativas se determina en la Guía de orientación metodológica para docentes (Anexo III) dirigida a las personas que van a realizar la labor de docencia y tutoría en esta acción formativa, elaborada para servir de guía orientativa y desarrollar las tareas propias de esta labor. Esta metodología se presenta en el diseño del sistema de tutorías.

La determinación del tamaño de agrupamiento más recomendado para cada actividad considerando los objetivos de aprendizaje, el diseño de la interacción y el tipo de tarea es:

- En la actividad principal el grupo completo participará en la resolución de la tarea de manera conjunta.

- Para algunas actividades colaborativas propuestas será necesaria la realización de grupos de entre 3 y 5 participantes, siempre teniendo en cuenta que la finalización de la actividad será con todo el grupo. 


\section{B. Medios/recursos didácticos.}

\section{B.1. Justificación de los recursos seleccionados.}

Los recursos que van a vertebrar este curso virtual como estrategias de aprendizaje basadas en la investigación social y el trabajo colaborativo para esta acción formativa con TIC, son un elenco de herramientas que, utilizadas de manera integrada, constituyen una metodología que creemos completa para facilitar la construcción compartida del conocimiento. Son:
a) WebQuest.
b) Wiki.
c) Foros.
d) Chat.
e) Blogs.
f) Glosario colaborativo.

a) La WebQuest como recurso para generar habilidades de indagación y exploración, búsqueda y selección de recursos y estrategias, propiciando el aprendizaje significativo y profundo.

La idea de las WebQuest se desarrolló por Bernie Dodge, de manera casual, en una actividad que realizó con estudiantes de Magisterio de la Universidad de San Diego, donde ejerce como profesor de Tecnología Educativa. Este autor define las WebQuest como «una actividad de investigación en la que la información con la que interactúan los alumnos proviene total o parcialmente de recursos de la Internet» (Valverde, 2008). Para Adell (2004) la WebQuest es «una actividad didáctica que propone 
una tarea factible y atractiva para los estudiantes y un proceso para realizarla durante el cual, los alumnos harán cosas con información: analizar, sintetizar, comprender, transformar, crear, juzgar y valorar, crear nueva información, publicar, compartir, etc.

Esta estrategia metodológica-didáctica presenta una tarea que el alumnado debe resolver, indicando los pasos que pueden seguir para llevarla a cabo y concretando recursos disponibles en la red para su resolución. La WebQuest tiene una estructura específica a través de la cual se plantea esa tarea que deben desarrollar los estudiantes. Esta estructura, como hemos indicado preelaborada por Bernie Dodge (1995), se concreta en un documento dirigido al alumnado, que suele ser una web disponible online, y que se compone de varias fases:

1. Introducción: Es el documento donde se presenta la información básica sobre la actividad, los objetivos de la misma y una orientación sobre lo que se debe desarrollar, despertando el interés y la motivación de los estudiantes. Es por ello, que esta presentación debe ser atractiva e interesante y relevante para el alumnado.

2. Tarea: En este apartado, debe describirse la actividad que deben resolver los estudiantes de manera clara y concreta. Las tareas pueden ser variadas. Dodge (1999) establece una tareonomía -taxonomía de tareas- con 12 tipos de tareas posibles: de repetición, de recopilación, de misterio, periodísticas, de diseño, de productos creativos, para la construcción el consenso, de persuasión, de autoconocimiento, analíticas, emisión de un juicio, y científicas ${ }^{97}$.

3. Proceso: En esta fase se describen los pasos que debe seguir el estudiante y el orden de desarrollo, para resolver la tarea propuesta. Se puede enunciar con una lista ordenada de pasos especificando los recursos que pueden utilizar. Estos recursos pueden ser tanto páginas

97 Para más información sobre esta tipología de tareas consultar a Del Moral y Villalustre (2007). 
web, videos, referencias bibliográficas, como libros, artículos, revistas, etc. con los que podrán contar para realizar la tarea.

4. Evaluación: En la evaluación se exponen, de manera clara y detallada, los criterios y aspectos de evaluación de cada una de las actividades implicadas en el desarrollo de la tarea solicitada.

5. Conclusión: En esta parte se refleja lo que el alumnado consigue o aprende tras completar la WebQuest. Se resume lo aprendido y estimula la reflexión acerca del proceso seguido. Proporciona el cierre a la actividad y retroalimentación para futuras tareas de esta índole.

6. Créditos y Referencias. En esta parte, deben mencionarse las fuentes de documentos y demás recursos que se han utilizado, incluyendo, en caso de ser posible, enlaces a las fuentes originales.

El que tenga esta estructura permite que la actividad se organice de manera intuitiva, presentando la finalidad de manera clara y concisa, lo que nos asegura que todo el alumnado tenga conocimiento adecuado de la tarea que tiene que desarrollar.

Se encuentran un número importante de estudios ${ }^{98}$ que corroboran que la WebQuest es un buen recurso para generar, en el alumnado, habilidades de indagación y exploración, búsqueda y selección de recursos y estrategias.

Mencionamos un estudio elaborado por el profesor Jesús Valverde Berrocoso (2008) en el que se concluye que las WebQuest:

- Son muy útiles para el desarrollo de actividades estructuradas y comprensibles para el estudiante.

98 Un compendio de estos estudios lo encontramos recogidos en la Tesis elaborada por Iolanda Bernabé Muñoz en 2008: «Las WebQuests en el Espacio Europeo de Educación Superior (EEES). Desarrollo y evaluación de competencias con Tecnologías de la Información y la Comunicación (TICs) en la universidad». Disponible en: http://www.tesisenxarxa.net/TDX-0731108-121832/index_cs.html. 
- Ofrecen una claridad expositiva para la descripción del proceso de resolución de la tarea y en la forma de evaluar y valorar al alumnado.

- Tienen un nivel adecuado de motivación y es posible adaptar la dificultad a las características y capacidades de los destinatarios.

- El alumnado se siente satisfecho con los logros.

- Hacen posible un aprendizaje significativo y profundo, con posibilidades de permanencia y transferencia a otros contextos.

- Por último la sitúa como una estrategia versátil y adaptable a cualquier contenido.

En este sentido, la WebQuest es una estrategia orientada a la investigación colaborativa, que ayuda a favorecer un trabajo grupal de construcción compartida de conocimiento.

Una WebQuest bien diseñada construye un andamiaje en el proceso, provocando procesos cognitivos superiores (transformación de información de fuentes y formatos diversos, comprensión, comparación, elaboración y contraste de hipótesis, análisis- síntesis, creatividad, etc.). Para que los alumnos y alumnas usen estas funciones superiores de la cognición, las WebQuest utilizan «andamiaje cognitivo» (Scaffolding), un concepto muy relacionado con el de Zona de Desarrollo Próxima de Vygotsky. Dodge (2001), en este sentido, define un andamio como «una estructura temporal que proporciona ayuda en puntos específicos del proceso de aprendizaje» y propone usarlos en tres momentos clave del proceso de resolución de la WebQuest:

- En la recepción de la información: cuando los y las estudiantes tienen que acudir a fuentes diversas de datos, hechos, conceptos, etc. y extraer la información relevante distinguiéndola de la no relevante en 
el contexto de la tarea. Estos pueden ser: guías de observación, glosarios, cronologías, gráficos, mapas conceptuales, etc.

- En la transformación de la información: cuando es necesario comprender, valorar, decidir, integrar con lo ya sabido, etc.

- En la producción de información: cuando los alumnos y alumnas deben crear un producto original con la información adquirida.

Se trata de estrategias de ayuda y apoyo al estudiante para organizar la información en unidades significativas, analizarla y producir respuestas nuevas. Éstas pueden consistir en preguntas, procedimientos o sugerencias que les permitan abordar tareas más complejas que luego se van retirando en función de la interiorización de esas capacidades desarrolladas mediante este andamiaje.

En conclusión, este recurso permite a docentes utilizar el aprendizaje centrado en el estudiante, trabajar en colaboración y promover una actividad de pensamiento crítico utilizando la red Internet. Creemos que la implementación de este tipo de actividades utilizando esta estrategia didáctica en entornos virtuales, en conjunto con el uso de las herramientas comunicativas que estas actividades promueven, favorece la participación y las actividades colectivas, incidiendo en el trabajo colaborativo. En este caso la WebQuest se va a utilizar como actividad dinámica de investigación orientada a realizar un estudio de la realidad, de forma colaborativa, para cuyo desarrollo se van a proponer, de manera parcial aunque mayoritaria, recursos de la red Internet. Esta práctica, a nuestro punto de vista, desarrollada y apoyada en el contexto formativo mediado por las TIC que presentamos, está caracterizada por un valor social añadido al aprendizaje. 
b) La Wiki como recurso para la creación de habilidades de trabajo colaborativo y presentación de proceso y resultados del proyecto de investigación.

Las Wikis fueron creadas por Ward Cunnigham, se definen como «un sitio web colaborativo llevado adelante por el perpetuo trabajo colectivo de muchos autores» (Santamaría, 2005). En las Wikis los autores pueden crear, modificar o borrar un mismo texto que todos comparten.

Como recurso educativo, en primera instancia, destaca por enriquecer la comunicación y el aprendizaje colaborativo entre los estudiantes, puesto que los textos creados o modificados aparecen de manera inmediata en la web sin requerir revisión previa. Estas dos potencialidades fundamentales que favorecen el desarrollo de proyectos colaborativos denotan en las Wikis una filosofía de corte socio-constructivista.

Es un recurso educativo interesante para la elaboración de documentos y proyectos colaborativos conjuntos que exijan la participación de distintas personas. Del Moral y Villalustre (2008) destacan como funcionalidades educativas de las Wikis:

- Son herramientas capaces de articular y favorecer el desarrollo de proyectos colaborativos, debido a su naturaleza abierta y flexible que a través de una interfaz sencilla y amigable posibilita la interacción y comunicación entre los estudiantes que forman un determinado grupo de trabajo facilitando el proceso de construcción colectiva del conocimiento (Seitzinger, 2006).

- Las Wikis favorecen una forma de aprendizaje participativo apoyado en las interacciones de los discentes que convergen en contextos virtuales, creando comunidades de aprendizaje orientadas al logro de unos objetivos comunes determinados y propiciando un aprendizaje activo y práctico al invitar a los estudiantes, no sólo a interaccionar 
con los materiales didácticos, sino a incorporar otros nuevos, editando las contribuciones y las reflexiones compartidas con otros a través del debate.

- Asimismo, les proporcionan la ocasión de observar y analizar los resultados de sus acciones, generando de este modo un aprendizaje constructivo y reflexivo, al tiempo que les permite que sean ellos los que marquen sus objetivos de aprendizaje y controlen sus progresos.

Por tanto, las Wikis potencian la comunicación y el aprendizaje colaborativo al posibilitar a los estudiantes compartir ideas, opiniones, experiencias, negociar y consensuar significados, desarrollar proyectos, redactar textos y trabajos conjuntos, entre otros. En este sentido, el proceso de creación de este tipo de tareas conjuntas, mediante la Wiki, logra visibilizar el proceso de formación creativo.

c) Los Foros como recurso de generación de habilidades de comunicación, de organización del discurso y de la documentación, fomento del debate, construcción de identidad, compromiso, promoviendo el trabajo colaborativo y propiciando el diálogo igualitario y la adquisición de aprendizajes.

El foro es un sistema de comunicación público y diacrónico que permite la comunicación de personas desde lugares diferentes y tiempos distintos (Vivina, 2004). La utilización de los foros es muy variada: sociales, de opinión, de novedades, académicos, etc., aunque nosotros nos detendremos en la utilización de los mismos para fines educativos. Desde este punto de vista, el foro es considerado un recurso adecuado para el aprendizaje colaborativo (Anderson y Kanuka, 1997; Adrián y Gros, 2004; Vivina, 2004), por las posibilidades que ofrece para interactuar, es decir, compartir e intercambiar información, experiencias, dudas, reflexiones, contrastar opiniones y en definitiva, para dialogar y colaborar. También permite 
establecer y construir conclusiones de manera conjunta, mediante un diálogo grupal (Vivina, 2004).

Destacamos las conclusiones de dos investigaciones en torno al Foro electrónico o virtual, como herramienta tecnológica para facilitar el aprendizaje colaborativo: Vivina (2004) presenta una investigación en la que estudia las posibilidades del foro, entre un grupo de estudiantes, como herramienta de discusión y construcción de conocimientos acerca de un tema de interés común entre ellos, para que los participantes llegaran a conclusiones concretas sobre la temática discutida. Entre las conclusiones más significativas destacan:

- Es un medio-estrategia que permite la discusión y facilita la interacción entre diferentes personas sobre un tema de interés, a distancia y asincrónicamente, sin tener que estar conectados simultáneamente.

- Favorece la construcción de conocimientos entre sus participantes, los cuales expondrán sus ideas, experiencias y opiniones con la finalidad de enriquecer la discusión y llegar a conclusiones que conlleven a la concreción.

- Favorece el aprendizaje colaborativo, puesto que permite la comunicación y la interacción entre un grupo de personas en la búsqueda de objetivos que le son comunes, logrando desarrollar nuevos conocimientos, aclarar dudas, compartir experiencias, etc., promoviendo la participación de todo el grupo para llegar a conclusiones sobre un tema en particular.

- Favorece, el aprendizaje basado en la interacción social con los demás miembros y no de manera aislada. 
- La figura del moderador del foro es clave, para evitar la desviación del tema y establecer las conclusiones a las que se llegó en las intervenciones de los participantes.

Por otro lado, Adrián y Gros (2004), han realizado un estudio sobre el foro electrónico como herramienta para el aprendizaje colaborativo. En su investigación, seleccionaron, de entre las asignaturas de la plataforma de la Universidad de Barcelona, 30 de ellas que presentaban los niveles más elevados de utilización de la herramienta del foro virtual. Adrián y Gros, en este estudio, afirman que «los foros electrónicos constituyen un espacio apto para la promoción de comportamientos colaborativos entre los estudiantes, bajo una modalidad asíncrona que permite que cada participante reconozca las aportaciones de los demás, reflexione sobre ellas y construya sus aportaciones según su propio ritmo de aprendizaje». Nombran a Barberà, Badia y Mominó (2001) para destacar que en ese proceso de diálogo social interactivo que se da en el foro, en el que el grupo negocia de manera conjunta el significado de los contenidos, es donde se produce la construcción situada del conocimiento. Estas autoras matizan que, dependiendo de la manera en que se diseña el flujo de comunicaciones entres los estudiantes, los roles que se determinan y el feedback obtenido, los niveles de colaboración pueden ser los adecuados para hablar de aprendizaje colaborativo.

d) El Chat, como recurso de comunicación y como facilitador del aprendizaje colaborativo en línea.

Sánchez Soto (2006:3), lo define como

«una aplicación telemática o herramienta sincrónica (mismo marco temporal) de comunicación textual (mensajes escritos) basada en un intercambio técnico simultáneo de información en el envío de mensajes a un panel de mensajería o box de chat permitiendo la 
comunicación de dos o más personas conectadas simultáneamente desde espacios diferentes a un interfaz común».

A diferencia de los foros, la comunicación en los Chat es síncrona, exigiendo fijar un día y hora específica en la que se va a usar esta herramienta, y requiere una lectura y una respuesta rápida.

Conocemos popularmente al Chat como medio de entretenimiento y ocio, aunque actualmente se utiliza como medio didáctico para la comunicación y el debate en línea, con muchas posibilidades pedagógicas que se exponen a continuación.

Desde un enfoque pedagógico-comunicativo, este recurso favorece la interactividad entre personas que se encuentran en un mismo espacio virtual de discusión, permitiendo la introducción de mensajes de texto de varias personas al mismo tiempo, pudiendo cada uno ver en su pantalla la lista de personas que están participando en la actividad y los mensajes que van escribiendo (García et al., 2004).

En relación a la potencialidad pedagógica, Ortega et al. (2000:38-39) comentan una serie de posibilidades educativas: favorece la innovación educativa, estimula la actualización de profesores, es útil en la formación y el perfeccionamiento del profesorado, es un instrumento para el trabajo en equipo, y propicia una actitud abierta al uso de las nuevas tecnologías. Por otro lado constituye una herramienta que despierta la motivación, la participación y la creatividad del alumnado. Cabero, Llorente y Román (2003), por su parte, matizan que, para poder obtener resultados adecuados, la utilización debe ser planificada por el docente: debe estructurarse, asegurarse de que los participantes conozcan las normas de funcionamiento, materiales y tiempo de comienzo y finalización.

En cuanto a los usos más comunes del Chat para la enseñanza virtual, Sánchez Soto (2006) los establece en cinco: como tutorías, para aclarar ideas; 
para debatir o reflexionar sobre temas en concreto; para el trabajo colaborativo, en el plano de reuniones o trabajos grupales; como conferencia, planteando interrogantes a un experto en una materia; y como evaluación formativa de los alumnos y alumnas.

En definitiva el Chat es una herramienta de comunicación interactiva y sincrónica que permite establecer diálogos de discusión, estimula las formas directas y ágiles de expresión de las ideas y proporciona, debido a esa respuesta rápida que exige, feedback inmediato.

e) Los Blogs como estrategia de aprendizaje basado en investigación social y trabajo colaborativo para generar habilidades de comunicación, de organización del discurso y de la documentación, fomento del debate, construcción de identidad, visibilidad y compromiso.

Un blog es una publicación en red que permite crear y editar el contenido de una página web con un mínimo de conocimientos técnicos (Huffaker, 2005). Generalmente, se componen de una página de entradas que son accesibles por el público, dispuestas cronológicamente en orden inverso, y que presentan enlaces a otros blogs o sitios web (Guenther, 2005). Salinas, Pérez y de Benito (2008) afirman que los blogs o bitácoras constituyen un sistema de comunicación colectivo que promueve la creación, el consumo de información original, el poder compartir experiencias y conocimientos; provoca así el análisis, la reflexión personal y social sobre problemas de los individuos, de los grupos de la humanidad.

García Aretio (2007) realiza una clasificación de los blogs educativos en académicos o de investigación, profesorado-alumnado o grupales. Subrayan, que las características de los blogs residen en que:

- Son un método de trabajo colaborativo y en grupo. 
- Generan una estructura horizontal para debatir, analizar y conjugar diferentes experiencias de producción y distribución de contenidos.

- Incentivan y activan la participación y el debate entre los propios alumnos y alumnas.

Asimismo, Lara (2005) añade que promueven la interacción social y dotan a los y las estudiantes con un medio para experimentación de su propio aprendizaje, siendo, además, un recurso de fácil asimilación basándose en algunos conocimientos previos sobre tecnología digital.

En este sentido, Santamaría (2005), sitúa las aportaciones de los blog para uso educativo:

- Son excelentes herramientas para la alfabetización digital.

- Aportan distintos niveles de redacción y escritura.

- Permiten valorar nuevas formas de aprender.

- Son herramientas colaborativas asíncronas que potencia la cohesión del grupo y la interacción profesorado-alumnado.

- Permiten disponer de un espacio para encontrar fuentes documentales (webgrafías y bibliografías) para el área de conocimiento.

- Facilitan la actualización de contenidos constante mediante la sindicación (RSS/ATOM).

Si tenemos en cuenta qué implicaciones tienen los blogs para el alumno o alumna que los crea y mantiene, permite desarrollar capacidades como menciona Lara (2005) de organización del discurso, el fomento del debate, la construcción de la identidad, el compromiso con la audiencia que lee el blog, apoyo al e-learning y de presentación de documentación. Esta autora sugiere 
que la posibilidad de interacción que proporcionan los blogs es complementaria a la función de los foros de discusión: los foros son herramientas útiles para dinamizar los debates y los blogs para la organización de la conversación si lo que se pretende es aportar nuevos datos y enlaces.

El valor que los blogs han tomado en la esfera educativa, entonces, es porque se consideran instrumentos de apoyo al aprendizaje, constituyendo una herramienta que promueve la interacción social, la comunicación profesorado-alumnado y que facilita la capacidad investigadora del estudiante. Además, como indica Lara (2005), «se pueden adaptar a cualquier disciplina, nivel educativo y metodología docente», lo que les confiere ser una herramienta potencial de uso en cualquier ámbito.

f) El Glosario colaborativo como recurso para la creación conjunta de conocimientos y el desarrollo de habilidades cognitivas superiores.

Está basado en el trabajo conjunto de elaborar y publicar definiciones de conceptos relacionados con las temáticas propuestas, que pueden ser introducidos, modificados, complementados y valorados o comentados por todos los participantes en su construcción.

De las potencialidades de este recurso no se encuentra documentación o estudios realizados, sólo las aportaciones que desde la Comunidad Moodle ${ }^{99}$ se ofrecen. Desde éstas, este recurso genera un foco de colaboración entre los estudiantes de un curso.

$\mathrm{Al}$ crear las definiciones, los estudiantes suelen recordar los conceptos sobre los que trabajan, enriqueciendo su aprendizaje.

Como potencialidad pedagógica se señalan:

99 Acceso a la Comunidad en: http://moodle.org/ 
- Que un glosario común puede ser un buen punto de partida para seguir construyendo conocimiento y el trabajo en colaboración.

- Definir es una capacidad cognitiva que desarrolla habilidades cognitivas superiores, por tanto la utilización del glosario colaborativo fomenta aprendizajes significativos y profundos.

Todas las herramientas mencionadas han contribuido a promover un cambio metodológico en los procesos de enseñanza-aprendizaje en entornos virtuales, donde el aprendizaje está más centrado en el estudiante y promueve procesos de participación, la interacción, la colaboración, la interdependencia positiva entre los participantes, el diálogo entre iguales y un nuevo rol del profesor como «facilitador».

Queremos recalcar, para finalizar, que la apuesta por una metodología de trabajo colaborativo basado en Webquest y su implementación en un entorno virtual, junto con el uso de los Blogs, Foros, Wikis y el Glosario colaborativo como herramientas para vertebrar las estrategias didácticas seleccionadas en la acción formativa propuesta, se convierte en una fórmula innovadora de gestión y construcción compartida del conocimiento, aprovechando las sinergias de todos los participantes en la acción formativa virtual para conseguir el logro de los objetivos comunes, y adquirir las competencias y habilidades necesarias para la resolución de las tareas y/o actividades propuestas.

\section{B.2. Recursos didácticos para el aprendizaje.}

En los entornos virtuales de aprendizaje las herramientas que se pongan en práctica han de cumplir varios requisitos para otorgar calidad al proceso de enseñanza-aprendizaje (Fainholc, 2005). En este caso, entre otras muchas, son importantes las características de flexibilidad y capacidad para adaptarse al cambio, debido al proyecto e-learning que se propone en su conjunto. A continuación vamos a explicar los recursos que se van a utilizar en esta acción 
formativa virtual, que se usarán en combinación con actividades ya comentadas, en nuestro caso con una WebQuest.

1. Foro.

El Foro es la herramienta asíncrona que por su versatilidad puede trabajarse de muy distintas maneras y con diferentes intenciones, ahora veremos cuáles son estas distintas formas y su aplicabilidad en cada caso. A la hora de plantear un foro como herramienta didáctica hemos de partir de las metas que se pueden conseguir utilizándolo (Vivina, 2004): intercambiar conocimiento permitiendo el aprendizaje entre iguales; conseguir que el alumnado ordene y construya su pensamiento de manera autónoma y favorecer la integración tecnológica permitiendo tratar temas, de la misma manera que en la vida cotidiana se expresan e intercambian opiniones.

Objetivos didácticos:

- Permitir una comunicación a tiempo real entre toda la comunidad de aprendizaje.

- Ejercitar el pensamiento crítico y creativo.

- Fomentar el intercambio de experiencias, opiniones, conocimiento.

Utilidad en este curso:

Los foros pueden tener múltiples usos, en función de su intencionalidad, estableciendo en este curso virtual los siguientes:

- Foro de presentación: en este foro se propone a las participantes que realicen una exposición breve sobre quiénes son, sus lugares de origen y sus expectativas para la acción formativa.

- Foro de direcciones Blog: es un foro destinado a compartir las direcciones web de los blogs creados por las participantes. 
- Foro de Tutorías: en este foro se recogen las dudas que el alumnado puede tener acerca del tema, actividad o cualquier aspecto de la acción formativa, por lo que en cada módulo de los que conste el curso existirá un foro destinado a la resolución de dudas.

- Foro Social (o Comunitario): Este foro tiene el objetivo de fomentar la comunicación entre toda la comunidad de aprendizaje con la característica que la temática no se basa en temas académicos si no en presentaciones, experiencias o propuestas de debate entre las participantes. Está abierto para la participación de toda la comunidad de aprendizaje, espacio donde no hay un tema de debate definido sino que sirve como entorno de socialización, lugar de charla de temas no académicos, presentaciones entre los estudiantes del curso, etc.

- Foros Sociales de trabajo: en este foro expertos en la materia exponen un tema de debate o discusión que esté relacionado con el contenido a estudiar y a través de preguntas para su reflexión, artículos, referencias bibliográficas, actividades interactivas, etc. intentando fomentar la participación del alumnado. Este foro es evaluable, desde el punto de vista de calidad de la aportación y reflexión por parte de las alumnas. Por tanto, está destinado al debate o discusión entre todos los participantes sobre un tema/caso/situación específica que sea guiado por el profesorado.

Una aplicabilidad de los foros es la de suscripción al correo electrónico de todas las participantes, lo que permitirá que reciban avisos de los mensajes nuevos que se produzcan.

\section{Mensajería electrónica.}

Toda la comunidad educativa que participa en un programa formativo puede comunicarse directamente a través de la plataforma; con esta herramienta de comunicación se pueden enviar y recibir mensajes de manera 
rápida y sencilla. Además, permite entre otras cosas, crear una red de contactos propia (agenda) para que sea más cómoda la comunicación, disponer de un historial de mensajes enviados, etc. De cara a tutores/as o dinamizadora, pueden comunicarse directamente con las estudiantes, seleccionar grupos,o enviar mensajes de manera individual. Normalmente, esta herramienta se utiliza cuando el contenido del mensaje no es de interés común, por ejemplo, explicaciones sobre una calificación o mensaje directo a una participante por alguna cuestión específica.

La mensajería instantánea permite la comunicación directa de toda la comunidad de aprendizaje, permitiendo tanto a estudiantes como a docentes ponerse en contacto a través de la plataforma, consultar actividades pendientes, recordatorios de eventos, cuestiones concretas con una estudiante, etc.

Objetivos didácticos:

- Permitir una comunicación directa, rápida y sencilla entre todas las personas participantes en el curso.

- Crear una lista de contactos que facilite la comunicación entre estudiantes y entre estudiantes y docentes.

Utilidad en este curso

El correo electrónico puede tener varias utilidades tanto para tutores/as y dinamizadora como para las estudiantes.

Utilidades para las estudiantes:

- Herramienta para el contacto con tutores, tutoras y dinamizadora a través de la plataforma del Campus Virtual, ya sea para exponer una duda, comentario, iniciativa, enviar una actividad, etc. 
- Herramienta de comunicación con el resto de participantes de la acción formativa.

\section{Utilidades para tutores/as:}

- Asignación individual de una tarea específica y medio por el que recibir cualquier actividad, permitiendo un acceso fácil y rápido a ésta al quedar registrada en la propia plataforma.

- Facilita el seguimiento de las estudiantes al poder comentar con cada una de ellas la calidad del trabajo realizado.

- Facilitar la comunicación instantánea con una estudiante o con varias.

3. Wikis y Blogs.

Una Wiki, como hemos indicado con anterioridad, es una herramienta que permite la creación de contenido de forma colaborativa. Una de las utilidades de un Wiki en entornos de formación es la de crear documentos conjuntos para un trabajo. Un contenido puede ser creado, modificado y borrado por distintos usuarios, por lo que como herramienta de aprendizaje tiene un potencial altamente pedagógico, ya que contribuye a la creación de pensamiento constructivo entre toda una comunidad de aprendizaje.

Un blog, a diferencia del wiki, es más una página personal, creada intencionadamente por docentes y estudiantes, donde se van insertando publicaciones que se ordenan cronológicamente. Las compañeras pueden opinar sobre lo que ahí está escrito, pero no pueden modificar el texto original, que es la diferencia principal con el wiki. En este sentido, el blog puede usarse en un contexto educativo de múltiples maneras, como por ejemplo, tener una bitácora sobre el proceso del curso, el desarrollo de una investigación, realizar síntesis sobre contenidos que se están trabajando, etc. Cualquiera de estas dos herramientas pueden estar directamente disponibles 
desde una plataforma de teleformación, pero también hay multitud de sitios en Internet donde poder utilizar estas herramientas de manera completamente gratuita.

Estos dos recursos tienen en común la creación de contenidos tanto por estudiantes como por docentes y cada una de ellas tiene una peculiaridad; en el caso del Wiki el espacio en el que se insertan estos contenidos puede ser modificado por el resto de participantes de una acción formativa, mientras que en el Blog, el único que edita los contenidos es el que los crea y el resto de participantes solo pueden realizar comentarios.

Objetivos didácticos:

- Permitir la creación conjunta de documentos, construyendo un aprendizaje colaborativo.

- Modificar y/u opinar constructivamente sobre los comentarios que otros participantes de la acción formativa hayan realizado sobre una actividad propuesta.

Utilidad en este curso:

Las utilidades son distintas según la herramienta:

Wiki: creación de un documento conjunto para una tarea específica, fomentando el pensamiento constructivo entre toda una comunidad de aprendizaje.

Blog: creación de contenidos de forma individual por parte de las estudiantes, pudiendo ver este contenido el resto de participantes y aportar sus comentarios. Por lo tanto puede ser utilizado como e-portafolio del desarrollo del curso, como síntesis de contenidos que se estén trabajando o para reflexiones personales, etc. 


\section{Glosario colaborativo interactivo.}

Este recurso de aprendizaje, disponible en la plataforma seleccionada, permite elaborar por varios usuarios al mismo tiempo un glosario de términos. Además, es un recurso interactivo puesto que está presente a lo largo de todos los contenidos de la plataforma, es decir, que allí donde un término del glosario aparezca, éste queda subrayado automáticamente de modo que las estudiantes puede hacer clic en él y leer inmediatamente su significado.

Un glosario es una información estructurada en «conceptos» $\mathrm{y}$ «explicaciones», como un diccionario o enciclopedia pero de los términos utilizados en una acción formativa concreta. Es una estructura de texto donde existen «entradas» que dan paso a una definición del término usado.

Un glosario interactivo es aquel que, unido a lo anterior, se encuentra ubicado en una plataforma virtual de aprendizaje y puede ser editado o bien sólo por el tutor de la acción formativa o en algunos casos está abierto a la inclusión de términos por parte del estudiante.

Objetivos didácticos:

- Ampliar vocabulario específico relacionado con la temática de la acción formativa.

- Construir conjuntamente conceptos básicos relacionados con las temáticas propuestas.

Utilidad en este curso:

En este caso, el glosario interactivo va a ser usado como diccionario de los términos de un tema concreto tratado en una acción formativa y que va a ser elaborado por las estudiantes, que tienen posibilidad abierta de edición del mismo. Como valor añadido la plataforma del Campus Virtual de la 
Universidad de Extremadura nos permite que, cada vez que mencionemos términos incluidos en el glosario, se autoenlace a la definición que hemos establecido del mismo.

Se propone la edición de un Glosario Interactivo Colaborativo entre las estudiantes:

- La pretensión es la construcción conjunta del conocimiento, no sólo fomentando la lectura pasiva de los términos de interés, si no que las estudiantes tienen la posibilidad de asociar comentarios en las entradas de los términos que ellas mismas incluyan. Además va a ser una actividad a considerar en la evaluación de los aprendizajes.

\section{Contenidos digitales específicos.}

Los contenidos digitales, por definición, son aquellos que han sufrido algún tipo de digitalización, ya sea ésta de bajo nivel (ej: formato pdf) o de alto nivel (ej: formato flash). Los tipos de formatos utilizados en contenidos digitales son todos aquellos realizados en paquetes de ofimática, formatos pdf, libros electrónicos, píldoras de aprendizaje en flash, documentos xhtml, etc. Estos recursos se ponen en práctica en las acciones formativas que se desarrollan en una plataforma virtual de aprendizaje y son todos aquellos contenidos que son digitalizados. Como hemos indicado, son muy diversos los formatos en los que pueden ser presentados pero a todos se accede a través de la plataforma en la que se esté llevando a cabo la acción formativa, en nuestro caso estarán disponibles en el espacio virtual del curso.

Concretamente, esta acción formativa consta de varias tipologías de contenido digital:

a. Documentos Base (Contenidos básicos): Documento en formato pdf

Documento que incluye los contenidos básicos sobre la propuesta temática. El documento base debe ajustarse a las siguientes características: 
- El documento deberá estar en formato pdf Este formato facilita la distribución, ofrece un acceso universal, permite compartir ficheros de forma segura y mantiene los rasgos estilísticos diseñados en origen.

- El número de páginas del documento base será variable en función de la temática, siempre recomendando documentos breves (entre 10 y 15 páginas) y de fácil lectura, pensando en las características de las participantes a las que nos dirigimos.

- La estructura de cada uno de los documentos base se ajustará a las siguientes características:

- En la primera página se reflejará con letra grande los siguientes epígrafes: «Bloque I, II O III con el título correspondiente al documento y el autor/a del mismo.

- El índice aparecerá posteriormente, indicando las páginas de cada uno de los apartados, si los hubiese.

- Los títulos de los apartados pueden presentarse en negrita y con un tamaño de 14 puntos o superior. Para el desarrollo de los contenidos se utilizará preferentemente letra tipo Arial o similar, de 11 puntos de tamaño, interlineado de espaciado y medio, y separación de 4 puntos, aproximadamente, antes y después de cada párrafo. Los márgenes deben estar comprendidos entre 2 y $3 \mathrm{~cm}$. Las páginas deben ir numeradas, evitando siempre la inclusión de páginas en blanco.

- Todas las referencias y recursos recogidos en el documento base deberán expresarse por completo en el apartado de bibliografía y webgrafía, al finalizar el tema. 
Cada tutor/a enviará el documento base y la propuesta de actividad, vía correo electrónico, en una fecha determinada, y, si se desea, otros archivos de ampliación relacionados con su contenido.

b. Guía de la participante.

Es un documento de referencia para las alumnas sobre las características y desarrollo de todo el programa formativo. En ella se recogen los objetivos, la metodología, los bloques de contenido, docentes, duración, horas lectivas, criterios de evaluación y pasos para el acceso a la plataforma y procedimientos fundamentales (Anexo IV).

c. Guía metodológica de orientación para profesorado.

Recoge la metodología a seguir para desarrollar la labor tutorial virtual en este curso. Se incluyen, además de los datos sobre competencias a desarrollar, metodología, bloques temáticos y responsables de cada propuesta, duración, horas lectivas, criterios de evaluación, proceso de diseño de documentos base, de materiales complementarios y los procedimientos para la gestión tutorial (Anexo III).

Objetivos didácticos:

- Transmitir los contenidos fundamentales y básicos de una forma accesible, en el caso de los documentos base.

- Guiar en el proceso de desarrollo de la acción formativa virtual, tanto a estudiantes como a docentes/tutores.

Utilidad en este curso

Los documentos base ofrecen unas líneas fundamentales en referencia a los conocimientos básicos que deben aprender las estudiantes. Estos documentos deben ser leídos y trabajados con ayuda de la persona que ejerce de tutora, en relación a la unidad de aprendizaje que le corresponda. Estos 
documentos pueden ser reutilizados y guardados de forma cómoda y sencilla, mostrando una acceso rápido a la información fundamental para las estudiantes.

Las Guías dirigidas tanto a docentes como a estudiantes, sirven de orientación en todo el proceso de desarrollo de la acción formativa virtual, y dan a conocer todos los aspectos clave de la misma.

6. Contenidos complementarios o de ampliación (multimedia, abiertos, enlaces, etc.)

Incluimos en el espacio virtual del curso, una apartado especial dedicado a contenidos complementarios o de ampliación. Los contenidos complementarios son archivos en diferentes formatos (videos, presentaciones, documentos, etc.) que el tutor de cada tema o de apoyo facilita durante el proceso de estudio para ayudar o complementar el aprendizaje, a demanda del estudiante o a iniciativa propia. Los documentos o recursos complementarios pueden llevar el formato y extensión que se determine por tutores y tutoras. Estos contenidos pueden estar presentados en soportes y formatos diferentes y pretenden que las estudiantes puedan acceder a otra serie de recursos audiovisuales, enlaces de interés, artículos, etc. que den un valor añadido al programa formativo en general.

Objetivos didácticos:

- Reforzar y afianzar los conocimientos estudiados en una Unidad de Aprendizaje.

- Reforzar el análisis de una cuestión concreta que se haya planteado durante el curso.

- Ampliar información sobre temas concretos tratados en los cursos, dando valor añadido al programa completo de formación. 
Utilidad en este curso:

En esta acción formativa mostramos contenidos complementarios de dos tipologías:

- Recursos multimedia: vídeos y presentaciones.

- Enlaces de interés: enlaces a textos, documentos, informes, estudios, etc. que sean de relevancia para la propuesta temática estudiada.

Este recurso de aprendizaje está enfocado a reforzar los conocimientos que se trasmiten en las distintas Unidades de Aprendizaje, de los que se compone la acción formativa.

Los enlaces de interés, como recursos disponibles en internet externos al espacio virtual del curso, pueden utilizarse bien como actividad planteada de la propuesta temática o como contenido complementario que permiten a las estudiantes disponer de información adicional y profundizar más en cada área.

Además de los materiales complementarios se ha creado una carpeta Biblioteca, donde se incluyen materiales de interés que pueden descargarse.

\section{Chat.}

El chat permite la comunicación síncrona entre sus participantes. Aunque su uso suele estar ligado a tutorías donde el profesorado está disponible, en un momento concreto, para que el resto de estudiantes puedan hacer consultas en tiempo real, también puede considerarse como un espacio de intercambio de ideas entre estudiantes.

El uso de esta herramienta está muy ligado a la disposición de las participantes por la exigencia de tener que estar conectadas al mismo tiempo.

Objetivos didácticos: 
- Permitir la comunicación síncrona entre las participantes en la acción formativa.

- Permitir, a iniciativa de tutores/as y estudiantes, charlas síncronas de tutoría y debate.

Utilidad en este curso:

En esta acción, este recurso está destinado a la comunicación abierta entre las estudiantes, no especificando tiempos para que se produzca la misma. Así mismo, se dispone de este recurso si, a iniciativa o petición de docentes y estudiantes, se quieren llevar a cabo tutorías virtuales síncronas o debates sobre alguna temática.

\section{Talleres presenciales.}

Esta herramienta de aprendizaje pone en práctica la metodología blended-learning para reforzar las competencias que se van adquiriendo.

Objetivos didácticos:

- Contextualizar y poner en práctica los conocimientos aprendidos en el espacio virtual de aprendizaje a través de simulaciones presenciales y feedback directo con la persona experta-tutora.

- Entrenar capacidades en el uso del Campus Virtual y de las herramientas disponibles para el proceso de aprendizaje.

- Entrenar habilidades específicas a través de técnicas de trabajo en grupo.

- Reforzar las relaciones del grupo y proceso de evaluación continua.

Utilidad en este curso: 
La herramienta taller presencial en este contexto e-learning se utiliza como refuerzo en esta acción formativa. Es necesaria la presencia física de las estudiantes en sesiones cortas para, por un lado, reforzar las competencias que se están trabajando y, por otro, como medio de motivación de las estudiantes que tienen la posibilidad de verse y conocerse personalmente. Para que exista una coherencia entre los contenidos trabajados y los talleres presenciales, la persona tutora asignada aprovechará estas sesiones para conectar éstas con lo tratado en los módulos estudiados de modo virtual teniendo en cuenta en la planificación previa del curso, cuál es el momento en el que mejor encajan estos talleres presenciales que refuerzan la parte elearning de una acción formativa.

9. Otros recursos.

\section{Calendario del curso}

El calendario permite tener una visión en el tiempo de los eventos de interés que tendrán lugar en el curso. Tales como, fechas de inicio y finalización del curso, de cada módulo, fechas de cada sesión con los profesionales expertos. En nuestro caso lo gestiona la dinamizadora que va actualizando todos los acontecimientos que se producen en el curso.

Foro Novedades: Tablón de anuncios

Es aquel lugar de la plataforma dedicado a las novedades y anuncios de interés relacionado con el desarrollo del curso, donde las personas expertastutoras plasman comunicados, notificaciones y proporcionarán información relevante y necesaria para la acción formativa. Por ejemplo: inicios y finalizaciones de módulos, fechas de interés, recordatorios de tareas, etc.

Una vez definidos los recursos didácticos, se recuerda que aquellas instancias que van a servir para las interacciones principales son las siguientes: 
- El Foro de discusión: en el que las participantes interaccionarán mediante el intercambio de ideas, experiencias, proyectos, realización de actividades propuestas, etc.

- Blogs: pensado para compartir recursos, experiencias propias, direcciones webs, referencias, reflexiones de interés.

- Chat: en la realización de las actividades colaborativas propuestas.

- Wiki: Pensado para compartir y desarrollar la actividad principal mencionada.

- Correo electrónico (mensajes): para el intercambio de mensajes entre las participantes.

A continuación se muestra, a modo de resumen, un cuadro con los recursos didácticos y las actividades principales:

\begin{tabular}{lll}
\hline Actividad/Recurso & Descripción y finalidad & Observaciones \\
\hline $\begin{array}{l}\text { Orientaciones para el } \\
\text { estudio }\end{array}$ & $\begin{array}{l}\text { Indicaciones acerca de los objetivos } \\
\text { y estrategias metodológicas para } \\
\text { trabajar durante el curso. }\end{array}$ & $\begin{array}{l}\text { Se realizará en la sesión } \\
\text { presencial inicial. }\end{array}$ \\
\hline Contenidos básicos & $\begin{array}{l}\text { Textos en formato pdf que } \\
\text { contienen los contenidos } \\
\text { presentados por tutores y tutoras } \\
\text { responsable de bloque. }\end{array}$ & $\begin{array}{l}\text { Su conocimiento es esencial } \\
\text { para poder debatir y reflexionar. } \\
\text { Tienen una extensión variable, } \\
\text { teniendo en cuenta los criterios } \\
\text { de breve y sencillo, adecuado a } \\
\text { las participantes. }\end{array}$ \\
\hline $\begin{array}{l}\text { Contenidos de } \\
\text { ampliación o } \\
\text { complementarios }\end{array}$ & $\begin{array}{l}\text { Archivos en diferentes formatos } \\
\text { (videos, presentaciones, } \\
\text { documentos, etc.) que el tutor de } \\
\text { cada tema o de apoyo facilita, } \\
\text { durante el proceso de estudio, con } \\
\text { objeto de ayudar o complementar el } \\
\text { aprendizaje a demanda del } \\
\text { estudiante o a iniciativa propia. }\end{array}$ & $\begin{array}{l}\text { Pueden encontrarse junto a los } \\
\text { contenidos básicos de cada } \\
\text { tema. Tienen una extensión } \\
\text { variable por tema, en función } \\
\text { del criterio de los tutores. Sirven } \\
\text { para aquella participante que } \\
\text { quiera extender y ampliar el o } \\
\text { los temas correspondientes. En } \\
\text { estos documentos se incluye la } \\
\text { bibliografía. Esto contenidos no } \\
\text { son evaluables. }\end{array}$ \\
\hline
\end{tabular}




\begin{tabular}{|c|c|c|}
\hline $\begin{array}{l}\text { Actividades de } \\
\text { aprendizaje }\end{array}$ & $\begin{array}{l}\text { El tutor o tutora propondrá una } \\
\text { tarea de aprendizaje que requiera } \\
\text { una revisión teórica, discusión o } \\
\text { aplicación práctica en torno a los } \\
\text { contenidos de uno o varios temas, } \\
\text { siempre relacionado con el estudio } \\
\text { de la realidad o con el fin último de } \\
\text { la acción formativa (Comunidad de } \\
\text { Práctica). }\end{array}$ & $\begin{array}{l}\text { Se debe intentar utilizar los } \\
\text { recursos disponibles (glosario } \\
\text { colaborativo, blog, foros) para la } \\
\text { realización de la actividad en el } \\
\text { periodo establecido por cada } \\
\text { tutor/a y se deben tener en } \\
\text { cuenta para la evaluación final. } \\
\text { Deben ir dirigidas a trabajar de } \\
\text { manera colaborativa. }\end{array}$ \\
\hline $\begin{array}{l}\text { Foro de evaluación- } \\
\text { autoevaluación }\end{array}$ & $\begin{array}{l}\text { Sistema de comunicación público y } \\
\text { diacrónico, dirigido a que tutores/as } \\
\text { y participantes realicen un análisis } \\
\text { acerca de los logros de objetivos, la } \\
\text { necesidad de modificaciones, la } \\
\text { motivación para la consecución de } \\
\text { aprendizajes más significativos y la } \\
\text { discusión sobre el grado de } \\
\text { cumplimiento de expectativas de las } \\
\text { participantes. A opción de la tutoría, } \\
\text { cada tema podrá disponer de un } \\
\text { cuestionario online, individual o } \\
\text { grupal que permita a las } \\
\text { participantes valorar y reflexionar } \\
\text { sobre sus propios logros y ayude a } \\
\text { fomentar una actitud constante de } \\
\text { análisis, reflexión y reorientación } \\
\text { del curso hacia los fines perseguidos } \\
\text { y hacia las expectativas de las } \\
\text { mujeres participantes y su } \\
\text { responsabilidad personal. }\end{array}$ & \\
\hline \multirow[t]{2}{*}{ Foro Social } & \multirow[t]{2}{*}{$\begin{array}{l}\text { Sistema de comunicación público y } \\
\text { diacrónico destinado al trabajo del } \\
\text { curso. }\end{array}$} & $\begin{array}{l}\text { Foro principal de trabajo entre } \\
\text { las participantes } \\
\text { (Responsables: tutores y } \\
\text { tutoras). }\end{array}$ \\
\hline & & $\begin{array}{l}\text { 'Éstas, como alumnas, deberán } \\
\text { participar en varias líneas de } \\
\text { discusión evaluables en cada } \\
\text { tema, según determine el/la } \\
\text { tutor/a responsable. Cada } \\
\text { debate estará abierto durante un } \\
\text { período limitado de tiempo de } \\
\text { modo que no existan múltiples } \\
\text { foros simultáneos. El/la tutor/a } \\
\text { podrá cerrar cualquiera de las } \\
\text { líneas cuando lo considere } \\
\text { oportuno. }\end{array}$ \\
\hline
\end{tabular}




\begin{tabular}{|c|c|c|}
\hline \multirow[t]{2}{*}{ Foro de tutoría } & \multicolumn{2}{|l|}{$\begin{array}{l}\text { Sistema de comunicación público y } \\
\text { diacrónico, dirigido a que tutores/as } \\
\text { y participantes solucionen todas las } \\
\text { dudas que surjan con el estudio del } \\
\text { tema, debatan, colaboren en la } \\
\text { realización de las actividades... }\end{array}$} \\
\hline & $\begin{array}{l}\text { También dirigido a que docentes y } \\
\text { participantes puedan enviar } \\
\text { mensajes centrados en cuestiones } \\
\text { administrativas y técnicas (fechas, } \\
\text { recordatorios, problemas } \\
\text { técnicos...). }\end{array}$ & \\
\hline Foro Opcional & $\begin{array}{l}\text { Sistema de comunicación público y } \\
\text { diacrónico, dirigido a que docentes y } \\
\text { participantes solucionen todas las } \\
\text { dudas surgidas en la realización de } \\
\text { una actividad de aprendizaje. }\end{array}$ & $\begin{array}{l}\text { Los tutores y tutoras } \\
\text { contestarán a las cuestiones que } \\
\text { planteen las participantes sobre } \\
\text { las actividades de aprendizaje } \\
\text { propuestas. }\end{array}$ \\
\hline Webquest & $\begin{array}{l}\text { Una WebQuest es «una actividad } \\
\text { de investigación en la que la } \\
\text { información con la que interactúan } \\
\text { los alumnos proviene total o } \\
\text { parcialmente de recursos de la } \\
\text { Internet» (Valverde, 2008) } \\
\text { Una WebQuest tiene la siguiente } \\
\text { estructura: } \\
\text { - Introducción } \\
\text { - Tarea } \\
\text { - Proceso } \\
\text { - Recursos } \\
\text { - Evaluación } \\
\text { - Conclusión } \\
\text { - Autores }\end{array}$ & $\begin{array}{l}\text { Mediante la WebQuest se } \\
\text { realizará la tarea principal } \\
\text { consistente en el estudio de la } \\
\text { realidad de las mujeres gitanas } \\
\text { extremeñas. La WebQuest } \\
\text { estará diseñada por la dirección } \\
\text { y codirección del curso. }\end{array}$ \\
\hline Blog individual & $\begin{array}{l}\text { Un blog es una publicación en red } \\
\text { que permite crear y editar el } \\
\text { contenido de una página web con un } \\
\text { mínimo de conocimientos técnicos } \\
\text { (Huffaker, 2005) }\end{array}$ & $\begin{array}{l}\text { El blog personal lo utilizaremos } \\
\text { como diario de campo virtual, } \\
\text { donde cada participante puede } \\
\text { ir colaborando con las } \\
\text { aportaciones personales que } \\
\text { desee. Se animará a las } \\
\text { participantes a que realicen } \\
\text { comentarios en los blog entre } \\
\text { unas y otras compañeras. }\end{array}$ \\
\hline
\end{tabular}


Comunidad de Práctica para la promoción sociocultural de mujeres gitanas en entornos virtuales de aprendizaje

\begin{tabular}{|c|c|c|}
\hline Blog grupal & $\begin{array}{l}\text { El blog grupal vamos a utilizarlos } \\
\text { como método de trabajo } \\
\text { colaborativo y de trabajo en grupo: } \\
\text { - } \quad \text { Generan una estructura } \\
\text { horizontal (varias bitácoras al } \\
\text { unísono) para debatir, } \\
\text { analizar y conjugar diferentes } \\
\text { experiencias de producción y } \\
\text { distribución de contenidos. } \\
\text { Incentivan y activan la } \\
\text { participación y el debate } \\
\text { entre los propios alumnos y } \\
\text { alumnas. }\end{array}$ & $\begin{array}{l}\text { Blog del curso donde las } \\
\text { participantes podrán ir } \\
\text { estableciendo sus opiniones, } \\
\text { reflexiones u actividades de } \\
\text { aprendizaje que se propongan } \\
\text { por parte de tutores y tutoras. }\end{array}$ \\
\hline Glosario colaborativo & $\begin{array}{l}\text { El glosario es el repertorio de } \\
\text { términos utilizados en el curso, con } \\
\text { el fin de comprender mejor los } \\
\text { significados y la comprensión de } \\
\text { algunos conceptos. Este glosario } \\
\text { será elaborado por tutores y } \\
\text { participantes. El glosario lo vamos a } \\
\text { utilizar para la colaboración entre } \\
\text { tutores /as y participantes en el } \\
\text { curso. }\end{array}$ & $\begin{array}{l}\text { A cada tutor / a y participante } \\
\text { del curso se le va a asignar la } \\
\text { tarea de contribuir al glosario } \\
\text { con un término, una definición, } \\
\text { o bien comentarios acerca de } \\
\text { definiciones previamente } \\
\text { incorporadas. El glosario } \\
\text { colaborativo puede incorporarse } \\
\text { por cualquier tutor/a a la tarea } \\
\text { propia de su bloque. }\end{array}$ \\
\hline Wiki colaborativa & $\begin{array}{l}\text { Un/una wiki es un sitio web } \\
\text { colaborativo creado y desarrollado } \\
\text { por un grupo de personas que } \\
\text { trabajan de manera colectiva. En } \\
\text { estructura y lógica es similar a un } \\
\text { blog, pero en este caso cualquier } \\
\text { persona puede editar sus } \\
\text { contenidos, aunque hayan sido } \\
\text { creados por otra. }\end{array}$ & $\begin{array}{l}\text { En este caso la Wiki la } \\
\text { utilizaremos para ir volcando } \\
\text { datos e informaciones del } \\
\text { estudio de la realidad. Se } \\
\text { desarrollará de manera } \\
\text { colaborativa por las } \\
\text { participantes. }\end{array}$ \\
\hline $\begin{array}{l}\text { Correo electrónico o } \\
\text { Mensajes }\end{array}$ & $\begin{array}{l}\text { Sistema de comunicación privado y } \\
\text { diacrónico, dirigido a plantear } \\
\text { cuestiones personales o dudas a los } \\
\text { tutores/as. }\end{array}$ & $\begin{array}{l}\text { El/la tutor/a debe contestar en } \\
\text { el plazo establecido, como viene } \\
\text { determinado en la Guía de } \\
\text { orientación metodológica para } \\
\text { docentes (Anexo III) }\end{array}$ \\
\hline Chat & $\begin{array}{l}\text { Charla sincrónica y en grupo, } \\
\text { dirigida a participantes/tutores-as } \\
\text { para que pregunten y discutan } \\
\text { cuestiones relacionadas con el } \\
\text { estudio de los contenidos y la } \\
\text { realización de actividades, etc. }\end{array}$ & $\begin{array}{l}\text { Cada tutor/a podrá ofertar las } \\
\text { sesiones de chat que considere } \\
\text { oportunas. La participación no } \\
\text { es obligatoria para las } \\
\text { participantes. Deberán ser } \\
\text { públicas al inicio del curso. Las } \\
\text { sesiones de chat tendrán una } \\
\text { duración variable que } \\
\text { determinará y publicará cada } \\
\text { tutor/a. }\end{array}$ \\
\hline Calendario & $\begin{array}{l}\text { Recurso destinado a la cuenta } \\
\text { sistematizada de las actividades, que } \\
\text { utilizaremos para recordatorios o } \\
\text { fechas de interés para las } \\
\text { participantes. }\end{array}$ & $\begin{array}{l}\text { Estará disponible para que } \\
\text { todas/os tutoras y tutores } \\
\text { podamos introducir fechas de } \\
\text { interés o de recuerdo. }\end{array}$ \\
\hline
\end{tabular}

Tabla 18. Recursos Didácticos y actividades principales de la acción formativa 


\section{Sistema de tutorías.}

El propósito de la labor tutorial en este curso consiste en crear un ambiente de aprendizaje que tenga como base el diálogo entre iguales y la colaboración, ofreciendo a las participantes el apoyo y motivación necesaria para su continuidad, acompañarlas en el cumplimiento de las actividades planteadas, proporcionándoles orientación y ayuda en la solución de las dificultades que se les puedan presentar. Las funciones generales de los/as tutores/as se agrupan en las siguientes (Marcelo, 2006):

- Orientar y asesorar a las participantes a lo largo del proceso de formación. El tutor/a debe resolver dudas que se presenten durante el curso, ofrecer información que complete la formación de las participantes, enviar consejos y sugerencias sobre determinados aspectos de interés, $\mathrm{y}$ hacer las propuestas de fechas informando de la finalización de entrega de tareas, todo ello utilizando los recursos de comunicación del entorno virtual de formación. También debe ayudar a las participantes, en los primeros momentos del curso, a familiarizarse con la plataforma, contenidos y herramientas de comunicación y conocer $\mathrm{y}$ familiarizarse con las participantes y sus características.

- Promover la participación en el curso. Debe moderar los foros de debate, realizando sugerencias y comentarios que susciten la participación de las mujeres destinatarias de la formación; concertar y moderar sesiones de chat, si se dispone de este recurso; y realizar conclusiones generales de los foros recopilando las ideas más significativas del debate.

- Utilizar las herramientas de comunicación, para fomentar la interacción entre las participantes. Para ello se enviarán mensajes 
de apoyo, que eviten la sensación de soledad y abandono, y se atenderán las sugerencias e iniciativas que propongan.

- Evaluar las tareas del curso con adecuación a los criterios establecidos, asumiendo un enfoque formativo, es decir, señalando los aspectos positivos y negativos de sus trabajos, planteando opciones y sugerencias de mejora.

Esta acción, como tutores/as, debemos afrontarla teniendo en cuenta la infinidad de variables y hetereogeneidad de las mujeres participantes, que es preciso abordar de manera singular. Para ello la formación de este grupo de mujeres, se adentra en la diferencia y diversidad y en las necesidades y problemáticas comunes, intentando, así mismo, dar respuestas a esa variedad. Dicho esto:

- Debemos fomentar la creación de un ambiente de confianza para que las participantes se sientan cómodas y respetadas.

- Cada una puede expresarse libremente y emitir juicios de valor que deben ser respetados, así como también sus características culturales. Las participantes, como hemos indicado, tienen características heterogéneas y diversas, aunque comparten objetivos comunes en cuanto a la promoción del grupo cultural al que pertenecen y con el que se identifican.

- Partiendo de esas características diferentes, asumimos que las estudiantes tienen ritmos de aprendizaje diversos.

- Las estudiantes estarán informadas desde el primer momento del proceso que seguimos en el curso: objetivos, qué se va a trabajar, y cuál es nuestra propuesta metodológica. 
- Debemos motivar a las estudiantes para que se expresen, que se animen entre ellas, para evitar el abandono prematuro.

- Visibilizar los logros alcanzados por las estudiantes, dando valor a sus conocimientos, experiencias y aportaciones a nivel individual y, sobre todo, como colectivo.

Por todo lo que se indica y desde el punto de vista del proceso de aprendizaje, se promoverá la creación de campos epistemológicos nuevos y la experimentación de metodologías didácticas y herramientas de intervención innovadoras. Las estudiantes tendrán posibilidad de encontrarse y formar parte de una comunidad propia, de dialogar y de analizar las situaciones que les sean comunes junto con las distintas realidades en las que están inmersas en un intento de teorizar sobre las propias prácticas y articular claves conjuntas para entender y mejorar la situación.

El proceso de aprendizaje de las mismas se apoyará con material didáctico en soporte digital que cada participante deberá trabajar desde un ordenador, vía Internet, a través del Campus Virtual de la Universidad de Extremadura. El sistema de formación a través de la red pretende ser flexible, por ello se adaptará a los diferentes ritmos de aprendizaje, características de acceso y uso de las herramientas y horarios de las estudiantes.

\section{a. Gestión de los foros de trabajo de cada bloque temático}

La persona que asume la función tutorial en este curso debe realizar una labor de moderador/a y animador/a del Foro Social de trabajo que le corresponde. Esto implica no sólo plantear el tema de debate, sino participar activa y frecuentemente en el mismo. Esta participación del tutor o tutora implica el desarrollo de las siguientes tareas: 
- Confirmar respuestas a las participantes, mostrar posibles errores conceptuales o profundizar en ideas que no se han comprendido de modo significativo.

- Provocar el debate y la reflexión conjunta mediante la aportación de diferentes puntos de vista, solicitando opiniones razonadas o estimulando la actitud crítica de las participantes.

- Ejemplificar, completar, aclarar o argumentar ideas planteadas en mensajes anteriores o solicitar que lo hagan las propias alumnas.

- Aportar fuentes de información complementarias obtenidas de Internet y accesibles (documentos, sitios web, imágenes, vídeos, etc.).

- Realizar un resumen de las ideas más importantes trabajadas en cada tema, a modo de recapitulación. Las líneas de debate no deben alcanzar más de 50 intervenciones (aproximadamente), de modo que cuando se supera tal número el tutor o tutora debe cerrar el debate, resumiendo y concluyendo con las principales ideas aportadas en la discusión o pidiendo a las estudiantes que las resuman. Tiene posibilidad de abrir una nueva línea de debate en el mismo foro.

A partir de intervenciones concretas en el foro, introducir sub-líneas o focalizar el debate en la que interese profundizar a raíz de intervenciones de las propias participantes.

La gestión concreta se establece de la siguiente manera:

- En la primera semana del curso cada tutor /a responsable, con apoyo de los demás tutores/as, debe abrir, entre 1 y 3 líneas dentro del Foro Social del tema activo, en base a la actividad propuesta: 
1. Línea/s de debate sobre algún tópico relacionado con el tema que favorezca la discusión, la toma de postura, el desarrollo de argumentos, etc.

2. Línea/s para el debate o el trabajo colaborativo, a partir de una tarea propuesta por el profesor (comentario de un texto, estudio de un caso, etc.).

3. Línea sobre la/s actividad/es propuesta/s en el tema (el profesorado puede comentar errores o carencias detectadas en las primeras actividades enviadas, responder a dudas formuladas por los estudiantes, así como comentar un modelo de resolución de la actividad, una vez que termine el plazo de envío).

4. Línea sobre los contenidos básicos.

La dinamizadora propondrá, además, 1 o 2 líneas dentro del Foro de Evaluación:

1. Preguntas de autoevaluación.

2. Preguntas o reflexiones para la evaluación grupal.

- Cada docente realizará de manera constante una labor de moderador y animador del foro, lo que supone, no sólo plantear el tema de discusión, sino intervenir frecuentemente (entre 2 y 6 mensajes de los estudiantes, como máximo).

- Los mensajes de las participantes se valorarán una vez cerrada la línea de debate, teniendo en cuenta los siguientes criterios:

1. Se valorarán positivamente las intervenciones pertinentes, en las que las participantes hagan una aportación coherente con la 
línea propuesta por el/la tutor/a, así como aquellas en las que realizan una pregunta de interés.

2. Para propiciar que haya un auténtico diálogo, no deben considerarse válidas las intervenciones en los que las participantes se limitan a enviar un mensaje «inconexo», sin leer lo escrito anteriormente.

- Cuando una de las línea de discusión sea ya demasiado extensa (en todo caso, antes de que se alcancen las 40 intervenciones) el docente/tutor enviará un mensaje de cierre de dicha línea, y abrirá una nueva en su lugar. Posteriormente, resumirá lo discutido y enunciará algunas conclusiones o pedirá a las participantes que las enuncien.

En cada una de las Unidades de Aprendizaje, las estudiantes contarán con el apoyo del profesional o docente responsable de cada propuesta temática; será la persona encargada de proponer la tarea a realizar, siendo la persona responsable de solventar las dudas y cuestiones sobre los temas propuestos y la tarea. Toda la labor la ejercerá junto con la dinamizadora, cuya función será de dinamizar el bloque correspondiente, y animar y motivar a las estudiantes. Ambas, serán las personas responsables de valorar esa parte temática. La comunicación entre tutores y tutoras y estudiantes, así como entre ellas, se realizará mediante los foros, correo electrónico, chat, teléfono y personalmente durante los tres talleres presenciales.

\section{b. Tutorías individuales y grupales}

Tutoría individual.

Responde a un requerimiento por parte de alguna participante a alguno/a de los tutores/as. Puede darse en función de aspectos metodológicos, motivacionales, afectivos, tecnológicos, $\mathrm{u}$ otros. La participante plantea al tutor/a, a través de Mensajes o del Correo Electrónico una dificultad para la 
que espera solución. La respuesta debe ser en un plazo que no va más allá de 24 horas, por lo que los tutores/as deben revisar a diario su correo y mensajes. Responsables: tutor/a de la propuesta temática y dinamizadora.

Tutorías metodológica a través del Foro tutorial.

Esta modalidad de apoyo está orientada a la resolución de dudas y dificultades que presenten las estudiantes en la realización de las actividades propuestas. Debe, también contestarse en un plazo de no más de 24 horas, puesto que en caso contrario puede derivar en desmotivación y/o posterior abandono. En esta tutoría se presenta la oportunidad de revisar el estado de avance de las actividades y tareas propuestas.

Gestión del Foro tutorías.

Cada Bloque tendrá una línea dedicada a tutorización específica del mismo, que debe ser gestionada por el tutor/a principal y por la dinamizadora. Además de eso, cualquiera de los/a tutores/as del Bloque puede contestar a la estudiante o estudiantes que requieran de tutoría.

Tutoría telefónica (opcional)

Podrán establecerse horas de tutoría telefónica, facilitando por parte del tutores/as los horarios y posible contacto.

Tutoría de motivación

En una modalidad colaborativa virtual, es fundamental la participación de las personas tutoras en el desarrollo de la animación de los espacios de colaboración y la motivación de las estudiantes. Esto quiere decir, la labor de propiciar un clima de trabajo agradable y de confianza que permita a las estudiantes involucrarse sin temor en todas las instancias de participación diseñadas para apoyar su proceso de aprendizaje. 
Las tareas de animación y motivación, propias de la persona que ejerce la labor de dinamización, deben efectuarse por lo menos dos veces en la semana a través del Foro de tutorías y utilizando el correo electrónico para animar individualmente a las estudiantes. En caso de que no se reciba respuesta de alguna de ellas, la dinamizadora deberá estimular la participación, con apoyo del tutor o tutora, mediante nuevos mensajes que indaguen las razones de esa ausencia. Si es fluida, el rol deberá ser el de apoyar mediante mensajes de estímulo y reconocimiento, visibilizando los logros alcanzado por las estudiantes. La persona tutora debe apoyar estos mensajes de ánimo para lo que debe estar en constante coordinación con la dinamizadora.

\section{c. La figura de la dinamización del curso como apoyo a la labor tutorial}

La dinamización es una de las figuras clave en el proceso de enseñanzaaprendizaje bajo un entorno e-learning, ya que aporta, además de un soporte técnico-administrativo para tutores y tutoras y para las estudiantes, un soporte didáctico para motivar la participación, orientar el aprendizaje de las estudiantes, resolver dudas, incidencias, en definitiva, promover el éxito de la acción formativa.

Esta persona, que sirve de enlace entre las estudiantes y las personas tutoras a lo largo de todo el proceso, mantiene un contacto directo con ambos, lleva un seguimiento individualizado de la actividad de cada participante para evitar el abandono, hace sentir a las estudiantes acompañadas, actúa como facilitadora y es responsable de mantenerlas informadas de las fechas e hitos más importantes de la acción formativa, con el objeto de hacer cumplir la planificación académica.

La persona dinamizadora presta una asistencia permanente durante el desarrollo de la acción formativa, estando a disposición de estudiantes y 
docentes por diferentes vías de comunicación: correo electrónico, foros, mensajería instantánea (chat), teléfono, etc.

En definitiva, la dinamizadora es la referencia para estudiantes y docentes en todo lo relativo a aspectos académicos de una acción formativa, siendo una de las piezas clave a lo largo del proceso. Entre sus funciones se encuentran: soporte didáctico, gestión administrativa y soporte técnico.

\section{Función 1: Soporte didáctico}

Aunque las personas tutoras resuelven las dudas de contenido, la dinamizadora puede apoyar esta labor orientando a las estudiantes sobre su proceso de aprendizaje individual; cómo pueden estudiar, cómo pueden resolver las actividades, serían algunas cuestiones sobre las que esta figura guía y orienta, ayudando en el desarrollo de las tareas a resolver en el proceso formativo.

\section{Función 2: Gestión administrativa}

Una función importante de la persona que dinamiza el curso es la coordinación de todo el profesorado apoyando, además, la labor tutorial del mismo.

Por otro lado todas las cuestiones administrativas relacionadas con matriculaciones, certificaciones y demás, son funciones de esta figura.

Función 3: Soporte técnico

Para todas aquellas cuestiones relacionadas con el uso de la plataforma virtual, imposibilidades de acceso, en general, para todos los problemas técnicos o dudas de funcionamiento de los recursos del campus virtual, es responsabilidad de la persona que dinamiza la acción formativa. 


\subsubsection{Diseño del Sistema de evaluación.}

La evaluación es uno de los factores más críticos y de mayor relevancia en todo proceso formativo $\mathrm{y}$, particularmente, si evaluamos en base a la consecución de unas determinadas competencias. Constituye un criterio de referencia que define el valor del aprendizaje para cada estudiante y determina, además, una experiencia de éxito o de fracaso, es decir, teniendo en cuenta el diseño del sistema de evaluación que se adopte será posible comprobar si el o la estudiante va logrando los conocimientos, habilidades y actitudes que se requieren que adquiera mediante la definición de la competencia establecida. Blázquez y Alonso (2006) desarrollan una breve revisión de las aportaciones que varios autores realizan a la temática, señalando que la mayoría la incorpora entre las estructuras generales del elearning y destacan, entre otros, a Wilcox y Wojnar (2000) que han defendido la evaluación como un elemento útil a la hora de valorar el conocimiento de los estudiante y eficaz para proporcionarles nuevos retos; Murphy (2000) la describe como un elemento de carácter formativo que ha de utilizar diferentes metodologías; y a Rovai (2004) que considera que la importancia de la evaluación virtual ha de ser la misma que en un curso presencial, lo que cambiaría sería el modo en que se realiza.

Como campo de conocimiento específico, la evaluación ha ido evolucionando como resultado de diferentes factores modificando sus enfoques y formas de realización según el propósito con el que se evalúa, el tipo de resultado que se pretende evaluar, quién evalúa, quién es evaluado, cuándo se realiza, y desde qué perspectiva se realiza esa evaluación. La evaluación, en la acción formativa virtual que nos compete, se plantea como la forma de ayudar a las estudiantes a seleccionar su propio modo de expresión, trabajar colaborativamente, a pensar sobre su aprendizaje y repensar y revisar sus ideas sobre cómo construyen sus estructuras cognitivas. En este proceso se potenciará que las participantes sean 
autorresponsables y se comprometan de su aprendizaje. Partimos de que, a partir del diseño que se expone, los espacios concedidos, la mediación pedagógica, la interacción con el grupo, el trabajo de equipo, las oportunidades que se le ofrezcan para reflexionar, razonar e interpretar, empujará los límites de sus propios conocimientos y habilidades y las motivará interiormente para desear aprender y superarse.

\section{A. La evaluación de las competencias.}

Desde el punto de vista de la evaluación de competencias, los docentes establecen valoraciones basadas en evidencias que se muestran a través de diversas fuentes (tareas o actividades) y que definen si un estudiante ha logrado los requisitos planteados a través de un conjunto de criterios expresados en forma de resultados de aprendizaje. Por evidencia se entiende entonces «el conjunto de pruebas que demuestran que se ha cubierto satisfactoriamente un requerimiento o un parámetro de desempeño, una competencia o un resultado de aprendizaje» (Barcelata, 2005:6). Se asume que se deben establecer una serie de indicadores que la mayoría de las estudiantes pueden alcanzar, que diferentes modo de desempeño pueden reflejar esos indicadores y que los docentes pueden establecer una valoración basándose en esos desempeños. La evaluación, de este modo, es entendida entonces como un proceso continuo y permanente de recopilación de evidencias que permiten verificar el cumplimiento de los resultados de aprendizaje establecidos para emitir una valoración sobre el desempeño de una estudiante.

Siguiendo este marco, nuestro proceso de evaluación de competencias se resumiría en el siguiente esquema: 


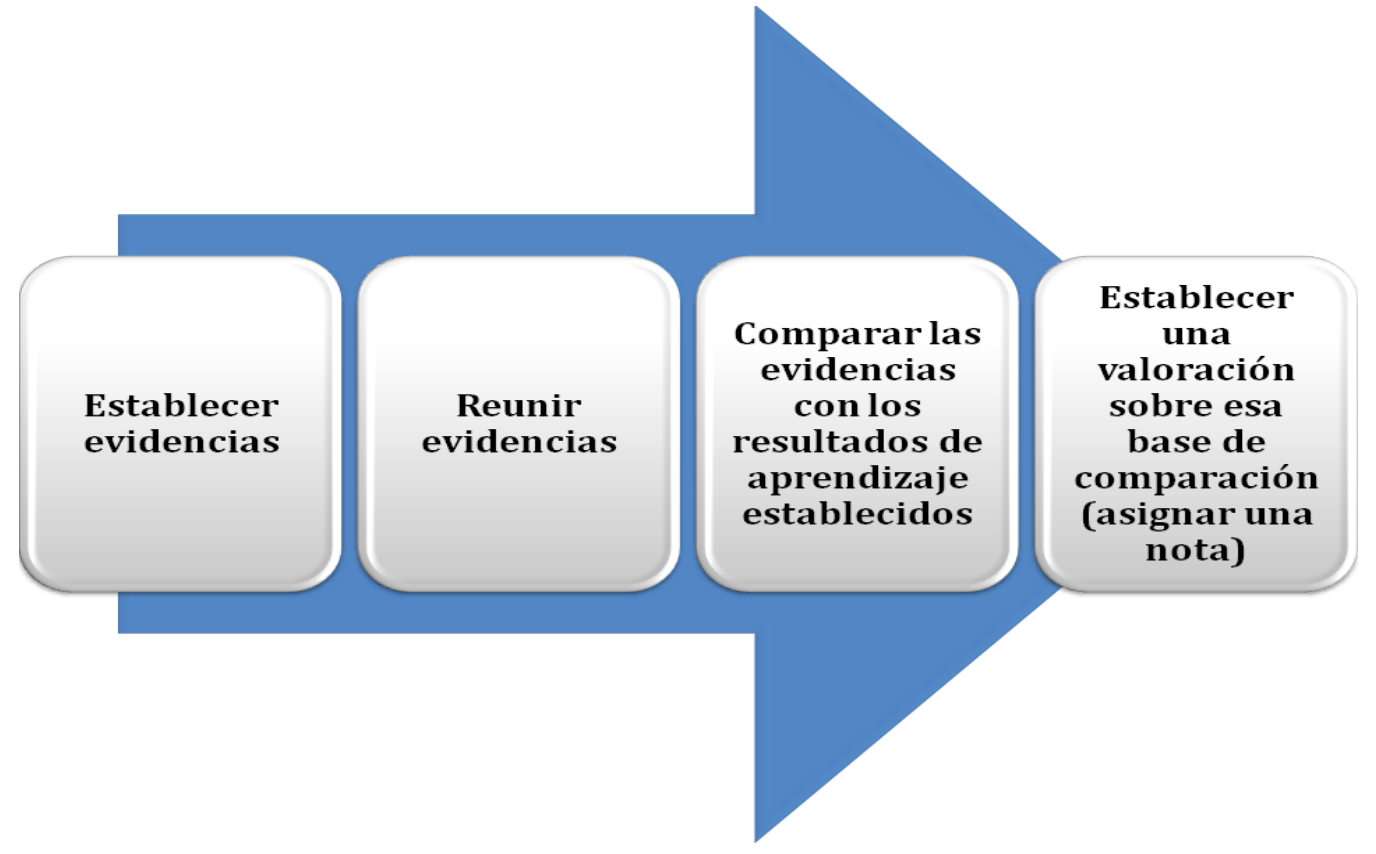

Figura 27. Proceso de evaluación de competencias de la acción formativa.

1. Establecer evidencias. En primer lugar se deben fijar los resultados de aprendizaje, previo análisis de las competencias a lograr.

2. Reunir evidencias. Como segundo paso, se deben recopilar elementos de información que nos permitan demostrar que los estudiantes pueden conseguir esos resultados de aprendizaje establecidos. A partir de este momento, se deben diseñar los instrumentos de evaluación, describiendo las características del mismo.

3. Comparar las evidencias con los resultados de aprendizaje establecidos. Una vez recopiladas las evidencias y aplicados los instrumentos de evaluación, la siguiente fase del proceso se refiere a analizar y comparar las mismas con el criterio establecido, centrándose en la información reunida previamente. 
4. Establecer una valoración sobre esa base de comparación y asignar una nota o porcentaje de la nota global.

Una vez determinadas las competencias y la concreción de las mismas en conocimientos, habilidades y actitudes, así como la definición de las Unidades de Aprendizaje con los recursos, actividades, propuestas temáticas, etc. que se deben trabajar en cada una, debemos asegurarnos de que las estudiantes han alcanzado esas competencias definidas.

La calidad en el sistema de evaluación es también un factor determinante, pues con sistema de evaluación de alta calidad, los y las estudiantes pueden confiar, a su vez, en la calidad de su formación y las competencias adquiridas (Bautista, Borges y Forés, 2006). En este sentido, hablamos de una evaluación de los aprendizajes conseguidos, es decir, de entender la evaluación como una parte integrante de todo el proceso de aprendizaje que nos va a ayudar a hacer un seguimiento individual de cada estudiante, para ir reorientando o mejorando el aprendizaje que va adquiriendo.

La evaluación, así, debe estar relacionada con las competencias. En algún momento del proceso las estudiantes van a tener que mostrar una evidencia de que han alcanzado ese aprendizaje. Vamos a determinar la unión entre las Unidades de Aprendizaje y qué esperamos realmente de las participantes, es decir, qué resultados de aprendizaje debemos mostrar que deben haber aprendido tras la acción formativa virtual. Estos resultados se tienen que definir desde una perspectiva de las mismas, concretando lo que se espera que aprendan.

Se debe aclarar que, de una misma competencia pueden definirse diferentes resultados que van, a su vez, a determinar los niveles de dificultad de cada competencia.

Desde el enfoque de la Evaluación Basada en Competencias, deben utilizarse instrumentos referidos a los criterios (Bonsón, 2009), debido a que 
la adaptación a la situación concreta y al contexto pedagógico es mayor. En este sentido, se puede hablar de una diversificación de los recursos e instrumentos de evaluación de los aprendizajes ya que los recursos que utilizamos para aprender podemos utilizarlos también para evaluar, siempre que muestren el saber, saber hacer, saber ser y estar del estudiante. Cada recurso tiene diversos grados de potencialidad para evaluar competencias, por lo que deben ser analizados con detalle asegurando su pertinencia, confiabilidad, validez y transparencia, entre otros criterios. Entre los instrumentos para obtener información necesaria para valorar las competencias adquiridas nos encontramos, con una clasificación según la finalidad, siguiendo a Barcelata (2005):

a) Aquellos en los que la persona o personas que evalúan, observan y registran información directa del desempeño de los estudiantes en el aula o en otros espacios de formación (observación directa).

b) Los que se basan en el análisis de documentos y otros productos del proceso de aprendizaje (observación indirecta).

c) Los recursos en los que el evaluado o evaluada (estudiante) reacciona a los estímulos orales o escritos que presenta la persona o personas que evalúan y que constituyen instrumentos de medición en sentido estricto (exámenes de distinta naturaleza, fundamentalmente los tradicionales, de lápiz y papel).

Para conferir validez, fiabilidad y transparencia, en definitiva calidad al proceso, es necesario la selección de recursos que permita establecer una evaluación más objetiva y basada en criterios observables y evidentes. Con esa intención se vienen utilizando, dentro del contexto educativo y en los últimos tiempos, las rúbricas o matrices de evaluación.

Las rúbricas, también conocidas como matrices de valoración, son un instrumento de evaluación basado en una escala o nivel asociado a unos 
criterios específicos que tienen como finalidad medir y valorar el aprendizaje, los conocimientos y/o las competencias logradas por los y las estudiantes en un trabajo, tarea, actividad y materia en concreto. Son desarrollados por docentes/evaluadores para orientar el análisis de los resultados del proceso de aprendizaje de los estudiantes (Brookhart, 1999). Algunos autores (Mertler, 2001; Roblyer y Wiencke, 2003) caracterizan a este instrumento como versátil, ya que puede utilizarse de manera diferente para evaluar las competencias adquiridas por los estudiantes. Por un lado, proporciona un feedback sobre cómo mejorar el trabajo realizado y, por otro lado, permite que el docente, previamente, manifieste las expectativas sobre los resultados a conseguir en base a las competencias fijadas. De este modo, se evidencia aquello que el o la estudiante debe lograr para conseguir una puntuación determinada, facilitando, a estudiantes y docentes, una evaluación con criterios más objetivos y conocidos previamente por las personas evaluadas.

Se pueden dividir en dos tipologías (Moskal, 2000):

- Holística o global, cuando se evalúa la totalidad del proceso o resultado sin una valoración por separado de las partes que lo componen. En esta línea, se evalúan actividades de desempeño que requieren que el estudiante llegue a una respuesta, sin que haya un sólo o único resultado. El objetivo se centra en la calidad, dominio o comprensión generales tanto del contenido específico como de las habilidades que incluyen la evaluación en un proceso unidimensional.

- Analítica: cuando se evalúan por separado las diferentes partes del proceso y se suma el final para obtener la calificación global. Esta tipología se centra en valorar aspectos concretos de un proceso.

Si nos acercamos a este instrumento desde las ventajas que ofrece, creemos que recoge todos los aspectos que estamos considerando para 
evaluar los aprendizajes de las estudiantes de la acción formativa virtual, como puede observarse en el siguiente cuadro:

\begin{tabular}{ll}
\hline Docentes & Estudiantes \\
\hline Instrumento de evaluación de calidad & Reduce la subjetividad en la evaluación \\
\hline Clarifica los objetivos y expectativas del docente & $\begin{array}{l}\text { Permite que conozca previamente los criterios } \\
\text { específicos con los que va a ser evaluado }\end{array}$ \\
\hline $\begin{array}{l}\text { Determina, de forma específica, los criterios con } \\
\text { los que va a medir y documentar el progreso del } \\
\text { estudiante }\end{array}$ & Permite que evalúe su propio trabajo \\
\hline $\begin{array}{l}\text { Permite una descripción cualitativa de logros } \\
\text { Provee información de retorno sobre la } \\
\text { efectividad del procesos de enseñanza que se } \\
\text { está utilizando. }\end{array}$ & $\begin{array}{l}\text { Proporciona retroalimentación sobre fortalezas } \\
\text { estudiantes y es fácil de utilizar y de explicar. }\end{array}$ \\
\hline $\begin{array}{l}\text { Ayuda a mantener los logros del objetivo de } \\
\text { aprendizaje centrado en los estándares de } \\
\text { desempeño establecidos (criterios) }\end{array}$ & $\begin{array}{l}\text { Proporciona criterios específicos para medir y } \\
\text { documentar su progreso }\end{array}$ \\
\hline
\end{tabular}

Tabla 19. Basada en Zazueta y Herrera (2008:3)

Nuestro modelo es una matriz global centrada en una evaluación holística de las competencias conseguidas por las estudiantes, y se muestra en la siguiente tabla:

\begin{tabular}{|c|c|c|c|}
\hline Competencia & Subcompetencia & Resultado de Aprendizaje & $\begin{array}{l}\text { Actividad de } \\
\text { Evaluación }\end{array}$ \\
\hline \multirow[b]{2}{*}{ C1 } & $\mathrm{C} 1 \mathrm{~A}$ & $\begin{array}{l}\text { Añade definiciones propias al } \\
\text { Glosario colaborativo }\end{array}$ & Glosario Colaborativo \\
\hline & $\mathrm{C} 1 \mathrm{~B}$ & $\begin{array}{l}\text { Usa conceptos básicos } \\
\text { relacionados con igualdad en } \\
\text { los post que realiza en los } \\
\text { foros. }\end{array}$ & $\begin{array}{l}\text { Dinámicas } \\
\text { colaborativas en Foros }\end{array}$ \\
\hline \multirow[t]{3}{*}{ C2 } & \multirow{2}{*}{$\mathrm{C} 2 \mathrm{~A}$} & $\begin{array}{l}\text { Responde correctamente a } \\
\text { mensajes de las participantes }\end{array}$ & \multirow[t]{2}{*}{$\begin{array}{l}\text { Dinámicas } \\
\text { colaborativas en Foros }\end{array}$} \\
\hline & & $\begin{array}{l}\text { Sigue el hilo de las } \\
\text { conversaciones }\end{array}$ & \\
\hline & $\mathrm{C} 2 \mathrm{~B}$ & $\begin{array}{l}\text { Realiza síntesis de datos } \\
\text { recogidos }\end{array}$ & $\begin{array}{l}\text { Dinámicas } \\
\text { colaborativas en } \\
\text { Foros: Guía de análisis } \\
\text { realidad }\end{array}$ \\
\hline
\end{tabular}




\begin{tabular}{|c|c|c|c|}
\hline & \multirow{2}{*}{$\mathrm{C}_{2} \mathrm{C}$} & Colabora en la WebQuest & \multirow{2}{*}{$\begin{array}{l}\text { Proyecto Colaborativo } \\
\text { (WebQuest y Wiki) }\end{array}$} \\
\hline & & Aporta contenido a la Wiki & \\
\hline & \multirow{2}{*}{$\mathrm{C} 2 \mathrm{D}$} & $\begin{array}{l}\text { Postea mensajes } \\
\text { comprensibles y claros }\end{array}$ & $\begin{array}{l}\text { Dinámicas } \\
\text { colaborativas en Foros }\end{array}$ \\
\hline & & Publicas entradas en el Blog & Blog individual \\
\hline \multirow{3}{*}{ C3 } & $\mathrm{C}_{3} \mathrm{~A}$ & $\begin{array}{l}\text { Postea mensajes en foros } \\
\text { mostrando respeto hacia las } \\
\text { opiniones de las compañeras y } \\
\text { tolerando los puntos de vista } \\
\text { de las demás, manifestando } \\
\text { una actitud empática y } \\
\text { negociadora. }\end{array}$ & \multirow{3}{*}{$\begin{array}{l}\text { Dinámicas } \\
\text { colaborativas en Foros }\end{array}$} \\
\hline & $\mathrm{C}_{3} \mathrm{~B}$ & $\begin{array}{l}\text { Postea mensajes en foros } \\
\text { relacionados con sus } \\
\text { sentimientos, conocimientos y } \\
\text { experiencias, incluyendo } \\
\text { reflexiones propias. }\end{array}$ & \\
\hline & $\mathrm{C}_{3} \mathrm{C}$ & $\begin{array}{l}\text { Manifiesta interés en } \\
\text { formaciones futuras }\end{array}$ & \\
\hline \multirow{2}{*}{$\mathbf{C 4}$} & $\mathrm{C} 4 \mathrm{~A}$ & \multirow{2}{*}{$\begin{array}{l}\text { Postea mensajes en foros con } \\
\text { calidad, incorporando } \\
\text { reflexiones, experiencias } \\
\text { propias. }\end{array}$} & \multirow{2}{*}{$\begin{array}{l}\text { Dinámicas } \\
\text { colaborativas en Foros }\end{array}$} \\
\hline & $\mathrm{C}_{4} \mathrm{~B}$ & & \\
\hline
\end{tabular}

Tabla 20. Matriz de valoración de las competencias

La evaluación será realizada por el grupo de docentes de la Unidad de Aprendizaje, coordinados y orientados por la dinamizadora de la acción formativa. Esta matriz se incluirá en el espacio virtual desde el comienzo del curso.

\section{B. Actividades de Autoevaluación.}

Concebimos que las actividades de autoevaluación son prácticas experienciales para el desarrollo, en el alumnado, de la responsabilidad personal de valorar el proceso y resultado de su propio aprendizaje.

Se utiliza la autoevaluación, individual y grupal, para fomentar una actitud constante de análisis, reflexión y reorientación del curso hacia los 
fines perseguidos y hacia las expectativas de las mujeres participantes y su responsabilidad personal.

Para ello, se habilitan foros de evaluación, guiados y orientados por la dinamizadora, donde realizaran el análisis acerca de los logros de objetivos, la necesidad de modificaciones, la motivación para la consecución de aprendizajes más significativos y la discusión sobre el grado de cumplimiento de expectativas de las estudiantes.

\subsection{Fase de Producción}

Estamos de acuerdo con Suárez (2007) cuando afirma que para asegurar el desarrollo eficaz de las actividades de aprendizaje en el desarrollo en la modalidad virtual, no basta sólo con contar con una plataforma, sino que es necesario establecer una Estructura Pedagógica de Aprendizaje (EPA) que nos permita orientar de manera ventajosa los procesos de aprendizaje en los contextos de virtualidad donde se desarrollarán las unidades de aprendizaje.

Se presenta la estructura pedagógica de la acción formativa, es decir, cómo se organiza el diseño planteado dentro de la plataforma seleccionada. Este diseño se estructura con diversos elementos que buscan la implementación del modelo pedagógico, apostando por dos vías complementarias: una de carácter individual y otra de carácter social. En primer lugar se pone a disposición de las estudiantes diversos materiales relacionados con los contenidos del curso, en el segundo se hace uso de diversas herramientas asíncronas para lograr interacción entre las participantes y entre éstas con los y las tutoras y la dinamizadora. Este espacio virtual de desarrollo de la acción formativa, cuenta con herramientas para la comunicación entre las estudiantes y la tutorización y dinamización, 
que permiten una interacción entre las estudiantes y el equipo docente. Es por ello que, el bloque central e inicial del curso, recoge herramientas de comunicación destinadas a estos fines que estimulan la motivación y la participación, fomentando el sentimiento de grupo dentro del curso (herramientas sociales). Así mismo, debemos contemplar las herramientas para la evaluación por parte de las estudiantes.

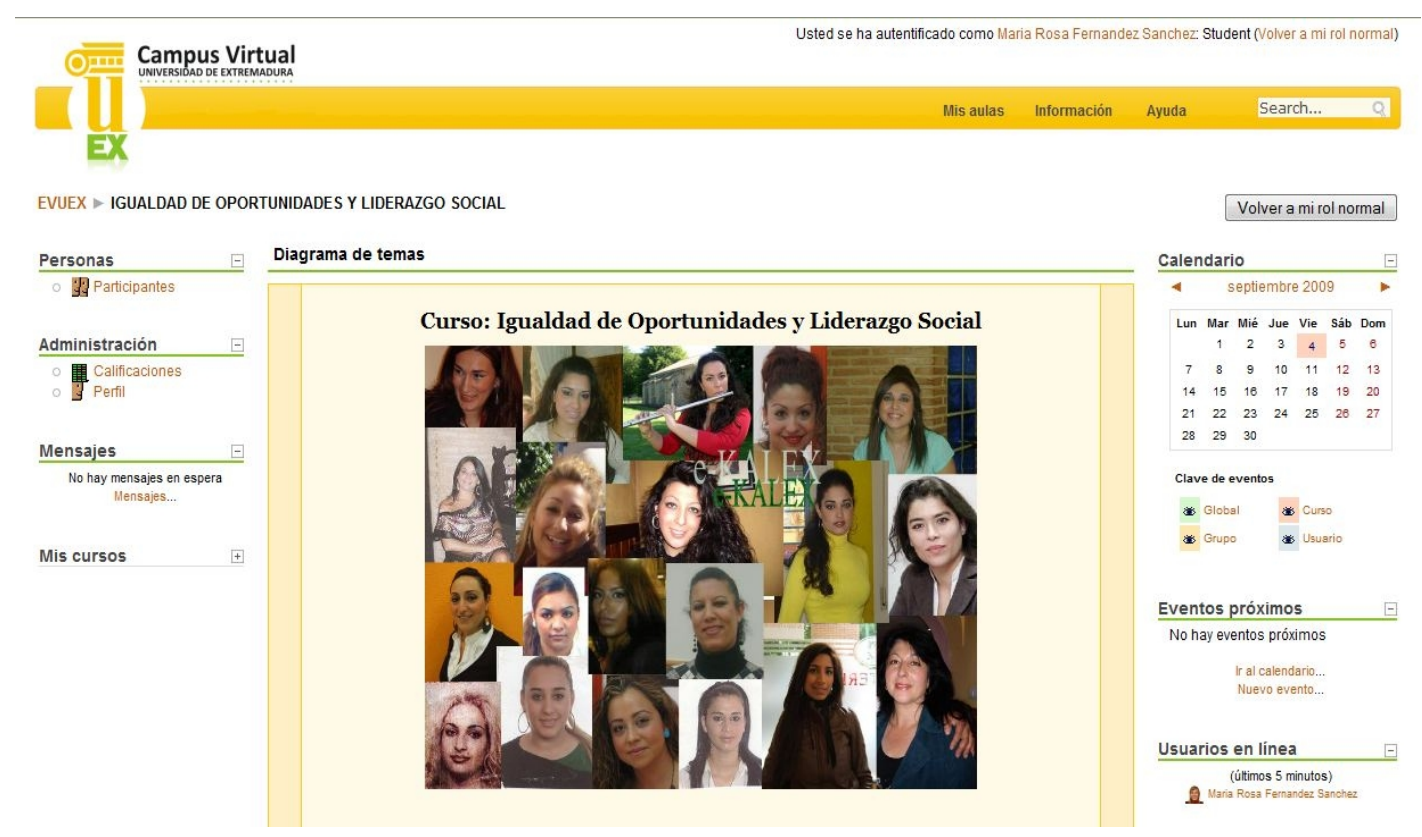

Figura 28. Apariencia del curso en la plataforma virtual. Bienvenida.

Se encuentra, en primer lugar, el panel central, con un espacio permanente denominado Espacio Social de Trabajo (Figura 28), transversal a las propuestas temáticas del curso y disponibles durante toda su desarrollo, que incluye: 


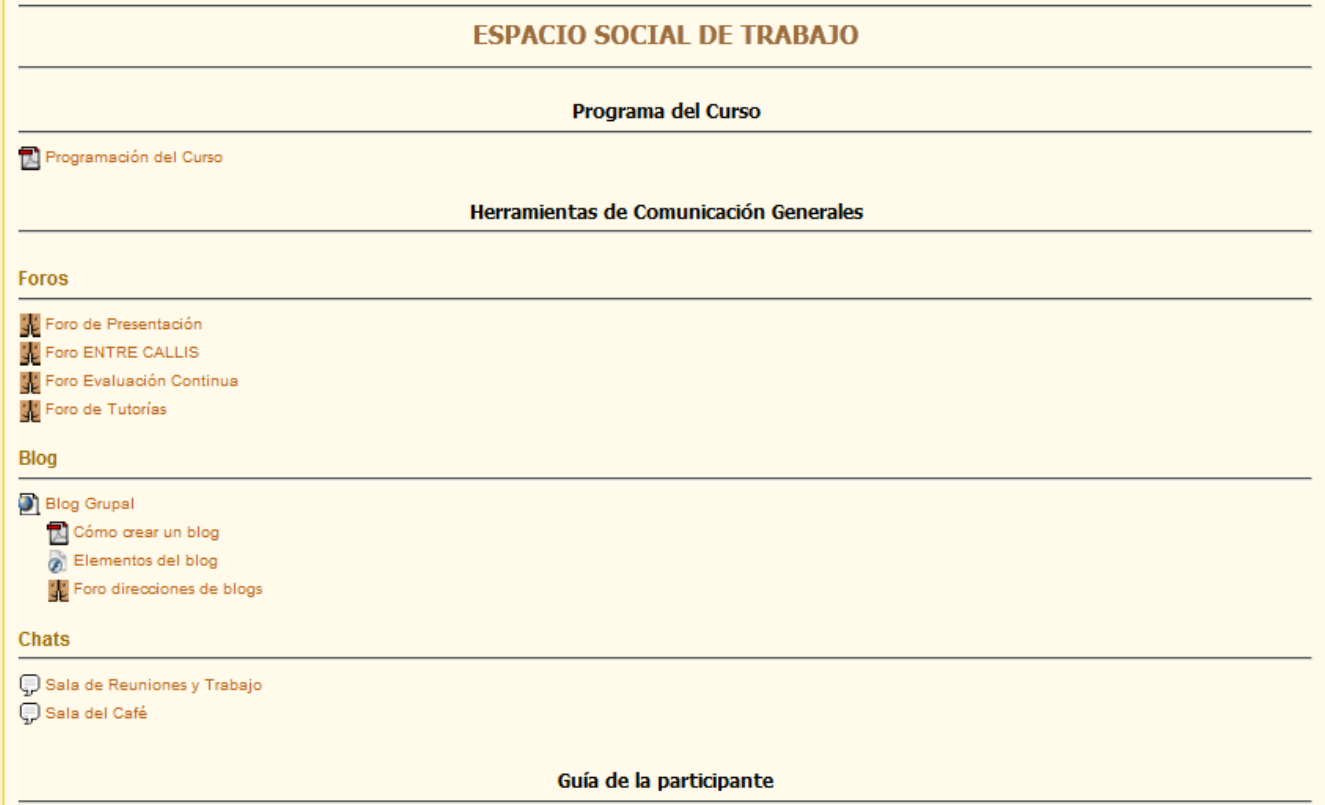

国 Guia de las participantes

Figura 29. Apariencia del curso en la plataforma virtual. Espacio Social de Trabajo.

- La programación del curso: un documento dirigido a las estudiantes que recoge las competencias, el programa temático, la temporalización, la metodología a seguir y la evaluación de los aprendizajes.

- Las herramientas de comunicación generales, entre las que se encuentran los foros, enlaces a los blogs y los chats. En cuanto a los foros, aparecen:

- Foro de Presentación: para que todas las personas que conforman la comunidad educativa virtual de esta acción formativa se conozca.

- Foro Comunitario: como espacio para la interacción en temas planteados por las estudiantes, abierto sólo a su participación. 
Es el «Foro de la Comunidad» y lo gestionan las propias estudiantes del curso virtual.

- Foro de Evaluación Continua: Las estudiantes deben evaluar, semanalmente, cómo va el desarrollo del curso, lo que más y lo que menos les está costando, lo que les gusta, lo que no, e incluir una autoevaluación personal mencionando cómo está resultando su participación, su esfuerzo, etc.

- Foro de tutorías: dedicado a la labor propia de tutoría virtual. En él se consultarán dudas y se solicitarán asistencias técnicas referidas al desarrollo de la acción formativa virtual.

- Blog, que incluye:

- Un enlace al Blog grupal de la acción formativa virtual, desarrollado y actualizado por varios docentes del curso.

- Cómo Crear un Blog: con las instrucciones generales para crearlos en Blogger.

- Elementos del Blog: video, elaborado por un docente, con los pasos básicos para crear un blog.

- Foro de direcciones Blogs, para incluir la dirección de los blogs individuales, para que las estudiantes tengan acceso a todos y puedan comentar las entradas $\mathrm{y}$ publicaciones de las compañeras.

- Aparece después el Chat, como el espacio para hablar en tiempo real con las personas conectadas al mismo tiempo al curso. Incluye: 
- El Chat Sala de Reuniones y de Trabajo: para aquella actividad que exija que estudiantes y docentes se conecten al mismo tiempo para realizar una práctica, debate o actividad. Es decir, para actividades que exijan la comunicación síncrona.

- El Chat Sala del Café, que constituiría la «Cafetería Virtual», como un espacio para charlar en tiempo real con las participantes que estén conectadas al mismo tiempo.

- La guía de la participante: su objetivo principal es guiar en los pasos que deben seguirse y en las funciones básicas asociadas al curso. Las estudiantes disponen de una "guía de referencia rápida» para que, en cualquier momento, si no se recuerda cómo realizar estas funciones (por ejemplo, cómo enviar un mensaje) se pueda consultar cómo se realizaría paso a paso. Esta Guía incluye explicaciones sobre la plataforma virtual, cómo acceder paso a paso y una explicación detallada sobre la estructura pedagógica con cada una de las partes y los recursos que pueden encontrar en cada una de ellas, así como las funciones de estas herramientas. Se añade además, un apartado de «Recomendaciones y orientaciones para el estudio», referidas al tiempo y modo de estudio para realizar y superar con éxito la acción formativa, así como los pasos a seguir para modificar y actualizar el perfil personal, descargar los contenidos y documentos, cómo utilizar los foros -postear, responder un mensaje, añadir un archivo-, cómo introducir definiciones en el recurso Glosario, y cómo enviar y responder mensajes. Todas estas directrices se acompañan de imágenes que reflejan visualmente la operación a realizar. 
Un segundo apartado corresponde a las propuestas de trabajo, es decir, el espacio que corresponde a los Tópicos, bloques o propuestas temáticas 1,2 y 3.

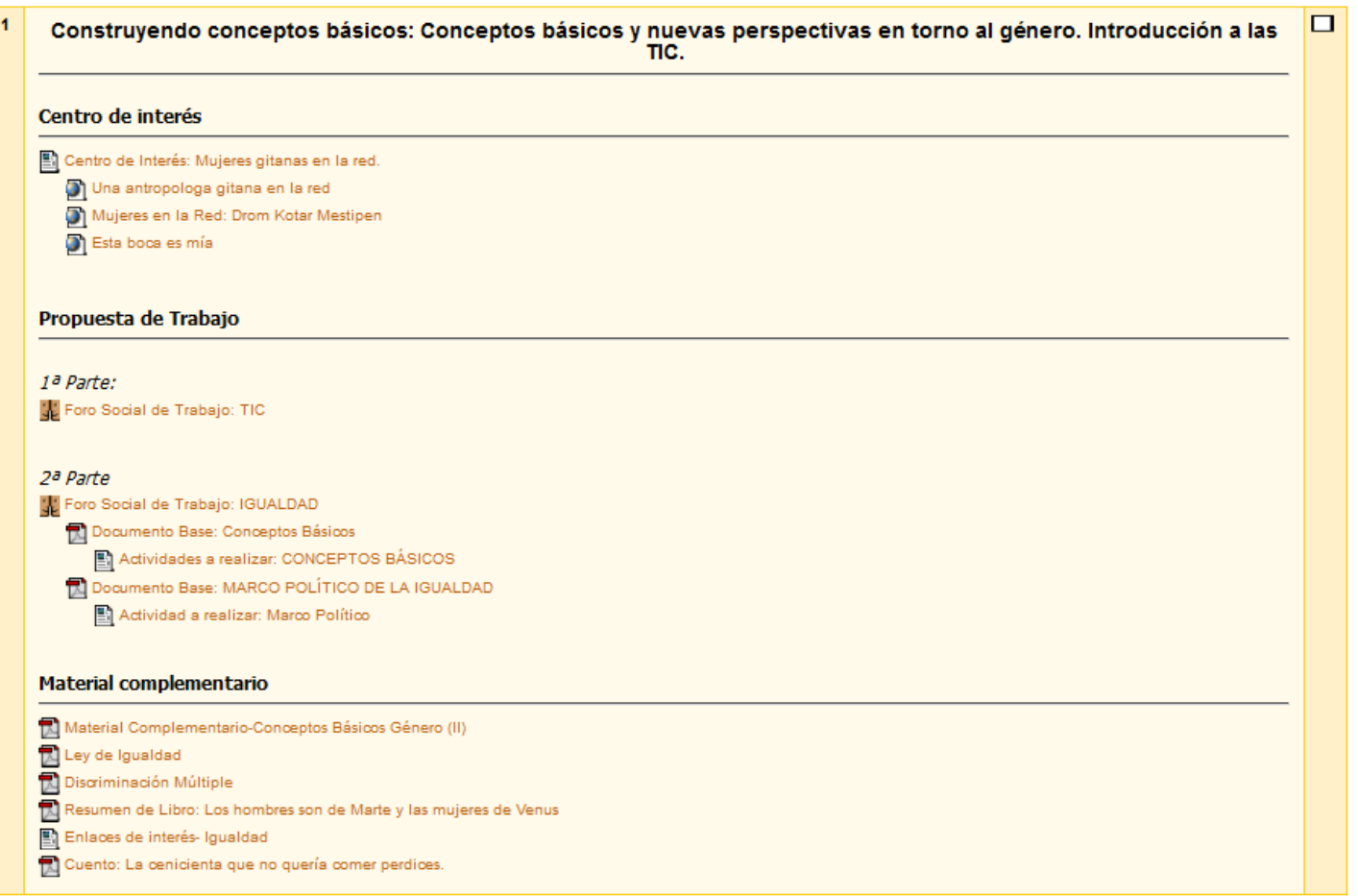

Figura 3o. Apariencia del curso en la plataforma virtual. Bloque temático 1.

La estructura temática en bloques se propone, no para controlar los procesos internos de aprendizaje, sino para organizar la enseñanza virtual de esta acción formativa. En este sentido, tampoco se trata de un modelo poco flexible y que no acepte adaptaciones progresivas, sino que se requiere un dinamismo de acuerdo a la naturaleza del diseño, de las estudiantes, del tiempo, de las tareas y actividades, etc. Con esta estructura se busca potenciar la interacción, la motivación y la participación como bases de la estrategia didáctica, como ya comentamos en la fase de diseño. 
Comunidad de Práctica para la promoción sociocultural de mujeres gitanas en entornos virtuales de aprendizaje

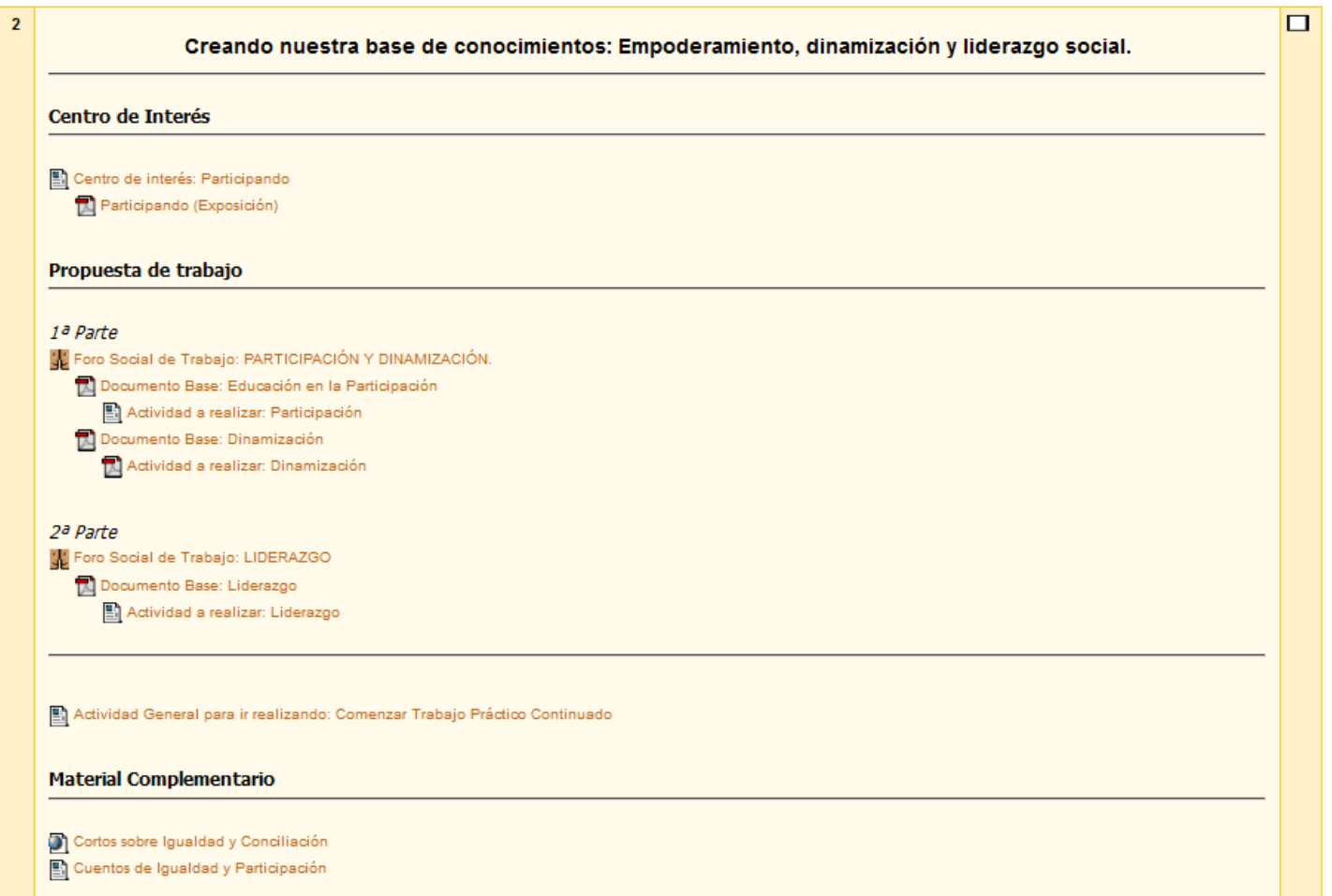

Figura 31. Apariencia del curso en la plataforma virtual. Bloque temático 2.

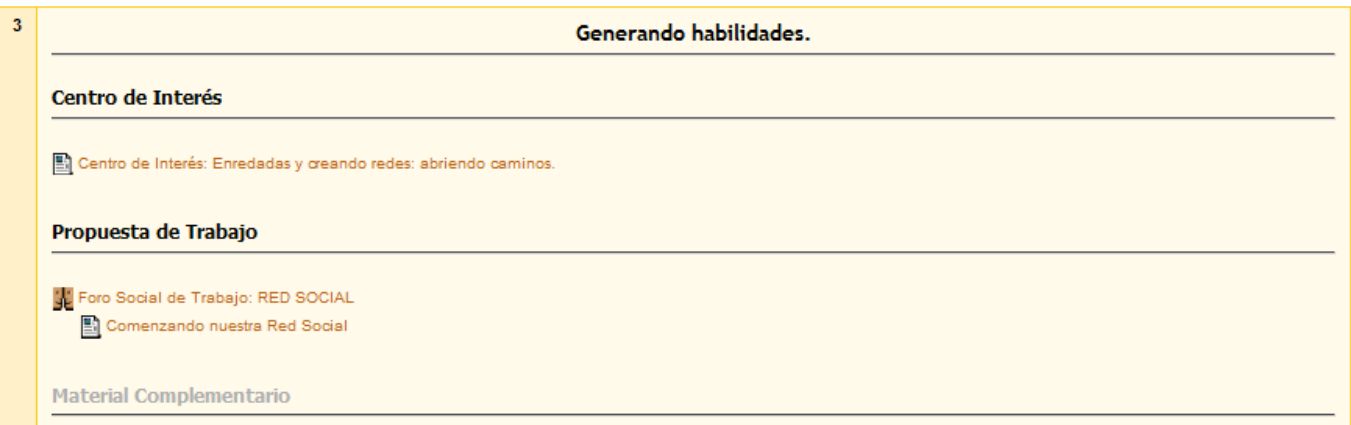

Figura 32. Apariencia del curso en la plataforma virtual. Bloque temático 3.

Están estructuradas de la siguiente manera:

A. Centro de Interés: 
Incluye el centro de interés del Bloque y resume lo que se va a aprender desde esa propuesta temática. Puede ser un documento de breve lectura que las estudiantes deben seguir, enlaces externos a páginas web o un documento multimedia para visualizar.

B. Propuesta de trabajo:

Aquí encontramos: los Documentos Base, las actividades sobre la temática y el Foro Social de Trabajo sobre ese tópico.

- Documentos Base: Los documentos base de la temática, documento en formato *.pdf y que son de lectura obligatoria.

- Las actividades referidas a la temática trabajada que deben ser resueltas para superar el curso.

- El Foro Social de Trabajo sobre cada tópico: espacio de desarrollo de actividades, debates y donde se responderán las dudas, cuestiones, reflexiones que hayan surgido trabajando los temas o realizando las actividades.

C. Material Complementario:

Como añadido a esos documentos base, se encuentra el material complementario para ampliación de conocimientos sobre la temática o temáticas relacionadas con el documento base.

Siguiendo con la estructura, encontramos el apartado Trabajo Práctico

\section{Continuado}


G Foro Social de Trabajo Práctico Continuo

Blog Individual

国 Elaboración y Mantenimiento de Blog Individual

Glosario Colaborativo

Hes Glosario Colaborativo

Actividad Principal

En este apartado se sitúan las tres actividades principales que, además de las correspondientes a las propuestas temáticas, se van a desarrollar en el curso.

En primer lugar se encuentra el Foro Social destinado al Trabajo Práctico Continuado para compartir todas las ideas, reflexiones, etc. en referencia a este trabajo.

Los tres siguientes apartados se refieren a la explicación y desarrollo de cada una de las tres actividades propuestas:

- Blog Individual. Indicaciones para realizar y mantener el Blog Individual.

- Glosario Colaborativo. Con la explicación de la actividad en la que se deben aportar definiciones propias y sugerencias, al menos a dos términos que otras compañeras ya hayan definido.

- Ya no queremos ser invisibles y Sinamos Calís (WebQuest y Wiki). Esta es la actividad principal del curso y en este apartado se establecen todas las orientaciones y recursos para su resolución. Recoge la WebQuest y la Wiki que deben resolver y desarrollar. 
- El siguiente espacio se denomina Biblioteca recoge una serie de documentos, enlaces a videos, presentaciones, de interés para las temáticas trabajadas en el curso.

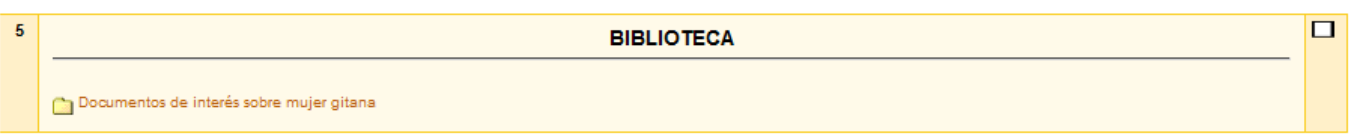

Figura 34. Apariencia del curso en la plataforma virtual. Biblioteca.

Por último, nos encontramos el Espacio Docente, de acceso exclusivo a profesorado del curso, consistente en un Foro donde debatir sobre las dudas y cuestiones que surjan en el desarrollo del curso. Incluye:

- Guía del Profesorado-Tutor/a: Documento de referencia para el equipo de tutores (docentes), en el que se recoja detalladamente todas las necesidades para cada unidad de aprendizaje. Es decir, es el documento descriptivo del desarrollo docente del curso. En dicho documento se describen didácticamente todos los módulos temas y los recursos disponibles.

- Un documento web con las expectativas y motivaciones previas sobre la acción formativa virtual de las mujeres que participan como estudiantes en el curso.

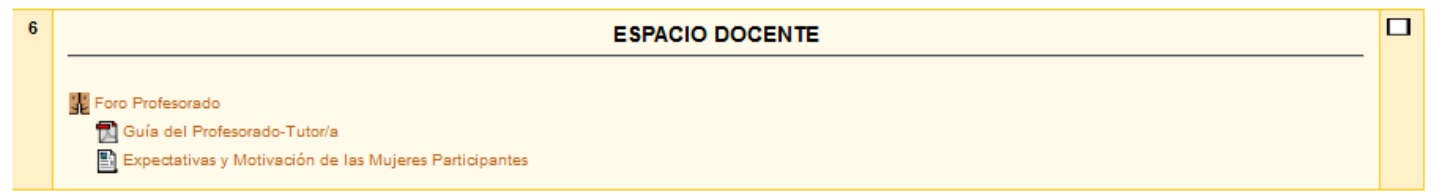

Figura 35. Apariencia del curso en la plataforma virtual. Espacio Docente.

Además del panel central, la estructura del curso incluye recursos en los paneles o menús de la derecha y la izquierda. 
En el panel izquierdo, se sitúan los recursos:

- Mensajes: En el que se puede comprobar los mensajes que nos han enviado y continuar la conversación si la otra persona está en línea.

- Administración:

- Calificaciones: Con este módulo podemos ver las calificaciones que vamos obteniendo.

- Perfil: Esta opción nos muestra nuestro perfil de usuaria.

- Participantes: Este módulo permite tener una visión de los miembros del curso. Podemos hacer clic sobre cualquier nombre y encontraremos los datos de la persona seleccionada, permitiéndonos enviar un mensaje privado.

\section{Personas $\quad \square$ \\ .}

\section{Administración}

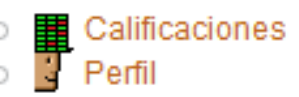

\section{Mensajes}

No hay mensajes en espera

Mensajes...

Mis cursos

Figura 36 Apariencia del curso en la plataforma virtual. Panel izquierdo.

En el panel derecho se muestran también varios recursos. 


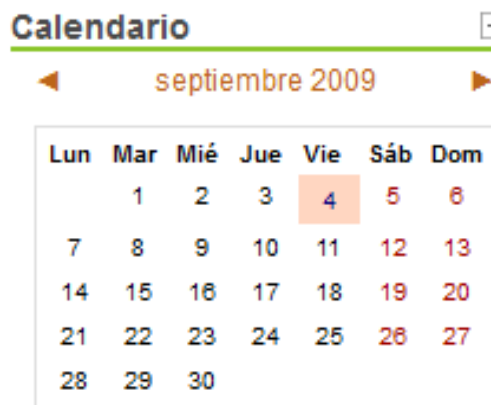

Clave de eventos

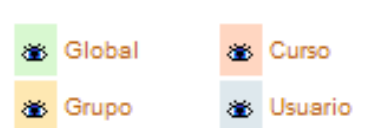

\section{Eventos próximos \\ No hay eventos próximos \\ Ir al calendario... \\ Nuevo evento...}

Usuarios en línea

(últimos 5 minutos)

A. Maria Rosa Fernandez Sanchez

Figura 37 Apariencia del curso en la plataforma virtual. Panel derecho.

- Calendario: Muestra un calendario con las novedades del curso. En este módulo vemos de manera rápida las actividades programadas para un mes concreto en función de las diferentes agrupaciones de estudiantes existentes (Global, Grupo, Curso, Usuario). Se considera un organizador del trabajo diario, en el que se sugiere una forma de trabajo, pero cada estudiante posee la flexibilidad de reorganizar el día de acuerdo a sus conocimientos previos y su disponibilidad. Esta estructura de organización del trabajo de las estudiantes sigue el planteamiento de Barberà y Badia (2004) en el sentido de presentar de forma clara la organización de las actividades y que se articulen a través de ellas el acceso a los diferentes recursos, teniendo en cuenta 
las características de las estudiantes y contexto en el que se desarrolla la acción formativa virtual.

- Eventos próximos: nos muestra los acontecimientos y novedades del curso que tienen comienzo inmediato.

- Usuarios en Línea: Permite ver cuántas personas hay conectadas a nuestro curso en ese momento. Si está conectada alguna estudiante o docente, se sugiere abrir el Salón del Café y chatear en ese momento.

\subsection{Fase de Evaluación}

La fase de evaluación se ha convertido en un requisito indispensable para las corrientes que enfatizan la mejora de la calidad en los procesos educativos incluidos los desarrollados a través de los entornos virtuales de aprendizaje. Rubio (2003) afirma que la importancia que va adquiriendo evaluar los procesos de e-learning va provocando el surgimiento de iniciativas y experiencias que se dirigen a establecer estándares para certificar la calidad de esta metodología formativa. Esta autora, mencionando sitúa dos grandes enfoques en relación a estas prácticas para evaluar los proyectos e-learning:

Un enfoque parcial, si la evaluación se centra en elementos como:

- La actividad formativa; si se evalúa una acción formativa concreta, independientemente de su duración.

- Los materiales de formación utilizados en el proceso.

- Las plataformas tecnológicas; si la evaluación se orienta a definir la calidad de los entornos a través de los cuales se implementa el proceso formativo virtual. 
- La relación coste/beneficio en relación a la inversión realizada y el beneficio que se obtiene del desarrollo de una acción formativa virtual.

Un enfoque global, si en la evaluación de la calidad se tiene en cuenta el conjunto total de los elementos que intervienen en un proceso e-learning. En este enfoque se sitúan los sistemas de evaluación centrados en modelos y/o normas de calidad estándar y calidad total y los sistemas basados en la práctica del benchmarking (indicadores en relación a las mejores prácticas de evaluación de calidad en procesos de e-learning).

En este diseño se considera que la evaluación debe aplicarse a todas las fases de desarrollo de una acción formativa virtual, creándose a tal efecto un plan de evaluación. Podría considerarse una meta-actividad que va a comprender todos los aspectos de la experiencia e-learning. Así, la evaluación la consideramos desde un enfoque global y de calidad, como un proceso continuo y planificado que nos va a permitir la recopilación y análisis de la información relevante, sobre la que vamos a sostener juicios de valor en cuanto al objeto evaluado : el proyecto completo de e-learning.

Se considera necesario, además, realizar un análisis pormenorizado y más concreto de determinados elementos relacionados con los resultados obtenidos, por tanto, realizamos en el capítulo siguiente un análisis en profundidad de los resultados de la acción formativa.

El proceso de evaluación global del proyecto e-learning debe responder a cinco cuestiones: ¿Para qué evaluar? ¿Qué evaluar? ¿Cómo evaluar? ¿Quiénes evalúan? ¿Cuándo evaluar? 


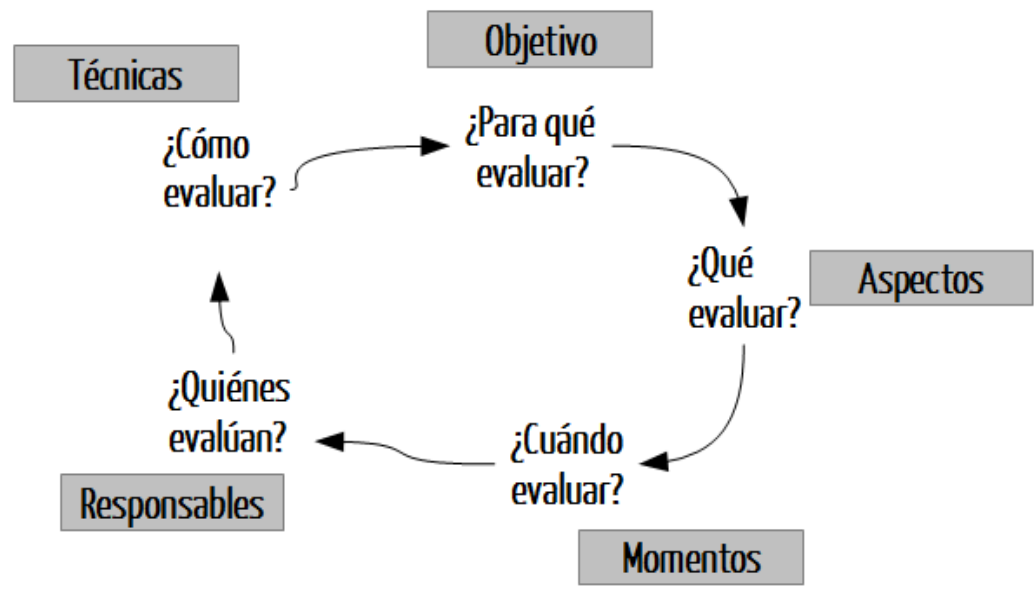

Figura 38. Proceso de Evaluación del proyecto e-learning

Así, teniendo en cuenta estas cinco preguntas, establecemos las siguientes fases en la planificación del proceso de evaluación del proyecto e-learning:

1. Definición del objetivo de la evaluación (Para qué evaluar).

2. Identificación de aspectos a evaluar (Qué evaluar).

3. Momentos del proceso de evaluación e identificación de personas o fuentes de información (Cuándo evaluar).

4. Identificación y selección de responsables y expertos de la evaluación (Quiénes evalúan).

5. Elección de las Técnicas de Evaluación (Cómo evalúan).

En cuanto a la definición del objetivo de la evaluación, la propuesta evaluativa de este proyecto e-learning, quiere mostrar la viabilidad y resultados de la aplicación de un diseño de un curso virtual a un grupo de mujeres gitanas, generando una Comunidad de Aprendizaje Virtual para ir 
cultivando Comunidad de Práctica. Constituye una nueva modalidad de intervención socioeducativa con TIC para la promoción sociocultural de mujeres gitanas.

En referencia a la identificación de aspectos, momentos, responsables y técnicas de evaluación, se presenta, a continuación, cuadro explicativo, mostrando todas estas cuestiones: 


\section{Objetivo de la evaluación \\ Mostrar la viabilidad y resultados de la aplicación de un diseño de una acción formativa virtual a un grupo de mujeres gitanas para generar una Comunidad de Práctica}

\section{Identificación de aspectos a evaluar} evaluar

Evaluación del contexto de aplicación y de las destinatarias

\section{Momentos del proceso de evaluación e identificación de personas o fuentes de} información

1er Momento: Evaluación del contexto de aplicación y de las destinatarias. Este momento evaluativo constituye una valoración inicial del contexto al que nos dirigimos y de las destinatarias de la acción formativa.

\section{Identificación y selección de responsables y expertos de la evaluación}

Investigadora + entidad + participantes

(Equipo Asesor)
Elección de las Técnicas de Evaluación

Técnica DAFO

Grupo de trabajo: consenso en el equipo asesor
Evaluación del diseño de la acción formativa virtual. Feedback y rediseño.

$2^{\circ}$ Momento: Fase de evaluación del diseño e implementación del mismo. Se evalúa el diseño realizado a través de expertos en el campo de la formación a través de las TIC. Feedback y rediseño. A continuación se produce e implementa a través de la acción formativa virtual: Igualdad de Oportunidades y Liderazgo Social.

$3^{\circ}$ Momento: Fase de evaluación del modelo pedagógico de desarrollo de la acción formativa virtual. Una vez implementada la acción se pretende saber si el modelo de aprendizaje que se desarrolla ha

Evaluación del desarrollo de modelo de aprendizaje de la acción formativa.

a expertos en diseño pedagógico de e-learning.

Evaluación del desarrollo de la acción formativa virtual.

Evaluación de aprendizajes, desarrollo y los resultados de la accion formativa.
$4^{0}$ Momento: Evaluación de aprendizajes, desarrollo y los resultados de la acción formativa virtual, que conlleva:

- Evaluación de competencias adquiridas por las estudiantes.

- Evaluación de la conformación de la Comunidad de Práctica.
Evaluación del diseño de la acción

formativa virtual por expertos y expertas:

Dr. Joaquín Paredes Labra (Universidad

Autónoma de Madrid), Dr. Antonio Víctor

Martín García (Universidad de Salamanca.),

Dra. Rocío Anguita Martínez (Universidad

de Valladolid) y Dra. Prudencia Gutierrez

Esteban (Universidad de Extremadura).

Rediseño por investigadora.

Evaluación del modelo pedagógico de desarrollo por expertos y expertas: Dr.

Francisco Revuelta Domínguez

(Universidad de Extremadura), Dra. Laura

Alonso Díaz (Universidad de Extremadura)

y Dr. Eloy López Meneses (Universidad

Instrumento de análisis didáctico

de modelos y estrategias de

enseñanza de cursos

Pablo de Olavide).
Evaluación del diseño de

la acción formativa virtual.
Evaluación de competencias adquiridas por las estudiantes: profesorado y estudiantes.

Evaluación de la conformación de la Comunidad de Práctica: Investigadora.
Ficha de evaluación de competencias.
Dimensiones Social, Cognitiva y Docente a través del modelo

«Comunidad de Indagación» (Garrison y 
Archer, 2005). Análisis de contenido cualitativo de

Foros de Discusión de

curso.

- Evaluación del desarrollo y resultados de la acción formativa virtual.
Evaluación del desarrollo y los

resultados de la acción formativa

virtual: estudiantes y profesorado.

Estudiantes:

Autoevaluaciones (Foro de

Evaluación Continua),

Grupo de Discusión

Comunicativo,

Cuestionario de Evaluación

de la acción formativa.

Profesorado: Entrevistas

Triangulación de Datos

Obtenidos.

Tabla.21. Objetivo, aspectos, momentos responsables y técnica de evaluación del proyecto e-learning. 
En este capítulo hemos presentado el diseño completo de la acción formativa virtual «Igualdad de Oportunidades y Liderazgo social» dirigida a 20 mujeres gitanas extremeñas. Para el diseño y planificación de la misma hemos seguido el modelo de diseño genérico ADDIE desde las fases de concepción, análisis, diseño, producción y evaluación. En la fase de concepción se ha realizado un recorrido por los antecedentes del proyecto, las motivaciones y las primeras reflexiones sobre los fines del mismo. También se ha establecido la selección de la plataforma de formación y los expertos y expertas responsables de la labor tutorial, así como la planificación estratégica y los modelos pedagógicos que la justifican. En la fase de análisis hemos realizado un estudio previo sobre las destinatarias de la acción formativa, los resultados esperados y las metas de la propia acción formativa. En la fase de diseño se ha presentado y justificado el modelo pedagógico, así como el diseño de las unidades de aprendizaje, la estrategia de motivación, la planificación de las interacciones y el sistema de evaluación. En la siguiente fase, denominada de producción, hemos planteado la arquitectura pedagógica de la acción formativa, conformando el diseño pedagógico en la propia plataforma virtual. Y por último, la fase de evaluación, establecemos la definición del objetivo de la misma y la identificación de aspectos, momentos, selección de responsables de los mismos y elección de las técnicas más adecuadas para realizar esas evaluaciones. 


\section{Capítulo 7. La construcción de la Comunidad de Práctica a través de entornos virtuales de aprendizaje (Estudio 2).}





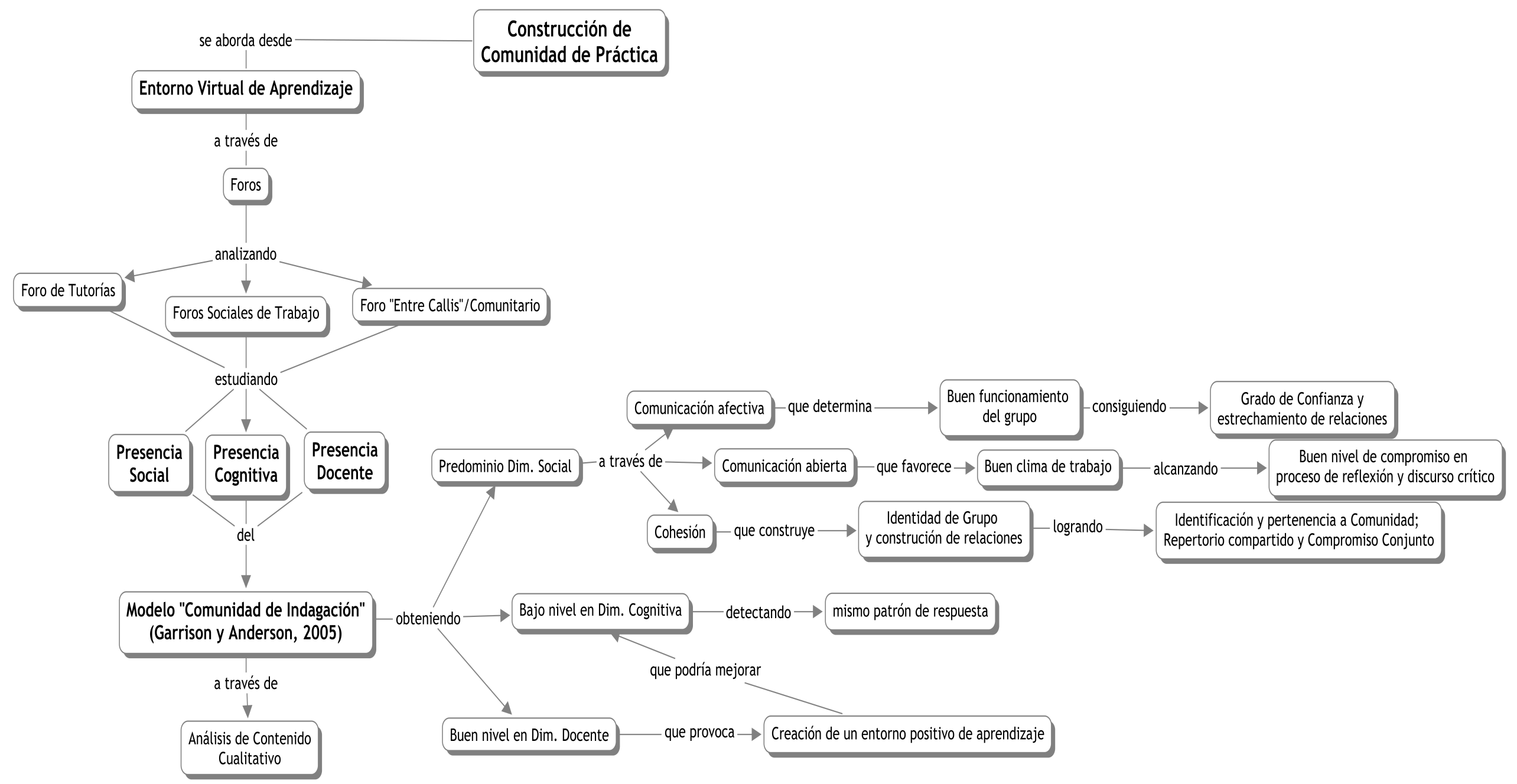





\subsection{Contexto del estudio.}

Para el estudio de la Comunidad virtual de Aprendizaje hemos tomado como referencia varios temas de los foros que forman parte de la actividad académica virtual del curso Igualdad de Oportunidades y Liderazgo Social, dirigido, como hemos indicado, a mujeres gitanas de diferentes puntos geográficos de Extremadura y desarrollado a través del Campus Virtual de la Universidad de Extremadura.

Recordamos que esta acción formativa se ha implementado online, a excepción de tres talleres presenciales de tres horas de duración, constituyendo la parte virtual el $90 \%$ del curso. Los foros, específicos para cada una de las propuestas temáticas, han constituido el soporte comunicacional fundamental en el aprendizaje de las estudiantes. La participación en los mismos constituía, además, un porcentaje en la evaluación, formando parte de las tareas del curso. En este caso, la participación no debía consistir sólo en enviar un mensaje al foro, sino que debían responder a la cuestiones que tanto docentes como compañeras planteaban, aportando ideas nuevas.

La plataforma que utiliza el Campus Virtual de la Universidad de Extremadura, Moodle, informaba, una vez accedías a la misma, de los mensajes nuevos en los foros del curso, intentando animar a leerlos y responder. Las participantes en la formación, de manera inicial, son un total de 20 estudiantes, 4 docentes de sesiones presenciales, 6 tutores/as virtuales y una tutora-dinamizadora del curso, todos con acceso a la plataforma.

Recordando el marco metodológico de este estudio, al exponer el procedimiento para el análisis de los datos, explicamos que la metodología propuesta en este estudio es de índole cualitativa, a través del análisis de 
contenido, siendo la unidad de análisis y codificación el mensaje en el contexto del «tema o línea temática» abierta, seleccionando las unidades sintácticas como la palabra, la proposición, la frase o el párrafo para el estudio de las diferentes dimensiones o «presencias» propuestas por Garrison y Anderson (2005). Debemos añadir que, a pesar de que esa unidad de codificación ha sido el mensaje completo, un mensaje puede hacer referencia a las tres presencias, como indican los autores, de ahí que que se tome la palabra, frase o párrafo/fragmento para el estudio de cada una de las categorías.

Procedemos, para una identificación más minuciosa, a segmentar las comunicaciones de las participantes en aquellas categorías que estos investigadores proponen, recurriendo al uso de puntos suspensivos y paréntesis en la indicación del segmento del discurso seleccionado a modo de «posting».

Debemos aclarar, por último, que se indican las expresiones textuales, sin omitir las faltas ortográficas y gramaticales, con el fin de mostrar la aportación real que se ha realizado. 


\subsection{Análisis de foros.}

Presentamos, antes de entrar en el análisis de contenido, datos cuantitativos básicos en referencia a la participación. Estos datos se han obtenido de la propia plataforma, que registra el número de ocasiones en que el alumnado accede a la plataforma y a los recursos del espacio virtual de la acción formativa.

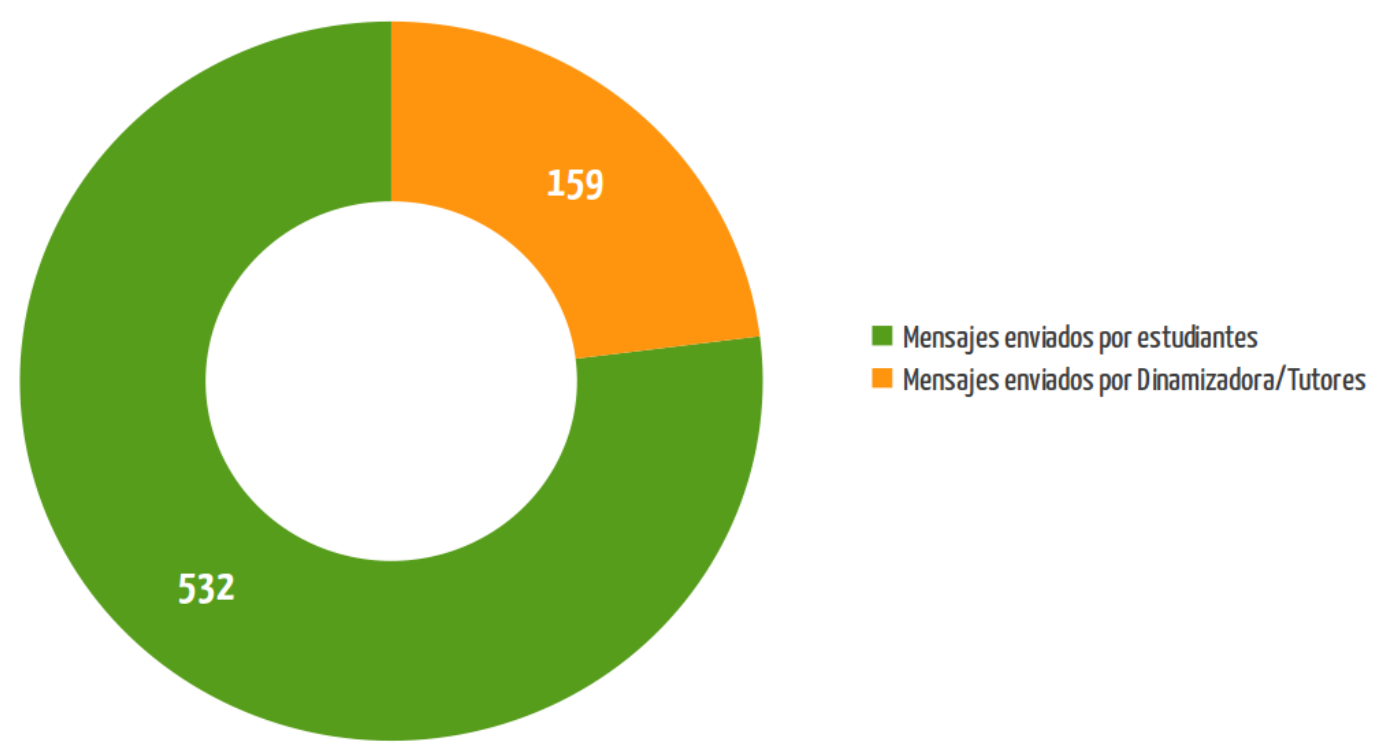

Gráfico 1. Número total de mensajes enviados a los Foros.

Como se describe en los gráficos anteriores, el número total de mensajes enviados por docentes y por la dinamizadora asciende a 159 mensajes frente a los 532 enviados por las estudiantes. Esta dato es acorde a la dinámica del curso, que tiene como eje central a las estudiantes e intenta que participen y dialoguen en los foros abiertos en la plataforma donde se desarrolla la acción formativa. 
Si hablamos de la participación de docentes y de la dinamizadora, se observa una mayor participación de esta última, dato que se relaciona con las funcionen que tiene asignada en su labor dinamizadora, de motivación y seguimiento a las estudiantes.

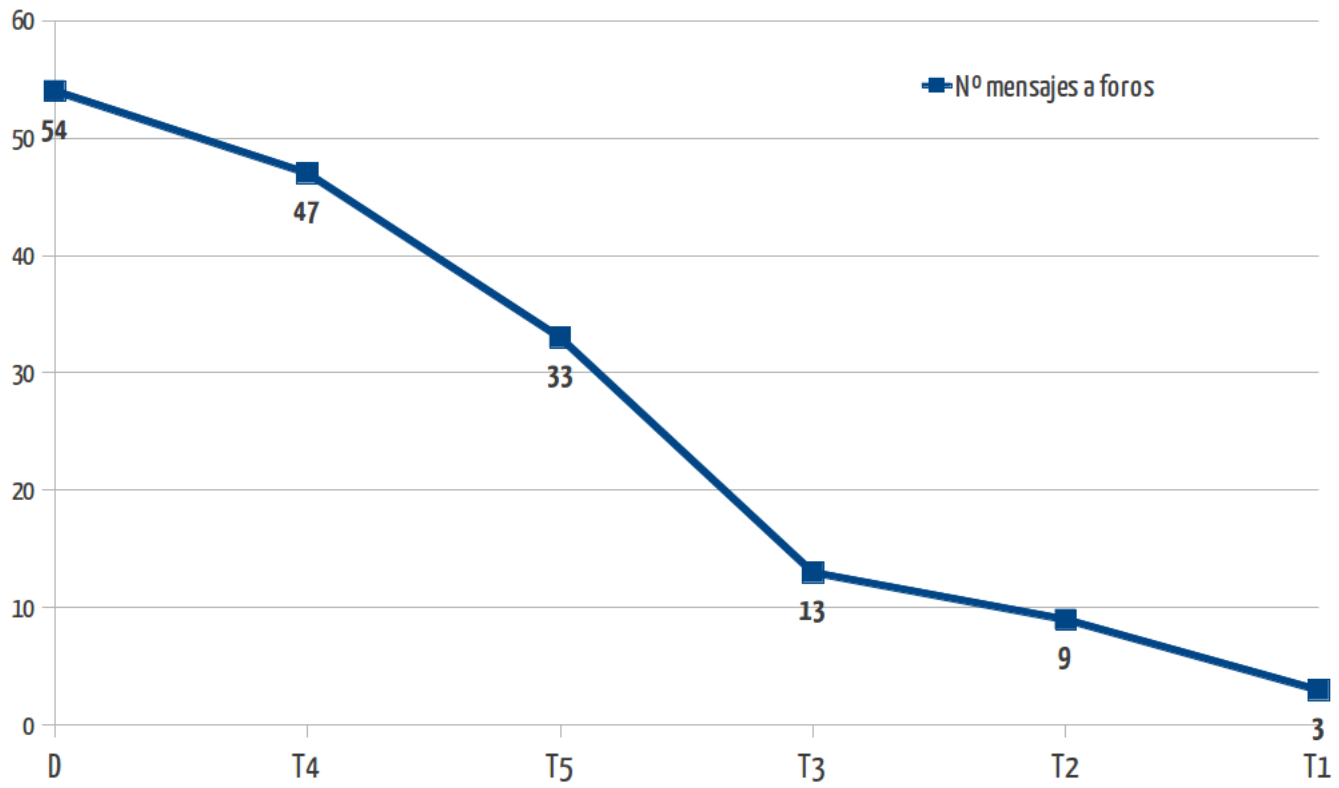

Gráfico 2. Participación de docentes en Foros.

Los datos ofrecidos corresponden a los y las docentes que han participado en la parte virtual del curso, que son un total de 5 , a la que se suma la participación de la dinamizadora del mismo.

Obteniendo una tabla con los datos de participación de las alumnas, observamos que la media de mensajes de las estudiantes han sido de entre 25 y 40, observando cinco estudiantes que tiene una participación más baja de lo estipulado en el compromiso de realización del curso, de las cuáles una no emite ningún mensaje, lo que quiere decir que no comienza la acción formativa. Una de las estudiantes despunta sobre las demás, con un total de 66 mensajes. 


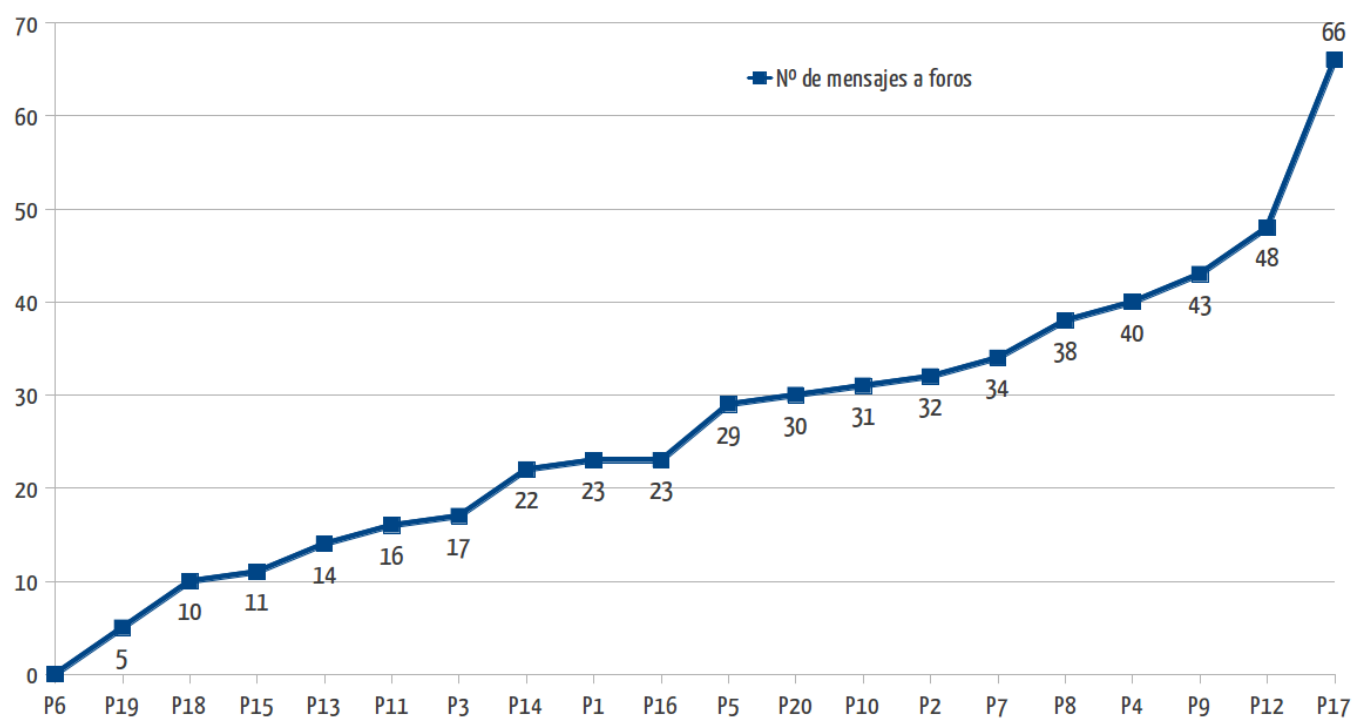

Gráfico 3. Participación de estudiantes en los Foros.

A continuación, se ofrece el análisis de contenido cualitativo de los foros estudiados. Éstos son un total de 5 foros, que agrupamos en tres, por la finalidad a la que se dirigen:

- Foro Entre Callis, dirigido a la comunicación entre las estudiantes, en el que se analizan 7 temas abiertos.

- Foro Social de Trabajo, destinado al debate y trabajo de las propuestas temáticas abordadas. En este caso se analizan 6 temas abiertos en un total de 3 Foros:

- Foro Social de Trabajo: Igualdad.

- Foro Social de Trabajo: Participación y Dinamización.

- Foro Social de Trabajo: Liderazgo. 
- Foro de Tutorías, destinado a resolver dudas y cuestiones relacionadas con las tareas y la plataforma. En este foro se analiza uno de los temas abiertos.

El Foro de Evaluación Continua, no se analiza desde este estudio, puesto que forma parte de la evaluación del curso y, por tanto, del tercer estudio que se presenta.

Por tanto el total de temas abiertos analizados es de 14, con 301 mensajes en total.

\subsubsection{Análisis de Foro «Entre Callis».}

\section{Datos Generales}

Identificación del Foro: Entre Callis

Participantes: Estudiantes

Temas analizados:

- $1^{\circ}$ Tema: Cambio del nombre del foro Comunitario/ Nuevo nombre del foro comunitario.

- $\quad 2^{\mathrm{O}}$ Tema: cintegrarse es perder parte de nuestros valores?.

- $\quad 3^{\mathrm{o}}$ Tema: Mujer gitana actual??.

- $4^{0}$ Tema: Marcha del curso.

- $5^{0}$ Tema: Qué piensas las mujeres de su gitaneidad.

- $6^{0}$ Tema: Loli de Cáceres está malita.

- $7^{0}$ Tema: Un Compromiso.

Total de mensajes analizados: 85 .

(Todos los mensajes son abiertos por las participantes)

Tabla 22. Datos Identificación Foro «Entre Callis»

Este Foro se crea con la finalidad de constituir un espacio libre para la comunicación entre las participantes, en el que pueden establecer sus propias informaciones, discusiones y debates y compartir experiencias. De manera inicial, y en relación con esa meta, consideramos que en este Foro los 
indicadores que encontremos van a referirse, en una parte muy importante, a las categorías de la Presencia Social, sin omitir la Presencia Cognitiva en alguna de las discusiones que se desarrollen y a la Presencia Docente en el rol que alguna de las participantes ejerza en este Foro. En este sentido, si nuestra pretensión era la construcción de una Comunidad de Práctica, mantener el grupo y su unión es fundamental para este fin, siendo la Presencia Social el máximo exponente de la consecución de esa Comunidad, además de para conseguir una experiencia educativa de calidad para las participantes (Garrison y Anderson, 2005).

Inicialmente, este Foro era denominado Comunitario pero fue cambiado de nombre a propuesta de las participantes, que abrieron un tema en este mismo Foro para el debate sobre el cambio de denominación y que analizaremos a continuación.

Dentro de este Foro se han seleccionado los temas relacionados con discusiones propuestas por las participantes, no considerando algunos temas abiertos con fines exclusivamente informativos, tipo:

«Hola a todas!!! os informo que este viernes dia 13 es el Taller presencial en mérida para ello hemos quedado en el mcdonals que hay en el foro a las 4 de la tarde. Creo que ya os han informado a todas pero por si acaso hay alguien que no hayan podido localizar pues aquí queda la información [...]»

Mensaje de P4

donde no son significativos o no aparecen los indicadores de Presencia Social, Cognitiva o Docente. 
10-. Tema Foro Entre Callis: «Cambio del nombre del foro comunitario» y «Nuevo nombre del foro comunitario»

En la primera sesión presencial destinada a la enseñanza del uso básico de la plataforma donde se va a desarrollar el curso, se presenta a las participantes el que se denominaba «Foro Comunitario», para compartir ideas, experiencias, novedades, etc. entre las participantes sin que ningún tutor, tutora o la dinamizadora participasen en el mismo. En ese momento una de las participantes propone que, ya que es un foro destinado a ese fin, cambiar de nombre por uno que ellas mismas decidan. Así la participante que promueve este cambio crea un tema inicial con una lluvia de ideas sobre el posible nombre del foro y un segundo tema en el que anuncia el nuevo nombre del mismo.

\section{$\underline{\text { a. Presencia Social }}$}

Observamos un número significativo de frases y palabras en las intervenciones relacionadas con los indicadores que muestra la dimensión social.

Comenzamos por la categoría de «afecto», en el que se detectan los indicadores de expresión de emociones en la totalidad de mensajes analizados. Este indicador se muestra mediante el uso de repeticiones y mayúsculas como símbolo de expresar una determinada emoción positiva, a la vez que aparecen expresiones coloquiales que manifiestan la definición de este indicador. Algunos ejemplos son los siguientes, comenzando por el mensaje de apertura del tema:

«CHICASSSSSSSSS!!!! vamos a pensar entre todas un nombre preciosisimo y ke nos guste a todas para nuestro foro... asi ke id proponiendo y empezamos a votar. Yo propongo: PODEROSAS ke os gusta???» 
En este mensaje aparece la expresión «CHICASSSSSSSSS!!!!», en mayúsculas, con repetición de la última consonante y del signo de admiración en un intento de llamar la atención a las demás participante, así como la palabra PODEROSAS y las últimas repeticiones del signo de interrogación final.

Este indicador también se destaca en los mensajes de algunas participantes, con el uso de emoticones. En el ejemplo se observa que «expande» este icono con la finalidad expresada anteriormente:

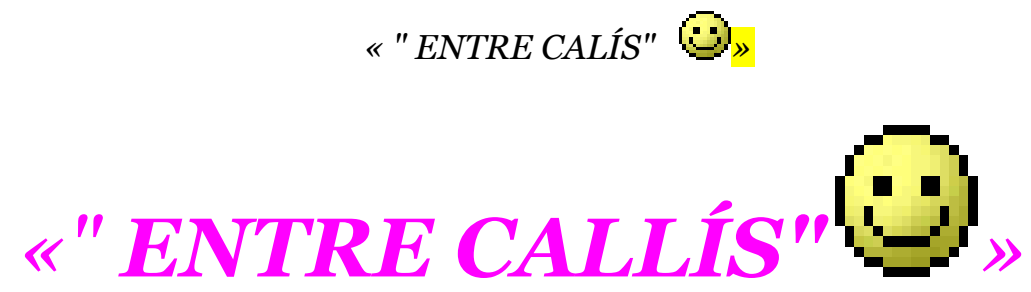

Fragmentos de mensajes de P4

Se pueden identificar dos intervenciones claras que recurren a las bromas, a la vez que expresan emociones mediante palabras de cariño para referirse a sus compañeras y expresiones en mayúsculas o repetitivas; ambas cuestiones son indicadores de la categoría «afecto»:

«hola a todas,yo estoy un poco de acuerdo con cada una es cierto $q$ esta muy visto lo de calo, romi, sastipen....ect pero $q$ nombres nos dicen mas q esos???? yo el orto dia estube viendo la tele el programa este de la 5 q se llama salvame y me recordo mucho a lo q hacemos la mayoria de nosotras y me gustaria ponerle al foro "VALGAME" ya $q$ nosotras lo vamos a utilizar para contarnos cosas y cotilleos iiii nose ya me direis me pido ser belen esteban........... iiiii jjajajajajajajajajajajajajajajajajajajajajiiii besitos para todasiii»

Mensaje de P2 
"pues vidas yo estoy deacuerdo com el de "entre callis" 'bsts »

$$
\text { Mensaje de } P_{3}
$$

«[...] el nuevo nombre del foro comunitario será... tachán, tachán....»

Fragmento de mensaje de $\mathrm{P} 4$

En algunas ocasiones hablan de sus vidas externas para apoyar la propuesta del nombre; es un indicador de expresión abierta dentro de la categoría «afecto».

Centrándonos en la categoría «comunicación abierta», todas siguen el hilo, empleando la respuesta correctamente. La expresión de acuerdo, indicador de esta categoría, se muestra en varios mensajes en referencia a la selección del nombre nuevo del foro, mostrando aceptación al que una de ellas propone, por ejemplo en los siguientes mensajes:

«Yo voto por el nombre de "entre callis", me gusta y me parece muy adecuado para este foro comunitario.....»

\section{Mensaje de P17}

"Yo voto por el nombre ke propone $M^{a}$ CArmen Vega "entre callis" me parece ke lo define muy bien »

\section{Mensaje de P4}

«ola chicas yo tambien voto por el nombre entre callis creo que lo define muy bien, un beso!!! »

\section{Mensaje de P8}

«hola soy kety denuevo e visto la propuesta de Loli-Calis avanzando $y$ me encanta»

Mensaje de $P_{5}$ 
En esta última intervención se observa una carga afectiva, mostrando aprecio con respecto al acuerdo con su compañera.

La «cohesión» es una categoría destacada apareciendo multitud de elementos fáticos y saludos, que expresan, a su vez, la inclusión de las participantes en el grupo. El siguiente mensaje es una muestra de inclusión en el mismo grupo étnico en relación al nombre que están poniendo en el grupo:

«Parece que el nombre entre callis" gusta más y la verdad es que somos todas gitanas. ¿Algún otro nombre?»

Mensaje de P2o

También aparecen calificativos positivos a modo de expresión de aprecio, en la categoría «comunicación abierta» en los saludos. Esto puede observarse claramente en ejemplos como: «CHICASSSSSSSSS!!!!», «hola atodas guapisimas!», «ola chicas», «Hola a todas», entre otras. En las despedidas, observamos también este indicador: «besos», «un beso!!!», «bsts», «besitos para todasiii», etc. Se observa también que, en varias ocasiones, se dirigen unas a otras por sus respectivos nombres, como se puede comprobar en los ejemplos de mensajes expuestos anteriomente.

\section{b. Presencia Cognitiva}

El primer mensaje que plantea la participante sugiere un nuevo tema en el que deben tomar una decisión consensuada: un nuevo nombre para el foro, a modo de «hecho desencadenante».

A partir de este momento comienza la «exploración de ideas»; éstas se basan sobre todo en intervenciones que recogen la aportación de cada participante sobre el nombre del Foro, algunas sugieren un nuevo nombre, llamando a la reconsideración del primero que se propone: 
«Como se comentó al principio de cambiar el nombre del foro propongo el siguiente título: "ENTRE CALLIS" ...que ante todo es lo que somos ¿no?»

Mensaje de P12

«me gusta "entre calis" pero no me convence, otras opciones podria ser "camelamos nakerar"»

\section{Mensaje de P18}

«'Poderosas' es muy significativo pero 'entre callís' me parece muy correcto»

Fragmento de mensaje de P16

La mayor parte de ellas muestra una convergencia con compañeras del grupo o con otros mensajes en un intento de «integración» de la idea propuesta. La primera que aparece es una convergencia con el primer mensaje, pero con idea de provisionalidad:

«A mí el nombre que le quieres dar me parece bien, ya que nos tenemos que sentir así, para poder ir realizando el cambio que estamos intentando en nuestra sociedad.

Yo voto por él, claro que todavía no he visto otras propuestas».

Fragmento de mensaje de P2O

«Yo creo que lo importante en esto no es el nombre del foro si no lo que nosotras consigamos asi que el nombre que le pongais me parecerá bien. Perooooooo yo propongo el de "nosotras contamos", mas que nada es por todo lo que tenemos que esforzarnos para que se nos escuche. lo dejo en vuestras manos».

Fragmento de mensaje de P1

A partir de la segunda propuesta de nombre, aparecen varias intervenciones seguidas que ya muestran el indicador de convergencia, que va integrando las opciones para llegar a un acuerdo, a modo de los siguientes: 
«Yo voto por el nombre de "entre callis", me gusta y me parece muy adecuado para este foro comunitario.....»

Mensaje de P17

«pues vidas yo estoy deacuerdo com el de "entre callis" 'bsts »

\section{Mensaje de P3}

«Parece que el nombre entre callis" gusta más y la verdad es que somos todas gitanas. ¿Algún otro nombre?»

Mensaje de P2o

Alguna plantea un pequeña discrepancia en la selección del nombre que, en principio, la mayoría parece votar:

«Hola a todas me gusta entre cllis, pero mas me gusta el $q$ ha dicho pauli camelamos nakerar.para q nuestra voz se escuche».

\section{Mensaje de P13}

"Hola a todas, oye le he estado dando vueltas y que os parece " Foro ExtreRomí". A mí me gusta, bueno pues ya me direís que os parece.Besos a todas»

\section{Mensaje de P7}

A esta segunda intervención le discrepan dos de las participantes, discrepancias que además muestran indicadores de la categoría «afecto», dentro de la dimensión social:

«No me mola, creo que el término ROMI está ya muy usado!!!! Lo siento mi niña, pero no me gusta. Besos»

\section{Mensaje de P17}

«[...] yo estoy un poco de acuerdo con cada una es cierto q esta muy visto lo de calo, romi ,sastipen....ect pero $q$ nombres nos dicen mas $q$ esos???? yo el orto dia estube viendo la tele el programa este de la $5 \mathrm{q}$ se llama salvame y me recordo mucho a lo q hacemos la mayoria de 
nosotras y me gustaria ponerle al foro "VALGAME" ya q nosotras lo vamos a utilizar para contarnos cosas y cotilleos iiii[...]»

Fragmento de mensaje de P2

Aparecen en el tema otras tres intervenciones que también discrepan del nombre más votado hasta el momento, proponiendo otro, en una nueva fase de «exploración», como en el ejemplo:

«Yo estoy entre poderosas y camelamos nakerar ya $q$ las dos $m$ parecen originales pero reo q tiro más $x$ camelamos nakerar»

Mensaje de P11

Sin embargo algunas participantes siguen apoyando la idea anterior, o incluso alguna apoya otro de los nombres propuestos, intentando una convergencia («integración»), como observamos en el fragmento siguiente:

«[...] como se suele decir mejor tarde que no nunca jejejeje. Viendo las propuestas de nombres para el foro comunitario me parecen muy bien los nombres propuestos sobretodo el de "entre callis" ( ¿se escribe así o "entre calis"?). Pero a mí me gusta también "CALIS AVANZANDO" ya que como toda mujer en esta sociedad estamos sufriendo cambios y avances al igual que el resto de personas, sin dejar de recordar que si tenemos dificultades por el hecho de ser mujeres tenemos que añadirle el de ser mujeres GITANAS ino creeis? nose es mi opinion y es por ello que me gustaria dejar claro que somos gitanas avanzando. Lo que salga esta bien por que las propuestas son buenas».

Fragmento del mensaje de P9

Aparece, por último, el mensaje en el que se anuncia el resultado de la discusión sobre el nuevo nombre del Foro, llegando a la fase de «resolución» basada en la convergencia anterior:

«[...] Bueno pues yo creo y por mayoria absoluta el nuevo nombre del foro comunitario será... tachán, tachán.... 


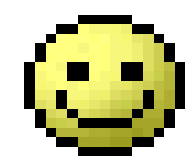

\section{Bueno chicas pues queda bautizado »}

Fragmento del mensaje de $P_{4}$

Sin embargo, una manifiesta una sugerencia en torno al nombre que inicia un nuevo «hecho desencadenante»:

«Hola a todas guapas. Me alegro que haya salido mi propuesta de nombre para el foro comunitario pero creo que se escribe "ENTRE CALLIS" no "ENTRE CALIS". Es lo que siempre he entendido como gitana en Romanó. (Si no preguntarselo a vuestros padres).»

Mensaje de P12

Una de las participantes apoya mediante acuerdo esta propuesta en dos intervenciones continuadas, saltando la fase de «exploración», situándose directamente en una fase de «integración». Mostramos como ejemplo el siguiente mensaje:

«Yo también creo que esentre callis, no entre calis, además suena mejorrrrrrrrrrr por favorrrrrrrrrrrrrr no pongais entre calis que es muy raro????? »

Mensaje de P17

En último lugar, aparece el mensaje de «resolución» final:

«[...] Lo siento por escribir el nombre del foro mal, lo rectifico...

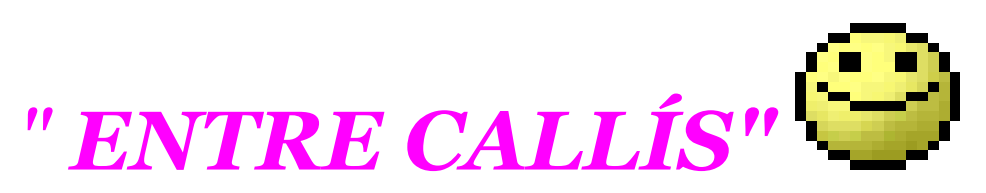

Ahora si no?? buenopos ya tenemos nuestro muevo nombre BIENNNN !!!!!!!!!!!!» 
Como se puede observar en los ejemplos, en la mayoría de los mensajes se integran indicadores relacionados con la Presencia Social analizada anteriormente.

\section{c. Presencia Docente}

En cuanto a la Presencia Docente, en este tema se destacan dos intervenciones que muestran indicadores de esta dimensión:

- Una de las participantes ejerce un rol docente en la apertura del foro planteando la cuestión a debatir, que podemos situar en el indicador «enseñanza directa» como presentación de una cuestión a resolver. Ella misma ejerce el rol durante el debate sin intervenir hasta el final, cuando muestra la resolución del debate. Lo hace, además, mostrando de manera constante, indicadores de Presencia Social, como se puede observar en su primer mensaje:

«CHICASSSSSSSSS!!!! vamos a pensar entre todas un nombre preciosisimo y ke nos guste a todas para nuestro foro... asi ke id proponiendo y empezamos a votar. Yo propongo: PODEROSAS ke os gusta???»

\section{Mensaje de P4}

- En un momento del debate algunas participantes asumen un rol de mediadoras, promoviendo la participación de las demás estudiantes, continuando el debate, solicitando la aportación de otro nombre, como en el fragmento del mensajes de P2O en el que pregunta: « (....) ¿Algún otro nombre?». 
20.-Tema Foro Entre Callis: «¿Integrarse es perder parte de nuestros valores?»

Una de las participantes abre un tema en este Foro a modo de pregunta. Mediante esa pregunta se observa Presencia Social con función de Presencia Docente, a través de la categoría «facilitación del discurso», intentando promover un análisis y debate de un tema entre las participantes.

«bien soy Kety me alegro muxo de xarlar de nuevo con vosotras es que he estado sin ordenador y no he podido

Pero os hare analizar de mi nuevo tema ya que yo me lo he preguntado a veces y he llegado a la coclusion de que si debemos de perder o se pierden cosas en el camino con la integracion

Os pido siempre disculpas por mis faltas de ortografia »

Mensaje de apertura de tema propuesto por $P_{5}$

\section{a. Presencia Social}

En este caso, encontramos algunas pistas visuales y de entonación mostradas a través del uso de emoticones y letras mayúsculas en la expresión, indicadores de la categoría «afecto», en mensajes como: «Ya estoy aquí!!!!! jajajja».

En dos de los mensajes se envían besos unas a otras, símbolo claramente afectivo en su significado: «...un besito guapa», «...un beso». También se destaca el uso de algunas expresiones como «Ea pus menos mal, porque el susto que me habías "pegao»...» «Ahí prima fini...», que se entienden como palabras de apoyo afectivo a la participante a la que se dirigen ${ }^{100}$.

100 Prima o primo es un nombre que utilizan las personas gitanas para denominarse entre ellas, en el reconocimiento a esa identidad gitana conjunta (Autor/a). 
Una de ellas utiliza el humor, mediante una frase popular para continuar con su opinión al debate establecido: «...he tenido algunas dificultades para poder incorporarme al curso, pero ya estoy aquí, toquemos maderaii». Otra, utiliza una expresión coloquial, del mismo modo, para explicarse sobre un calificativo que hace sobre las mujeres gitanas: «...la mujer gitana de hoy es luchadora, valiente y muy cabezona (de buen rollo)...».

Observamos otro indicador de la categoría «afecto», a través del emoticón que expresa «sonrisa» y de la entonación que pretende dar a su mensaje a través de signos de admiración, que a su vez expresa «cohesión» del grupo al dirigirse a una de sus compañeras para aclararla su acuerdo.

\section{«LAS PERSONAS NO TIENE QUE ELEGUIR INTEGRARSE O SER GITANO/A}

\section{PUEDEN SER AMBAS COSAS}

¿Coincido con Guadalupe en su opinión! 9 »

Fragmento del mensaje de P9

La unión que se va consiguiendo en el grupo, se observa en los saludos de las participantes: "me alegra mucho charlar de nuevo con vosotras...», «Hola muy buenas chicas», «Hola a todasiii», «Hola chicas», Hola a todas...».

Este indicador también se observa en otros mensajes de otras participantes en referencia al nombre de las compañeras: «Ahí prima fini...», «Hola Fini!!!» o como el siguiente mensaje:

«LOLI estoi de acuerdo con tigo SE PUEDE SER AMBAS COSAS.»

Fragmento de mensaje de P12

En varios mensajes se incluye el término «nosotras» o la referencia indirecta a ese término, para dirigirse a las personas que pertenecen al grupo 
de participantes en esa comunidad, asimilando la percepción de la misma por parte de varias de las destinatarias («cohesión» del grupo). Algunas de estas expresiones son:

«...los gitanos cuando nos integramos (y no sólo me refiero a la hora de la educación, sino de adaptarnos a la sociedad en general) es cierto que ya hemos perdido nuestros valores...»

«...no debemos quedarnos calladas!!!»,

«...ninguna de nosotras DESPRECIEMOS LO MEJOR...»

«...no es perder nuestra identidad como gitanos...»

«...la llave la tenemos nosotras...».

Fragmentos de mensajes de varias estudiantes

Estas muestras de afecto y cohesión del grupo, llevan consigo una interacción entre las participantes que establecen una «comunicación abierta». En este sentido observamos mensajes en los que aprecian las aportaciones de otras participantes: «...LOLI estoy de acuerdo contigo». Todas siguen el hilo de respuesta, utilizando de manera correcta la opción de respuesta a mensajes del foro.

También, en esta categoría observamos el cuestionamiento que una de las participantes hace de la aportación de otra, provocando que las demás participantes opinen sobre el tema propuesto ya que tiene que ver con sus vidas fuera de la acción formativa en la que participan y que es indicador, a su vez, de expresión abierta en la categoría «afecto».

«Primero me gustaria que me digas de lo mejor de nuestra cultura ¿ que has DESPRECIADO tú al estar estudiando? porque creo que tu reflexión te afecta a ti.No creo que ninguna de nosotras DESPRECIEMOS LO MEJOR DE NUESTRA CULTURA. Y para nada estoy de acuerdo con tu reflexión, me parece que los gitanos deberiamos seguir el ritmo de la sociedad y no quedarnos atrás y por 
ese motivo no perdemos nuestros valores mas preciados, ¿cuando tengas hijos que les vas a inculcar? ¿ no querrás que estudien?»

\title{
Mensaje de P4
}

\section{c. Presencia cognitiva}

Esta Presencia en el tema se destaca de manera evidente, como se analiza a continuación.

La categoría «hecho desencadenante», se muestra en dos ocasiones. Mostramos la primera que se produce a través del mensaje de apertura en el que la estudiante plantea un análisis de un problema:

\begin{abstract}
«[...] os hare analizar de mi nuevo tema ya que yo me lo he preguntado a veces y he llegado a la conclusion de que si debemos de perder o se pierden cosas en el camino con la integración [...]».
\end{abstract}

\section{Fragmento de mensaje de $P_{5}$}

Esta sugerencia de análisis provoca una reacción en las demás compañeras que comienzan a intercambiar información y dar sus opiniones iniciales sobre el problema planteado («exploración»).

Durante el intercambio de información ocurre un desacuerdo con una de las estudiantes que ha expresado su opinión y comienzan a pedirle explicaciones sobre la respuesta dada al tema: «Primero me gustaría que me digas de lo mejor de nuestra cultura, ¿qué has DESPRECIADO tú al estar estudiando?...». Seguidamente expresa divergencia (categoría «exploración») con la opinión de su compañera: «...Y para nada estoy de acuerdo con tu reflexión...» y sigue con un intercambio de información «...me parece que los gitanos deberíamos seguir el ritmo de la sociedad y no quedarnos atrás y por este motivo...». En este sentido le pide explicaciones sobre su mensaje a través de preguntas directas: «¿Cuándo tengas hijos que les vas a inculcar? ¿no querrás que estudien?» 
En la respuesta a la compañera en desacuerdo, la participante comienza y termina pidiendo perdón (volvemos a la Presencia Social, categoría «afecto»), para luego expresarse en mayúsculas y con una frase en la que cambia la fuente a «negrita», utilizando este modo de expresión como imperativo para que se entendiese su opinión:

"perdonar si me he expresado mal. PARA NADA PIENSO QUE

DESPRECIEMOS NUESTROS VALORES CUANDO NOS

INTEGRAMOS Y NOS ADAPTAMOS A LA SOCIEDAD!!!! SI NO NO

ESTARIA EN ESTE CURSO!!!! YO SOLO QUERIA EXPRESAR QUE

TENEMOS MUCHOS VALORES BONITOS Y QUE LO

APROVECHEMOS AL MISMO TIEMPO QUE ACOGEMOS VALORES

POSITIVOS DE LA SOCIEDAD PAYA!! COMO LA EDUACIÓN Y POR

SUPUESTO QUIERO QUE EL DIA DE MAÑANA MIS HIJOS

ESTUDIEN Y YO SE LO INCULCARE EN MI EDUCACIÓN!!!!

UN BESO Y LO SIENTO!!!»

Mensaje de P8

El contenido de este mensaje conlleva la fase de «integración» a través de un acuerdo (convergencia) con lo expresado con la compañera anterior. Otras estudiantes asumen el rol de mediadoras en el conflicto generado intentando llevar de nuevo al acuerdo entre las participantes, lo observamos en las siguientes expresiones:

«Yo pienso que ha habido un pequeño error, no?»

«Yo también pienso que ha sido una equivocación, pero como dice un refrán (el mejor escritor tiene un borrón), y ya ha rectificado».

Fragmentos de mensajes de estudiantes

Por último, derivada de esta fase de integración se produce la fase de «resolución», en la que las estudiantes consensúan el resultado, encontrando los puntos comunes de acuerdo. 
«No hay que perder nuestros valores por integranos en la sociedad,sólo hay que evolucionar,y cambiar un poco, si se pierden algunas cosas no son las más importantes».

Fragmento de mensaje de P2O

Incluso una de las estudiantes toma el conflicto producido como positivo para el debate grupal: «Yo creo que el error o el mal expresar de Fini nos ha dado un poco de vidilla...».

\section{c. Presencia Docente}

En este Foro no participa, como se apuntó con anterioridad, ningún tutor o tutora ni la persona que dinamiza el curso: es un espacio exclusivo para la comunicación de las estudiantes.

Se identifica que una de las estudiantes adopta el rol de docente, proponiendo a las demás un tema para el debate grupal. Esto puede ser considerado como el indicador referido a presentar cuestiones, dentro de la categoría «enseñanza directa».

A partir de ese primer planteamiento, varias estudiantes van adoptando un rol docente compartido, que permite identificar especialmente la categoría «facilitación del discurso» a través de algunos indicadores que hemos detectado en varios de los mensajes de esta línea temática.

Además del indicador antes comentado, en referencia a la participante que abre este tema para promover el debate entre las compañeras, vemos varios intentos por alcanzar un consenso ante el desacuerdo producido entre dos de las estudiantes:

«Yo pienso que ha habido un pequeño error , no?...».

«...la llave la tenemos nosotras ya que la mujer gitana de hoy es luchadora valiente y muy cabezona (de buen rollo) tenemos que educar a nuestros pequeños para el mañana, ellos serán quien se 
beneficien de nuestros pasitos ayudemos a que no se vean entorpecidos por roles ni estereotipos y por supuesto en educarles en igualdad ».

«...Los payos han ido dejando costumbres suyas atrás. Ellos también pedían la mano de una mujer, también estaba feo que una mujer fumara, las mujeres tenían limitaciones, muchas de las moras van dejando sus hábitos atrás... todos vamos cambiando...Está claro,que los gitanos vamos a paso muy lento,pero ahí vamos...».

Fragmento de mensajes de las estudiantes

Una de las estudiantes, reconoce que el mensaje de la compañera que provoca el desacuerdo, les ha generado una reacción y que, debido a ello se ha continuado el debate: «Yo creo que el error de Fini nos ha dado un poco de vidilla...».

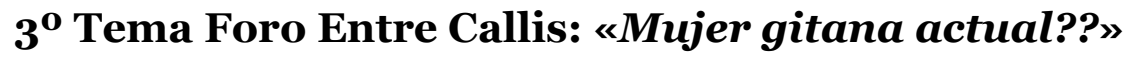

\section{$\underline{\text { a. Presencia Social }}$}

Comenzando con la categoría «afecto» se observa expresión de emociones, usando además elementos que desempeñan la función social de saludar y despedirse, indicadores de «cohesión»: «Hola a todas!!» que se repite tres veces en el conjunto de mensajes. O las despedidas como: «un mua grandote», «besos a todassssssssssssssssssssssss», en el que ambas categorías se explicitan, destacando una repetición continuada de caracteres en la expresión. Incluso en algunos casos, también se identifican cambio de colores en las fuentes.

El indicador «afecto» se repite incluso en el uso de calificativos positivos, dirigiéndose a la participante que abre el tema: «Mayte guapa». 
El uso del humor también se identifica en algunas expresiones como: «ole nosotras!!!jjaj», que a su vez muestra «cohesión» al incluir a todas con al pronombre «nosotras». En todos los mensajes se observa expresión abierta al referirse a temáticas relacionadas con su propias vidas.

En la categoría «comunicación abierta», podemos observar que se sigue el hilo de esta conversación, respondiendo al mensaje de apertura del tema y a la persona que lo abre. En ocasiones se hace referencia explícita al mensaje de otras compañeras, mostrando además acuerdo con sus intervenciones:

«[...]Estoy de acuerdo con Magdalena en que se confunde estos terminos, el temor de que "la niña se esta soltando mucho" o "esta niña es muy liberal demasiado se esta volvinedo paya"...[...]».

Fragmento de mensaje de P9

\section{$\underline{\text { b. Presencia Cognitiva }}$}

Observamos la categoría «Hecho desencadenante» en la intervención de la participante que realiza una pregunta intentando iniciar una nueva discusión:

«[...] En algunas respuestas de los foros se ha hablado de MUJER GITANA ACTUAL, pero qué entendemos por eso?? se acepta? se tienen 'prejuicios' o tenemos prejuicios (entre nosotras mismas incluso) ante lo que hemos denominada mujer gitana actual?? Tratemos esto y vamos viendo...»

Mensaje de apertura de $P_{5}$

La «exploración de ideas» se observa ya en el primer mensaje de respuesta, en el que se detecta, además, una divergencia con el tema del debate, sugiriendo una nueva idea para reconsiderar el problema inicial propuesto: 
«si somos cinceras las gitanas confundimos los terminos entre gitana actual y gitana liveral uno es una cosa y lo otro es otra,para mi una gitana actual es una mujer q esta prepara para cualquier puesto de trabajo q es capaz de hablar con cualquier persona q tiene suficiente capacidad como para desembolverse muy bien en la vida.»

Mensaje de P13

Esto sucede en casi todos los mensajes, en el que las estudiantes dan su propia versión sobre el problema:

"parami gitana actual es las que luchan por intregase en lasocidad que se adadta a los nuevostienpos.que se propone metas ylas con sigen. parami no es igual gitana liveral que astual »

«la mujer gitana actual es una mujer en proceso de concienciación y una mujer en avanze, sin embargo debido a los prejuicios y los obstáculos que nos ponemos las unas a las otras es muy difícil, te critican por ser una mujer actual [...]»

«[...] PARA MI MUJER GITANA ACTUAL SON TRES PALABRAS Q VAN DE LA MANO HACIA EL CAMINO DE LA INCORPORACION (no de la integracion) LA MUJER GITANA ACTUAL ESTA FORMADA Y PREPARADA PARA "LA BATTALLA" SOCIAL"

«Bueno pues para mi una mujer gitana actual es :Una mujer que viva SIN MIEDOS, si pensamos lo único que nos para y no nos deja avanzar como nosotras queremos es el miedo. Miedo a dejar de ser más ó menos gitana, miedo a estar mal vista, miedo a que hablen de nosotras.... [...]»

Fragmentos de mensajes de varias estudiantes

Por otro lado la tercera fase «integración», se muestra en un sólo mensaje que recoge la divergencia con la idea inicial, mostrando a su vez convergencia con otras ideas argumentada, ayudando a la resolución/construcción de la idea final: 
«[...] Entiendo por mujer actual a una mujer formada, desenvuelta, con ganas de superación, .... a una mujer capacitada y al nivel de la sociedad de hoy en día. Que el hecho de ser gitana no te quita para que puedas desenvolverte y valerte por una misma. (al igual que ha comentado Devora o Magdalena) [...] Son miedos que tienen y esos miedos hacen que alguna smujeres nno avancen o nueestro pueblo aun sufra un "atraso" con respecto a la sociedad mayoritaria».

Fragmento de mensaje de P9

No se llega a la fase reconocida de «resolución», observamos una falta, en este sentido, del rol docente que guía y orienta para que el grupo llegue a esta última fase.

\section{c. Presencia Docente}

Detectamos esta dimensión a través del mensaje de la participante que toma la iniciativa, aunque se debe destacar que la Presencia Docente es prácticamente inexistente en esta línea temática del Foro Entre Callis. En esta dimensión, se observa un planteamiento del tema en forma de pregunta («enseñanza directa»), intentando promover la participación de las demás compañeras en la discusión, indicador de «facilitación del discurso»:

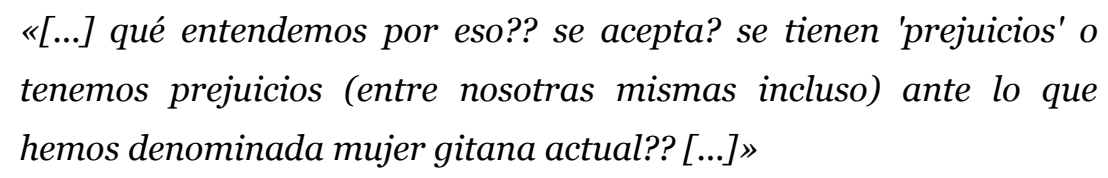

Fragmento de mensaje de $P_{5}$

Aunque todas las que participan responden a la pregunta inicial planteando sus ideas, no encontramos referencia a otras categorías e indicadores de esta dimensión. 


\section{$4^{\circ}$ - Tema Foro Entre Callis: «Marcha del curso»}

\section{a. Presencia Social}

Las categorías referentes a la Dimensión Social son las más acentuadas en este tema como veremos a continuación.

En la categoría «afecto» se observan un número sustantivo de fragmentos de mensajes en el que se detectan indicadores de esta categoría. Mostramos ejemplos como el siguiente, donde observamos una repetición de caracteres y signos de admiración:

«[...] Yoli tu tranquila tia, ke no es complicado y seguro ke no tardas en ponerte las pilas, es solo cogerle el truquillo, pero de verdad ke no es nada complicado... Esto tiene ke salir ehhhhhhhhhhhh!!!!!! [...].»

\section{Fragmento de mensaje de $\mathrm{P} 4$}

Encontramos constantes recurrencias al humor/bromas, que va generando un buen ambiente, observándose que tras la expresión de la primera broma, varias estudiantes se animan a recurrir a ellas.

«Si, mucho, creo que esto e hacer cursos virtuales e s uy moderno para nosotras. .ajajajjaja(es broma), me parece muyn bien porque vamos a aprender mucho, me molaaaaaaaaaa Saludos!!!!»

\section{Mensaje de P17}

«Hola ¿¿¿¿qtal todas???’ Yoli que te quejas mucho y luego te sale todo jajajajja, vas a ver la mejor curso.[...] ¿Que se nos va a resistir a un grupo de gitanas tan listas y emprendedoras? $\underline{\text { Nada jajajajaja }}$ nosotras podemos $[\ldots]$ »

\section{Fragmento de mensaje de P9}

«Hola, yo no he podido entrar hasta hoy por problemas técnicos como en la tele jajajaj.»

Mensaje de P12 
Se observa, igualmente, expresión abierta en muchos mensajes en los que hacen referencia a aspectos de sus vidas privadas.

La categoría «comunicación abierta» aparece en varios indicadores que se identifican en los mensajes de las estudiantes donde, además de expresar sus sentimientos, animan y felicitan a las demás compañeras:

«[...] Pues yo el otro día tenía una mezcla de sensaciones: alegría, nerviosismo, preocupación, satisfacción...[...]. »

Fragmento de mensaje de P16.

«Hola a todas yo es la primera vez $q$ entro aki y estais todas $q$ bieniiii ya se donde encontraros jajajajajajaiii bueno un besito a todas y perdonarme por q no me e conectado mucho esta semana pasada pero bueno hoy llebo ya un buen rato y boy a mejor me voy entendiendo mas con el ordenadoriii besitos y muchas fuerzas $y$ ganas para todas tenemos que continuar.........iiii . »

Mensaje de P2

En la categoría «cohesión», se observa como se dirigen unas a otras por sus nombres, se envían besos en las despedidas e incluyen el término «todas» como parte ya de un grupo que se va formando: Esta es mi Yoli... abriendo tema...», «[...] `besitos a todas vidas», «Chicas soy yo, he vuelto.»

También se observan varios indicadores que muestran ayudas de unas a otras, como en el siguiente fragmento: «[...] Pasate si kieres por la FSG y vemos algo , besos a todas»

\section{$\underline{\text { b. Presencia Cognitiva }}$}

La categoría «hecho desencadenante» se genera por la intervención de una de participante que introduce, como ella misma afirma, un nuevo tema de discusión relacionado con el comienzo de la acción formativa. 
«[...] Voy a introducir un nuevo tema: El comienzo del Curso. ¿Que tal habeis comenzado? yo solo me puedo conectar por la noche cuando mis peques se duermen. Estoy un poco oxidada, espero ponerme las pilas y que me cueste menos. ¿Os parece complicado el comeinzo?»

Mensaje de P2O

En la fase de «exploración de ideas», cada una de las estudiantes va estableciendo una respuesta a la pregunta de la compañera, como observamos en los siguientes ejemplos:

«a mi me encanta, creo que para nada es dificil aunque eso depende del manejo de cada una con internet, por ejemplo mi madre tiene problemas para entrar y no le puedo ayudar porque yo estoy en caceres y ella en zafra!!»

\section{Mensaje de P8}

«Bueno ayer por la tarde nos reunimos todas las mujeres de Badajoz para realizar el curso desde la fundación, ya que algunas de ellas no tienen ordenador en casa, y fué imposible acceder, toda la tarde dando error y al final no pudimos [...]»

Fragmento de mensaje de $\mathrm{P}_{4}$

«[...] Decir q me acostado un poco entrar ya $q$ es un poco lioso pero vamos que es como todo lo nuevo, hasta q una le coge el hilo $y$ weno $x$ lo menos sabemos q contamos con la ayuda d todas y d Rosa claro»

Fragmento de mensajes de P11

«yo a dia de hoy es y no entiendo muy bien esto pero bueno se va sacando poco apoco,lo q si me parece muy interesante»

Mensaje de P13

En esta línea temática las estudiantes se quedan en esta fase, sin llegar a desarrollar las dos fases siguientes. 


\section{c. Presencia Docente}

Esta dimensión se observa en sólo un planteamiento del debate en forma de pregunta por parte de una estudiante («Enseñanza directa»), intentando promover la participación de las demás compañeras en la discusión, indicador de «Facilitación del discurso», mediante el mensaje inicial de apertura. No se observan más indicadores de esta presencia en este tema.

50.- Tema Foro Entre Callis: «QUÉ PIENSAS LAS MUJERES DE SU GITANEIDAD»

\section{a. Presencia Social}

Se observan indicadores de la categoría «afecto» en el uso de mayúsculas con el fin de llamar la atención de lo que se intenta comentar. También se identifican repetición de caracteres para expresar risas, y otras expresiones coloquiales, recurriendo al humor en varios fragmentos, como los siguientes:

«[...] La cabra por mucho que no quiera siempre tira al monte jajajaj $[\ldots] »$

Fragmento de mensaje de P9

«[...] Yo pienso mucho en todas estas cosas, hasta llega a dolerme mucho la cabeza creerme...jajaja.[...]»

Fragmento de mensaje de P7

«estoy con Yoli por qu eyo tambien saco siempre un 1o jajajjajja»

Fragmento de mensaje de $\mathrm{P9}$ 
En este último mensajes se detectan otros indicadores como el dirigirse a una participante por su nombre, dentro de la categoría «cohesión» y expresión de acuerdo en la categoría «comunicación abierta».

En casi todos los mensajes, se observa expresión abierta, haciendo referencia a sentimientos en sus vidas fuera del curso:

«[...] aunque tengo que reconocerlo: a veces devido a las dificultades del medio que me rodeaba y me rodea pienso que seria mi vida si no fuera gitana y me gustaria exprimentarlo por unos dias. [...]»

Fragmento de mensaje de P9

«[...] Oye seguiremos reflexionando que hoy estoy un pelín melancolica, besos a todas»

Fragmento de mensaje de P7

Todas siguen el hilo de la conversación, indicador de «comunicación abierta», utilizando correctamente el símbolo de respuesta del foro.

El indicador de «cohesión» que más frecuencia tiene es dirigirse al grupo usando pronombres inclusivos, como puede observarse, a modo de ejemplo, en el siguiente mensaje:

«Yo creo que por suerte o por desgracia los gitanos y gitanas actualmente estamos continuamente reforzando nuestra identidad [...] y lo que nos pasa [...] necesitamos tener señas de identidad que nos unan; una parte de los gitanos, estamos reforzandonos así, hablando, reflexionando, uniendonos en torno a distintos temas[...]»

\section{Fragmento de mensaje de P7}

Aparece también, de manera constante, referencia a los nombres de otras compañeras y saludos y despedidas cargadas de comunicación afectiva. 


\section{b. Presencia Cognitiva}

En este tema se detectan varios indicadores de «hecho desencadenante», que se producen en momentos diferentes del tema.

El primero se refiere a la propuesta de una estudiante, que abre el tema con una pregunta:

«no se si creeis es que pudiera aver un medidor de gitaneria como aveces nos hacen pensar que nos miden ipero realmente que significa ser gitano,acaso esto es algo que puedas levantarte una mañana y quitartelo.-o ponertelo? decirme si deseais contestar ¿nos pueden hacer dudar de nuestros valores por hacer cierts cambios $y$ abiendo nacido de padre-s gitanos?»

\section{Mensaje de $P_{5}$}

A partir de esa pregunta, varios mensajes refieren el indicador «exploración», seguido de «integración», ya que casi todas las respuestas dan ideas exploratorias y tras ellas, explicaciones al respecto de la pregunta. Puede observarse en fragmentos como el que presentamos:

«Kety nosotras le llamamos " El Gitanómetro" y a veces muchos gitanos /as nos lo pasan a diario, pero yo no me preocupo porque siempre saco $10 .[\ldots]$ »

\section{Fragmento de mensaje de P9}

«Yo creo que eso no es una cosa que se pueda quitar o poner y el que luche por que evolucionemos no significa que no me guste ser gitana $y$ es verdad que siempre no estan cuestionando pero estoy muy orgullosa de lo que tengo y de lo que soy por lo tanto aunque se pudiese quitar o poner nunca me lo quitaria.ser GITANA es mi mayor orgullo»

Mensaje de P1 
La fase «integración» aparece más directamente en algunos mensajes posteriores, donde hay una reflexión más intensa con un discurso más crítico y en el que se implican un mayor número de estudiantes:

«creo que existe en la mente de los gitanos y está continuamente en alerta con un intento continuo de demostrar su gitanidad con palabras como aiotebe!!! Lo hacen inconscientemente para reforzar su identidad»

\section{Mensaje de P8}

«Yo creo que por suerte o por desgracia los gitanos y gitanas actualmente estamos continuamente reforzando nuestra identidad con distintos comportamientos o actitudes, y lo que nos pasa es que nuestra identidad como la de cualquier otro individuo va cambiando, adaptándose a las circunstancias . Yo pienso mucho en todas estas cosas,hasta llega a dolerme mucho la cabeza creerme...jajaja. Pero en realidad es que al estar en un momento fuerte de transformación necesitamos tener señas de identidad que nos unan ; una parte de los gitanos, estamos reforzandonos así, hablando , reflexionando, uniendonos en torno a distintos temas ; otros que son los que más preocupan, la refuerzan como pueden ..asimilando cosas que no son gitanas con ser gitanos.. en fin creo que entendeis lo que digo verdad?Oye seguiremos reflexionando que hoy estoy un pelín melancolica, besos a todas»

Mensaje de P7

No se llega a la fase de «resolución» del tema, quedándose en la fase de «integración». Creemos que hubiera sido necesaria una presencia docente más intensiva en este sentido. 


\section{0.- Tema Foro Entre Callis: «Loli de cáceres está malita»}

En este tema sólo se establecen indicadores referentes a la_Presencia Social.

Una de las estudiantes propone, a consecuencia de que una de las compañeras se ha puesto enferma, darle ánimos a través de la apertura de una línea temática, abierta expresamente para esa finalidad:

«Hola a todas!!!! Vamos a darle mucho ánimo a nuestra primita "la Loli" de Cáceres que se ha roto el pie y pobrecita eso duele mucho gitanita...

Mensaje de P9

En todas las intervenciones encontramos la categoría «afecto», a través del uso de emoticones, repetición de caracteres, como en expresiones: «Ayyyyy mi Loly!!», «Muuuuuaaakk!@».

Y uso del humor conjuntamente con el indicador anterior, en casi todas las intervenciones, como mostramos en la siguiente conversación breve mantenida entre dos estudiantes:

«jajajaja ya ves no nos libramos ninguna trabajadora de la fsg de tener el pie al menos escayolado jejejejeje $\hat{\Theta}^{\mathrm{y}}$ y bueno no es que lo lleve muy bueno es lo que me ha tocado y hay que tirar palante!! jajajjaja estare por aqui siempre que pueda $\bigodot_{\text {» }}$

\section{Mensaje de P9}

«hola loli eso te pasa por ponerte tantos tacones altos asi que cuando nos veamos no vas ha ser tan buena moza iasi que los tacones altos esta vez me los pndre yo!, es broma pon te buena un beso»

Mensaje de P15.

«Y no llevaba tacones, si si estaba con planas tia jajajaja 
pero habe cuando una cosa esta de pasar pues pasa jejejeje y nada gracias nos vemos! bsst iiiLOS TACONES ME LOS PONDRE JAJAJAJAJA!»

Mensaje de P9

Los saludos y despedidas, indicadores de «Cohesión», llevan también una carga afectiva como se observa en las expresiones siguientes: «Muchos ánimos y paciencia», «[...] Gracias wapisima jajajaja $९$ » «Un beso muy gordo». Todos los mensaje que se dirigen a la participante que está enferma, llevan calificativos positivos:

«[...] guapa, que dirás que hay que ver que no me acuerdo de ti, pero no es eso, es que he tenido a la niña mala y no me he podido conectar mucho. Bueno ten paciencia con lo del pie y ahora déjate mimar[...]»

Fragmento de mensaje de P2o

\section{$7^{0}$.- Tema Foro Entre Callis: «UN COMPROMISO».}

Una de las estudiantes abre el último tema en la semana anterior a la finalización de la acción formativa: Un Compromiso, que analizamos a continuación.

\section{a. Presencia Social}

En el mensaje inicial encontramos ya varios ejemplos claros de Presencia Social, mucho más acentuados que en los temas anteriores:

\footnotetext{
«Hola chicas!! Mirad, lo he puesto en otro lugar, pero quería abrirlo como un tema y que todas dijéramos algo. Todo lo que estamos compartiendo, aprendiendo, avanzando, descubriendo... todo, todo esto no se puede quedar para nosotras solas. NO! tenemos que poner en práctica lo que hemos aprendido del liderazgo moral, y ponernos al servicio de nuestras mujeres y de nuestra comunidad, para
} 
conseguir un fin común, el desarrollo de nuestro pueblo. Para ello, os recuerdo: EFECTO MULTIPLICADOR!! lo recordáis?? que cada una de nosotras seamos capaces de mover a otro tanto de mujeres, motivarlas, acompañarlas, contar con su opinión, enseñarlas... Imaginaros, si somos 20 y somos capaces de mover cada una a 2 mujeres, quiere decir que seremos 40, si mas tardes, ellas a su vez mueven a otras 2, seremos $80 . .$. y así sucesivamente. Imaginaros si multiplicamos por 3, por 4, por 5... Si aceptáis este compromiso, por favor, entrad y escribid algo. Gracias a todas! De todas vosotras he aprendido algo. Besos»

Mensaje de apertura de tema propuesto por P16

La categoría de «afecto» encontramos varias ocasiones de utilización de puntuación repetitiva con uso de mayúsculas («EFECTO MULTIPLICADOR!! lo recordáis??» «NO!») que denotan una expresión de emoción ante lo que la participante quiere expresar. También repite palabras («...todo, todo esto...»). Otras dos estudiantes expresan, con emoticones y palabras en mayúsculas, su sonrisa y aceptación ante el acuerdo con las palabras expresadas por sus compañeras:

$$
\text { «A MULTIPLICARNOSSSS CHICAS!!!!!!». }
$$

\section{Mensaje de P8}

$$
\begin{aligned}
& \text { «Buenas Mayte } \Theta \text { bueno por mi parte me comprometo a practicar y } \\
& \text { esforzarme aun mas en el efecto MULTIPLICADOR [...] pensar en las } \\
& \text { aceptaciones qu evamos a conseguir } \Theta \text { » }
\end{aligned}
$$

Fragmento de mensaje de una de P9

Alguna otra utiliza repetición del signo de admiración: «...en todo lo que quierasiii». Una de las estudiantes recurre al humor en su expresión, como observamos en su mensaje: 
«Me parece genial tu idea,sería muy interesante que ésto lo hicieran más gitanas. Estoy segura que tendria diversas consecuencias... jejeje $[\ldots] »$

Fragmento de mensaje de P10

En referencia al «afecto» advertimos que se expresa abiertamente la posibilidad de utilización de lo aprendido en sus vidas fuera de la acción formativa:

\begin{abstract}
«[...] tenemos que poner en práctica lo que hemos aprendido del liderazgo moral, y ponernos al servicio de nuestras mujeres y de nuestra comunidad, para conseguir un fin común, el desarrollo de nuestro pueblo».
\end{abstract}

Fragmento de mensaje de P16

Esta expresión refleja un sentimiento intenso de «cohesión» del grupo, cuando incluye a todas en: «nuestras mujeres» «nuestra comunidad» «nuestro pueblo». Observamos también, elementos fáticos y saludos en todos los mensajes de este tema, sobre todo destacamos las despedidas a las que se refieren con «Besos» «UN BESO» «Un beso» «Besitos a todas», que a su vez muestra en aprecio («comunicación abierta») creado entre las estudiantes.

«Cohesión» también se denota en expresiones como «...todas dijéramos algo». Incluso finaliza el mensaje con agradecimiento generalizado a todas las estudiantes: «Gracias a todas!. De todas vosotras he aprendido algo», que también puede considerarse como una expresión de aprecio («comunicación abierta») a las demás compañeras. En los demás mensajes que responden al primero se evidencia que siguen el hilo del mismo. Puede observarse este hecho, inicialmente, en la generalidad de todos los mensajes que saludan a la participante que escribió el primero, dirigiéndose a ella para responder a su tema: «Hola Mayte» «Hola MAITE» «Buenas Mayte ;-)» «Hola prima Mayte», etc.; en otros como «...a ese fin 
último que comentas, Mayte, el desarrollo de nuestro pueblo». Eso refleja la cohesión y vínculo entre las estudiantes, además, el vocativo dirigiéndose directamente a la participante por su nombre.

Estos mensajes se acompañan por expresar acuerdo con la propuesta de la compañera: «...estoy contigo en esto de multiplicar...» «... Cuenta conmigo y con las que yo multiplique...» «Me parece perfecto y ójala lo consigamos, TODAS...» «Me parece genial tu idea...» «Yo también haré lo que esté en mi mano...».

\section{b. Presencia Cognitiva}

Se advierte esta presencia, comenzando por la primera fase en la categoría «Hecho desencadenante», que comienza con la propuesta de una de las estudiantes de afianzar un compromiso, como se ha mostrado anteriormente en el mensaje de apertura del tema del foro. En este mensaje se identifica, además de la propuesta que desencadena las respuestas de las demás estudiantes, una conexión de ideas con lo aprendido anteriormente: «...tenemos que poner en práctica lo que hemos aprendido del liderazgo moral, y ponernos al servicio de nuestras mujeres...».

En este caso se produce un salto de esta fase inicial a la «integración/construcción» e incluso a la «resolución». Todas expresan acuerdo con la propuesta y siguen la propia reflexión en torno a la misma, como mostramos en los siguientes fragmentos:

«[...]me parece oportuna tu propuesta.a mayor mujeres mayor poder jejeje es interesante transmitir todos esos conocimientos que estamo a prendiendo para poder concierciar y sensibilizar a mujeres de nuestro en torno $[\ldots] »$

Fragmento de mensaje de P12 
«[...] Me parece genial tu idea,sería muy interesante que ésto lo hicieran más gitanas. Estoy segura de que tendria diversas consecuencias... [...]»

Fragmento de mensaje de P1O

«[...] bueno por mi parte me comprometo a practicar y esforzarme aun mas en el efecto MULTIPLICADOR. La realidad es que es un metodo muy efectivo y con muy bueno resultados ya que creo que nadie ni nada mejor que las propias gitanas para dar ejemplo $y$ «arrastrar» de cierto modo a mujeres a ese fin común que comentas Mayte, el desarrollo de nuestro pueblo [...]»

Fragmento de mensaje de P9

\section{c. Presencia Docente}

$\mathrm{Al}$ ser un Foro exclusivo de las estudiantes observamos pocos indicadores de esta dimensión didáctica. Encontramos algunos sobre todo referidos a la adquisición del rol «docente» por parte de la estudiante que abre el tema.

Identificamos un planteamiento a nivel macro del tema, situándonos en primer lugar en la categoría «diseño educativo y organización», propuesto en el mensaje inicial de apertura, que también contiene, como hemos visto, indicadores de las dos dimensiones anteriores. La estudiante plantea un compromiso sobre los temas estudiados con anterioridad, concretamente con la última propuesta temática referida al liderazgo social. Por otro lado, en este mismo mensaje se observa gestión de la información intentando establecer un determinado orden en el discurso, a fin de mantener la atención y participación activa de las demás estudiantes: para ello presenta la cuestión (la propuesta de un «compromiso») y centra el debate en ese tema, siendo reflejo de la categoría «enseñanza directa». Por último, se destaca el final de la aportación de esta estudiante con: «[...] Si aceptáis este compromiso, por favor, entrad y escribid algo», pretendiendo 
que las estudiantes participen en el tema abierto indicador de la categoría «Facilitar el discurso».

No se observan otros indicadores de esta dimensión en esta línea temática.

\subsubsection{Análisis de los Foro Sociales de Trabajo.}

Los Foros denominados «Foro Social de Trabajo» constituyen los dedicados al trabajo virtual sobre las propuestas temáticas del curso, estando dirigidos por un tutor o tutora. Estos foros se crean con la finalidad de trabajar, de manera conjunta, los temas por parte de las estudiantes y las personas tutoras del curso basándose en actividades cooperativas que promuevan la colaboración, el debate, la discusión y el intercambio de ideas. Todo con el fin último de construir, entre todas, las propuestas resolutivas y por tanto, el conocimiento nuevo que se genera en estos procesos.

En este caso, la Presencia Cognitiva y la Docente son tan fundamentales como la Social para la constitución de la Comunidad de Práctica. Así, vamos a proceder al análisis de las tres presencias tomando como referencia las tres líneas temáticas de este Foro: dos de ellas abiertos por la tutora de la propuesta temática y una que, libremente, abre una participante tomando la iniciativa. 


\section{A. Análisis del Foro Social de Trabajo: Igualdad.}

\section{Datos Generales}

Identificación del Foro: Foro Social de Trabajo: Igualdad.

Participantes: Tutora 3 (T3), Tutora 4 (T4) y Estudiantes.

Temas analizados:

- $\quad 1^{\mathrm{o}} \dot{\mathrm{CS}} \mathrm{Somos}$ iguales? (Abierto por Tutora)

- $\quad 2^{\circ}$ Empoderamiento (Abierto por Tutora)

- $\quad 3^{\mathrm{o}}$ Fomentan algunas mujeres el machismo (Abierto por Participante de manera voluntaria)

Total de mensajes analizados: 109

Tabla 23. Datos generales del Foro Social de Trabajo: Igualdad.

\section{0.-Tema del Foro Social de Trabajo Igualdad: «íSomos iguales?»}

\section{a. Presencia Social}

Situándonos en la categoría «afecto» en el indicador expresión de emociones, identificamos la presencia de éste en varios mensajes, en su mayor parte de las estudiantes, que utilizan la repetición de signos de puntuación o de caracteres, cambio de colores de palabras o frases, entrecomillado de expresiones, emoticones y utilización de mayúsculas para llamar la atención de alguna palabra. Como ejemplo, mostramos algunos de estos fragmentos, entre muchos que aparecen:

«Primitaaaaaaaaaaaa [...] y tenemos que aceptaro así!!!!»

"Ultimamente nos pasamos el dia diciendo:"aquí igualdad", sobre todo las mujeres que somos tan reivindicativas!!!!!!!!! [...] hacer que "nuestra vida sea nuestra" y poder disfrutar [...] ya los cromosomas son distintos, por lo tanto algunas diferencias deben existir no???? sino, que sería la vida????» 
«[...] se busca es conseguir la plena LIBERTAD del ser humano [...].

NO, ni física ni emocionalmente [...]»

«[...] pero áun nos queda una largo camino, así que iiiÁNIMO!!!»

«[...] las mujeres somos diversa y heterogéneas y LAS MUJERES

GITANAS TAMBIÉN (lo ponga en mayúsculas porque la sociedad mayoritaria suele tener un concepto preconcebido sobre nosotras, piensa que somos todas iguales) [...]»

«[...] Yo creo que si $\Theta^{9}[\ldots] »$, «iiMuy buenas!! 9

Fragmentos de mensajes de estudiantes

En este tema encontramos sólo una recurrencia al humor explícita, quizá porque es el primer debate del foro de trabajo y está comenzando a configurarse el grupo:

«[...] Sería bueno ya que aprenderíamos mas unas de otras. (observando se aprende!!! Jajaja) [...] $><$

«[...] Son diferentes, para mí ni uno ni otro son mejores o peores xicas!!! Estamos hablando de igualdad!! JAJAJAJ [...]»

Fragmentos de mensaje de P9

En algunos mensajes, esta vez en menos que en otros temas dentro de esta misma categoría, encontramos expresión abierta mediante la presentación de detalles de sus vidas, puesto que la reflexión propuesta por la docente, exige que éstas apliquen los conceptos y conocimientos a sus vidas cotidianas.

Si hacemos referencia a la «comunicación abierta», en primer lugar, se emplea correctamente el signo de respuesta al mensaje general, bien para realizar una reflexión general o bien para responder a la compañera correspondiente si se quiere mostrar acuerdo, desacuerdo o reflexión sobre la aportación de la participante en cuestión. En este sentido se contesta en 
varias ocasiones a mensajes de otras compañeras, estableciendo escalones de respuesta.

La categoría «cohesión» también se destaca en indicadores como uso de vocativos para referirse a los nombres de las estudiantes, sobre todo por parte de la docente. Por otro lado sí que se identifican algunos pronombres inclusivos, aún en pequeña medida, refriéndose a la totalidad de las estudiantes como grupo: «Buenas tardes a todas![...]» «[...] el texto me pareció bastante complicado para algunas de las compañeras [...]», «[...] El concepto de igualdad es muy diferente para cada una de nosotras, depende mucho del ambiente que nos rodea, de la cultura, de la educación, de la experiencias, etc...[...]», "[...] Creo que cada persona tiene cosas positivas y también negativas, así que vamos a seguir sacando lo mejor de nosotras $[\ldots] »$.

Los elementos fáticos y saludos se encuentran en todos los mensajes, con relación expresa a la categoría «afecto»: «hola a todasiii», Primitaaaaaaaaaaaa, «Buenas a todas [...]» «[...] besos a todas», «Hola de nuevo!!!!!!!!!», «hola chicas!!!!!!», «Un saludo», «Saludos».

\section{b. Presencia Cognitiva}

Comenzando por la categoría «hecho desencadenante», la línea temática se inicia con la presentación de varias cuestiones por parte de la tutora. De manera casi inmediata a esta presentación una de las estudiantes expresa la posible dificultad de sus compañeras ante el contenido que deben leer previamente a contestar a la pregunta. Ante esta respuesta, la tutora indaga en la comprensión de los conceptos, mediante otra pregunta. Detectamos en los primeros mensajes indicadores referidos a esta categoría sobre el reconocimiento del problema y la sensación de confusión, que requieren la explicación de la tutora. 
Esta categoría se vuelve a plantear en una ocasión cuando una participante plantea un nuevo tema de discusión, como observamos en el mensaje que se presenta:

«Ya que el objetivo de estas actividades es que participemos, os propongo lo siguiente: Hemos caido en conclusión que no hay igualdad entre hombres y mujeres con lo cual: . ¿que soluciones harían posible la igualdad entre hombre y mujeres? »

Mensaje de P12

Tanto ante la primera cuestión como en esta segunda idea, la respuestas de las estudiantes muestran indicadores de la categoría «exploración de ideas», mostrando, en primer lugar, una divergencia con el grupo en el caso de una participante:

«Primitaaaaaaaaaaaa. Yo creo que no es mejor el modelo femenino que el masculino, son diferentes y tenemos que aceptaro así!!!!»

Mensaje de P17

Continúa esta aportación con una reflexión extensa, mostrando «integración», presentando sugerencias de algunas ideas ya presentadas por otras estudiantes y por la tutora, para que sean consideradas por el grupo, como se observa en la intervención completa de la participante:

«El concepto de igualdad es muy diferente para cada una de nosotras, depende mucho del ambiente que nos rodea, de la cultura, de la educación, de la experiencias, etc.... Para mi el término de igualdad lo enfoco, sobre todo, a la igualdad entre géneros. Debemos tener, tanto hombres como mujeres, las mismas oportunidades en la vida para poder realizarnos como personas e individuos. [...] Si que está claro que dentro de esa igualdad los hombres y las mujeres ya somos diferentes desde el momento de nuestra fecundación, ya los cromosomas son distintos, por lo tanto algunas diferencias deben existir no???? sino, que sería la vida????? [...] Pero lo que si es cierto, es que dentro de las mujeres somos muy distintas según nuestras 
culturas, experiencias, conocimientos, educación, cmportamiento, etc..... $[\ldots ..] \gg$.

\section{Fragmento del mensaje de P17}

Aparecen otros mensajes que hacen referencia a sugerencias de reconsideración de algunas ideas, siempre justificando la reflexión; por ejemplo en el siguiente fragmento:

«Para mi la igualdad significa libertad, respeto y educación. Lo que buscamos es libertad para vivir nuestras vidas, para poder ir de un sitio. Buscamos y necesitamos respesto, hacia nuestra persona, hacia el trabajo que realizamos y lo que queremos, necesitamos tener las mismas oportunidades laborales [...]»

Fragmento del mensaje de P2O

Se continúa identificando la categoría «integración», comenzando por el indicador de convergencia con los mensajes anteriores del grupo, como en:

"Creo como dicen mis compañeras...que la"libertad" y el "respeto" son valores fundamentales para el ser humano,sin diferenciar el sexo y así crear una sociedad igualitaria y sin injusticias»

Mensaje de P14

Incluso se identifican planteamientos ya con propuestas de soluciones, como en estos dos ejemplos de intervenciones en los que va mostrándose la categoría «resolución»:

«[...] creo que tanto el hombre como la mujer tiene derecho a decidir,pensar, realizar todo lo que se proponga sin que la sociedad le marque limites. La mujer y el hombre son diferentes fisicamente,pero juntos pueden llegar a un equilibrio,no hay ningun modelo mejor que otro,ya que ese modelo lo impone la sociedad,cada persona se debe hacer una misma y seguir sus ideales,respetando siempre las costumbres y tradiciones(en este caso como mujer gitana)» 
Mensaje de P14

«[...] La desigualdad existe desde tiempos preistoricos ya sea entre hombres y mujeres como entre grupos. Esta a sido causas de diferentes conflictos de diversa magnitud. Por eso, la igualdad de oportunidades entre hombres y mujeres es necesario ya que vivimos en tiempos donde los derechos de cada uno se a de tener en cuenta ya sea hombre o mujer.[...] Para ello la solución no se basa en imponer el modelo masculino o femenino, sino desde la educación, promover una igualdad de derecho, ya sea en la cultura, en organizaciones, en el trabajo y en general en toda la sociedad [...]»

Mensaje de $P_{5}$

En este caso la «resolución» final se identifica en varios mensajes donde se aplica el conocimiento a la vida cotidiana, algunas con ejemplos claros como en la siguiente intervención extensa de la que mostramos un fragmento:

«[...] El problema comienza cuando intentamos llevarlo a la práctica, la mujeres en general tenemos interiorizado un rol que a mi parecer nos dificulta para alcanzar una igualdad real, algunas por decisión propia y otras no. Yo pienso que sí es por decisión propia esta justificado pero no estoy de acuerdo cuando es algo impuesto ya sea por tu grupo cultural , por tu familia........] No se si se entiende esta reflexión, pero vamos que lo que yo digo que muy pocos hombres o ninguno dejan de lado su carrera profesional para dedicarse a ser padres, las mujeres en este aspecto somos distintas ...[...] las mujeres somos diversas y heterogéneas [...]»

Fragmento de mensaje de $P 7$

\section{c. Presencia Docente}

Tratamos, en primer lugar, la categoría «diseño y organización», reflejada a través del planteamiento del tema que deben reflexionar, las preguntas que deben contestar, qué organización van a seguir, ofreciendo 
nuevos conocimientos recurriendo a fuentes de internet y audiovisuales para ampliar el tema central. Confluye, además, con la categoría «enseñanza directa» en el indicador mencionado (remisión a fuentes externas). En este misma categoría se observa otro indicador referido a la presentación de cuestiones: la docente presenta los temas a trabajar a modo de pregunta. Vemos, por tanto, varios indicadores referidos a dos categorías de esta dimensión didáctica en este mensaje de apertura de esta línea temática:

«[...] ¿Qué es la igualdad entre mujeres y hombres?, la igualdad legal, está reconocida, ningún texto legal europeo discrimina a la mujer por el hecho de serlo respecto al hombre..bueno, con excepción de la sucesión a la corona..pero y la real, ¿está conseguida? ¿Realmente buscamos ser iguales a los hombres adoptando el modelo masculino por el que la sociedad se rige, o por el contrario, la igualdad implica imponer el modelo femenino? Cuando reflexionamos sobre la igualdad, también debemos plantearnos como entre las propias mujeres existen diferencias [...] Como veis, en torno a la igualdad, surgen reflexiones, muchas de ellas contradictorias, que hacen que nos replantemos constantemente, que buscamos con la igualdad de oportunidades y el foro es un espacio más para expresarlas y compartirlas con el resto de compañeras. ¿Qué es para cada una de nosotras la igualdad de oportunidades entre mujeres y hombres?¿¿Que buscamos con la igualdad? ¿Somos iguales mujeres y hombres? ¿Somos iguales entre nosotras?¿H Habría que tener en cuenta las diferencias que existen entre cada uno y cada una de nosotras?¿̇s mejor el modelo femenino que el masculino?.Queremos concer vuestra opinión y que estas preguntas os sirvan como guía para participar en foro. Como podreis imaginaros, el feminismo, como corriente cultural, ha generado libros, peliculas (os recomendamos AGORA de Amenabar), hasta comics, porque el reirse de nuestras actitudes también es positivo. En este enlace http://www.facebook.com/pages/MAITENA/52795916259 podreis encontrar tiras de Maitena, una ilustradora argentina, que dibuja y escribe sobre lo que piensan las mujeres, no de forma reflexiva...todo lo contrario, espontánea y divertida. Disfrutadla.[...]» 
En todos los mensajes de la docente, se identifica la categoría «facilitación del discurso», a través de expresiones de ánimo, agradecimiento y refuerzo a las contribuciones que todas las estudiantes aportan. Este hecho se observa, por ejemplo, en: «Gracias Mayte! [...] Gracias de nuevo!», «Gracias Ostalinda por tu aportación», «Gracias Antonia por tu aportación», «Muchas gracias por tu aportación», «Gracias por tu mensaje!», entre otros similares.

En esta categoría encontramos varios indicadores que confluyen, como extraer opiniones de las estudiantes matizando cuestiones conceptuales, promover el debate, y reforzar los conocimientos. Aparece esta estructura en varios mensajes de la tutora, como en el siguiente ejemplo, en el que refuerza la opinión de la aportación de la estudiante aprovechando para reflexionar sobre la cuestión, intentando promover diversas opiniones:

«Buenos días Guadalupe!

ES cierto, cada una de nosotras es distinta y vive de forma completamente diferente las desigualdades, y eso también hay que tenerlo en cuenta cuando se diseñan políticas para mujeres, nuestra diversidad. Respecto al abandono de la carrera profesional, es cierto que a las mujeres, a una gran mayoría, nos han educado para formar una familia (estereotipo de género) y eso nos obliga en un momento determinado de nuestras vidas a elegir entre el desarrollo profesional o el formar una familia, ya que tal y como está estructurada la sociedad, compatibilizarlo es complicado, puesto que no hay medidas de conciliación que lo permitan. Pero no debemos olvidar, que en el caso de que un hombre decidiese abandonar su carrera profesional por atender a su familia, sería sancionado socialmente, y eso también es una carga de género. Muchas gracias por tu aportación. Un saludo»

Mensaje de T4 
La docente intenta, desde el principio, establecer un clima de estudio adecuado como se observa en este mensaje donde da una explicación a una participante que ve complejos los conceptos de partida.

«[...] Podemos utilizar el foro para ir resolviendo las dudas que vayan surgiendo sobre el texto. Los conceptos básicos en materia de Igualdad de Oportunidades están definidos de forma técnica y hemos intentando que sea de la forma más objetiva posible, eliminando en la medida de lo posible el peso ideológico del feminismo. ¿Qué definiciones son las que no se entienden?»

\section{Fragmento de mensaje de T4}

Observamos en un momento del debate un intercambio de roles entre una participante y la tutora. La estudiante plantea un nuevo tema intentado promover ella misma el discurso de sus compañeras:

«Ya que el objetivo de estas actividades es que participemos, os propongo lo siguiente: Hemos caido en conclusión que no hay igualdad entre hombres y mujeres con lo cual: ¿que soluciones harían posible la igualdad entre hombre y mujeres?»

Mensaje de P12

En este momento, la tutora cambia el rol y contesta a la participante como una estudiante más:

«Hola Carmen! Para mi la clave está en una EDUCACIÓN IGUALITARIA Y EN VALORES. Un saludo»

\section{Mensaje de T4}

Se muestra también la categoría «enseñanza directa» a través del indicador referido a la inyección de conocimiento por parte de la docente, desde diferentes fuentes, en este caso a través de enlaces de Internet con artículos, videos y noticias. Esta propuesta de ampliación de conocimientos, no sólo mediante fuentes externas sino mediante explicaciones $y$ 
matizaciones a los mensajes de las estudiantes, se encuentran en prácticamente todos los mensajes de la tutora. Algunos ejemplos de lo indicado, los encontramos fragmentos de mensajes como:

«[...] Respecto al abandono de la carrera profesional, es cierto que a las mujeres, a una gran mayoría, nos han educado para formar una familia (estereotipo de género) y eso nos obliga en un momento determinado de nuestras vidas a elegir entre el desarrollo profesional o el formar una familia, ya que tal y como está estructurada la sociedad, compatibilizarlo es complicado, puesto que no hay medidas de conciliación que lo permitan. Pero no debemos olvidar, que en el caso de que un hombre decidiese abandonar su carrera profesional por atender a su familia, sería sancionado socialmente, y eso también es una carga de género. [...]»

«[..] En este enlace http://www.injuve.mtas.es/injuve/contenidos.downloadatt.action? id=199572796 podeis encontrar un documento que relaciona la igualdad con los derechos humanos [...]»

«[...] Es cierto, las mujeres no somos iguales entre nosotras pero si tenemos una reivindicación comùn, la consecución de la igualdad. Es la doble vertiente del empoderamiento, el poder personal o interior, como lo llamaba la feminista Starhawk, nuestra autoestima y el público, que no es más que cuestionar el sistema de poder existente para alcanzar un equilibrio en las relaciones de género y eso es común a todas y todos. [...]»

Fragmentos de mensajes de T4

Dentro de esta categoría y en varias ocasiones, la tutora intenta confirmar si todo se entiende correctamente, dando feedback explicativo; como por ejemplo en uno de los primeros mensajes:

«[...] Podemos utilizar el foro para ir resolviendo las dudas que vayan surgiendo sobre el texto. Los conceptos básicos en materia de Igualdad de Oportunidades están definidos de forma técnica y hemos intentando que sea de la forma más objetiva posible, eliminando en 
la medida de lo posible el peso ideológico del feminismo. ¿Qué definiciones son las que no se entienden? [...]»

Fragmento de mensaje de T4

La tutora, de manera continuada, diagnostica y da explicaciones sobre algún error de concepto en base a lo expresado por las estudiantes y propone su aclaración en casi todas las intervenciones, como se expresa en el siguiente ejemplo:

«[...] Quiero destacar en tu aportación, las dos últimas reflexiones: ¿Somos iguales entre nosotras? obviamente no, $y$ en eso el género también influye, nada tiene que ver una mujer europea y el reconocimiento de sus derechos, con otra, que coincidiendo en el tiempo, desarrolla su vida en otro espacio, marcado culturalmente de diferente forma. [...] Respecto a la última, coincido contigo, muchas veces somos las mujeres las que nos ponemos los límites, eso forma parte de la autoestima femenina colectiva, con la que tanto hay que trabajar, y que además forma parte del EMPODERAMIENTO [...]»

Fragmento de mensaje de T4

En un momento del debate, valora positivamente la intervención de una de las estudiantes, planteando su respuesta como resumen de todas las intervenciones:

«Gracias Loli! Con tus respuestas has resumido todo lo expuesto por tus compañeras. Un saludo»

\section{Mensaje de T4}

Finalmente la tutora, en los últimos mensajes del tema, realiza un resumen completo de las intervenciones estableciendo una idea final como conclusión, identificando, por tanto, la categoría «enseñanza directa»:

«[...] Antes de empezar con el segundo bloque...cंqué podemos

concluir de todo lo expuesto en el foro? La igualdad de oportunidades 
entre mujeres $y$ hombres es un derecho $y$ un principio de justicia social que no solo debe ser reconocido legalmente, que ya lo está en muchos paises, sino en la realidad. La igualdad real es la que debemos reivindicar sin olvidar que en estos últimos años hemos avanzado mucho, pero que aún siguen dandose situaciones de desequilibrio que perjudican mayoritariamente a las mujeres, ya que los patrones sociales en los que nos movemos son masculinos, que son los predominantes en el ámbito público [...]»

Fragmento inicial del mensaje de T4

No aparecen en el tema preguntas referidas a cuestiones técnicas, ya que existe un foro de tutorías específico para estas cuestiones, gestionado por con la dinamizadora.

En definitiva, deriva del análisis de este foro, que la dimensión didáctica se enlaza con la social y la cognitiva para facilitar y mantener esa Comunidad de aprendizaje activa.

\section{$2^{\circ}$.- Tema Foro Social de Trabajo Igualdad: Empoderamiento}

\section{a. Presencia Social}

En referencia a la presencial social, encontramos indicadores de la categoría «afecto», en primer lugar como indicativos de emociones, expresándolas con letras en mayúsculas o utilizando la repetición de signos de puntuación y comillas para remarcar algunas palabras, como vemos en los siguientes ejemplos: «[...] 'mirar hacia dentro'[...]», «[...] hago las cosas con EMOCIÓN [...]», «[...] en definitiva MI VIDA y basta como ejemplo [...]», «[...] y ellas pueden!!!!!, Esta ‘capacidad mia'[...]», «[...] las gitanas hoy dia!!!!!, [...] Y te aseguro que funciona!!!!!!!!!». 
La recurrencia al humor la encontramos en alguna ocasión, como en el ejemplo siguiente, con la finalidad de «relajar» una discusión mantenida entre dos estudiantes:

«[...] lo único que intento es dar un poco de juego al foro y al tema, de
esta forma creo que podemos sacar más
conclusiones.............K?????? "Meto los dedos"'"'jajajajjajaja, sino nos
aburrrimos!!!!!!!!!!![...]»

Fragmento de mensaje de P17

Como observamos la intervención recoge muchos indicadores referidos a la expresión de emociones a través de signos repetidos de puntuación y simulación de risas.

El indicador de expresión abierta está presente en casi todas las intervenciones, pues la docente solicita a las estudiantes que busquen ejemplos de experiencias personales cotidianas que tengan relación al tema y lecturas presentadas.

En la «comunicación abierta» todas siguen el hilo de la propuesta temática abierta, debido a la propia estructura del foro; además surge una discusión entre dos estudiantes que se rebaten sus intervenciones, creando «escalones» de respuesta.

El indicador referido a aludir al contenido de los mensajes de otras, en este caso, se hace presente en varias ocasiones como mostramos en el siguiente ejemplo y en la discusión entre las estudiantes:

«Lo que resaltaria de mi sería mi responsabilidad, entrega y dedicación aun que a veces no logre conseguir. Como Ostalinda creo ser un referente par abien en mi comunidad y es por ello qu eintento dar lo mejor de mí»

Mensaje de P9 
En este mensaje se observa también una expresión de acuerdo con el mensaje de la otra participante.

Por otro lado, la docente hace referencia continua a mensajes de las estudiantes, al responder a sus intervenciones en el foro.

Encontramos mensajes de desacuerdo de unas estudiantes con otras, con preguntas solicitando aclaraciones a las aportaciones, lo que pone de manifiesto la interactividad del recurso para la comunicación.

En la categoría «cohesión», observamos intervenciones en las que se identifican los tres indicadores. En primer lugar se observa el uso de vocativos, tanto en las estudiantes como en la docente, al referirse a las aportaciones de cada una de ellas. En este caso, la que más se dirige por sus nombres a las estudiantes es la tutora de esta propuesta temática.

En cuanto al uso de pronombres inclusivos, se repite con frecuencia el término «nosotras» «nuestra», identificando al grupo y a la comunidad por parte de las estudiantes; se observan en mensajes como:

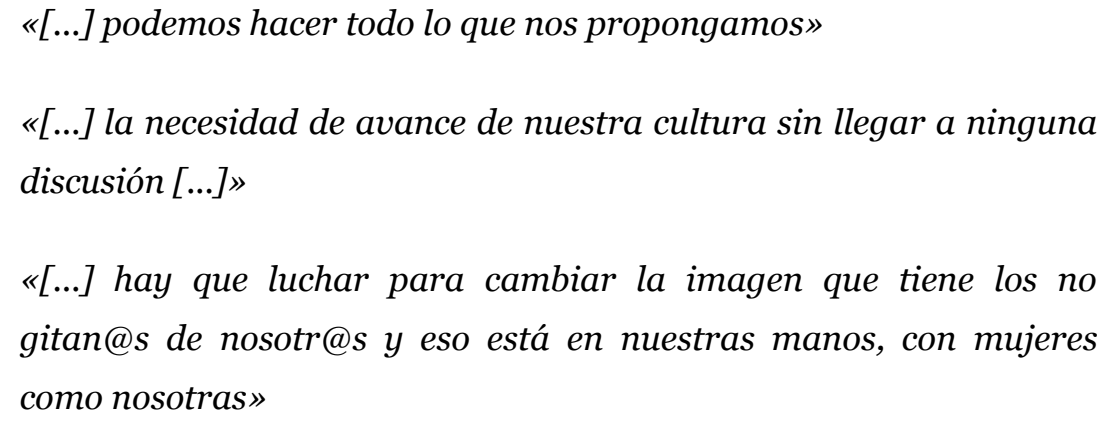

Fragmentos de mensajes de estudiantes.

Por último, aparecen otros elementos referidos a formalidades en la comunicación y a saludos y despedidas, también con expresividad referida a emociones, como en las despedidas con «Besos a todas», «besos», «besitosss», a modo de ejemplo. 


\section{b. Presencia Cognitiva}

El tema comienza con una propuesta de la docente para aplicar el el contenido de la lectura a sus vidas diarias, donde se encuentra la categoría «iniciación», en el indicador reconocimiento del problema.

La primera participante que responde muestra sensación de confusión, aunque realiza su intervención y pone su ejemplo, esperando feedback de la docente y de sus compañeras que apoyen su argumento o la corrijan:

«Hola! Es por si hacer un análisis de una misma, y al principio va a costar, pero tenemos que empezar a ver nuestras virtudes y tener confianza y seguridad en ellas [...]. La relación tal vez sería esta: --> Le pongo emoción a las cosas -->Por que me creo lo que hago y lo siento. Lo vivo --> Eso se transmite y hace que la gente crea en lo que estas haciendo/ produce cambios. No sé si es correcto expresarlo así, pero con esto empiezo a pensar sobre el tema. [...]»

Fragmento de mensaje de P17

En las intervenciones de las demás estudiantes se comienza a vislumbrar una «exploración de ideas» a través del intercambio de información: cada una de ellas establece sus ideas respondiendo a la tarea planteada por la docente.

Algunas estudiantes comienzan con una muestra de acuerdo en ese intercambio, para posteriormente discrepar en lo que van comentando compañeras e incluso la tutora, puntualizando cuestiones con las que están en desacuerdo, indicando ya un comienzo de la fase de «integración», como se muestra en el siguiente mensaje:

«De acuerdo, pero no solo hablando se consigue convencer, se necesita tener ejemplos diarios de avance en las mujeres gitanas para que el resto se vea, de alguna forma, reflajada. Tú debes luchar y hacer muchas cosas para que llas sigan tus pasos, sea un modelo a seguir para todas ellas. Y te aseguro que funciona!!!!!!!!! El mejor 
modelo a seguir es el de la imitación,el ser humano por naturaleza necesita ser imitado e imitar en todo los ámbitos de la vida...... No lo creo, las mujeres no se infravaloran ellas mismas, sinos que son infravaloradas por el resto de la sociedad gitana. Pasan a ser mujeres conformistas, aparentemente!!!!!!!»

Mensaje de P17

La tutora intenta dirigir el tema hacia una convergencia, sintetizando una idea y proponiendo sugerencias de reconsideración del tema:

«La verdad es que, lamentablemente y a pesar de lo que dice Ostalinda, muchas mujeres se infravaloran. Supongo que ella expresa un deseo que comparto como imagino que compartimos todas, pero la verdad es que muchas, gitanas o payas, se infravaloran. [...] ¿Os habéis parado a pensar la cantidad de mujeres que han pensado que no servían para nada cuando de las sobras de un pollo hacen una croquetas o una sopa, son capaces de ayudar a sus hijos e hijas con los deberes mientras preparan la cena o cosen el pantalón que tiene que llevar al colegio al día siguiente y además atienden al teléfono para interesarse por su suegra o su cuñada.... y mientras hacen estas cosas van haciendo una lista en su cabeza de las cosas que tienen que comprar para comer el resto de la semana [...] ¿Como es posible que haciendo tantas cosas a la vez y tan bien muchas mujeres piensen que ellas no valen o que no saben hacer cosas?»

Fragmento de mensaje de $T_{3}$

Las estudiantes retoman el intercambio de información con esta nueva pregunta y llegan a una nueva fase de «integración», sin dar a la propuesta una resolución del dilema.

\section{c. Presencia Docente}

En el mensaje de apertura del tema, la tutora establece el programa de estudio así cómo la metodología que deben seguir para resolver la actividad. 
En este sentido aparece la categoría «diseño educativo y organización» en los indicadores de referencias al programa y diseño de métodos; se hace un breve resumen de la lectura del texto para explicar los tres pasos a seguir para trabajar la actividad y aplicar el conocimiento a su vida cotidiana:

«1. Cada una de vosotras tenéis que pensar en algo que sabéis hacer, en algo que se os da bien. Aquí tenéis un ejemplo[...].

2. Una vez que hayáis elegido algo que se os da bien hay que explicar porqué decís eso, es decir, hay que dar una razón [...].

3. Ahora llega el momento de relacionar vuestra vida cotidiana con la actividad de liderazgo. Esto quiere decir que debéis intentar relacionar esa cualidad o capacidad elegida con las necesidades de las mujeres gitanas. Para ello además de pensar en vosotras mismas, debéis pensar en el colectivo, en para qué aspecto de la situación de las mujeres gitanas vuestra capacidad puede servir [...]».

Fragmento del mensaje de apertura del tema propuesto por $T_{3}$

La docente, al ver que, en 24 horas no ha contestado ninguna de las estudiantes, intenta «facilitar el discurso» animando a participar reforzando lo que las estudiantes puedan contestar.

"Parece que nos hemos empezado aún a compartir en qué creemos que somos buenas inadie quiere romper el hielo? quizá la actividad sea un poco complicada así que la podemos hacer por partes. Podeís empezar a contar algun ejemplo de cosas que se os da bien y luego entre todas empezamos a buscarle la miga al asunto, a ver en qué le sirve al grupo o a la comunidad. yo os echaré una mano, animo... un abarzo»

\section{Mensaje de T3}

Sus ánimos tienen una respuesta, una de las estudiantes intenta cumplir la tarea, facilitando el discurso a las otras estudiantes, mediante un mensaje de apoyo: 
«[...] al principio va a costar, pero tenemos que empezar a ver nuestras virtudes y tener confianza y seguridad en ellas[...]»

Fragmento de mensaje de P16

La docente, en la «facilitación del discurso», reconoce y apoya las contribuciones que las estudiantes van haciendo: «Me gusta, Mayte [...] Muy bueno...», «Estupenda tu respuesta....», «Muy buena tu aportación....Cuánto me alegro!», «MUy bien el pequeño rifi-rafe [...]», «Lo expresas muy bien», entre otros ejemplos.

También se encuentran indicadores de creación de un clima de estudio adecuado, tanto animando a que las estudiantes realicen sus intervenciones, como reforzando la discusión que se ha producido entre dos estudiantes, valorándola positivamente. Se entremezcla este indicador con el de promover el debate en las estudiantes en las intervenciones de la docente. Todos estos aspectos se muestran en mensajes como el siguiente

\begin{abstract}
«Bien bien, que alegría que os vayáis animando ....Yolanda psicoanalizarse, como tu dices, no es facil, pero lo has hecho muy bien y generar confianza es fundamental para ejercer el liderazgo.. ¿como vamos a seguir o a hacer caso a alguien si desconfiamos de el o de ella, si no nos fiamos? Me parece muy bien que digas que también has conseguido que muchas personas no gitanas cambien el concepto de lo que es un gitano.... ES un efecto de la confianza..... Vaya vaya, Ostalinda y tu habéis mantenido un mini diálogo muy interesante. [...] De todos modos, es fundamental que estéis convencidas de la necesidad del cambio hacia una sociedad igualitaria. No valen las medias tintas... MUy bien el pequeño rifirafe entre tu y Ostalinda. Lo expresas muy bien»
\end{abstract}

Fragmento de mensajes de $T_{3}$

Se reflejan en este tema indicadores referidos a la «enseñanza directa», en primer lugar presentando contenidos y cuestiones para el 
debate, plantea preguntas a modo de reflexión, para aclarar conceptos o centrar el debate, como en el siguiente ejemplo:

«[...] no es facil, pero lo has hecho muy bien y generar confianza es fundamental para ejercer el liderazgo.. ¿como vamos a seguir o a hacer caso a alguien si desconfiamos de el o de ella, si no nos fiamos? Me parece muy bien que digas que también has conseguido que muchas personas no gitanas cambien el concepto de lo que es un gitano.... ES un efecto de la confianza.....Seguimos pensando!»

Fragmento de mensaje de $T_{3}$

Centra el debate en temas específicos, pidiendo la reflexión a modo de pregunta:

«[...] ¿Os habéis parado a pensar la cantidad de mujeres que han pensado que no servían para nada cuando de las sobras de un pollo hacen una croquetas o una sopa, son capaces de ayudar a sus hijos e hijas con los deberes mientras preparan la cena o cosen el pantalón que tiene que llevar al colegio al día siguiente y además atienden al teléfono para interesarse por su suegra o su cuñada.... y mientras hacen estas cosas van haciendo una lista en su cabeza de las cosas que tienen que comprar para comer el resto de la semana? [...]

Fragmento de mensaje de $T_{3}$

La tutora relaciona cada intervención de las estudiantes con una inyección de conocimientos en referencia a conceptos fundamentales del tema. Se observa en varios mensajes de la tutora siendo la tónica general de sus intervenciones, como se muestra en este fragmento:

«[...] La verdad es que, lamentablemente y a pesar de lo que dice Ostalinda, muchas mujeres se infravaloran. [...] No está en la "naturaleza" sino que es el resultado de siglos y siglos de una mentalidad patriarcal que se ha ido colando en las imágenes de las propias mujeres. Demasiado tiempo viviendo en sociedades y grupos que ha colocado lo masculino por encima de lo femenino, una relación jerarquica que establece que "lo masculino" es mejor que"lo 
femenino", que lo que hacen los hombres (trabajar fuera de casa)

tiene más valor que trabajar dentro [...]»

Fragmento de mensaje de $T_{3}$

Tampoco aparecen en el tema preguntas referidas a cuestiones técnicas ya que éstas se establecen a través del foro de tutorías o vía correo electrónico.

\section{$3^{\text {o.- }}$ Tema Foro Social de Trabajo Igualdad: «Fomentan algunas mujeres el machismo»}

Recordamos que este tema es abierto a iniciativa de una de las estudiantes. Participa una tutora, en este caso integrada como una participante más, detectándose ese intercambio de rol entre docenteparticipante.

\section{a. Presencia Social}

En la categoría «afecto», encontramos varios indicadores referidos a la expresión de emociones, a través de la repetición de caracteres de una palabra, de signos de puntuación y del uso de mayúsculas para llamar la atención de una palabra, como se observa en los siguientes ejemplos: «[...] le pones hasta los calcetinesssssssssssssssss jajajajajajjajaa [...]», «[...] cuando se case piensas que no existirá el machismo en su casa?????», «[...] EXISTIRÁ, y le tendrá que hacer todo a su marido [...]» «[...] me gusta escucharte...jajajjajajaj no te lo tomes a mal!!!!!!!!!un beso», «[...] labado de cerebro que le hago todos los dias...ajjajaajajjajajj............]».

En algunas ocasiones, unido al anterior indicador, se detecta recurrencia al humor, como se muestra en los siguientes fragmentos: 
«[...] y lo está viendo en su propia hija, ahora está cambiando y eso es consecuencia de mi labor de concienciación, en el labado de cerebro que le hago todos los dias...ajjajaajajjajajj.........

[...] Seguro que tu hijo llega de trabajar y le pones hasta los calcetinesssssssssssssssss jajajajajajjajaa [...]»

Fragmentos de mensajes de estudiantes

En todas las intervenciones, las estudiantes presentan detalles de la vida cotidiana. Podemos observarlo claramente en los ejemplos que se ponen unas a otras:

«[...] Te pongo otro ejemplo: Fini, cuando se case piensas que no existirá el machismo en su casa????? [...]»

Fragmento de mensaje de $P_{17}$

«[...] Manolo me ayuda un monton en las tareas de la casa si trabajamos los dos [...]»

Fragmento de mensaje de $P_{5}$

En la categoría «comunicación abierta», en primer lugar, vemos como emplean de manera correcta el hilo de respuesta de la plataforma, contestando a la intervención de una participante, en un comunicación bidireccional o multidireccional, cuando responden a todas desde el mensaje inicial.

Destacamos varias intervenciones en las que se refieren, de manera explícita, al mensaje de otras expresando acuerdo o desacuerdo con el mismo, difiriendo dos indicadores de esta categoría:

«Ostalinda, tienes muchas razón en que las mujers gitanas son machistas [...]» 
«[...] tienes razón en que la educación nos marca, a mujeres y hombres, pero no debemos utilizar el término de culpabilidad, en todo caso responsabilidad. [...]»

«Kety, cariño, te digo lo mismo que a Mari Carmen, las culpables son las madres gitanas. [...]»

«[...] bien mi respuesta es sobre todo para Osta,yevas muxa razon o casi toda,menos en una Fini en casa a visto poco maxismo ya qe Manolo me ayuda un monton en las tareas de la casa si trabajamos los dos [...]»

«[...] Estoy totalmente de acuerdo, pero hay que tener en cuenta que en la mayoría de los casos es un rol aprendido, parece como algo innato $[\ldots .]$.

Fragmentos de mensajes de estudiantes

Encontramos también indicadores que muestran la expresión de aprecio, cuando se dirigen a las demás con un «cariño» o «guapa», o se despiden con «Besos a todas», «un beso guapa».

Observamos, tanto en estos fragmentos como en otros de esta línea temática, la relación con la categoría «cohesión», ya que todas se refieren a las demás por sus nombres. Unas y otras se dirigen continuamente al grupo con un «nosotras», «llevamos» o "somos», como identidad de la misma comunidad no sólo cultural, sino local. También identificamos en los mensajes, elementos que facilitan la comunicación como saludos y despedidas con expresión de emociones, enlazándose con la categoría «afecto»: «Gracias. Un saludo», «Besos», «HOla a todas!!», «besos a todas», entre otras.

\section{b. Presencia Cognitiva}

Una de las estudiantes abre un tema y hace una breve reflexión que finaliza en pregunta; se identifica la categoría «hecho desencadenante», 
reconociendo el dilema que presenta, dando la sensación de confusión, expresado a modo de pregunta:

«bien siempre he pensado que hay mujeres que ademas de haber sufrido y arrastrar el dolor del machismo lo sigen defendiendo, creo que lo hacen inconscientemente, pero es hora de espabilar ino creeis?»

\section{Mensaje de apertura de tema de $P_{5}$}

A partir de este momento, se identifica la categoría «exploración de ideas», en varios mensajes de las estudiantes en el que se produce intercambio de impresiones e ideas sobre la temática propuesta.

Aparecen las discrepancias entre las opiniones e ideas de unas y otras estudiantes, unas con todo el grupo, pero sobre todo, con algunas de ellas en concreto, encontrando momentos de discusión bidireccionales.

Los intercambios de información que se producen vienen acompañados de concreción de ideas, indicador de la categoría «integración», como se muestra en el siguiente ejemplo:

«Decirte que en la mayoria de los casos si que la mujer es consciente de lo que la rodea, pero yo como gitana y somitida a ello he de decirte que no es que lo defendamos y si erroneamente lo aceptamos por que es la educación que se nos enseña desde pequeñas y claro que hay que espabilar!nosotras mismas nos encargaremos de darle diferente educación a nuestros hijos sin perder los valores de nuestra cultura»

\section{Mensaje de P1}

Se manifiestan, seguidamente, algunas sugerencias de reconsideración, pidiendo nuevas opiniones sobre la propuesta, como se observa en el siguiente mensaje: 
«Como comente en el blog, la educacion es mui importante ya que crea nuestra personalidad, nuestra forma de ser y de actuar. Yo como mujer que ya tiene 47 años, he vivido una educacion mas bien machista, donde los derechos y la libertad de la mujer eran mas escasos. Esto hacia que el machismo se viera como una cosa normal y de este modo, la educación se basaba en asimilar esa conducta de machismo. ¿que creeis acerca de esto?»

Mensaje de P12

En la categoría «integración», detectamos indicadores de acuerdo con otras compañeras del grupo y con mensajes concretos, interrelacionados con la concreción y la síntesis de ideas basadas en la experiencia personal, como por ejemplo en el siguiente mensaje:

«Ostalinda tienes mucha razón en que las mujeres gitanas son machistas no solo porque aguantamos muchas cosas de los maridos, sino tambien con nuestros propios hijos. Por mi parte, no tengo hijas pero si la tuviera, y seguro que estaríais de acuerdo conmigo, no me gustaría que se fuera de botellón y viniera a las tantas. En cambio mis hijos vienen al día siguiente y no pasa nada. LLegamos a la misma conclusión: "hoy día, entre nosotras no somos iguales hombres y mujeres"»

Mensaje de P12

En varias intervenciones se ofrecen posibles propuestas de solución, situándonos en la fase de «resolución» en aplicación de los conceptos aprendidos al mundo real, como por ejemplo en el siguiente fragmento:

«Estoy totalmente de acuerdo, pero hay que tener en cuenta que en la mayoría de los casos es un rol aprendido, parece como algo innato . [...] Hay que empezar por educar igual a un niño y a una niña por que si no luego vendrán las dificultades, aunque reconozco que mis padres no me han educado a mí igual que a mi hermano.....Yo creo que es una lucha dura y constante por lo que tenemos que ser fuerte $y$ tener claro cual es el objetivo[...]» Fragmento de mensaje de P7 
En este también se muestra la propuesta de consenso y solución, realizada por parte de la tutora que se integra en el debate:

«Hola Ostalinda! tienes razón en que la educación nos marca, a mujeres y hombres, pero no debemos utilizar el término de culpabilidad, en todo caso responsabilidad. El sentimiento de culpa que tradicionalmente las mujeres hemos arrastrado, también nos ha supuesto un obstáculo a la hora de conseguir la igualdad. Las mujeres como madres, no somos culpables de la educación machista, primero porque la educación en el hogar es o debe ser compartida por el padre y la madre si es una familia tradicional $y$ es monomarental o monoparental por el hombre o la mujer, pero como ya hemos dicho, en nuestro crecimiento como personas, influyen desde nuestra familia, publicidad, medios de comunicación, centros educativos, religión...»

Mensaje de T4

\section{c. Presencia Docente}

En referencia a la dimensión didáctica de este tema abierto por una de las estudiantes, los indicadores muestran el intercambio de roles entre unas y otras, asumiendo un rol docente compartido. En este sentido se identifican sólo algunos indicadores de las categorías propuestas.

En primer lugar aparece la categoría «enseñanza directa», a través de la cuestión que presenta la participante, en un intento de promover un nuevo debate entre las compañeras, indicador, a su vez de «facilitar el discurso».

La docente asume en algunos casos su rol, diagnosticando errores de concepto, como en el siguiente ejemplo, en el que clarifica dos de los conceptos usados por las estudiantes:

«El machismo, a diferencia del feminismo, es una actitud, que pueden tener tanto hombres como mujeres, $y$ si es cierto, hay mujeres machistas que con su comportamiento perpetuan roles, pero no hay que culpabilizarlas, como estamos viendo, una gran parte de 
la socialización de género tiene su origen en la educación y aún hoy , la educación es sexista, por tanto muchas veces nuestros comportamientos "machistas" son inconscientes, porque nos han sido enseñados y los tenemos interiorizados sin cuestionarlos»

Fragmento de mensaje de $T_{3}$

Y también «facilitando el discurso» a través de mensajes de acuerdo con las estudiantes, reconociendo sus aportaciones. Esto también sucede entre ellas que se felicitan en alguna ocasión por sus mensajes.

\section{b. Análisis del Foro Social de Trabajo: Participación y Dinamización.}

\section{Datos Generales}

Identificación del Foro: Foro Social de Trabajo Participación e Identificación.

Participantes: Tutora 4 (T4) y Estudiantes.

Temas analizados:

- $\quad 1^{\mathrm{o}}$ EDUCACIÓN IGUALITARIA ¿Cómo educamos? ¿nos educaron de forma igualitaria? ¿cuáles son nuestros valores y que influyen en ellos? (Abierto por tutora)

Total de mensajes analizados: 42 .

Tabla 24. Datos generales del Foro Social de Trabajo: Participación y Dinamización.

\section{a. Presencia Social}

El mensaje de apertura muestra, por parte de la docente, una «comunicación abierta» con carga afectiva, mediante la expresión: «...Sois fantásticas!», ofreciendo este cumplido a las estudiantes y utilizando ese recurso para motivarlas.

$\mathrm{Al}$ igual que en los temas analizados anteriormente, observamos un índice alto de Presencial Social, transmitida por la categoría «afecto» desde el indicador expresión de emociones, del uso reiterado de signos de admiración 
y uso de emoticones para expresar sentimientos, como mostramos en los siguientes fragmentos como:

«hola muy buenas en el foro de igualdad e sido la ultima pero en este soy la primer q gustoiiiii [...]»

«Hola chicas me encanta vuestra forma de expresaros 9 si todas pensaramos igual nuestro pueblo seria muy diferente»

Fragmentos de mensajes de estudiantes

Se identifica una clara expresión abierta en este fragmento de una de las estudiantes que recurre a detalles de su vida personal como ejemplo, utilizando varios signos de puntuación a modo de expresión de emociones:

«Sin embargo, tengo una hijita pequeña de 4 meses y sin darme cuenta la «educo como mujer», es difícil expulsar ese aprendizaje de tantos años...lo tenemos interiorizado!!!!!!!!!!y cuando me doy cuenta me rio de mí misma, jajajjajaja..........pero que haces Ostalinda??????......

\section{Creo que es una tarea muy difícil y sobre todo en el mundo gitano"}

Mensaje de P17

Otra de las estudiantes, como ejemplo en este indicador, también se expresa abiertamente cuando habla de lo que piensa la sociedad gitana:

«[...]...mira en nuestra sociedad gitana opinamos todos pero la opinion de un hombre es la que tiene sentencia [...]»

Fragmento de mensaje de P2

En la categoría «comunicación abierta», siguen el hilo de manera continuada, incluso haciendo mención directa: «[...] Siguiendo el debate , comentar que «la maternidad», en sí ya nos diferencia...[...]». En algunas ocasiones se refieren a mensajes de otras, en algunos casos mencionando directamente el nombre de la compañera: «[...] Como ha dicho Briyi, 
nosotras las gitanas tenemos siempre [...]» «Hola Emi, creo que no. es que no lo dijeran [...]». Incluso a la tutora: «maría y todasii[...]»

Encontramos, como en ocasiones anteriores aunque esta vez en menor medida, elementos fáticos y saludos, en la categoría «cohesión» en algunos mensajes de este tema, destacando nuevamente las despedidas que muestran cariño mediante: «besos!!», «besos a todas!!!!!!!», «bsosssssss», «Un abrazo», que a su vez sigue mostrando el aprecio («comunicación abierta») que se va creando entre las estudiantes.

Destaca el comienzo del mensaje de una de las estudiantes, en referencia a la «cohesión», porque incluye los tres indicadores de esta categoría: saluda y se dirige a todas como «chicas», las incluyen en el grupo a todas ellas y las considera como «nuestro» pueblo:

«si todas pensáramos igual nuestro pueblo seria diferente [...]».

Fragmento de mensaje de P12

\section{b. Presencia Cognitiva}

En la Presencia Cognitiva, el «hecho desencadenante» viene determinado por las cuestiones y preguntas que plantea la tutora de un modo abierto. Van destinadas a un primer intercambio de información entre las estudiantes a través de preguntas directas basadas en sus experiencias personales sobre el tema de debate, intentando provocarlas para conseguir su implicación en la participación. Todas esas cuestiones se refieren a un tema central que está basado en la propuesta temática del Bloque, en este caso, se refieren a la «Participación y Educación Igualitaria».

«[...] En el foro de Igualdad, hemos hablado sobre la importancia de la educación para conseguir una igualdad real, y lo determinante de los valores que transmitimos y recibimos..pero irealmente educamos de forma igualitaria a nuestros hijos e hijas, o las personas con la que convivimos?, y si pensamos en la forma en la que hemos sido 
educadas nosotras...cilo han hecho para participar de forma igualitaria en la sociedad? ¿cómo nos sentimos cuando dejamos a nuestras criaturas (lenguaje no sexista) en las guarderías para volver a nuestros puestos de trabajo? ¿qué influencias recibimos no solo en nuestro entorno privado, con la familia como agente de socialización...fuera, en nuestros centros de trabajo, centros educativos...medios de comunicación..¿¿Qué mensajes se envían sobre mujeres y hombres? [...]»

Fragmento de mensaje de T4

La siguiente fase «exploración», se va produciendo a medida que las estudiantes van participando con su intercambio de información. Identificamos algunos fragmentos interesantes, que manifiestan observaciones, experiencias y comentarios sobre la información que ofrecen:

«mira en nuestra sociedad gitana opinamos todos pero la opinion de un hombre es la q tiene sentencia (aunque sea mentira,q la mujer es quien propone y dispone)al menos cara alos gitanos (que da lache hija,q esta hay ese hombre callate) quien me dice ami q nunca a escuchado algo asi de boca de algun hombre de su familia lo podeis decir no pasa nada y si no lo decis tampoco pasa nada solo $q$ tardaremos mas ala hora de tener todos esos derechos $q$ hoy sabemos q tenemosii la educacion gracias a dios ya esta menos "mal vista" para las madres de hoy. lo de las gurderias es un peso q las madres llebamos por q creemos q nadie puede cuidar mejor o iguaal $q$ nosotras a nuestros pequeñines pero los despegamos por su bien para q enpiezen a incorporase ala "vida" [...]»

Fragmento de mensaje de P2

Esta fase, quizá debido a la experiencia en temas de foros anteriores, va solapándose con la «integración», en la que las estudiantes reflexionan sobre las preguntas propuestas por la tutora y por otras compañeras, aportando nuevas ideas sobre la base de éstas; incluso plantean otras cuestiones para integrar esa novedad: 
«A la pregunta de como educamos, no educamos igual a hijos e hijas ni siquiera las nuevas generaciones de padres aunque lo intentemos. Quisieramos que nuestros hijos/as tenga los mismos derechos y obligaciones pero cilo tratamos igual?ċo le exijimos mas a los hijos o a las hijas? cuando tenemos que hablar de sexualidad clo hacemos igual a hijo y a hija? [...] Los valores tienen que ver con la forma de pensar de cualquier persona. Si una madre considera que los estudios no son nada importante, influirá en sus hijos haciendo que estos no tengan motivacion por los estudios. Si los padres inculcan a sus hijos que la formación es importante, los hijos tendrán mas probabilidad de que vayan a la escuela [...]»

Fragmento de mensaje de P12

En algunos casos, se responden unas a otras, matizando algunas cuestiones, en la que se identifica esta fase:

«Hola Emi, creo que no es que no lo dijeran con palabras, pero si con acciones , tú misma lo has dicho, por lo tanto nos han educado a todas igual, de forma no igualitaria».

\section{Mensaje de P17}

A todo ello la tutora ayuda en la profundización de conocimiento para continuar construyendo, inyectando nuevos conocimientos y enlazando con otras fuentes en Internet (Presencia Docente).

"[...] Hablas de tus sobrinos y sobrinas, ¿sabes en que se nota especialmente en la epoca de adolescentes por el aspecto de la inseguridad? En este artículo puedes encontrar referencias a este tema. http://www.cronica.com.mx/nota.php?id_nota=35115o [...]

Fragmento de mensaje de $T_{4}$

Destaca que una de las estudiantes, solicita la «visita de su blog» para seguir indagando sobre el tema: 
«...Si los padres inculcan a sus hijos que la formación es importante, los hijos tendrán mas probabilidad de que vayan a la escuela (pasar por mi blog)»

Fragmento de mensaje de P12

Se observa la última fase de Presencia Cognitiva, ya que en la medida que comparten esas ideas y se flexiona sobre las mismas, van aplicándolas a sus vida y experiencias personales:

"A mi por suerte han sido pocas veces las que me he sentido rechazada. He trabajado cara al publico desde que tenia 16 años y nunca me han negado un trabajo por ser "gitana" 'la verdad que siempre antes de saber que era gitana me han conocido como persona ,es muy importante que creamos en nosotros mismos para que los demas crean en nosotros [...] ami no me dieron la oportunidad de ir al instituto,pero cada dia intento hacerles entender amis padres que la educación es lo primero,yo lucho porque mi hermano pequeño no deje de ir al instituto y no sienta el rechazo de los demas y sea alguien en la vida [...]»

Fragmento de mensaje de $P_{3}$

«[...] la educacion gracias a dios ya esta menos "mal vista" para las madres de hoy. [...] yo esto si q lo pongo vajo mi punto de vista yo nunca e sufrido rechazo por ser gitana si e visto el rechazo en otras gitanas pero como decia el otro dia el respeto se gana,tenemos $q$ estar en una sociedad integrarnos, no me gusta me gusta el termino de incorporarnos,pues tenemos q seguir las pautasde esta sociedad a la $q$ nos vamos a incorporar. ejemplo: si llebamos al niño al colevestirnos con ropa de calle o si vamos a una tienda y nuestro niño es muy inquieto no dejar $q$ desmonte escaparates, si nuestros niños traen tareas a casa ponerles una hora para q las hagan, no se si me entendeis pero no dudeis q yo kiero a mi pueblo y estoy muy orgullosa de pertenecer a el. ya me ireis diciendo mañana siguo $q$ si no acabo en un momento [...]»

Fragmento de mensaje de P2 
Para finalizar, la tutora contextualiza las posibles respuestas a las cuestiones planteadas en la fase de «resolución». Esto se denota en la última parte del mensaje, en la que tutora expresa:

«[...] Gracias por vuestra participación, felicitaros por vuestros blogs y animaros a continuar con lo que habeis iniciado a través de este curso, porque habeis generado un movimiento hacia el cambio y eso es un reto, pero también un logro. Hay una frase de Benedetti.."Cuando creíamos que teníamos todas las respuestas, de pronto, cambiaron todas las preguntas" y eso es lo que sucede ..y somos parte de todo ésto, buscando compartir espacios,tiempos y recursos con nuestros compañeros, pero en igualdad, con las mismas oportunidades y con el mismo reconocimiento a nuestros valores $[\ldots] »$

Fragmento de Mensaje de T4

\section{c. Presencia Docente}

La primera categoría identificada en este tema, es la referida al «diseño y organización», ya que la tutora, en su mensaje de apertura, presenta el plan de trabajo y fija el contenido a tratar a modo de preguntas que deben responder. Se observa un planteamiento en el nivel macro del contenido a trabajar, recordando lo aprendido en la propuesta temática anterior:

«En el Foro de Igualdad, hemos hablado sobre la importancia de la educación para conseguir una igualdad real, y lo determinante de los valores que transmitimos y recibimos...pero irealmente educamos de forma igualitaria a nuestros hijos e hijas, o las personas con las que convivimos?...».

Fragmento de mensaje de $T_{4}$

Esta primera pregunta, denota, a su vez, «Enseñanza directa», junto con la presentación de varias cuestiones más que le siguen, intentando provocar la reflexión de las estudiantes. 
En todos los mensajes de la docente, se identifica la categoría «Facilitación del discurso», a través de expresiones de ánimo, agradecimiento y refuerzo a las contribuciones que todas las estudiantes aportan. Observamos claramente ese indicador en fragmentos como: «Gracias por tu aportación, es muy interesante!», «Gracias por tu mensaje», «Gracias por tu respuesta» «Buenas noches Antonia!! felicidades...vaya repaso a los estereotipos de género. Gracias...» «Gracias por tu reflexión...».

En esta categoría, encontramos varios indicadores que convergen: extraer opiniones de las estudiantes, promover el debate, reforzar y centrar el tema. Un ejemplo es el siguiente, en el que se refuerza la opinión de una estudiante y se plantea una cuestión para que las demás den su opinión. En este mismo fragmento la docente está centrando el tema de debate para que continúe:

«...Tienes razón, nos educan y educamos de forma diferente. ¿Pero
que valores transmitimos a niños y niñas? si son diferentes, pero no
decimos cuales son...ंen que se diferencia tu educación a la de los
hombres de tu casa?...»

Fragmento de mensaje de T4

Esto sucede en otras tres ocasiones en las que, a la vez que refuerza el contenido de la aportación de la participante, se presenta una nueva cuestión de debate, dirigiendo éste hacia los temas que la docente les propone. Continuando en esta categoría, podemos afirmar que la tutora pretende establecer un clima de estudio positivo a través de mensajes donde ésta intenta fomentar la participación de todas las estudiantes y que éstas den su propia opinión sin temor a cometer algún error.

También se observa, de manera clara, la categoría «enseñanza directa» a través del indicador referido a la ampliación de conocimiento desde diferentes fuentes, en este caso a través de enlaces de internet con artículos, videos y noticias. Este hecho aparece en prácticamente todos los mensajes de 
la tutora, que aporta conocimientos a las respuestas que las estudiantes van dando, enlazando esas fuentes para ampliar el conocimiento nuevo. Presentamos ejemplos de lo anterior, con fragmentos de mensajes como:

"[...] Mencionas la "responsabilidad de la madre" en relación a todo el ámbito doméstico... http://www.cunoticias.com/search.php? $q=$ coeducación. En este enlace podreis encontrar noticias sobre coeducación $[\ldots .$.$] »$

«[...] Respecto a la educación en los centros educativos, es cierto que se intenta de forma transversal incluir la perspectiva de género, la realidad es que no se lleva a cabo de forma eficaz y que si analizamos los valores en la población adolescente, sorprendentemente nos encontramos con un machismo, tanto en ellos como en ellas, bastante arraigado. Habrá que revisar el sistema, no creeis? http://www.injuve.migualdad.es/injuve/contenidos.downloadatt.ac tion?id=1586300430»

«[...] Tienes razón sobre la publicidad. Habitualmente las mujeres aparecemos como objeto sexual o madre y los hombres como "personas torpes" pero hay campañas publicitarias que rompen esa tendencia. Recuerdas la campaña de Puntomatic? Pues incluso en ese anuncio había sesgos sexistas http://www.youtube.com/watch? $v=W n 7-3 D y 5 A b I[\ldots]$ »

En estos fragmentos puede observarse cómo la tutora intenta confirmar lo que han aprendido, dando feedback explicativo. Ésta diagnostica y da explicaciones sobre algún error de concepto de lo expresado por las estudiantes y propone su aclaración:

«[...]...Haceis mención a la posición de la mujer en vuestro pueblo, pero sabes qué? el género afecta en mayor o menor medidas a todas las mujeres y hombres del mundo, y en eso los valores también influyen...[...]»

Fragmento de mensaje de T4 
Finalmente, la tutora analiza y resume todas las respuestas y opiniones sobre la cuestión en el mensaje final, identificando, por tanto, la categoría «enseñanza directa».

«Toca cerrar este tema...y no podemos concluirlo sin agradaceros vuestra participación y todas las reflexiones, el intercambio de opiniones que habeis generado y que nos ha permitido comprobar como con independencia de culturas seguimos teniendo la sensación de que nos nos educan ni educamos de la misma forma a hombres $y$ mujeres, y que siendo importante el avance legistativo este nunca podrá consolidarse si no inculcamos valores igualitarios a las personas que formarán la sociedad del futuro. La coeducación es un elemento fundamental para la construcción de un mundo de iguales, entendiendo por igualdad el respeto absoluto de las diferencias, que son las que nos enriquecen a unos y otras. [...]».

Fragmento inicial del mensaje de T4 para el cierre del tema

En definitiva, en esta ocasión también se observa que la presencia docente se enlaza con la social y la cognitiva para facilitar y mantener esa comunidad de aprendizaje activa.

\section{c. Análisis del Foro Social de Trabajo: Liderazgo.}

\section{Datos Generales}

Identificación del Foro: Foro Social de Trabajo: Liderazgo.

Participantes: Tutora 5 ( $\mathrm{T}_{5}$ ) y Estudiantes.

Temas analizados:

- $\quad 1^{\mathrm{o}}$ Tema Modelos Mentales Prevalecientes del Liderazgo (Abierto por Tutora)

- $\quad 2^{\circ}$ Tema La Toma de Decisiones mediante la Consulta (Abierto por Tutora)

Total de mensajes analizados: 46

Tabla 25. Datos generales del Foro Social de Trabajo: Liderazgo 
En este Foro de trabajo sobre el tema Liderazgo se abren cuatro líneas por parte de la docente, relacionado con su propuesta de diseño y organización de la actividad sobre la temática. Para el análisis se han seleccionado los dos temas con mayor número de mensajes.

\section{0.- Tema del Foro de Trabajo Liderazgo: «Modelos Mentales Prevalecientes del Liderazgo»}

\section{a. Presencia Social}

Observando la categoría «afecto» podemos hablar de expresión de emociones desde el primer mensaje de apertura por parte de la docente, que comienza por : «Amigas» para dirigirse a las estudiantes del curso. En este mensaje, aparece una aclaración de ésta sobre su nombre, que además de expresar afecto -para que se dirijan a ella por su diminutivo en castellano-, refleja el indicador de expresión abierta, al contar esta anécdota de su vida, a modo de posdata:

«[...] P.D. Como habrán notado, mi nombre legal es "Joan"; pero
después de 39 años de vivir en América Latina, donde todos me dicen
"Juanita", me he encariñado con ese nombre. Así, espero que me
permitan usarlo»

Fragmento de mensaje de T5

Varias estudiantes acompañan su saludo de varios signos de admiración, expresando énfasis en el mismo: «Hola Juanita!!» «[...] encantada de saludarte!!!!». En una ocasión se identifica uso de emoticones: «Es natural que niños pequeños, como los suyos, dependen de ti. Por eso, somos madres @». Encontramos una expresión clara de humor de una de las estudiantes, haciendo mención expresa a que es una broma:«QUe se casen yaaa!!!! es broma.intentar que tomen sus propias decisiones». En casi todos los mensajes de este tema, localizamos expresión abierta, con la presentación o la mención a detalles de las vidas privadas de las estudiantes. 
En la categoría «comunicación abierta», observamos, en primer lugar, el indicador referido a seguir el hilo de los mensajes, puesto que todas responden empleando el signo de respuesta adecuadamente. En este tema no encontramos referencia explícita a los mensajes de otras compañeras, quizá porque cada una responde según su experiencia vital a lo que les pide la docente. Tampoco se hace referencia a expresiones de acuerdo, aunque sí de aprecio por parte de la docente que felicita a alguna participante por el contenido de su mensaje: «...Me gusta tu reflexión...», que a su vez expresa «facilitación del discurso», dentro de la Presencia Docente, al reforzar la aportación de la participante.

La categoría «cohesión», está muy presente en este tema. Todas se dirigen a la docente por su nombre «cariñoso», y a la vez, la docente se dirige a todas por su nombre al responder a sus mensajes. Identificamos el uso de saludos con función social:«Buenas...» «Muy buenas...» «Hola Juanita, encantada de saludarte!!!!». O en el mensaje de la docente que se despide: «Con mucho cariño para todos...».

\section{b. Presencia Cognitiva}

Analizando la dimensión cognitiva, el «hecho desencadenante» se identifica claramente por el estudio de caso que plantea la tutora destinado a la reflexión personal de las estudiantes. Éstas deben leer un texto escrito por la tutora que organiza un plan de estudio de ese documento en base a conceptos fundamentales que deben examinar y experimentar en sus vidas diarias para luego compartirlo con las demás. En este caso se trata del tema «Modelos Mentales Prevalecientes del Liderazgo». En el segundo mensaje de la tutora, observamos como expone el caso para su resolución:

«Pregunta de Reflexión para páginas 1 a 9 del Documento de "Liderazgo" Deben tratar de responder esta preguntas hasta el 9 noviembre: "Todos tendemos a utilizar algunos de los modelos mentales prevalecientes de liderazgo en determinados momentos de 
nuestras vidas. Ahora que hemos visto algunos de los problemas que genera cada modelo, identifique uno de los modelos que a veces practique en su vida, las personas o las circunstancias en que lo utilice, cualquier efecto negativo al cual lleva y cambios que desea hacer" $[\ldots]$...

\section{Fragmento de mensaje de $T_{5}$}

Este hecho desencadena una sobreposición de las tres siguientes fases de esta presencia: «exploración» e «integración», puesto que cada una de las estudiantes aplica el concepto central a su experiencia vital, identificando los factores por los cuáles cree que adopta un «modelo mental» u otro en correspondencia con el texto estudiado. A su vez, plantean una «resolución» para el cambio de «modelo mental» si el que adoptan no es el adecuado. La docente ayuda exponiendo su resolución ante la reflexión de la estudiante:

«Carmen,

Has captado muy bien. Esta es la idea--de analizar tu propia vida. Ahora itienes alguna idea concreta, por pequeña que sea, de lo que puedes hacer para ser menos paternalista, ayudando a tus hijos y esposo a depender menos de ti?»

Mensaje de T5

Siguiendo esta línea también va exponiendo a algunas estudiantes esta reflexión para el planteamiento de la solución:

«Es muy positivo que sinceramente desees el bienestar de los demás y que estés motivado por un verdadero sentimiento de cariño. Lo importante es no crear dependencia. El mejor servicio que podemos dar a otros es ayudarles a desarrollar sus propias capacidades. Así, manteniendo tu cariño y deseo para el bienestar, es importante preguntarte: ¿Cómo puedo ayudar a estas personas a desarrollar sus talentos, capacidades, confianza, etc.?» 
Fragmento mensaje T5 a una estudiante

O le propone un truco, a modo de solución:

«El "truco" es aprender de hacer esto, sin caer en ser "autoritaria". La diferencia muchas veces tiene que ver con el tono de voz. Cuando uno grita, habla fuerte, o amenaza, se le percibe como "autoritaria". Cuando dirige, pero con calma y auto-confianza, se le respete la autoridad, sin considerarle como autoritaria»

Fragmento mensaje T5 a una estudiante

\section{c. Presencia Docente}

Situándonos ya en la Presencia Docente, observamos, en la categoría «Diseño educativo y organización» que la docente fija, de manera clara, el plan de estudio del documento que deben leer y estudiar, diseña el método que considera más adecuado -propuesta de división del texto en cuatro partes, sugerencia de impresión y lectura- y establece una propuesta de calendario para la primera y segunda parte, además utilizando el medio de forma efectiva solicitando la respuesta al caso que va a plantear. Todo ello se identifica en el primer mensaje:

«[...] Como verán, el documento sobre Liderazgo es de varias páginas, aunque es de fácil comprensión. Por lo tanto, para facilitar la reflexión, sugiero que lo lean en cuatro partes, las cuales corresponden a las temáticas principales del documento. Para cada parte, plantearé una pregunta que ayuda a promover la reflexión. Estas preguntas no son parte de las actividades obligatorias. Simplemente sirven para ayudarles en su crecimiento personal, para que saquen el mayor provecho posible del estudio del documento. Por lo tanto, en cuanto esté disponible el documento en el sitio web, sugiero que lo impriman y comiencen por leer páginas 1 a 9, que enfocan las temáticas: "La Necesidad de Liderazgo y Este Momento Histórico" y los "Modelos Mentales Prevalecientes del Liderazgo". En mi próximo mensaje, plantearé una pregunta sobre esta primera parte, la cual debe ser respondida hasta el 4 noviembre. Luego, del 5 
al 9 noviembre, enfocaremos en "El Marco Conceptual del Liderazgo

Moral", que es de la página 9 al 36. [...]

Fragmento de mensaje de $T_{5}$

En este mensaje también establece la finalidad del debate que plantea y distribuye el contenido presentado como propuesta de diseño y organización de la actividad:

«[...] Simplemente sirven para ayudarles en su crecimiento personal, para que saquen el mayor provecho posible del estudio del documento».

«[...] Ahora es tiempo de comenzar a trabajar sobre el liderazgo. Ya deben haber leído las primeras 9 páginas del documento base y comenzado a comentar la pregunta que coloqué el 4 noviembre. Puesto que no hay comentarios todavía, por supuesto pueden seguir comentando durante el tiempo que desean.

Sin embargo, mañana colocaré la pregunta que corresponde a la parte principal del documento base "El Marco Conceptual del Liderazgo Moral" (páginas 10 al 36) que se debe responder basado en sus reflexiones sobre la lectura de estas páginas hasta el 14 noviembre[...]»

Fragmentos de mensajes de T5

La categoría «facilitación del discurso» aparece cuando la docente reconoce las contribuciones de las estudiantes y su comprensión de los conceptos en los mensajes de respuesta: «Me gusta tu reflexión» «Has captado muy bien», "iQué bueno que te están tomando conciencia de los efectos negativos de estos modelos de liderazgo!».

Establece, de manera continuada un buen clima de estudio desde el comienzo, por ejemplo animando a las estudiantes a esforzarse para avanzar: «Ya que los conceptos son de fácil comprensión, hagamos un esfuerzo por ponernos al día». 
En cuanto a la «enseñanza directa», la docente presenta la cuestión a estudiar:

«[...] "Todos tendemos a utilizar algunos de los modelos mentales prevalecientes de liderazgo en determinados momentos de nuestras vidas. Ahora que hemos visto algunos de los problemas que genera $[\ldots] »$.

Fragmento de mensaje de T5

En varias ocasiones diagnostica errores o aclaraciones sobre conceptos. Veamos algunos ejemplos:

«Con respecto al uso del modelo autoritario en el trabajo, es importante aprender a distinguir entre "ser autoritario" y "ejercer autoridad legítima" [...]».

«Sólo quería aclarar un punto que me parece importante. No es sabio ir de un extremo a otro [...]»

«(....) Para aclarar, ninguno de los modelos presentados en las primeras páginas es ideal. Cada uno tiene sus limitaciones [...].»

Fragmentos de mensajes de T5

En este tema, la docente transmite nuevos conocimientos basados en su experiencia personal, aportando cuestiones para la reflexión en situaciones reales:

«El mejor servicio que podemos dar a otros es ayudarles a desarrollar sus propias capacidades. Así, manteniendo tu cariño y deseo para el bienestar, es importante preguntarte: ¿Cómo puedo ayudar a estas personas a desarrollar sus talentos, capacidades, confianza, etc.?»

«Más bien, hay que aprender a "acompañar", ayudando a la persona a desarrollar capacidades y responsabilidad. Es algo como ayudar a un niño a aprender a andar. Primero, anda tomado de nuestra mano. Luego, le soltamos, pero andamos trás de él, listas para 
agarrarle si lo necesita; entonces le alentamos a tomar 2 o 3 pasos solos; y gradualmente aprende a tomar más pasos por sí mismo, hasta que llegue a caminar por todas partes solo, sin ni pensar en necesitarnos. Es natural que niños pequeños, como los suyos, dependen de ti. Por eso, somos madres 9 Pero según van creciendo, $y$ con otras personas mayores, tenemos que tomar un paso por atrás»

Fragmentos de mensajes de T5

\section{$2^{0}$.- Tema del Foro Social de Trabajo Liderazgo: «La toma de decisiones mediante la consulta»}

\section{$\underline{\text { a. Presencia Social }}$}

En esta ocasión, encontramos inicialmente varios indicadores de la categoría «afecto» como indicativos de expresión de emociones mediante uso de emoticones en el saludo a la docente: «Buenas Juanita, 9 ». O para hacerse entender: «[...] (no se si me entiendes????)».

Todas siguen el hilo de las conversaciones, muestra del indicador de la categoría de «comunicación abierta», respondiendo tanto al mensaje inicial para contar su experiencias, como a las preguntas directas que les hace la docente solicitando aclaraciones. La docente también expresa aprecio en esta categoría mediante su agradecimiento a las aportaciones de las estudiantes: «Gracias por sus opiniones. Me alegra que todas están practicando la consulta [...]» .

Encontramos una expresión que busca la «cohesión» del grupo, a la vez que «facilita el discurso» (Presencia Docente) estableciendo un clima de estudio: 
«[...] También les agradezco por estar compartiendo el documento, y las ideas que contiene, con otros. De esta manera, todos nos volvemos «multiplicadores» de esta práctica tan importante [...]».

Fragmento de mensaje de T5

La unión del grupo se observa en el uso de los nombres para dirigirse tanto a la docente como a las participante. Esta categoría se muestra también a través del indicador elementos fáticos o saludos desempeñando una función social, tanto en la docente: «Amigas» «Deseándoles muchos éxitos» «Buena suerte!»; como en las estudiantes en las que estos elementos aparecen en algunos mensajes: «Hola muy buenasii» «Abrazo a todas».

\section{b. Presencia cognitiva}

Como en el anterior tema analizado, el «hecho desencadenante» se observa en el planteamiento de la tutora de la cuestión sobre la que se debe reflexionar: deben, como en el anterior, leer un documento y practicar los conceptos en sus vidas cotidianas. En este caso se trata de aplicar «La toma de decisiones mediante la consulta».

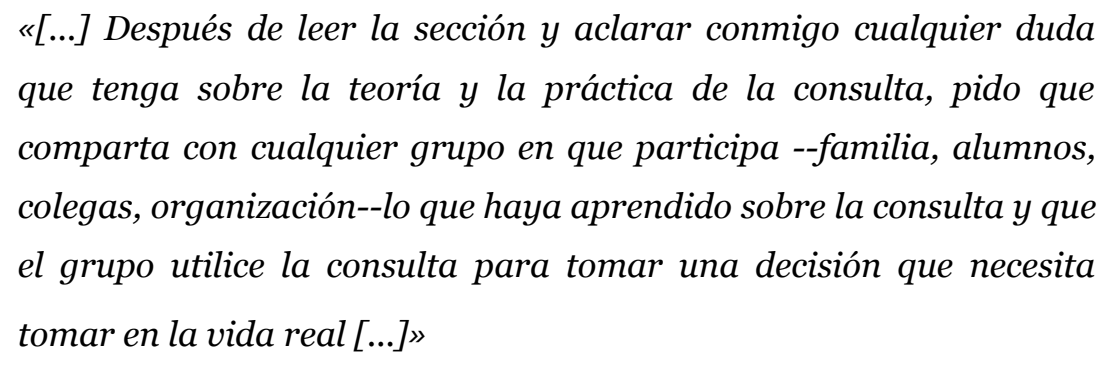

Fragmento de mensaje de $T_{5}$

Este hecho vuelve a desencadenar una confluencia de las tres siguientes fases: «exploración» e «integración» con las estudiantes comentando su experiencia sobre la aplicación de ese modo de tomar decisiones a sus vidas. A su vez, plantean una «resolución» si la experiencia requiere de mejoras y agradecen las que ofrecen las demás compañeras: 
"Me ha gustao mucho leer el texto las reflexiones sobre "la verdad". Yo pienso que todo es relativo y hay una frase que me gusta utilizar mucho sobre esto , me la enseño mi padre un día...."Nunca estamos en plena posesión de la verdad"; yo creo que esto es así hay que aprender más , escuchar más, nadie tiene la total razón sobre ningún tema siempre habrá distintos puntos de vistas que por supuesto nos harán aprender más. Esto como dice el docuemnto es muy fácil decirlo es más complicado llevarlo a la práctica porque sin querelo nos dejamos llevar por juicios negativos que tenemos hacia una determinada persona, o situaciones similares... La verdad que me hace bien leer todas estas reflexiones....»

\section{Mensaje de P7}

«[...] la consulta la he llebado acabo en una reunion de madres para la cabalgata de reyes, ha tenido lugar hoy por la tarde,he intentado seguir las pautas: pensar y actuar desde el cariño,ayudar y apoyar a quien lo necesite, debatir en grupo respetando ideales o inquietudes personales adaptandolas al grupo. Ha sido de locos todas las mamas creian que su idea era la mejor y luchaban para que las otras madres lo reconocieran [...] al final hemos llegado a un acuerdo $y$ solucionado, se va hacer de los simpson ya que hay personajes de varias edades y tanto femeninos como masculinos al final todos contentos, los niños, las mamas y la cordinadora [...]».

Fragmento de mensaje de P2

La docente ayuda en esta fase intentando cerrar el tema a la vez que establece una conclusión, como se observa en el siguiente fragmento:

"[...] Asi, cuando hay que tomar decisiones en grupo, en vez de considerar que uno ya sabe la mejor acción, se pide que cada uno comparte sus ideas, tratando de captar la "parte de la verdad" dentro de cada idea, e integrándolas para llegar a una decisión final que es mejor que cualquiera de las ideas originales. Cuando todos participan con este espíritu de aprendizaje, la experiencia muestra que, de hecho, se logran tomar mejores decisiones». 
Fragmento de mensaje de T5

\section{c. Presencia docente}

El primer mensaje de la docente, fija el programa de estudio para esa parte del documento, situándonos en la categoría «diseño educativo y organización». Recordando el tema anteriormente analizado, la docente divide el documento en cuatro partes, cada una de las cuales trata en una línea de discusión -tema abierto- diferente. En este caso, se corresponde a la última parte del documento: «La Toma de Decisiones mediante la Consulta». Además de establecer el programa, diseña el método (lectura-aclaracióncomprensión-práctica) y da las pautas para responder en el foro, como se observa en el mensaje:

«[...] una vez que haya terminado de estudiar la sección sobre "El Marco Conceptual de Liderazgo Moral", debe leer páginas 36 a 44 sobre "La Toma de Decisiones mediante la Consulta". Después de leer la sección y aclarar conmigo cualquier duda que tenga sobre la teoría y la práctica de la consulta, pido que comparta con cualquier grupo en que participa --familia, alumnos, colegas, organización--lo que haya aprendido sobre la consulta y que el grupo utilice la consulta para tomar una decisión que necesita tomar en la vida real.

Luego, en este foro, favor de compartir:

1) los aspectos de la consulta que compartió,

2) la experiencia de aplicar la consulta en la toma de decisiones, comentando especialmente cualquier mejora que haya notado o en el proceso de tomar la decisión o en a calidad de la decisión tomada.

Deseándoles muchos éxitos, Juanita»

Mensaje de T5 
Si nos centramos en la categoría «Facilitación del discurso», destacan los mensajes de ánimo constante y refuerzo de las aportaciones que las estudiantes aportan, como se identifica en estos fragmentos:

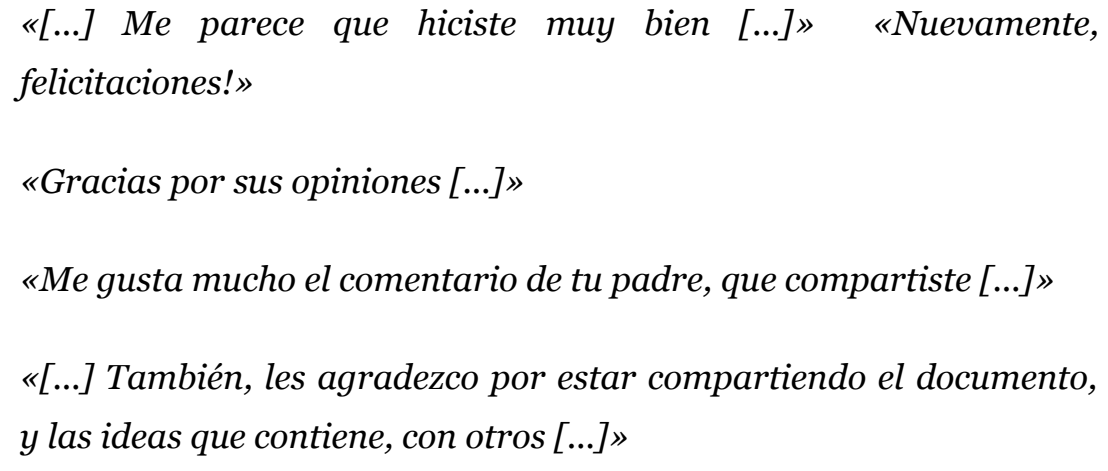

Dentro de esta categoría, identificamos algunas contribuciones, por parte de la tutora, intentando establecer un clima de estudio positivo para extraer las opiniones de las participantes.

«Es muy positivo que sinceramente desees el bienestar de los demás y que estés motivado por un verdadero sentimiento de cariño. Lo importante es no crear dependencia. Ahora itienes alguna idea concreta, por pequeña que sea, de lo que puedes hacer para ser menos paternalista, ayudando a tus hijos y esposo a depender menos de ti? $[\ldots]\rangle$

«iQue bueno que estéis tomando conciencia de los efectos negativos de estos modelos de liderazgo![...] »

«Es muy positivo que sinceramente desees el bienestar de los demás y que estés motivado por un verdadero sentimiento de cariño. Lo importante es no crear dependencia. El mejor servicio que podemos dar a otros es ayudarles a desarrollar sus propias capacidades. Así, manteniendo tu cariño y deseo para el bienestar, es importante preguntarte: ¿Cómo puedo ayudar a estas personas a desarrollar sus talentos, capacidades, confianza, etc.? [...]» 
Fragmentos de mensajes de T5

En la categoría «Enseñanza directa», una vez que la docente establece la organización y calendario presenta las cuestiones para reflexionar, como se puede observar en el mensaje de apertura expuesto con anterioridad. La docente intenta centrar el debate en nuevas experiencias, solicitando a las estudiantes que reflejen sus ideas novedosas sobre el tema en cuestión, como se observa en la última parte de este mensaje:

\begin{abstract}
«[...] Me alegra que todas están practicando la consulta en sus vidas, en diferentes ámbitos. Me interesaría saber, si hubo cualquier idea novedosa en la lectura sobre "La Consulta" en que se han fijado y que les ayude a mejorar más todavía, su práctica de esta importante capacidad [...]».
\end{abstract}

Fragmento de mensaje de T5

La docente aclara errores de conceptos, como se puede observar en la respuesta a una de las estudiantes, puntualizando la terminología:
«[...] Hay que distinguir entre la «toma de decisiones en grupo», $y$ «la consulta». Lo que distingue la consulta es la forma de tomar la decisión $[\ldots . . . »$.

En otro caso hace mención expresa a una aclaración a un concepto, como en el siguiente fragmento:

\begin{abstract}
«[...] Una aclaración: El significado de "consulta" en el documento no es el significado común de pedir la opinión de otra persona, tal vez porque no sabemos qué hacer nosotras. Más bien, la "consulta" se refiere a una forma de tomar decisiones, basada en la convicción que "varias mentes piensan mejor que una" [...]»
\end{abstract}

Fragmento de mensaje de $T_{5}$

Sigue después poniendo ejemplos e intentando obtener feedback de las estudiantes: 
«[...] Si un grupo trata de practicar éstas y las demás normas de la consulta, está consultando. Si no las practica, y ciertos miembros dominan en la toma de decisiones, es una «toma de decisión en grupo», pero no llega a ser una «consulta», si me captas la diferencia $[\ldots]$ »

Fragmento de mensaje de T5

Como vemos en el siguiente fragmento, diagnostica e intentan solventar errores de conceptos:

«[...] Me gusta mucho el comentario de tu padre, que compartiste: "Nunca estamos en plena posesión de la verdad". Sin embargo, creo que hay que hacer una distincción entre decir "la verdad es relativa", y "nuestra comprensión de la verdad es relativa".[...]»

Fragmento de mensaje de T5

Siguiendo en esta categoría, la docente inyecta conocimientos desde su experiencia personal y profesional como especialista en Liderazgo Moral en casi todos sus mensajes.

Como se ha indicado en varias ocasiones anteriores, la docente no responde a cuestiones técnicas, indicador de esta última categoría, puesto que hay un foro establecido para esta finalidad (Foro Tutorías). 


\subsubsection{Análisis del Foro de Tutorías.}

\section{Datos Generales}

Identificación del Foro: Foro de Tutorías.

Participantes: Dinamizadora (D) y Estudiantes.

Temas analizados:

- $\quad$ Tareas del Bloque II.

Total de mensajes analizados: 19.

Tabla 26. Datos generales del Foro de Tutorías

El Foro de Tutorías tiene como finalidad la resolución de dudas y cuestiones técnicas relacionadas con la plataforma. Hemos tomado el tema «Tareas del Bloque II» por ser el más numeroso en respuestas y el de mayor cantidad de tareas encomendadas a las estudiantes. En este foro la comunicación que se produce es bidireccional ya que, aunque las preguntas son referidas a la misma temática, la respuesta que se produce por parte de la dinamizadora es directa a la pregunta realizada por la estudiante.

\section{a. Presencia Social}

Se observan indicadores de presencia social en el foro tanto en los mensajes de la dinamizadora del curso como en los de las estudiantes. Si nos centramos en la categoría «afecto» hay muestras de emociones en la dinamizadora que pretende llamar la atención en alguna de sus intervenciones. Se muestra, por ejemplo, cuando dice: «[...]leedlo detenidamente, pero de-te-ni-da-men-te [...]», utilizando una marca entre caracteres para que se preste atención a la misma. Identificamos también simulación de risa, repitiendo caracteres: «[...] tiene su recompensa...jejeje».

Alguna estudiante utiliza repetidamente la expresión de admiración y puntos suspensivos para acentuar su expresión al plantear las dudas sobre la 
cuestión: «[...]...me equivoco????», «[...] tiene que ser de toda la poblacion verdad?????»; preocupación: «[...] no encuentro la guia para realizar la tarea de Carmina!!!!!!!!!!», "[...] no se que me pasa???me he ploqueado!!! [...]»; o bien de alegría, simulando incluso risas: «Y la encontre!!!!!!!!!!!», «ya lo averigüeeeee... jajajajaj». También encontramos en alguna ocasión uso de caracteres en mayúsculas.

\section{b. Presencia Cognitiva}

No se observan indicadores de esta dimensión en el tema analizado.

\section{c. Presencia Docente}

La dinamizadora plantea un resumen de las tareas semanales que deben realizar, que podemos entender como fijar el programa de estudios dentro de la categoría «diseño educativo y organización», a la vez que intenta establecer un clima de estudio, evitando la preocupación de las estudiantes:

$$
\begin{aligned}
& \text { «[...] No os asustéis con las tareas de este bloque. Falta una por } \\
& \text { poner aún sobre el tema de Dinamización. Os explico todo en el } \\
& \text { Taller Presencial del día 23. Leeros bien los dos documentos e ir } \\
& \text { participando en los Foros que os pongan las tutoras [...]» }
\end{aligned}
$$

Fragmento de mensaje de D.

Este fragmento también denota un establecimiento de una pauta de conducta para la resolución de la tarea, cuando dice «Leeros bien los dos documentos e ir participando en los Foros que os pongan las tutoras».

De igual manera da un mensaje de ánimo a las mismas, ambos indicadores de «facilitación del discurso», mediante una despedida con: «Ánimo!». En varias ocasiones más se detecta indicador de ánimo a las estudiantes mediante el mensaje siguiente: «Muy bien, la insistencia tiene su recompensa...[...]», «[...] Venga ánimo y despacio, sin correr...[...]». 
Aparece, una vez más, el indicador que se refiere a favorecer un clima positivo de estudio en el fragmento: «[...] Pero no os preocupéis [...]».

En una ocasión, establece un calendario, respondiendo a la pregunta de una de las estudiantes, corrigiendo errores en el desarrollo de las tareas:
«[...] Esta semana eso no es. Te estás adelantando. De hecho te has adelantado con lo de Salud. Hemos quedado que esta semana: la Guía de Carmina, el debate con María y de la Actividad Principal solo el paso 1. [...]»
«¿te refieres a la Guía? hay que hacerlo de una parte de la Guía y sólo en refencia a ese barrio en concreto».

Fragmentos de mensajes de D.

Confirma en una ocasión que todo lo que les ha propuesto se ha entendido correctamente, indicador de «enseñanza directa» y vuelve a dar una instrucción para las tareas, estableciendo pautas de conducta, indicador de «diseño educativo y organización».

\begin{abstract}
«[...] Os envié un e-mail con las tareas, por favor, leedlo detenidamente, pero de-te-ni-da-men-te, porque estas dudas podéis resolverlas solas si leéis despacio las tareas. Todas habéis recibido ese e-mail que envié el lunes de esta semana, ¿̇verdad? [...]».
\end{abstract}

Fragmento de mensajes de $D$

En general, se observa que la dinamizadora anima a las estudiantes a la vez que resuelve dudas sobre las tareas a realizar en la semana. Puede entenderse como dar respuesta a preocupaciones académicas, más que técnicas, situándolo como indicador en «enseñanza directa».

En resumen, la dinamizadora, dentro de sus funciones de motivación de las estudiantes, ejerce una presencia docente, aunque con menor incidencia que tutores y tutoras, en su labor didáctica de tutoría académica. Según indica en uno de los foros, envía e-mail con las indicaciones de las tareas a 
desarrollar semanalmente, ofreciendo apoyos para resolver actividades pendientes.

\subsection{Resultados.}

En esta segunda parte, ofrecemos un resumen de los resultados con las conclusiones obtenidas en cada una de las dimensiones y categorías.

\subsubsection{Presencia Social.}

La presencia social, definida como la capacidad de los participantes en una comunidad de investigación para proyectarse a sí mismos social y emocionalmente, como personas «reales» (es decir, de personalidad plena) mediante el medio de comunicación que se emplee (Garrison, Anderson y Archer, 2000:94), incluye, como ya hemos indicado, todas aquellas aportaciones en las que se fomenta la creación de una dinámica grupal mediante una expresión abierta, se promueven las relaciones sociales, se expresan emociones y sentimientos y, por tanto, el grupo se afirma como tal.

Consideramos en su momento, la posibilidad de realizar tres talleres presenciales, añadidos a la acción formativa virtual con el fin de que nos sirviesen de medio para facilitar a las estudiantes el conocerse y relacionarse, al menos, durante esas tres reuniones. Nuestra pretensión era, fundamentalmente, «acelerar el establecimiento de la presencia social» (Garrison y Anderson, 2005), en un intento de orientar, de manera más rápida, la dinámica del grupo hacia actividades más productivas y para facilitar la conformación de la «Comunidad de Práctica». Se aprovecharon estas tres reuniones para establecer lazos de comunicación, además de para trabajar conjuntamente sobre las temáticas planteadas, aclaración de dudas 
en referencias a actividades y planificación de actividades posteriores, en estrecha relación con la presencia docente.

En primer lugar, centrándonos en el planteamiento de los resultados referidos a la Presencia Social, se destaca montaje fotográfico inicial que situado la página principal del Espacio Virtual en el que se desarrolla el curso. Este montaje está realizado por la dinamizadora de la acción formativa virtual, con el fin de que constituya una primera imagen del grupo que se pretende conformar. Esta fotografía, desde nuestro punto de vista, da idea de «cohesión», categoría muy importante dentro de la dimensión social, que va a reflejar, fundamentalmente, si la Comunidad de Práctica se crea o no.

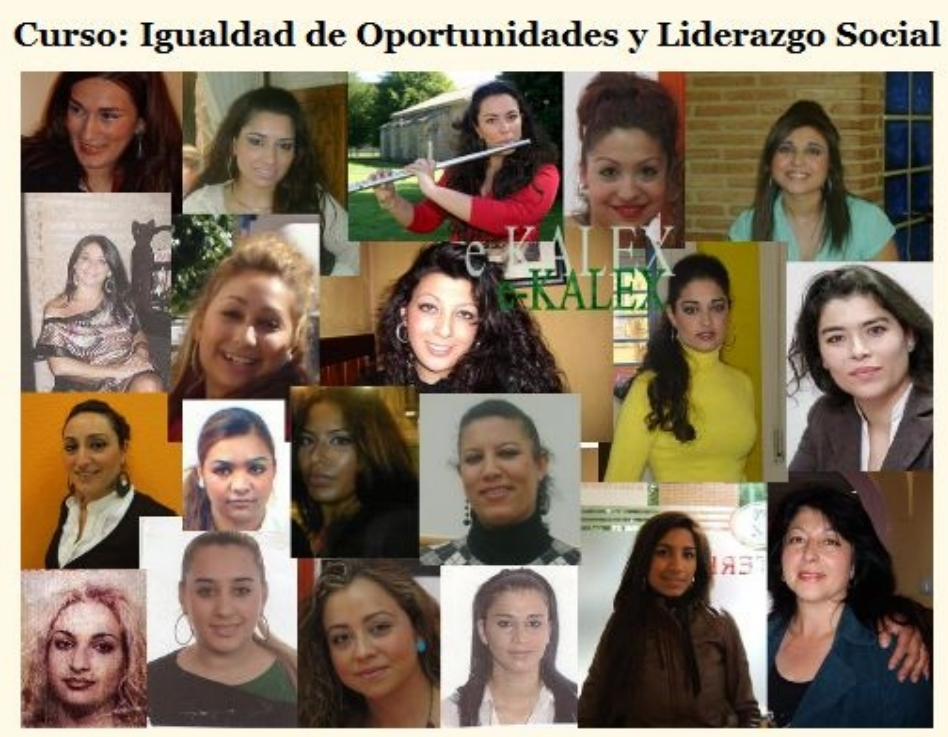

Figura 4o. Montaje fotográfico situado como página inicial del curso

Dentro de esta dimensión observamos bastantes referencias de «comunicación afectiva», es decir, aparecen explícitos indicadores que denotan que las estudiantes comparten una esfera socio-emocional, que según los autores, es esencial a la función comunicativa y a la cohesión de una comunidad. Esta categoría recoge la expresión de emociones y sentimientos, que ante la imposibilidad de establecer pistas visuales y de entonación se manifiestan a través de recursos escritos de puntuación, 
emoticones y letras mayúsculas. Teniendo en cuenta el medio virtual en el que se desarrolla, la comunicación afectiva se convierte en un elemento clave para el buen funcionamiento del trabajo de grupo (Garrison y Anderson, 2005).

Dentro de esta expresiones de emociones hemos observado:

- Emociones positivas: manifestación de alegría, satisfacción o aprecio.

- Pero también debemos mencionar las emociones negativas: expresiones de decepción, preocupación o problemas individuales, aunque significativamente en menor medida que las anteriores, y sobre todo dirigido a la no participación continua durante un período de tiempo, por asuntos personales o por problemas tecnológicos o de conexión. En una ocasión fue debido a un malentendido (conflicto) entre dos estudiantes, que se superó en la conversación mantenida en el foro de debate. En este sentido nos apoyamos en los resultados obtenidos por Rodríguez et al. (2002), en el que concluyen que los conflictos se han dado en mayor medida en los grupos con mayor rendimiento e implicación. Encontramos siempre mensajes de apoyo y ayuda de las demás compañeras ante esta expresión de emociones negativas, relacionado ya con la categoría de «comunicación abierta».

La repetición abundante del uso de emoticones, puntuación repetitiva, uso de mayúsculas para llamar la atención en las expresiones y otras frases coloquiales denotan, notablemente que este indicador es visible en los foros analizados.

También se ha señalado, en algunas ocasiones, que las estudiantes recurren al humor mediante bromas y medias palabras, en dos direcciones: 
- Por un lado, con el fin de demostrar ese afecto a las demás participantes.

- Para reducir la tensión, en algún momento del debate, quitando importancia al asunto que se trata.

En muchos momentos se observa el indicador de expresión abierta, en la narración de experiencias sobre aspectos de la vida cotidiana o personal de las estudiantes, debido también a que la mayoría de los/as docentes les solicitan aplicación de conocimientos a su experiencia, acorde a la dinámica de la acción formativa.

Los aspectos anteriores denotan que existe un grado importante de confianza en el que el grupo va estrechando las relaciones entre ellas.

Se observa una mayor presencia de estos indicadores en aquellos temas que abren las propias estudiantes, frente a los que abren las tutoras para trabajar las propuestas temáticas.

Otra de las categorías relacionadas con la Presencia Social es la «comunicación abierta», la cual recoge los mensajes enviados por las estudiantes donde se hace referencia a seguir el hilo de la conversación, citar o mencionar los mensajes de otras compañeras, la expresión de acuerdo o desacuerdo, hacer cumplidos por el contenido de los mensajes de otras o preguntar sobre cuestiones que en otro momento otra estudiantes haya expresado. En esta categoría podemos clasificar las aportaciones en dos:

1. Referencia explícita al contenido de mensajes de otras compañeras para mostrar acuerdo o desacuerdo con la aportación. Se observa una número mucho más intenso de mensajes de acuerdos que de desacuerdos.

2. Aportaciones que muestran aprecio, felicitación, apoyo o agradecimiento a otras estudiantes. Las aportaciones, sobre todo las de 
felicitación a otras compañeras por el contenido de sus mensajes, son muy frecuentes, denotando una dinámica muy activa con un buen clima de trabajo entre el grupo, y relacionándose con indicadores de la categoría «cohesión», en cuanto a que en estas aportaciones están inundadas de vocativos, dirigiéndose unas y otras estudiantes, por sus nombres y utilizando, constantemente, pronombres inclusivos como «nosotras» 0 «nuestra». También se expresan agradecimiento, en esta línea, bien como modo de reconocimiento social en el grupo, o bien como agradecimiento por mensajes de ánimo y motivación de otras estudiantes. Los mensajes de ánimo y motivación, como hemos indicado anteriormente, se relacionan estrechamente con la manifestación de una emoción negativa en alguna participante (categoría «afecto»). Encontramos mensajes de agradecimiento de una compañeras a otras, y relacionadas con los mensajes de refuerzo del/la docente (Presencia Docente/indicador «facilitación del discurso»), en agradecimiento por el reconocimiento social de su aportación.

Siempre se sigue el hilo de las conversaciones por la propia estructura de los foros en la plataforma. Se observa la creación de escalones de respuesta cuando se responden unas a otras en algunas discusiones. Emplean, así, de manera correcta el signo de respuesta de la plataforma, contestando a la intervención correspondiente cuando es bidireccional en respuesta a una de las estudiantes, o multidireccional cuando responden a todas.

Es evidente, en este sentido, la interactividad en la expresión de acuerdo o desacuerdo con un mensaje de otra compañera, inyecta un sentido de reciprocidad, apoyándose en los mensajes de otros/as y reconociendo sus aportaciones, contribuyendo a la dar sentido de grupo con intencionalidad. Se aprecia un buen nivel de compromiso en el proceso de reflexión y de discurso crítico (relacionado estrechamente con la dimensión cognitiva) sobre los temas que se proponen. 
La tercera categoría relacionada con la Presencia Social, la «cohesión», hace referencia a la aparición, en las intervenciones de las estudiantes, de una identidad de grupo o comunidad, a través del uso de vocativos, de pronombre inclusivos como nosotras/nuestra, el grupo, compañeras, amigas, etc., así como elementos fáticos, saludos, despedidas, que desempeñan una función meramente social, y que representan formalidad en las comunicación (Garrison, Anderson y Archer, 2000; Marcelo y Perera, 2007). Las intervenciones referidas a esta categoría tienen una clara finalidad de construcción de las relaciones (Fung, 2004), implicando un grado de interacción que va un poco más allá de los formalismos comunicativos y que son la base fundamental de la construcción para el desarrollo de relaciones sociales, sobre todo en la construcción y sentimiento de pertenencia a la comunidad de práctica. Dentro de esta categoría, en referencia a los indicadores establecidos por Garrison, Anderson y Archer (2000), encontramos tres tipos de intervenciones:

- El primer grupo de intervenciones que localizamos pertenecen a los formalismos en la comunicación como son presentaciones, saludos y despedidas.

- Un segundo grupo de intervenciones en las que la estudiante o estudiantes se manifiestan identificadas dentro del grupo a través de expresiones como nosotras, nuestra, el grupo, la comunidad, compañeras, amigas, entre otras. Son numerosas, como hemos visto en el análisis realizado, las expresiones de esta tipología. Creemos que el pertenecer al mismo grupo étnico favorece la cohesión en esta acción formativa, pues la identidad de grupo viene determinada por su pertenencia a la etnia gitana y su identificación con los valores y nuevos valores de la comunidad gitana (González, 2005; Fundación Secretariado Gitano, 2009). En este sentido detectamos el repertorio compartido y con el que se reconocen, en principio basado en su 
identidad cultural, que genera uno de los aspectos presentes en toda Comunidad de Práctica (Wenger, 2001).

- En tercer lugar, nos parece apropiado situar las intervenciones donde las estudiantes plantean propuestas o cuestiones, relacionadas o no con esta acción formativa, que incluyen a todo el grupo. Encontramos en este grupo de intervenciones dentro del Foro Entre Callis, dos temas abiertos por dos estudiantes diferentes:«Cambio de nombre del Foro Comunitario»y «Un Compromiso». Estos aspectos, propios de una relación informal, hacen referencia a temas tratados al margen del trabajo y actividades propuestas (Crook, 2000) que deben desarrollar en la acción formativa, y desempeñan una importante función social para la conformación de la Comunidad de Práctica. En el caso de «Cambio del nombre del Foro Comunitario» parte de la propuesta de una de las estudiantes para «hacer el foro propio», de ellas mismas, para debatir temas relacionados con intereses conjuntos, denota un acercamiento a la idea de empresa conjunta en la búsqueda de objetivos comunes (Wenger, 2001), como un elemento de las Comunidades de Práctica. Por otro lado, «Un Compromiso» constituye la búsqueda, propuesta por una de las estudiantes, con el acuerdo positivo de las demás, del compromiso conjunto que determina otro de los aspectos fundamentales de las Comunidades de Práctica (Wenger, 2001).

Destacamos, por último, que en esta dimensión, las intervenciones de las estudiantes que contienen indicadores de las categorías de Presencia Social son más numerosas que las de los/as docentes, acorde al establecimiento del Foro como espacio de encuentro, interacción e intercambio de conocimientos y experiencias, además de para el fomento de la cohesión del grupo y la constitución de la comunidad virtual de aprendizaje. Al realizar la codificación de los temas del Foro «Entre Callis», podemos establecer una 
línea de evolución de la presencia social en estos temas, teniendo en cuenta las fechas de apertura de esos temas y en base a tres momentos en la acción formativa virtual.

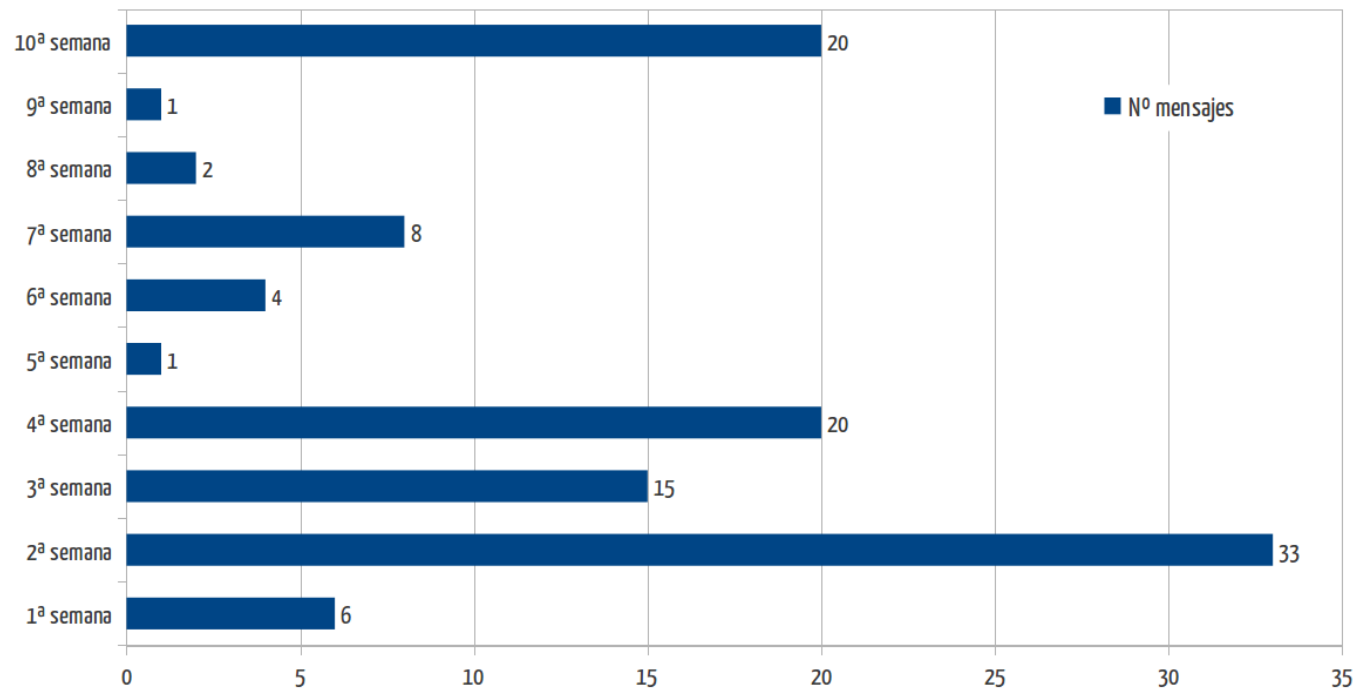

Gráfico 4. Línea de evolución de la participación de las estudiantes en el Foro «Entre Callis»

Como observamos en el gráfico, el número de mensajes va variando según el tiempo de desarrollo del curso, comenzando con una primera etapa de intercambio de mensajes con frecuencia alta, para luego ir en disminución en la segunda fase, volviendo a aumentar en el último periodo de la acción formativa.

- Etapa inicial: formación y consolidación del grupo: se caracteriza por un alto número de mensajes enviados al foro, cargados de indicadores de la categoría «afecto» y «cohesión». Se puede interpretar como la necesidad de aceptación en el grupo establecido y el intento de favorecer las primeras relaciones y lazos con otras participantes. También destacan mensajes destinados a crear un buen clima de trabajo 
- Etapa de desarrollo: la frecuencia de los mensajes baja, pero se siguen manteniendo la Presencia Social, a través de mensajes que muestran, igual que en la etapa anterior, «afecto», «cohesión»y «comunicación abierta». Comienzan a destacar el intercambio de experiencias personales que les va ocurriendo durante el desarrollo de la acción formativa.

- Etapa final: entre los mensajes de la etapa final, los últimos mensajes enviados a este foro, van en la línea de afianzar las relaciones establecidas y del trabajo desarrollado y aprendido. En este sentido, el tema abierto más claro es el de «UN COMPROMISO», último tema abierto en el Foro Entre Callis con la pretensión de crear un compromiso de unión y apertura del grupo hacia otras mujeres que persigan sus mismos objetivos: quieren multiplicar el grupo y transmitir y utilizar lo que han aprendido para favorecer el desarrollo de su propia comunidad.

\subsubsection{Presencia Cognitiva.}

La Presencia Cognitiva, se refiere al entorno intelectual que sirve de base al discurso crítico sostenido a la adquisición y aplicación del conocimiento de alto nivel (Garrison y Anderson, 2005). Aunque, desde nuestro enfoque, la Presencia Social es la fundamental en el asentamiento de las bases de la Comunidad de Práctica, ésta tiene una finalidad y se debe relacionar con el logro de resultados cognitivos. Así, la Presencia Cognitiva significa promover el análisis, construir y confirmar significados y comprobar su comprensión mediante la reflexión y el discurso dentro de la comunidad.

El modelo conceptual que Garrison, Anderson y Archer (2000), desarrollaron para el análisis de la Presencia Cognitiva en cuatro fases, es la 
base para el estudio de los indicadores referidos a esta dimensión en nuestra investigación, asociada a la construcción de conocimientos en el contexto educativo de los foros analizados. Este modelo, consta de cuatro fases, con indicadores generales de cada una de ellas:

- Fase iniciación: Comienza con un hecho desencadenante, que puede ser una pregunta,un dilema o problema, una actividad, una reflexión, etc. referido a un hecho o concepto que, de manera general, realiza la tutora y que implica una respuesta de las estudiantes. En todos los temas abiertos, siempre aparece un hecho desencadenante, planteado por las docentes o por las propias estudiantes en el caso de los temas propuestos en el Foro Entre Callis. En varias ocasiones se identifican múltiples hechos desencadenantes derivados de la fase de integración y/o fase de resolución, que hacen que el proceso vuelva a comenzar desde esta fase de iniciación.

- Fase exploración: Es una fase de pensamiento divergente que consiste en explorar la naturaleza del problema, dilema, pregunta planteada para comprenderla y buscar información relevante a modo de «lluvia de ideas». Hemos observado una confluencia de esta fase con la siguiente que puede ser debido a que las estudiantes han realizado un proceso de trabajo individual previo en la búsqueda de sus propios significados y plantean, posteriormente, las cuestiones sobre un discurso ya trabajado, confluyendo esa fase exploratoria con la reflexión conjunta.

- Fase integración: es una fase reflexiva donde las estudiantes deben implicarse activamente en el discurso crítico tanteando el nivel de comprensión de los significados. En esta fase sí que hemos observado aportaciones que establecen reflexiones profundas sobre las cuestiones propuestas basadas, en ocasiones, en planteamientos de otras compañeras. 
- Fase resolución: en esta fase se trata la resolución del dilema, problema o pregunta, aportando soluciones o reduciendo el marco de complejidad del mismo. Observamos en varios temas, sobre todo en los referidos al foro propio de las estudiantes, que no se llega a esta fase en algunas de las discusiones planteadas. Creemos que, en estos casos, se necesitaría un rol explícito docente para ayudar a llegar a la fase final. En los temas, se observa, sin embargo, como la resolución planteada no se crea como definitiva sino que abre puertas a nuevas cuestiones y preguntas, comenzando un nuevo ciclo de investigación práctica.

Ahondando con más profundidad en esta dimensión y observando la evolución de las fases en los diferentes temas, identificamos momentos de respuesta muy similar en los foros analizados, como se recoge en el siguiente esquema: 


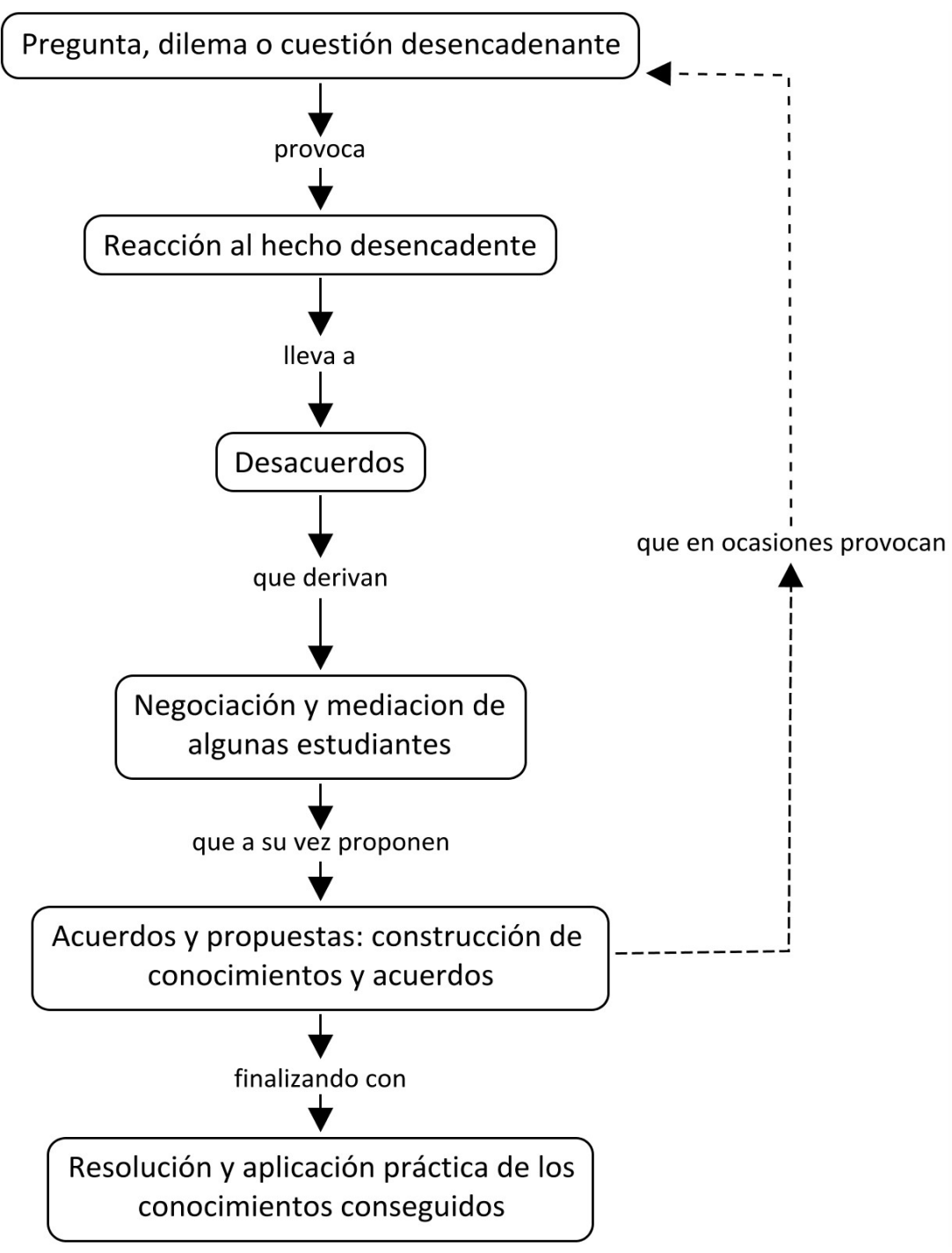

Figura 41. Diferentes momentos de respuestas en el desarrollo de los foros (Presencia Cognitiva)

Podemos observar que la presencia cognitiva ha resultado bastante frecuente, aunque en menor medida que la presencia social en los foros analizados. Aunque sí se constata que existe una elevada frecuencia de mensajes en los que las estudiantes muestran su integración de los conocimientos que van aprendiendo, la frecuencia de la categoría resolución ha sido baja con relación a las anteriores. Este hecho puede deberse a dos cuestiones: 
- Muchos de los foros analizados se abren a iniciativa de las estudiantes, compartiendo un rol docente compartido, que, en ocasiones, deriva en falta de guía y orientación en el debate establecido.

- La mayor parte de las estudiantes no había participado nunca en una acción formativa de estas características. Esto, unido al bajo nivel de alfabetización digital de algunas estudiantes puede haber contribuido a que no se consiga llegar, en todas las ocasiones, a la fase de resolución.

Contrastaremos esta cuestión en profundidad en el siguiente estudio, con las opiniones obtenidas de los tutores y tutoras participantes y de las propias estudiantes.

\section{7•3.3. Presencia Docente.}

La dimensión didáctica o presencia docente, es planteada como el diseño, facilitación y orientación de los procesos cognitivo y social con el objetivos de obtener resultados educativos significativos desde el punto de vista personal y docente (Garrison, Anderson y Archer, 2000).

Como hemos diferenciado entre las categorías que estos autores analizaron en su modelo de comunidad de investigación, comenzamos por la categoría de «Diseño Educativo y organización».

En el grupo de indicadores que representa esta categoría hacen referencia a aspectos relacionados con la planificación, organización y gestión del medio. No sólo son planteamientos macro de los contenidos o temáticas a trabajar, sino del programa de trabajo, los recursos y las normas de trabajo en cuanto a métodos y calendario. 
Observamos que en la mayor parte de los foros analizados las tutoras establecen un programa de estudios comentando el método de trabajo -que además es el mismo en todos los foros y está establecido para las estudiantes en la «Guía a las destinatarias»- y, en el caso de varios mensajes de las docentes, se establece el calendario de trabajo sobre la temática correspondiente. En este caso, se detectan dos fases dentro de esta categoría:

$1^{\text {a }}$ Establecer programa, método y calendario. El establecimiento del programa, metodología y tiempo disponible se realiza en la primera entrada del foro de trabajo específico que abre la tutora para trabajar la temática que le corresponde. En algún caso se hace alusión al método de trabajo que sigue esta metodología:

LECTURA $\longrightarrow$ ACLARACIÓN $\longrightarrow$ COMPRENSIÓN $\longrightarrow$ PRÁCTICA

Figura 42. Esquema de trabajo en el establecimiento del programa de trabajo, metodología y calendario.

es decir, lectura del documento de la propuesta temática, aclaración de conceptos, dudas y/o cuestiones, comprensión del tema en el debate conjunto en el foro y puesta en práctica del conocimiento relacionando estos con la vida personal de cada estudiante.

$2^{\text {a }}$ Planteamiento del tema a nivel macro. Este planteamiento se refiere a observaciones sobre la temática general a trabajar y el marco de referencia de la misma. También lo realiza la docente en el mensaje de apertura.

Los indicadores de las intervenciones relacionadas con el modo de emplear el medio de forma efectiva y establecer pautas de conducta en la comunicación son menos significativos, apareciendo sólo en la temática a debatir con la Dinamizadora (Foro de Tutorías). 
«Facilitar el discurso» es la segunda categoría analizada, en la que la preocupación central de la docente debe ser mantener la comunidad de estudio, favoreciendo un buen clima de trabajo y manteniendo un equilibrio en su participación en el tema. Es decir, facilitar un entorno positivo de aprendizaje donde se produzcan resultados cognitivos.

En esta categoría predominan varios indicadores que relacionamos:

- Animar, reconocer o reforzar las contribuciones de las estudiantes e intentar extraer opiniones, promoviendo el debate. En este estudio se observa que la mayor incidencia de indicadores se produce en esta categoría, en la que los/as docentes contribuyen a que las alumnas se motiven, se impliquen y participen continuamente en la discusión establecida. Los mensajes de ánimo y refuerzo son numerosos, lo que facilita esta participación. Observamos que dos de las docentes suelen responder a casi todas las respuestas que las estudiantes van ofreciendo, reforzando sus respuestas. Podría parecer excesiva esta participación cuando hemos hablado anteriormente de establecer un equilibrio en la presencia docente. Sin embargo, en este caso, vemos necesario aumentar esa presencia en temas que puedan suponer una complejidad alta para las estudiantes, ya que recordemos, para algunas era la primera vez que participaban en una acción formativa online de esta características con niveles de competencia digital más bien bajos.

- Creación de un buen clima de estudio. Todo lo anterior lo realizan con un ánimo de establecer un buen clima de estudio, lo que se observa continuamente en todos los temas analizados y por todo el personal docente que ha participado. 
- En muy pocas ocasiones, la figura docente se encarga de centrar el tema para evitar que las estudiantes se pierdan del asunto que se está trabajando.

La «Enseñanza directa», tercera categoría de la Presencia Docente, se relaciona con aspectos específicos de enseñanza de contenidos, que suponen «intervenciones directas y proactivas que dan soporte a una experiencia educativa eficaz y eficiente» (Garrison y Anderson, 2005:104).

En los foros virtuales estudiados detectamos una mayor participación de las estudiantes que de los tutores y tutoras invirtiendo la tendencia que suele encontrase en la enseñanza presencial en la que el profesorado interviene y participa más que el alumnado, centrándose más en el proceso de enseñanza que en el de aprendizaje. Incluso nos hemos encontrado con que la presencia docente, no sólo es exclusiva del/a docente sino que las estudiantes han adoptado esta función en alguna ocasión:

- En uno de los temas se observa la horizontalidad con que una de las tutoras interviene en un tema abierto por una de las estudiantes, como una más de ellas, intercambiando el rol, asumiendo la docente el papel de estudiante y viceversa. En este sentido se aprecia una comunicación interactiva «horizontal» estudiante-docente-estudiante.

- En algunos otros temas, especialmente en aquellos abiertos por las estudiantes, se destacan algunos indicadores que muestran el intercambio de roles entre unas y otras estudiantes, asumiendo un rol docente compartido entre las mismas. Sucede, sobre todo, en el Foro Entre Callis; recordamos que va destinado a la comunicación entre las estudiantes sin intermediación de docentes y en temas que abren ellas mismas por iniciativa propia. Podemos hablar de 
una comunicación interactiva «vertical» estudiante-estudiante, según se va adoptando un rol u otro.

Queremos destacar la figura de dinamización en esta dimensión, que ejerce, al igual que las docentes, una labor didáctica de tutoría académica y técnica aunque, como hemos indicado, con menor muestra de indicadores de presencia docente que las tutoras, por las funciones propias del rol que ejerce.

\subsubsection{A modo de resumen.}

Una de las cuestiones que consideramos de mayor importancia para uno de los objetivos planteados en la investigación, es el análisis de la presencia social. Encontramos un alto porcentaje de mensajes que pertenecen a esta dimensión, especialmente referidos a la categoría de «cohesión». En este sentido podemos decir que se crea una identidad de comunidad de aprendizaje, integrando a las demás en el discurso y reconociéndolas como parte de la misma. En este sentido, teniendo en cuenta el análisis completo de las categorías que conforman la Presencia Social y los datos de evolución de las categorías de esta dimensión, se puede afirmar que la base de la Comunidad de Práctica está establecida y que, en este momento, podemos considerar la conformación de una Comunidad de Práctica dentro de esta acción formativa virtual.

Por otro lado, comprobamos que la confluencia de las tres presencias son necesarias para la consecución de una Comunidad de Práctica con sentido educativo. Podemos afirmar que este modelo y sus categorías se entrecruzan entre las distintas dimensiones siendo, en nuestro estudio, la Presencia Social la que establece la base aportando un sentido a la gestión del conocimiento a través de las emociones, manteniéndose a lo largo de toda la acción formativa, y que la Dimensión Cognitiva ha necesitado de la base creada por la Presencia Social y de la Presencia Docente para que se llegue a la fase de 
resolución final en el proceso de construcción de conocimientos. Es decir, para que las fases de investigación práctica se completen es necesario que tomen fuerza la comunicación afectiva y la dimensión didáctica.

Confluye todo ello con la relación que Garrison y Anderson (2005) establecen en la representación que realizan de estas dimensiones en la gráfica ya presentada y que recordamos, donde las tres Presencias están relacionadas y son fundamentales para mantener esa comunidad de estudio activa mediante la creación de un clima de estudio apropiado.

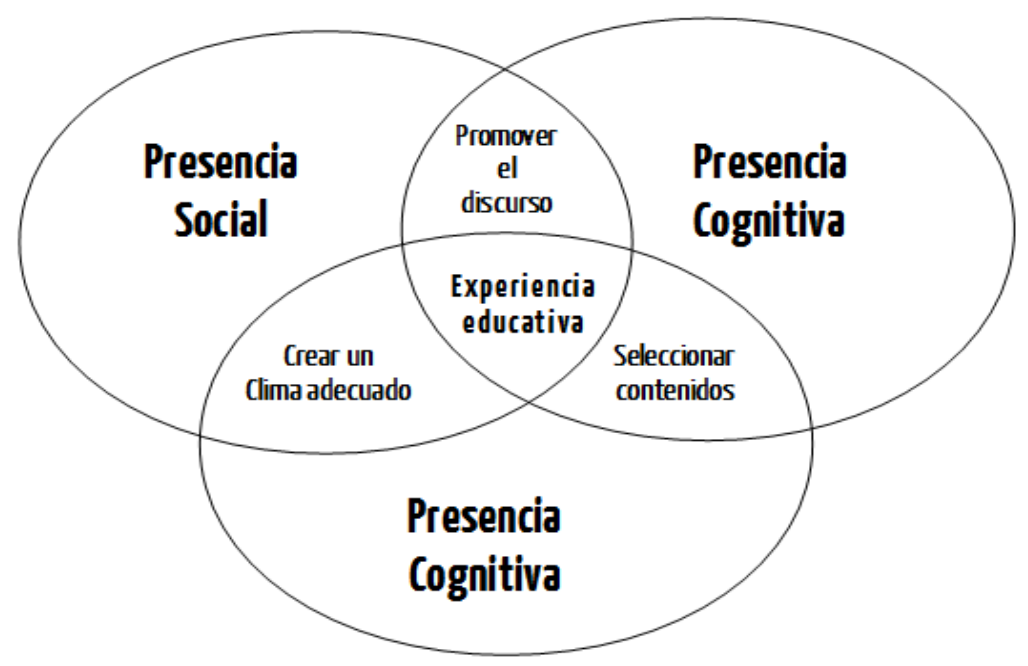

Figura.43. Relación entre las tres dimensiones del modelo «Comunidad de Indagación» (Garrison y Anderson, 2005: 49)

Queremos hacer referencia, además, a varias cuestiones sobre el contexto donde acontecen las acciones que se han analizado desde las dimensiones social, cognitiva y didáctica/docente: los foros virtuales. Los foros analizados son espacios de encuentro social, donde las tutoras y las estudiantes han interactuado, formulado $\mathrm{y}$ respondido preguntas, expuesto ideas, 
experiencias, etc. con una finalidad, no sólo de aprendizaje, sino también social y comunicativa. Este aspecto comunicativo y social (en referencia directa a la «Presencia Social») hace que se cree un ambiente de confianza entre estudiantes y tutoras y un buen clima que favorece el estudio y el aprendizaje entre iguales (Aubert et al., 2008). Todo ello da sentido a la conformación de una Comunidad de Aprendizaje, pudiendo afirmar que los foros son un medio que, basándose en un diseño pedagógico adecuado, pueden favorecer el desarrollo de aspectos sociales de los grupos, además de procesos interactivos de enseñanza-aprendizaje. Desde la perspectiva constructivista en que nos situamos, entendemos que, este medio puede facilitar la construcción social del conocimiento.

No obstante, al poner en práctica el modelo didáctico propuesto, nos encontramos que, llevar a las estudiantes desde el nivel de intercambio de ideas y reflexiones a la construcción conjunta del conocimiento (relación con «Presencia Cognitiva»), es una tarea que entraña dificultades en la enseñanza virtual. Hemos observado que las estudiantes participan en el intercambio de opiniones, en el compartir ideas, pero cuesta profundizar en el conocimiento de algunas cuestiones a través del debate en los foros. En este sentido, creemos que la actividad educativa que se desarrolla a través del foro por las docentes, es fundamental («Presencia Docente») para llegar a la fase de resolución y construcción del conocimiento. Esta dimensión didáctica conlleva en los docentes la asunción de diferentes roles: como facilitadores de debate, moderadores, guías-orientadores, expertos que responden cuestiones individuales y grupales, gestores, etc.

Para finalizar se recogen, en el siguiente mapa conceptual y a modo de resumen, los principales resultados y relaciones del estudio realizado en referencia a la construcción de la Comunidad de Práctica de las mujeres gitanas participantes en la acción formativa virtual. 


\section{OJOOOO}

AQUII VA MAPA GRANDE (APERTURA DOBLE)

Figura 44. Resultados y relaciones del estudio de conformación de la Comunidad de Práctica a través del modelo «Comunidad de Indagación» 

Capítulo 8. Evaluación de la aplicación de la acción formativa virtual (Estudio

3) 



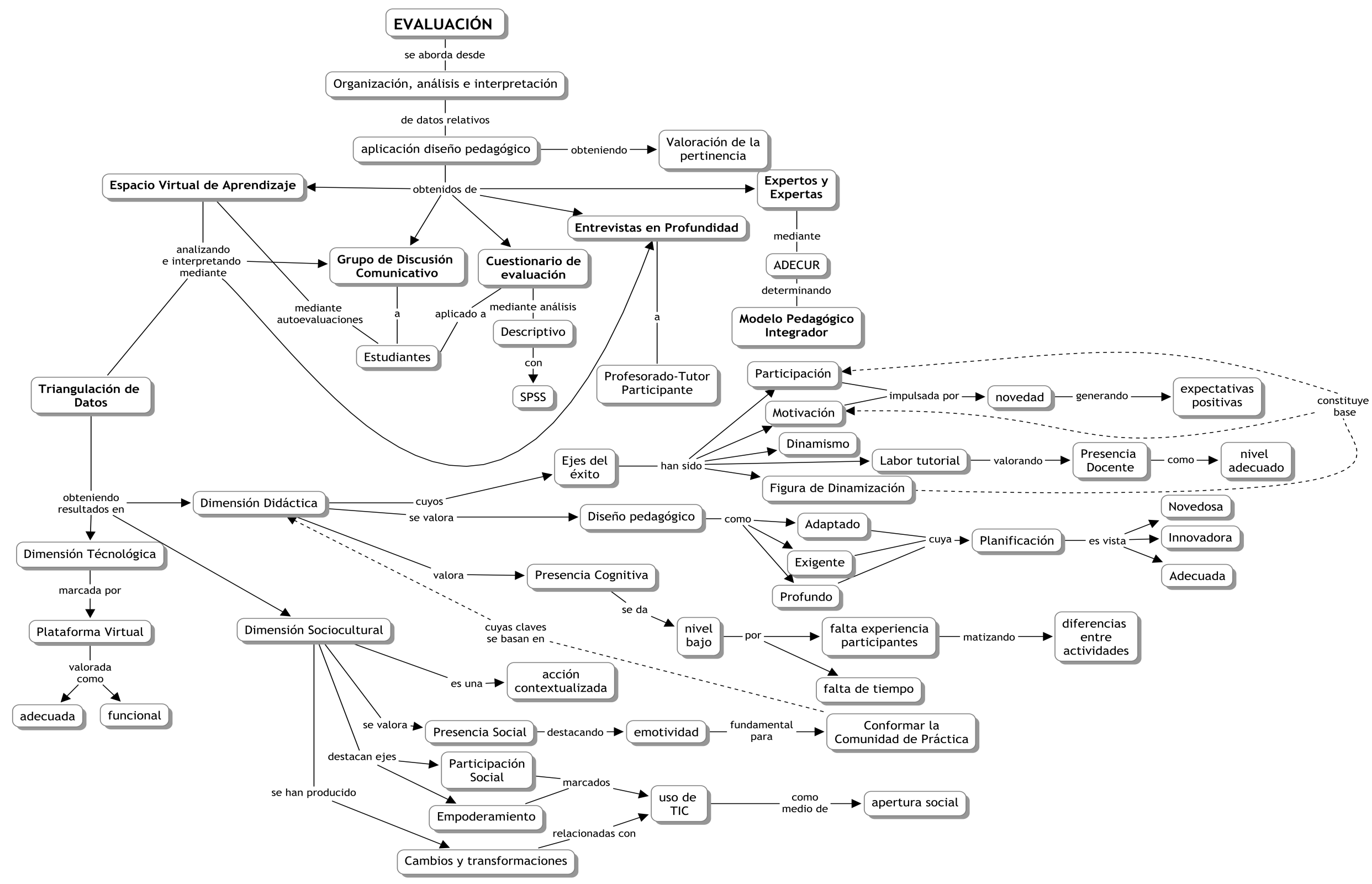





\subsection{Introducción}

En los capítulos anteriores presentamos la propuesta didáctica y metodológica de la acción f1ormativa virtual con la finalidad de conformar una Comunidad de Práctica. Posteriormente, se ha realizado un primer estudio, en base a las dimensiones cognitiva, docente y social comprobando si el desarrollo seguido para esa conformación había sido adecuado. En este capítulo, abordamos la evaluación de la acción formativa virtual, procediendo a la organización, análisis e interpretación de los datos relativos a la pertinencia en la aplicación del diseño pedagógico propuesto desde el punto de vista de las estudiantes, de expertas y expertos externos y del profesoradotutor participante.

El desarrollo de la acción formativa se ha realizado según previsión, entre los meses de Octubre y Diciembre de 2009, realizándose la evaluación del curso entre enero y marzo de 2010 finalizando con el acto de entrega de diplomas. De modo general, en referencia a incidencias, al comienzo hubo algún problema en el acceso al Campus Virtual que quedó solventado inmediatamente. Por otro lado, no comenzaron la acción formativa tres estudiantes, alegando motivos laborales. Una estudiante abandona un mes después del comienzo indicando razones familiares de gravedad. Finalmente, el curso es completado por 15 estudiantes.

Los datos sobre los que trabajamos en este capítulo, fueron obtenidos a partir de cinco tipos de instrumentos de recogida de datos, comentados con anterioridad en el marco metodológico. Estos instrumentos son (Anexo I): el cuestionario aplicado a la finalización del curso a las estudiantes, en un total de 16 ; la herramienta ADECUR, para la evaluación sobre el modelo y estrategias didácticas utilizadas en el curso virtual, por parte de expertos y expertas; las entrevistas realizadas al profesorado participante tanto en las 
sesiones virtuales como presenciales, en un total de 7 entrevistas, los datos recogidos a través del Foro destinado a la evaluación continua del curso, así como los datos obtenidos de un grupo de discusión desarrollado con las participantes.

\subsection{Datos relativos al Cuestionario de Evaluación del Curso: participantes.}

El cuestionario de evaluación del curso fue aplicado al finalizar la acción formativa de forma presencial en la sesión de entrega de diplomas y virtualmente, a través del correo electrónico a aquellas estudiantes que no pudieron asistir. Las preguntas formuladas responden a las opiniones y valoración de la totalidad del curso: valoración y opinión global de la experiencia, diseño, desarrollo, sesiones presenciales y visión de las TIC.

El objetivo de este cuestionario era validar la opinión y valoración de las estudiantes en relación a la pertinencia del diseño y desarrollo de la acción formativa virtual de forma global y conocer si se han sentido parte de una Comunidad de Aprendizaje Virtual.

En la Tabla 27 se presentan el conjunto de variables/categorías que conforman el cuestionario. 


\section{Relativas a la caracterización de las estudiantes (sujetos del estudio)}

\begin{tabular}{|l|l|}
\hline Estado Civil & Lugar de Procedencia y barriada \\
\hline Edad & Situación Laboral \\
\hline Hijos/as (Número y edad) & Disposición de ordenador \\
\hline Estudios & Disposición de internet y lugar de acceso \\
\hline
\end{tabular}

Relativas a la valoración global de las estudiantes sobre el curso

\begin{tabular}{|l|l|}
\hline \multicolumn{2}{|c|}{ Preguntas globales } \\
\hline Información previa & Capacidades para la formación online \\
\hline Cumplimiento expectativas & Establecimiento de nuevas relaciones \\
\hline $\begin{array}{l}\text { Aumento conocimientos/Mejora } \\
\text { conocimientos }\end{array}$ & Mantenimiento de contactos con compañeras \\
\hline Habilidades nuevas & $\begin{array}{l}\text { Adecuación de formación online a } \\
\text { circunstancias personales }\end{array}$ \\
\hline Desenvoltura en ambiente virtual & Aumento de interés por formación online \\
\hline Adaptación al ritmo individual de trabajo & Continuación de formación online \\
\hline
\end{tabular}

Punto de vista

\begin{tabular}{|l|l|}
\hline Interés & Actitudes modificadas \\
\hline Calidad & Uso de lo aprendido \\
\hline Conocimientos adquiridos & Transferencia/aplicación a vida diaria \\
\hline Destrezas(habilidades) adquiridas & \\
\hline
\end{tabular}

Relativas a la valoración de las estudiantes sobre el diseño del curso

\begin{tabular}{|l|l|}
\hline \multicolumn{2}{|c|}{ Objetivos } \\
\hline Claridad & Ajustados a expectativas \\
\hline Realistas & \\
\hline
\end{tabular}

Tópicos o temas (propuestas temáticas)

\begin{tabular}{|l|l|}
\hline Interés & Adecuados/adaptados \\
\hline Novedosos & Consulta material complementario \\
\hline \multicolumn{2}{|c|}{ Tareas y actividades } \\
\hline Adecuadas & Mejor aprendizaje \\
\hline Carga de trabajo & Comprensión \\
\hline
\end{tabular}


Interés e importancia de actividades desarrolladas (Lecturas, Búsquedas, Trabajos individuales y grupales, Debates)

\begin{tabular}{|l|l|}
\hline \multicolumn{2}{|c|}{ Recursos } \\
\hline Programa/Guía Participante & Herramientas utilizadas en el espacio virtual \\
\hline Documentación base & Entorno de trabajo virtual \\
\hline Materiales complementarios & Medios informáticos (a su alcance) \\
\hline Tutoría electrónica & \\
\hline $\begin{array}{l}\text { Valoración de la utilidad de las herramientas } \\
\text { (por orden): Foros de trabajo, Chat, WebQuest, } \\
\text { Glosario Colaborativo, Blog y Correo } \\
\text { electrónico. }\end{array}$ & $\begin{array}{l}\text { Valoración del grado de utilización/uso de las } \\
\text { herramientas: Foros de trabajo, Chat, } \\
\text { WebQuest, Glosario Colaborativo, Blog y } \\
\text { Correo electrónico. }\end{array}$
\end{tabular}

\begin{tabular}{|l|l|}
\hline \multicolumn{2}{|c|}{ Clima } \\
\hline Satisfacción & Ambiente de colaboración y participación \\
\hline Colaboración personal & Colaboración de compañeras \\
\hline \multicolumn{2}{|c|}{} \\
Duración (temporalidad)
\end{tabular}

\begin{tabular}{|l|l|}
\hline Suficiente para intercambiar experiencias & Suficientes horas \\
\hline Suficiente para relación de actividades y tareas & \\
\hline
\end{tabular}

\begin{tabular}{|l|l|}
\hline \multicolumn{2}{|c|}{ Profesorado } \\
\hline Conducción del trabajo & Prestación de ayuda o apoyo \\
\hline Preparación & Constancia y Fluidez en comunicación \\
\hline Rapidez de respuesta & Satisfacción con el papel de tutores/as \\
\hline Facilidad en comunicación & \\
\hline \multicolumn{2}{|c|}{} \\
\hline
\end{tabular}

Utilidad del Foro de evaluación

\begin{tabular}{|l|l|}
\hline \multicolumn{2}{|c|}{ Relativa a la valoración de las estudiantes sobre el desarrollo del curso } \\
\hline \multicolumn{2}{|c|}{ General } \\
\hline Implicación & Productividad de actividades \\
\hline Saber lo esperaban de mí & Actividades nuevas e innovadoras \\
\hline Intervención y participación & \\
\hline \multicolumn{2}{|c|}{ Cumplimiento } \\
\hline Participación & Comunicación tutores/as \\
\hline
\end{tabular}


Evaluación de la aplicación de la acción formativa virtual (Estudio 3)

\begin{tabular}{|c|c|}
\hline Trabajo individual & Cooperación y colaboración \\
\hline Trabajo grupal & Motivación \\
\hline \multicolumn{2}{|l|}{ Comunicación compañeras } \\
\hline \multicolumn{2}{|c|}{ Actitudes } \\
\hline Cambio de visión sobre aprendizaje con TIC & Compartir ideas, respuestas y visiones \\
\hline Responsabilidad & Compromiso \\
\hline \multicolumn{2}{|l|}{ Motivación para trabajar } \\
\hline \multicolumn{2}{|c|}{ Trabajo desarrollado } \\
\hline Sin ayuda & Participación en debates originados \\
\hline Ayuda de aportaciones de compañeras & Aprender compartiendo \\
\hline \multicolumn{2}{|l|}{ Revisión de respuestas de compañeras } \\
\hline \multicolumn{2}{|c|}{$\begin{array}{c}\text { Relativas a la valoración de las estudiantes sobre desarrollo de las sesiones } \\
\text { presenciales }\end{array}$} \\
\hline Adecuación en número & Relaciones compañeras \\
\hline Calidad & Valoración positiva global \\
\hline \multicolumn{2}{|l|}{ Ambiente trabajo } \\
\hline \multicolumn{2}{|c|}{ Visión de las estudiantes sobre las TIC } \\
\hline Trabajo grupal & Compartir conocimientos \\
\hline Motivación & Comunicarse con facilidad \\
\hline Acceso a información & Relación y establecimiento amistades \\
\hline Transferencia & Modificación actitudes y creación nuevas \\
\hline \multicolumn{2}{|c|}{ Opinión de las estudiantes sobre la experiencia (Preguntas abiertas) } \\
\hline Opinión general & Aplicación de lo aprendido \\
\hline Comunidad Virtual de Aprendizaje & Aspectos positivos y negativos \\
\hline Curso de formación online & Otra opinión no preguntada \\
\hline
\end{tabular}

Tabla 27. Variables/categorías del cuestionario de evaluación

Para la valoración se han utilizado dos escalas tipo Likert que responden a las siguientes claves: «totalmente en desacuerdo», «en desacuerdo», 
«indiferente», «de acuerdo», «totalmente de acuerdo»; «nada», «poco», «regular», «bastante», «mucho».

El cuestionario fue contestado por 16 estudiantes, 15 de las cuales consiguieron finalizar el curso. Contesta, también, una de las estudiantes que abandonó el curso.

El Bloque 1 recoge datos sobre 8 cuestiones referentes a la caracterización e identificación los sujetos que responden al cuestionario, en este caso, las estudiantes.

La edades de las 16 estudiantes oscilan entre 18 y 47 años, predominado el tramo de 18 a 35 años, como se observa en el gráfico:

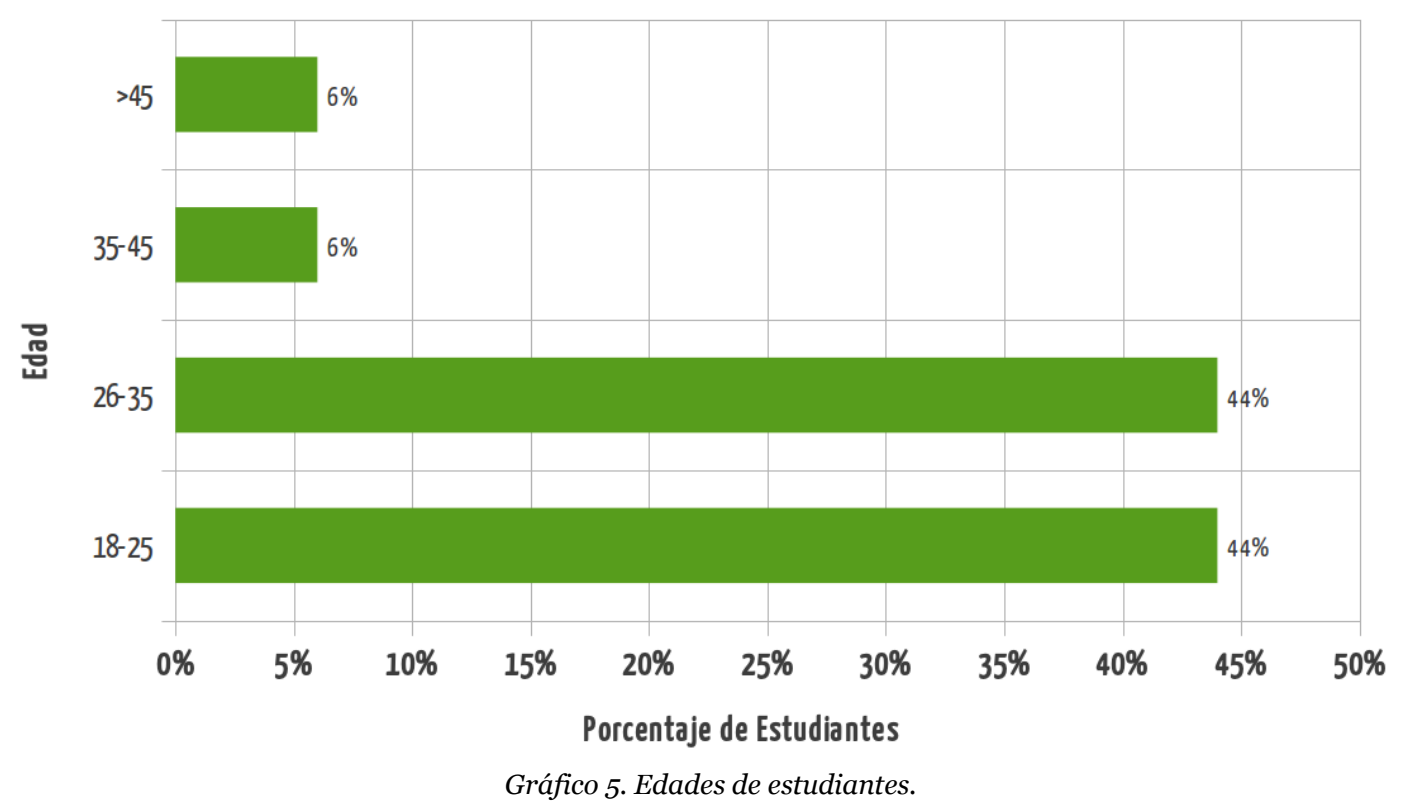

El perfil en cuanto al estado civil es de 50\% casadas y 50\% solteras. Un $37,5 \%$ tienen hijos e hijas a su cargo. Debemos tener en cuenta el matiz de considerar casadas a aquellas parejas que establecen un matrimonio por el rito gitano, y a aquellas que están ya «juntadas» con una pareja estable, aunque legalmente aparezcan como solteras. 
En el nivel formativo tienen el título de Graduado Escolar o ESO el 56\% frente al 12,5\% con el Certificado de Escolaridad, el 6,5\% posee un título de FP de Grado Medio y el 25\% tienen estudios universitarios. De este porcentaje de universitarias, todas han finalizado los estudios a excepción de una, que aún es estudiante.

La procedencia es de diferentes lugares de Extremadura, predominando la provincia de Badajoz, con el 94\% de las mujeres que finalizan la acción formativa.

En cuanto a la situación laboral se encuentra prácticamente el 50\% entre las que tienen un trabajo remunerado y otro 50\% las que no lo tienen o están en paro.

De las 16 mujeres que finalizan el curso, el 75\% disponían de ordenador para realizar las tareas y actividades encomendadas en casa: 3 de los equipos eran portátiles prestados por la entidad organizadora para la realización del curso. El 25\% de mujeres que no disponen de ordenador en casa han accedido desde un Telecentro, desde casa de un familiar o desde el puesto de trabajo.

Entrando en la valoración global del curso (Bloque 2), todos los ítems se situán por encima de la valoración «De acuerdo», considerando ésta como positiva.

Las estudiantes consideran que la información previa ofrecida sobre la acción formativa ha sido adecuada (94\%) y que las expectativas iniciales del curso se han visto finalmente cumplidas también por la práctica totalidad del grupo (94\%). Un elevado porcentaje $(87,5 \%)$ cree que han conseguido incrementar y mejorar sus conocimientos, así como adquirir nuevas habilidades. 
Tras la realización de la acción formativa, valoran positivamente sus capacidades para el uso de plataformas de e-learning $(87,5 \%)$ y todas las alumnas afirman que han sido capaces de trabajar con autonomía durante el curso, marcando su propio ritmo de aprendizaje.

La experiencia formativa ha permitido a las estudiantes establecer nuevas relaciones con compañeras (94\%), si bien el mantenimiento de estos contactos una vez concluido el curso, se reduce al $63 \%$.

Un porcentaje ligeramente superior al 80\% de las estudiantes opinan que los cursos de formación online son más adecuados que los presenciales dadas sus circunstancias personales (familiares, laborales, económicas o geográficas). De hecho, todas confirman que estarían dispuestas a realizar, en el futuro, otras actividades formativas en esta modalidad virtual (81\%). Aún en referencia a la valoración global del curso, les solicitamos que dieran su punto de vista de 1 a 5 (oscilando entre «muy alto» y «muy bajo») en aspectos como los siguientes que presentamos, y que en una media de todos se sitúa en «alto». La acción formativa es considerada de interés y calidad por las estudiantes (94\%) afirmando haber adquirido nuevos conocimientos (70\%), destrezas (81\%) y actitudes (70\%) y considerando que todo lo aprendido es útil y se puede transferir a su vida diaria (81\%).

En general, hemos observado que la valoración global del curso, por parte de las propias estudiantes, se sitúa en valores altos, pudiendo establecer una evaluación global positiva de la acción formativa desarrollada.

La valoración del diseño (Bloque 3) de la acción formativa virtual es una de las cuestiones que más interés nos suscita puesto que uno de los principales objetivos es valorar la pertinencia de este diseño por parte de las propias destinatarias del mismo, tras haberlo implementado.

Los objetivos planteados son claros y realistas para las estudiantes (88\%) además de considerarse adaptados a sus necesidades formativas $(81,5 \%)$, al 
igual que los tópicos y la documentación presentada para trabajar en el curso, que han suscitado el interés de las participantes por considerarse novedosos $(87,5 \%)$ y adecuados a su nivel (94\%). El material complementario añadido, además de los temas y materiales propios de la acción formativa, ha sido consultado y utilizado por las estudiantes (81\%).

Las tareas y actividades y la carga de trabajo que ha conllevado su resolución también ha sido apropiado $(81,5 \%)$, han ayudado a comprender mejor el contenido de cada propuesta temática $(87,5 \%)$ y, por tanto, les ha permitido mejorar sus aprendizajes (94\%). En cuanto al grado de importancia de las actividades vemos que, en el primer nivel, se sitúan los debates dirigidos por tutoras y tutores (94\%) como la actividad que mayor interés ha despertado, seguido de la lectura de documentos $(87,5 \%)$, los trabajos individuales y grupales $(81,5 \%)$, los debates dirigidos por compañeras (74\%) y la búsqueda de información (63\%).

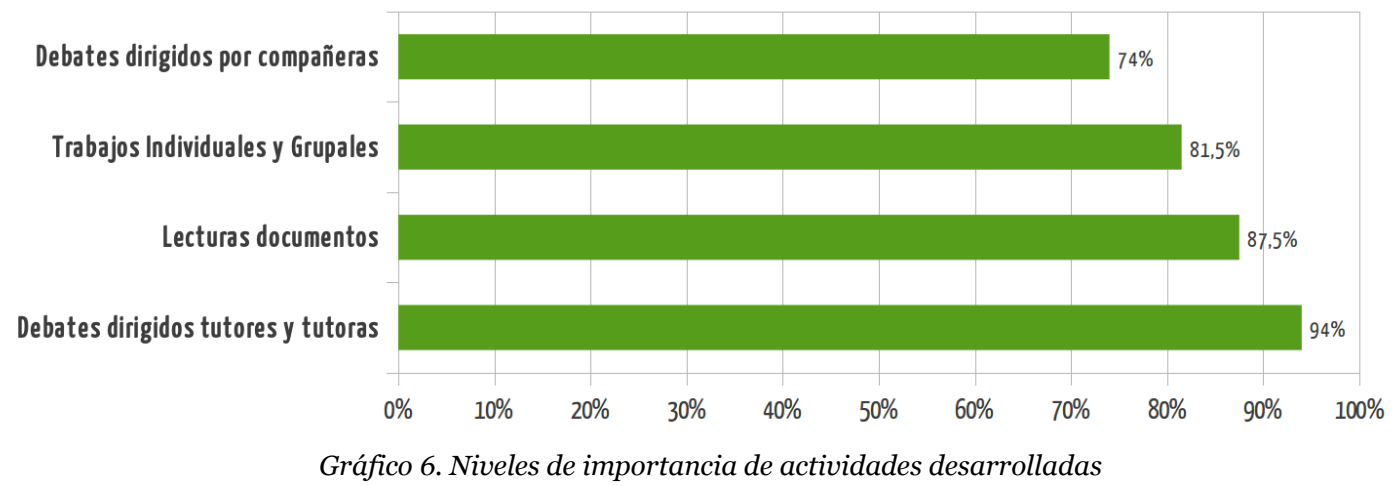

Los recursos ofrecidos para un mejor seguimiento y desarrollo del curso también obtienen diferentes niveles de interés, siendo los materiales y documentos base los mejor valorados (100\%), seguidos de las herramientas utilizadas -foros, webquest, glosarios, mensajes y chat- (94\%), del programa del curso o «Guía de la participante» (94\%), la tutoría electrónica $(87,5 \%)$ y los materiales complementarios $(75,5 \%)$. 


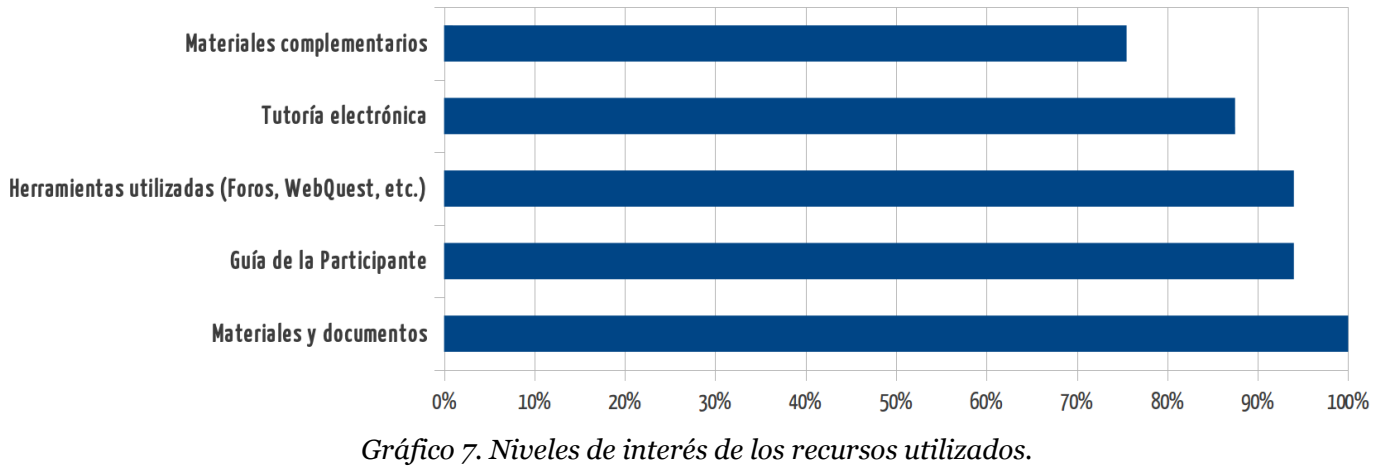

El entorno virtual de trabajo, refiriéndonos al Campus Virtual (CVUEx), alcanza el $100 \%$ de valoraciones positivas de la estudiantes en cuanto a uso y adecuación, al igual que los medios informáticos al alcance las participantes (94\%). Esto nos hace pensar que los recursos puestos a su disposición (Telecentros, portátiles) han sido adecuados y bien valorados por ellas.

Nos interesaba indagar un poco más en la opinión sobre las herramientas en cuanto a su utilidad y grado de uso. Para ello solicitamos, en una puntuación de 1 a 6 , que ordenaran la lista de recursos en función del grado de mayor utilidad, obteniendo los siguientes resultados. Despuntan en primer lugar los Foros Sociales de Trabajo, seguidos del Correo electrónico, los Blogs, el Glosario colaborativo, la WebQuest y por último, en sexto lugar, el Chat.

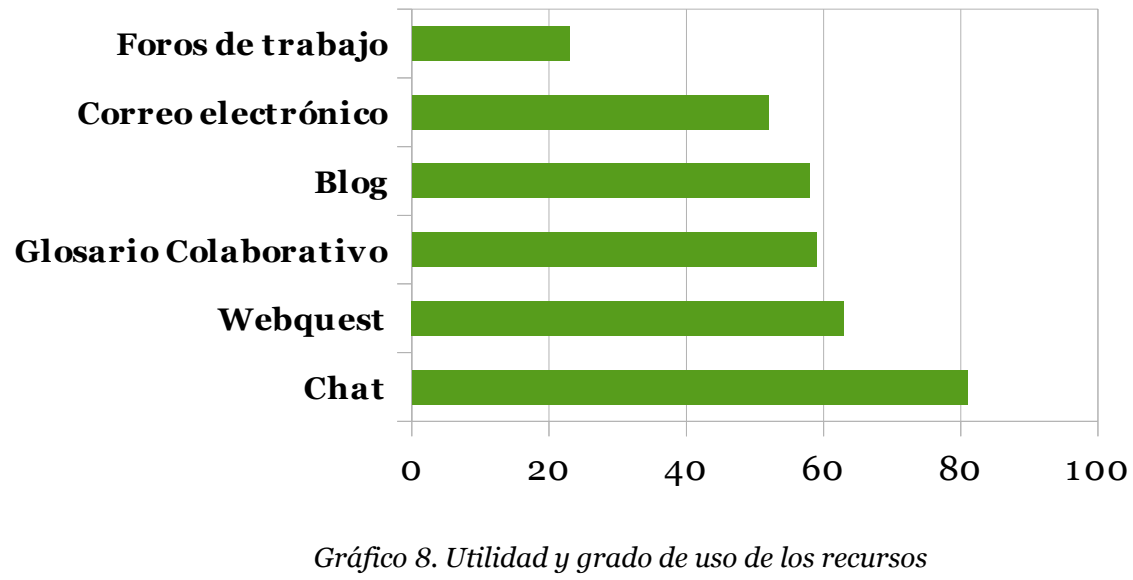


Se muestra en el gráfico los puntos totales calculados con respecto a la puntuación valorada en utilidad de la herramienta, siendo «1» la primera posición y «6» la última. Se interpreta, por tanto, que la menor puntuación es el recurso más valorado y de mayor utilidad.

Les solicitamos, en relación con lo anterior, una valoración sobre el grado de utilización de estos recursos, sobre la escala de «nada-mucho» y en estos resultados obtuvimos datos que se corresponden con las valoraciones anteriores sobre la utilidad y también con los recursos más utilizados para las actividades en el espacio virtual. El Foro Social de Trabajo vuelve a situarse como el recurso más utilizado $(81,5 \%)$, situándose en segundo lugar el glosario colaborativo (81,5\%), el correo electrónico y los Blogs (75\%) y la WebQuest (70\%). El Chat se sitúa, como antes, en la última posición (44\% lo ha usado «poco» o «nada»)

Si combinamos las dos últimas cuestiones sobre valoración de utilidad y grado de uso, comprobamos que los recursos más valorados son los que más se han utilizado durante el curso, correspondiendo con el Foro Social de Trabajo, el correo electrónico y el Glosario colaborativo. El menor ha sido el Chat, que también se corresponde con el menos utilizado, habiéndose registrado tan sólo 7 sesiones abiertas de Chat, alguna con sólo un mensaje de saludo.

Uno de los aspectos importantes para la conformación de la Comunidad de Práctica es el favorecer un buen clima en el desarrollo del curso. Las estudiantes consideran que el clima del curso ha sido satisfactorio (94\%) y ha habido un buen ambiente de colaboración y participación (87,5\%). La mitad de las estudiantes (50\%) cree que, de manera personal, ha colaborado en el mantenimiento de ese ambiente, siendo un porcentaje mayor $(87,5 \%)$ las que opinan que sus compañeras también han contribuido a crear un buen clima. 
La duración de la acción formativa ha sido suficiente para el intercambio de experiencias y para desarrollar las tareas y actividades encomendadas (70\%), cuestión que se relaciona con la valoración de las horas totales dedicadas al curso y que las participantes muestran como suficientes en un $62,5 \%$.

La valoración de tutores y tutoras es muy buena por parte de todas las estudiantes. Creen que los y las docentes están muy preparados y son especialistas en la temática trabajada (100\%), han sabido conducir el trabajo a realizar (94\%) y han respondido con rapidez a sus demandas (100\%), cuestión fundamental para el mantenimiento de la motivación. La comunicación con el profesorado ha sido fluida y constante (94\%), valorando su desempeño como muy satisfactorio (100\%). El recurso «Foro de Evaluación», destinado a la evaluación y autoevaluación continua de la acción formativa, ha sido muy útil para todas las estudiantes.

En el Bloque 4 les preguntamos acerca del desarrollo del curso realizando algunas afirmaciones genéricas sobre el mismo que debían valorar en la escala de 1 a 5 correspondientes a «totalmente de acuerdo» y «totalmente en desacuerdo»

El 94\% de las estudiantes cree que su implicación, intervención y participación ha sido máxima durante el curso sabiendo, en todo momento, qué se esperaba de ellas (75\%). Las actividades que han desarrollado les han resultado productivas (100\%) por ser actividades innovadoras (94\%). Consideran, así mismo, que han cumplido con los compromisos adquiridos para desarrollar de manera adecuada la acción formativa y conseguir los logros perseguidos $(87,5 \%)$ tanto individualmente como de forma grupal (100\%). La colaboración con las demás compañeras ha sido constante $(87,5 \%)$, así como la comunicación con éstas, que es valorada en un nivel alto en la escala propuesta, de tal modo que el 62,5\% de las participantes considera que esa comunicación ha sido muy buena, valorando en un 
porcentaje superior (94\%) la comunicación con tutores y tutoras. Han estado motivadas de forma continua (94\%), autovalorando su trabajo, su asunción de responsabilidad y su actitud positivamente.

La visión del aprendizaje con TIC ha cambiado para las estudiantes tras realizar el curso (94\%) considerando además, un acierto la modalidad seleccionada, pues las ha motivado a trabajar (100\%); han compartido ideas, respuestas y visiones con las compañeras y con el profesorado $(87,5 \%)$. Sin embargo, cuando preguntamos si la mayoría de las cosas que han aprendido durante el curso lo han hecho sin ayuda de tutores y tutoras, los datos se distribuyen equitativamente entre los niveles de «desacuerdo» (37,5\%) y «acuerdo» (44\%). Esto puede ser por dos cuestiones de las siguientes: una, porque entienden que las aportaciones de las compañeras han sido de ayuda para trabajar los temas (94\%); otra, porque creen que pueden aprender más compartiendo sus ideas con otras personas (100\%). De hecho, un porcentaje alto de las estudiantes (94\%) afirma haber revisado las respuestas de las compañeras a los debates planteados para establecer su propia aportación.

Las sesiones presenciales (Bloque 5) han sido muy bien valoradas, de forma global por las participantes (94\%), habiéndose desarrollado un número adecuado (70\%) con algunas valoraciones que muestran que podría haberse planteado alguna sesión más. Estas sesiones han sido de calidad y han tenido un ambiente de trabajo muy bueno (87,5\%), manteniendo buenas relaciones con las demás compañeras.

Por otro lado, la visión de las TIC (Bloque 6), por parte de las estudiantes tras el desarrollo de la acción formativa virtual, es muy positiva. Creen que motivan al aprendizaje, facilitan el trabajo en grupo y permiten relacionarse y establecer amistades en relación a un interés común (94\%). Facilitan, además, el acceso a una gran cantidad de información y el intercambio de conocimientos, así como la creación de nuevas actitudes o su modificación (100\%). Todas las estudiantes piensan que las TIC ofrecen 
facilidades para transferir los conocimientos adquiridos y para comunicarse con otras personas.

Ofrecemos las respuestas a la formulación de preguntas abiertas de opinión (Bloque 7) con respecto a la experiencia completa.

En primer lugar solicitamos una valoración general de la experiencia. Todas las participantes destacan la experiencia como positiva y motivadora, como un proyecto gratificante con el que han aprendido ideas nuevas:

«Ha sido una experiencia muy positiva ya que me ha ayudado a conocer nuevas ideas de otras personas y a dialogar sobre ello, además de animarme en mi vida diaria y conocer nuevas cosas de mi cultura».

«Me ha gustado mucho, ha sido interesante y he aprendido mucho $y$ descubierto muchas cosas. Me ha gustado mucho el uso de internet para realizar un curso y compartir experiencias con mis compañeras».

Algunas destacan que la experiencia les ha servido de ayuda, no sólo a nivel profesional, sino personal. También se refieren a la flexibilidad que se ha tenido en su desarrollo, incidiendo en lo mucho que han aprendido de las demás participantes.

Por otro lado, les solicitamos que nos comenten si se han sentido parte de una Comunidad Virtual de Aprendizaje. En este sentido lo valoran afirmativamente en todos los casos, matizando el diálogo fluido, la buena comunicación, la participación, el dinamismo, la colaboración y ayuda entre compañeras y, además, señalando un matiz de diversión mientras aprenden. Se destaca la eficacia de la tutoría para fomentar esas relaciones positivas.

«La verdad es que ha sido muy dinámico y ha habido una gran colaboración y relación entre tutora, compañeras, dinamizadora. Hemos creado debates muy interesantes y todas hemos participado». 
Destacan, unido a lo anterior, la posibilidad de hacer nuevas amistades, de compartir ideas, de sentirse unidas pese a la distancia geográfica y formar parte de «algo» que se estaba generando.

«Sí, porque he aprendido mucho, he hecho nuevas amistades, he compartido ideas y he adquirido nuevos conocimientos».

«Me he sentido como diría yo, como en casa, éramos un grupo que poco a poco no hicimos una piña hasta llegar a ser una sola».

«Sí, ya que he formado parte de un grupo de mujeres con un interés común y que debido a la distancia el Campus Virtual nos ha servido como punto de encuentro y debate».

Además, de la posibilidad de compartir conocimientos, resaltan la posibilidad de conocer otros puntos de vista diferentes:

«La verdad que sí. Porque ves cada respuesta de cada una de ellas y ves como piensan y cada idea que de cada una son distintas».

Les preguntamos sobre la posibilidad de hacer un nuevo curso en modalidad online, a la que todas responden positivamente. Las razones que matizan son que les resulta fácil, gratificante y divertido, siendo fundamental el aprendizaje de cosas nuevas y el compañerismo. También varias insisten en la flexibilidad en el desarrollo y las posibilidades de adaptación horaria que permite esta modalidad, cuando se necesita conciliar.

Sobre la aplicación de lo aprendido a su vida diaria, personal y/o profesional, de manera mayoritaria señalan que todo lo que han aprendido lo aplican a sus vidas, destacando cuestiones como:

- Defender el derecho de la mujer gitana en sus vidas cotidianas con más fuerza, animando a otras mujeres a que sean más luchadoras y «pensar en hacer más», aprovechando todas las oportunidades que les surjan. 
- El manejo de internet y de herramientas online, destacando el blog como medio para opinar y darse a conocer: «Lo de los Blogs me ha parecido algo muy bueno y algo para que podamos dar nuestra opinión y que nos conozcan más cómo somos». Alguna afirma tener otros blogs creados ya.

- Buscar información sobre la cultura gitana.

- Aplicar el liderazgo como un medio para escuchar, de respeto de nuevas opiniones, para ejercerlo a diario en sus hogares, trabajos y en sus relaciones personales.

«Todo el aprendizaje de internet, el blog que sigo usando y los temas de igualdad y liderazgo, sobre todo liderazgo que es muy aplicable a mi vida diaria».

Les pedimos en la siguiente cuestión que destacaran tres aspectos positivos y tres aspectos negativos de la experiencia.

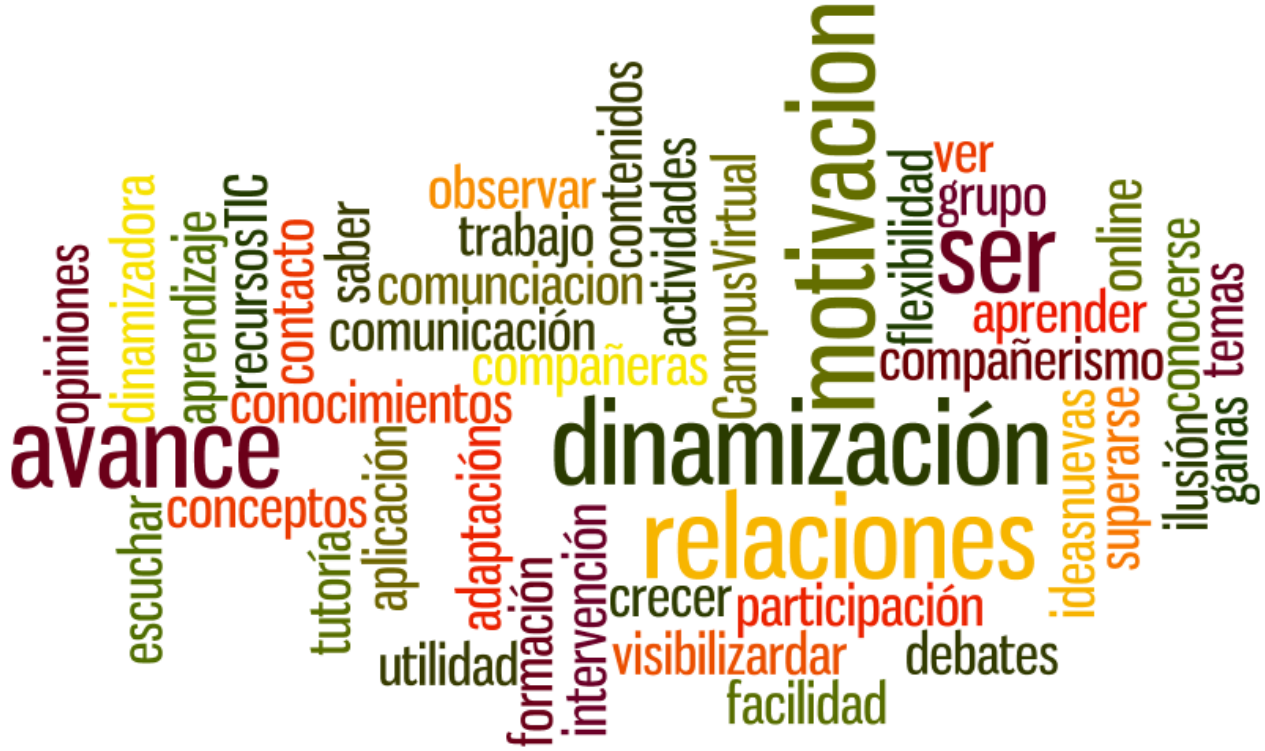

Figura 46. Aspectos positivos del desarrollo de la acción formativa.

En cuanto a los positivos, lo podemos agrupar en: 
Relacionados con el aprendizaje y el desarrollo del curso: conciencia de conceptos, conocimientos aportados, ideas nuevas, contenidos y temas trabajados, utilidad y aplicación a nivel personal y profesional, ganas e ilusión por aprender. En cuanto al desarrollo del curso: flexibilidad en tiempos y espacios, adaptación a circunstancias personales, facilidad para desarrollar el trabajo y actividades, debates, tutoría y figura de la dinamizadora.

Relacionados con las TIC: aprendizaje de recursos TIC, Campus Virtual de la Universidad de Extremadura y formación online.

Relacionados con aspectos sociales: conocerse a una misma («hay más en mí de lo que yo pensaba»), hacerse escuchar, visibilizar a mujeres gitanas, dar a conocer sus opiniones, participación, dinamización, conocer a otras gitanas que quieren crecer y superarse, ver que la comunidad gitana avanza: «El contacto con otras mujeres gitanas, el ver la forma de pensar y aprender de todas nosotras y el saber que somos y estamos presentes para muchas personas». Otro aspecto que destacan las estudiantes son las buenas relaciones con las compañeras, refiriéndose a ellas como el grupo, compañerismo, relaciones con los y las demás, buena comunicación, en definitiva, como indica una de ellas textualmente: «el grupo que ha salido del curso».

Los aspectos negativos señalados se clasifican de la siguiente forma:

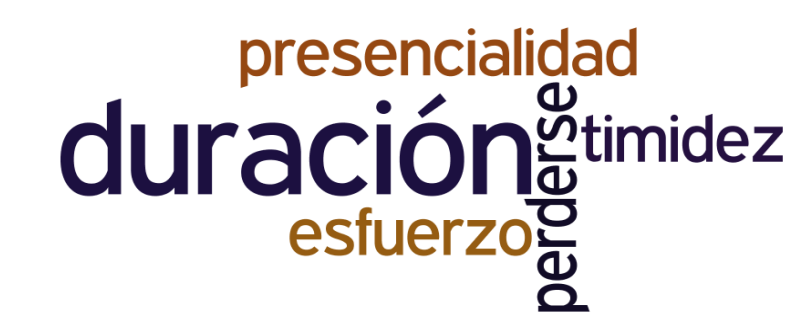

Figura 47. Aspectos negativos del desarrollo de la acción formativa.

En relación al desarrollo, señalan que si pierden el hilo de los debates, les cuesta mucho retomar el tema de nuevo para aportar sus opiniones. 
También, alguna estudiante comenta que ha terminado el curso con menos ganas que lo comenzó.

En relación a la duración, creen que ha sido corto, propondrían hacer un curso un poco más largo en el tiempo.

En relación a las sesiones presenciales destacan la falta de participación de alguna compañera y la timidez para hablar con éstas en un ambiente presencial: «Que por el Campus hablamos más que en persona». Alguna valora como negativa estas sesiones, por suponer un esfuerzo de traslado a personas con familias a cargo.

En relación a aspectos sociales, destacan como negativo que son pocas aún las que participan en iniciativas de esta índole, y además proponen la apertura a la participación de hombres gitanos en cursos de esta tipología: «Los hombres deberían participar, escuchar y aprender».

En el espacio abierto a cuestiones no preguntadas con anterioridad, las aportaciones de las estudiantes se refieren a la satisfacción con la experiencia y a felicitar a tutores y tutoras y a la dinamizadora por su labor y su trato además de agradecer la oportunidad que se les ha brindado. 


\subsection{Datos relativos a la Evaluación del Modelo de estrategias didácticas desarrolladas en el Curso: Expertos externos.}

\subsubsection{Explicación del instrumento de evaluación y expertos seleccionados.}

El instrumento utilizado se denomina A.D.E.C.U.R. (Análisis Didáctico de los modelos y Estrategias de Enseñanza de Cursos Universitarios en Red) y está elaborado por el Dr. Eloy López Meneses, fruto de su Tesis Doctoral titulada «Análisis de los modelos didácticos y estrategias de enseñanza en Teleformación: diseño y experimentación de un instrumento de evaluación de las estrategias de enseñanza de cursos telemáticos de formación universitaria», dirigida por los catedráticos Julio Cabero Almenara y Pedro Cañal de León de la Facultad de Ciencias de la Educación de la Universidad de Sevilla.

Este instrumento didáctico evalúa dos grandes dimensiones en cursos universitarios online, la dimensión psico-didáctica y la dimensión técnicaestética, con la finalidad de observar a qué modelo de enseñanza responden éstos. Estas dimensiones recogen varios elementos que a su vez se derivan en componentes, éstos últimos en ítems con sus correspondientes criterios de evaluación Cada criterio debe responderse en dos únicas opciones: un «1» si se cumple el criterio enunciado, o «O» en caso de no aparecer en el curso virtual evaluado.

La dimensión psico-didáctica, recoge los principales elementos curriculares, entre los que se encuentran: la intenciones y finalidades educativas, la información que se muestra, las actividades que presenta el curso y su secuenciación, el ambiente de aprendizaje, la tipología evaluativa y el seguimiento tutorial que se realiza. Esta dimensión se compone de seis 
ejes de progresión, que según Cabero y López (2009) vienen a representar el conjunto de componentes referidos a las concepciones didácticas y al pensamiento y la práctica del docente. La dimensión técnica-estética, por otro lado, valora todo lo referente al diseño del entorno, su sistema de navegación, usabilidad y elementos hipermedia.

Se han seleccionado tres expertos/as en temáticas diseño, implementación y evaluación de acciones formativas virtuales, incluido el creador de la herramienta A.D.E.C.U.R:

- Dra. Laura Alonso Díaz. Profesora del Área de Teoría e Historia de la Educación del Departamento de Ciencias de la Educación de la Universidad de Extremadura.

- Dr. Francisco Revuelta Domínguez. Profesor del Área de Didáctica y Organización Escolar del Departamento de Ciencias de la Educación de la Universidad de Extremadura.

- Dr. Eloy López Meneses. Profesor del Departamento de Ciencias Sociales de la Universidad Pablo de Olavide de Sevilla. Creador de la herramienta A.D.E.C.U.R.

\subsubsection{Resultados de la evaluación de expertos en referencia al modelo y estrategias didácticas utilizada en el curso virtual «Igualdad de Oportunidades y Liderazgo Social» •}

Se ofrece el siguiente cuadro con los resultados globales de la valoración de los expertos. 
Evaluación de la aplicación de la acción formativa virtual (Estudio 3)

\begin{tabular}{|c|c|c|c|c|c|}
\hline & EJE & Indicadores & EXPERTO 1 & EXPERTO 2 & EXPERTO $3_{3}$ \\
\hline \multirow{24}{*}{ 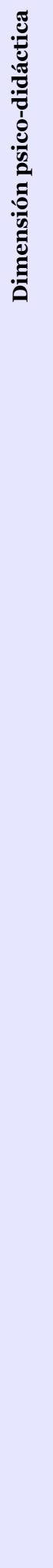 } & \multirow{2}{*}{$\begin{array}{l}\text { Ambiente } \\
\text { Virtual }\end{array}$} & $\begin{array}{l}\text { 1. Relaciones de poder } \\
\text { y afectivas. }\end{array}$ & $100 \%$ & $100 \%$ & $100 \%$ \\
\hline & & Porcentaje Total & $100 \%$ & $100 \%$ & $100 \%$ \\
\hline & \multirow{5}{*}{ Aprendizaje } & $\begin{array}{l}\text { 2. Significatividad/ } \\
\text { comprensión. }\end{array}$ & $61,54 \%$ & $76,92 \%$ & $69,23 \%$ \\
\hline & & 3. Interacción social. & $100 \%$ & $100 \%$ & $100 \%$ \\
\hline & & 4. Integración. & $50 \%$ & $100 \%$ & $50 \%$ \\
\hline & & 5. Funcionalidad. & $100 \%$ & $100 \%$ & $100 \%$ \\
\hline & & Porcentaje Total & $72,22 \%$ & $94,44 \%$ & $77,78 \%$ \\
\hline & \multirow[b]{3}{*}{ Objetivos } & 6. Función. & $0 \%$ & $100 \%$ & $50 \%$ \\
\hline & & 7. Formulación. & $100 \%$ & $100 \%$ & $100 \%$ \\
\hline & & Porcentaje Total & $50 \%$ & $100 \%$ & $75 \%$ \\
\hline & \multirow{4}{*}{ Contenidos } & 8. Función. & $100 \%$ & $100 \%$ & $100 \%$ \\
\hline & & $\begin{array}{l}\text { 9. Diversidad de } \\
\text { contenidos y fuentes. }\end{array}$ & $71,43 \%$ & $100 \%$ & $100 \%$ \\
\hline & & $\begin{array}{l}\text { 10. Significatividad } \\
\text { potencial y validez } \\
\text { didáctica. }\end{array}$ & $81,82 \%$ & $72,73 \%$ & $100 \%$ \\
\hline & & Porcentaje Total & $78,95 \%$ & $84,21 \%$ & $100 \%$ \\
\hline & \multirow{7}{*}{$\begin{array}{l}\text { Actividades y } \\
\text { secuenciación }\end{array}$} & $\begin{array}{l}\text { 11. Tipos de } \\
\text { actividades. }\end{array}$ & $77,78 \%$ & $88,89 \%$ & $88,89 \%$ \\
\hline & & 12. Colaboración. & $100 \%$ & $100 \%$ & $100 \%$ \\
\hline & & 13. Autonomía. & $40 \%$ & $100 \%$ & $80 \%$ \\
\hline & & 14. Secuenciación. & $75 \%$ & $91,67 \%$ & $100 \%$ \\
\hline & & $\begin{array}{l}\text { 15. Coherencia entre } \\
\text { objetivos, contenidos y } \\
\text { actividades. }\end{array}$ & $100 \%$ & $100 \%$ & $100 \%$ \\
\hline & & 16. Contextualización. & $100 \%$ & $100 \%$ & $100 \%$ \\
\hline & & Porcentaje Total & $53 \%$ & $62,71 \%$ & $64,57 \%$ \\
\hline & \multirow{3}{*}{$\begin{array}{l}\text { Evaluación y } \\
\text { acción tutorial }\end{array}$} & 17. Tipo de evaluación. & $77,78 \%$ & $88,89 \%$ & $100 \%$ \\
\hline & & $\begin{array}{l}\text { 18. Instrumentos de } \\
\text { evaluación. }\end{array}$ & $42,86 \%$ & $85,71 \%$ & $85,71 \%$ \\
\hline & & $\begin{array}{l}\text { 19. Criterios de } \\
\text { evaluación. }\end{array}$ & $100 \%$ & $100 \%$ & $100 \%$ \\
\hline
\end{tabular}




\begin{tabular}{|c|c|c|c|c|c|}
\hline & $\begin{array}{l}\text { 20. Tipo de acción } \\
\text { tutorial. }\end{array}$ & $100 \%$ & $75 \%$ & $100 \%$ \\
\hline & & Porcentaje Total & $80,16 \%$ & $87,40 \%$ & $96,43 \%$ \\
\hline \multirow{4}{*}{ 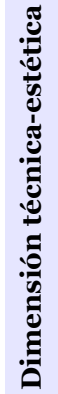 } & \multirow{4}{*}{$\begin{array}{l}\text { Recursos y } \\
\text { aspectos } \\
\text { técnicos }\end{array}$} & $\begin{array}{l}\text { 21. Calidad del entorno } \\
\text { hipermedia. }\end{array}$ & $100 \%$ & $100 \%$ & $100 \%$ \\
\hline & & $\begin{array}{l}\text { 22. Diseño y sistema } \\
\text { de navegación. }\end{array}$ & $85,71 \%$ & $100 \%$ & $100 \%$ \\
\hline & & $\begin{array}{l}\text { 23. Facilidad de uso } \\
\text { (Usabilidad). }\end{array}$ & $50 \%$ & $50 \%$ & $50 \%$ \\
\hline & & Porcentaje Total & $81,82 \%$ & $90,91 \%$ & $90,91 \%$ \\
\hline
\end{tabular}

Tabla 28 Resultados de la evaluación experta sobre las dimensiones, ejes de progresión y grupos de indicadores de A.D.E.C.U.R.

En la dimensión psico-didáctica se obtiene una puntuación en cumplimiento de criterios alta, situando la valoración de los expertos en un $92,31 \%, 91,35 \%$ у $75,96 \%$.

El porcentaje de evaluación del eje ambiente/clima del aula virtual, el 100\% de las repuestas por parte de los expertos y la experta, confirma que en el conjunto del curso se fomenta un ambiente de trabajo reflexivo, dinámico y participativo, estimulando a las estudiantes sobre la importancia y la utilidad del curso y favoreciendo el trabajo en grupo. Además, se crean espacios comunes para el diálogo y el desarrollo de lazos sociales entre las participantes del curso, invitando a éstas a la implicación, a la responsabilidad personal y colectiva. Se valora la utilización de un estilo de lenguaje abierto y empático, promoviendo un buen clima del aula virtual. Por tanto, el curso promueve un ambiente motivador, afectivo y democrático.

En el eje aprendizaje, los porcentajes de valoración son del 72,22\%, 94,44\% y 77,78\%. Si indagamos en los ítems, observamos que, según los expertos y la experta, el curso estimula una reflexión inicial sobre las ideas de las estudiantes al trabajar nuevos conocimientos, facilitando que éstas interaccionen con las nuevas informaciones en la construcción de los mismos. En cuanto a la significatividad/comprensión, se valora con la máxima 
puntuación la estimulación de la reflexión inicial sobre las ideas y conocimientos de las estudiantes al trabajar nuevos conocimientos y la promoción, en todo momento, para que las ideas interaccionen con las nuevas informaciones en la construcción de los conocimientos. También se considera que se tienen en cuenta los conocimientos iniciales de cada participante a la hora de plantear y dinamizar las actividades para facilitar los aprendizajes. Sin embargo, no hay acuerdo en el ítem referido a la posibilidad de inscribirse en el curso en diferentes niveles de profundización. Esta valoración es idónea, puesto que en nuestra acción formativa no se han establecido niveles. La valoración de la funcionalidad, que hace referencia a la inclusión de recursos que generen reflexión sobre experiencias personales para facilitar el planteamiento de nuevas experiencias, se evidencia para dos de los expertos. En al acción formativa, se dan diferentes procedimientos para facilitar y mejorar la comprensión: aportando recomendaciones didácticas orientando las tareas hacia la asimilación y el aprendizaje significativo, incluyendo metáforas o ideas familiares y cotidianas, clarificando la información y presentando ejemplos claros y cotidianos e incluyendo, por último, preguntas/interrogantes y un glosario colaborativo para facilitar la adquisición de conceptos. Hay dos de los expertos/a que plantean la falta de mapas conceptuales aclaratorios o simulaciones y aplicaciones de realidad virtual para conseguir esta finalidad. En cuanto a la interacción social, se cumple con el criterio de estimular la negociación y contraste de las concepciones personales entre las estudiantes, desde el punto de vista de los tres expertos. Así, creen que se proporcionan recursos para facilitar las relaciones entre los conocimientos porque se incluyen actividades colaborativas. Por otra parte, también se valora el cumplimiento de los criterios relacionados con la inclusión de actividades de aplicación real para la adquisición de competencias relacionadas con el perfil del curso.

En referencia a la función de los objetivos, en nuestro caso competencias, hay acuerdo en valorar que cada estudiante puede seguir su propio ritmo de 
aprendizaje. Y en cuanto a la formulación, se considera que son significativas y están enunciadas correctamente.

Los contenidos son entendidos como información procedente de diversas fuentes y son valorados como suficientes, bien secuenciados, relevantes y actualizados. El lenguaje empleado es adecuado (directo, conciso y adaptado) a las participantes.

De manera general, en las actividades se cumplen todos los criterios a valorar, comenzando por los tipos de actividades, que están relacionadas con los intereses, ideas y expectativas previas de las estudiantes, orientadas a la integración de los conocimientos previos y nuevos. Sin embargo, un experto plantea la falta de actividades de elaboración de mapas conceptuales o similares. Se considera que las actividades están expresadas para promover la comprensión, negociación, la resolución conjunta de problemas y la reflexión sobre lo aprendido, desde los diferentes puntos de vista. También se destaca la promoción de la colaboración, con actividades que posibilitan los trabajos grupales y el intercambio de ideas y experiencias. Se valora con el cumplimiento de algunos criterios la referencia a toma de decisiones, sugerencias y propuestas que fomentan el trabajo autónomo de las estudiantes. En cuanto a la secuenciación se estima que las situaciones se han creado para facilitar el enfoque integrador, es decir, que existen actividades para seleccionar problemas motivadores que promuevan el contraste de conocimientos y exploren diferentes fuentes de información. También se cumplen los criterios referidos a estructurar, relacionar, comunicar y sintetizar los hallazgos encontrados. Según los expertos/as, hay congruencia entre todos elementos didácticos de la acción formativa virtual (competencias, contenidos, actividades y proceso de evaluación) y las actividades están adecuadamente contextualizadas.

El último eje de progresión, referido a la dimensión psico-didáctica, es la evaluación y acción tutorial. Consta de cuatro componentes para la 
valoración del cumplimiento de los criterios referidos, en primer lugar, al tipo de evaluación. Se cumplen que la evaluación desarrollada es formativa, se realiza de forma procesual y continua y está basada en la práctica educativa. Según los expertos y la experta se plantea como un proceso de orientación del estudiante, incluyendo evaluaciones conjuntas a través de foros virtuales destinados a esta labor. Aunque se cumple ese criterio, no se cumplen los referidos a la inclusión de la realización personal de diferentes pruebas de evaluación sobre los resultados de aprendizaje del curso. A pesar de ello, los criterios cumplidos confirman que la evaluación presenta un enfoque integrador. El tipo de acción tutorial es un eje también valorado con el cumplimiento de todos los criterios a excepción de uno referido a la inclusión de figuras virtuales animadas que va aportando al estudiante diferentes informaciones necesarias en determinados momentos para seguir el programa del curso. Por lo demás, se cumplen los indicadores que se relacionan con los roles de tutores y tutoras con la función de asesoría, orientación, supervisión y dinamización del proceso formativo.

La dimensión técnica-estética también se sitúa en porcentajes altos de cumplimiento de criterios, siendo la valoración de expertos y experta del $90,91 \%$ y $81,82 \%$ relativamente.

La calidad del entorno hipermedia tiene todos los criterios especificados en la herramienta, refiriéndose al texto, imagen fija, movimiento, sonido e iconos, siendo significativos, intuitivos, didácticos y relevantes para la formación de las estudiantes. Por otro lado, el diseño del sistema de navegación cumple los criterios de homogeneidad, uniformidad, consistencia y transparencia, considerándose adecuada. Aparecen, además, calendarios y tablones que muestran la propuesta de planificación temporal del curso. Aunque están bien puntuados los criterios referidos a la usabilidad del entorno gráfico, hay uno que no se cumplen: el uso de listas con viñetas. Según los expertos/as no se permite a las estudiantes guardar, recuperar o imprimir historiales de recorrido, marcadores y/o rutas seguidas. 
La evaluación completa de los expertos y experta $(86,4 \%, 87,5 \%$ y 76,7\%) del cumplimiento de los criterios que propone el modelo A.D.E.C.U.R. valida el modelo pedagógico utilizado en el curso virtual una vez finalizado, respondiendo, como establecimos en su diseño, a un modelo integrador.

\subsection{Análisis e interpretación de los datos obtenidos en la evaluación del desarrollo de la acción formativa virtual: participantes y profesorado-tutor.}

Entramos, en último lugar, en el análisis y la interpretación de los datos obtenidos de la evaluación del desarrollo de la experiencia e-learning. Esta evaluación del desarrollo de la acción formativa virtual valora la pertinencia o no, de la complejidad de todos los aspectos tenidos en cuenta en el diseño de la misma, ahondando en la opinión de los agentes participantes sobre su utilización y desarrollo. Esta es la finalidad que se ha pretendido mediante el análisis de las entrevistas, el grupo de discusión realizado y los datos obtenidos del foro de evaluación continua. En suma, todos estos elementos nos proporcionan una visión holística de lo que ha sucedido en la acción formativa virtual teniendo en cuenta los diferentes puntos de vista. Así se puede construir una realidad más fidedigna de lo que ha acontecido puesto que se tienen en cuenta a los agentes participantes en esta experiencia.

De las entrevistas realizadas a siete tutores y tutoras, tanto de la parte virtual como de las sesiones presenciales, se han obtenido diferentes temas que han ordenado en categorías que conforman a su vez un modelo o dimensión explicativa de la evaluación de esta acción formativa que se ha desarrollado. Estos instrumentos, por tanto, nos han dotado de información con la cual se han extraído tres dimensiones que consideramos fundamentales para la evaluación de acciones e-learning desde una perspectiva social: la dimensión didáctica, la sociocultural y la tecnológica. 
Debemos aclarar que se han recogido las expresiones textuales de las participantes en el caso de la información recogida a través del Foro de Evaluación continua, sin omitir las faltas ortográficas y gramaticales, con el fin de mostrar la aportación real que se ha efectuado. 


\section{INDICADORES/CÓDIGO}

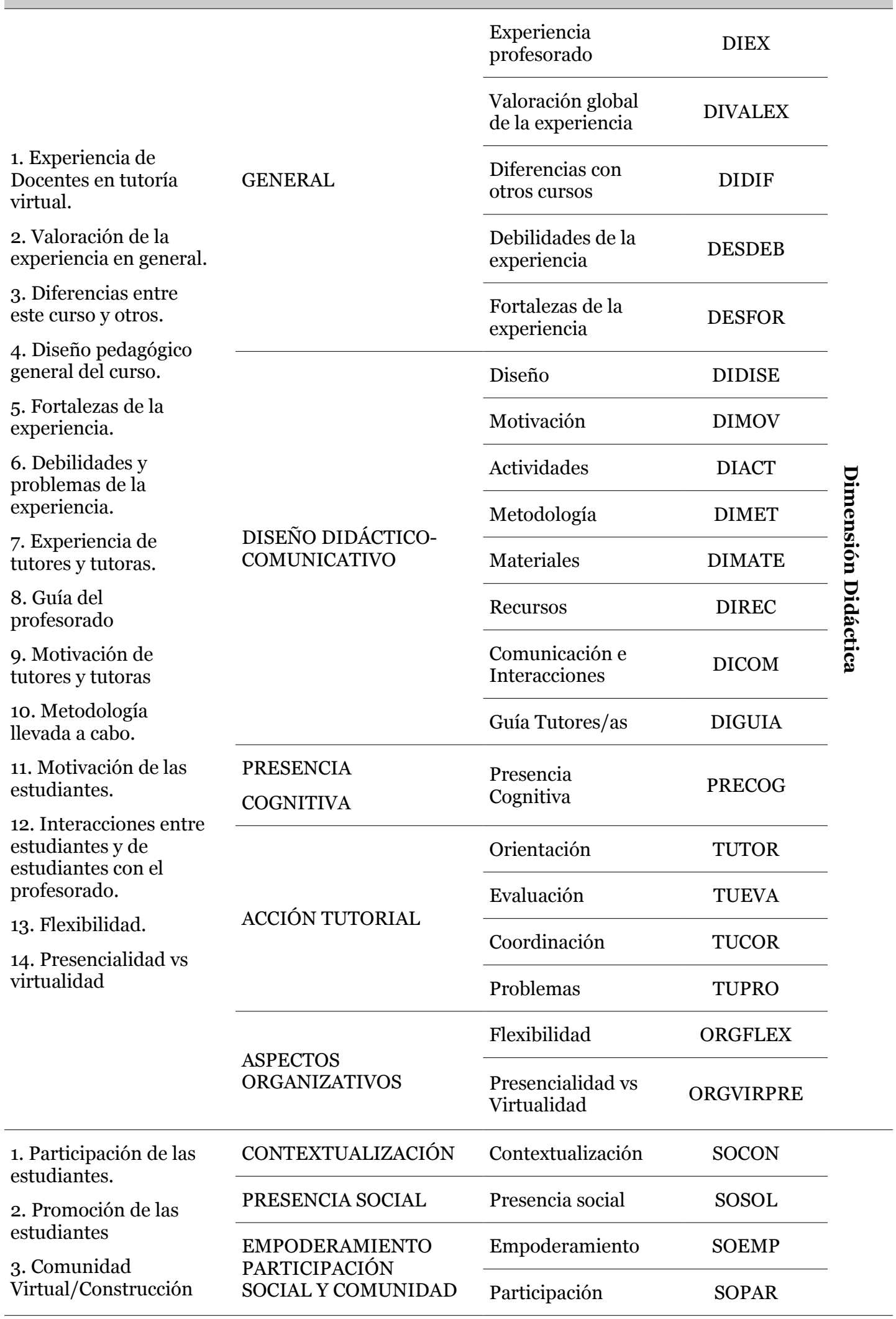




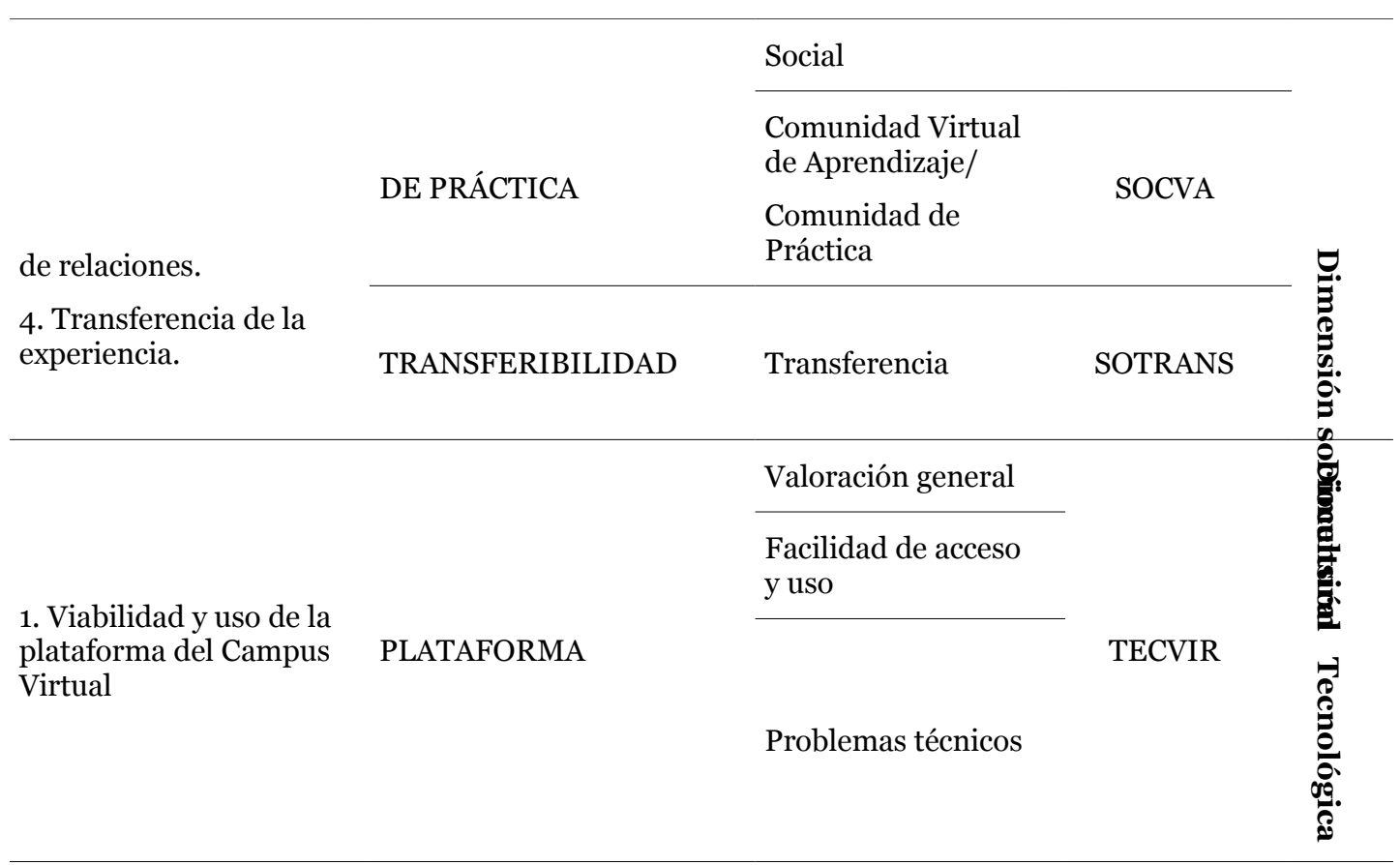

Tabla 29. Temas, categoría, indicadores, códigos y dimensiones de análisis de los datos obtenidos (Triangulación)

A partir de estas dimensiones se ha procedido a la triangulación de técnicas e informantes, obteniendo los resultados que se presentan a continuación. 


\subsubsection{Dimensión didáctica.}

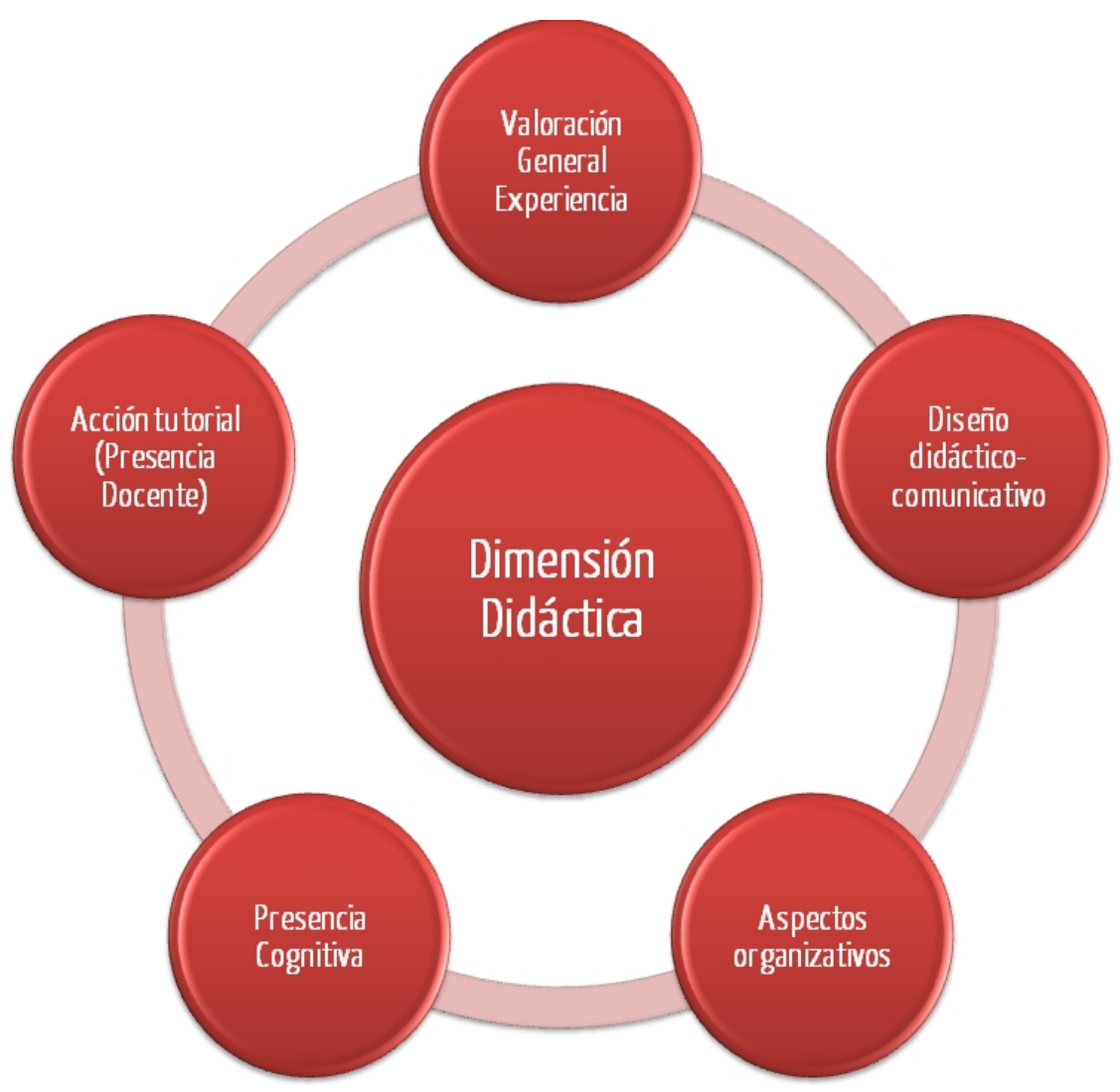

Figura 48. Dimensión didáctica.

Esta dimensión responde a la evaluación del modelo general pedagógico del proceso formativo online, a lo que se refiere García del Dujo y Martín (2002) cuando hablan del diseño y construcción de la perspectiva pedagógica de los entornos virtuales de aprendizaje.

El Grupo de Investigación «Nodo Educativo» trabaja la dimensión didáctica desde el punto de vista de buenas prácticas con TIC (Valverde, 2011) en la incorporación de éstas a los centros educativos, tomando referencias para esta dimensión de Chickering y Erhman (1996), Epper y Bates (2004), Marqués (2006), Area (2007), Bernal y Rodríguez (2007), Casanova (2007), Valverde et. al (2010), entre otros. 
En primer lugar, se determinan preguntas generales sobre la experiencia del profesorado y la valoración global de la acción formativa.

En cuanto a la experiencia previa del profesorado en acciones formativa virtuales, los y las docentes cuentan con una experiencia anterior, de índole universitario y no universitario, en cursos profesionales sobre igualdad de oportunidades, liderazgo y empoderamiento femenino, a excepción de una tutora que no tiene experiencia previa en ningún tipo de formación online, pero tiene una larga trayectoria en el campo del liderazgo social y moral.

La experiencia realizada, de forma global, ha sido valorada como positiva por estudiantes y profesorado. En el caso del profesorado, se unifica que la experiencia, desde sus puntos de vista, ha sido gratificante y la razón fundamental es la participación, motivación y dinamismo que han mostrado las estudiantes:

«En este caso concreto la experiencia ha sido muy gratificante, las alumnas de este curso, concretamente, han sido muy dinámicas, han utilizado mucho la plataforma y los servicios a su disposición, y el resultado ha sido un gran aprendizaje por su parte, por lo que creo que es una experiencia muy positiva» (T7/DIVALEX)

«Para mí ha sido una experiencia muy gratificante ya que no había encontrado tanta motivación entre las personas participantes, especialmente en los foros, que suelen ser poco participativos» (T4/DIVALEX).

«Fantástica. Lo he dicho además en voz alta a ellas. Yo jamás me he encontrado con un grupo que tenga tanto interés, que tenga tanta motivación y que tenga tantas ganas de aprender, jamas.» (T2/DIVALEX)

En el caso de las estudiantes, desde la primera sesión, valoraban la oportunidad de poder participar en una experiencia de estas características: 
«La experiencia en sí me parece muy interesante y gratificante, cuando llegué a casa no paraba de darle vueltas en la cabeza lo que allí habíamos visto, creo que todo fue muy positivo. Besos a todas» (P7/DIVALEX/FEC)

La acción formativa virtual se califica como bien organizada, excelente, motivadora, enriquecedora y de la que han sacado muchos aspectos positivos remarcando dos: tomar conciencia de lo que pasa a su alrededor y sacar ideas para el futuro.

«En cuanto al curso en general he de decir que ha sido muy enriquecedor y que ha estado muy bien organizado y se han sacado aspectos e ideas e ilusiones de futuro con mira no muy lejana» (P8/DIVALEX/FEC)

«En curso en general ha sido excelente, tanto los contenidos como las formas. Ha sido realmente motivador ya que nuestra familia ha ido aportando ideas que hacen posible el diálogo y la reflexión» (P12/DIVALEX/FEC)

«El curso en general creo que ha sido muy positivo, sobre todo porque creo que hemos tomado conciencia de muchas cosas que ocurren a nuestro alrededor y que a veces no reparamos en ellas» (P17/DIVALEX/FEC)

Alguna estudiante reconoce que, en un principio, no estaba muy segura de lo que el curso iba a ofrecerle, sobrepasando finalmente sus expectativas iniciales.

«Este curso me ha dado más de lo que esperaba, pensaba que iba a ser un "coñazo" y aburrido, pero ha sido todo lo contrario [...]» (P17/DIVALEX/FEC)

Esa superación de las expectativas es algo que todas mencionan en sus intervenciones, incluso una de las estudiantes considera que la experiencia ha sido un gran reto que ha podido vencer. 
«Antes de empezar a evaluar, es importante saber cual era mi meta. Como ya he comentado, esto ha sido un reto para mí, el cual me ha costado mucho hacerlo posible. No poseo estudios ni conocimientos de informática, pero aquí me tenéis con trabajo y constancia llegamos al sprint final» (P12/DIVALEX/FEC)

El diseño pedagógico, como marco general de esta categoría, se ha calificado por los docentes como un diseño adaptado, exigente y profundo, idóneo para las estudiantes destinatarias, cuyas estrategias didácticas se han cumplido de forma rigurosa pero sin una rigidez excesiva.

«El diseño pedagógico del curso es idóneo para el grupo destinatario, evidencia una respuesta a las necesidades concretas de las personas que iban a participar [...]» (T4/DIDISE)

«[...] la verdad es que el proyecto estaba muy bien pensado, pero dentro de eso yo creo que sí, que se ha sabido adaptar en cada momento a necesidades que el grupo manifestaba, yo creo que ahí no ha habido tampoco una rigidez, excesiva. Excesiva, es lógico, porque muchas veces el diseño se plantea sobre unos presupuestos que luego a la hora de la verdad hay que saber adaptarlos ¿no? Entonces yo creo que es importante, que el diseño ha sido exigente, riguroso, y se ha cumplido [...]. (T1/DIDISE)

«Muy profundo, muy bien organizado, y teniendo muy claras las cosas» (T2/DIDISE)

«A mi me ha parecido extraordinario» (T3/DIDISE)

Debemos tener en cuenta que las destinatarias a las que se dirigía la acción formativa virtual responden a unas características concretas que exigen un cierto rigor en el planteamiento del diseño pedagógico, pero a su vez una determinada flexibilidad en cuanto a la adaptación del mismo a las participantes y a sus situaciones específicas. El profesorado lo valora como un aspecto que se ha tenido muy en cuenta a la hora de la aplicación del mismo y que ha ofrecido, en su conjunto, resultados sorprendentes, debido a los obstáculos que se debían salvar en un principio, como se observa en la 
intervención recogida en la entrevista a uno de los tutores cuando se solicita que establezcan algunas diferencias entre el curso desarrollado y otros cursos virtuales que hayan tutorizado:

«[...] sí hay diferencia, para empezar por las personas que han participado que tenían unos perfiles muy diferentes y al mismo tiempo homogéneos en algunos aspectos. Estaba la dificultad de personas que nunca habían accedido a un entorno de esa naturaleza, y no sólo eso, sino que además ni siquiera tenían, digamos las competencias básicas en el uso de Internet o de algunas herramientas. Con lo cual, claro, digamos que el obstáculo inicial a superar era muchísimo mayor. Y yo creo que en ese sentido, que los resultados son en alguna medida sorprendentes, cómo han sabido adaptarse a ese entorno, han participando de una manera bastante intensa, activa, con lo cual la verdad es que hay muchas diferencias. Es decir, en las asignaturas que yo tengo los alumnos generalmente, a medida que va avanzando el tiempo [...] sus competencias básicas en tecnología suelen ser bastante, digamos, adecuadas y entonces realmente era mucho más arriesgado esta experiencia que en las que yo podría habitualmente trabajar» (T1/DIDIF)

Aunque debe matizarse que, como comenta el tutor anterior, al principio puede parecer arriesgado, o como lo califica una tutora, audaz e incluso excesivo en una primera visión:
«[...] Al principio quizás excesivo, que cuando lo leí la primera vez, es tan, esta todo tan medido, tan controlado, que si no conoces el tema, se te escapa, se te escapa porque... pero cuando lo ves dos veces, a la tercera dices: pero si es que todo tiene sentido, y todo esta relacionado uno con lo otro y con fundamento» (T3/DIDIF)

También se considera la posibilidad de modificar algunas cuestiones del diseño, sin apuntar a ningún aspecto en concreto.

"[...] algunas cosas lógicamente si ahora lo realizamos, las
modificaríamos en algún sentido, pero como había un buen 
conocimiento previo, de quienes eran los destinatarios, el diseño ha sido bastante ajustado» (DIDIF/T1)

Sin duda alguna, el núcleo principal de todas las entrevistas a estudiantes y profesorado radica en el constructo de la participación y la motivación. En todas las entrevistas se alude reiteradamente a que el eje central del éxito de la acción formativa virtual es el resultado de estudiantes motivadas y participativas.

\begin{abstract}
«[...] se lo he dicho a ellas públicamente, que jamás me he encontrado a nadie que muestre tanto interés, por aprender, por estar, por superar... En un curso de este tipo, y dada las características... en otros casos la gente es pasiva, se limita a participar por obligación, y a entregar las cosas, pues lo mismo que me la entregas en el despacho, me la mandas a la plataforma. Pero jamás me he encontrado un grupo de participantes con esa motivación y con esas ganas. [...] porque no eres tú la que tiene que estar siempre tomando la voz cantante y haciendo que puedan participar, las has visto que ellas respondían a lo que tu le decías, lo que le mandabas y además que te daban otro tipo de.., te hacían otro tipo de demanda» (T2/DIMOV)
\end{abstract}

Recordemos que la motivación y participación de las estudiantes se constituía como eje clave de la estrategia didáctica, y que por tanto, se validan como ejes fundamentales de esta experiencia formativa virtual.

\footnotetext{
«Yo creo que ellas se han sentido en todo momento, que eran capaces de hacer cosas, y cosas que luego pudieran valer en el futuro» (T2/DIMOV)

«La motivación se ha reflejado en su alto nivel de participación y considero que se ha respondido a sus expectativas» (T4/DIMOV)
}

Esto lo corroboran las estudiantes, que dicen, desde el comienzo, estar motivadas para aprender: 
«Mi participación creo que ha sido correcta, me veo implicada y con muxas ganas de aprender» (P9/DIMOV/FEC)

Como se ha recogido ya en algunas intervenciones, el profesorado del curso se ha comprometido en esta tarea, considerada como reto por alguna docente, que además destaca un aspecto importante en referencia a su experiencia en tutoría online en otros cursos virtuales, como es el trabajo constante de animar y fomentar la participación del alumnado:

«... tienes que estar muy pendiente de motivarlos mucho, porque son muy.. acaban siendo muy pasivos la gente tiene muchas obligaciones y si no estas encima de ellos no lo hacen...» (T2/DIVALEX)

Por otro lado, la motivación del profesorado también se ve reflejada en sus respuestas, desde el punto de vista de enfrentarse a la tarea de tutoría en una experiencia de esta tipología:
«[...] creo que las participantes han mostrado su motivación y compromisos con el curso y con el resto de participantes, y a nivel personal tanto la sesión presencial como otros espacios en los que he podido compartir con las integrantes del curso han sido muy interesantes tanto profesional como personalmente para mí» (T7/DIVALEX)

Igualmente, las estudiantes han mostrado su entusiasmo constantemente, incluso consideraban el curso como algo entretenido y divertido a la vez que motivante:

\footnotetext{
«Pues para mí era también como un entretenimiento porque (risas) es verdad, porque surgían debates que me gustaban, que me picaban y decía anda pues lo que ha dicho... y me acuerdo una que me dice, ialaa lo que has dicho! y dije pues me voy a meter corriendo y voy a contestar otra vez. Y yo que sé, esas cosas pues me gustan, y por supuesto la información, he aprendido muchísimo, no sé... a mí me ha encantado» (P8/DIMOV/GD)
} 
En la diferenciación entre la experiencia desarrollada y otras experiencias de acciones formativas online tutorizadas por el profesorado participante, se siguen identificando como factores singulares de esta experiencia la motivación de las participantes, su entusiasmo, implicación y participación. Ésta última, una tutora la determina por los temas trabajados que según ella han asegurado la participación por el interés que suscitaban a las estudiantes:

«Si, era un tema en el que la participación estaba garantizada ya que entraba de lleno en los roles y estereotipos de género, que en la cultura gitana son fácilmente detectables» (T4/SOPAR)

«La participación del alumnado en las sesiones y los foros. La implicación y su entusiasmo ha sido, en mi opinión, impresionante» (T4/DIMOV)

«[...] pero además yo se lo he dicho a ellas cuando las he visto. En los cursos anteriores que necesitas estar constantemente, poniendo preguntas en el foro motivando, dando elementos positivos, las alumnas de este curso, ellas solas iban. Entonces yo no sé si es por la oportunidad que se les ha dado de algo nuevo de algo que ellas han visto que les puede servir y que estaban motivadas, no ha hecho falta motivación ninguna, es mas a veces te avasallaban con correos, $y$ con intervenciones, y con cosas en el foro, que yo jamás me encontré en ningún curso» (T2/DIMOV)

Sin embargo, a pesar de que casi todo el profesorado reconoce y valora como alta esa motivación, una de las tutoras manifiesta que, en comparación con otros cursos virtuales, ella sintió ansiedad con esta experiencia porque, desde su punto de vista, no ha sabido conjugar la formación a través de las TIC y el nivel de las destinatarias, lo que le ha provocado insatisfacción con su tarea:

«Este me ha producido mas ansiedad. Ha sido mas corta la experiencia, aunque también creo que no he hecho todo que de debiera hacer, lo digo claramente, y por eso no estoy satisfecha, y me ha producido mas ansiedad, porque no sabía como conciliar la 
formación a través de este medio virtual con los contenidos adecuados al capital cultural de la población» (T3/DIDIF)

Aunque los resultados han sido positivos, las estudiantes realizan una autocrítica de su trabajo en la última fase del curso, en la que parecen haber notado una disminución de la participación, que les ha llevado a una cierta desmotivación. Consideran que la dinamizadora ha estado muy en contacto con ellas para incentivar esa participación y finalmente ha tenido que esforzarse para conseguirla:

«Yo lo que pienso, y antes lo hemos comentado cuando veníamos en el coche, que cuando a principios de curso todas lo cogimos con muchas ganas, incluso hacíamos los trabajos antes de tiempo (risas) y al final de curso hemos estado ahí...que nos has tenido que achuchar mucho, venga que quedan tres días para terminar el curso, que si no, no os vamos a dar el título, venga que os quedan dos días, y al final hemos estado ahí un poco como desganadas [...]» (P12/DIMOV/GD)

Cuando se ahonda en las razones de esta desmotivación, se alude sólo a algunas de ellas, sobre todo a las que no han finalizado el curso por motivos profesionales. Una sola de las estudiantes, sin embargo, reflexiona sobre la posibilidad de que el tema final, el más complicado a nivel aprendizaje, haya podido incidir en este hecho:

«[...] el mejor pero quizá el más duro de aprendizaje, entonces desde mi punto de vista yo creo que eso sí nos ha hecho bajar la participación, porque a mí misma también me costaba un esfuerzo superior ponerme a aprenderlo, a entenderlo pero aún así reconozco que ha sido el mejor, para mí el más duro el mejor» (P7/DIMOV/GD)

Pese a todo ello, en la acción formativa en cuestión, se revelan la pertinencia de varias estrategias didácticas diseñadas y puestas en práctica para conseguir mantener esa motivación e incentivar la participación constante, como la figura de la dinamizadora o los centros de interés: 
«...yo creo que están bien elegidas las temáticas, los centros de interés, creo que el profesorado ha funcionado también, por lo que valoran las alumnas, razonablemente bien en cuanto a su dinámica....» (T1/DIMOV)

«Distinto, el que se les ha estado motivando también a ellas, ellas estaban motivadas, pero nunca se ha perdido el contacto con ellas. A veces en otro tipo de cursos, tu tienes una sesión inicial, les hablas tal, y luego sólo a lo que ellas te preguntaban. $Y$ en este, a parte de las sesiones presenciales, ellas han tenido siempre como el refuerzo continuo por parte, o de los profesores o de la dinamizadora [...] (T2/DIMOV)

Esa figura de la dinamizadora ha sido fundamental, según nos indica una docente, que explica que el rol de ésta constituye una base para mantener la motivación y la participación constante de las estudiantes, además de evitar ese sentimiento de soledad que, en ocasiones, caracteriza a algunas acciones formativas virtuales.

«[...] Si, fundamental porque yo creo que también las que las han mantenido, ellas no se sentían solas [...]» (T2/DIMOV)

«[...] Yo si me pongo en su lugar, no se sentían sola a pesar de que tenían dificultades, sobre todo al principio, tecnológicas, que no accedo, que no sé qué, que no sé cuanto... pero saben que hay alguien de apoyo, entonces yo creo que eso les ha sentido, les ha hecho sentirse a ellas respaldadas, de decir: bueno hoy no puedo, pero mañana si puedo. Sé que cuento con alguien [...]» (T2/DIMOV)

Además de estos aspectos, se mencionan otros que se consideran claves de la motivación y participación de las estudiantes: en primer lugar la novedad, que genera expectativas positivas para afrontar el curso en un principio, la Universidad como centro de educación superior que acoge un curso de estas características. Por otro lado el propio diseño del curso, cercano, significativo para las estudiantes y previamente planificado $\mathrm{y}$, por último, el Campus Virtual como herramienta tecnológica que ha llamado su atención. 
Señalamos dos respuestas de una tutora y un tutor que destacan claramente estos puntos clave:

«[...] el que una Universidad acoja a un grupo de estas características, ¿no? Yo creo que eso ya, evidentemente, eso es algo llamativo, algo que no es habitual, y que por lo tanto, yo creo que las personas han valorado muy bien [...] el propio diseño... yo creo que ha facilitado también el que el que las alumnas estén motivadas e interesadas por el tema que se trataba. Era cercano, se ha sabido llevar a su terreno, por lo tanto, era algo que les tocaba. Era significativo de alguna manera... la propia herramienta tecnológica, yo creo que también llama mucho la atención, incluso alguna manifiesta en algún momento pues, yo pensaba que esto de lo virtual era muy complicado, no saber que iba a ser capaz. Entonces ver que se superan determinadas barreras y que se utiliza una tecnología que nos permite comunicarnos y tal, yo creo que también aumenta ese interés por el curso» (T1/DIMOV)

«Este curso, concretamente desde su planificación, ha tenido en cuenta a las destinatarias y no al revés como en la mayoría de cursos: primero se planifica la formación y luego se oferta a las futuras alumnas y alumnos. En este caso sabíamos la población diana a la que iba a estar dirigido el curso, por lo que se adaptaba a sus necesidades e intereses, lo que ha hecho que responda a la mayoría de sus expectativas y haya mantenido la motivación del alumnado hasta el final» (T7/DIDIF)

Incluso se señalan las TIC como herramienta de motivación relacionado con la novedad que suponen para la formación de las destinatarias.

«[...] La introducción de una nueva herramienta que puede resultar por su dificultad disuasoria, también creo que puede ser muy motivante, especialmente para algunos grupos con mayores dificultades de aprendizaje. Es decir el ordenador puede ser una herramienta muy buena» (T3/DIMOV) 
Y por supuesto, se incide en que la comunicación ha sido un elemento motivador e impulsor de la continuidad en una acción formativa virtual de estas características.

\begin{abstract}
«[...] Porque yo creo que es el elemento motivador y que les hace seguir en un curso, que no son tres días [...]. Como no los motives y no estés en comunicación con ellos, no te ven la cara y como no te ven la cara tienes que hacerlo de otra manera, porque si no piensan que estas perdida. O te pones una fecha limite, o no haces lo que tienes que hacer. Pues esto igual, o te pinchan y te motivan y te tal o... [...]» (T2/DIMOV)
\end{abstract}

Por su parte, las estudiantes comentan que con la acción formativa se han superado sus expectativas. Su motivación residía, según indican en sus intervenciones, en varias cuestiones: las temáticas trabajadas, el apoyo de la Universidad en esta acción y el profesorado y la dinamizadora, tanto por su profesionalidad como por la cercanía mostrada:

«[...] a mi me pareció desde el principio una idea muy buena no me esperaba tanto apoyo de la Universidad de Extremadura, la verdad $[\ldots] \gg\left(P_{3} / D I M O V / F E C\right)$

«[...] además, cuando dijísteis (refiriéndose al profesorado) que éramos uno de los grupos que más nos conectábamos y participábamos, hizo que me motivara más aún» (P1/DIMOV/FEC)

En referencia al proceso de comunicación que se produce en el curso, a través de la herramientas destinadas a esa finalidad, el foro resalta como recurso fundamental.

Aunque la comunicación y la interacción han sido constantes, algunas de las estudiante matizan un aspecto de esta comunicación asíncrona:

«sí, como hoy aquí, tenía su parte fría que digamos...exactamente, no como aquí ahora que estamos hablando y nos vemos cara a cara $y$ 
nos contestamos aquí, que cuando tú contestas ahí al aire» $(P 1 / D I C O M / G D)$

Una docente nos comenta lo que considera un factor más de motivación: que el aprendizaje se ha producido entre iguales (Aubert et al., 2008); cada persona comparte su conocimiento y experiencia con las demás, sintiendo útil su aportación.

\begin{abstract}
«En algo virtual porque rompe el aislamiento, y el aislamiento puede ser un elemento de desmotivación, así que ese componente de sociabilidad que se debe potenciar, hace grupo, tiene la finalidad de conseguir cohesión social, porque si no lo que hay es desbandada, la gente abandona, eso para empezar. Desde el punto de vista de la construcción de aprendizajes, porque desde la dimensión dialógica favorece el aprendizaje mas significativo, yo creo. Porque por la propia estructura, porque aprendemos de los otros, nuestra fuente de conocimiento no es solamente uno si no que pueden ser mas, incluso mas democrático así que aprendemos principio de ciudadanía si me apuras, ya no solo el profesor me abre la puerta al conocimiento, sino que mis iguales también saben cosas y yo experimento la sensación de que yo puedo enseñar con mi aportación. Con lo cual es un elemento mas de motivación, cuando uno sabe que lo que dice puede ser útil al resto» (T3/DIMOV)
\end{abstract}

La planificación de la acción formativa virtual se remite al profesorado en forma de «guía docente»; recordamos que su finalidad era constituir un documento de referencia para el desarrollo óptimo del curso, explicitando competencias, finalidad, proceso de gestión de la tutoría virtual, propuestas de actividades y dinámicas colaborativas virtuales. El profesorado valora esta guía como completa, bien desarrollada y de mucha ayuda para su labor. Lo cercioran las opiniones vertidas sobre la misma en las entrevistas, que además inciden en que necesitaban más de una lectura para asimilar la acción formativa diseñada y en la que debían desarrollar su labor tutorial.

«[...] me parece muy clara y completa» (T6/DIGUIA) 
«La guía del profesorado al principio me resultó en una primera lectura rápida, me di cuenta que con una lectura rápida no me permitía asimilar. $Y$ en la segunda lectura ya me pareció extraordinaria, me pareció que esta muy bien confeccionada» (T3/DIGUIA)

«También, positiva. Tener que leerla dos veces, para saber como va cada cosa. Pero en el momento que la lees dos veces, le ves el sentido de que tenia [...] Estaba muy bien hecha» (T1/DIGUIA)

La metodología desarrollada -concretando más ese diseño didáctico de la acción formativa virtual y dirigida hacia la actividad colaborativa y de diálogo entre las participantes y a su interacción- se ha considerado como novedosa para el grupo destinatario, con un planteamiento original e incluso innovador, desde el punto de vista del profesorado. Sobre todo, se destaca la participación de las estudiantes, lo que nos muestra el segundo constructo clave, que también es mencionado de forma continua en las entrevistas realizadas a los tutores y tutoras participantes.

«Yo lo que me gusta del diseño, sobre todo, es que está enfocado hacia la actividad del alumno y yo creo que eso se refleja bien, tanto la comunicación, como luego todos los documentos, que tienen que manejar. Están siempre orientados hacia una actividad, hacia una reflexión personal, un trabajo personal, o grupal en algunos casos, y yo creo que eso, además, se valora también, por parte de las alumnas. El hecho de que se las haya implicado en eso y que no sea algo más teórico sino que se le implique activamente en en el curso [...]. O sea que desde esos puntos de vista me parece innovador, por los destinatarios, por cómo se ha planteado, y luego, sobre todo, por cómo se ha implementado, por los resultados [...]» (T1/DIMET)

«La metodología virtual, en este grupo poblacional, es novedosa, destacando lo participativo del diseño de la plataforma, que contaba con espacios que permitían a las personas participantes manifestar y exponer sus opiniones, así como construir elementos del propio curso [...]. La metodología, ha permitido la participación de las participantes, especialmente la interacción entre ellas por los 
espacios diseñados para el intercambio y exposición de ideas. Como ya he manifestado anteriormente, su nivel de participación en los foros ha sido muy superior al de otros cursos con el mismo formato. Su respuesta, puede tener causa en que para la mayoría de ellas era su primer acercamiento a las nuevas tecnologías y a este tipo de formación, lo que hace mucho más valiosa su participación» (T4/DIMET)

También lo afirman las estudiantes, que remarcan algunas de las temáticas trabajadas como muy enriquecedoras y generadoras de debate, es decir, que fomentaban su participación debido al interés que suscitaban:

"El tema de igualdad de la semana pasada fue muy enriquecedor en cuanto a opiniones de todas las alumnas y además generó debate entre nosotras y eso significa que el tema en cuestión nos ha interesado mucho» (P2o/DIMET/FEC)

Además, se considera que ha sido totalmente adaptada al grupo de destinatarias, con matices diferentes en cuanto a otros cursos similares en la misma plataforma. Una tutora menciona este aspecto, interpretando que la metodología, a pesar de implementarse bajo la plataforma Moodle, era diferente a otras que en su experiencia ha tutorizado:

«[...] me daba la experiencia de que estaba familiarizada con la plataforma Moodle, pero la metodología y el planteamiento, pues es muy distinta porque esta es una metodología «ad hoc», para el colectivo [...]» (T3/DIMET)

Nos centramos, ahora, en la valoración sobre los materiales, recursos y actividades desarrolladas.

La adecuación, tanto de los materiales como de recursos y actividades en el desarrollo de la acción formativa virtual, es bien valorada por tutores y tutoras. Concretando, los materiales se han considerado adecuados, cada docente ha realizado un esfuerzo por adaptar los propios a las destinatarias del curso. En este sentido, encontramos sentimientos contrapuestos entre 
tutores y tutoras que sí consideran que han logrado esa adecuación aunque una realiza una autocrítica en referencia a la inclusión de más materiales complementarios, y una tutora que siente que no ha sido capaz de adaptarlos.

«Para lo básico que yo quería que ellas consiguieran, yo creo que conseguí adaptarlo, y que lo pudieran entender y a parte aprovechar. Hoy sí le hubiera puesto algo más complementario, para que ellas lo tuvieran como información o en algún momento dijeran: bueno pues aquí tengo algo más. Es debilidad por mi parte, no por la suya [...] En ese sentido, los materiales son adecuados, lo único que quizás le hubiera faltado, como he dicho, algún complemento» (T2/DIMATE)

«[...] ha habido una parte que yo he notado, y es que, los contenidos que me correspondían, posiblemente eran los menos motivantes para los estudiantes, así que... Y de esto te vas dando cuenta [...] son contenidos muy teóricos, muy abstractos, con poca, con ninguna dimensión de instrumentalidad y de aplicabilidad y dada las condiciones de las alumnas, su capital cultural y su realidad social, que probablemente se rige mas por una perspectiva y una forma $y$ una estructura cognitiva mas particularista, esos niveles de abstracción, y de teórico pues les resultan lejanos y ajenos» (T3/DIMATE)

Finalmente las misma docente valora que están muy bien, y matiza que lo que está realizando es una autocrítica.

«Muy bien, muy bien. Sobre esa parte no tengo... La critica que yo hago es a mi misma, no al sistema» (T3/DIMATE)

Pese a lo que comenta esta tutora, las estudiantes consideran que los materiales estaban adaptados. Así se recoge en sus intervenciones de manera manifiesta:

«Los temas propuestos me han parecido muy apropiados pero sobre todo el tema de liderazgo ha sido crucial para mi, he aprendido mucho en este tema» (P17/DIMATE/FEC) 
Las actividades diseñadas, tanto las colaborativas comunes, como las concretas propuestas por los tutores y tutoras, son bien valoradas al igual que los recursos y los materiales.

«Todas, todas bien. Yo creo que se ha ido de lo mas básico, que ellas controlaran las herramientas básicas para moverse y se le quitaran esos miedos tecnológicos, y pudieran pasar a lo que era el contenido en sí, entonces yo creo que en eso bien» (T3/DIACT)

En cuanto a las comunes, las actividades colaborativas continuadas como el blog, la WebQuest o la wiki, pese a ser consideradas arriesgadas, se demuestra que finalmente el resultado ha sido positivo.
«[...] algunas actividades son incluso arriesgadas para este nivel de uso y sin embargo funcionaron razonablemente bien, los blogs, la wiki, son todavía, digamos, es añadir una dificultad mayor al proceso. Pero bueno, al nivel que se pretendía ha funcionado también razonablemente bien [...]» (T1/DIACT)

Una profesora realiza una autocrítica a la actividad que ella misma propone, por lo que podría parecer una cierta rigidez inicial en el desarrollo de la tarea que luego se convierte en más flexible. Como se ha indicado antes, y lo corroboran tutores y tutoras de la experiencia, es necesario, debido a las características de las destinatarias de la acción formativa virtual, un cierto rigor inicial en el planteamiento de las actividades, que luego pueden adaptarse y flexibilizarse en el desarrollo.

«Es que el mío tenia una guía que realizar y tal. Entonces ha habido cierta... a lo mejor rigidez inicial, pero luego les he permitido que ellas adaptaran. Y en eso luego en los resultados he visto, que han ido adaptando en función de lo que ellas han podido recoger la información y analizar y tal, entonces sí que había, en el mío en concreto, una rigidez inicial. Había una guía que tenían que completar, pero dentro de esa guía que tenían que completar, sí que ahí ya, he sido mas flexible» (T2/DIACT) 
Ya hemos recogido una sugerencia de un docente en referencia a la inclusión de más material multimedia. Otra docente, tras una interesante valoración sobre las actividades, realiza una propuesta referida al contenido de los debates en los foros.

\begin{abstract}
«[...] En mi opinión, hay que tener en cuenta que para la mayoría de ellas era su primer contacto con este tipo de formación y uno de los objetivos era el aprovechar un espacio en el que intercambiar opiniones y manifestar ideas con total libertad. En general, las actividades han sido correctas y diseñadas buscando el resultado que finalmente se ha obtenido, no obstante, hubiese sido interesante introducir temas ajenos a la cultura gitana y a la situación de la mujer en la misma y que con toda probabilidad habrían generado polémica, ya que en todo momento, las discusiones han tenido un matiz endogámico, sin que nos haya permitido observar su percepción respecto a otras realidades y como se posicionan ante las mismas» (T4/DIACT)
\end{abstract}

Los recursos se valoran en adecuación y utilidad, considerando que se ha realizado una adaptación a las necesidades de las destinatarias, que los han considerado útiles para su vida personal y profesional. También se añade como mejora la posibilidad de inclusión de más materiales multimedia.

«[...] Porque estaban adaptados, porque respondían, a lo mejor, a necesidades suyas, de su colectivo y de su entorno, y porque ellas han visto que se podían sentir útiles [...]. Útiles para ellas porque podrían aprovechar otros cursos y otra formación, y útiles en el entorno en el que se mueven. Yo creo que incluso, han descubierto una calidad que no eran conscientes de ello, me da la impresión».(T2/DIREC)

«En cuanto a los recursos pues yo creo que sí que han sido adecuados... para cada uno de los temas [...]. ¿Podrían enriquecerse? Probablemente. En estos entornos se echa a veces de menos, más material multimedia, y ese tipo de cuestiones, pero bueno yo creo que para los objetivos que tenía el curso, han sido los materiales adecuados» (T1/DIREC) 
Si concretamos en los recursos utilizados los foros son, claramente, los que predominan en las intervenciones. Se explica porque es el recurso más utilizado estando, además, situado en el primer lugar cuando se valora su uso por las estudiantes en los cuestionarios, como se ha presentado con anterioridad.

Una tutora califica los recursos como una «apuesta arriesgada» teniendo en cuenta las características de las estudiantes y muestra sorpresa ante el resultado de participación en los mismos. Por ello valora su utilización como positiva.

«Si, además era una apuesta arriesgada teniendo el cuenta el perfil de las participantes, aunque la plataforma Moodle es de fácil uso. La valoración sobre su utilización ha sido muy positiva, y una grata sorpresa como docente» (T4/DIREC)

Otra de las tutoras de la parte virtual opina que hubiera sido necesaria una discusión presencial con las estudiantes. Este hecho quizá se deba a que es la primera participación de la tutora en una acción formativa de estas características y que, por la distancia geográfica y la diferencia horaria del lugar donde reside -Santa Cruz de la Sierra en Bolivia-, no ha podido participar en ninguno de los tres talleres presenciales.

«Fueron bien. Aunque es más complicado por la coordinación de tiempos, ocasionalmente una discusión en vivo habría sido bueno» (T7/DIREC)

Uniendo los recursos a la valoración sobre la comunicación e interacción entre las participantes y con tutores y tutoras, recordamos que la comunicación se ha considerado un factor de motivación y de continuidad en el curso para las estudiantes. En este sentido se considera que ha sido fundamental para la consecución de la finalidad del curso virtual desarrollado: 
«La comunicación es fundamental ya que suple el contacto físico y visual de la formación presencial, así como el intercambio de opiniones y exposición de ideas» (T4/DICOM)

«Las herramientas virtuales permiten una comunicación más personalizada que en las clases tradicionales» (T5/DICOM)

En los foros ha sido donde se han generado los debates, dinámicas, se han producido las interacciones entre las participantes y de éstas con los tutores y tutoras y donde se han realizado las actividades, lo que los caracteriza como fundamentales en esta acción formativa; ha sido el recurso clave para la interacción y comunicación entre las participantes y para compartir y construir conocimientos de forma conjunta. Como observamos en las siguientes intervenciones, la totalidad de tutores y tutoras corroboran esa idea.

«Sí yo creo que los foros claramente. Se ve y se observa que ahí ha habido interacción, además incluso sólo viendo los números, a veces, de las participaciones en cada dinámica, en cada debate, destaca que ahí ha habido movimiento, ha habido interacción « (T1/DIREC)

«[...] Fundamentales en este caso los foros, la comunicación a través de los foros es básica. Básica por que es la que ha permitido pues todo eso que hemos dicho de la comunicación entre ellas, todo esa comunicación con los profesores, me parece que eso era básico». (T2/DIREC)

Recogemos una de las intervenciones de un tutor que sintetiza la importancia que ha tenido el foro como recurso de comunicación multidireccional, frente al chat y al correo electrónico, como medio de comunicación uno a uno.

«Es básico en un entorno virtual, es decir...como en cualquier proceso educativo, sabemos que la comunicación es básica, pues aquí hay que buscar la vía a través de la cual se pueda realizar. Y el foro funciona muy bien, en ese sentido, tiene unas ventajas muy buenas, 
es fácil de utilizar, los mensajes llegan a todos, mucho mejor que el correo electrónico que es una comunicación uno a uno, en el cual hay cosas que se pueden perder. Entonces yo creo que ahí el foro tiene mucha ventaja. Y el chat, pues lo da la inmediatez, lo que pasa es que el chat también depende de si los alumnos están familiarizados, no a saber utilizarlo, qué es fácil [...] sino a saber cómo comunicarme en ese entorno; entonces si están familiarizados pues puede ser una dinámica de comunicación útil para algunas cosas concretas. Si no pues la verdad es que puede ser una pérdida de tiempo. Y el correo electrónico bueno pues... para el diálogo eso... uno a uno, y ahí se pierde también, ya digo, muchas veces las posibilidades de que uno comenta lo puedan escuchar los demás. Como ocurre en el aula presencial» (T1/DICOM)

Una tutora destaca, además del foro, la plataforma Moodle que se ha utilizado, en general, y remite a su diseño para favorecer la comunicación en las personas.

«La plataforma ha sido diseñada, en mi opinión, para favorecer la comunicación entre las personas participantes y han aprovechado la oportunidad, potenciada por las sesiones presenciales. En mi caso, el foro ha servido como espacio de comunicación fluido y continuado, ya que cualquier comentario ha sido respondido por todas las participantes e incluso, ellas han propuesto otros temas a raíz de los expuestos inicialmente» (T4/DICOM)

Indagamos un poco más en la dimensión didáctica, preguntando por las fortalezas y debilidades observadas en el desarrollo de la experiencia.

Como fortalezas se destacan los dos constructos clave, la motivación y la participación, lo que verifica lo anteriormente comentado en este aspecto del diseño: que ha sido una acción formativa totalmente adaptada a las destinatarias

«La fortaleza muy clara era la alta motivación, o sea que eso yo creo que muy destacable, es una motivación que se ha mantenido, porque 
a veces este tipo de cuestiones se inicia con algo un gran interés y luego a lo mejor puede decaer. Y aquí, sin embargo, se ha mantenido, ha habido apoyo también entre las personas para poder llevar a cabo las tareas. Entonces yo creo que eso ha sido importante» (T1/DESFOR)

«¿Fortaleza? el alto grado de compromiso, interés y participación de las alumnas[...]» (T6/DESFOR)

«[...] el material, que estaba muy claro, que yo creo que se adaptaba al nivel que ellas tenían [...]» (T2/DESFOR)

La mayor debilidad que se observa por parte del profesorado tiene relación con el tiempo de desarrollo del curso, tanto de la parte virtual como de las sesiones presenciales. En el caso del tiempo dedicado a la parte virtual, lo califican como «limitado».

«Evidentemente, el tiempo ha sido limitado. $Y$ entonces quizá eso habría que considerarlo [...]» (T1/ DESDEB)

Sin embargo, desde el punto de vista de las estudiantes, la mayor debilidad ha sido el tener que tomar el hilo de las conversaciones cada vez que se quería participar en el foro, sobre todo si se estaba varios días sin acceder al espacio virtual:

«Yo lo que más resaltaría lo que más me ha costado a mí, que hay veces que pierdes el hilo. Hay veces que a lo mejor ya te quedas un día sin entrar a lo mejor en lo que es el foro o lo que sea y ya ves tantas repuestas y tantas contestaciones a la misma cosa, que tu dices, ahora ¿̇a qué contesto? (risas) que te pierdes un poco, que es lo que yo más diría, que es eso, que si te descuelgues un día o dos, te pierdes, ya te cuesta volver... saber de qué va la contestación, las respuestas...» (P11/DESDEB/GD)

Incluso consideran que, en ocasiones, la respuesta era demasiado abierta, aspecto que hacía que se entretuviesen en otras cuestiones que no tenían que ver con lo preguntado. 
«En determinados momentos también como es muy libre la respuesta pues no se acorta lo suficiente y una se puede ir por los cerros de Úbeda (risas) en cualquier momento claro, sin darte cuenta te pones a escribir a escribir, pero si esto no lo han preguntado (risas) $[\ldots] \gg(P 7 / D E S D E B / G D)$

Una estudiante considera como debilidad el haberse sentido sola en alguna ocasión:

«Yo sí, me he sentido sola en algún momento porque no me ha dado tiempo, si he estado mucho tiempo fuera y eso, cuando he llegado y veía, ahora te toca hacer y ya me liaba o lo que sea pues no había nadie físicamente para ver, preguntarle y contestar rápidamente. Es la única diferencia que puede haber de eso...» (P8/DESDEB/GD)

Las demás rebaten este argumento destacando que para ellas ha sido lo contrario, incluso las ha servido de desahogo, considerándolo, al contrario que la anterior, una fortaleza:

\begin{abstract}
«Yo creo que al contrario (risas) no es verdad, mira hubo una noche que yo estaba...para mí ha sido una experiencia novedosa, ya os digo que no me ha gustado nunca hablar por el chat, y estaba yo así un poco baja de moral una noche y dije voy a entrar en el curso este a ver que pongo por ahí y me acuerdo que entré en el blog y había ido a Fregenal, la entrada esta que tengo de Fregenal de la Sierra (todas asienten) y escribí una frase. Como que me desahogué, alaa ahí...toma, ya me quedé más agusto, lo hice de esa manera con ese sentido, con lo cual, yo que sé lo utilicé de esa manera [...]» (P7/DESFOR/GD)
\end{abstract}

En las sesiones presenciales se destaca como debilidad la escasez de tiempo para llegar a todo lo que las estudiantes querían debatir o en lo que querían indagar:

«[...] la sesión fue algo escasa de tiempo» (T6/DESDEB) 
Dos de las tutoras apuntan debilidades propias a modo de autoevaluación: una porque cree que podría haber incluido más material complementario y otra porque considera que su propuesta temática era difícil de adaptar en la lectura previa por constituir conceptos que requieren un nivel alto de abstracción.

«A ver, debilidades, que por mi parte a lo mejor tendría que haber indagado mas, e incluir algún material mas complementario, entonces, debilidad mía no de las chicas» (T2/DESDEB)

«La debilidad es que hablar de políticas de igualdad a personas si no tienes ninguna dificultad, implica ya de entrada el concepto de política, probablemente de mostrar lo que es política, que esta tan desvirtuada socialmente, ya es difícil. Mucho más creo que la otra parte de la expresión que es igualdad. Creo que el concepto de política esta tan desvirtuado que no se entiende, creo que es muy abstracto $[\ldots]$... (T3/DESDEB $)$

Se añade, por parte de una tutora de talleres presenciales y de las participantes, la falta de asistencia de alguna de ellas como debilidad en el desarrollo de la acción formativa:

«Las mujeres que asistieron fueron muy participativas, muy receptivas a las explicaciones y a seguir ahondando en el tema, el problema mayor es que no todas las alumnas estuvieron presentes en la sesión» (T7/DESDEB)

Las debilidades se convierten en retos y así finaliza la intervención en este aspecto una tutora:

«Hay una parte que me ha gustado y es el reto de enfrentar una cosa que era completamente dificil, eso me ha gustado, vaya por delante. Lo que pasa es que... Yo no he hecho creo, que no lo he hecho yo bien como podría haberlo hecho «(T3/DESDEB)

Hemos querido indagar en las tres presencias planteadas por Garrison y Anderson (2005), situándolas en las diferentes dimensiones tratadas en este 
estudio. En esta dimensión, que hemos englobado como didáctica, situamos la presencia cognitiva y la docente. En referencia a la cognitiva, se solicita a tutores y tutoras que valoren de 1 a 5 y expliquen su valoración sobre varias afirmaciones: esta experiencia favorece la construcción de significados, esta experiencia favorece la toma de acuerdos y, por último, la generación de propuestas, que se corresponden, de manera general, con alguna de las fases que estos autores proponen dentro de esta categoría a valorar. Por otro lado a las estudiantes se le pregunta directamente qué han aprendido.

En referencia a si se ha producido construcción conjunta de significados en el desarrollo del curso, los tutores y tutoras valoran con alta puntuación esta afirmación. Según su opinión, sí se ha logrado llegar a este nivel de aprendizaje; lo explican refiriéndose a las actividades diseñadas, que pretendían promover esta cuestión:

«Yo pondría la máxima puntuación. La máxima puntuación porque
el tipo de actividad, el tipo de aprendizaje que se ha buscado, va
orientado fundamentalmente a eso. En ningún caso a almacenar
información, o a otro tipos de cosas, sino que fundamentalmente a
crear, a crear y a construir, bien de modo individual con la reflexión
personal, o bien de modo colaborativo, unos significados con
relación a las temáticas que se planteaban, por lo tanto yo ahí le
pondría, yo creo que es el enfoque adecuado [...]» (T1/PRECOG)
«[...] Más concretamente, creo que las discusiones por internet
favorecen el diálogo entre iguales y dan la oportunidad al docente a
valorar los aportes de cada participante, respondiendo a sus
comentarios. Esta a su vez lleva a la construcción de significados
[...]» (T5/PRECOG)

Incluso reconociendo las diferencias en cuanto a niveles académicos de las estudiantes, creen que se ha llegado a la construcción de significados, en el que cada una aprovechaba ese aprendizaje adecuado a esos conocimientos 
previos. Pese a este reconocimiento, una tutora duda de si con todos los docentes han sucedido situaciones similares.

«Fíjate, yo veo diferencia, porque las chicas tenían un nivel académico, cultural, lo que quiera, distinto. Pero yo creo que incluso dentro de eso, ellas han sabido, se les ha permitido que cada una en el nivel que tiene, pudieran aprovecharlo desde ahí. No sé si las actividades estaban, o los profesores han sabido o no, han orientado, para que las actividades tuvieran un punto de partida y que cada uno pudiera aprovechar el bagaje que tenía y sacarle el máximo rendimiento» (T2/PRECOG)

Sin embargo, pese a lo comentado, una tutora comenta que, posiblemente, no se ha llegado a la máxima puntuación por falta de experiencia de las participantes, es decir, porque era la primera vez que se enfrentaban a una acción formativa virtual.

«De experiencia por parte de ellas. Quiero decir, que a lo mejor no ha llegado al cinco, porque ha sido un primer recorrido, y del primer recorrido es muy difícil llegar al cinco» (T2/PRECOG)

En cuanto a la toma de acuerdos y la generación de propuestas, las opiniones entre los tutores y tutoras difieren. Para algunos llegaron a ambos niveles, incluso resaltan el que se crearon nuevas líneas de discusión a raíz de los debates propuestos sobre otras cuestiones.

«La participación en el foro, todas las participantes aportaron ideas y expusieron sus opiniones, en la mayoría de los casos, en más de una ocasión, creando incluso nuevos temas a raíz de las manifestaciones de las participantes. (T4/PRECOG)

«Quizás le diría que sí, sobre todo par la generación de propuestas» [...] En los foros y tal. A lo mejor llegaba al cinco» (T2/PRECOG)

Sin embargo, para otros tutores y tutoras, no se llega al más alto nivel en este aspecto por carencia de conocimientos de la plataforma en la que se 
desarrolla el curso y por una falta de experiencia en realización de acciones formativas virtuales:

«Sí, si se puede lograr, lo que pasa es que yo creo que en ese sentido, yo creo que, ahí sí que hay competencias que, no tanto tecnológicas, en el sentido de utilizar herramientas, cuanto estár familiarizados con ellas, desde el punto de vista del uso» (T1/PRECOG)

«Entonces, ahí claro, y eso se nota a veces, los foros pues sí, hay intercambio de ideas, pero a veces no hay una fluidez (duda) y una dinámica suficiente ino? Es todo un poco rígido... pero eso simplemente yo creo que se debe a que no hay una familiarización con la herramienta. Entonces yo ahí bajaría un poco la puntuación, entre el 3 y el 4, diría yo» (T1/PRECOG)

Una tutora realiza una diferencia entre actividades, comentando que con algunas sí se ha llegado a ese nivel alto de aprendizaje conjunto y con otras actividades ha sido más «instrumental»:

«Claro. Mucha practica experiencial, incluso de sacar y de reflexionar. Yo creo que muchas han reflexionado sobre temas que tienen ahí que a lo mejor lo veían de una manera, como muy banal, como que no tiene importancia, y que se han dado cuenta de que les podía valer. Yo ahí diferenciaría entre actividades que han sacado algo instrumental y que ellas puedan, y actividades también que han sacado de reflexión, de análisis y de tal, suyo y del contexto en el que se mueven» (T2/PRECOG)

Algunas estudiantes mencionan la propuesta que han realizado de nuevos temas a trabajar en el eje temático en el que se encontraban en cada momento. Estas estudiantes provocaban, conscientemente la controversia para conseguir una respuesta de las demás, lo que constituía el «hecho desencadenante» al que Garrison y Anderson (2005) se refieren. Todo esto se observa en esta conversación obtenida en el Grupo de Discusión: 
«P8: yo lo que he visto es que he enlazado algunos temas como que no motivaban... como que no contestaban por miedo o yo no sé por qué. Siempre se hablaba...hombre es lógico porque estamos ...el curso se trataba sobre ello pero digo bueno por poner otro tema o lo que sea, por ejemplo puse: el aborto, y yo digo, estas se han asustado o algo porque (risas de todas) no me contestaban...

P9: porque esperaban a ver si otra contestaba para ver qué es lo que ponía... porque siempre la que más hablaba...yo veía siempre a Ostalinda,

(todas hablan a la vez)

P7: es que ese es un tema de controversia...

P5: nos ha picado, ha hecho bien, nos ha picado y eso es una forma de que nos...respondamos...es una forma...y está bien.

P8: sí que he picado, sí... (risas)»

$\left(P_{5}, P_{7}, P 8, P 9 / P R E C O G / G D\right)$

Recordamos los resultados sobre la Presencia Cognitiva del estudio anterior anterior en el que las intervenciones y los debates en los foros respondían en su mayoría un esquema común y que además se observaba que la frecuencia de esta dimensión no eran tan habitual como las dimensiones docente y social. Este hecho lo relacionábamos con dos cuestiones:

- Muchos de los foros analizados se habían abierto a iniciativa de las estudiantes, asumiendo un rol docente compartido que, en ocasiones, derivaba en falta de guía y orientación en el debate establecido.

- La mayor parte de las estudiantes no había participado nunca en una acción formativa de estas características. Esto unido a un bajo nivel de alfabetización digital, puede haber contribuido a que no se consiga llegar, en algunas ocasiones, a la fase de resolución. 
Si comparamos estas dos cuestiones con las intervenciones del profesorado en las entrevistas realizadas, éstos remarcan la segunda cuestión, en el sentido de que, para llegar al más alto nivel, tanto de toma de acuerdos como de generación de propuestas, tendría que haberse dado un más alto nivel académico y de conocimientos previos de algunas de ellas y también un nivel adecuado de uso de las TIC, ya que se puede haber producido un cierto «miedo a las tecnologías», que como indica un tutor es «fácilmente superable». Además varios tutores y tutoras añaden el factor «tiempo» que podría haber ayudado a llegar a este nivel alto, si hubiese sido mayor.

«En mi opinión el desarrollo de aprendizajes requiere de una interorización para la que se hace necesaria una mayor profundización en los diferentes temas tratados, es una cuestión de tiempo de ejecución del curso» (T4/PRECOG)

" [...] es decir es mucha la exigencia en el tiempo corto con lo cual algunos desarrollos, a lo mejor, podrían haber sido un poco, con más tiempo, haberse conseguido algo más. Pero, en general, yo creo que que hay, yo valoraría más las fortalezas, las debilidades [...] se han superado muy bien, quizá es que a veces tienes el miedo, incluso las propias alumnas lo manifestaban el miedo a lo tecnológico... y te das cuenta que eso fácilmente se supera, no requiere mucho, mientras que luego lo otro, que es la propia actividad de aprendizaje, es una exigencia mucho mayor, que a lo mejor también hay que interesarse por ella; el miedo inicial ese de lo técnico parece que es lo más importante, pero uno cuando se da cuenta de que no es tan complicado, luego hay que insistir sobre, a lo mejor, sobre otras cuestiones» (T1/PRECOG)

Una tutora además añade otras dos cuestiones: la falta de experiencia en formación virtual y un cierto miedo a hablar, pensando que no era interesante para las compañeras:

«La experiencia y la si, y el miedo que pudieran tener ellas al principio» (refiriéndose al miedo a las TIC) [...] «Y hablar, y a decir, 
y a decir lo que pensaban y decir: lo estoy diciendo, será una tontería (T2/PRECOG)

En cuanto a las estudiantes, se ha comentado que responden a la pregunta directa de qué han aprendido. Una de ellas resume lo que todas las demás estudiantes aportan a esta cuestión:

«He aprendido a:

- Manejar internet y el teclado.

- A expresar mejor mis ideas.

- A concienciar a mi familia que puedo hacer lo que me propongo.

- A saber la importancia de concienciar y sensibilizar.

- A saber motivar a gitanas para que sus hijos vallan a la escuela.

- A conocer la palabra interculturalidad y su importancia, al igual que otros conceptos como igualdad y liderazgo» (P12/PRECOG/FEC)

Además de todo esto, otras estudiantes inciden en las competencias relacionadas con el uso de internet para la búsqueda de la información y añaden otras cuestiones como el mejorar la expresión escrita y aspectos relacionados con el conocimiento y desarrollo personal.

«Gracias al curso, gracias al curso que he hecho, además del curso pues he aprendido a meterme en internet porque yo tenía ordenador e internet en casa pero yo no sabía ni abrir el ordenador, sin embargo ahora todo lo que necesito buscar, lo busco» (P12/PRECOG/GD)

"yo creo que me expreso mucho mejor, porque en el curso por ejemplo yo todo lo que he hecho lo he pensado lo he escrito, [...]» (P12/PRECOG/GD)

«yo creo que te ayuda a conocerte a ti misma, a conocer más tu vida, a conocer más de tu casa, porque en realidad es un conocimiento... 
Por ejemplo a mi edad conocía hasta cierto punto, pero sí que conoces más de ti misma, y más de los demás, y hasta dónde puedes llegar y que puedes llegar más lejos de lo que tú piensas» (P1/PRECOG/GD)

Como vemos las estudiantes enfocan su aprendizaje en dos niveles:

- Uno más individual relacionado con las competencias

- Y otro colectivo de incidencia directa en su grupo de iguales.

En referencia a la presencia docente incidimos en la valoración de si la experiencia favorece el diálogo entre iguales. Todo el profesorado entrevistado considera que ha sido democrático y que se ha favorecido de manera constante, como se observa en la siguiente expresión realizada por un docente:

«Yo creo que aquí sí, digamos, es decir, más democrático que esto, no puede estar, o sea estamos todos al mismo nivel, todos tienen la posibilidad de hablar cuando quieran, como quieran. $O$ sea, esto mucho más que en un aula, digamos presencial. Que generalmente el que toma la palabra es quien toma la palabra y luego la cede... Pero aquí no, aquí directamente tienes el espacio, abierto para poder hacerlo todo, entonces se dan todas las posibilidades para que exista ese diálogo entre iguales y directo y democrático» (T1/TUTOR)

En cuanto a la valoración de logros de las participantes, tutores y tutoras creen que no han hecho favorablemente esta función establecida a su rol, debido a su propia falta de tiempo:

«Esto es algo que a mí me pasa en las asignaturas virtuales, a veces tienes exceso de información, y no eres capaz de dar el feedback suficiente porque no tienes tiempo, porque es mucho lo que tienes que manejar. $Y$ entonces ahí se pierde, yo creo que se pierde, se pierde bastante, porque, claro, recoges mucho, y todo eso si lo procesas, pues dedicas... exige bastante [...]» (T1/TUTOR) 
La evaluación de la labor tutorial realizada por el profesorado tiene una valoración muy positiva por parte de las estudiantes. También el profesorado cree haber desarrollado una buena labor de orientación y guía en los foros, respondiendo a lo requerido y en el tiempo estipulado, tema en el que coinciden todos los tutores y tutoras entrevistados:

«He intentado atenderla y ser rápida en la respuesta a las peticiones que ellas hacían» (T2/TUTOR)

«Al responder a los comentarios de las participantes, a menudo ampliaba las explicaciones más allá de lo que hay en el texto, beneficiando así a todos los participantes y no sólo quién hizo el comentario» (T5/TUTOR)

Se incide, por parte de algunas tutoras, en que la participación de las estudiantes ha facilitado esa labor:

«[...] El desarrollo del tema y la participación de las alumnas ha facilitado la labor de todas las personas que hemos participado como docentes» (T4/TUTOR)

Desde el comienzo, las estudiantes han valorado el trabajo del profesorado y su cercanía con ellas:

«...los docentes muy cercanos, ya que nos explicaron la información todas las veces que fue preciso y nos dieron muchos ánimos además de las herramientas necesarias para poder empezar» (P2O/TUTOR/FEC)

Las estudiantes, en la evaluación final, mencionan en todos sus mensajes el agradecimiento al profesorado y dinamizadora, con mensajes muy emotivos y reconociendo el trabajo de tutoría llevado a cabo.

«En primer lugar, dar las gracias a todos los profesionales que han hecho posible este curso (sobre todo a ti Rosa). Han estado geniales! sobre todo han tenido mucha compresión. Gracias Juanita por hablar de esos temas tan interesantes ya que la interculturalidad 
debe de formar parte ya de los políticos (pero de verdad), gracias Maricarmen y Carmina por ese tema de la igualdad, ya que es un derecho fundamental y de desarrollo» (P12/TUTOR/FEC)

«Respecto a los docentes, decir que han trabajado al 10o\%, estoy muy contenta por lo que nos habéis ayudado y lo que os habéis entregado en este curso, haciendo ameno y divertido este viaje por la red» (P17/TUTOR/FEC)

«Los docentes y dinamizadores,me han parecido geniales,yo no he tenido ningún problema a la hora de entender las tareas a realizar» (P1O/TUTOR/FEC)

«En cuanto a las docentes e de decir que ha sido maravillosa su labor os habéis moldeado a nuestras dificultades, a la más mínima duda nos habéis contestado y sobre todo hemos aprendido muchísimas cosas» (P8/TUTOR/FEC)

«Gracias a tod@s personal docente por ser tan específicos ,claros y amables. Yo les agradezco de todo corazón que se hallan implicado tanto en este proyecto,que al principio parecía tan inalcanzable o muy cuesta arriba.....jajajaj. A Emi, nuestra dinamizadora gitana, le he visto poco por aquíiiii pero es super buena gente y una gitana de ejemplo a seguiri [...] Y a ti ROSA no hay números para calificarte ni palabras para describir tu gran labor con todas GRACIAS. Sin ti esto no hubiese sido posibleii» (P2/TUTOR/FEC)

\section{Dirigiéndose a la dinamizadora:}

«...eres un cielo con un sol radiante gracias por todo lo q te esfuerzas en comprendernos y en solventar nuestros problemas con la redii sin ti seguro q no hubiéramos llegado ni ala primera semana gracias por que siempre tienes un no te preocupes en tu boca [...]» (P2/TUTOR/FEC)

Denotan, además, esa implicación de tutores y tutoras en el buen desarrollo del curso. 
«creo que las docentes y animadoras aveis dado mucho, osea os aveis implicado creo que asta aveis disfrutado y eso os a echo hacer un trabajo------1O» (P5/TUTOR/FEC)

La labor de evaluación de los aprendizajes por parte de tutores y tutoras se valora positiva y respetando lo establecido en el diseño:
«[...] En la evaluación, también he ido atendiendo a cada una, y luego cuando les he dado la nota, he explicado también el porqué. En el proceso ha habido algunas que habían tenido problemas, o dudas y tal, he intentado ir encauzando también» (T2/TUEVA)
«El trabajo realizado por las alumnas, en su gran mayoría, ha sido excelente» (T4/TUEVA)

Se valora con puntuación alta, como indica uno de los tutores, el diseño previo de la evaluación y la respuesta positiva a este diseño evaluativo por parte de las estudiantes.

\begin{abstract}
«[...] yo valoraría con una puntuación alta esto, sobre todo porque ha habido preocupación en el diseño de que esto ocurriera. En los Foros por ejemplo, cada vez que ha habido un taller, o tal, ha habido una valoración, un foro para evaluarlo, para valorarlo, con lo cual estaba bien diseñado eso. Luego las respuestas pueden haber sido más o menos, más o menos participativas, porque la verdad es que lo que se les pedía era bastante (risas), pero yo creo que es razonable lo que han comentado incluso algunas intervenciones de evaluación ya general y tal, realmente son rigurosas [...]» (T1/TUEVA)
\end{abstract}

Ahondando en los resultados de la evaluación del curso en general, una tutora señala que estos han sido en su mayoría logros relacionados con un cambio social.

«[...] Es difícil ¿no? Yo creo que y en este tipo de cosas además porque hay logros, que hay buena parte de los logros de este curso, probablemente en un porcentaje muy alto mas del 5o\% de los distintos logros, tiene que ver con, son de naturaleza no cognitiva, no de conocimientos, sino sociales [...]. Se supone que el curso quería 
provocar cambios y entonces esos cambios hay que valorarlos» (T4/TUEVA)

En general, por tanto, la labor tutorial y su valoración por parte de las estudiantes ha sido satisfactoria para tutores y tutoras.

\begin{abstract}
«[...] Las del Foro de Evaluación, o las que se han propuesto para cuando se hacían seminarios, que los valoraban e incluso las que espontáneamente algunas veces hacían. Había unas cosas que gustaban otras que no y tal, ese tipo de cuestiones. Entonces, yo creo que el tema de tutorías ha funcionado bien» (T1/TUEVA)
\end{abstract}

La coordinación entre profesorado y dinamizadora se ha ajustado a las expectativas.

«La coordinación con la dinamizadora ha respondido a las expectativas $[\ldots] »\left(T_{4} /\right.$ TUCOR $)$

La totalidad de tutores y tutoras afirman haber establecido relaciones de coordinación con la dinamizadora. Sin embargo, se ha echado en falta la apertura hacia otros profesores y profesoras del curso, en este sentido sólo se han coordinado quiénes, prácticamente por obligación para no solaparse, han tenido que hacerlo:

«No tuve mucho contacto con otros profesores, sólo con Rosa quien me resolvió varias dudas» (T5/TUCOR)

«Con otros profesores no, con la dinamizadora si, con otros profesores no ha sido necesaria, creo que no ha sido necesaria» (T5/TUCOR)

«Nos pusimos en contacto, ¿Qué vas a dar? Como no nos vamos a solapar, y no mas» (T3/TUCOR)

Un tutor valora la coordinación como positiva, piensa que el rol tutorial estaba tan claro y tan definido en el diseño, que el funcionamiento ha sido adecuado. 
«Yo entiendo que sí, yo entiendo que sí, vuelvo a lo mismo, como el diseño era bastante claro, yo creo que eso facilita que cada uno sepa que rol desempeña y donde está su papel. Entonces de ahí, como todo habrá sido mejorable pero yo creo que ha funcionado. Ha funcionado bien ese papel» (refiriéndose al papel del tutor/a) (T1/TUCOR)

Quizá la razón que da el tutor pueda haber derivado en esa falta de coordinación entre profesorado.

Se destacan pocas incidencias que hayan irrumpido en la labor tutorial. Algún problema técnico puntual de acceso al campus virtual.

«[...] sé que ha habido algunas incidencias técnicas, ha habido algún momento de falta de conexión puntual del Campus Virtual, pero vamos, que se superaron rápidamente. Y por lo demás ninguna» (T1/TUPRO)

Sólo una tutora reconoce abiertamente, como problema en su labor, que no tenía suficientes conocimientos didácticos para enfrentar esta experiencia de tutoría y cree que hubiese necesitado una formación didáctica en este sentido, aspecto que se unía al grupo destinatario de la acción formativa virtual.

«Si creo que debía haberlo hecho mejor. Es verdad que me costaba mucho. Que mas allá que la guía este muy bien hecha, si notaba algunas carencias en cuanto a herramientas didácticas por mi parte [...] Se que en este caso me faltaban herramientas didácticas. Era lo virtual y a un grupo... Es que se juntaban dos cosas, a un grupo muy peculiar, con muy bajo capital cultural, en un medio novedoso y con unos contenidos que había pensado hacerlos asequibles, y a veces tenía esa sensación de trivializarlos para hacerlos cercanos. Entonces ahí se juntan una serie de cosas, que creo que son subsanables con algo más de formación didáctica, que yo creo que tengo algo de formación didáctica después de los años y que me he preocupado. Pero también otro entorno, es decir que yo me estoy introduciendo en un entorno mas presencial. Que yo me estoy introduciendo en esto. Pero me faltaban cosas» (T3/TUPRO) 
En cuanto a los aspectos organizativos, en todo momento se destaca una flexibilidad por la adaptación constante a las estudiantes y a sus ritmos de aprendizaje, pero también a sus ritmos de vida diaria, ya que algunas deben conciliar por las responsabilidades que deben asumir:
«[...] había un tiempo inicial pero luego he sido flexible a la hora de hacerlo, porque surgían temas personales y me he adaptado a ellos $y$ sin problemas» (T2/ORGFLEX)
«Porque son de diferentes sitios, porque la estructura les permite intervenir cuando quieren y cuando pueden y dentro de la regulación que implica el curso hay un elemento de desregulación que se adecua muy bien a determinados estilos de vida [...]» (T3/ORGFLEX)
«Definitivamente, en el sentido que algunos se atrasaron por motivos personales pero tuvieron la oportunidad de ponerse al día., sin perjuicio» (T3/ORGFLEX)

De este modo, al preguntar por las diferencias entre si esta acción hubiese sido presencial en lugar de virtual, se alude a esa conciliación y a la distancia geográfica entre las participantes, como razones fundamentales para no haber seleccionado la modalidad presencial en el desarrollo. Un aspecto que destaca, para una de las tutoras, es la importancia de poder realizarlo desde sus hogares, siendo ejemplo para sus familias e hijos:
«[...] El aprendizaje de conocimiento, instrumentos, la colaboración entre ellas. Pero yo creo que dada las características de ellas, la situación personal, laboral y tal, si no se hace de esta manera no hubiera sido posible. No hubiera sido posible que se encuentren a la hora que sea a través de un foro, porque unas eran madres, porque otras estaban trabajando, porque unas en Cáceres, otras en Badajoz, no hubiera sido posible. Lo haces un día pero se les olvida hasta la otra vez. No, no hubiera sido posible» (T2/ORGVIRPRE)

«Posiblemente se podía haber organizado un curso con estos contenidos de forma presencial, pero lo que no se hubiese conseguido es que las alumnas hubiesen asistido, o hubiesen finalizado con éxito 
el mismo, ya que muchas de ellas, tienen responsabilidades que no hubiesen podido dejar de lado para asistir a todas las sesiones presenciales mientras que, de esta forma, no solo ellas han podido finalizar el curso, sino que al hacerlo desde sus casas, conectadas al ordenador, haciendo los ejercicios, etc. ...han sido un ejemplo para sus familias e hijos» (T7/ORGVIRPRE)

«[...] las cuestiones de tiempo, también, es decir son personas que o son amas de casa o están trabajando y evidentemente implicarlas en un curso con una asistencia, un horario y demás bloquearía además mucho aspectos posibles» (T1/ORGVIRPRE)

Las estudiantes comparten las opiniones de tutores y tutoras, comentando que no hubieran podido realizar la formación si se hubiese desarrollado en modalidad presencial por aspectos relacionados con la conciliación familiar. Por ello, realzan la importancia de la flexibilidad para realizarlo en el tiempo disponible que tuviesen:

«Es que hacía mucho tiempo que no tenía tiempo para hacer cursos, hacía mucho tiempo que no hacía un curso... (hablan todas a la vez) es que yo por ejemplo, si el curso hubiera sido presencial todo todo, no podía hacerlo...»(P7/ORGVIRPRE/GD)

«Me lo has quitado de la boca...yo si hubiese sido presencial no lo hubiese hecho porque soy ama de casa y no tengo tiempo, tengo la casa muy grande, es que...mira allí mismo me gustaría a mí sacarme el graduado escolar, porque tengo que hacerlo, y como tengo que ir no voy [...] yo estaba en casa y por ejemplo cuando acababa de hacer la cena y de cenar me ponía, y yo he estado hasta las tres de la mañana, que las he estábamos sólo éramos Ostalinda y yo, y Mayte que también me ha visto muchas veces a la una» (P12/ORGVIRPRE/GD) 


\subsubsection{Dimensión sociocultural.}

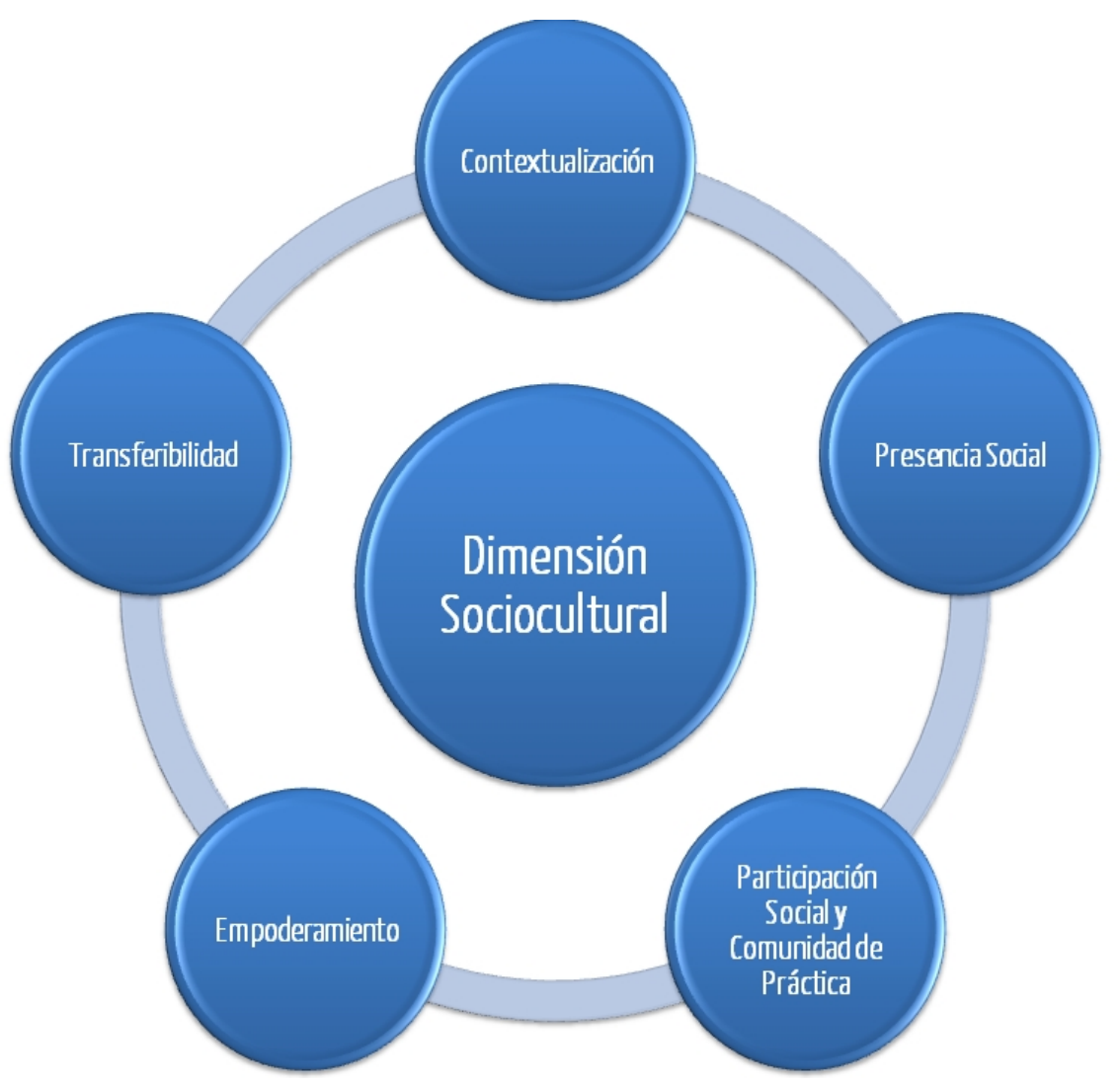

Figura 49. Dimensión sociocultural.

La dimensión sociocultural, desde nuestro análisis, también responde a indicadores estudiados por autores y autoras como Planella y Rodríguez (2004a, 2004b y 2004c), Casacuberta (2004), Ros (2004), Wahrhafting, (2004), Garrison y Anderson (2005).

En referencia a la contextualización de la acción y situándonos en la dimensión sociocultural, tutores y tutoras reflejan que esta experiencia ha estado contextualizada y adecuada a la realidad de las estudiantes, teniendo en cuenta su diversidad. Opinan que ha tenido en cuenta que los contenidos trabajados, a través de las actividades, puedan aplicarse a sus contextos 
socioculturales; esto permite que, según el profesorado esta acción se haya llevado a cabo de forma eficaz.
"[...] yo creo que atendía a una necesidad suya, de las participantes y se ha sabido darle contenido al curso, para que ellas realmente lo pudieran aprovechar y lo vieran útil, en el contexto suyo y dada las características que tenían, y además de la diversidad, porque todas eran gitanas, pero tenían intereses completamente distintos $y$ situaciones completamente distintas. Pero había por ahí un punto, el tema en si le daba un punto de unión, que era el que yo creo que ha hecho que todas estuvieran tan interesadas en hacerlo» (T2/SOCON)
«Sí, está contextualizada, y eso ha permitido afrontarla de forma mucho más eficaz» (T4/SOCON)
«Me parece que sí, ya que todas las participantes pudieron accederse al internet y pudieron encontrar maneras de aplicar los contenidos a su realidad» (T5/SOCON)
«Considero por supuesto que la acción estaba contextualizada y que se adaptaba a las necesidades del alumnado» (T7/SOCON)

Incluso, dentro de acción contextualizada, un tutor la califica de innovadora dentro del campo profesional de la acción social y las mujeres gitanas:

«Sí. Es una acción innovadora en un campo donde se necesitaba, ¿cuántos cursos de cierto nivel de empoderamiento de mujeres gitanas se desarrollan en España?»(T6/SOCON)

Recordamos que la Presencia Social es la capacidad de los participantes en una comunidad de investigación para proyectarse a sí mismos social y emocionalmente, como personas «reales» (es decir, de personalidad plena) mediante el medio de comunicación que se emplee (Garrison, Anderson y Archer, 2000:94). Esta dimensión incluye indicadores relacionados con la creación de una dinámica grupal que se caracteriza por la 
expresión de emociones, sentimientos, experiencias, como un aspecto clave para la generación de una Comunidad de Práctica.

Hemos detectado, en las intervenciones del profesorado entrevistado, datos que corroboran los resultados del anterior estudio, donde esta dimensión tomaba protagonismo sobre las demás. De hecho los docentes piensan que el componente «emotividad» sobrepasaba las expectativas iniciales, destacando factores como los aspectos culturales e incluso la virtualidad como determinantes de este componente. Para éstos la Comunidad de Práctica se ha conformado.

«Creo que sí. De hecho a veces entendía que las... Que había un exceso de emocionabilidad. Demasiada emoción frente a razón. Probablemente $y$ eso tiene que ver con aspectos culturales, con aspectos de clase, con su propio rol social, en donde no están acostumbradas a moverse en un ámbito mas intelectual [...]» $\left(\mathrm{T}_{3} / \mathrm{SOSOL}\right)$

«Las participantes, quizá por ser en su mayoría el primer acercamiento a las nuevas tecnologías y a un espacio en el que manifestar opiniones de forma libre, ya que lo hacían sin la presión social de su grupo de iguales puesto que el hecho de participar en el curso ya las igualaba en cuanto a la situación de partida, han sido espontáneas y emotivas en sus intervenciones. Han compartido sentimientos, ideas y opiniones identificándose con el grupo de participantes» (T4/SOSOL)

El profesorado también corrobora que esta dimensión tiene una relación directa con la conformación de Comunidades de Práctica a través de espacios virtuales, como observamos en la última intervención mostrada en la que la tutora afirma que las estudiantes se han identificado con el grupo.

Hay factores mencionados por el profesorado que se consideran determinantes de la conformación de la Comunidad de Práctica, entre ellos destacan: el diseño de la forma de trabajo, la plataforma virtual, el sistema de 
interacciones, la adaptación a las estudiantes y a sus conocimientos previos, las temáticas abordadas y la dinámica seguida en la formación

Uno de los tutores refleja todos esos factores en una de sus intervenciones durante la entrevista:

«Bueno, para empezar yo creo que las temáticas que se han abordado, [...] les interesaba desde el punto de vista personal, luego eso quiere decir que favorece que determinados contenidos se compartan, se traten, se reflexionen, se aporten ideas. Todos podían participar en eso porque todas tenían experiencias por lo cual podían aportar cosas; eso ya es un nivel, porque claro, si se da una serie de conceptos de ideas muy ajenas a las personas a las que se dirige, pues evidentemente, queda todo en un plano bastante artificial. Aquí yo creo que otorga la propia vida, y por lo tanto, en ese sentido, es más fácil generar una comunidad en el que puedas compartir todo lo que sabes, tus experiencias, sin necesidad de que seas un experto en eso, por una parte. Por otra parte, el hecho de la propia plataforma agrupa y une a personas dentro de un entorno, las comunica directamente entre ellas, y eso establece redes y yo creo que esas redes fomentan el que se cree la comunidad también. No es que sea definitivo para ello pero ya si es una facilidad. Es decir, si estamos, si sabemos donde nos encontramos, si sabemos cómo comunicarnos, si sabemos que sé yo de esto y a todos les llega, pues eso evidentemente, facilita mucho que que se puedan generar esta posibilidad de comunidad de aprendizaje. Y luego es una cuestión también importante la de la dinámica de los tutores, coordinadores, dinamizadores, en orientarlos hacia los objetivos que se pretendan $y$ hacer ver que lo que estamos buscando es precisamente compartir y el compartir genera unos conocimientos, esos tres elementos. Los contenidos, los tópicos, los temas que se facilita el generar redes y luego la dinámica que intencionalmente se ocupa de que la gente se agrupe en comunidad, favorece esto" (T1/SOCVA) 
En todos se incide en la adaptación de la acción formativa a las destinatarias y a sus conocimientos previos, en cuanto a acción contextualizada.

«Creo que el primer factor es un buen diseño de la forma de trabajo, un buen diseño de la plataforma, del sistema, una regulación de la utilización del esto. En segundo lugar eso va íntimamente unido, perdón, o viene definido porque sea una experiencia claramente contextualizada en las características del grupo, osea, que se adecue perfectamente. Creo que eso son dos elementos fundamentales, que el diseño se haga fundamentalmente a tenor de las características del grupo, y que este perfectamente definido. Creo que tiene que haber un trabajo de elaboración muy, muy largo previamente [...]. Eso es fundamental para cualquier proceso de aprendizaje, pero en este caso mas (refiriéndose al conocimiento previo del destinatario)» $\left(T_{3} / S O C V A\right)$

Una profesora señala que un factor previo fundamental ha sido que no se conocían todas, que el grupo no estaba conformado. Cree que, de esta forma, encuentran el punto de unión en ser estudiantes de la misma acción formativa. Por otro lado, otra docente considera que el ser mujeres y gitanas las ha proporcionado una línea de unión para el buen desarrollo de la experiencia:

«Se toma mas confianza. Si hubiese sido... si entre todas se hubiesen conocido, yo creo que hubiese habido, había un riesgo, y es que nuestra cotidianidad al margen del curso, acabe ganándole terreno al propio curso. Así que las identidades grupales se han construido en el propio grupo, no fuera, y eso es bueno. Eso era lo peligroso, lo difícil mejor dicho, pero que el grupo ya este formado previamente $y$ vaya al curso, no se si eso es bueno. Yo lo cuestiono, porque lo cotidiano que te ha unido puede invadir el curso así que no. Lo que nos une es que somos estudiantes de un curso. Otra cosa es que de allí salgan intimidades que trascienda al propio curso, pero de lo contrario, a veces pienso que puede haber un peligro [...]» (T3/SOCVA) 
«Es clave que se cree una buena sintonía personal, afectiva y efectiva, entre los miembros del grupo. Creo que se ha conseguido. Todas ellas eran mujeres gitanas y eran conscientes de que les unían muchas cosas, aunque algunas tenían más edad que otras. Creo que en líneas generales se ha superado la barrera de la edad» (T6/SOCVA)

A todo esos aspectos se une la idea de sentir que «forman parte de un grupo» con esta acción en común:

«Completamente. Ademas yo creo que eso ha sido, lo que yo destacaría del curso. Aparte de los instrumentos que ellas han podido, de los conocimientos que hayan podido tener, en esa parte de sentirse, no se, iba a decir útiles, pero no es útiles... es parte de un grupo y con algo en común y en que todas estaban interesadas y a todas podían sacar beneficios...» (T2/SOSOL)

Las estudiantes inciden, también, en que se han sentido parte de «un grupo común», realizando matices entre personas con las que han sentido una mayor afinidad. Manifiestan, asimismo, las ganas de seguir trabajando juntas:

«Yo creo que afinidad, yo por ejemplo, he tenido, por supuesto, más afinidad con unas personas que con otras, eso está claro, pero [...] yo sí he sentido a todas, sin excluir a ninguna, como grupo de un curso que estoy haciendo. De hecho, fisicamente, yo me he encontrado con alguna de ellas, recuerdo a Esperanza, que vino muy poco, vino el primer día, y físicamente yo me encontrado con ella en otro lugar y antes yo no la conocía, yo me he acercado a ella y sólo la había visto una vez, y le dicho: oye qué tal, ¿no vienes al curso? ¿no te metes en el espacio?» (P7/SOCVA/GD)

«Me encantó, estábamos todas como más cómodas, nos conocemos un poco más y palpé las ganas de trabajar juntas» (P17/SOCVA/FEC) 
Por otro lado, se destaca la iniciativa de las estudiantes por abrir nuevos temas, por responderse entre ellas, ayudarse y animarse, como claves en esa conformación, tema relacionado con las «emociones» y la «cohesión», indicadores de la «presencia social» (Garrison y Anderson, 2005):

«[...] Pero propuestas por ellas mismas, que ellas se preguntan, ellas se contestan, y no necesitaban a nadie» (T2/SOSOL)

«Pues mira. Te lo digo porque, porque las que iban con miedo, con ser la primera vez, con el gusanillo ese que tenían, de que no podían y tal, yo creo que se han viso reforzadas por parte del profesorado $y$ sus compañeras. Porque yo no puedo, porque yo no se qué... y en el momento tenían respuesta de otras, animando o haciéndoles ver que sí, que era posible hacerlo» (T2/SOSOL)

Otro aspecto que creen que ha sido fundamental para la conformación de la Comunidad de Práctica es la implicación de la Universidad en esta experiencia, a través de profesorado y espacios, y la implicación de todos los tutores y tutoras en la acción, lo que ha incidido en su motivación por formar parte del grupo:

"Que ellas han visto desde el principio la posibilidad que se les ha dado de acceder a algo, a lo que ni eran conscientes de que pudieran hacerlo y haberle dado esas herramientas, además haberles hecho ver, que se le iban a dar unas herramientas que podían aprovechar para el futuro. Creo que desde el principio se les ha hecho ver que podían. El primer día cuando estaban aquí, en el aula de tecnología en la Universidad, impensable para algunas, que ellas pudieran estar. Entonces el contexto en sí y el hacerle ver que estábamos a su disposición, que podían, que se le ayudaba, que tal. Creo que ni eran conscientes de eso, fijate. Entonces yo creo que ha sido un factor que ha influido para el buen desarrollo y la implicación que han tenido» (T2/SOCVA)

Como hemos indicado, todos y todas las docentes muestran acuerdo en la conformación de la Comunidad de Práctica y se refieren a uno de los temas 
abiertos por una participantes en el Foro Entre Callis, denominado «Un Compromiso» que fue analizado en el anterior estudio. Coinciden en que este tema muestra la necesidad de continuar el trabajo y la relación, una vez finalizada la acción formativa:

\begin{abstract}
«[...] por ejemplo, un dato concreto, en algún momento determinado alguien dice, yo esto, como cuando ya está acabando, esto no deberíamos perderlo, esa necesidad del grupo que se ha creado, se quiere trasladar a fuera de de la formación. Entonces eso es un indicador claro de que ha conseguido ese objetivo de crear una comunidad, de generar la necesidad de compartir cosas y demás, cuando no se quiere acabar aquí, sino que se quiere continuar, entonces eso es un buen ejemplo de una... de generar ahí unas actitudes, positivas, a mantener esto, yo creo que sí que se ha conseguido [...], incluso la idea de grupo, yo creo que también se ha conseguido y eso que eran personas de diferentes, de muy distintos sitios y tal, en alguna medida se identificaban [...]» (T1/SOSOL)
\end{abstract}

En ese aspecto, la motivación por seguir conectadas y aprendiendo, se baraja como el éxito de la posible continuidad de la Comunidad de Práctica:

«La motivación por seguir conectadas en red, por seguir aprendiendo y formándose, siempre que vean en la comunidad de aprendizaje una oportunidad de empoderamiento de ellas mismas, $y$ una promoción personal y/o profesional [...]» (T7/SOCVA)

Profundizamos más en la conformación de la Comunidad de Práctica, preguntando al profesorado por los factores determinantes en las diferentes etapas iniciales, de desarrollo y final.

En cuanto a la etapa inicial, se consideran fundamentales los indicadores de «Presencia Social»:

«[...] En primer lugar, es decir, en los primeros momentos es la presencia, fundamentalmente, es decir, que se note que...que estamos 
ahí, de alguna manera, aunque sean todavía unos mensajes en los que la interacción o tal...es simplemente ponerme yo. Pero esa esa primera...de estar ahí, de estar presente, de... no sólo que se ha actuado en los foros sino por ejemplo que también se ha ido a ver los documentos, se ha curioseado para ver que hay, es decir, que se vea que hay una presencia. Si en los primeros momentos hay presencia, en todo este tipo de cosas y se puede ver en un aula virtual si eso ocurre, yo creo que eso es un indicador de que esto se está construyendo bien [...]» (T1/SOCVA)

Se destaca también, en esa primera etapa, el conocer a las personas que van a formar parte de la acción formativa, así como marcar la finalidad de la experiencia y lo que se espera de las personas que van a participar. Se incide en que el grupo era de mujeres y gitanas, facilitándose el primer acercamiento al compartir valores culturales:

«[...] Fundamental que todas eran mujeres gitanas. Que eran conscientes de que pertenecen a un colectivo, con unas características determinadas y además, se les ha hecho ver que podían aprovechar el curso en beneficio suyo y del grupo» (T2/SOCVA)

En la segunda etapa, donde se va desarrollando la experiencia formativa, se destacan, por parte de los tutores y tutoras, indicadores ya no sólo de Presencia Social, sino Cognitiva y Docente. Lo reflejan claramente estas tres intervenciones:

«Pues ahí, un criterio que podemos ver es en qué medida de una manera autónoma las personas provocan, por ejemplo, un debate o abren una nueva línea de un foro, proponen alternativas. Es decir, que toman ya, digamos, el control, no sólo de su aprendizaje sino que proponen también a los demás cosas a hacer o bien a través de un debate o de algo que han leído... y quieren que los demás opinen o toman, por tanto, un rol más activo en eso. Ya no están esperando a ver que recibo, que sería esa primera fase inicial, estoy a ver que hay, sino que ahora ya estoy y además, propongo, intervengo, veo de qué manera puedo mejorar. Eso se puede ver en los Foros, no sólo porque uno responde a lo que dice el tutor sino porque responden a lo 
que otros dicen...y entonces se ve que ahí hay algo mucho más allá de la presencia, sino además yo quiero interactuar» (T1/SOCVA)

«Puede ser interno, el apoyo que han tenido por parte del profesorado, los dinamizadores y tal. La comunicación que se ha establecido entre ellas. Yo creo que eso es fundamental» (T2/SOCVA)

«Yo creo que hay una parte importante, y es que si al principio es muy bueno motivar, también poco a poco el curso tiene que dar la sensación de que van aprendiendo cosas y de que hay cierta formalidad. Lo digo porque hay una cosa que es importante especialmente para determinados grupos sociales y es no solo el estar motivado y que me lo pase bien, sino que uno adquiera conciencia de la formación y de que las cosas se tienen que hacer con cierto rigor. Compaginar seriedad con divertimento es dificil, pero entonces sí creo que durante el proceso hay que seguir motivando, es importante para que la cosa no vaya decayendo, pero también, hay que ir gestionando el esfuerzo de manera que este sea un poquito ascendente» (T3/SOCVA)

En cuanto a la etapa final, tres aspectos han sido fundamentales: la valoración positiva por parte de las estudiantes mostrada en sus intenciones futuras; la valoración de los aprendizajes y logros conseguidos; y, por último, efectuar un reconocimiento público de la acción realizada, además de la certificación recibida.

«Pues ahí una valoración en la que diga volvería a hacer otro curso en un entorno de esta naturaleza, es decir, la intención futura de seguir utilizando herramientas para seguir aprendiendo, pues ya nos daría un indicador de que ha funcionado. El querer repetir, el decir, me gustaría continuar más tiempo, estar más tiempo, o sea la necesidad de continuar de alguna manera es un indicador de que lo que se ha hecho lo valoras y te gustaría seguir aprendiendo [...]» (T1/SOCVA)

«El reconocimiento publico que se ha podido hacer. De que han llegado, de que lo han conseguido, de que lo han hecho bien, y de que 
han sido capaces. Y yo creo también, la satisfacción propia de haber llegado hasta el final [...]. Sí, algo visible. (refiriéndose al certificado final) [...]. Válido reconocido por parte de la Universidad como institución, que a lo mejor a ellas les venía, el haber hecho un acto público en el que los demás han visto que han hecho algo y que ese algo tenía un sentido y que valía también. El reconocimiento social, público» (T2/SOCVA)

«Yo creo que es importante que al final ellas sepan cuales son los logros colectivos y los individuales. Ellas deben conocerlos y además que se les haya dado un diploma. Deben reflexionar sobre lo que han aprendido, como grupo y como personas. Creo que eso es fundamental» (T3/SOCVA)

Por otro lado, también se profundiza en las actitudes necesarias por parte de las participantes para la conformación de la Comunidad de Práctica. En este sentido se incide en la predisposición, la curiosidad, la apertura hacia temas nuevos y el querer progresar y cambiar, la dedicación, la motivación, el compromiso y el deseo de participar.

«Venían predispuestas a que era algo bueno y algo que tenían que aprovechar [...] Y que era una oportunidad que se no se les había dado hasta ahora. Es decir, cuando a ti, directamente, nadie te pregunta, nadie te dice, piensas que a lo mejor no puedes servir, y que no lo puedes hacer, que no estás capacitada para ello, que no vas a ser capaz. Yo creo que como ha sido lo contrario, ha sido el punto de inicio y que ha hecho surgir que participaran tanto y que pudieran aprovecharlo» (T2/SOCVA)

«Por lo que yo he visto pues sí, (refiriéndose a la heterogeneidad en el grupo). Y cuando alguien por ejemplo planteaba como una actitud menos...o mas pesimista, o mas «esto no lo puedo hacer» o siempre ha sido así... las demás actúan como agentes de cambio y decían: oye, oye qué estás diciendo» (T3/SOCVA)

Muy relacionado con la promoción sociocultural de las mujeres participantes, están los conceptos de «participación social» $\mathbf{y}$ 
«empoderamiento». En este sentido, solicitamos a tutores y tutoras que comentaran su valoración sobre si la acción formativa ha fomentado $\mathrm{y}$ conseguido estas dos cuestiones. También se debate sobre ello en el Grupo de Discusión llevado a cabo con las estudiantes.

En relación al empoderamiento, el total de tutores y tutoras creen que las estudiantes han salido un poco más empoderadas de este curso. En casi todas las intervenciones se habla del aprendizaje con TIC y de recursos como el Blog, como herramientas que han motorizado ese factor.

«Firmemente empoderadas. Porque mas allá de que haya logros de cambio social, que todavía no se puede medir, o que son dificil medibles, hay una serie de logros, objetivamente y concretos que pueden ser claramente se puede hacer una relación de logros: han aprendido a encender un ordenador, saben lo que es un foro, participan en un blog, han desarrollado unidades de lectroescritura, que más de una y de dos probablemente, hacía años que no hacía... Entonces habrán mejorado su lectura, fijo. Hay una serie de logros que no son cuestionables. Cuando tú empiezas a saber cosas, te motivas, te sientes mejor, te da seguridad» (T3/SOEMP)

«Por supuesto que favorece el empoderamiento de las mujeres gitanas participantes, porque pueden, como comentaba, seguir ejerciendo alguna de sus responsabilidades como mujeres dentro de su comunidad, a la vez que tener una ventana abierta, a través de las TIC con otros espacios y redes de mujeres» (T7/SOEMP)

«[...] Seguramente, esta experiencia permitió a varias de las participantes a cobrar seguridad con el uso del Internet en general, $y$ de las TIC específicamente, dándoles confianza para seguir utilizando esta herramienta tan vital en otros aspectos de su vida» (T5/SOEMP)

Una de las participantes refuerza estos aspectos en su intervención, destacando que habla de las compañeras, a su familia, mostrándolas de ejemplo de mujeres gitanas actuales: 
«[...] yo hablo por mí misma. Y a mí me gusta, me siento muy apoyada cuando veo a otra persona que estudia, cuando a una persona...o no que estudia sino que tiene esa mentalidad de decir: ipues valgo para algo más que estar en casa! o iyo puedo estudiar!. A mí me fortalece mucho, a mí personalmente...Y el conocer a todas las que he conocido (refiriéndose a las compañeras del curso), unas estudiando, otras trabajando, con sus hijos, ver ese tipo de cosas a mí me anima mucho, animarme yo y animar a los que tengo alrededor que le puedo poner ejemplos. Yo creo que por ejemplo ver una gitana que sigue siendo gitana... tiene sus costumbres pero se le añade el que estudia, el que se forma, el que se sabe ....y sabe lo que quiere. Para mí es muy importante y el hacer el curso, bueno, me ha acercado a ellas y hablo a la gente, yo hablo mucho de ellas a mi madre, a mis tías, hablo mucho de ella (señalando a una compañera) [...]. Se quedan con la boca abierta. Entonces, bueno, pues en un momento dado, podemos llamarnos [...] el entorno virtual es mucho más cómodo, es mucho más fácil » (P9/SOEMP/GD)

Además, las estudiantes valoran como positivo esa posibilidad de mostrar lo que haces a la familia y manifiestan lo bien que les hace sentirse transmitir lo que están estudiando en la Universidad, tema que argumentan con orgullo hacia sus familiares:

«yo se lo he enseñado a todo el que ha venido a mi casa, el curso, el blog, todo. Venía un sobrino: mira lo que estoy haciendo, aprende tú y hazlo tú. Eso a mis sobrinos pero a todo el que ha venido a mi casa se lo he enseñado. De hecho, casi todos mis sobrinos saben que he venido hoy aquí a por un título, a la Universidad. [...] ¿qque te vas a por un título?, yo siíi...y todos: ialaaaa!. Yo creo que se ha enterado todo el pueblo...hay una sobrina que quería venir, pero se ha tenido que quedar alli’ P12/SOEMP/GD

$\mathrm{Al}$ aprendizaje con TIC y a los recursos TIC se une, según un tutor y una tutora, el descubrir la utilidad de éstas para su apertura social y ser consciente de que se han adquirido nuevas capacidades. Además de destacar 
un aspecto de género que alguna de las estudiantes comentaba, relacionado con la diferencia entre su marido y ella en el uso de las TIC:

«En la situación, en el mundo en el que estamos fundamental, fundamental (refiriéndose a las TIC), además algunas ya lo sabían, lo podían mas o menos controlar, pero otras no eran conscientes ni de que eran capaces de que eso pudiera ser así, ni de que eran capaces de hacerlo, entonces en el mundo en el que estamos, donde nos movemos ahí, yo creo que se le ha abierto una puerta a algunas de ellas que jamás pensaron que podían ser capaces de hacerlo» (T2/SOEMP)

«[...] Tradicionalmente, en algunos estudios, cuando se analizan las TIC se hace, se utiliza la variable de sexo, ¿no? Para diferenciar entre actitudes hacia, e incluso también utilización y demás. Yo creo que está muy bien incluso hay quien lo manifestaba: mis hijos, mi marido sabía mucho de esto y yo no. Desde ese punto de vista, el darse cuenta de que son perfectamente capaces, no cabría ninguna duda de eso. De que puedan utilizar las tecnologías independientemente del sexo que tengas, yo creo que genera una autoestima, hace también valorar, a lo mejor, unas herramientas que inicialmente no motivan, no interesan, pero que descubres que tiene una utilidad importante, sobre todo yo creo que para la comunicación [...] es donde encuentran una primera herramienta aquí útil, esto me permite comunicarme con personas, poder crear grupos. Yo creo que desde ese punto de vista, favorece ese empowerment este que estamos diciendo. De que son, de que pueden dominar una técnica, una tecnología, y que la puedan utilizar pues para mejorar su calidad de vida y para mejorar sus propias condiciones de vida» (T1/SOEMP)

Las estudiantes apoyan esta opinión, son conscientes de que las TIC las ayuda a aprender y a progresar, además de adquirir conocimientos y a buscar y organizar información, en este caso, se refieren a la adquisición de «cultura»: 
" yo creo que nos actualiza más, nos hace crecer más rápido porque yo creo que las necesitamos, entonces nos adaptamos, nos esforzamos por hacer» (P1/SOEMP/GD)

«bueno yo creo que también se adquiere cultura de esa forma porque igual que te entras para chatear con un amigo pero mañana quieres otra información y como ya sabes que te has entrado ahí y conoces el medio, pues...hombre también para organizarla» (P5/SOEMP/GD)

Hay un aspecto que también se destaca en esta línea y es la posibilidad de compartir a través de un espacio virtual, superando la timidez y el miedo a hablar que, según algunas estudiantes, tienen las mujeres gitanas. Este hecho hace que hayan expresado abiertamente sus opiniones y reflexiones:
«Además es lo que yo creo, ahora mismo directamente, porque las mujeres gitanas yo pienso que tenemos mucho miedo a hablar, muchos prejuicios...hay mucho silencio y por medio de este curso, como es por escrito, yo creo que nos hemos abierto muchísimo y hay mucha sinceridad, pienso yo» (P5/SOEMP/GD)

Sin embargo, una de las docentes duda de esta cuestión en relación con el empoderamiento, porque considera que no se han dado todos los componentes de ese término, aunque matiza que este término puede ser demasiado teórico y quizá la realidad en la que se maneja no signifique lo mismo. De todos modos, apela a las TIC como recurso indirecto que facilita una serie de cuestiones que sí tienen que ver con el empoderamiento:

«No de forma directa, considero que el uso de las TIC desarrolla habilidades y facilita el acceso a espacios que de otro modo no se conseguirían, pero el empoderamiento como tal en sus tres aspectos, y en su totalidad, necesita de otros componentes que no se han dado. Como otros términos feministas, el empoderamiento se utiliza y busca desde el marco teórico sin que la realidad responda a la idea que se tiene sobre el término [...] el grupo poblacional (mujeres gitanas) con el que trabajaba, para mí era desconocido y por supuesto, tenía ideas preconcebidas, aunque al trabajar en el ámbito social intentas siempre eliminar prejuicios y estereotipos que en la 
mayoría de las ocasiones son equivocados. Ha sido realmente gratificante el comprobar cómo mujeres que han sido educadas en una cultura que de partida las sitúa en una situación de partida en clara desventaja, están haciendo un esfuerzo por empoderarse y acercarse a todo aquello que se lo permita» (T4/SOEMP)

Incidiendo en la participación social, los recursos TIC aprendidos también han sido el tema recurrente, sobre todo aquellos que permiten a las estudiantes comunicarse con otras personas a través de la web:

«[...] Pero yo creo que muchas de las alumnas, les ha servido para, para saber que hay otras maneras de comunicarse y que la pueden aprovechar en beneficio suyo, suyo y del grupo con el que están» (T2/SOPAR)

«Hombre yo creo que claramente, las herramientas de comunicación, los foros fundamentalmente, la experiencia de los Blogs [...]» (T1/SOPAR)

"Tengo que decir, que nunca he vivido esta participación tan activa con gitanas, la verdad que hemos sido muy responsables, trabajadoras y sinceras. Hemos expuesto todas las ideas y tengo la sensación que hemos aprendido mucho de todos los profesores. Personalmente estoy orgullosa de "mí misma", pensaba que nunca podría hacer un curso virtual y con tanta facilidad. Siempre que ofertaban un curso virtual me daba pánico hacerlo, ahora me apuntaré la primera (risas)....... esto ha sido así gracias a ti, Rosa, que me pareces la persona más competente del mundo, y con una gran facilidad para enseñar, eres maravillosa!!!!!!!!!!» (P17/SOPAR/FEC)

Aunque, como una de las docentes explica, no es el único medio, sino que se necesita interiorizar cómo y para qué utilizarlo de cara a la participación social:

«La participación social no es más que la total democratización de las decisiones públicas y construir colectivamente la sociedad en la que queremos vivir y desarrollarnos, el uso de las TIC es una 
herramienta más, un medio, pero que no sirve sin una interiorización previa de la posibilidad de participar a ese nivel» (T4/SOPAR)

Dos de las tutoras coinciden en reflexionar sobre TIC y el favorecimiento de la participación social de las mujeres gitanas porque las permiten abrirse, participar, sin romper con sus roles en la comunidad. En ambos casos se destaca la superación de las limitaciones espacio-temporales como característica principal de ese favorecimiento:

«Muchas de las destinatarias de este curso no hubiesen podido realizarlo si la modalidad no hubiese sido virtual, por lo que las TIC dan la oportunidad, en este caso, a muchas mujeres gitanas, a no tener que romper drásticamente con su rol dentro de la comunidad, a la vez que avanzar en su formación» (T7/SOPAR)

«De entrada porque rompe la lógica del tiempo y del espacio. Así que, en cuanto a los tiempos, en el caso de ellas que tenían obligaciones familiares, les permite ajustarse más a su estructura cotidiana, temporal. $Y$ la distancia, lo virtual a veces... nos comunicamos mejor cuando no es el cara a cara. [...] No necesariamente lo virtual nos hace mentir o fingir, que es un poco la idea que se tiene [...]. A veces somos mas sinceros cuando no hay una distancia corta [...] por eso digo que el espacio y el tiempo pueden ser en algunas circunstancias favorecedores en muchas cosas» (T3/SOPAR)

Una última cuestión, de máxima importancia y en relación con la valoración del desarrollo de la acción por parte de las participantes, tiene estrecho nexo de unión con los planteamientos metodológicos. Asumimos el proceso de investigación-acción como un proceso de intervención para producir un cambio destinado a la mejora y la promoción de las mujeres gitanas participantes. Pero, ¿cuáles han sido estos cambios? Los datos obtenidos en las manifestaciones de las estudiantes, muestran evidencias de los siguientes: 
- Si en un principio algunas mostraban como debilidad el hecho de ser una acción formativa virtual, mediante la valoración del primer taller presencial en el Foro de Evaluación Continua:

«las dificultades principales fueron manejar el ordenador y mis grandes faltas de ortografia» (P5/DESDEB/FEC)

«creo que me va a resultar un poco dificil por el tema del ordenador yo y el no nos entendemos» (P18/DESDEB/FEC)

ahora se han producido cambios en el discurso:

"pues yo ¿̇sabéis lo que pienso? Que al ser tecnológico, nos ha abierto un poco la idea de, venga, el ordenador, pues voy a ver qué es eso de un cortafuegos o, como lo digo, te va despertando ese interés por internet $[\ldots] \gg$

«yo busco el prospecto de los medicamentos, pongo el nombre del medicamente $y$ te sale todo...(risas)»

«y eso también ha sido gracias a este curso, el ordenador, pues que lo utilizamos más».

(muestra de conversación entre P11 y P12 /SOPAR/GD)

- Compra de un ordenador propio e instalación de internet en el domicilio o intención de hacerlo:

«yo estoy con ella, además ya sabéis que me he comprado un ordenador y hemos puesto internet, ahora ya no puedo estar sin mirar el correo (risas)» (P9/SOPAR/GD)

«bueno yo ya me tengo que poner internet $y$ tengo que comprar un ordenador» (P12/SOPAR/GD)

- Discurso sobre las posibilidades de las TIC como medio para comunicarse, para conocer otras personas, para buscar información y 
trabajo, y para estudiar conciliando vida laboral y familiar, e incluso para desarrollar nuevo hábitos:

a) Como medio de comunicación:

«...es importantísima porque es una forma de comunicarse, hay épocas en las que han surgido otras formas de comunicación como el teléfono, anteriormente las cartas y ahora, actualmente, pues son las tecnologías... de internet y todo lo nuevo que hay» (P5/SOPAR/GD)

b) Comunicación, búsqueda de información y trabajo:

«yo creo que son mucho más rápidas. Además en la lejanía puedes comunicarte con cualquier persona, puedes conocer a gente muy interesante, información que te ayuda para trabajo, para muchas cosas... lo que es ya casi imprescindible...» $(P 8 / S O P A R / G D)$

c) Conciliación vida laboral/vida familiar:

"pues yo me ha servido para darme cuenta que puedo formarme desde mi casa y compatibilizar mi trabajo, mi familia y mi formación...» (P7/SOPAR/GD)

d) Desarrollar nuevos hábitos:

«[...] lo hemos estado hablando, $M^{a}$ Carmen, que el haber hecho el curso, nos ha hecho también tener otros factores para abrirnos $y$ tener expectativas para hacer otras cosas nuevas por este medio» (P5/SOPAR/GD)

- Ante la pregunta directa: ¿algo ha cambiado en la mujer gitana debido a las tecnologías? Nos dan respuestas relacionadas con la actualización y adquisición de conocimientos, el crecimiento personal y el esfuerzo, el contacto con otras personas y la superación de la timidez al comunicarse, como se observa en estos ejemplos: 
«yo creo que nos actualiza más, nos hace crecer más rápido porque yo creo que las necesitamos, entonces nos adaptamos, nos esforzamos por hacer...» (P1/SOEMP/GD)

«hay más contacto entre nosotras» (P12/SOEMP/GD)

«lo que yo me he dado cuenta también que por internet, pues sí, como hemos dicho es más fácil, opinamos con más facilidad y tal pero luego cuando estamos entre nosotras pues como que nos cortamos más $[\ldots . . . »(P 8 / S O E M P / G D)$

«¿sabes que pasa? Que cuando nos comunicamos a través del tema virtual, del ordenador, yo creo que se dicen cosas que a veces, yo creo que son mu real, que personalmente no te dirías y que escribiendo sí te atreves... Me empiezo a inspirar y esas cosas...» (P5/SOEMP/GD)

Un aspecto más que nos interesaba indagar es si esta experiencia y los modelos generados se pueden transferir a otros contextos como práctica con otros grupos e incluso a otras instituciones no lucrativas. Unas se refieren a la experiencia global en sí, otras al modelo pedagógico y sus estrategias didácticas, como fuente principal de esa transferencia, siempre adaptándolo al nuevo contexto.

«[...] la verdad es que se aprende mucho porque al ser, en ese sentido, una experiencia innovadora por las características del grupo. Entonces visto el éxito, en los términos generales, de acceso y de participación y de satisfacción general al finalizar el mismo, yo creo que sería factible pensar en otros grupos, con características similares... que a través de esta vía se pudiesen incorporar a una formación de esta naturaleza» (T1/SOTRANS)

«Yo creo que es valido para cualquiera. Quiero decir, que esto se puede utilizar con cualquiera, además la prueba la tenemos que había mujeres que jamás habían cogido un ordenador, con lo cual, todos podríamos acceder o todos podrían acceder a un curso de este tipo. Lo importante yo creo es que el planteamiento inicial, el que este claro que es lo que se quiere, el que tenga un contenido adaptado a las necesidades suyas, a los intereses suyos, y que luego se siga 
liando. Yo creo que el desarrollo en lo que es el planteamiento inicial del curso, que estaba adaptado a ellas, que taba bien organizado, que estaba muy claro lo que se quería y la guía que sea tenido, digo guía como la dinamizadora y profesores que se han tenido durante el curso, eso es básico. Entonces si eso se mantiene se puede trasladar a otro contexto» (T2/SOTRANS)

«[...] se puede hacer con colectivos de inmigrantes, adaptando, puede ser interesante, incluso a entornos en mujeres llamadas de zonas rurales, de menos de 5000 habitantes, puede ser interesante» (T3/SOTRANS)

«Dentro de las entidades no lucrativas que tienen contenidos interesantes para intercambiar con otras entidades $u$ otros actores sociales, me parecería muy interesante la utilización de este tipo de formaciones virtuales y espacios» (T7/SOTRANS)

Las estudiante añaden a lo anterior, el poder llevarlo a cabo a nivel nacional.

"[...] y en general el curso me a parecido tan bueno que en un futuro me parece emprenderlo a gran escala, por ejemplo a nivel nacional» (P5/SOTRANS/FEC) 


\subsubsection{Dimensión tecnológica.}

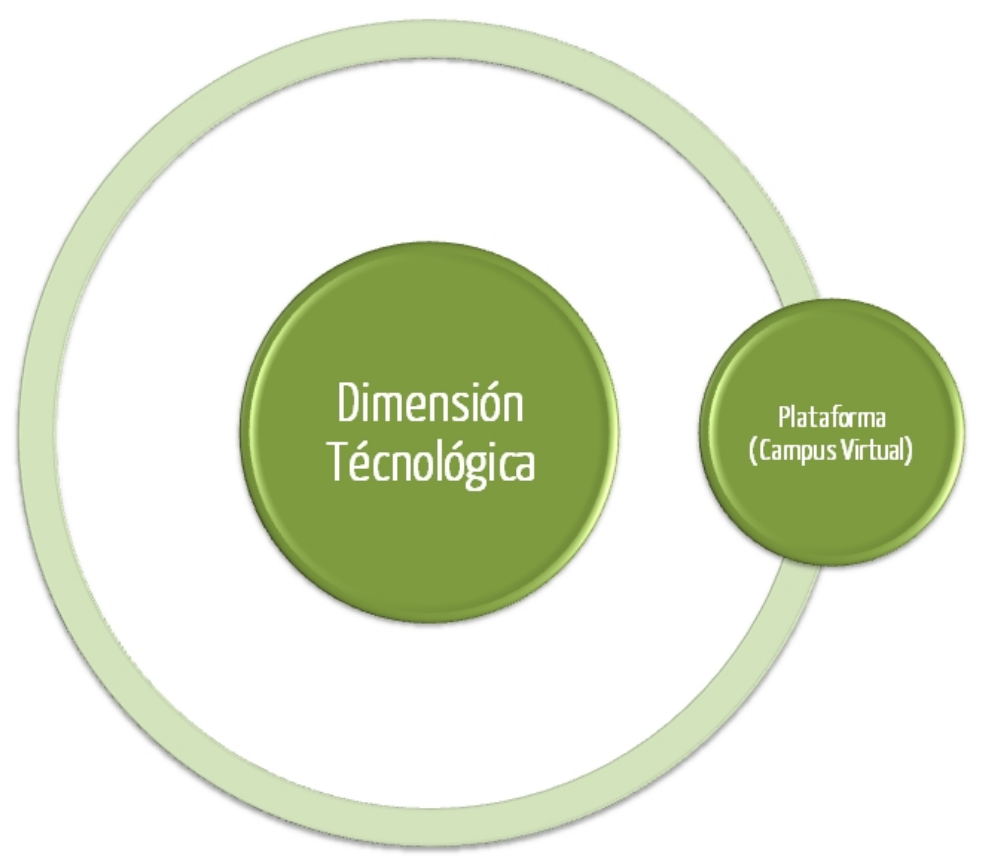

Figura 50. Dimensión Tecnológica

En la dimensión tecnológica se valora la plataforma utilizada, que en este caso ha sido Moodle a través del Campus Virtual de la Universidad de Extremadura (CVUEx).

A excepción de un profesor de los entrevistados que no ha utilizado la plataforma -uno de los docentes de un taller presencial- el profesorado-tutor valora la plataforma utilizada como sencilla, funcional y acorde a los principios pedagógicos que orientan la acción formativa virtual.

«El paquete de software Moodle es sencillo y utilizado mayoritariamente para la impartición de cursos ya que permite un estilo constructivista y participativo. Es fácil de utilizar, tanto para el profesorado como para las personas participantes» T4/TECVIR 
«Bien. Como la conocía, me parece que era fácil y que sin problemas» T3/TECVIR

«Me ha parecido una plataforma muy completa y fácil de entender y manejar» T7/TECVIR

Una tutora destaca una sola incidencia al comienzo del curso, que se resolvió de manera rápida.

«[...] La única incidencia que tuve durante el curso fue el acceso inicial con el usuario y contraseña asignado y fue solventada de forma inmediata» T4/TECVIR

Se destaca la facilidad de acceso y uso rápido por parte de las estudiantes, aspecto que ha permitido dedicar más tiempo a las labores docentes y menos a las cuestiones técnicas. Puede decirse, por tanto, que el funcionamiento del CVUEx fue adecuado.

«[...] yo creo que el entorno funciona muy bien, además hemos visto que para las alumnas ha sido fácil de entender y de utilizar, no hemos dedicado excesivo tiempo a cuestiones técnicas, con lo cual quiere decir que el entorno fácilmente es asumible [...]» T1/TECVIR 


\subsubsection{Resumen de resultados por dimensiones.}

Se presenta, a continuación, un resumen de los resultados obtenidos en las tres dimensiones analizadas.

En referencia a la dimensión didáctica, el profesorado considera que los ejes claves del éxito han sido la participación, motivación y dinamismo de las estudiantes. Para las estudiantes, la posibilidad de realizar un acción formativa universitaria a través de su campus virtual ha sido valorada como una buena oportunidad, motivadora, enriquecedora y de la que han sacado muchos aspectos positivos, como tomar conciencia de lo que pasa a su alrededor y sacar ideas para el futuro. Para todas ha supuesto un gran reto y se han superado todas sus expectativas. En este sentido, la investigación aporta tres ejes fundamentales planteados en la experiencia como claves en el diseño pedagógico de acciones e-learning desde una perspectiva social: participación, motivación y aprendizaje. Éstos parten de la novedad de la experiencia para las estudiantes, generando expectativas positivas para afrontar el curso desde el comienzo.

En cuanto a fortalezas de la experiencia se destacan los dos constructos clave: la motivación y la participación. La mayor debilidad que se observa tiene relación con el tiempo de desarrollo del curso, tanto de la parte virtual, como de las sesiones presenciales. Las estudiantes también manifiestan que han tenido, en ocasiones, dificultades para tomar el hilo de las conversaciones cada vez que se quería participar en el foro, sobre todo si se estaba varios días sin acceder al espacio virtual. Se añade otra cuestión relacionada con la participación en los talleres presenciales y es la falta de asistencia de alguna de ellas a esas sesiones.

En cuanto al diseño pedagógico, se ha valorado como un diseño adaptado, exigente y profundo, idóneo para las estudiantes destinatarias, cuyas 
estrategias didácticas se han cumplido de forma rigurosa pero sin una rigidez excesiva. Se ha considerado un diseño arriesgado, audaz e incluso muy exhaustivo, en una primera visión. Los tutores y tutoras manifiestan resultandos sorprendentes frente a los obstáculos de los que partíamos inicialmente, por las características de las estudiantes. Aunque los resultados han sido positivos, las alumnas realizan una autocrítica de su trabajo en la última fase del curso, en la que parecen haber un cierta disminución de su participación, que les ha llevado a una cierta desmotivación. Consideran que la dinamizadora ha estado muy en contacto con ellas para incentivar esa participación y que, sobre todo en el tramo final, han tenido que esforzarse para conseguirla. Cuando se ahonda en las razones de esta desmotivación, se hace referencia a las participantes que abandonaron el curso por motivos profesionales y/o personales. Una sola de las estudiantes plantea la posibilidad de que el tema final, el más complicado a nivel aprendizaje, haya podido incidir en este hecho.

La planificación de la acción formativa virtual y de la metodología desarrollada, concretando más ese diseño didáctico, está dirigida hacia la actividad colaborativa y de diálogo entre las participantes y a su interacción; se ha considerado como novedosa para el grupo destinatario con un planteamiento original e incluso innovador, desde el punto de vista del profesorado. Y sobre todo, se destaca la participación de las estudiantes, lo que nos muestra el segundo constructo clave, que es mencionado de forma continua en las entrevistas realizadas a los tutores y tutoras participantes.

Los materiales, recursos y actividades desarrolladas son consideradas como adaptadas. Como se ha indicado antes y lo corroboran tutores y tutoras de la experiencia, es necesario, debido a las características de las destinatarias de la acción formativa virtual, un rigor inicial en el planteamiento de las actividades, en este caso, que luego pueden adaptarse y flexibilizarse en el desarrollo. Los recursos se valoran en adecuación y utilidad, considerando que se ha realizado una adaptación a las necesidades 
de las destinatarias y por ello creen que han sido útiles para su vida personal y profesional. Por otro lado, también se añade como mejora la posibilidad de inclusión de más materiales multimedia. Si concretamos en los recursos utilizados, los foros son claramente los que predominan en las intervenciones. Esto tiene relación directa con que es el recurso más utilizado y también, recordemos, situado en el primer lugar cuando se valora el uso por las estudiantes. Además, a través de este recurso, se han generado los debates, dinámicas y por tanto, es donde se han producido las interacciones entre las participantes y de éstas con los tutores y tutoras y donde se han realizado las actividades; lo que los caracteriza como fundamentales en esta acción formativa: ha sido el recurso clave para la interacción y comunicación entre las participantes y para compartir y construir conocimientos de forma conjunta. En referencia al proceso de comunicación que se produce en el curso a través de la herramientas destinadas a esa finalidad, se constituye como un proceso motivador en el que el aprendizaje se ha producido entre iguales (Aubert et al., 2008) y en colaboración, compartiendo conocimientos y experiencias.

En referencia a la Presencia Cognitiva, el profesorado, reconociendo las diferencias de niveles académicos de las estudiantes, creen que se ha llegado a la construcción de significados, en el que cada una aprovechaba ese aprendizaje adecuado a sus conocimientos previos. Pese a esto, se manifiesta que no se ha llegado a la máxima expresión de esta dimensión por la falta de experiencia de las participantes en una acciones formativas virtuales. Se matiza que quizá haya habido una diferencia entre actividades, con algunas en las que sí pueden haber llegado a ese nivel alto de aprendizaje conjunto, y otras actividades que han sido más «instrumentales». Comparando ambas cuestiones (apertura de temas por las estudiantes y bajo nivel de alfabetización digital) con las intervenciones del profesorado en las entrevistas realizadas, éstos remarcan la segunda cuestión, pues para llegar hasta ese nivel, tanto de toma de acuerdos como de generación de 
propuestas, tendría que haberse dado un mayor nivel académico y de conocimientos previos de algunas de ellas y también un conocimiento adecuado del uso de las TIC, ya que se puede haber producido un cierto «miedo a las tecnologías», que como indica un tutor, es «fácilmente superable». Además, varios tutores y tutoras añaden el factor «tiempo», que podría haber ayudado a llegar a este nivel alto.

Desde este punto de vista, nuestro trabajo confirma que se hace necesario fomentar la creación de contextos de aprendizaje entre iguales que ayuden en la comunicación entre los diferentes participantes en una acción formativa virtual. Creemos que mediante este ambiente de intercambio, de la información obtenida de diversas fuentes, se posibilita la reflexión y la adquisición de nuevos conocimiento desde el marco del aprendizaje autónomo, siempre valorando los tiempos para esta adquisición.

La dinamizadora ha sido fundamental, porque constituye el pilar básico para mantener la motivación y la participación constante de las estudiantes, además de evitar ese sentimiento de soledad que, en ocasiones, caracteriza a algunas acciones formativas virtuales. La coordinación entre profesorado y dinamizadora se ha ajustado a las expectativas. El rol de tutor estaba claro y definido, previamente, en el diseño y el funcionamiento ha sido valorado como adecuado. Se destacan pocas incidencias que hayan irrumpido en la labor tutorial, como algún problema técnico puntual de acceso al campus virtual.

Al preguntar por las diferencias entre si esta acción hubiese sido presencial en lugar de virtual, se alude a esa conciliación vida familiarprofesional y a la distancia geográfica entre las participantes como razones fundamentales para no haber seleccionado la modalidad presencial en el desarrollo. Un aspecto es la importancia de poder realizarlo desde sus hogares, siendo, las estudiantes, un ejemplo para sus familias e hijos/as. 
Las estudiantes, en la evaluación final, mencionan en todos sus mensajes el agradecimiento al profesorado y a la dinamizadora, con mensajes muy emotivos que reconocen el trabajo de tutoría llevado a cabo.

La labor de evaluación de los aprendizajes por parte de tutores y tutoras se valora positivamente, tanto el diseño previo de la evaluación como la respuesta positiva a este diseño evaluativo por parte de las estudiantes. Ahondando en los resultados de la evaluación del curso en general, se afirma que los logros están relacionados, en su mayoría, con un cambio social.

Que la Universidad, como centro de Educación Superior, acoja un curso de estas características es destacado como un factor de máxima relevancia para las estudiantes, que sienten que la institución apoya su formación continua pese a no ser universitarias.

Refiriéndonos ahora a la dimensión sociocultural, en cuanto a la contextualización de la acción, en general tutores y tutoras reflejan que esta experiencia ha estado contextualizada, teniendo en cuenta la hetereogeneidad de las estudiantes, y su adecuación a su realidad. Se establece que los contenidos trabajados a través de las actividades pueden aplicarse a sus contextos socioculturales. El hecho de haber incidido en todo ello ha permitido, según tutores y tutoras y estudiantes, que esta acción pueda llevarse a cabo de forma eficaz, lo que también ha resultado innovador, dentro del campo de acción en que se ha desarrollado.

En cuanto a la «presencia social» se señala, sobre todo, el componente «emotividad», que supera las expectativas iniciales, destacando factores como los aspectos culturales e incluso la virtualidad como determinantes de este componente y para favorecer el establecimiento de las bases de una Comunidad de Práctica. Hay otros factores que se mencionan como determinantes de esa conformación de la Comunidad de Práctica, entre los que figuran: el diseño de la forma de trabajo, la plataforma virtual, el sistema 
de interacciones, la adaptación a las estudiantes y a sus conocimientos previos, las temáticas abordadas y la dinámica seguida en la formación. Por otro lado, también se profundiza en las actitudes necesarias en las participantes para la conformación de la Comunidad de Práctica. En este sentido, se incide en la predisposición, la curiosidad, la apertura hacia temas nuevos y el querer progresar y cambiar, la dedicación, la motivación, el compromiso y el deseo de participar. Las estudiantes confirman haberse sentido parte de una Comunidad Virtual de Aprendizaje matizando el diálogo fluido, la buena comunicación, la participación, el dinamismo, la colaboración y ayuda entre compañeras y, además, señalando como matiz que les resultaba divertido, como claves de este sentimiento comunitario. Se indica la eficacia de la tutoría para fomentar esas relaciones positivas y el buen desarrollo de la acción formativa.

Muy relacionado con la promoción sociocultural de las mujeres participantes están los conceptos de «participación social» y «empoderamiento». En cuanto al empoderamiento, la valoración fundamental es que las estudiantes han salido un poco más empoderadas tras realizar el curso. En casi todas las intervenciones se habla del aprendizaje con TIC y de recursos como el Blog, como herramientas que han ayudado a fomentar esa idea de empoderamiento. Tanto tutores y tutoras como estudiantes valoran la utilidad de las TIC para la apertura y participación social de éstas últimas, sin romper roles en el seno de su comunidad y para hacerse conscientes de que se han adquirido nuevas capacidades. Las alumnas confirman que las TIC les han servido de ayuda para aprender y progresar, además de para adquirir conocimientos, buscar y organizar información y para la adquisición de «cultura». También hay un aspecto que se destaca en esta línea y es la posibilidad de compartir experiencias a través de un espacio virtual, superando la timidez y el miedo a hablar, que según algunas estudiantes, tienen las propias mujeres gitanas. 
Una última cuestión de máxima importancia relativa a la valoración del desarrollo de la acción por parte de las participantes es la evidencia de cambios y transformaciones en ellas. Se destacan: cambios en los discursos; apertura a las posibilidades de las TIC como medio para comunicarse, para conocer otras personas, para buscar información y trabajo, y para estudiar conciliando vida laboral y familiar e incluso para desarrollar nuevos hábitos; y adquisición de equipos informáticos e instalación de internet en los domicilios. Así mismo se destaca la actualización y adquisición de conocimientos, el crecimiento personal y el esfuerzo, el contacto con otras personas y la superación de la timidez al comunicarse.

Un último aspecto de esta dimensión referido a la transferencia a otros contextos confirma que, tanto el modelo pedagógico como las estrategias didácticas de esta acción, pueden ser la fuente principal de esa transferencia para desarrollarse como práctica con otros grupos siempre adaptándose al nuevo contexto.

Para finalizar, desde la dimensión tecnológica se ha valorado que la plataforma tecnológica utilizada ha sido funcional y adecuada, sin incidencias significativas en el desarrollo de la acción formativa. 

Capítulo 9. Conclusiones y Prospectiva 



\section{CONCLUSIONES}

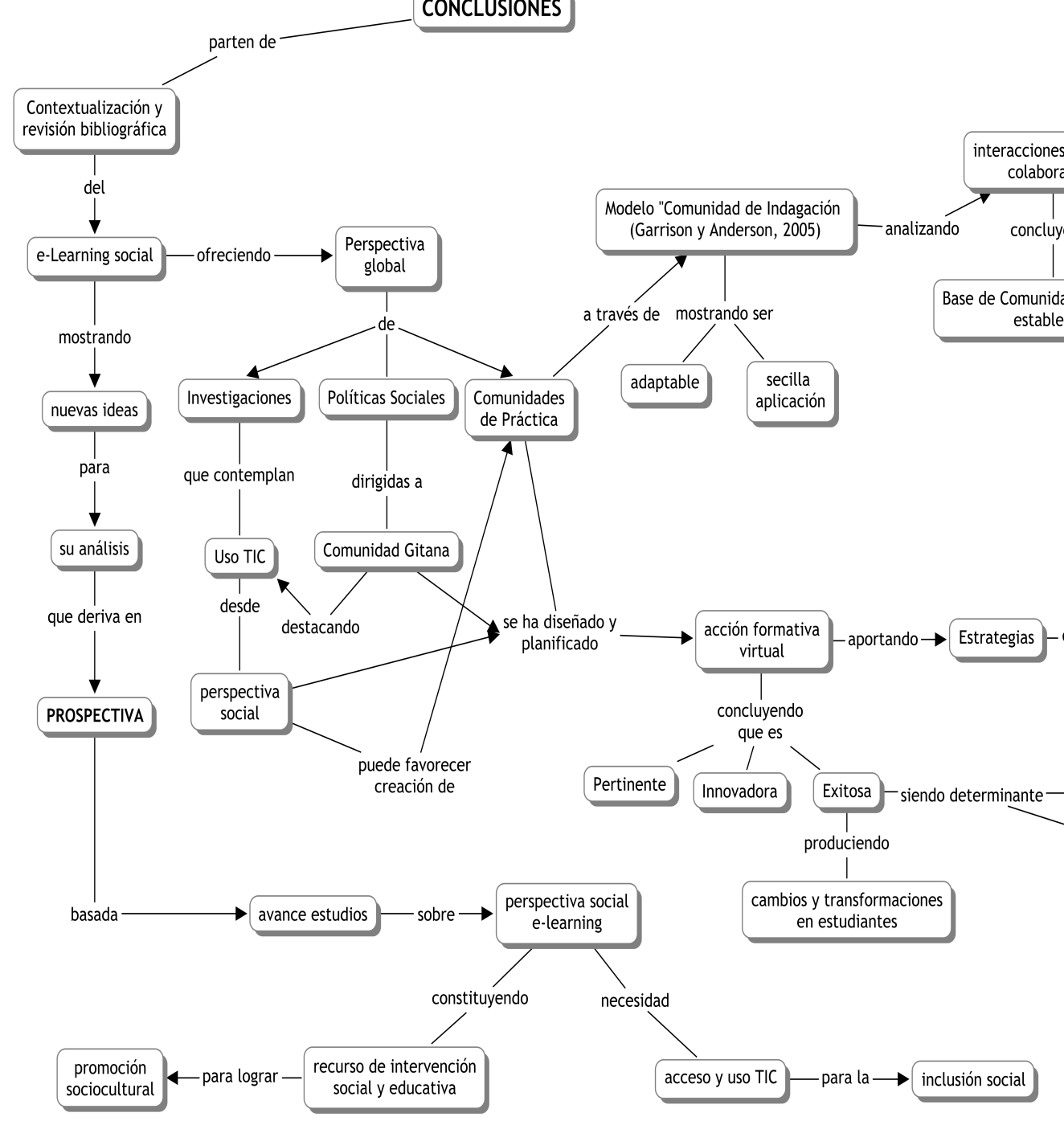

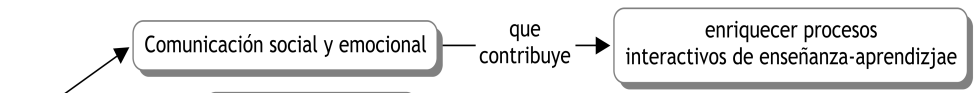

para que favorece $\rightarrow \begin{aligned} & \text { Intercambio de roles } \\ & \text { Docentes-Estudiantes }\end{aligned}-$ diferentes a $\longrightarrow$ enseñanza tradicional

Docentes-Estudiantes

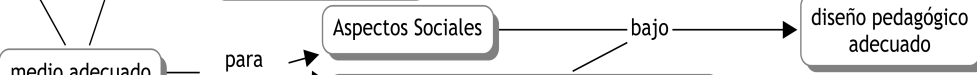

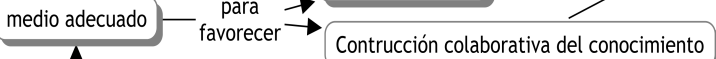

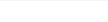





\subsection{Introducción: Cerrando Perspectivas}

Comenzamos nuestro trabajo de investigación «abriendo puertas», punto inicial del que partimos en la introducción. Y una vez finalizado este proceso de investigación, debemos plantear las conclusiones que sinteticen los principales hallazgos y los resultados más sobresalientes de los estudios llevados a cabo en esta tesis. Ahora toca «cerrar las perspectivas».

Este trabajo continúa indagando en las líneas que se abrieron en el curso de doctorado realizado y ahondando en el enfoque social en los entornos virtuales de aprendizaje, en este caso desde los planteamientos del e-learning social. Esa aproximación, se conjuga además con la perspectiva didáctica, comprendiendo que ambas deben confluir en los procesos de aprendizaje a través de entornos virtuales.

Antes de centrar la atención en las conclusiones de la investigación es necesario referirnos a algunas de las limitaciones de este estudio.

En primer lugar, el propio objeto de estudio y el espacio y tiempo en el que se ha desarrollado. El estudio se ha realizado sobre un fenómeno socioeducativo que se ha desarrollado durante un tiempo determinado, en torno a un contexto geográfico concreto y a un número limitado de participantes con unas características y valores culturales comunes. Por consiguiente, los resultados obtenidos se aplican a este fenómeno concreto y no pueden extrapolarse sin comprender el contexto donde suceden. Esto es inherente a los estudios sociales y educativos relacionados con la investigación-acción, debido a la variabilidad de los contextos explicativos

que se estudian. Las variables, en este sentido, tienen una imposibilidad de determinación, es decir, la identificación de variables y la formulación de los elementos críticos de un proceso observado, y de sus relaciones, están 
contextualizados desde el punto de vista histórico, pues es imposible imaginar en una representación abstracta la emergencia de nuevos condicionantes, como puede suceder en las cuestiones investigadas desde la metodología científica tradicional. En un intento por superar esta limitación, la adopción más adecuada ha sido el enfoque multimétodo (Ruiz, 2008).

Nuevos contextos y prácticas educativas, como los entornos virtuales de aprendizaje, están siendo objeto de investigación en las últimas décadas, pero sus constructos teóricos no poseen aún el grado suficiente de madurez para explicarlos y comprenderlos en profundidad. Si bien hemos optado, de manera selectiva, por aquellas teorías o enfoques con mayor rigor científico, nos hemos encontrado con una gran diversidad de conceptos y significados que fue necesario decantar para evitar ambigüedades e imprecisiones en las ideas y los resultados.

Teniendo en cuenta estas limitaciones, a continuación presentamos las conclusiones de nuestro trabajo, los puntos fuertes y débiles, las recomendaciones fruto de los resultados obtenidos y la prospectiva de nuevas líneas de investigación que se pueden desarrollar tomando como referencia o punto de partida, todas o algunas cuestiones de este trabajo.

\subsection{Conclusiones}

La finalidad de esta tesis era cultivar una Comunidad de Práctica a través de una acción formativa virtual dirigida a la promoción social y cultural de un grupo de mujeres gitanas. Ese era el objetivo principal de este proceso de investigación que se derivaba de «la misión» de la entidad en que trabajaba, consistente en conformar un grupo de mujeres gitanas en Extremadura para que participaran activamente en los movimientos relacionados con la 
igualdad de oportunidades en la región. La finalidad general era hacer visible el movimiento gitano femenino en cada Comunidad Autónoma apostando por su promoción sociocultural. En esa misión, nos embarcamos cinco personas, tres de ellas mujeres gitanas, trabajadoras de la entidad Fundación Secretariado Gitano (miembros del Grupo de Mujeres Gitanas de la FSG y dirección territorial de Extremadura), una profesora del «Grupo Nodo Educativo» de la Universidad de Extremadura y la autora de esta tesis, que en ese momento era trabajadora en la Fundación. Este grupo se constituyó como «equipo asesor» aportando conocimientos y reflexiones, revisando documentación, orientando sobre el desarrollo del proyecto, controlando que éste se desarrollara teniendo en cuenta todas las voces y valorando todo el proceso de investigación y las conclusiones, así como que el resultado del proceso contribuyera a transformar la realidad de las mujeres gitanas participantes. Tras un proceso de cuestionamientos y búsquedas conjuntas de respuestas, se determinó diseñar, implementar y evaluar, una acción elearning basada en los principios del constructivismo social, que buscara, bajo una formación en competencias adaptadas a las participantes, dotar a las estudiantes de herramientas necesarias para el diseño, desarrollo y evaluación de distintas dinámicas en torno al género, a la igualdad de oportunidades entre mujeres y hombres y a ejercer, de manera activa, el liderazgo social, estableciendo estrategias pedagógicas para su consecución basadas en la perspectiva mencionada.

Siguiendo esta finalidad, además de plantear un modelo práctico que enfatiza un paradigma de aprendizaje propicio para entornos virtuales, se ha planteado la aplicación de este modelo en una experiencia formativa virtual, se han estudiado y analizado las dimensiones social, cognitiva y docente resultantes de la aplicación, concluyendo con la percepción del resultado del aprendizaje en las estudiantes y el profesorado participante, así como con la evaluación global de la experiencia formativa. 
Con todo este proceso hemos llegado a varias conclusiones que cierran la perspectiva de nuestra investigación.

En primer lugar, nuestro estudio aporta una contextualización y revisión bibliográfica de la perspectiva social del e-learning, indagando en los programas y planes internacionales, nacionales y regionales y sus bases científicas, destacando los factores socioculturales. En este sentido, esta tesis muestra nuevas ideas, para el análisis de los factores determinantes de la visión social del e-learning y puede servir como base para futuros estudios relacionados con esta perspectiva. Por otro lado, se proporciona una perspectiva global de las políticas sociales dirigidas a la población gitana y una revisión de investigaciones que contemplan el uso de las TIC como parte de los procesos de inclusión, así como experiencias y proyectos previos destinados exclusivamente, (o en los que participa), este grupo social, destacando aquellos elementos que son importantes para el desarrollo de programas e-learning desde la perspectiva social.

Teniendo en cuenta toda esta visión, y estableciendo como marco las «Comunidades de Práctica» (Wenger, 2001), se ha diseñado y planificado una acción formativa virtual completa, incluyendo tres sesiones presenciales (que representan el 6\% del tiempo total), desde el análisis de cinco fases fundamentales: (1) concepción, (2) análisis, (3) diseño -didáctico-, (4) producción y (5) evaluación, respondiendo a las preguntas iniciales planteadas y a la misión que se afronta desde el «equipo asesor» y nuestra práctica profesional. De este diseño, planificado y orientado por este equipo, revisado por expertos y su posterior desarrollo, nuestro trabajo aporta varias estrategias que pueden guiar procesos de e-learning, en un ámbito no formal, dirigidas a colectivos específicos y constituido como Comunidad de Práctica en entornos virtuales de formación. Así, planteamos cuatro aportaciones desde el punto de vista didáctico. 
1.- Para realizar una experiencia e-learning desde una perspectiva social se debe diseñar y planificar desde un modelo de aprendizaje basado en ejes de participación, motivación y el aprendizaje/interacción. La participación involucra todas las acciones que se susciten en el ambiente de aprendizaje del entorno virtual. La motivación es un paso previo al aprendizaje y se constituye como motor del mismo, siendo clave en el diseño de acciones formativas de estas características, por la modalidad virtual y sobre todo, por las personas destinatarias del mismo. Se debe definir claramente una estrategia de motivación que mantenga un buen nivel de participación durante todo el desarrollo de la acción formativa y evitar el abandono prematuro. Como recursos para motivar y animar a la participación y al desarrollo recomendamos situar claves a través de «centros de interés» de las personas destinatarias de la acción, agrupándolos en principios colectivos comunes. Por último, el aprendizaje debe realizarse en interacción y colaboración con otros y otras a través de un proceso comunicativo comunitario.

2.- Los resultados de la aplicación del diseño sugieren que es adecuado adoptar una perspectiva globalizadora (Zabala, 1989) e integradora de corte constructivista (Jonassen, 1991, 1994, 2000; Jonassen, Peck y Wilson, 1999; Jonassen y Rorher-Murphy, 1999; Bonk y Cunningham, 1998; Gros, 2002, 2004, 2008; Cabero, 2004; De Pablos, 2004; Onrubia, 2005; Marcelo, 2006; Prendes, 2006; Valverde, 2011; entre otras y otros autores), desde las cuales deben establecerse unas pautas para organizar el proceso de enseñanza-aprendizaje basadas en los intereses de las propias y propios estudiantes y en la organización de la actividad constructiva y comunicativa. Integradora, porque debe responder a modelos didácticos donde las interacciones y discusiones colaborativas y comunicativas online de los y las estudiantes, así como las tareas colectivas, sean el núcleo de este modelo. Desde esta óptica, los procesos de enseñanza-aprendizaje son de carácter muy abierto en toda su configuración y están centrados en la actividad 
generadora de conocimientos por parte del estudiante. La finalidad debe ser la búsqueda de soluciones a problemáticas de muy diversa índole o, dicho de otra manera, las intenciones educativas pueden responder a una meta a conseguir, sea un documento, un trabajo de investigación, la búsqueda de medidas alternativas ante situaciones conflictivas, etc. Los contenidos de las acciones e-learning integradoras deben ser fluidos y vienen determinados por la actividad individual y grupal. Por otra parte, la comunicación en tiempo real por parte de estudiantes y profesorado, por las diferentes vías, se debe utilizar frecuentemente para apoyar y complementar las actividades y tareas. Desde este modelo, con un marcado nivel de interacción y discusión, la función del docente se basa en la mediación, orientación y coordinación del proceso de enseñanza-aprendizaje.

3.-Las evidencias obtenidas demuestran que es necesario establecer una figura, además del tutor o tutora, que dinamice todo el proceso de aprendizaje. La dinamización debe ser una de las figuras clave en el proceso de enseñanza-aprendizaje bajo un entorno e-learning, ya que aporta, además de un soporte técnico-administrativo para tutores y tutoras y para el alumnado, un soporte didáctico para motivar la participación, orientar el aprendizaje, resolver dudas, incidencias, en definitiva, promover el éxito de la acción formativa. Esta figura, que sirve de enlace entre todas y todos los agentes participantes, a lo largo de todo el proceso, mantiene un contacto directo con ambos, lleva un seguimiento individualizado de la actividad de cada participante para evitar el abandono, realiza un acompañamiento en el estudio, actúa como facilitadora y es responsable de informar, a profesorado y estudiantes, de las fechas e hitos más importantes de la acción formativa con el objeto de hacer cumplir la planificación académica. De esta manera, la persona dinamizadora debe prestar una asistencia permanente durante el desarrollo de la acción formativa, estando a disposición de estudiantes y docentes por diferentes vías de comunicación: correo electrónico, foros, mensajería instantánea (chat), teléfono, etc. En definitiva, debe ser una figura 
de referencia en todo lo relativo a aspectos académicos de una acción formativa, siendo una de las piezas clave a lo largo del proceso.

4.- La última estrategia se debe basar en la selección apropiada de un entorno virtual para la formación en el que deben existir herramientas de comunicación y de trabajo colaborativo indispensables para el dialogo y la interacción, y por tanto, para el aprendizaje.

Por otro lado, desde el enfoque "Comunidades de Práctica» (Wenger, 2001), como punto de llegada y medio de promoción social y cultural de las mujeres gitanas en entornos virtuales de aprendizaje, también nuestro estudio muestra algunas aportaciones importantes. Partíamos de la idea de que el uso de las Tecnologías de Información y Comunicación puede contribuir en la creación de Comunidades de Práctica. Para ello realizamos un recorrido por la concepción de las mismas y por aquellos estudios que trataban de la conformación de comunidades utilizando diferentes modelos metodológicos. Entre ellos se destacó el modelo «Comunidad de Indagación» (Garrison, Anderson y Archer, 2000; Garrison y Anderson, 2005) para analizar las interacciones virtuales colaborativas. De manera particular, se muestra cómo se realizan los tres constructos propuestos por el modelo aplicado: la presencia social, la presencia cognitiva y la presencia docente. El estilo horizontal y participativo que caracteriza las comunidades de aprendizaje es ilustrado a través de la aplicación del modelo elaborado por el equipo canadiense, para señalar de qué manera se construyen las diferentes presencias en el grupo. Es a través de ese modelo, como estudiamos y analizamos el cultivo de la Comunidad de Práctica conformada por las mujeres gitanas participantes en la acción formativa virtual.

El análisis realizado a través del modelo «Comunidad de Indagación» en los foros de discusión online generados en el proceso de desarrollo de la acción formativa, permite obtener una valiosa información para comprender dichas interacciones, la forma en que se producen, el tipo de interacciones, 
los factores que las afectan de cara a mejorarlas en el futuro para explotar al máximo su valor pedagógico y social. Para ello, se ha considerado que el análisis debía ejecutarse con parámetros cualitativos, a través de un análisis de contenido, basados en las dimensiones social, cognitiva y docente, derivadas de este modelo.

Una de las cuestiones de mayor importancia para el objetivo principal planteado en la investigación es el análisis de la presencia social. La investigación realizada demuestra que el fuerte sentido de comunidad aumenta la participación de las estudiantes en la acción formativa. También se enfatiza la necesidad de generar ese sentido de "presencia social» en las comunidades virtuales de aprendizaje, donde se realza la importancia de la interacción a partir del flujo de información que posibilite el trabajo colaborativo, desde el incremento del sentimiento de cohesión social. Encontramos un alto porcentaje de mensajes que pertenecen a esta dimensión, especialmente referidos a la categoría de «cohesión». En este sentido podemos decir que se crea una identidad de comunidad de aprendizaje, integrando a las demás en el discurso y reconociéndolas como parte de la misma. Partíamos no obstante, de la identificación que sienten las participantes con el grupo, determinado por su pertenencia a la comunidad gitana y su identificación con los valores tradicionales y con los nuevos valores de esta comunidad (González, 2005; Fundación Secretariado Gitano, 2009). Así se detecta, desde el comienzo, un repositorio compartido (Wenger 2001) con el que se identifican, basándose en su identidad cultural, que evidencia uno de los aspectos presentes en toda Comunidad de Práctica. Durante el desarrollo de la acción formativa, surgieron intervenciones que las participantes plantearon fuera de la misma, como temas tratados al margen del trabajo (Crook, 2000) que han desempeñado una importante función social para la conformación de la Comunidad de Práctica. Uno de ellos fue hacer propio uno de los foros cambiándolo de nombre, para debatir sobre cuestiones relacionadas con intereses conjuntos, cuestión que denota un 
acercamiento a la idea de «empresa conjunta» (Wenger, 2001) en la búsqueda de objetivos comunes, como otro de los elementos de las Comunidades de Práctica. Ese foro se ha mantenido activo durante toda la acción formativa, siendo su último tema lo que han venido a llamar «un compromiso» entre las mujeres participantes para expandir los conocimientos adquiridos y ponerlos en práctica. Este «compromiso mutuo» determina otro de los aspectos fundamentales de las Comunidades de Práctica enunciado por Wenger (2001). De este modo y teniendo en cuenta el análisis completo de las categorías que conforman la Presencia Social, y observando la evolución de las categorías de esta dimensión, se puede afirmar que la base de la Comunidad de Práctica está establecida.

Por otro lado, comprobamos que la confluencia de las tres presencias son necesarias para la consecución de una Comunidad de Práctica con sentido educativo. Con esto podemos afirmar que este modelo y sus categorías se entrecruzan entre las distintas dimensiones, siendo en nuestro estudio, la Presencia Social la que establece la base, aportando un sentido a la gestión del conocimiento a través de las emociones, manteniéndose a lo largo de toda la acción formativa, y que la Dimensión Cognitiva ha necesitado de la base creada por la Presencia Social y de la Presencia Docente para que se llegue a la fase de resolución final en el proceso de construcción de conocimientos. Esto quiere decir que, para que las fases de investigación práctica se completen es necesario que tomen fuerza la comunicación afectiva y la dimensión didáctica.

Confluye, todo ello, con la relación que Garrison y Anderson (2005) establecen en la representación que realizan de estas dimensiones: tres círculos concéntricos en el que las tres «presencias» están interrelacionadas y son fundamentales para mantener esa comunidad de estudio activa mediante la creación de un clima de estudio apropiado. 
Queremos hacer referencia, además, a varias cuestiones referidas al contexto donde acontecen las acciones que se producen y que se han analizado desde las dimensiones social, cognitiva y didáctica/docente: los foros donde se producen todas estas acciones. Los foros analizados son espacios de encuentro social, donde además tutores/as y estudiantes interactúan, formulan y responden preguntas, exponen ideas, etc. con una finalidad, no sólo de aprendizaje, sino también social y comunicativa. En este sentido, podemos establecer tres conclusiones. En primer lugar, el foro ha constituido el medio adecuado para la comunicación social y emocional, una de las variables fundamentales en la conformación de una Comunidad de Práctica a través de aprendizaje en entornos virtuales. Este aspecto comunicacional, derivado de la dimensión social del modelo «Comunidad de Indagación», crea ese ambiente de confianza entre las participantes y de éstas con los tutores y tutoras de la acción formativa, que promueve, además, un aprendizaje en colaboración. Así, la comunicación social y emocional ayudan a desarrollar ese sentido de comunidad de aprendizaje, siendo entonces, ese aspecto social de los grupos en el foro un factor que contribuye a enriquecer los procesos interactivos de enseñanza y aprendizaje. En segundo lugar, entendemos que los foros han constituido los espacios para facilitar esa construcción social de conocimientos. Como explicamos a continuación, hemos detectado que las participantes comparten e intercambian ideas con esa finalidad de construcción conjunta pero, sólo en algún caso llegan a profundizar en ese conocimiento a través de los debates en los foros. Es difícil que las participantes logren esa aplicación de lo aprendido, llegando a ese nivel cognitivo superior. De las entrevistas realizadas a tutores y tutoras en el tercer estudio se desprende la idea de que este hecho podría explicarse por la falta de experiencia en formación virtual de las participantes y que alcanzar esos niveles es complejo, y suelen darse en grupos muy experimentados en realizar acciones formativas online. En tercer lugar, a través de la actividad didáctica que se desarrolla en el foro, 
estudiantes $y$ docentes comparten perfiles y roles diferentes a los que se asumen en una enseñanza de tipo tradicional. Así, tutores y tutoras han asumido roles como facilitadores de debate, moderadores, guíasorientadores, expertos que responden cuestiones individuales y grupales, gestores, etc., e incluso han compartido los roles en alguna ocasión concreta, convirtiéndose, alguna estudiante, en la tutora en esa temática. De esta forma, las estudiantes han adquirido un papel más activo en el proceso de aprendizaje, interviniendo con sus ideas, planteamientos e incluso adoptando el rol de docente, en algunos casos.

Este aspecto comunicativo y social (en referencia directa a la «presencia social») hace que se cree un ambiente de confianza entre estudiantes y tutores y tutoras y un buen clima que, hemos observado, favorece el estudio y el aprendizaje entre iguales (Aubert et al., 2008). De hecho, hay estudios, como el de Rodríguez et al. (2002) cuyos resultados muestran que un mal clima de grupo o unas relaciones sociales deficientes dificultan en gran medida la construcción conjunta de conocimiento y, por tanto, el aprendizaje presenta un grado de construcción de conocimiento muy pobre. Todo ello da sentido a la conformación de una comunidad de aprendizaje, pudiendo afirmar que los foros son un medio que, basándose en un diseño pedagógico adecuado, pueden favorecer el desarrollo de aspectos sociales de los grupos, además de procesos interactivos de enseñanza-aprendizaje. Es decir, desde la perspectiva constructivista en la que nos hemos situado, entendemos que, de esta manera, se ha facilitado la construcción social del conocimiento.

No obstante, al poner en práctica el modelo didáctico propuesto, nos encontramos que, llevar a las estudiantes desde el nivel de intercambio de ideas y reflexiones a la construcción conjunta del conocimiento, en relación con «presencia cognitiva», es una tarea que entraña dificultades en la enseñanza virtual. También debemos destacar los aspectos críticos o inconvenientes que hemos detectado con el estudio, y es que la presencia cognitiva está menos desarrollada. Hemos observado que las estudiantes 
participan en el intercambio de opiniones, comparten ideas, pero les cuesta profundizar en el conocimiento de algunas cuestiones a través del debate en los foros. En este sentido, creemos que la actividad educativa que se desarrolla a través del foro por los/as docentes, es fundamental («presencia docente») para llegar a la fase de resolución y construcción del conocimiento. Pero no sólo eso, sino que como hemos indicado con anterioridad, se necesita una determinada experiencia de las estudiantes en formación online. Esto tiene relación con los estudios de Borthick y Jones (2000) que reparan en que el aprendizaje a través de entornos virtuales, requieren habilidades que necesitan ser aprendidas, no sólo en referencia a competencias tecnológicas, sino habilidades en la participación de debates asíncronos y en la colaboración en línea. Quizá, hubiera sido necesario una formación previa relacionada con el aprendizaje en entornos virtuales. Sin embargo, pese a que la «presencia cognitiva» es menos generalizable que las otras dos dimensiones, ha sido adecuada para evaluar comunidad desde el punto de vista del pensamiento crítico, conflicto cognitivo y debate/diálogo como actividad didáctica.

Desde el punto de vista del enfoque de aprendizaje colaborativo, la aplicación de este modelo nos ha permitido observar que este enfoque estuvo centrado en la colaboración para la consecución conjunta de los objetivos, más que en el conflicto cognitivo intrapersonal (Garrison y Anderson, 2005), y en el estímulo, por parte de docentes y dinamizadora, de la participación a través del fomento de sentimiento de comunidad (presencia docentepresencia social). En este sentido, destacamos, que se acentúa la colaboración concreta entre las participantes en la dimensión social, para conformar y sentirse parte de la comunidad, y no sólo en la construcción de conocimiento, en esa dimensión más cognitiva. Ello incide en que, en este caso, existe una implicación personal que refuerza el sentido de comunidad y confianza para que el aprendizaje colaborativo pueda darse. Así, se corrobora la 
importancia máxima de la dimensión social en el cultivo de la Comunidad de Práctica.

Podemos señalar, de esta forma, que entre las ventajas que ha tenido el modelo para nuestro análisis, se encuentra la identificación de los tres componentes/dimensiones que deben estar presentes en una Comunidad de Práctica (social, cognitiva y docente) y su análisis. Por otro lado, el modelo «Comunidad de Indagación» se puede adaptar a variedad de diseños pedagógicos de acciones formativas online, siendo un modelo de sencilla aplicación para tutores y tutoras y docentes, que además pueden practicar la presencia docente compartida con el alumnado.

Evidentemente, los resultados que se obtienen de este estudio corresponden a una muestra de un grupo étnicamente definido, y las conclusiones e interpretaciones podrían variar en la aplicación a otros grupos. Sin embargo, creemos que nuestro trabajo permite vislumbrar la utilidad de un proceso de aplicación de una acción formativa online a un grupo de mujeres gitanas, al que posteriormente se aplica un análisis de las dimensiones que responde al modelo indicado (Garrison, Anderson y Archer, 2000; Garrison y Anderson, 2005), para el análisis de las bases de conformación de una Comunidad de Práctica, y del tipo de conclusión e interpretaciones que puede derivarse de la aplicación del modelo. Creemos que el método utilizado en el estudio puede ser usado como método para investigadores y docentes que buscan la conformación de comunidades de aprendizaje, utilizando como medio los espacios virtuales. Es preciso considerar dos recomendaciones fundamentales para este proceso:

- La relación entre presencia social y satisfacción de estudiantes con el proceso formativo virtual (Benbunan-Fich, Hiltz, y Turoff, 2003; Arbaugh y Benbunan-Fich, 2006). El diseño de la acción e-learning debe acentuar el sentido de presencia social. Esto puede hacerse desde una doble vertiente pedagógica: desarrollando actividades que 
promuevan de aprendizaje colaborativo (Rovai, 2002; Richardson y Swan, 2003) y facilitando, a su vez, la discusión en línea, para la que debemos establecer una buena estrategia basada en interacciones (Akyol y Garrison, 2008), pudiendo tomar de modelo nuestro diseño de la interacción planteado. Este elemento constituye una clave de suma importancia pues es la base del diseño de actividades y espacios para la interacción cotidiana, para la comunicación informal no académica que contribuye a la presencia social y que hemos observado que tiene un impacto positivo para lograr, posteriormente, aumentar esa «presencia cognitiva» en el trabajo colaborativo e individual de las participantes. Como hemos indicado, se construyen lazos afectivos y, en definitiva, se fortalece el sentido de pertenencia a la comunidad, es decir, se crean ambientes de aprendizaje con una fuerte «cohesión» en los que se fortalece la interacción para el aprendizaje y la comunicación.

- Intentar establecer un contacto inicial cara a cara para garantizar un comienzo de las relaciones. De acuerdo con Borthick y Jones (2000), los entornos síncronos proporcionan un mejor ambiente de aprendizaje que los ambientes asíncronos o las aulas tradicionales. Sin embargo, se matiza que la colaboración era en realidad más rica, porque las participantes realmente se habían conocido previamente entre sí. Hemos comprobado, que, en nuestro caso, esta relación inicial a través del primer taller presencial fue fundamental para el inicio del proceso formativo online.

Otro aspecto clave de esta tesis es la componente estratégica para conseguir el cultivo de la Comunidad de Práctica, y es la valoración sobre la pertinencia de la aplicación del diseño pedagógico en el contexto de aplicación del mismo, es decir una valoración sobre el desarrollo de la 
acción formativa virtual y sus sesiones presenciales, a través de la evaluación de expertos externos y de los agentes participantes en la experiencia.

Desde las dimensiones planteadas en el último estudio y en contraste con los datos obtenidos del cuestionario de evaluación aplicado a las estudiantes, podemos afirmar que la experiencia e-learning es pertinente y se ha desarrollado con éxito. Además, ha sido una experiencia innovadora dentro del campo profesional de la acción social y las mujeres gitanas. Acorde a los resultados del estudio anterior, la aportación más significativa se ha obtenido de datos que corroboran el estudio de la Comunidad de Práctica y la dimensión social, acentuando el protagonismo de ésta sobre las demás presencias. Se ha destacado un componente que incide sobre todos: el emocional o «emotividad» de las estudiantes (García Carrasco, 2006a, 2006b), que ha sobrepasado las expectativas iniciales. Se destacan dos factores importantes que han sido determinantes en este componente: los aspectos de identidad de las mujeres participantes y la virtualidad. Se muestran evidencias con relación a que, el que las estudiantes sean mujeres y compartan rasgos culturales ha sido determinante en el éxito de la acción formativa. Para facilitar esa identificación inmediata con el grupo se han creado espacios con el fin de promover procesos sociales y de interacción entre ellas, lo que ha promovido su implicación emocional desde el comienzo. La virtualidad es otro de los componentes básicos de ese éxito, pues a través de los foros virtuales compartidos, las participantes han superado su timidez, su miedo a hablar -como ellas mismas indican- y han expresado opiniones, reflexiones e incluso, sentimientos, aspectos fundamentales de la cohesión y unión del grupo y de la conformación de la Comunidad de Práctica.

Una última cuestión, de máxima importancia y en relación con la valoración del desarrollo de la acción por parte de todas y todos los agentes participantes, tiene estrecho nexo de unión con los planteamientos metodológicos y con la perspectiva adoptada. Recordemos la justificación de 
las TIC como medio para aumentar las posibilidades de organización y actuación de los grupos, de defensa de los intereses a través de los recursos virtuales de difusión de información y, por otro lado, para permitir acceder a información y conocimientos y compartirlos. En este estudio se puede afirmar que estos medios han favorecido el aspecto individual porque han brindado una oportunidad para el aprendizaje y el desarrollo personal, por la flexibilidad en el manejo del tiempo, que han permitido combinar las aspiraciones de crecimiento laborales, profesionales y personales de las mujeres participantes. Desde este punto de vista la investigación aporta, en sí misma, un nuevo modelo de intervención a través de las TIC porque el planteamiento adoptado basado en la investigación-acción, pretendía ser un proceso de intervención que produjese un cambio destinado a la mejora y la promoción de las mujeres gitanas participantes. Tras el último estudio, se evidencian los siguientes cambios:

- Adquisición de un ordenador propio e instalación de internet en el hogar, o bien muestra intenciones de hacerlo.

- Cambio en los discursos sobre las posibilidades de comunicación e importancia de las TIC en la sociedad actual.

- Discurso sobre las posibilidades de las TIC para el crecimiento personal -formación- y como medio idóneo para conciliar éste con la vida laboral y familiar.

- En cuanto al uso de internet y sus servicios también se han modificado las prácticas:

- Utilizan internet para búsquedas.

- Utilizan internet para expresar sus opiniones y reflexiones. 
- Utilizan el correo electrónico como medio de comunicación asiduamente.

- Utilizan la red para establecer relaciones comunicativas con otros/as a través del blog y de redes sociales.

- Superación de timidez y «miedo a hablar»: utilizan recursos para expresión de ideas y reflexiones (foros y blogs).

- Transmiten lo aprendido a otras personas y a otras mujeres de sus familias.

Todo ello confirma que el diseño pedagógico y los principios en los que se enmarca se corresponden con los resultados obtenidos, validando, a su vez, el mismo como adecuado para la misión: conformar una Comunidad de Práctica de Mujeres Gitanas Extremeñas. Esta misión está acompañada de cambios que plantean la posibilidad de una promoción sociocultural de las mujeres participantes en esa Comunidad.

\subsection{Prospectiva}

Las características de la investigación y la especificidad de la realidad estudiada, así como el periodo de estudio que se ha invertido en ella, hacen que se deba considerar como un estudio en profundidad, que abre nuevas líneas de trabajo y perspectivas de investigación.

Como indican Serradell, Sordé y Vargas (2006: para. 2):

«[...] A lo largo de la historia, las investigaciones realizadas han sido «sobre» la cultura gitana pero sin contar con la participación de personas gitanas. Cuando las personas académicas han contactado 
con nosotros y nosotras ha sido para obtener información y después ya no les hemos vuelto a ver. En varias ocasiones, hemos leído sus conclusiones, que rechazamos por estar basadas en estereotipos racistas sobre las personas gitanas, pero además, estos proyectos de investigación se han convertido en la base de políticas y acciones que han incrementado nuestra exclusión social en lugar de contribuir a superarla. Esta falta de rigor científico conduce a realizar proyectos de investigación que no tienen ninguna utilidad social».

Esta investigación, por sus características, ha adoptado un enfoque multimetodológico en el que predomina la investigación cualitativa y las cuestiones epistemológicas relacionadas con la investigación-acción. Desde esa concepción, y en máximo acuerdo con la idea que plantean Serradell, Sordé y Vargas, era clara la idea de contar con la participación directa de personas gitanas desde el comienzo de la misma. Aunque nuestro propósito no estaba relacionado con la interpretación cultural y simbológica del pueblo gitano, ni con analizar y profundizar en la perspectiva de género en esta experiencia, sino más con aspectos didácticos y metodológicos relacionados con el planteamiento de una intervención a través de una acción formativa, dirigida a la promoción de mujeres gitanas extremeñas, dentro de un marco de trabajo en una entidad que lucha por esa promoción integral del pueblo gitano. No podíamos permitirnos no contar con la población a la que va dirigida la acción. Así, en el seno de nuestra metodología de investigación, hemos adoptado un enfoque de diálogo entre iguales (Aubert et al., 2008) con las destinatarias de la acción y con otras mujeres gitanas, especialistas en intervenciones con mujeres de su propia comunidad. En este sentido todas las argumentaciones han sido útiles para la investigación, reconociendo la subjetividad de los actores sociales, que forman parte de los procesos de interpretación (Habermas, 2001a). Con esta metodología, las mujeres participantes han podido observar cómo sus contribuciones han sido parte esencial de la investigación. Creemos que ha sido una pequeña contribución por promocionar un grupo de mujeres gitanas extremeñas. Desde el punto de 
vista de la investigadora, esta aportaciones han sido no sólo fundamentales, sino enriquecedoras para entender e interpretar algunas cuestiones sociales relativas al contexto estudiado, y además, contribuyen a un pequeño avance en estudios sobre la perspectiva social del e-learning. Como ya se ha indicado, es una perspectiva que apunta a la idea de que el e-learning puede ser una herramienta para la inclusión social, que puede contribuir a reducir e incluso atajar, situaciones de desigualdad y exclusión social relacionadas con las posibilidades que ofrece para la enseñanza-aprendizaje, comprometiendo, además, a la Universidad en esa transformación de la sociedad. De este modo, el e-learning puede considerase un instrumento para la transformación social. Por ello, hemos planteado un escenario en el que las TIC sean utilizadas desde este enfoque social con el objetivo de contribuir a potenciar el empoderamiento de mujeres gitanas a través de una formación por competencias, que además, fomente su liderazgo social dentro y fuera del grupo étnico al que pertenecen. Ante lo que puede ser un nuevo entorno de aprendizaje para estas estudiantes, se considera importante proporcionarles un ambiente de aprendizaje que las anime a la construcción conjunta de conocimiento, apoyándose en la reflexión crítica y la interacción social con otras en una comunidad, que al tener como objetivo común los aprendizajes se le puede denominar comunidad de aprendizaje (Palloff y Pratt, 1999; McConnell, 2000) facilitada por las TIC. Nuestra investigación, desde este punto de vista, puede contribuir a la consideración del e-learning como un recurso para la intervención social y educativa. La estrategia ha sido no sólo diseñar e implementar un programa de estas características desde la perspectiva social, sino producir un avance, por pequeño que sea, que pueda provocar un cambio social. Así mismo y siguiendo la perspectiva de Casacuberta (2007), hemos determinado dos imperativos fundamentales: por un lado, centrándonos no sólo en la superación de barreras para las estudiantes que pudiesen tener una cierta desconfianza hacia las TIC, sino en nuestras propias barreras derivadas de las percepciones y representaciones, actitudes y creencias sobre las tecnologías (García del Dujo, 2009; García del 
Dujo, Martín y Muñoz, 2010), recorriendo un camino que va más allá de la superación de los obstáculos de acceso a las Tecnologías de la Información y Comunicación. Así, hemos buscado y negociado aquellos contenidos que pudiesen resultar atractivos y útiles para las estudiantes. Por otro lado, nos hemos centrado en la capacitación en competencias que les pueden ser útiles para su vida profesional y personal tales como generar un pensamiento crítico para fomentar la creación de opiniones y, también, desde una perspectiva más social y cultural, para organizarse socialmente con la finalidad de reivindicar sus propios derechos. Desde este punto de vista el $e$ learning ha supuesto una estrategia de intervención para la promoción social y cultural de esas mujeres gitanas.

Luque (2004) realiza una serie de propuestas para implementar procesos e-learning desde una perspectiva de cambio social: (a) reflexionar acerca de los grupos humanos en los que el e-learning pretende introducirse; (b) considerar qué distancia (espacial, temporal, tecnológica, cultural) se debe tener en cuenta con el objeto de resolverla y establecer las estrategias que hagan posible realizar una vigilancia crítica de contenidos y actividades, desde el punto de vista de la calidad en el proceso e-learning; (c) pensar cuál es la naturaleza de los problemas a los que se quiere dar respuesta desde una perspectiva social del e-learning, ya que éste puede colaborar aportando soluciones, para lo que se propone esclarecer su misión y función desde la Universidad. A esas recomendaciones habría que añadir una fundamental y es (d) contemplar el e-learning como un recurso de intervención socioeducativa para lograr la promoción social y cultural de las personas participantes. A través de nuestra investigación se muestra la viabilidad de esta recomendación.

Por otro lado, en el análisis de las políticas sociales dirigidas a la población gitana, tanto a nivel europeo, nacional y autonómico, resulta evidente que se ha realizado un gran avance y se siguen realizando esfuerzos para que la estrategia de inclusión social de la población gitana tenga 
influencia en los diversos planes, proyectos e iniciativas en el ámbito de la política social de la Comunidad Autónoma de Extremadura. Los diferentes objetivos del desarrollo de esta estrategia, ámbitos de actuación, así como la concepción misma de la inclusión social de este grupo, han sido la concreción en los distintos momentos históricos de iniciativas y políticas europeas, nacionales y autonómicas.

En referencia al marco Europeo, en los últimos años la inclusión social del pueblo gitano ha ido adquiriendo una gran relevancia política en la agenda Europea y en la de todos los Estados miembros. La Unión Europea (UE), en este sentido, ha desempeñado y está actualmente desempeñando un importante papel para la mejora de las condiciones de vida de los gitanos y gitanas en dos niveles: en primer lugar, en asegurar el respeto al principio de no-discriminación, para lo que la UE cuenta con capacidad legislativa propia, como se ha presentado; en segundo lugar, en coordinar, estimular, promover y liderar la acción coordinada de los Estados de acuerdo a unas bases comunes, para lo que la UE cuenta con algunos instrumentos y programas con potencial para ser utilizados por los Estados y otros actores a favor de las comunidades gitanas europeas. La relación de los instrumentos que se presentan en el Capítulo 4 indica que existe un marco de políticas de la UE que puede ser utilizado para promover la inclusión social de la población gitana complementando la acción de los Estados miembros. Aunque la realidad es que la alfabetización digital y el acceso a las TIC aparecen como aspectos recogidos dentro de las declaraciones institucionales que contemplan la atención al pueblo gitano, dichas iniciativas se enmarcan dentro de las problemáticas generales y eso conlleva que encontremos pocas menciones a este aspecto o, los que encontramos, se incluyan dentro del ámbito de intervención más general. En España la población gitana ha alcanzado unas condiciones de vida y cotas de integración social altas, pero pese a estos avances, la pertenencia a la comunidad gitana sigue siendo un factor de desigualdad. Las medidas relacionadas con las TIC se han 
establecido de manera diferente por cada entidad $u$ organización social que trabaja en este ámbito, siempre de manera transversal a la áreas principales de intervención, por lo que es complejo situar, de manera específica, los aspectos referidos a las TIC y al e-learning como recursos de acción social con población gitana. En Extremadura, al igual que en el ámbito europeo y nacional, no se desarrollan políticas en exclusividad referidas a la inclusión digital dirigidas a la población gitana, sino que esta cuestión se integra en las políticas generales relacionadas con la Sociedad de la Información.

Desde la visión que este panorama nos ha ofrecido, destacamos la necesidad de plantear el acceso y uso de las TIC como un requisito indispensable para la inclusión social. En este sentido la incorporación masiva de ordenadores a las aulas en las escuelas, con el actual proyecto Escuela 2.0, con el que se persigue implantar en las aulas, de manera generalizada y progresiva, la utilización de las Tecnologías de la Información y la Comunicación como herramientas habituales de trabajo en todas las áreas de conocimiento. Así, todos los cursos y, por ende, todos los niños y niñas gitanos escolarizados tienen acceso al ordenador y están trabajando para aumentar su competencia digital y de tratamiento de la información desde la perspectiva de multialfabetización (Area, 2009; García Carrasco, 2009).

Todo lo que se ha expuesto con anterioridad implica un aporte al desarrollo de la denominada «perspectiva social del e-learning».

También debemos señalar que esta investigación tiene, además del valor científico que emerge de los resultados de la investigación, uno social que aporta también originalidad al estudio, desde el momento en que nuestro interés se dirige a indagar cómo las TIC inciden en las dinámicas sociales y educativas, y de qué manera, a través de ellas y en última instancia, se puede contribuir al desarrollo y promoción de un grupo perteneciente a una comunidad cultural que aún vive, habitualmente, situaciones de 
discriminación, incluso de discriminación múltiple (Rey, 2008) como son, en este caso, las mujeres gitanas. Apuntando que la contribución de las TIC al desarrollo sociocomunitario de esta comunidad puede constituir objetivo posible de investigación posterior derivada de esta tesis.

Desde nuestra propia investigación se plantea el estudio de la evolución de esa Comunidad de Práctica. Aprendizaje, conocimiento y participación son los polos fundamentales sobre los que se basan las Comunidades de Práctica ¿seguirá hacia adelante? ¿cómo será la evolución de esa Comunidad de Práctica? ¿cuáles serán las claves de esa evolución? Aunque se evidencia su continuidad a través de algunas noticias en prensa, en redes sociales y en los últimos informes de la Fundación Secretariado Gitano en Extremadura, podría ser interesante estudiar su evolución e impacto en el aspecto individual, en el entorno familiar y en la comunidad, avanzando en la línea de los estudios sobre la perspectiva del e-learning social. 



\section{Apéndices}





\section{Referencias bibliográficas}



Adell, J. (1997). Tendencias en educación en la sociedad de las tecnologías de la información. Edutec-e, Revista Electrónica de Tecnología Educativa, 7. Recuperado de: http://edutec.rediris.es/Revelec2/Revelec7/revelec7.html

Adell, J. (2004). La red como instrumento para la formación: de los cursos on-line a las comunidades de aprendizaje. En J. Cabrero y R. Romero (Coord.), Nuevas tecnologías en la práctica educativa (pp. 185-212). Granada: Arial.

Adell, J. y Sales, A. (1999). El profesor online: elementos para la definición de un nuevo rol docente. Comunicación presentada al IV Congreso de Nuevas Tecnologías de la Información y de la Comunicación para la educación: Edutec'99, Sevilla, Universidad de Sevilla.

Adrián, M. y Gros, B. (2004). Estudio sobre el uso de los foros virtuales para favorecer las actividades colaborativas en la enseñanza superior, Revista Electrónica Teoría de la Educación: Educación y Cultura en la Sociedad de la Información, $5 . \quad$ Recuperado de: http://campus.usal.es/ teoriaeducacion/rev_numero_05/n5_art_gros_ adrian.htm

Akyol, Z. \& Garrison, D.R. (2008). The Development of a Community of Inquiry over Time in an Online Course: Understanding the Progression and Integration of Social, Cognitive and Teaching Presence. Journal of Asynchronous Learning Network, 12 (2-3), 3-22. Recuperado de: http://www.eric.ed.gov/PDFS/EJ837483.pdf

Alcorn, P.A. (2000). Social issues in Technology. A Format for Investigation. Columbus: Prentice Hall.

Alonso, L. (2007). La formación de tutores de e-learning o e-formación (Tesis Doctoral Inédita). Universidad de Extremadura, Departamento de Ciencias de la Educación.

Ander-Egg, E. (1990). Repensando la Investigación-Acción-Participativa. Vitoria-Gasteiz: Servicio Central de Publicaciones del Gobierno Vasco.

Ander-Egg, E. (1995). Técnicas de investigación social. Buenos Aires: Lumen.

Ander-Egg, E. (2006). Metodologías de acción social. Jaén: Universidad de Jaén.

Anderson, T. \& Elloumi, F. (Eds.) (2004). Theory and Practice of Online Learning. Athabasca: Athabasca University. Recuperado de: http://cde.athabascau.ca/online_book/pdf/TPOL_book.pdf 
Anderson, T. \& Kanuka, H. (1997). On-Line Forums: New Platforms for Professional Development and Group Collaboration. Journal of Computer-Mediated Communication, 3(3). Recuperado de: http://jcmc.indiana.edu/vol3/issue3/anderson.html

Anderson, T., Rourke, L., Garrison, D. R., \& Archer, W. (2001). Assessing teaching presence in a computer conferencing context. Journal of Asynchronous Learning Networks, 5(2), 1-17.

Anguita, R. y Alario, A.I. (2004). Mujeres y educación en la era digital: ¿nuevas oportunidades para la igualdad? Red digital, Revista de Tecnologías de la Información y Comunicación Educativas, 5. Recuperado http://reddigital.cnice.mecd.es/5/firmas/articulo_1_ind.html

Arbaugh, J.B. \& Benbunan-Fich, R. (2006). An Investigation of Epistemological and Social Dimensions of Teaching Online Learning Environments. Academy of Management. Learning \& Education, 5(4), $435-447$.

Arbaugh, J.B., \& Hwang, A. (2006). Does teaching presence exist in online MBA courses?. The Internet and Higher Education, 9(1), 9-21.

Ardèvol, E., Bertrán, M., Callén, B., y Pérez, C. (2003). Etnografía virtualizada: la observación participante y la entrevista semiestructurada en línea. Athenea Digital: revista de pensamiento e investigación social, 3 . Recuperado de: http://psicologiasocial.uab.es/athenea/index.php/atheneaDigital/issue/v iew/4

Area, M. (2007). Algunos principios para el desarrollo de buenas prácticas pedagógicas con las TICs en el aula. Comunicación y pedagogía, 222, 4247.

Area, M. (2009). Introducción a la Tecnología Educativa. Universidad de la Laguna. Recuperado http://webpages.ull.es/users/manarea/ebookte.pdf

Area, M., Gros, B. y Marzal, M.A. (2008). Alfabetizaciones y Tecnologías de la Información y Comunicación. Madrid: Síntesis.

Area, M. (2011) La investigación en Tecnología Educativa en España. Una breve aproximación a las líneas de desarrollo actuales. En J. Valverde (Ed.), Actas del I Simposio Internacional «Buenas Prácticas Educativas con TIC» (pp. 37-46). Universidad de Extremadura. Servicio de Publicaciones. 
Area, M. y Adell, J. (2009). E-Learning: enseñar y aprender en espacios virtuales. En J. De Pablos Pons (Coord.), Tecnología educativa. La formación del profesorado en la era de Internet (pp. 391-424). Málaga: Aljibe.

Argyris, C., Putnam, R., \& Smith, D.M. (1985). Action science: concepts, methods, and skills for research and intervention. San Francisco: JosseyBass.

Arias, M. (2000). Triangulación metodológica: sus principios, alcances y limitaciones. Investigación y Educación en Enfermería, XVIII(1), 37-57.

Aubert, A., Flecha, A., García, C., Flecha, R. y Racionero, S. (2008). Aprendizaje dialógico en la sociedad de la información. Hipatía: Barcelona.

Aviv R., Erlich Z, Ravid G. \& Geva A. (2003). Network Analysis of Knowledge Construction in Asynchronous Learning Networks, Journal of Asynchronous Learning Networks, 7(3), 1-23.

Bakhtin, M. (1981). The dialogic imagination: Four essays. Austin: University of Texas Press.

Barberà, E. (2008). Aprender e-learning. Barcelona: Paidós.

Barberà, E. y Badía, A. (2004). Educar con aulas virtuales: Orientaciones para la innovaciones el proceso de enseñanza y aprendizaje. Madrid: A. Machado.

Barberà, E., Badia A. y Mominó, J.M. (2001). La incógnita de la educación a distancia. Barcelona: ICE-UB/Horsori.

Barberà, E., Mauri, T. y Onrubia, J. (Coords.) (2008). Cómo valorar la calidad de la enseñanza basada en las TIC: pautas e instrumentos de análisis. Barcelona: Graó.

Barcelata, S. (2005). Guía Técnica para la evaluación de unidades de aprendizaje desde un enfoque de EBC. (Informe Coordinación). Universidades Politécnicas.

Barnes, S.B. (2003). Computer-Mediated Communication: human-tohuman communiciation across the Internet. Allyn \& Bacon Publishers.

Bardin, L. (1986). El análisis de contenido. Madrid: Akal.

Barrit, C., Lewis, D. \& Wieseler, W. (1999). Cisco Systems Reusable Information Object Strategy . Definition, Creation Overview, and Guidelines. U.S.: Cisco System Inc. Recuperado de: 
http://www.cisco.com/warp/public/779/ibs/solutions/learning/whitepap ers/el_cisco_rio.pdf

Basela, E. (2003). El proyecto Omnia. En M. A. Essomba (Coord.), Educación e inclusión social de inmigrados y minorías. Tejer redes de sentido compartido (pp. 283-292). Barcelona: Praxis.

Bates, A.W. (1995). Technology open learning and distance education. London: Routledge.

Bates, A.W. (2001). Aspectos culturales y éticos en la educación internacional a distancia. Conferencia en el programa de Doctorado Interdisciplinario e Internacional sobre la Sociedad de la Información y el Conocimiento. Barcelona: UOC. Recuperado de: http://www.uoc.es/web/esp/art/uoc/bates1201/bates1201.html

Bautista, G., Borges, F. y Forés, A. (2006). Didáctica universitaria en Entornos Virtuales de Enseñanza-Aprendizaje. Madrid: Narcea.

Bell, D. (1976). El advenimiento de la sociedad post-industrial. Madrid: Alianza.

Benbunan-Fich, R., Hiltz, R., \& Turoff, M. (2003). A comparative content analysis of face-to face vs. asynchronous group decision making. Decision Support Systems, 34(4), 457-469.

Bereiter, C. (1997). Situated cognition and how to overcome it. En D. Kirshner \& J. A. Whitson (eds.), Situated cognition: Social, semiotic, and psychological perspectives (pp. 281-300). Hillsdale, NJ: Erlbaum.

Bereiter, C. (2002). Design research for sustained innovation. Cognitives studies. Bulletin of the Japanes Cognitive Science Society, 9, 321-327.

Bereiter, C., \& Scardamalia, M. (2003). Learning to work creatively with knowledge. En E. De Corte, L. Verschaffel, N. Entwistle, \& J. van Merriënboer (Eds.), Powerful learning environments: Unraveling basic components and dimensions (pp. 55-68). Oxford, UK: Elsevier Science.

Bericat, E. (1998). La integración de los métodos cuantitativo y cualitativo en la investigación social. Barcelona: Ariel.

Bernal, C. y Rodríguez, A. (2007). La presentación de las prácticas docentes como vía para la integración curricular de los recursos digitales y el desarrollo profesional. Revista Comunicación y Pedagogía, 222, 66-71.

Berge, Z.L. (1995). Facilitating Computer Conferencing: Recommendations From the Field, Educational Technology, 35(1), 22-30. Recuperado de: http://www.emoderators.com/moderators/teach_online.html 
Bigun, C. \& Kenway, J. (1998). New Information Technologies and the Ambiguous Future of Schooling. Some Possible Scenarios. En A. Hargreave, A. Lieberman, M. Fullan \& D.W. Hopkins (Eds.), International Handbook of Educational Change (pp. 375-395). London: Kluwer Academic Publishers.

Blández, J. (2000). La investigación-acción: un reto para el profesorado. Barcelona: INDE.

Blanton, W., Moorman G., \& Trathen, W. (1998). Telecommunications and teacher education: To social constructivist review, Review of Educational Research, 23, 235-275.

Blázquez, F. y Alonso, L. (2006) Aportaciones para la evaluación on-line, Revista de Ciènces de l'Educació, 4, 207-228. Recuperado de: http://pedagogia.fcep.urv.cat/revistaut/revistes/ferreres/capitol4article1. pdf

Blumschein, P. y Fischer, M. (2007). E-learning en la formación profesional: diseño didáctico de acciones de elearning. Montevideo, Uruguay: Cinterfor/OIT.

Bonk, C., \& Cunningham, D. (1998). Searching for learner-centered, constructivist, and sociocultural components of collaborative educational learning tools. In C. Bonk \& K. King (Eds.), Electronic collaborators (pp. 25-50). Mahwah, N. J.: Erlbaum.

Bonsón, M. (2009). Desarrollo de competencias en Educación Superior. En A. Blanco (Coord.), Desarrollo y Evaluación de Competencias en Educación Superior (pp. 17-34). Madrid: Narcea.

Borthwick, A. \& Jones, R. (2000) The motivation for collaborative discovery learning online and its applications in an information systems assurance course. Issues in Accounting Education, 15(2), 181-210.

Bowes, J. (2002). Building . Online Communities for Professional Networks. Paper presented at the Global Summit of Online Knowledge Networks, Adelaide, Australia. Recuperado de: http://www.educationau.edu.au/globalsummit/papers/jbowes.htm.

Branch, R.M., \& Gustafson, K.L. (1998). Re-visioning models of instructional development. Recuperado de: http://eric.ed.gov/ERICDocs/data/ericdocs2/content_storage_01/oooo ooob/8o/24/ao/91.pdf 
Brants, K. \& Firssen, V. (2003). Inclusion and exclusion in the Information Society. Final deliverable, The European Media and Technology in Everyday Life Network, 2000-2003.

Braslavsky, C. (1999). Bases, orientaciones y criterios para el diseño de programas de formación de profesores, Revista Iberoamericana de Educación, 19, 13-50. Recuperado de: http://www.rieoei.org/oeivirt/rie19a01.PDF

Brzezinski, Z. (1970). Between Two Ages. America's Role in the Technotronic Era. New York: Viking Press.

Brown, J.S. \& Duguid, P. (1991). Organizational learning and communities of practice. Toward a unified view of working, learning and innovation. Organization Science, 2(1), 40-57. Recuperado de: http://www.idi.ntnu.no/grupper/su/publ/ese/brown-duguid91.pdf

Brown, J.S., Collins, A. \& Duguid, P. (1989). Situated cognition and the culture of learning. Educational Researcher, 18(1), 32-41.

Brookhart, S.M. (1999).The Art and Science of Classroom Assessment. The Missing Part of Pedagogy. ASHE-ERIC Higher Education Report, Vol.27 (1).Association for the Study of Higher Education.; ERIC Clearinghouse on Higher Education, Washington, DC.; George Washington Univ., Washington, DC. Graduate School of Education and Human Development. Recuperado http://www.eric.ed.gov/PDFS/ED432937.pdf

Buendía, L. y Berrocal, E. (2001). La ética de la Investigación Educativa. Ágora Digital, $1 . \quad$ Recuperado de: http://www.uhu.es/agora/versiono1/digital/numeros/numeros_ppal.ht $\mathrm{m}$

Buendía, L., Colás, P. y Hernández, F. (2001). Métodos de Investigación en Psicopedagogía. Madrid: McGraw-Hill.

Bullen, M. (1997). A case study of participation and critical thinking in a university-level course delivered by computer conferencing. Doctoral Dissertation. Vancouver, Canada: University of British Columbia. Recuperado de: https://circle.ubc.ca/handle/2429/6775

Bultron, C. (2000). Nuevas tendencias en educación. UNESCO (Coord.) Informe mundial sobre la comunicación y la información 1999-200o (pp. 51-67). Ediciones UNESCO/CINDOC.

Burchardt, T, Le Grand, J. \& Piachaud, D. (2002). Degrees of exclusion: developing a dynamic, multidimensional measure. En J. Hills, J. Le Grand 
\& D.Piachaud, David, (Eds.), Understanding social exclusion (pp. 30-43). Oxford: Oxford University Press.

Bussone, M. (2010). Una experiencia de comunidad de indagación: hacia la comprensión de las interacciones realizadas en una comunidad virtual de aprendizaje. III Jornadas Virtuales de Educación a Distancia, Universidad Nacional de Córdoba, Argentina. Recuperado de: http://www.salvador.edu.ar/vrid/publicaciones/PonenciaBUSSONE.pdf

Bruner, J.S. (1988). Desarrollo cognitivo y educación. Madrid: Morata.

Cabero, J. (2001). Tecnología Educativa. Diseño y utilización de Medios en la enseñanza. Barcelona: Paidós.

Cabero, J. (2004). La función tutorial en la teleformación. En F. Martínez y M.P. Prendes, (Coords.), Nuevas tecnologías y educación (pp. 129-143). Madrid: Pearson Educación.

Cabero, J. (2006). Comunidades virtuales para el aprendizaje. Su utilización en la enseñanza. Edutec-e, Revista Electrónica de Tecnología Educativa, 20. Recuperado de: Disponible en: http://edutec.rediris.es/Revelec2/revelec20/cabero20.htm

Cabero, J. y López, E. (2009). Descripción de un instrumento didáctico para el análisis de modelos y estrategias de enseñanza de cursos universitarios en red (A.D.E.C.U.R.), Pixel-Bit. Revista de Medios y Educación, 34, 13 30. Recuperado de: http://www.sav.us.es/pixelbit/pixelbit/articulos/n34/2.pdf

Cabero, J., Llorente, M.C., y Román, P. (2003). Las herramientas de comunicación en el aprendizaje mezclado, Pixel-Bit: Revista de medios y educación, 23, 27-41. Recuperado de: http://www.sav.us.es/pixelbit/pixelbit/marcoabj23.htm

Cabrera, P.J. (Dir.), Rubio, M.J., Fernández, Y., Alexandres, S., Rúa, A., Fernández, E., López, J.A. y Malganesi, G. (2005). Nuevas tecnologías y exclusión social. Madrid: Fundación Telefónica.

Callejo, J. (2001). El grupo de discusión: introducción a una práctica de investigación. Barcelona: Ariel.

Calzadilla, M. E. (2002). Aprendizaje colaborativo y tecnologías de la información y la comunicación. Revista Iberoamericana de Educación, 28. Disponible en: http://www.rieoei.org/tec_edu7.htm

Carr, W. y Kemmis. S. (1988). Teoría crítica de la enseñanza: la investigación-acción en la formación del profesorado. Barcelona: Martínez Roca. 
Carracedo, J.D. (2006). Prácticas y discursos sobre brechas digitales y sus estratificaciones. En R. Casado (Coord.), Claves de la alfabetización digital (pp. 93-97). Barcelona: Fundación Telefónica.

Casacuberta, D. (2004). E-learning e inclusión social en el marco del sistema universitario español. RUSC, Revista de Universidad y Sociedad del Conocimiento, 1(1). Recuperado de: http://rusc.uoc.edu/ojs/index.php/rusc/article/view/v1n1-casacuberta

Casacuberta, D. (2007). Digital Inclusion: Best practices from eLearning, Elearning Papers, 6. Recuperado de: http://www.elearningpapers.eu/index.php? page $=$ doc\&doc_id $=10635 \&$ doclng $=6$

Casado, R. y Díez, E. (2006). 13 Claves de la alfabetización digital. En: R. Casado (Coord.), Claves de la alfabetización digital (pp. 203-214). Barcelona: Fundación Telefónica.

Casanova, J. (2007). Desafíos a la formación inicial del profesorado: Buenas Prácticas educativas en el contexto de la innovación con TIC. RELATEC, Revista Latinoamericana de Tecnología Educativa, 6 (2), 109-125. Recuperado de: http://campusvirtual.unex.es/revistas/index.php? journal $=$ relatec $\&$ page $=$ article\&op $=$ viewArticle $\&$ path []$=331$

Castell, M. (1997). La era de la información: la Sociedad Red, Vol. I. Madrid: Alianza Editorial.

Cerreruela, E.; Crespo, I.; Jiménez, R.; Lalueza, J. L.; Pallí, C. y Santiago, R. (2001). Hechos gitanales. Conversaciones con tres gitanos de Sant Roc. Barcelona: Universitat Autònoma de Barcelona.

Checkland, P. (1981). Systems thinking, systems practice. Chichester: Wiley.

Chickering, A. W., \& Ehrmann, S. (1996). Implementing the seven principles: Technology as lever. AAHE Bulletin, 49(2), 3-6.

Cicognani, A. (1998). On the Linguistic Nature of Cyberspace and Virtual Communities. Virtual Reality: Research, Development and Application, 3, 16-24. Recuperado de: http://www.springerlink.com/content/rj6211470t19x33n/

Clavería, E. (2004). La mujer gitana del S. XXI. En: A. Touraine, M. Wieviorka y R. Flecha (Coords.), Conocimiento e identidad: voces de grupos culturales en la investigación social (pp. 105-110). Barcelona: El Roure.

Cohen, L. y Manion, L (1994). Métodos de investigación educativa. Madrid. La Muralla. 
Coghlan, D. \& Shani, R. (2005). Roles, politics and ethics in action research design. Systemic Practice and Action Research, 18(6), 533-546.

Coll, C. (1990). Un marco de referencia psicológico para la educación escolar: la concepción constructivista del aprendizaje y de la enseñanza. En C. Coll, J. Palacios y A. Marchesi (Comps.). Desarrollo psicológico y educación, 2. Psicología de la educación escolar (pp. 435-453). Madrid: Alianza.

Coll, C. (1999). La concepción constructivista como instrumento para el análisis de las prácticas educativas escolares. En C. Coll (Coord.), Psicología de la Instrucción: la enseñanza y el aprendizaje en la educación secundaria (pp. 16-44). Barcelona: ICE/Horsori.

Coll, C. (2001). Constructivismo y educación: la concepción constructivista de la enseñanza y el aprendizaje. En: C. Coll, J. Palacios y A. Marchesi (Comps.), Desarrollo psicológico y educación, 2. Psicología de la educación escolar (pp. 157-188). Madrid: Alianza.

Coll, C. (2004). Psicología de la educación y prácticas educativas mediadas por las tecnologías de la información y la comunicación: una mirada constructivista, Sinéctica, 25, 1-24.

Coll, C. y Bustos, A. y Engel, E. (2008). Las comunidades virtuales de aprendizaje. En C. Coll y C. Monereo (Eds.), Psicología de la educación virtual (pp. 299-320). Madrid: Morata.

Coll, C., Bustos, A. y Engel, E. (2011). Perfiles de participación y presencia docente distribuida en redes asíncronas de aprendizaje: la articulación del análisis estructural y de contenido. Revista de Educación, 354, 657-688. Recuperado http://www.revistaeducacion.mec.es/re354/re354_26.pdf

Coll, C., Martín, E., Mauri, T., Miras, M., Onrubia, J., Solé, I., y Zabala, A. (1999). El constructivismo en el aula. Barcelona: Graó.

Comenares, A.M. y Castillo, N. (2009). Aproximación a un modelo metodológico para el análisis de las interacciones discursivas en línea. Apertura, Revista de Innovación Educativa, 1(1). Recuperado de: http://www.udgvirtual.udg.mx/apertura/num11/REVISTAELECTRONICA/Articulos\%2ohtml/Articulo_4.html

Cook, T.D. y Reichardt, C.S. (1986). Métodos cualitativos y cuantitativos en investigación evaluativa. Madrid: Morata.

Cornella, A. (2001). Educación y creación de riqueza. Revista Cuadernos de Pedagogía, 301, 52-55. 
Correa, J.M. (2005). La integración de plataformas de e-learning en la docencia universitaria: enseñanza, aprendizaje e investigación con Moodle en la formación inicial. RELATEC, Revista Latinoamericana de Tecnología Educativa, 4(1) 37-48. Recuperado de: http://campusvirtual.unex.es/cala/editio/index.php?

journal $=$ relatec\&page $=$ article\&op $=$ view\&path[] $=177 \&$ path[] $=167$

Cox, F.M., Erlich, J.F., Rothman, J. \& Tropman, J.E. (Eds.) (1987). Strategies of community organization. Itasca, IL: Peacock Publishers.

Crespo, I. (2001). Cambio cultural y desarrollo humano: el papel de la mujer en una comunidad gitana (Tesis Doctoral). Universitat Autònoma de Barcelona. Recuperado de : http://www.tdx.cat/handle/10803/4731

Crespo, I.; Lalueza, J. L. \& Pallí, C. (2002). Moving communities: a process of negotiation with a gypsy minority for empowerment. Community, Work and Family, 5 (1), 49-66.

Crespo, I., Lalueza, J.L, Portell, M. y Sánchez, S. (2004). Aprendizaje Interinstitucional, Intercultural e Intergeneracional en una Comunidad Gitana. Grupo CREA Informe técnico. Recuperado de: http://www.5d.org/postnuke/data/uploads/Documents/Aprendizaje \%20Interinstitucional,\%2oIntercultural\%20e\%20Intergeneracional \%20en\%2ouna\%2oComunidad\%2oGitana.pdf

Crespo, I., Lalueza, J. L., Portell, M. \& Sánchez, S. (2005). Communities for intercultural education: Interweaving microcultures. In M. Nilson and H. Nocon (Eds.), School of Tomorrow. Teaching and Technology in Local and Global Communities (pp. 27-62). Berna: Peter Lang.

Cronbach, L.J. (1975). Beyond the two disciplines of scientific psychology. American Psychologist, 30, 116-127.

Crook, C. (1998). Ordenadores y aprendizaje colaborativo. Madrid: Ediciones Morata.

Crook, C. (2000). Motivation and the ecology of collaborative learning. En R. Joiner, K. Littleton, D. Faulkner, \& D. Miell (Eds.), Rethinking collaborative learning (pp. 161-178). London: Free Association Press.

Cubero, R. (2005). Perspectivas constructivistas. La intersección entre el significado, la interacción y el discurso. Barcelona: Grao.

Cudero, T., Fernández, R. y Sabirón, F. (2000). La investigación sobre el aprendizaje colaborativo: enfoques, métodos y resultados. Anuario de Pedagogía, 2, 305-338. 
Cullen, J, Cullen, C., Hayward, D. \& Maes, V. (2009). Good Practices for Learning 2.o: Promoting Inclusion. An In-depth Study of Eight Learning 2.o Cases. JRC European Commission-Institute for Prospective Technological Studies. Recuperado de: http://ftp.jrc.es/EURdoc/JRC53578_TN.pdf

Cullen, J., Cullen, C. Fischer, T., Heid, S. \& Maes, V. (2010). LINKS-UP Learning 2.o for an Inclusive Knowledge Society -Understanding the Picture. Education, Audiovisual \& Culture Executive Agency-European Commission (Lifelong Learning Programme). Recuperado de: http://eacea.ec.europa.eu/llp/projects/public_parts/documents/ict/2011 /ict_mp_505544_Links-Up.pdf

Dana, N. F. (1995). Action research school change, and the silencing of teacher voice. Action in Teacher Education, 16, 59-70.

De Botton, L., Elboj, C. y Martín, S. (2001). Creando redes solidarias a través de los encuentros de estudiantes gitanas. I Jornadas de Trabajo «Drom Kotar Mestipen». Recuperado de: http://www.uv.es/ jbeltran/ase/textos/debotton.pdf

De Pablos, J. (2004). La formación superior y el reto de las nuevas tecnologías de la información: ideas para debate. En. F. Martínez y M.P. Prendes (Coord.), Nuevas tecnologías y educación (pp. 119-124). Madrid. Pearson Educacion.

De Wever, B., Schellens T., Valcke, M., \& Van Keer H. (2006). Content analysis schemes to analyze transcripts of online asynchronous discussion groups: A review. Computers \& Education , 46(1), 6-28.

Dede, C. (1996). The evolution of distance education: Emerging technologies and distributed learning. American Journal of Distance Education, 1O(2), 4-36.

Del Moral, M.E. y Villalustre, L. (2008). Las wikis vertebradoras del trabajo colaborativo universitario a través de WebQuest. Revista Latinoamericana de Tecnología Educativa, 7(1), 73-83. Recuperado de: http://campusvirtual.unex.es/cala/editio/

Dempster, J. (2004). The Changing Face of E-Pedagogy?. Interactions issue, 23, 8(2). Recuperado de: http://www2.warwick.ac.uk/services/ldc/resource/interactions/archive/i ssue23/epedagogy

Denzin, N.K. (1978). The research act. A theoretical introduction to sociological methods. New York: McGraW Hill. 
Denzin, N.K. \& Lincoln, Y.S. (1994). Entering the field of qualitive research. En N.K. Denzin \& Y.S. Lincoln (Eds.), Handbook of Qualitative Research. (pp. 1-17). Thousand Oaks, CA: Sage.

Der-Thanq, Ch. y Hung, D. (2002). Two Kinds of Scaffolding: The Dialectical Process within the Authenticity-Generalizibility (A-G) Continuum. En: Educational Technology \& Society, 5(4). Recuperado de: http://www.ifets.info/journals/5_4/chen.html

Deutsch M. (1994). Construttive conflict resolution. Principles, training and research, Journal of Sociale Issues, 5o, 13-32.

Días, M.A. (2004). Perspectiva social del e-learning en la universidad. RUSC, Revista de Universidad y Sociedad del Conocimiento, 1(1). Recuperado de: http://rusc.uoc.edu/ojs/index.php/rusc/article/view/v1n1-dias

Díaz, F. (1999). Estrategias docentes para un aprendizaje significativo. Una interpretación constructivista. México: Mcgraw-Hill.

Díaz, F. (2003). Cognición situada y estrategias para el aprendizaje. Revista Electrónica de Investigación Educativa, 5(2). Recuperado de: http://redie.uabc.mx/vol5no2/contenido-arceo.html

Díaz, F. (2005). Principios de diseño instruccional de entornos de aprendizaje apoyados en TIC: un marco de referencia sociocultural y situado. Tecnología y Comunicación Educativas, 41, 4-16. Recuperado de: http://investigacion.ilce.edu.mx/tyce/41/art1.pdf

Díaz, F. y Hernández, G. (2002). Estrategias docentes para un aprendizaje significativo. Una interpretación constructivista México: Mcgraw-Hill.

Dick, W., \& Carey, L. (1996). The Systematic Design of Instruction. New York: Haper Collins College Publishers.

Dillenbourg, P. (1999). What do you mean by collaborative learning?. En P. Dillenbourg (Ed). Collaborative-learning: Cognitive and Computational Approaches (pp. 1-19). Oxford: Elsevier.

Dodge, B. (1995). Some Thoughts About WebQuest. Recuperado de: http://webquest.sdsu.edu/about_webquests.html

Dodge, B. (1999). Webquest Tasconomy: A Taxonomy of Tasks. Recuperado de: http://edweb.sdsu.edu/webquest/taskonomy.html

Dodge, B. (2001). A Rubric for Evaluating WebQuest. Recuperado de: http://webquest.sdsu.edu/webquestrubric.html 
Doffy, T. y Cunningham, D. (1996). Constructivist: Implications for the design and delivery of instruction. En D.H. Jonassen, (Ed.), Handbook of Research for Educational Communications and Technology. New York: MacMillan Library.

Domínguez, C., Flecha, A. y Fernández, M. (2004). Mujeres gitanas y mercado laboral: mecanismos para superar su triple exclusión. Lan harremanak: Revista de relaciones laborales, 11, 2004, 81-94.

Domínguez, D. (2007). Sobre la intención de la etnografía virtual. Revista Electrónica de Teoría de la Educación: Educación y Cultura en la Sociedad de la Información, 8(1) . Recuperado de: http://www.usal.es/ teoriaeducacion/rev_numero_o8_01/n8_01_domi nguez_figaredo.pdf

Dougiamas, M. \& Taylor, P. (2002) Interpretative analysis of an internetbased course constructed using a new courseware tool called Moodle, en: Goody, A., J. Herrington y M. Northcote (Eds.), Proceedings of the 2002 Annual International Conference of the Higher Education Research and Development Society of Australasia. Perth, Western Australia: HERDSA. Recuperado de: http://dougiamas.com/writing/herdsa2002/

Dougiamas, M. \& Taylor, P. (2003). Moodle: Using Learning Communities to Create an Open Source Course Management System. En D. Lassner \& C. McNaught (Eds.), Proceedings of World Conference on Educational Multimedia, Hypermedia and Telecommunications (pp. 171-178). Chesapeake, VA: AACE.

Downes, S. (2008). The Future of Online Learning: Ten Years On (e-book). Recuperado de: http://www.downes.ca/files/books/future2008.pdf

Draves, W.A. (2000). Teaching online. River Falls, NJ: LERN Books.

Driscoll, M.P. y Vergara, A. (1997). Nuevas tecnologías y su impacto en la educación del futuro. Pensamiento educativo, 21, 81-124.

Drucker, P. (1969) The age of discontinuity. London: William Heinemann.

Duart, J. y Sangrá, A. (2000). Aprender en la virtualidad. Barcelona: Gedisa.

Duffy, T., Dueber, B. \& Hawley, C. (1998). Critical thinking in a distributed environment: a pedagogical base for the desgin of conferencing systems. En: C.Y. Bonk (Ed.), Electronic collaborators (pp. 51-78). New Jersey: Lawrence Erlbaum Ass.

Dutton, W.H. (2004). Social Transformation in an Information Society: Rethinking Access to You and the World. Paris: UNESCO. Recuperado de: http://unesdoc.unesco.org/images/oo15/o01520/152004e.pdf 
Elboj, C. y Flecha, A. (2002). Mujeres, aprendizaje dialógico y transformación social. Contextos educativos, 5, 159-172.

Elboj, C. y Vicén, M.J. (2007). Brudila Callí, las mujeres gitanas contra la exclusión: superación del absentismo y fracaso escolar de las niñas y adolescentes gitanas. Flumen, 10, 45-74

Elliott, J. (1990). La investigación-acción en educación. Madrid: Morata.

Elliot, J., Barrett, G., Hull, C., Sanger, J., Wood, M. y Haynes, L. (1986). Investigación/acción en el aula. Valencia: Generalitat Valenciana, Conselleria de Cultura, Educació i Ciència.

Engeström, Y. \& Cole, M. (1997). Situated cognition in search of an agenda. En D. Kirshner y J. A. Whitson (Eds.), Situated cognition. Social, semiotic and psychological perspectives, (pp. 301-309). Mahwah: Lawrence Erlbaum.

Epper, R.M y Bates, A.W. (2004). Enseñar al profesorado cómo utilizar la tecnología. Buenas prácticas de instituciones líderes. Barcelona: UOC.

Escudero, J. M. (2002). La Reforma de la Reforma ¿Qué calidad, para quiénes?. Barcelona: Ariel.

Euesden, P. (2009). Widening elearning through participation, WIPEL Final Report, The Sheffield College (TSC). Recuperado de: http://www.jisc.ac.uk/publications/reports/2009/wptefinalreport.aspx

Fainholc, B. (2005). El uso inteligente de las TIC para una práctica socioeducativa de calidad. Revista Latinoamericana de Tecnología Educativa, 4(2), 53-63. Recuperado de: http://www.unex.es/didactica/RELATEC/sumario_4_2.htm

Fandos, M. y González, A.(2006). Estrategias de Aprendizaje ante las Nuevas Posibilidades Educativas de las TIC. Recuperado de: http://www.colombiadigital.net/newcd/component/docman/doc_details /348-estrategias-de-aprendizaje-ante-las-nuevas-posibilidadeseducativas-de-las-tic

Fink, D. (2003). Creating Significant Learning Experiences: An Integrated Approach to Designing College Courses. San Francisco: Jossey-Bass.

Flecha, R. (1997). Compartiendo palabras. El aprendizaje de las personas adultas a través del diálogo. Barcelona: Paidós.

Flecha, R. (1999). Aprendizaje dialógico y participación social. Comunidades de aprendizaje. Recuperado de: http://www.educacionenvalores.org/spip.php?article1804 
Flecha, R. (2004). Investigar desde la igualdad de las diferencias. En: A. Touraine, M. Wieviorka y R. Flecha (Coords.), Conocimiento e identidad: voces de grupos culturales en la investigación social (pp. 34-49). Barcelona: El Roure.

Flecha, R.; Gómez, J. y Puigvert, L. (2001). Teoría sociológica contemporánea. Barcelona: Paidós.

Flecha, R., Vargas, J. y Dávila, A. (2004). Metodología comunicativa crítica en la investigación en ciencias sociales: La investigación Warkaló. Lan Harremana, 11, 21-33. Recuperado de: http://www.lanharremanak.ehu.es/p231content/es/contenidos/informacion/rrll_revista/es_revista/revista11.htm 1

Flick, U. (2004). Introducción a la investigación cualitativa. Madrid: Morata.

Foch-Lyon, E. \& Trost, J.F. (1981). Conducting focus group sessions, Studies in Family Planning, 12(12), 443-449.

FOESSA (2008). VI Informe sobre exclusión y desarrollo social en España. Madrid: Fundación FOESSA y Cáritas Española. Recuperado de: http://www.foessa.es/publicaciones_Info.aspx?Id=379

Forster, M., \& Washington, E. (2000). A model for developing and managing distance education programs using interactive video technology. Journal of Social Work Education, 36(1), 147-159.

Fox, D. (1981). El proceso de investigación en educación. Pamplona: Eunsa

Freire, P. (2003). Pedagogía del oprimido. Madrid: Siglo XXI.

Fulton, K. \& Riel, M. (2005). Professional development through learning communities. Recuperado de: http://www.edutopia.org/professionaldevelopment-online-learning-communities

Fundación Secretariado Gitano (2005a) Población gitana y empleo. Un estudio comparado. Madrid: Fundación Secretariado Gitano. Recuperado de:

http://www.gitanos.org/publicaciones/estudioempleo/estudioempleo/

Fundación Secretariado Gitano (2005b). Salud y Comunidad Gitana. Madrid: Centro de publicaciones del Ministerio de Sanidad y Consumo.

Fundación Secretariado Gitano (2005c). Dossier sobre Mujeres Gitanas, $\mathrm{n}^{\mathrm{0}} \mathbf{2}$. Gitanos, pensamiento y cultura, 27-28. Recuperado de: http://www.gitanos.org/upload/o3/o8/27_28Dossier.pdf 
Fundación Secretariado Gitano (2006). Incorporación y trayectoria de las niñas gitanas en la E.S.O. Madrid: CIDE/Instituto de la Mujer.

Fundación Secretariado Gitano (2007). Guía de motivación y recursos: Mujeres gitanas y nuevas tecnologías. Madrid: Fundación Secretariado Gitano.

Fundación Secretariado Gitano (2009). Informe sombra. 44 Sesión Comité para la eliminación de todas las formas de discriminación contra las mujeres. Presentado a la ONU en junio de 2009. Recuperado de: http://www2.ohchr.org/english/bodies/cedaw/docs/ngos/FundacionSecr etariadoGitanoReport_Spain44_sp.pdf

Fundación Secretariado Gitano (2010). Me Sim Rom (Yo Soy Gitana). Badajoz: Diputación de Badajoz.

Fundación Secretariado Gitano (2011) Informe anual FSG 2011. Madrid: Fundación Secretariado Gitano.

Fung, Y.H. (2004), Collaborative online learning: interaction patterns and limiting factors. Open Learning, 19(2), 135-149.

Gairín, J y Muñoz, M.P. (2006) Análisis de la interacción en comunidades virtuales. Educar, 37, 125-150. Recuperado de: http://ddd.uab.es/pub/educar/o211819Xn37p125.pdf

Garaizabal, C. (2000). La feminidad tradicional: cambios y crisis en la identidad de las mujeres, Gitanos. Pensamiento y Cultura, 5. Disponible en: http://www.gitanos.org/upload/93/88/o5_afondo.pdf

García Andújar, D. (2001). La utopía informacional; tecnología para desheredados. Revista Tchatchipen, 33, 27-34.

García Aretio, L. (2003). Comunidades de aprendizaje en entornos virtuales. En M. Barajas (Coord.), La tecnología educativa en la enseñanza superior : entornos virtuales de aprendizaje (pp. 117-199). Madrid: McGrawHill.

García Aretio, L. (2007). Redes y comunidades. Comunicación y Pedagogía, 223, 28-33.

García Aretio, L. (Coord.), Ruíz Corbella, M. y Domínguez Figaredo, D. (2007). De la educación a distancia a la educación virtual. Barcelona: Ariel.

García Cabrero, B., Márquez, L., Bustos, A., Miranda, G.A. y Espíndola, S. (2008). Análisis de los patrones de interacción y construcción del conocimiento en ambientes de aprendizaje en línea: una estrategia 
metodológica. Revista Electrónica de Investigación Educativa, 1o(1). Recuperado de: http://redie.uabc.mx/vol1ono1/contenido-bustos.html

García Carrasco, J. (1993). Acción pedagógica y acción comunitaria. Reflexiones a partir de textos de Habermas, Revista de Educación, 302, 129-164.

García Carrasco, J. (1997) (Coord.), Educación de Adultos. Barcelona: Ariel.

García Carrasco, J. (2001). La zona de construcción del sujeto. Curso de Doctorado Procesos de Formación en Espacios Virtuales. Universidad de Salamanca (Documento Policopiado).

García Carrasco, J. (2002). La educación de personas adultas en el contexto de la sociedad de la información. Aula, Revista de Pedagogía de la Universidad de Salamanca, 14, 69-92. Recuperado de: http://campus.usal.es/ revistas_trabajo/index.php/o2143402/article/viewFile/1303/1374

García Carrasco, J. (2006a). Los procesos formativos y el sistema emocional. Teoría de la educación, 18, 27-53. Recuperado de: http://campus.usal.es/ revistas_trabajo/index.php/11303743/article/viewFile/3198/3224

García Carrasco, J. (2006b). Las emociones en el "territorio" on-line. Teoría de la Educación: Educación y Cultura en la Sociedad de la Información, $7(2), \quad 4-27 . \quad$ Recuperado de: http://campus.usal.es/ teoriaeducacion/rev_numero_07_02/n7_02_joa quin_garcia.pdf

García Carrasco, J. (2007). Las formas de la alfabetización cultural en la sociedad de la información. Teoría de la Educación: Educación y Cultura en la Sociedad de la Información, 10(1), 49-75. Recuperado de: http://campus.usal.es/ teoriaeducacion/rev_numero_10_01/n10_01_ga rcia_carrasco.pdf

García Carrasco. J. y García del Dujo, A. (2001). Teoría de la educación II. Procesos primarios de formación del pensamiento y la acción. Salamanca: Ediciones Universidad de Salamanca.

García del Dujo, (2009). Análisis del espacio en los entornos virtuales de formación. Teoría de la educación, 21(1), 103-128. Recuperado de: http://campus.usal.es/ revistas_trabajo/index.php/11303743/article/viewFile/3157/3185

García del Dujo, A. y Martín, A.V. (2002). Caracterización pedagógica de los entornos virtuales de aprendizaje. Teoría de la educación, 14, 67-92. 
García del Dujo, A. y Martín, A.V, Muñoz, J.M. (2010). Análisis del tiempo en los entornos virtuales de formación. Teoría de la educación, 22(2), 111130. Recuperado de: http://campus.usal.es/ revistas_trabajo/index.php/11303743/article/viewFile/8298/8325

García, M., Ibañez, J. y Alvira, F. (2000) (Comps). El análisis de la realidad social. Métodos y técnicas de investigación. Madrid: Alianza Editorial.

García, M., Pérez, R., Pascual, Ma A., Álvarez, E yBombona, J. (2004). Uso Didáctico del Chat y su aplicación en Preseos. Comunicación presentada al Congreso Internacional sobre Educación y Tecnologías de la Información y la Comunicación: Educar con tecnologías, de lo excepcional a lo cotidiano. Edutec, o4, Barcelona, Universidad de Barcelona. Recuperado http://www.lmi.ub.es/edutec2004/pdf/154.pdf

García, F.J., García, J., López, M., López, R. \& Verdú, E. (2005) (Eds.), Educational Virtual Spaces in Practice: The Odiseame Approach. Barcelona: Ariel.

García-Peñalvo, F.J. (2008). Advances in e-Learning: Experiences and methodologies. Hershey, PA, USA: Information Science reference (formerly Idea group reference).

García, C.M. (2006). La interacción didáctica en los nuevos ambientes virtuales de aprendizaje. Recuperado de: http://www.elearningeuropa.info/directory/index.php? page $=$ doc\&doc_id $=7875 \&$ doclng $=7$

Garrido, A. (2003). El aprendizaje como identidad de participación en la práctica de una comunidad virtual. Barcelona. Trabajo de Doctorado TDo3-003. Recuperado http://www.uoc.edu/in3/dt/20088/index.html

Garrison, D.R. \& Archer, W. (2000). A transactional perspective on teaching and learning: A framework for adult and higher education. Oxford: Pergamon.

Garrison, D.R., Anderson, T. \& Archer W. (2000). Critical inquiry in a textbased environment: Computer conferencing in higher education. The Internet and Higher Education 2(2-3), 87-105. Recuperado de: http://communitiesofinquiry.com/sites/communityofinquiry.com/files/C ritical_Inquiry_model.pdf

Garrison, D.R. y Anderson, T. (2005). El e-learning en el siglo XXI. Barcelona: Octaedro. 
Gisbert, M. (2000). Las redes telemáticas y la educación del siglo XXI. En M. Cebrián (Coord.), Internet en el aula, Proyectando el futuro (pp. 15-25). Málaga: Grupo de Investigación y Nuevas Tecnologías Aplicadas a la Educación, Universidad de Málaga.

Glaser, B.G. \& Strauss, A.L. (1967). The discovery of grounded theory: Strategies for qualitative research. Nueva York: Aldine de Gruyter.

González, C. (2005). Romipen en Femenino. Gitaneidad en femenino. Aula Intercultural. Recuperado de: http://www.aulaintercultural.org/article.php3?id_article $=1552$

González, M. y Hernández, M.J. (2008). Interpretación de la virtualidad. El conocimiento mediado por espacios de interacción social. Apertura, Revista de Innovación Educativa, 9, 1-13. Recuperado de: http://www.udgvirtual.udg.mx/apertura/num9/pdfs/interpretacion.pdf

Grace, M. (1998). Using communication and information technologies to empower women in rural communities, En I. Falk, (Ed.), Conference proceedings of the International Simposium on Learning Communities, Regional sustainability and the Learning Society (pp. 150-158). Launceston: Centre for Research and Learning in Regional Australia.

Granados, J. M. (2008). La alfabetización tecnológica y el acceso a las tic en la dialéctica inclusión/exclusión. El caso de la minoría gitana. Revista de Educación, 346, 427-454. Recuperado de: http://www.revistaeducacion.mec.es/re346/re346_16.pdf

Greening, T. (1998). Building the constructivist toolbox: an exploration of cognitive technologies, Educational Technology, 38(2), 23-35.

Gros, B. (2000). El ordenador invisible. Barcelona: Gedisa.

Gros, B. (2002). Constructivismo y diseño de entornos virtuales de aprendizaje. Revista de Educación, 328, 225-247.

Gros, B. (2004). La construcción del conocimiento en la red: límites y posibilidades. Revista Teoría de la Educación: Educación y Cultura en la Sociedad de la Información, 5. Recuperado de: http://campus.usal.es/ teoriaeducacion/rev_numero_05/n5_art_gros.h tm

Gros, B. (2008). Aprendizajes, conexiones y artefactos. Barcelona: Gedisa.

Gros, B. y Silva, J. (2005). La formación del profesorado como docentes en los espacios virtuales de aprendizaje, Revista Iberoamericana de Educación, 36(1), 1-13. Recuperado de: http://www.campusoei.org/revista/tec_edu32.htm 
Gros, B. y Silva, J. (2006). Metodologías para el análisis de espacios virtuales colaborativos. Revista de Educación a Distancia, 16, 1-16. Recuperado de: http://www.um.es/ead/red/16

Guardia, L. (2000). El diseño formativo: un nuevo enfoque de diseño pedagógico de los materiales didácticos en soporte digital. En A. Sangrá \& J. Duart (Coords.), Aprender en la virtualidad (pp. 171-187). Barcelona: Gedisa.

Guba, E. (1983). Criterios de credibilidad en la investigación naturalista. En J. Gimeno y A. Perez (Coords.), La enseñanza. Su teoría y su práctica. (pp. 148-165). Madrid: Akal.

Guba, E.G., \& Lincoln, Y.S. (1994). Competing paradigms in qualitative research. En N.K. Denzin \& Y.S. Lincoln (Eds.), Handbook of qualitative research (pp. 105-117). Thousand Oaks, CA: Sage.

Guenther, K. (2005). Socializing your Web Site with Wikis, Twikis, and Blogs. Online, 29(6), 51-53. Recuperado de: http://www.infotoday.com/online/novo5/index.shtml

Gunawardena, C.N. (1995). Nuevos caminos en el aprendizaje: Nuevas formas de evaluar. Cuadernos de Educación a Distancia, 3, 57-83.

Gunawardena, C.N., Lowe, C.A. \& Anderson, T. (1997). Analysis of a global online debate and the development of an interaction analysis model for examining social construction of knowledge in computer conferencing. Journal of Educational Computing Research, 17(4), 395-429.

Guskey, T. (1986). Staff development and the process of teacher change. Educational Researcher, 5(15), 5-12.

Gustafson, G.R. \& Branch, R.M. (2002). Survey of instructional development models. Syracuse. NY: ERIC Clearinghouse on Information and Technology. Recuperado de: http://eric.ed.gov/PDFS/ED477517.pdf

Habermas, J. (1999). La inclusión del otro. Barcelona: Paidós.

Habermas, J. (2001a). Teoría de la acción comunicativa. Volumen I: Racionalidad de la acción. Madrid: Taurus.

Habermas, J. (2001b). Teoría de la acción comunicativa. Volumen II: Crítica de la razón funcionalista. Madrid: Taurus.

Hakkarainen, K., Paavola, S., \& Lipponen, L. (2004). From Communities of Practice to Innovative Knowledge Communities. LLine - Lifelong Learning in Europe, 9(2), 74-83. 
Hamman, R. (2001). Computer Networks Linking Network Communities. En C. Werry \& M. Mowbray (Eds.), Online Communities (pp. 71-96). Upper Saddle River, NJ: Prentice Hall.

Harasim, L. (1989). On-Line Education: A New Domain. In Mason, R. \& Kaye. A (Eds.), Mindweave: Communication, Computers and Distance Education (pp.50-62). Oxford: Pergamon Press.

Harasim, L.; Hiltz, S. R.; Turoff, M. y Teles, L. (2000). Redes de aprendizaje. Guía para la enseñanza y el aprendizaje en red. Barcelona: Gedisa.

Hathorn, L. G. \& Ingram, A. L. (2002). Cooperation and collaboration using computer-mediated communication. Journal of Educational Computing Research, 26(3), 325-247.

Haythornthwaite, C., Kazmer, M. M., Robbins, J., \& Shoemaker, S. (2000). Community development among distance learners: temporal and technological dimensions. Journal of Computer Mediated Communication, 6(1). Recuperado de: http://jcmc.indiana.edu/vol6/issue1/haythornthwaite.html

Helsper, E. J. (2008). Digital inclusion: an analysis of social disadvantage and the information society. London: Department for Communities and Local Government. Recuperado de: http://www.communities.gov.uk/publications/communities/digitalinclus ionanalysis

Henri, F. (1992). Computer conferencing and content analysis. En A. R. Kaye (Ed.), Collaborative Learning Through Computer Conferencing (pp. 117136). Berlín: Springer- Verlag.

Hernández, P. (1997). Construyendo el constructivismo: criterios para su fundamentación y aplicación escolar. En M. J. Rodrigo y J. Arnay (Comps). La construcción del conocimiento escolar (pp. 285-312). Barcelona: Paidós

Hernández, M.J. y González, M. (2002). La transición social y la mediación tecnológica: el fenómeno educativo desde las sociedades orales a la sociedad de la información y del conocimiento. Aula, Revista de Pedagogía de la Universidad de Salamanca, 14, 111-125. Recuperado de: http://campus.usal.es/ revistas_trabajo/index.php/o2143402/article/viewFile/1305/1376

Heredia, M. (2004). Prejuicios y seducciones de los gitanos sobre Internet. Recuperado de: http://www.cibersociedad.net/recursos/art_div.php? $\mathrm{id}=79$ 
Heredia, M. (2005). Entrar y salir, entrar y mirar, entrar y quedarse. Fases metodológicas a una aproximación etnográfica virtual gitana. Revista Periferia, 3, 10-29.

Heredia, M. (2008). La cultura gitana a través de las Nuevas Tecnologías de la Información y Comunicación. Cuadernos Gitanos, 3, 62-68.

Hiltz, S. (1992). The virtual classroom: software for collaborative learning. En E. Barrett (Ed). Sociomedia (pp.347-368). Cambridge: The MIT Press.

Hillman, D. (1999). A New Method for Analizing Patterns of Interaction. The American Journal of Distance Education, 13 (2), 37-47.

Hildreth, P \& Kimble, C (Eds.) (2004). Knowledge Networks: Innovation Through Communities of Practice. London: Idea Group Publishing

Hine, C. (2000). Virtual Ethnography. London: Sage.

Hrastinski, S. (2008). What is online learner participation? A literature review. Computers \& Education, 51, 1755-1765. Recuperado de: http://thorndike.tc.columbia.edu/ david/MTSU4083/Readings/hrastins ki\%202008\%20What\%20is\%20online\%2olearner\%2oparticipation\%3F \%20A\%2oliterature\%2oreview.pdf

Huffaker, D. (2005). The Educated Blogger: Using Weblogs to Promote Literacy in the Classroom. AACE Journal, 13(2), 91-98.

Hunsaker, L., y Johnston, M. (1992). Teacher under construction: a collaborative case study of teacher change. American Educational Research Journal, 29, 350-372.

Hunter, B. (2002). Learning in the Virtual Community Depends upon Changes in Local Communities. En: K. A. Renninger y W. Shumar (Eds.), Building Virtual Communities. Learning and Change in Cyberspace (pp. 96-126). New York: Cambridge University Press.

Ibáñez, R (2000). Más allá de la sociología. El grupo de discusión: técnica y crítica. Madrid: Siglo XXI.

Janesick, V. (1994). The dance Qualitative Research Design. En Denzin, N.K. \& Lincoln, Y.S. (Eds.), Handbook of qualitative research (pp. 209-219). London: Sage Publication.

Jarvela, S. \& Hakkinen, P. (2002). Web-based Cases in Teaching and Learning - the Quality of Discussions and a Stage of Perspective Taking in Asynchronous Communication. Interactive Learning Environments, 1O(1), 1-22 
Jonassen, D. H. (1991). Objetivism versus constructivism: Do we need a new philosophical paradigm?. Journal of Educational Technology Research and Development, 39(3), 5-14. Recuperado de: http://www.springerlink.com/content/joo8vo2u57u71827/

Jonassen, D. H. (1994). Thinking Technology: Toward a constructivist design model. Educational Technology, 34(3), 34-37.

Jonassen, D. (2000). El diseño de entornos constructivistas de aprendizaje. En Ch. Reigeluth (Ed.), Diseño de la instrucción. Teoría y modelos, vol. 1 (pp. 225-250). Madrid: Aula XXI Santillana.

Jonassen, D. y Rorher-Murphy, L. (1999). Activity Theory as a framework for designing constructivist learning environments. Educational Technology: Research and Development, 47(1), 61-79.

Jonassen, D. H., Peck, K. L., \& Wilson, B. G. (1999). Learning with Technology: A constructivist Perspective. Columbus, Ohio: Prentice Hall.

Johnson, C.M. (2001). A survey of current research on online communities of practice. Internet and Higher Education, 4(1), 45-60.

Johnson, R. B. \& Onwuegbuzie, A. J. (2004). Mixed methods research. A research paradigm whose time has come. Educational Research, 33(7), 14-26. Recuperado de: http://www.aera.net/uploadedFiles/Journals_and_Publications/Journal s/Educational_Researcher/Volume_33_No_7/o3ERv33n7_Johnson.pdf

Johnson, J., Dyer, J., Chapman, C., Hebenton, R., Lockyer, B. \& Luck, K. (2009). Online Mobile Communities to Facilitate the Social Inclusion of Marginalised Young People (Come In): Literature Review on Online Communities. Recuperado de: http://www.comein-project.eu/

Jorrín, I.M., Anguita, R., Rubia, B., Ruiz, I y Villagrá, S. (2007). Lo que el ojo no ve: un estudio de caso basado en procesos de indagación co(wiki)laborativos. RIED, Revista Iberoamericana de Educación a distancia, 10(2), 75-96. Recuperado de: http://espacio.uned.es/fez/eserv.php?pid=bibliuned:20543\&dsID=lo-que-el-ojono-ve.pdf

Junta de Extremadura (2001). Extremadura en la Sociedad de la Información: Hechos, Iniciativas y Políticas. Consejería de Educación, Ciencia y Tecnología. Recuperado de: http://www.webnuevastecnologias.com/newtecnofr/docinteres/libroverd e_ext.pdf 
Kanuka, H., Rourke, L. \& Laflamme, E. (2007). The Influence of Instructional Methods on the Quality of Online Discussion. British Journal of Educational Technology, 38(2) 260-271.

Kearsley, G. (2005). Online Learning. Personal reflections on the transformation of education. Nueva York: Educational technology publications.

Kember, D. \& Gow, L. (1992). Action reserch as a form of staff development in Higher Education. Higher Education, 23(3), 297-310.

Kemmis, S. (2009). Action research as a practice-based practice. Educational Action Research, $17(3), 463-474$.

Kemmis, S. \& McTaggart, R. (1988). Cómo planificar la investigaciónacción. Barcelona: Laertes.

Kimble, C. \& Hildreth, P.(Ed.) (2008). Communities of Practice: Creating Learning Environments for Educators. Charlotte NC: Information Age Publishinh.

Kimble, C., Hildreth, P.\& Wright, P. (2001). Communities of Practice: Going virtual. En Y. Malhotra (Eds.), Knowledge Management and Business Model Innovation (pp. 220-234). Hershey, London: Idea Group Publishing.

Ko, S. \& Rossen, S. (2004). Teaching online. A practical guide. Boston: Houghton Mifflin.

Kolb, D.A. (1984) Experiential Learning. Experience as the source of learning and development, Englewood Cliffs, NJ.: Prentice-Hall.

Koschmann, T. (1996). CSCL: Theory and practice of an emerging paradigm. Erlbaum: Mahwah, NJ.

Kottler, H., Parsons, J., Wardenburg, S., \& Vornbrock, F. (2000). Knowledge objects: Definition, development initiatives, and potential impact. En K. Mantyla (Ed.), The 200O/2001 ASTD Distance Learning Yearbook: The Newest Trends and Technologies (pp-177-185). New York: McGraw-Hill.

Lagarde, M., (2000). Claves feministas para la mejora de la autoestima. Madrid: Horas y Horas.

Lai, K.W., Pratt, K., Anderson, M. \& Stigter, A. (2006). Literature Review and Synthesis: Online Communities of Practice. Ministry of Education: New Zealand. 
Lalueza, J.L. y Crespo, I. (2001). Los gitanos en el siglo XXI, entre la asimilación, el ghetto y la conciencia de una identidad múltiple. Crítica, $889,24-29$.

Lazuela, J.L. y Crespo, I. (2003). Culturas minoritarias, educación y comunidad. Trabajo con Tic. En M.A. Essomba (Coord.), Educación e inclusión social de inmigrados y minorías. Tejer redes de sentido compartido (pp. 293-314). Barcelona: Praxis

Lalueza, J.L., Crespo, I. \& Bria, M. (2008). Microcultures, Local Communities and Virtual Networks. In T. Hansson. (Ed.), Handbook of research on digital information technologies: Innovations, methods, and ethical issues (pp. 117-130). Hershey, PA: IGI Global.

Lalueza, J.L., Crespo, I. y Camps, S. (2008). Las tecnologías de la información y la comunicación en los procesos de desarrollo y socialización. En C. Coll y C. Monereo (Eds.), Psicología de la Educación Virtual (pp. 54-73). Madrid: Morata.

Lalueza, J.L., Crespo, I., Pallí, C. y Luque, M.J. (1999). Intervención educativa, comunidad y cultura gitana. Una experiencia con nuevas tecnologías: la casa de Shere Rom. En M. A. Essomba (Coord.), Construir la escuela intercultural. Reflexiones y propuestas para trabajar la diversidad étnica y cultural (pp. 185-194). Barcelona: Graó.

Lalueza, J.L., Crespo, I., Pallí, C. y Luque, M.J. (2001). Socialización y cambio cultural en una comunidad étnica minoritaria. El nicho evolutivo gitano. Cultura y educación, 13(1), 115-130.

Lalueza, J.L., Crespo, I., Sánchez, S., Camps, S. y Cazorla, A. (2006). Intervención psicopedagógica en comunidades minoritarias. En Badía, A., Mauri, T. y Monero, C. (Eds.) La práctica psicopedagógica en educación no formal (pp. 305-326). Barcelona: EDIUOC.

Lalueza, J. L., Bria, M., Crespo, I., Sánchez, S. \& Luque, M. J. (2004). Education as microculture construction. From local community to virtual network. Interactive Educational Multimedia. 9, 16-31. Recuperado de: http://www.ub.edu/multimedia/iem/down/c9/Education_and_microcul tures_\%28SPA\%29.pdf

Laparra, M., Obradors, A., Pérez, B., Pérez, M., Renes, V., Sarasa, S., Subirats, J. y Trujillo, M. (2007). Una propuesta de consenso sobre el concepto de exclusión social: Implicaciones Metodológicas. Revista Española del Tercer Sector, 5, 15-57. Madrid: Fundación Luis Vives.

Lara, T. (2005). Blogs para educar. Usos de los blogs en una pedagogía constructivista. Telos, Cuadernos de Comunicación e Innovación, 65. 
Recuperado

de: http://sociedadinformacion.fundacion.telefonica.com/telos/articulocuade rno.asp@idarticulo=2\&rev=65.htm

Larrañeta, J.J. (2004). Metodología y herramientas para la generalización del e-learning en colectivos desfavorecidos. I Congreso Internacional: $E$ Learning e Inclusión Social. Barcelona. Recuperado de: http://www.el4ei.net/first/conf_es.htm

Latorre, A. (2003). La investigación-acción. Conocer y cambiar la práctica educativa. Barcelona: Grao.

Lave, J. (1997). The culture of acquisition and the practice of understanding. En D. Kirshner y J. A. Whitson (Eds.), Situated cognition. Social, semiotic and psychological perspectives (pp. 17-35). Mahwah, NJ: Lawrence Erlbaum.

Lave, J. y Wenger, E. (1991). Situated Learning: Legitimate Peripheral Participation. New York: Cambridge University Press.

Laviña, J. y Mengual, L. (2008). Libro Blanco de la Universidad Digital 2010. Barcelona: Ariel.

León, O.G. y Montero, I. (2002). Métodos de investigación en Psicología y Educación. Madrid: McGraw-Hill.

Leontiev, A. (1978). Actividad, conciencia y personalidad. Buenos Aires: Ciencias del Hombre.

Lethinen, E., Hakkarainen, K., Lipponen, L., Rahikainen, M. \& Muukkonen, H. (1999). Computer supported collaborative learning: A review.

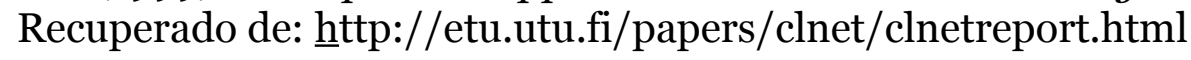

Lesser, E.L. \& Storck, J. (2001). Communities of practice and organizational performance. IBM Systems Journal, 4O(4), 831-841. Recuperado de: http://www.providersedge.com/docs/km_articles/CoP_and_Organizatio nal_Performance.pdf

Leshin, C.B., Pollock, J., \& Reigeluth, C.M. (1992). Instructional Design Strategies and Tactics. Englewood Cliffs, NJ: Education Technology Publications.

Lewis, D.\& Allan, B. (2005). Virtual Learning Communities. Berkshire: Open University Press.

Lewis, D. \& Allan, B. (2006) Virtual learning communities as a vehicle for workforce development: a case study. Journal of Workplace Learning, 18(6) $367-383$ 
Lewin, K. (1946). Action Research and Minority problems. Journal of Social Issues, 2(4), 34-46.

Lipman, M. (1991). Thinking in education. Cambridge: Cambridge University Press.

Livingstone, S. \& Helsper, E. J. (2007). Gradatons in digital inclusion: Children, young people and the digital divide. New Media \& Society, 9(4), 671-696.

Londinsky. A. (2011). Reflexiones sobre los Aspectos Sociales y Culturales del e learning. Cognición, 33 Recuperado de: http://www.cognicion.net/images/articulos/Cog33/33-reflexiones-sobreaspectos-sociales.pdf

López, E. y Roso, J. (2009). E-evaluación de cursos telemáticos universitarios, Tejuelo, 4, 19-30.

Lozano, A. (2004). Comunidades de aprendizaje en red: diseño de un proyecto de entorno colaborativo. Revista Electrónica de Teoría de la Educación: Educación y Cultura en la Sociedad de la Información, 5. Recuperado de: http://campus.usal.es/ teoriaeducacion/rev_numero_05/n5_art_lozano .htm

Luque, A., Ortega, R. y Cubero, R. (1997). Concepciones constructivistas y práctica escolar. En M.J. Rodrigo y J. Arnay (Coomps.). La construcción del conocimiento escolar (pp. 313-336 ). Barcelona: Paidós Ibérica.

Luque,M. (2004) Visión americana de la perspectiva social del e-learning en la educación superior. RUSC, Revista de Universidad y Sociedad del Conocimiento, 1(1). Recuperado de: http://rusc.uoc.edu/ojs/index.php/rusc/article/view/v1n1-luque

Luria, A. R. (1987). Desarrollo histórico de los procesos cognitivos. Madrid: Akal.

Macías, A. (2005). Migraciones internacionales de la minoría étnica gitana de Rumania hacia España: factores condicionantes de las migraciones internacionales, Documentación Social, 137, 79-98.

Machlup, F. (1962) The Production and Distribution of Knowledge in the United States. New Jersey: Princeton University Press.

Marcelo, C. (1994). Formación del profesorado para el cambio educativo. Barcelona: Promociones y Publicaciones Universitarias. 
Marcelo, C. (2006). Las nuevas Competencias en el e-learning: ¿qué formación necesitan los profesionales del e-learning?. En: C. Marcelo (Coord.), Prácticas de e-learning (pp. 46-75). Barcelona: Octaedro.

Marcelo, C. y Perera, V. H.(2007). Comunicación y aprendizaje electrónico: la interacción didáctica en los nuevos espacios virtuales de aprendizaje. Revista de Educación, 343, 381-429. Recuperado de: http://www.revistaeducacion.mec.es/re343/re343_17.pdf

Marcelo, C., Puente, D., Ballesteros, M. A. y Palazón, A. (2002). E-learning Teleform@ción.Diseño, desarrollo y evaluación de la formación a través de Internet. Barcelona: Gestión 2000.

Marqués, P. (2006). Nuevos entornos, nuevos modelos didácticos. Cuadernos de Pedagogía, 363, 80-89.

Martí, J. (2008). De las prácticas locales al conocimiento público: La investigación acción como contribución científica. Ensayo: Kathryn Herr \& Gary L. Anderson (2005). The Action Research Dissertation: A Guide for Students and Faculty. Forum Qualitative Sozialforschung / Forum: Qualitative Social Research, 9(3). Recuperado de: http://www.qualitative-research.net/index.php/fqs/article/view/989

Martínez, A. y Musitu, G. (Eds.) (1995). El estudio de casos: para profesionales de la acción social. Madrid: Narcea.

Martínez, M. A y Sauleda, N. (2006). Las Universidades en la era numérica: Nuevas tecnologías, nuevos problemas, nuevas teorías. En M. A. Martínez y V. Carrasco (Eds.), La construcción colegiada del modelo docente universitario del s. XXI (pp. 5-25). Alicante: Marfil.

Martínez, E. y Serrano, A. (2003). La Brecha Digital: Mitos y Realidades. México: UABC.

Mason, A (2005) Effectiveness and delight in an online learning community: A learner-centred approach Recuperado de: http://videolinq.tafe.net/learning2005/papers/mason.pdf

Masuda, Y. (1984). La sociedad informatizada como sociedad postindustrial. Madrid: Fundesco Tecnos.

Matthews, M. R. (1998). Constructivism in Science Education. A Philosophical Examination. London: Kluwer Academic Publishers.

Matthews, M. R. (2002). Constructivism in Science Education. A Further Appraisal, Journal of Science Education and Technology, 11(2), 121-134. 
Matzat, U. \& de Vos, H. (2000). Online Communities: Which conditions make them successful? Report of a research project commissioned by KPN Research. Recuperado de: http://www.ppsw.rug.nl/matzat/onlinecommunities.pdf

Maya, P. (2008). La brecha digital, brecha social. Los recursos humanos en el desarrollo y la capacitación a través del aprendizaje digital ('elearning'), Gazeta de Antropología, 24(2). Recuperado de: http://www.ugr.es/ pwlac/G24_45Pedro_Maya_Alvarez.html

McConnell, D. (2000) Implementing Computer Supported Cooperative Learning. London: Kogan Page.

McDermott, R. (1999). Why information technology inspired but cannot deliver knowledge management. California Management Review, 41(4), $103-117$.

McDermott, R. (2007). Building healthy communities. Inside Knowledge, $10(9), 14-19$.

McKernan, J. (2001). Investigación-acción y curriculum. Madrid: Morata.

McLuhan, Herbert Marshall (1985). La Galaxia Gutenberg. Génesis del "Homus Typographicus". Barcelona: Planeta-Agostini

Mead, G.H. (1982). Espíritu, persona y sociedad desde el punto de vista del conductismo social. Barcelona: Paidós.

Mele, C. (2003) El ciberespacio y las comunidades desfavorecidas. Internet como herramienta para la actuación colectiva. En M.A. Smith y P. Kollock (Eds.), Comunidades en el ciberespacio (pp. 345-370). Barcelona: UOC.

Mena, A. M. y Méndez, J.M. (2009). La técnica de grupo de discusión en la investigación cualitativa: aportaciones para el análisis de los procesos de interacción. Revista Iberoamericana de Educación, 49(3), 1-7. Recuperado http://www.rieoei.org/deloslectores/2859Manriquev2.pdf

Mercer, N. (2001). Palabras y mentes. Cómo usamos el lenguaje para pensar juntos. Barcelona: Paídos.

Merriam, S. B. (1988). Case Study research in education. A Qualitative Approach. San Francisco: Jossey-Bass.

Mertler, C.A. (2001). Designing scoring rubrics for your classroom. Practical Assessment, Research \& Evaluation, 7(25). Recuperado de:: http://pareonline.net/getvn.asp?v=7\&n=25 
Mehrotra, C. M., HollisterR, C.D. \& Mcgahey, L. (2001). Distance Learning: Principles for effective design, delivery, and evaluation. Thousand Oaks: Sage Publications.

Meyer, K. (2003). Face-to-Face Versus Threaded Discussions: The Role of Time and Higher- Order Thinking. Journal of Asynchronous Learning Networks, 7(3), 55-65.

Miller, J. L. (1992). Exploring power and authority issues in a collaborative research project. Theory Into Practice, 31, 165-172.

Miller, J. L., y Martens, M. L. (1990). Hierachy and imposition in collaborative inquiry: teacher-researchers' reflections on recurrent dilemmas. Educational Foundations, 4, 41-59.

Mínguez, A. y Fuentes, M. (2004). Cómo hacer una investigación social. Valencia: Tirant Lo Blanch.

Molnar, S (2003). The explanation frame of the digital divide. Budapest: BME-UNESCO Information Society Research Institute, TechnicalUniversity of Budapest.

Montañés, P. (2011). Una aproximación a la realidad de las mujeres gitanas desde la perspectiva de género. Acciones e investigaciones sociales, 29, 87-104. Recuperado de: http://zaguan.unizar.es/ojs/index.php/ais/article/view/539

Morales, M. y Moreno, R. (1993). Problemas en el uso de los términos cualitativo/cuantitativo en investigación educativa. Investigación en la escuela, 21, 39-50.

Moreno, F. y Bailly-Baillière, M. (2002). Diseño instructivo de la formación on-line. Aproximación metodológica a la elaboración de contenidos. Barcelona: Ariel.

Moreno. J. y Sánchez-Oro, M. (2006). Un estudio cualitativo de la minoría gitana. La vigencia de los componentes de la estructura social. Documentación Social, 143, 143-158.

Moro, L. (2009) Guía para la promoción personal de las mujeres gitanas: perspectiva psico-emocional y desarrollo profesional. Madrid: Instituto de la Mujer y Fundación Secretariado Gitano.

Morre, M., Lockee, B. \& Burton, J. (2002). Measuring success: Evaluation strategies for distance education. Educause Quarterly, 25(1), 20-26.

Morton, A.(1999). Ethics in action research. Systemic Practice and Action Research, 12(2), 219-222. 
Moskal, B. M. (2000). Scoring rubrics: what, when and how?. Practical Assessment, Research \& Evaluation, 7(3). Recuperado de: http://pareonline.net/getvn.asp?v=7\&n=3

Murphy, D. (2000). Instructional design for self-learning in distance education. Recuperado de: http://www.eric.ed.gov/PDFS/ED453377.pdf

Newman , D.R., Webb, B. \& Cochrane, C. (1995). A content analysis method to measure critical thinking in face-to-face and computer supported group learning. Interpersonal Computing and Technology Journal, 3(2), 56-77.

Niegemann, H., Brucken, R. y Leutner, D. (Eds.) (2002). Intructional design for multimedia learning. Munster: Waxmann.

Norris, P. (2001). Digital divide. Civil engagement, information poverty and the Internet world wide. Cambridge, Massachussets: Cambridge University Press

Olsson, S. (2000). Ethnography and Internet. Differences in doing ethnography in real and virtual environments. Goteborg Sweden: Viktoria Institute, Recuperado de: http://iris23.htu.se/proceedings/PDF/ 102final.PDF

Onrubia, J. (2005). Aprender y enseñar en entornos virtuales: actividad conjunta, ayuda pedagógica y construcción del conocimiento. RED, Revista de Educación a Distancia, 2. Recuperado de: http://www.um.es/ead/red/M2/

Ontoria, A. (2006). Aprendizaje centrado en el alumno: metodología para una escuela abierta. Madrid: Nancea.

Ortega, F. D., Isla, J. L. y Pavón, F. (2000). El IRC como herramienta para la formación flexible y a distancia. Pixel Bit. Revista de medios y educación, 14, 31-41. Recuperado de: http://www.sav.us.es/pixelbit/pixelbit/marcoabj14.htm

Ortí, A. (1994). La apertura del enfoque cualitativo o estructura: la entrevista semidirectiva y la discusión de grupo. En. M. García, J. Ibañez, y F. Alvira, (Eds.), El análisis de la realidad social. Métodos y técnicas de investigación (pp. 219-282). Madrid: Alianza Editorial.

Ortoll, E. (2007). Conceptos clave en alfabetización y exclusión digital. En E. Ortoll (Coord.), Casacuberta, D y Collado A.J. La alfabetización digital en los procesos de inclusión social (pp. 13-56). Editorial UOC.

Pahl, C. (2004). Managing evolution and change in web-based teaching and learning environments. Computers \& Education, 4O, 99-114. 
Palloff, R., \& Pratt, K. (1999). Building learning communities in cyberspace: effective strategies for the online classroom. San Francisco: Jossey-Bass.

Patton, M.Q. (1990). Qualitative Evaluation and Research Methods. Newbury Park, CA: Sage.

Pappert, S. (1999). Ghost in the Machine: Seymour Papert on How Computers Fundamentally Change the Way Kids Learn. Interview of Seymour Papert by Dan Schwartz. Recuperado de: http://www.papert.org/articles/GhostInTheMachine.html

Peña-Shaff, J.B. \& Nicholls, C. (2004). Analyzing student interactions and meaning construction in computer bulletin board discussions. Computers and Education, 42, 243-265.

Peña, I (2003) Acción social en red y en la Red. Documentación Social, 219, 187-203.

Perera, V.H. y Torres J.J. (2005). Análisis de las condiciones pedagógicas, sociales y cognitivas en los foros de discusión online. I Congreso Internacional El Profesorado ante el reto de las Nuevas Tecnologías en la Sociedad del Conocimiento. Granada. Recuperado de: http://prometeo.us.es/idea/publicaciones/hugo/10.pdf

Pérez Serrano, G. (1990). Investigación-acción: aplicaciones al campo social y educativo. Madrid: Dykinson

Pérez, G. (1994). Investigación cualitativa. Retos e interrogantes. I. Métodos. Madrid: La Muralla.

Pérez, A. (2002). Elementos para el análisis de la interacción educativa en los nuevos entornos de aprendizaje. Pixel-Bit, Revista de medios y educación, $19 . \quad$ Recuperado de: http://www.sav.us.es/pixelbit/pixelbit/articulos/n19/n19art/art1904.htm

Pérez, A. (2004). Comunicación mediada por ordenador, estrategias didácticas y tutoría. En J. Salinas, J. Cabero y J.I. Aguaded (Coords.), Tecnologías para la educación. Diseño, producción y evaluación de medios para la formación docente (pp. 295-310). Madrid: Alianza.

Pérez-Mateo, M. y Guitert, M. (2007). La dimensión social del aprendizaje colaborativo virtual. RED. Revista de Educación a Distancia, 18, 1-21. Recuperado de: http://www.um.es/ead/red/18/perez_mateo_guitert.pdf

Plan Info XXI (2000). La Sociedad de la Inform@ción para todos. Comisión Interministerial de la Sociedad de la Información y las Nuevas Tecnologías. de: http://www.internautas.org/documentos/infoxxi.pdf 
Planella, J. y Rodríguez, I. (2004a). E-learning e innovación social. RUSC, Revista de Universidad y Sociedad del Conocimiento, 1(1). Recuperado de: http://rusc.uoc.edu/ojs/index.php/rusc/article/view/1120

Planella, J. y Rodríguez, I. (2004b).Del e-learning y sus otras miradas: una perspectiva social. RUSC, Revista de Universidad y Sociedad del Conocimiento, 1(1). Recuperado de: http://rusc.uoc.edu/ojs/index.php/rusc/article/view/v1n1-planellarodriguez

Planella, J. y Rodríguez, I. (2004c). La condición circular de la dimensión social del e-learning. RUSC, Revista de Universidad y Sociedad del Conocimiento, 1(1). Recuperado de: http://rusc.uoc.edu/ojs/index.php/rusc/article/view/v1n1-planellarodriguez2

Plaza, A. H. (2007). Uso Social de TIC con perspectiva de género. Seminario La perspectiva de Género en las organizaciones. Nuevos aportes para ampliar el conocimiento y la acción. Red de Mujeres Latinoamericanas y del Caribe en Gestión de Organizaciones.Universidad Javeriana de Cali, Recuperado de: http://www.redgenerotic.es/index.php? option $=$ com_rubberdoc\&view $=$ category\&id $=82 \&$ Itemid $=52$

Potts, M. K. \& Hagan, C.B. (2000). Going the distance: Using systems theory to design, implement, and evaluate a distance education program. Journal of Social Work Education, 36(1), 131-145.

Prendes, M. P. (2006). Herramientas para el trabajo colaborativo en red. Comunicación y pedagogía: Nuevas tecnologías y recursos didácticos, 210, 39-44.

Pérez-Mateo, M., y Guitert, M. (2007). La dimensión social del aprendizaje colaborativo virtual. RED. Revista de Educación a Distancia, 18, 1-21. Recuperado de: http://www.um.es/ead/red/18/

Puigvert, L. (2001). Las otras mujeres. Barcelona: El Roure.

Rea, A. (2006). La europeización de la política migratoria y la transformación de la otredad. Revista Reis, 116, 157-183.

Reason, P. \& Bradbury, H. (Eds.) (2006). Handbook of Action Research. London: Sage

Redecker, C., Ala-Mutka, K., Bacigalupo, M., Ferrari, A. \& Punie, Y. (2009). Learning 2.0: the impact of Web 2.O Innovations on Education and Training in Europe. Sevilla: Institute for Prospective Technological Studies. Recuperado de: ftp://ftp.jrc.es/pub/EURdoc/JRC55629.pdf 
Resnick, M. (2002). Rethinking Learning in the Digital Age. En G. S. Kirkman, P. K. Cornelius, J. D. Sachs \& K. Schwab. (Coomp.) The Global Information Technology Report 2001-2002. Readiness for the Networked (pp. 32-37). World. New York: Oxford University Press. Recuperado de: http://hasp.axesnet.com/contenido/documentos/harvard \%20global\%2oit\%2oreadiness.pdf

Resta, J. y Laferrière, T. (2007). Technology in Support of Collaborative Learning. Educational Psychology Review, 19(1), 65-83.

Revuelta, F.I. (2009). Los mecanismos de socialización en grupos de discusión y listas de distribución. Propuestas sociales para el aprendizaje en espacios virtuales (Tesis Doctoral Inédita). Departamento de Teoría e Historia de la Educación. Universidad de Salamanca.

Revuelta, F.I. y Pérez, L. (2009). Interactividad en los entornos de formación on-line. Barcelona: UOC.

Rey, F. (2008). La discriminación múltiple, una realidad antigua, un concepto nuevo. Revista española de derecho constitucional, 28, 84, 251283.

Rheingold, H. (2002). The virtual community. Recuperado de: http://www.rheingold.com/vc/book/

Richardson, J., \& Swan, K. (2003). Examing social presence in online courses in relation to students' perceived learning and satisfaction. Journal of Asynchronous Learning Networks, 7(1). Recuperado de: http://sloanc.org/publications/jaln/v7n1/pdf/v7n1_richardson.pdf

Ridings, C.M., Gefen, D., \& Arinze, B. (2002). Some antecedents and effects of trust in virtual communities. Journal of Strategic Information Systems, 11, 271-295

Riel, M. \& Polin, L. (2004). Online learning communities: Common ground and critical differences in designing technical environments. En: R. Barab, J. Kling, \& H. Gray (Eds.), Designing for virtual communities in the service of learning (pp. 16-50). Cambridge: Cambridge University Press.

Ripa M.E. (2007). ¿Cómo abordar el estudio de una comunidad de aprendizaje blended learning?. Revista Electrónica de la Educación: Educación y Cultura en la Sociedad de la Información, 8(3), 200-221. Recuperado de: http://www.usal.es/ teoriaeducacion/rev_numero_o8_03/n8_o3_ripa 
Robottom, I. \& Colquhoun, D. (1992). Participatory research, environmental health education and the politics of method. Health Education Research, 7, 457-469.

Roblyer, M.D. \& Wiencke, W.R. (2003). Design and use of a rubric to assess and encourage interactive qualities in distance courses. The American Journal of Distance Education, 17(2), 77-97.

Robson, J. (2000). Evaluating online teaching. Open Learning, 15(2), 151-73.

Rodríguez, L.M., Escudero, T., Fernández, R. y Sabirón, F. (2000). La investigación sobre el aprendizaje colaborativo: enfoques, métodos $\mathrm{y}$ resultados, Anuario de Pedagogía, 2, 305-338.

Rodríguez, L.M., Fernández, R. y Escudero, T. (2002). Aprendizaje entre iguales y construcción de conceptos, Infancia y aprendizaje, 25(3), 277297.

Rodríguez, J.L. (2003). Estrategias de enseñanza y aprendizaje. En M. L. Sevillano y F. Martín-Molero. Estrategias metodológicas en la formación del profesorado (pp. 67-106). UNED: Madrid.

Rodríguez, J.L. (2008). Comunidades virtuales, práctica y aprendizaje: elementos para una problemática. En J. L. Rodríguez (Coord.), Comunidades virtuales de práctica y aprendizaje (pp. 11-23). Barcelona: Universidad de Barcelona.

Rodríguez, J.L. y Medrano, G. (1993). La formación en las organizaciones. Madrid: Eudema.

Rodríguez, G., Gil, J. y García, E. (1996). Metodología de la investigación cualitativa. Málaga: Aljibe.

Rodríguez-Mena, M. (2007). El aula como comunidad para aprender. Cultura y Educación, 19(1), 17-30.

Rodríguez-Mena, M., García, I., Corral, R. y Lago, C. (2004) Aprender en la empresa. Fundamentos sociopsicopedagógicos del Programa de Formación de Aprendices Autorregulados en Comunidades de Aprendizaje. La Habana: Editorial Prensa Latina.

Rodríguez, I. (2011). El proceso de inclusión de la comunidad gitana en España ¿un modelo para Europa?. Revista Gitanos, Pensamiento y Cultura, 58, 48-51. Recuperado de:http://www.gitanos.org/upload/70/28/48-51_a_fondo.pdf

Rogoff, B. (1993). Aprendices del pensamiento. El desarrollo cognitivo en el contexto social. Barcelona: Paidós. 
Ros, A. (2004). La verdadera apuesta del aprendizaje virtual: los aspectos sociales del e-learning. RUSC, Revista de Universidad y Sociedad del Conocimiento, 1(1). Recuperado de: http://rusc.uoc.edu/ojs/index.php/rusc/article/view/v1n1-ros

Ros, J. y López, J. (1994). Políticas de Información y Documentación. Madrid: Síntesis.

Rourke, L., Anderson, T. Garrison, D. R., \& Archer, W. (1999). Assessing Social Presence in Asynchronous Text-based Computer Conferencing. Journal of Distance Education, 14(2), 51-70.

Rourke, L., Anderson, T., Garrison, D. R., \& Archer, W. (2000). Methodological issues in the content analysis of computer conference transcripts. International Journal of Artificial Intelligence in Education, 11. Recuperado de: http://iaied.org/pub/951/file/951_paper.pdf

Rourke L. \& Kanuka H. (2009). Learning in Communities of Inquiriry: a revieuw of the literature, Journal of distance education. 23(1), 19-48. Recuperado de: http://www.jofde.ca/index.php/jde/article/view/474/815

Rourke, L., Anderson, L., Garrison, D. \& Archer, W. (2001). Methodological Issues in the Content Analysis of Computer Conference Transcripts. International Journal of Artificial Inteligence in Education, 12, 8-22.

Rourke, L. \& Anderson, T., (2002) Using web-based, group communication systems to support case study learning at a distance. The International Review of Research in Open and Distance Learning, 3(2). Recuperado de: http://www.irrodl.org/index.php/irrodl/article/view/107/555

Rovai, A. P. (2002). Building a Sense of Community at a Distance. International Review of Research in Open and Distance Learning, 3(1), 1-16. Recuperado http://www.irrodl.org/index.php/irrodl/article/view/79

Rovai, A. (2004). A constructivist approach to online college. The Internet and Higher education, 7, 79-93. Recuperado de: http://cnr.ncsu.edu/it_services/files/wrap/constructivist\%20approach \%20online.pdf

Rubia, B., Jorrín, I. y Anguita, R. (2009). Aprendizaje Colaborativo y Tecnologías de la Información y Comunicación. En J. De Pablos Pons (Coord.), Tecnología educativa. La formación del profesorado en la era de Internet (pp. 191-214). Málaga: Aljibe.

Rubio, M. J. (2003) Focus and models of evaluation of the e-learning. RELIEVE, Revista Electrónica de Investigación y Evaluación Educativa, 
9(2), 101-120. Recuperado de: http://www.uv.es/RELIEVE/v9n2/RELIEVEv9n2_1eng.pdf

Ruiz, C. (2008). El enfoque Multimétodo en la Investigación Social y Educativa. Una mirada desde el Paradigma de la Complejidad. Teré: Revista de Fílosofía y socio-política de la Educación, 8, 13-28. Recuperado de: http://dialnet.unirioja.es/servlet/articulo? codigo $=2785456$

Ryder, M. (2006). Instructional Design models. University of Colorado at Denver, School of Education. Recuperado de:: http://carbon.cudenver.edu/ mryder/itc_data/idmodels.html

Ryan, S., Scott, B., Freeman, H. \& Patel, D. (2000). The virtual university: the Internet and resoursce-based learning. London: Kogan Page.

Saint-Onge, H. \& Wallace, D. (2003). Leveraging Communities of Practice. Butterworth Heinemann,.

Salinas, J. (1999). Criterios generales para la utilización e interpretación curricular de los medios. En J. Cabero (Ed.), Tecnología Educativa (pp. 107-130). Madrid: Síntesis.

Salinas J. (2000). El aprendizaje colaborativo con los nuevos canales de comunicación. En J. Cabero (Ed.), Nuevas tecnologías aplicadas a la educación (pp. 199-227). Madrid: Síntesis.

Salinas, J (2003). El diseño de procesos de aprendizaje cooperativo en situaciones -virtuales. En F. Martínez (Coomp.), Redes de comunicación en la enseñanza (pp. 157-182). Barcelona: Paidós.

Salinas, J. (2004). Evaluación de entornos virtuales de enseñanzaaprendizaje. En J. Salinas, J. L. Aguaded, y J. Cabero (Coord.), Tecnologías para la educación. Diseño, producción y evaluación de medios para la formación (pp.189-206). Madrid: Alianza.

Salinas, J., Pérez, A. y de Benito, B (2008). Metodologías centradas en el alumno para el aprendizaje en red. Madrid. Síntesis.

Salmon, G. (2000). E-moderating: The key to teaching and learning online. London: Kogan Page.

Salmon, G. (2004). E-actividades. El factor clave para una formación en línea activa. Barcelona: UOC.

San Román, T. (1997). La diferencia inquietante. Madrid: Siglo XXI. 
Sánchez M. (2002). Feminismo gitano. Una aportación solidaria a la superación de las desigualdades de género. Jornada Dona Gitana: un espai per a la participació. Barcelona: Fundación Secretariado General Gitano.

Sánchez, M. (2004). El feminismo gitano. En: A. Touraine, M. Wieviorka y R. Flecha, (Coords.), Conocimiento e identidad: voces de grupos culturales en la investigación social (pp. 111.-117). Barcelona: El Roure.

Sánchez Soto, J. (2006). El chat en la teleenseñanza: implicaciones comunicativas y la oportunidad de un enfoque didáctico. Actas del Congreso Internacional EDUTEC 2005. Formación del Profesorado y Nuevas tecnologías. Santo Domingo (República Dominicana). Recuperado de: http://www.ciedhumano.org/edutecNo12.pdf

Sancho, J.M. (2004). Expanding learning experiences: posibilitess and limitations of virtual learning environment. En J. Bento (Ed.), Collaborative design and learning competence building for innovation (pp 55-77). Westport: Greenwood.

Sandín, M.P. (2003). Investigación cualitativa en educación. Fundamentos y tradiciones. Madrid: McGraw-Hill.

Santamaría, F. (2005). Herramientas colaborativas para la enseñanza usando tecnologías web: weblogs, redes sociales, wikis, web 2.0. Recuperado de: http://www.fernandosantamaria.com/descargas/herramientas_colaborat ivas2.pdf

Santoro, G. (1995). What is Computer-Mediated communication. En Berge, Z., Collins, M. (Eds.), Computer Mediated Communication and the Online Classroom. Vol. I. Overview and perspectives (pp. 11-28). Cresskill, New Jersey: Hampton Press.

Sanz, S. (2005). Comunidades de práctica virtuales: acceso y uso de contenidos. Revista de Universidad y Sociedad del Conocimiento (RUSC), 2(2), 26-35. Recuperado de: http://www.uoc.edu/rusc/2/2/dt/esp/sanz.pdf

Scardamalia, M. \& Bereiter, C. (1994) Computer support for knowledgebuilding communities, The Journal of the Learning Sciences, 3(3), 265283.

Scardamalia, M., \& Bereiter, C. (1999). Schools as knowledge-building organizations. En D. Keating \& C. Hertzman (Eds.), Today's children, tomorrow's society: The developmental health and wealth of nations (pp. 274-289). New York: Guilford. 
Scardamalia, M., \& Bereiter, C. (2006). Knowledge building: Theory, pedagogy, and technology. In K. Sawyer (Ed.), Cambridge Handbook of the Learning Sciences (pp. 97-118). New York: Cambridge University Press.

Schrire, S. (2006). Knowledge Building in Asynchronous Discussion Groups: Going Beyond Quantitative Analysis. Computer \& Education, 46(1), 4970 .

Schön, D.A. (1983). The reflective practitioner: How professionals think in action. New York: Basic Books.

Schön, D.A. (1987). Educating the reflective practitioner. Toward a new design for teaching and learning in the professions. San Francisco: Jossey-Bass.

Schön, D. (1998). El profesional reflexivo. Cómo piensan los profesionales cuando actúan. Barcelona: Paidós.

Scriven, M. (1996). Types of evaluation and types of evaluator. Evaluation Practice, 17(2), 151-62.

Seitzinger, J. (2006). Be Constructive: Blogs, Podcasts, and Wikis as Constructivist Learning Tools. Learning Solutions e-Magazine, Practical Applications of Technology for Learning. Recuperado de: http://www.elearningguild.com/pdf/2/073106DES.pdf

Seely, J. y Duguid, P. (1991). Organizational learning and communities of practice. Toward a unified view of working, learning and innovation. Organization Science, 2, 40-57.

Selltiz, C.,Wringhstman, L. \& Cook, S. (1980). Métodos de Investigación en las relaciones sociales. Madrid: RIALP.

Selwyn, N. \& Facer, K. (2007). Beyond the digital divide: Rethinking digital inclusion for the 21st century. Bristol: Futurelab.

Seufert, S., Lechner, U. \& Stanoevska, K. (2002) The Reference Model for Online Learning Communities. International Journal on E-Learning, 1(1), 43-54.

Serradell, O., Larena, R. y Fisas, M. (2004). Hacia la articulación de mecanismos favorecedores de la inclusión de la comunidad gitana: mecanismos de acreditación de las competencias y nuevas formas de organización laboral. Lan harremanak: Revista de relaciones laborales, 11, 95-112. Recuperado de: http://www.lan-harremanak.ehu.es/p231content/es/contenidos/informacion/rrll_revista/es_revista/revista11.htm 1 
Serradell, O., Sordé, T. y Vargas, J. (2006). Resultados del Proyecto RTD Workaló, «The creation of new occupational patterns for cultural minorities: the gypsy case». En M. García, A. Calvo, J.M. Osoro, S. Rojas (Coords.), Convergencia con Europa y cambio en la universidad: XI Conferencia de Sociología de la Educación (pp. 246-247). Texto completo recuperado de: http://dialnet.unirioja.es/servlet/articulo? codigo $=2377303$

Shea, P., Li, C. S., \& Pickett, A. (2006). A study of teaching presence and student sense of learning community in fully online and web-enhanced college courses. The Internet and Higher Education, 9(3), 175-190.

Shea, P., Vickers, J. \& Hayes, S. (2010). Online Instructional Effort Measured through the Lens of Teaching Presence in the Community of Inquiry Framework: A Re-Examination of Measures and Approach. The International Review of Research in Open and Distance Learning, 11(3), 127-154 Recuperado de: http://www.irrodl.org/index.php/irrodl/article/view/915/1650

Shin, N. (2002). Beyond Interaction: the relational construct of Transactional Presence. Open Learning, 17 (2), 121-137.

Shotsberger, P. G. (1999). Forms of Synchronous Dialogue Resulting from Web-based Professional Development. En J.D. Price, J Willis, D. A. Willis, M. Jost \& S. Boger-Mehall (Eds.), Proceedings of Society for Information Technology \& Teacher (pp. 1777-1782). Education International Conference . Chesapeake, VA: AACE.

Shumar, W. \& Renninger, A. K. (2002). On Conceptualizing Community. En: A.K. Renninger y W. Shumar (Eds.), Building Learning communities. Learning and change in cyberspace (pp. 1-17). Cambridge: Cambridge University Press.

Sigalés, C. (2002). El potencial interactivo de los entornos virtuales de enseñanza y aprendizaje en la educación a distancia. Ponencia presentada en X Encuentro Internacional de Educación a Distancia. Recuperado de: http://www.uoc.edu/web/esp/art/uoc/sigales0102/sigales0102.html

Silva Quiroz, J. (2004). El rol de moderador del tutor en la conferencia mediada por computador. Edutec: Revista Electrónica de Tecnología Educativa, $17 . \quad$ Recuperado de: http://edutec.rediris.es/Revelec2/revelec17/silva_16a.pdf

Smith, L.M. (1978). An evolving logic of participation observation. Educational Etnography and other caso studies. En: L. Shulman (Ed.), Review of Research in Education (pp. 316-377). Itasca, IL.: Peacock. 
Smulyan, L. (1988). The collaborative process in action research. Educational Research Quarterly, 12(1), 47-56.

Stake, R.E. (1998). Investigación con estudio de casos. Madrid: Morata.

Stones, E. (1989). Pedagogical Studies in the Theory and Practice o Teacher Education. Oxford Review of Education, 15(1), 3-15.

Stenström, A. (1994). An introduction to spoken interaction. Nueva York: Logman.

Stenhouse, L. (1985). El profesor como tema de investigación y desarrollo. Revista de Educación, 277, 43-53.

Stehr, N. (2002). Knowledge and Economic Conduct. The Social Foundations of the Modern Economy, Toronto: Toronto University Press

Strauss, A.L. (1987). Qualitative Analysis for social scientists. Cambridge: Cambridge University Press.

Strickland, A.W. (2006). ADDIE. Idaho State University College of Education, Science, Math \& Technology Education. Recuperado de:http://ed.isu.edu/addie/index.html

Strijbos, J.W. \& Fischer, F. (2007). Methodological challenges for collaborative learning research. Learning and Instruction, 17, 389-393. Recuperado de: http://media.leidenuniv.nl/legacy/Strijbos_Fischer_2007_Methodologic al\%20challenges\%2ofor\%20collaborative\%2olearning \%20research_LAE_389-393.pdf

Stufflebeam, D. L. (2001). Evaluation checklists: Practical tools for guiding and judging evaluations. American Journal of Distance Education, 22(1), 71-79.

Suárez, M. (1998). Desarrollo de un grupo de investigación-acción colaboradora en proyectos curriculares innovadores. Revista de Educación, 316, 369-382.

Suárez, C. (2007). La dimensión pedagógica del modelo de formación blearning USIL. Quaderns digitals: Revista de Nuevas Tecnologías y Sociedad, $52 . \quad$ Recuperado de: http://www.quadernsdigitals.net/index.php? accionMenu=hemeroteca.VisualizaArticuloIU.visualiza\&articulo_id=1047 5

Suárez Saavedra, V. (2007). Etnicidad, identidad y cultura. Cuadernos Gitanos, 1, 14-19. 
Subirats, J. y Gomà, R. (2004). Un paso más hacia la inclusión social. Generación de conocimiento, políticas y prácticas para la inclusión. Plataforma de ONGs de Acción Social.

Swan, K., Shea, P. Fredericksen, E., Pickett, A. Pelz, W. \& Maher, G. (2000). Building knowledge building communities: consistency, contact and communication in virtual classroom, Journal Educational Computing Research, 23(4), 359-381.

Swan, K., \& Shih, L.F. (2005). On the Nature and Development of Social Presence in Online course Discussions. Journal of Asynchronous Learning Networks, 9(3), 115-136.

Tashakkori, A. \& Teddlie, C. (2003). Handbook of Mixed Methods in Social \& Behavioral Research. Thousand Oaks: Sage.

Taylor, S.J. y Bogdan, R. (1987). Introducción a los métodos cualitativos de investigación. Barcelona: Paidós.

Toffler, A. (1981). La Tercera Ola. México: Provenex .

Tolmie, A. \& Boyle J. (2000). Factors influencing the success of computer mediated communication (CMC) environments in university teaching: a review and case study, Computers \& Education, 34(2), 119-140.

Torres, J. (1994). Globalización e interdisciplinariedad: el curriculum integrado. Madrid: Morata.

Touraine, A. (1973). La sociedad post-industrial. Barcelona: Ariel.

Touraine, A., Wieviorka, M. y Flecha, R. (Coords.) (2004). Conocimiento e identidad. Voces de grupos culturales en la investigación social. Barcelona: El Roure Editorial.

Tu, C.H. \& McIsaac, M. (2002) The relationship of social presence and interaction in online classes. The American Journal of Distance Education, 16(3), 131-150

UNESCO (1996). La educación encierra un tesoro. Madrid: Santillana.

UNESCO (1998). Aprendizaje abierto y a distancia. Perspectivas y consideraciones políticas. Madrid: UNED-UNESCO.

UNESCO (2005). Hacia las sociedades del conocimiento. París: Ediciones UNESCO.

Valls, R., Lorenzo, N., Flecha, A., Fisas, M., Gómez, J., Perez Grande, M. D. y Martínez, I. (2005). Callí Butipén: Mujer Gitana y Mercado Laboral. En: 
M.A. Ortiz y A. Ocaña (Coord). Estudios sobre Cultura Gitana. Aspectos históricos, sociológicos, educativos y folklórico-musicales (pp. 89-97). Granada: Labayen y Liébana.

Valverde, J. y Garrido, C. (2005). La función tutorial en los entornos virtuales de aprendizaje: comunicación y comunidad. Revista Latinoamericana de Tecnología Educativa, 4(1), 153-167. Recuperado de: http://campusvirtual.unex.es/cala/editio/index.php? journal $=$ relatec $\&$ page $=$ issue $\&$ op $=$ view $\&$ path []$=9$

Valverde, J. (2008). Webquest como estrategia metodológica en entornos virtuales de aprendizaje de Educación Superior: evaluación de una experiencia. En Ma E. Del Moral y R. Rodríguez (Coords.), Experiencias docentes y TIC (pp. 129-149). Barcelona: Octaedro.

Valverde, J. (2011). Introducción. En J. Valverde (Ed.), Actas del I Simposio Internacional «Buenas Prácticas Educativas con TIC» (pp. 9-11). Universidad de Extremadura. Servicio de Publicaciones.

Valverde, J. y López, E. (2009). Modelos pedagógicos en la docencia universitaria a través de entornos virtuales de enseñanza-aprendizaje, Campo Abierto, 28(2), 47-68.

Valverde, J., Garrido , M. C. y Fernández, M. R. (2010). Enseñar y aprender con tecnologías: un modelo teórico para las buenas prácticas educativas con TIC. Revista Electrónica Teoría de la Educación: Educación y Cultura en la Sociedad de la Información, 11(1), 203-229. Recuperado de: http://revistatesi.usal.es/ revistas_trabajo/index.php/revistatesi/article/ view/5840/5866

Van Dijk, T.A. (2000). El discurso como interacción social. En: T.A. Van Dijk (Eds.), El discurso como interacción social (vol. II) (pp. 19-66). Barcelona: Gedisa.

Vargas, F. (2001). La evaluación basada en competencias. Una breve guía ilustrada con un caso de aplicación práctica. Centro Interamericano para el Desarrollo del Conocimiento en la Formación Profesional (CINTERFOR): México.

Vargas, J. (2004). Nuevos perfiles profesionales para minorías étnicas en la Sociedad del Conocimiento. En: A. Touraine, M. Wieviorka y R. Flecha (Coords.), Conocimiento e identidad: voces de grupos culturales en la investigación social (pp. 53-57). Barcelona: El Roure.

Varis, T. (2004). Perspectiva social del e-learning en el marco del sistema educativo nacional. RUSC, Revista de Universidad y Sociedad del 
Conocimiento, 1(1).

Recuperado

de: http://rusc.uoc.edu/ojs/index.php/rusc/article/view/v1n1-varis

Vázquez, R. y Angulo, F. (Coords.) (2003). Introducción a los estudios de casos: los primeros contactos con la investigación etnográfica. Málaga: Aljibe.

Vaughan, N., \& Garrison, D. R. (2005). Creating cognitive presence in a blended faculty development community. Internet and Higher Education 8, 1-12.

Veerman, A., \& Veldhuis-Diermanse, E. (2001). Collaborative learning through computer-mediated communication in academic education. En P. Dillenbourg, A. Eurelings, \& K. Hakkarainen (Eds.), European perspectives on computersupported collaborative learning. Proceedings of the First European Conference on CSCL (pp. 625-632). Maastricht: McLuhan Institute, University of Maastricht.

Vilar, J. (2002). Responsabilidad y compromiso ético de los formadores en Pedagogía Social y Educación Social. Revista Interuniversitaria de Pedagogía Social, 9, 143160.

Villalba, P., Bezunartea, P, Zapata, M., Rincón, P. y Calón, P. (2000). La promoción de la mujer gitana desde una perspectiva de género. Revista Gitanos, Pensamiento y Cultura, 5, 20-26.

Vivina, B. R. (2004). El foro electrónico: una herramienta tecnológica para facilitar el aprendizaje colaborativo. Edutec, Revista Electrónica de Tecnología Educativa, 17, 1-20. Recuperado de: http://edutec.rediris.es/Revelec2/revelec17/brito_16a.pdf

Vygotsky, L. (1979). El desarrollo de los procesos psicológicos superiores. Barcelona: Crítica.

Vygotsky, L. (1985). Pensamiento y Lenguaje. Buenos Aires: Pléyade.

Wals, A. E. J. y Alblas, A. H. (1997). School-based research and development of environmental education: a case study. Environmental Education Research, 3, 253-267.

Walker, B. \& Haslett, T. (2002). Action research in management-Ethical dilemmas. Systemic Practice and Action Research, 15(6), 523-533.

Warschauer, M. (2004). Technology and social inclusion: Rethinking the digital divide. Cambridge, MA: MIT Press.

Wahrhaftig, R. (2004). Perspectiva social del e-learning en el sistema universitario de Brasil. RUSC, Revista de Universidad y Sociedad del 
Conocimiento, 1(1). Recuperado de: http://rusc.uoc.edu/ojs/index.php/rusc/article/view/v1n1-wahrhaftig

Waterman, H., Tillen, D., Dickson, R. \& de Koning, K. (2001). Action research: a systematic review and assessment for guidance. Health Technology Assessment, 5 (23).

Wells, G. (2001). Indagación dialógica. Hacia una teoría y una práctica socioculturales de la educación. Barcelona: Paidós.

Wellman, B. (1999). The network community: An introduction to networks in the global village. En B. Wellman (Ed.), Networks in the Global Village (pp. 1-48). Boulder, CO: Westview Press.

Wegerif, R. (1998). The Social Dimension of Asynchronous Learning Networks. Journal of Asynchronous Learning Networks, 2(1), 34-49.

Wenger, E. (2001). Comunidades de práctica: Aprendizaje, significado e identidad. Barcelona: Paidos.

Wenger, E., McDermott, R., \& Synder, W.M. (2002). Cultivating Communities of Practice: A Guide to Managing Knowledge. Boston: Harvard Business School Press.

Wenger, E., White, N., Smith, J.D. \& Rowe, K. (2005). Technology for communities. CEFRIO Book Chapter. Recuperado de: http://technologyforcommunities.com/CEFRIO_Book_Chapter_v_5.2.p df

Wilcox, B. L. y Wojnar, L. C. (2000). Best practice goes online. Reading online, 4(2). Recuperado de: http://www.readingonline.org/articles/art_index.asp?

$\mathrm{HREF}=/$ articles/wilcox/index.html

Wilson, B. (1996). What is a constructivist learning environment?. En B. Wilson (Ed.) Constructivist learning environments: case studies in Instructional design (pp. 3-8). Englewood Cliffs, New Jersey: Educational Technology Publications.

Yus, F. (2007). Virtualidades Reales: Nuevas formas de comunidad en la era de internet. Alicante: Universidad de Alicante.

Zabala, A. (1989). El enfoque globalizador. Cuadernos de Pedagogía, 168, 22-27.

Zabalza, M. A. (2003). Competencias docentes del profesorado universitario. Calidad y desarrollo profesional. Madrid: Narcea. 
Zazueta, M.A. y Herrera, L.F. (2008). Rúbrica o matriz de valoración, herramienta de evaluación formativa y sumativa. Quaderns Digitals, 55 . Recuperado de: http://www.quadernsdigitals.net/index.php? accionMenu=hemeroteca.DescargaArticuloIU.descarga\&tipo=PDF\&articu lo_id=10816

Zhu, E. (1996). Meaning negotiation, knowledge construction, and mentoring in a distance learning course. Indianapolis National Convention of the Association for Educational Communications and Technology. Recuperado de: htttp://www.eric.ed.gov/PDFS/ED397849.pdf

Zuber-Skerritt, O. \& Fletcher, M.(2007). The quality of an action research thesis in social sciences. Quality Assurance in Education, 15(4), 413-436. 


\section{Anexos}

(Disponibles en CD) 



\section{Índices de figuras, tablas y gráficos}





\section{Índice de Figuras}

Figura 1. Estructura básica de la Tesis Doctoral.

Figura 2. Objeto de estudio de la tesis dentro del Grupo de Investigación Nodo Educativo, las investigaciones sobre Tecnología Educativa y las líneas del Doctorado.................27

Figura 3. Perspectiva Social del e-Learning........................................... 45

Figura 4. Fuentes principales de las que nutre el concepto de e-Learning (Barberà,

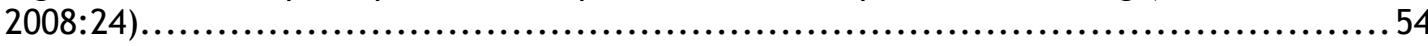

Figura 5. Niveles de investigaciones sobre e-learning social (Planella y Rodríguez,

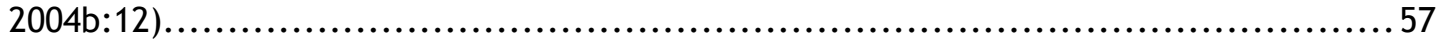

Figura 6. Ideas comunes de estudios sobre e-learning e inclusión social.................63

Figura 7. Iniciativas Europeas relaciOndas con las TIC para la inclusión social.............67

Figura 8. Programas Europeos relacionados con la inclusión digital......................83

Figura 9. Relación políticas y planes Europeos y Nacionales............................91

Figura 10. Relación entre iniciativas Ingenio 2010 y Avanz@.............................. 96

Figura 11. Evolución Políticas Extremeñas en relación a las Tecnologías de la Información y Comunicación..................................................................... 101

Figura 12. Factores socioculturales del e-learning...................................110

Figura 13. Contexto, estudio y conformación de Comunidades de Práctica en entornos virtuales de aprendizaje......................................................... 129

Figura 14. Dinámicas de los tipos de comunidades virtuales en función de los objetivos de sus miembros (Coll et al., 2008:309) ........................................... 152

Figura 15. Modelo «Comunidad de Indagación» (Garrison y Anderson, 2005: 49)..........168

Figura 16. Políticas de inclusión social, TIC y población gitana............................185

Figura 17. Planes de Inclusión Social de Extremadura y relaciones con otros planes

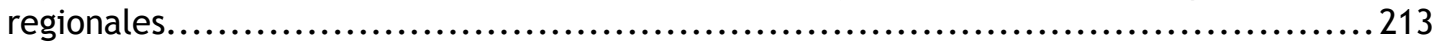

Figura 18. Planteamiento metodológico de la investigación...........................247

Figura 19. Proceso Cíclico de la investigación-acción (basado en Carr y Kemmis, 1988). .260

Figura 20. Disposición del espacio en el desarrollo del Grupo de Discusión Comunicativo.

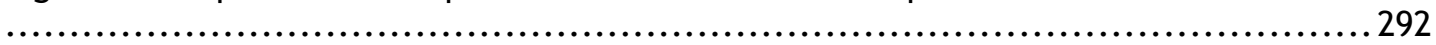

Figura 21. Fases de elaboración del Cuestionario..................................... 306

Figura 22. Diseño de la acción formativa virtual................................... 323

Figura 23. Áreas de trabajo de la Fundación Secretariado Gitano........................326

Figura 24. Proceso de diseño de la acción formativa virtual siguiendo el Modelo ADDIE...348

Figura 25. Modelo de Cinco Pasos de Gilly Salmon (Imagen tomada de: http: / / www.atimod.com/e-activities/5stage.shtml)

Figura 26. Adaptación del modelo de construcción del diálogo de Pérez, Salinas y de Benito

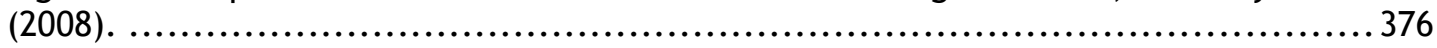

Figura 27. Proceso de evaluación de competencias de la acción formativa..............460

Figura 28. Apariencia del curso en la plataforma virtual. Bienvenida....................467

Figura 29. Apariencia del curso en la plataforma virtual. Espacio Social de Trabajo.......468

Figura 30. Apariencia del curso en la plataforma virtual. Bloque temático 1............471

Figura 31. Apariencia del curso en la plataforma virtual. Bloque temático 2. ...........472

Figura 32. Apariencia del curso en la plataforma virtual. Bloque temático $3 . . . \ldots \ldots \ldots . . .472$ 
Figura 33. Apariencia del curso en la plataforma virtual. Trabajo Práctico Continuado.. .474

Figura 34. Apariencia del curso en la plataforma virtual. Biblioteca.....................475

Figura 35. Apariencia del curso en la plataforma virtual. Espacio Docente...............475

Figura 36 Apariencia del curso en la plataforma virtual. Panel izquierdo.................476

Figura 37 Apariencia del curso en la plataforma virtual. Panel derecho.................477

Figura 38. Proceso de Evaluación del proyecto e-learning.............................480

Figura 39. Estudio de la conformación de la Comunidad de Práctica......................487

Figura 40. Montaje fotográfico situado como página inicial del curso ....................581

Figura 41. Diferentes momentos de respuestas en el desarrollo de los foros (Presencia Cognitiva)...................................................................... 591

Figura 42. Esquema de trabajo en el establecimiento del programa de trabajo, metodología y calendario.

Figura.43. Relación entre las tres dimensiones del modelo «Comunidad de Indagación» (Garrison y Anderson, 2005: 49).

Figura 44. Resultados y relaciones del estudio de conformación de la Comunidad de Práctica a través del modelo «Comunidad de Indagación»...........................599

Figura 45. Evaluación de la pertinencia de la acción formativa virtual...................603

Figura 46. Aspectos positivos del desarrollo de la acción formativa......................620

Figura 47. Aspectos negativos del desarrollo de la acción formativa....................621

Figura 48. Dimensión didáctica.................................................634

Figura 49. Dimensión sociocultural..............................................672

Figura 50. Dimensión Tecnológica..................................................693

Figura 51. Conclusiones y Prospectiva...............................................704

\section{Índice de Tablas}

Tabla 1. Dimensiones, categorías e indicadores de análisis del modelo «Comunidad de Indagación» de Garrison y Anderson (2005).............................................172

Tabla 2. Clasificación de proyectos e-learning dirigidos, o en los que participa, población gitana....................................................................226

Tabla 3. Términos Racionalistas y Naturalistas apropiados para los cuatro aspectos de

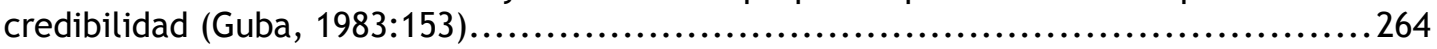

Tabla 4. Dimensiones, ejes de progresión y componentes de los ejes de la herramienta A.D.E.C.U.R. (basado en López y Roso, 2009:29).....................................295

Tabla 5. . Dimensiones y categorías del modelo «Comunidad de indagación»...............304

Tabla 6. Distribución de ítems por ejes de evaluación (Cuestionario de Evaluación).......307

Tabla 7. Unidades de las preguntas abiertas del cuestionario..........................310

Tabla 8. Dimensiones, categorías e indicadores del modelo de análisis de datos

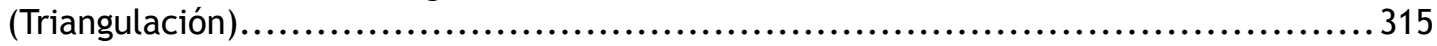

Tabla.9. Matriz DAFO de factores claves del éxito de la acción formativa.................364

Tabla 10. Propuesta temática de la acción formativa.................................. 388

Tabla 11. Requerimientos técnicos mínimos para realizar acción formativa................392

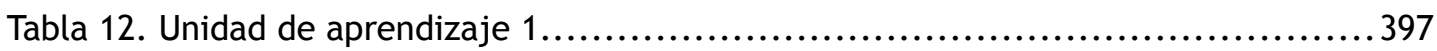




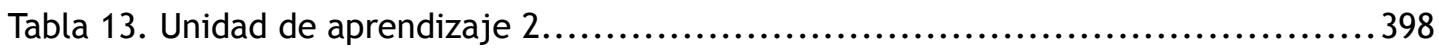

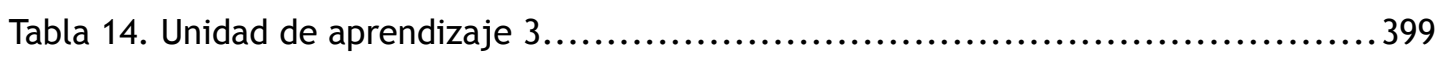

Tabla 15. Unidad de aprendizaje 4 ..................................................400

Tabla 16. Correspondencia de Centros de interés con bloques temáticos.................403

Tabla 17. Dinámica colaborativas.................................................... 417

Tabla 18. Recursos Didácticos y actividades principales de la acción formativa...........448

Tabla 19. Basada en Zazueta y Herrera $(2008: 3)$.......................................464

Tabla 20. Matriz de valoración de las competencias.................................. 465

Tabla.21. Objetivo, aspectos, momentos responsables y técnica de evaluación del proyecto e-learning...................................................................... 483

Tabla 22. Datos Identificación Foro «Entre Callis»...................................494

Tabla 23. Datos generales del Foro Social de Trabajo: Igualdad.........................529

Tabla 24. Datos generales del Foro Social de Trabajo: Participación y Dinamización......554

Tabla 25. Datos generales del Foro Social de Trabajo: Liderazgo.........................563

Tabla 26. Datos generales del Foro de Tutorías........................................ 577

Tabla 27. Variables/categorías del cuestionario de evaluación .........................609

Tabla 28 Resultados de la evaluación experta sobre las dimensiones, ejes de progresión y

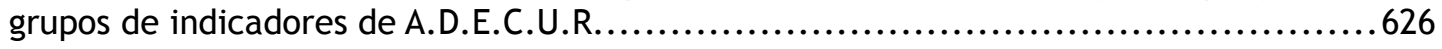

Tabla 29. Temas, categoría, indicadores, códigos y dimensiones de análisis de los datos

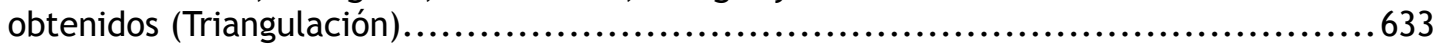

\section{Índice de Gráficos}

Gráfico 1. Número total de mensajes enviados a los Foros.............................491

Gráfico 2. Participación de docentes en Foros........................................492

Gráfico 3. Participación de estudiantes en los Foros....................................493

Gráfico 4. Línea de evolución de la participación de las estudiantes en el Foro «Entre

Callis».................................................................................. 587

Gráfico 5. Edades de estudiantes....................................................6 610

Gráfico 6. Niveles de importancia de actividades desarrolladas........................613

Gráfico 7. Niveles de interés de los recursos utilizados.................................6614

Gráfico 8. Utilidad y grado de uso de los recursos....................................6614 
